


\title{
Die Wolkswint/dyaft
}

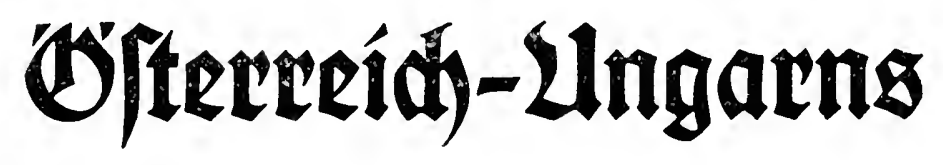

\section{und die Đerftảndígung mít Deutfahland}

\author{
Won \\ Dr. Eríđ Piltor \\ Getretär der Wiener Gandelafammer
}

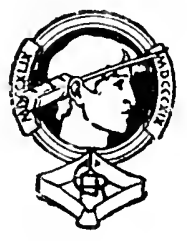

Berlin 1915

Druak und berlag von Georg Reimer 


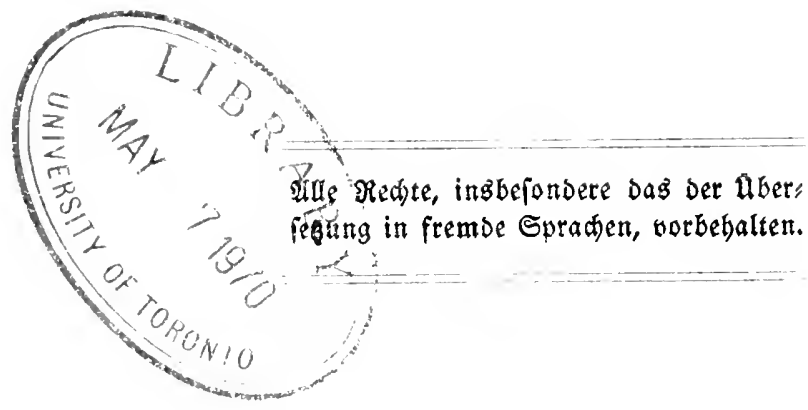


Das vorliegende Bud tradtet folgende Ziele zu fördern:

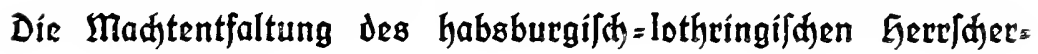
haules.

Díe endlíde vollftändíge Er/aliésung der Reídtümer der Donau= monardir an Men/dien und Gütern.

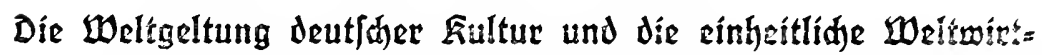
(d)aftspolitit der Mittelmädte und îher Bundesgenol|en.

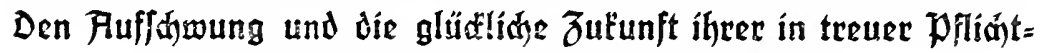
erfüllung lís freudig aufopfernden boúlere. 



\section{Jinbalt.}

\section{$\mathfrak{D} \mathfrak{a} \mathfrak{E} \mathfrak{a} \mathfrak{n}$.}

Beugrapgirdi:

Eette

Die Ronardie, ein Bebiet Des Dftens und Des Fítüinffems der I Donau. - Das Sampfland gutifen জeftert und Dften. - Der Bergftrom Donaut. - Die Bebeutung Der Glbe und von Şamburg für Difterreia.).

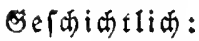

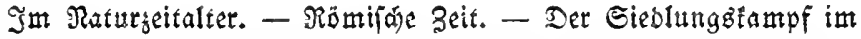
Beitalter bes Borbertidens Der Gandwittidaft. - Sulturtoirtidaft. -

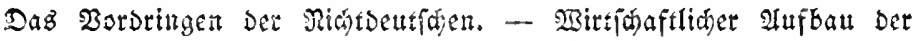

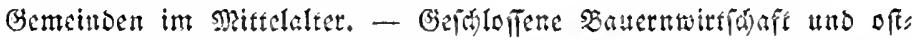

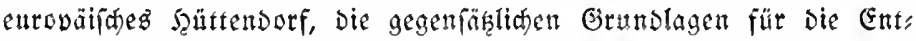

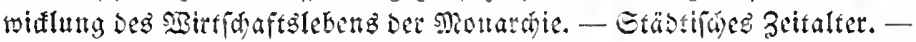

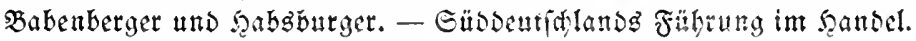
- Rergeblide SRaßnămen Dagegen in D̈ferreid.

3ell: und STandelspolitifa):

Marimilian I. als moderner Szandélspolitifer. - Die caport: und

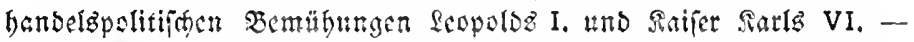
Ganere Rolonifation. - Ibpermngspnlitif Jofefs II. - Einfeit" Jiđes zollgebiet I8;0.

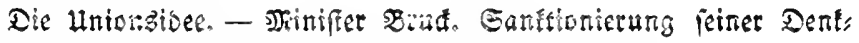
furift Durd Saifer Frams Jolef I. - Die Ftrangen.

\section{Dis \&eute.}

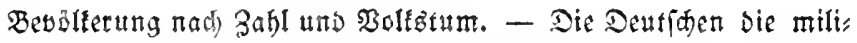

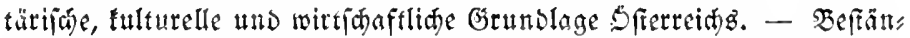
Digfeit Der Epradengerizen auf Dam fladen Eande. - Die Elaven wo:

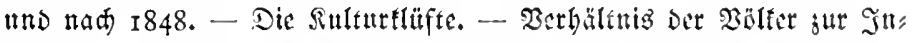
Dnftrie - Thathen - Slowafen - Polen - Hfrainer - Slowenen Magyaren, bertichaft bes Irbels unb Der Gentry. Unbefriebigte

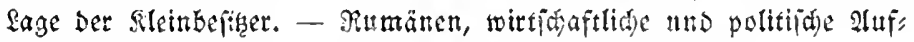
f̆wungäbefitebungen. - Serben uno Iroater. - Juben. 


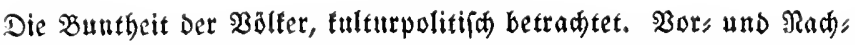

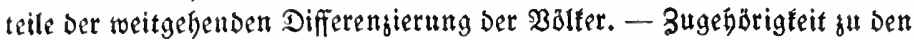

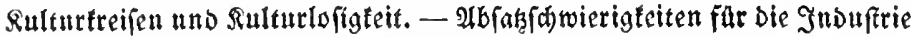

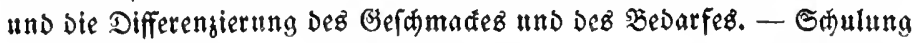
Der TnDuftrie.

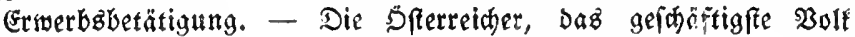
Europaz. - Bolfsbilsung und Sterblidfeit. - Inalphabeten unfer Den Retruten. - Sriefoerfegr.

Ronfum. - Šn Getreide und Rartoffeln. - Fleifa. - Sonftigez.

Das ßuđer", Saly, und Petroleumland mit Dem geringen Figen" tonfum.

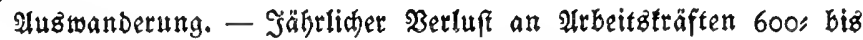
700000 RDpFe.

Sogialpolitif nno Irbeitguermittung. - Die fleip̈ige, genügiame Bewölferung baurt Deu endliđen, volffändigen Erfhließ̧ung, welde

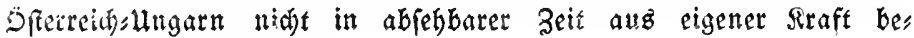
friebigend Durafügren fann.

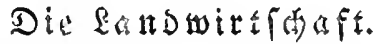

Bünftige sobenbernaffenbeit. - Sontinentales flima ungarnz,

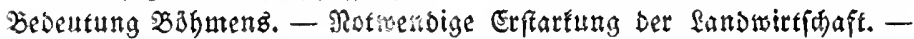
Die Monardic if tein Getreive exportierendes Sand mebr. - Geringe

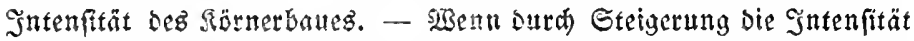
Rorwegen gleichgebracht werben tönnte, wärben 400 biz 800 Millionen jährlich mefr für Betreide allein eingenommen werben tönnen. - 230 ein und $D B f t$.

Diebsut

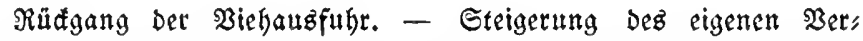

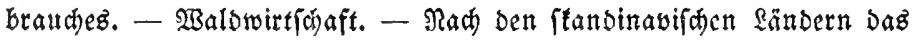

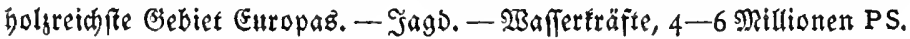

\section{Die Snduftie.}

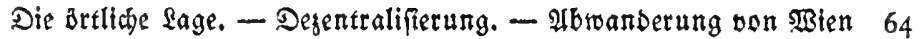
nach Der \roving.

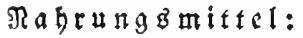

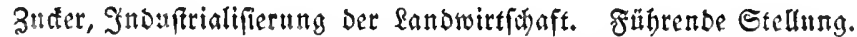

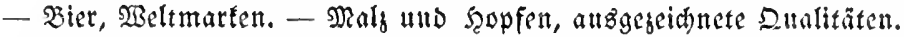

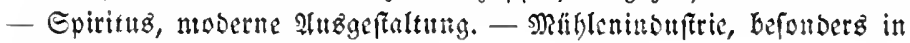
Ungarn auggejcidnct entwidelf.

Berguergerodation a

Soble. Mebr Bienn als Stetnfoble. - Eifenerze, auterorbent:

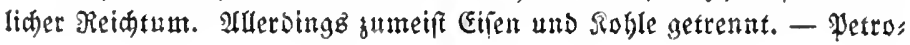


leum, reides 2orlommen. Rampf mit Den amerikanifłen Truftz. -

Erdgaz. - Ealg. - Nimeralien nto Dmellen. - Eijen. Ģlängender

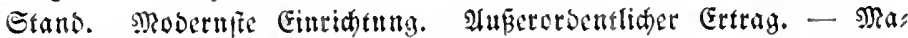

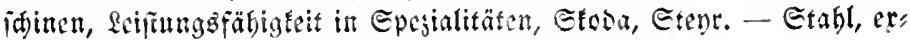
porţäbige Sualitätsinonfirie.

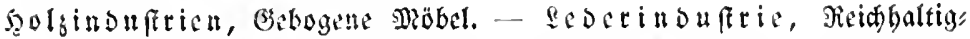

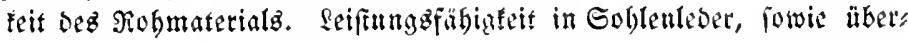

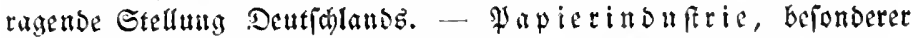

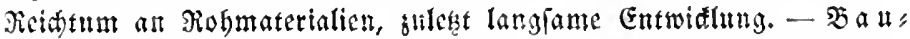
gewerbr, griste Petbreitung. Şobe Soften gegenüber Dentidilanb.

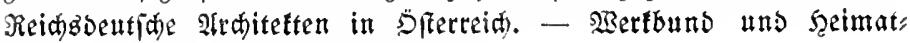

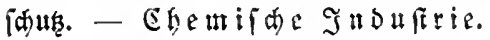

Sextilinduftrie:

Miatigfte Gropinduftrie Der Monardie. - Baummollpinnerei, 96

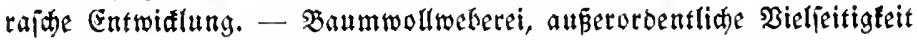

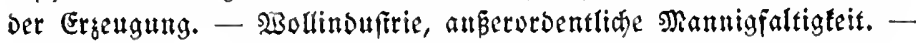
Rogfeide, Seibenpinnerei. - Seibenweberei, Degentraliferung, Biel; feitigleit Der Erzeugung. - Eeineninouftrie, im gropen uno ganzen im

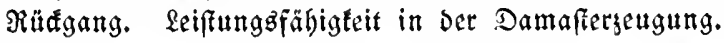

Ge

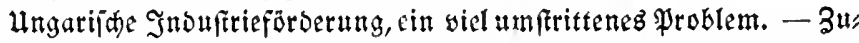
lammenfafing ergibt trog Sdwierigteiten uno Scinberniffen anjer" ordentlidie leiftungen ber Sonduftrie.

\section{Der Şandel und ber Bertebr.}

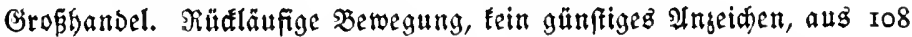

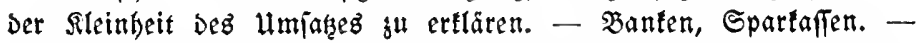

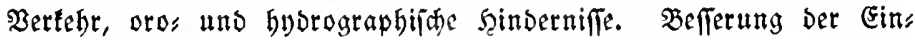
nahmen Der Gijenbahnoerwaltung. Anfífinug in ungarn. - Sees

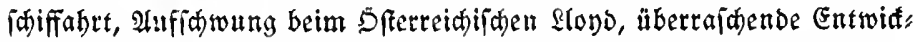

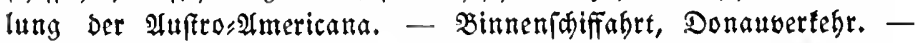

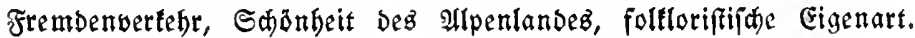

\section{Die widrtigften Bilangen.}

Şandelbbilamben ber widtigften Etaaten, ber Monaraie. - I I9

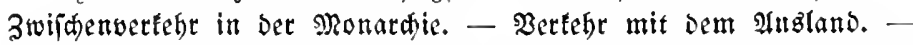

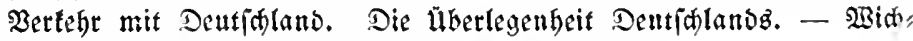
tigfte Unterídiede ber wirtidaftliden Entmiatung.

\section{Die $3 \mathfrak{u} \mathfrak{t} \mathfrak{u} \mathfrak{n} \mathfrak{t}$.}

Beltfrieg uno Beltwirtidaft. - Die hambelspolitifden granb: 130 legenden Uriadien des Sirieges. - Notwendigfeit oer $\mathfrak{A}$ ägeftaltung bes̉ 


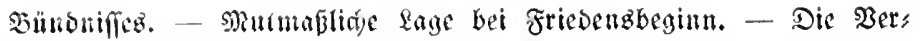
fänbigutg mit Dentid)lanb, Die Grundlage Der ğkünftigen vorteillaften Entwiflung. Rotivendige gegeufeitige lunterfïtung. - Mitfelenropä"

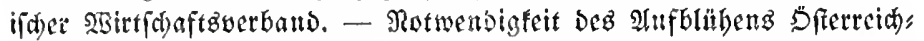

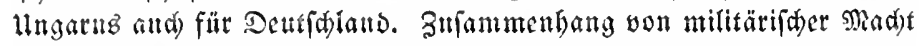

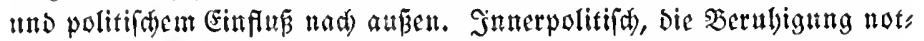

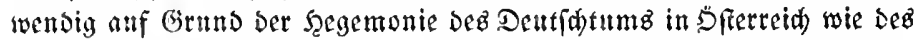
Nagyarentumb in Ungarn. - Rotionaltwirtfanaftic), gegenleitige (Ex"

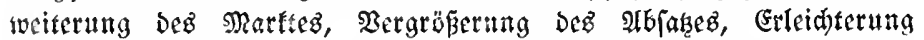
Der Epegialifierung. - Exportpolitifक, Ermöglidung, Den überiđu自

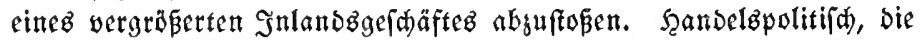

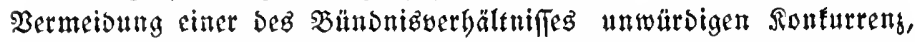
Daber sinbeitlides Bufanmenarbeiten notwendig. Sonfumpolitifa, billige Beriorgung auf Gruno Der vergröperten, planmäpigen Maflen, produttion - Sobneftone - Bizmara.

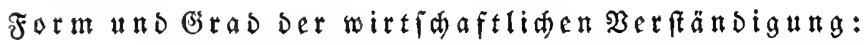

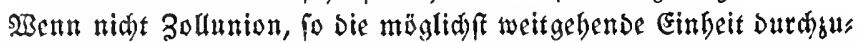

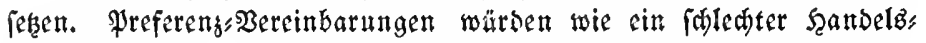
vertrag wirken. - Die Bereinbarungen fitts womb̆glich wor Friebenz:

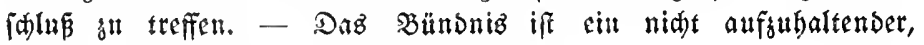
naturgemäper weltwirtfdaftlider Proses.

Die mögliden Eintendungen und ibre wiberlegung: Die Stelung Der Landwirtialaft jur Frage. Die Eandwirtfaaft ift nidt gegenteilig, eher Dafür intereffiert. - Die oftereidifhe Sndu ftrie fann fid überwiegend Dafür ausipreden. - Die ungarifđe Snduftrie hat ein regerez Rapitalsintereffe Deutfhlanbs su erboffen. - Die Rü fidnahme auf bie polnifhe Sonouftrie wärde fogar bie lunion forbern.

S d) $\mathfrak{u} \mathfrak{m} \mathfrak{m}$ if $\mathfrak{t} \mathfrak{l}$ :

Rartelle bei gleidjeitiger Reform Der Rartell, Gefegegebung. Eifen, babnfract)ten. Gegenfeitige Gewohnheit bei Räufetn nno Berkänfern.

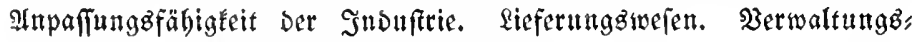
maß̧nabnen. Sdlieplid) Der 3wifhengull.

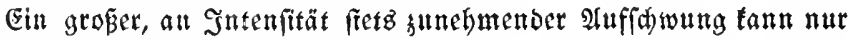
im Einverfändniz mit Dentfolano ergielt toerden. Ifppell an Das Deutfac $\mathfrak{B o l l}$ in Deutfalano. 


\section{Bemertungen.}

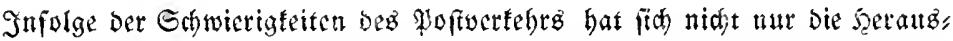

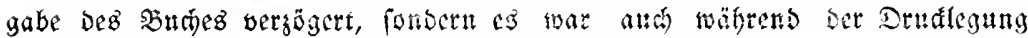

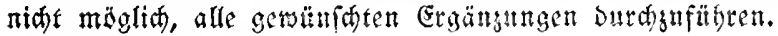

Rachigtrager: fei:

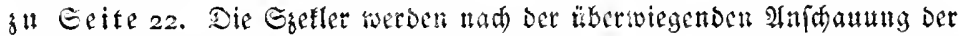

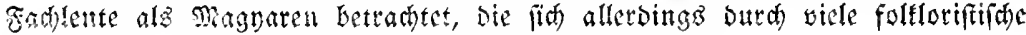
Sonderbeitet wot Den fonftigen Miagyaren unteridecioen.

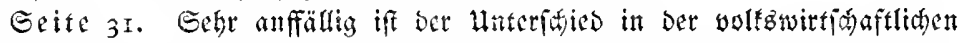

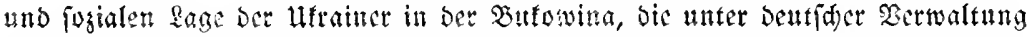

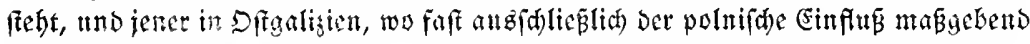

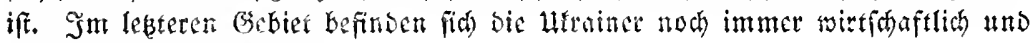
pogial auf Dem Tieffinto.

Seite 32. Wei ben MRagyaren yehört jull Dligardie ves Gentry, betive fuiammen rund ro doo Familien. 



\section{Das Sand.}

Da alles Betwordene Daz Ergebniz yon Entwiftung uno bes

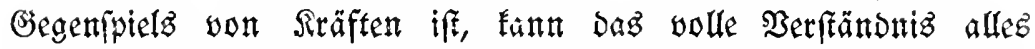

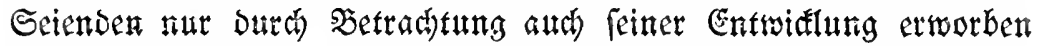
merden. Dei Der Darftellung Der produftiven Rräfte einez $23 i r t s$

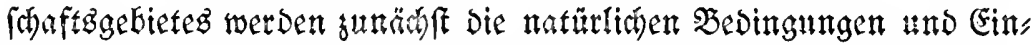

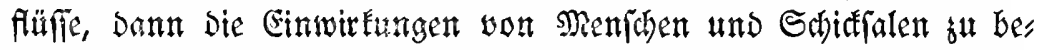

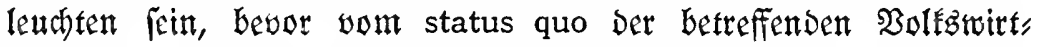

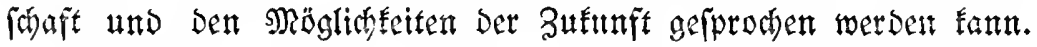

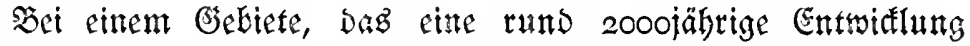

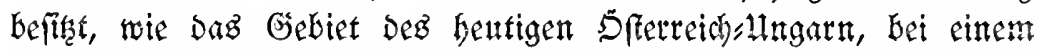

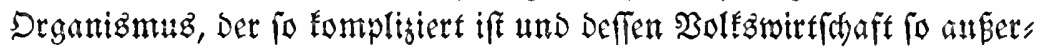

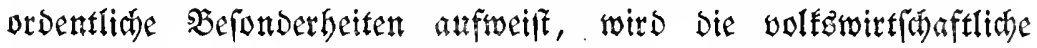
Betrachtung bie (Entwidtung um fo mentger unberd)tet laffen fünren,

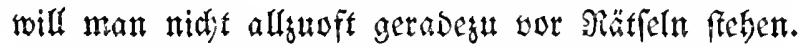

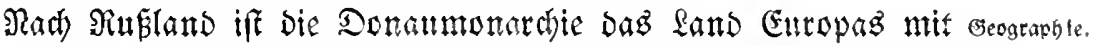

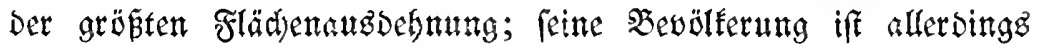
fleiner als bie Dettffglands (Iofo 5 I gegenüber 65 Millionen).

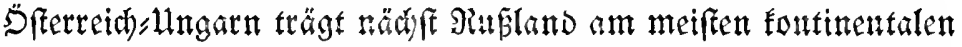
Sharafter. Nur ein Eectifel feiner Grenten ift vom Meere Eefpült.

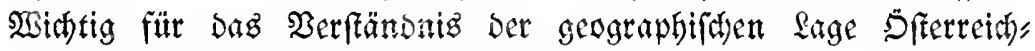

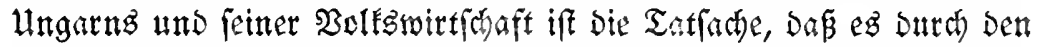

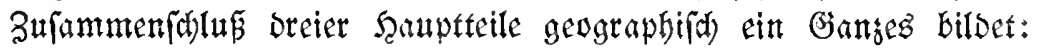

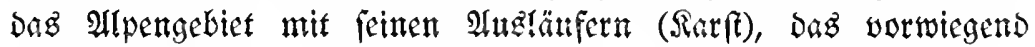

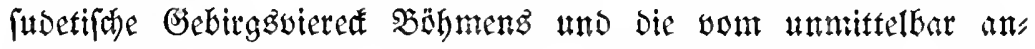
fále

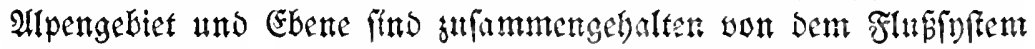

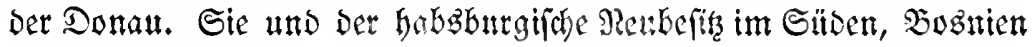

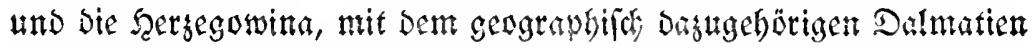
verbittden bie Monardjie mit Dent Drient, Der Dbarlauf Der Donau 


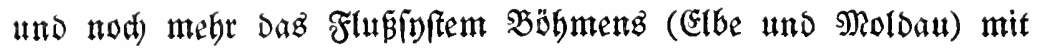
Dem $\mathfrak{B e} \mathfrak{i t e n}$.

Die Monar: die ald Gie blet bes

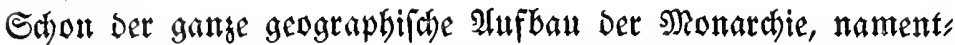

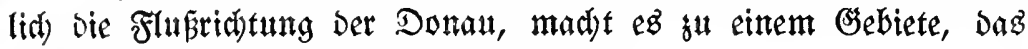

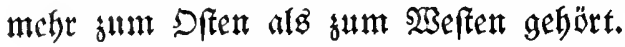

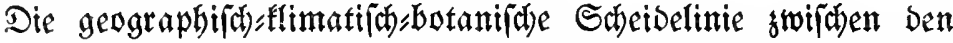
Dft: uns $\mathfrak{B e f t g e b i e t e n ~ E u r o p a s ~ i f t ~ u ̈ b e r ~ D a n g i g - X i s i e n - T r i e f t ~ z u ~}$

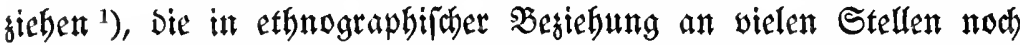

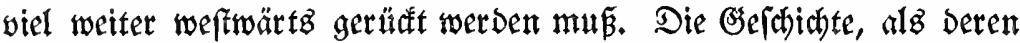

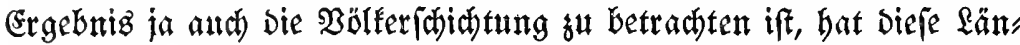
Derftrecten innerbalb Der Donaumonarchie in endlojen, blutigen

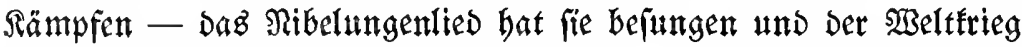
unferer Tage iff aud eime Phaje Darin - Dem Dften abgerungen, polififa uno fulturell an Den \$̧eften gefnüpft uno bamit zum über, gangżgebiete wom $\mathfrak{B e f t e n ~ n a d ) ~ D e m ~ D f t e n ~ g e m a d j t . ~}$

So ift bie Monardjie von Ratur aus ein Tampfland, wo Dit und Weft leit faft zmei Jabrtaulenden aufeinanderpreffen uno auf frete Fortfegung Dez Rampfes angerwiefen find. Sn unjerer zeit fenn

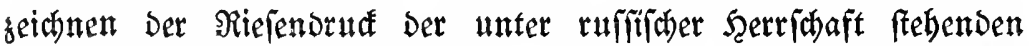

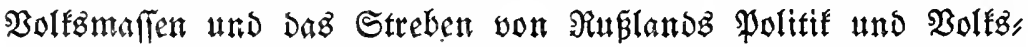

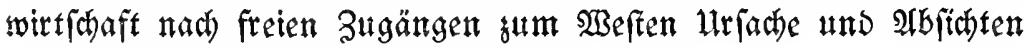
Des tobenden 2 Beltfrieges.

Diz teiltwetife bis in bie Saneeregion ragenden Gebirgsinfteme Ser Alpen, Dez Sarftez, Der Sarpathen entzieben weite flächen Der Beftediung überbaupt. Nicht weniger als $14 \%$ Der Flähte Der Monardjte liegen über rooo m hod', Der oberften Grremge Der normalen Deftedlungżmöglidbett. Diefe Gekirgzteile beeinfuffen nidht mut Das Slima, fie eridheren auth Die Beftedlung, bas Eindringen Der

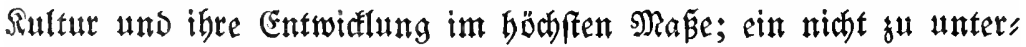

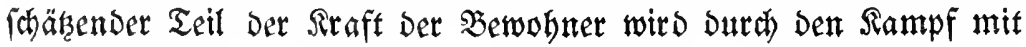
Den Raturgewalten aufgegebrt. Daglt fommt die weite Berbreitung unfrudtbaren Ralfes, ber wieber Io \% Der Dberfläche Der Monarchie auszmatht ${ }^{2}$ ).

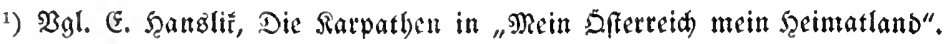
Bien.

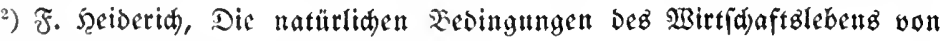

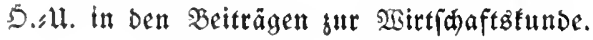




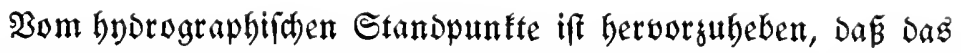
Alpen=Sarftsarpatheníftem vorwiegend die Gewäfter Der Donau

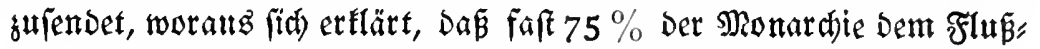
gebiete Der Donau angebören. Die zaflreichen Rebenflüfe find gan ober äberwiegend ober wenigftens in ifren widtigften Teilen $\mathfrak{B} e r g=$ fröme. Die Drau, bie Save fint in ifrem ganten öfterreidfifden Dberlauf nicht faffifbar. Sa felbft bie Donau trägt, obwobl fie idfon von Regenşurg an fhiffbar ift, biz Wien Den Eharakter eines aus,

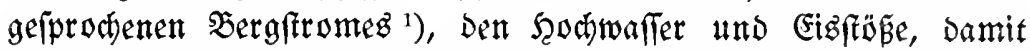

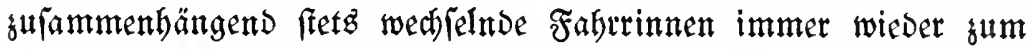

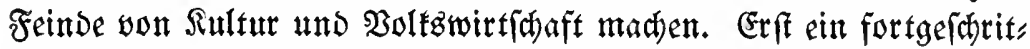
tener Stanopunt moderner Technif, Die Dampftraft, begann biefe

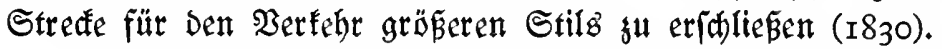

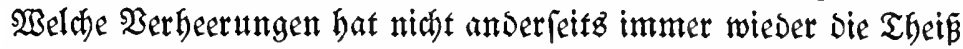

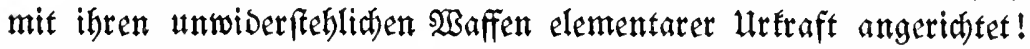

Der Gebirgzadaratter bez Donauteides bringt es mit fíd

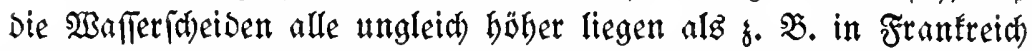
oder gar in Deutjaland, was für ben $\mathfrak{b a h n}$, befonders aber für Den

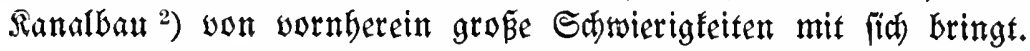

Für ein berart von Gebirgen Durdsogenes und umidjlofienes Gebiet, wie Die Monarajie, belitht die Berbinoung mit Dem Meere und in biefem Sinne bie Ridhtung fhiffbarer Flülle befondere

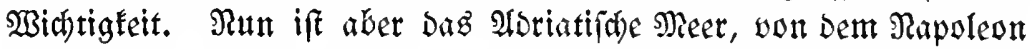
Die Monardyie im Sabre I809 Durds enggegogene Staatengrengen

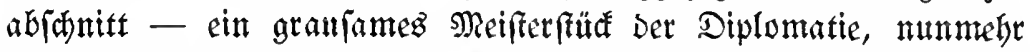

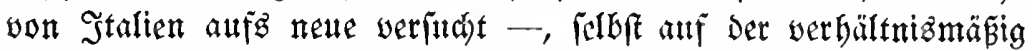

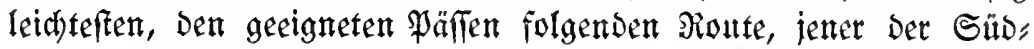
bahn, Surd) mebrere Gebirgzłetten (Der alpen, Der Sarawanten und beg

1) $\mathfrak{A} u \mathfrak{f}$ Der Strede $\mathfrak{P} a$ fian-Wien-Budapeft und Semlin-Turn=Severin

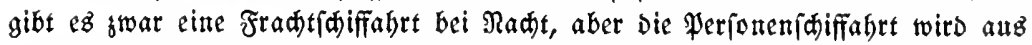

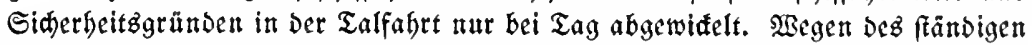

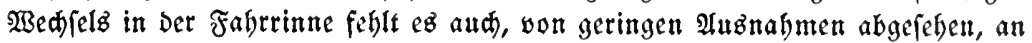

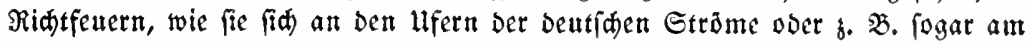
Amar befinden (ygl. Piftor, Durd Sibirien nad) Der Sübjee, Berlag Bran,

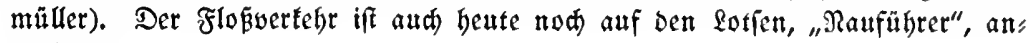
gewielen.

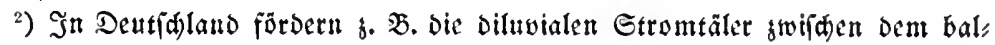

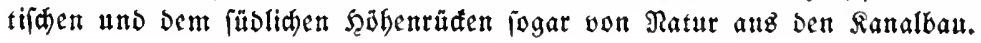




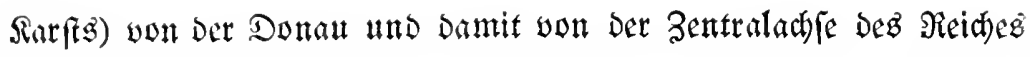
gefrentit.

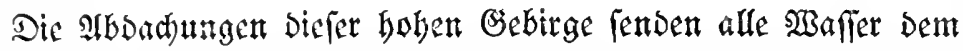

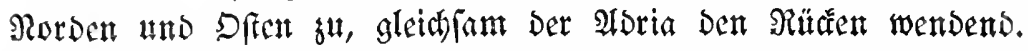

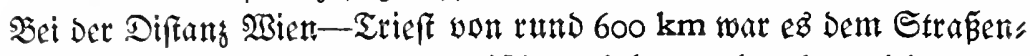

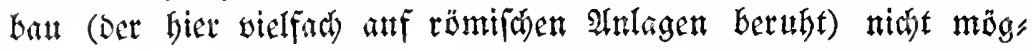
lid), bas Berkegraproblem entfpreftend gul löfen und bie einer

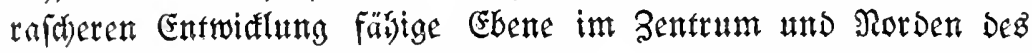

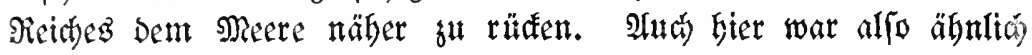
waie bei ber Donat Der Sieg über bie retarbierenden, natürtiduent

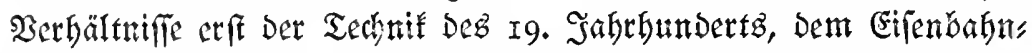
verkegre, vorbehalten. Gegenibber Maffergütern bleibt aber bekannt" lid) Die Eeifung

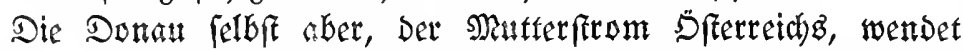
(iti) Dem Difen und nod) Dağl einem abgelegenten Sinnenmeere zu.

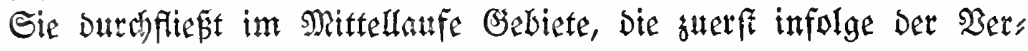

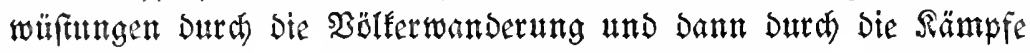

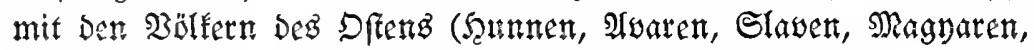

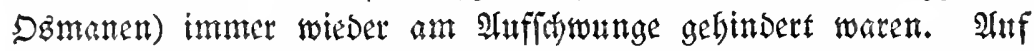

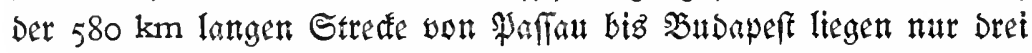

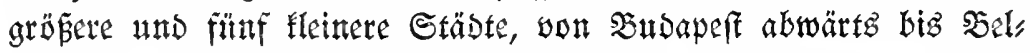

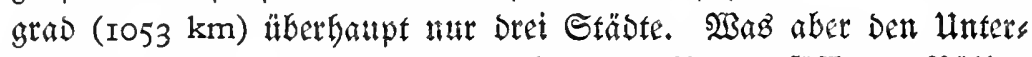

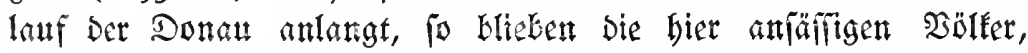
bie Eerber, Bulgaren und \$utmänen, infolge Der langen Dauer

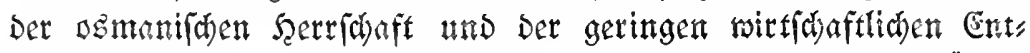
wielung fo lange geringtwertige Sonjumenten, bis die leid)tere litber" tragting won Sultur und Drganifution, wie fie bas Ende Des

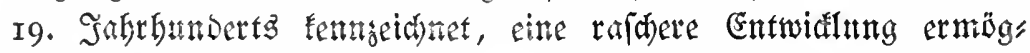

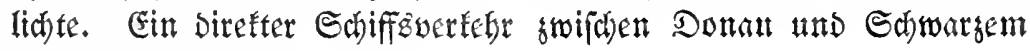
Meer if nautifá unmöglich.

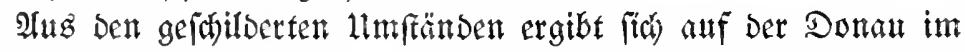

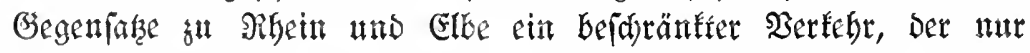

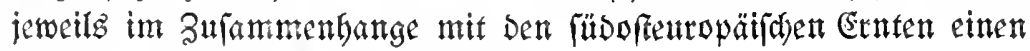
umfang größęen Stiles annimmt.

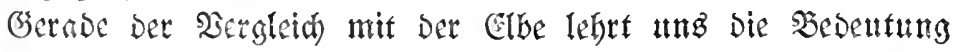
Der Dontal als eines Siromez fenten, Der biz in unfere Zeit un

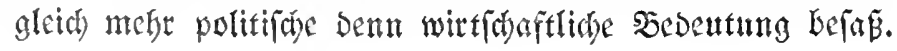


Die Glbe Gat einen gang Kurgen Dberlanj in Dfterretch. Bei

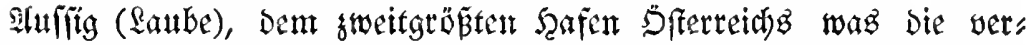

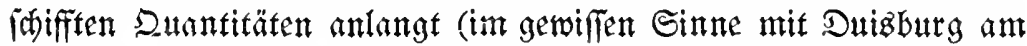

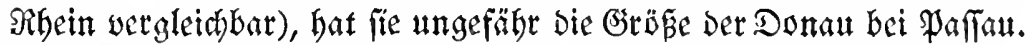
Dag bebiet ber Shiffbarfeit warbe in Den lekzten Safren Duth bie Ranalifierung ber unteren Moldau erweitert. Bei Der geringen Ent,

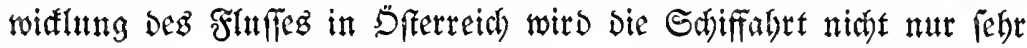

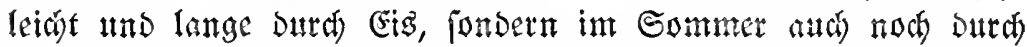

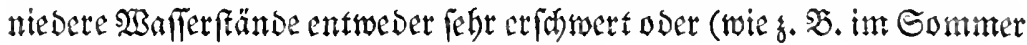
Des Saftes 1907) unmöglid) gematjt.

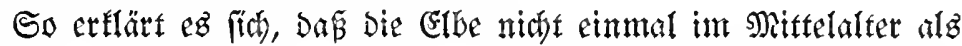

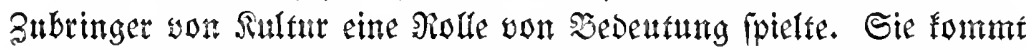

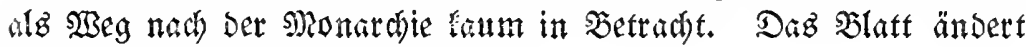
fich erft in Den leteten 50 Sahren.

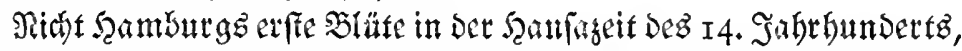

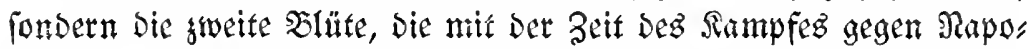

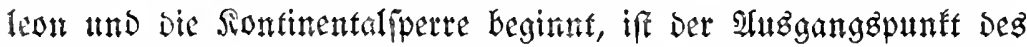
(3) (bebndels mit Dfferteid

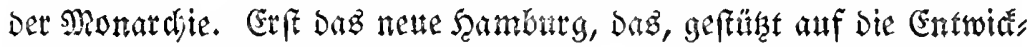

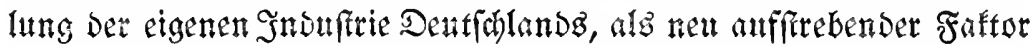

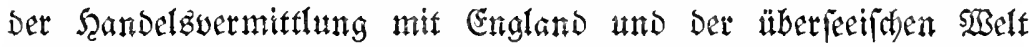

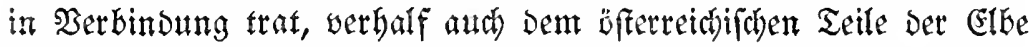

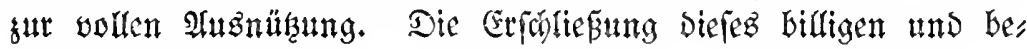

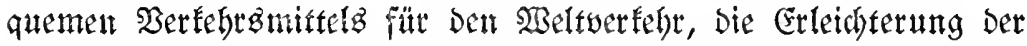
Bufugr von Maflengüterit Der Robptoduftion brachten Der öfter"

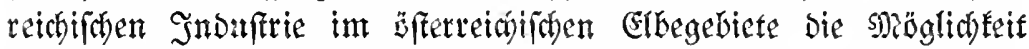
einet glänzenden Entwiflung. So wurde Durch die unmittelbare

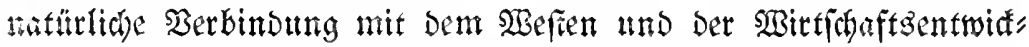

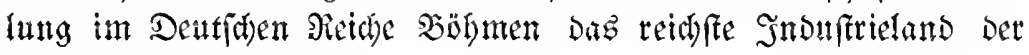
babzburgif́cten Irone.

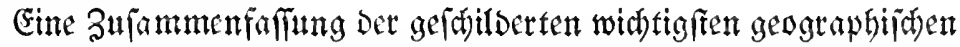
Sorbebingungen fellt bemttad) Diferreid)

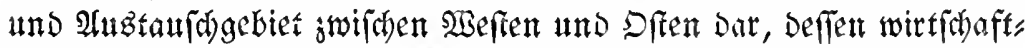

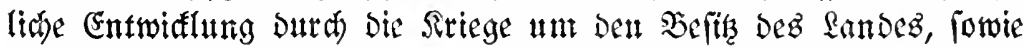
infolge Der in früherer Zeit faum befiegbaren, ungümftigen geogras phifasen $\mathfrak{B e r b a ̈ l t n i f f e ~ b u t c h ~ S a b t h u n d e r t e ~ w e i t g e h e n d ~ g e b e m m t ~ w a r . ~}$

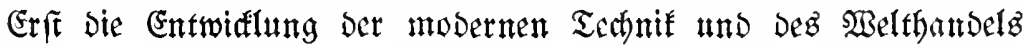


bat bie llugunft biefer Semmniffe im vorigen Sabrbuttoert fu bebeben begonmen.

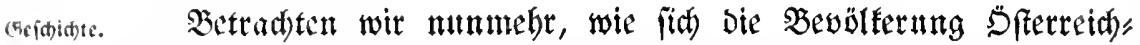
llngarns in Den veridjedenen Epod)en den geographifaen Borbe: Dingungen angepa aft hat.

Ratur: seitaltet.

Die gefoloffene Bälkeranfiedung in Europa erfülte in altertum nur bie Snbtropenzone uno reidfte an Feiner Stelle über bas Gebiet

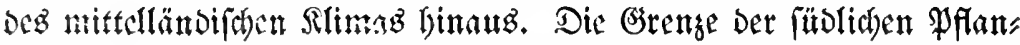

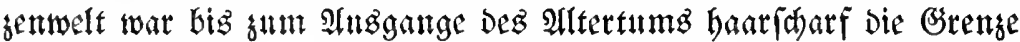
Der fultivierten and anfultivierten entopäifonen Frde. Alles fand nördith) Der fpanifbear Mefeta, Der Sevennen, Alpen, Dez dinarifden

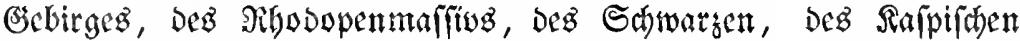

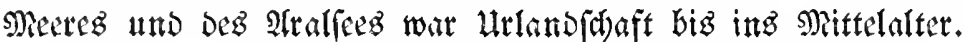

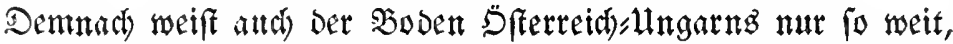
als er mebiterrat ift, gefdoloffene antife Stedelung und 2 Sirtidnaft anf. Dagegen find Die Sitbhänge Der $\mathfrak{A l p e n}$ und die abriatifhe Sinfte ältefter europäifcher Sulturboden wie Stalien uno Grtied)enlans.

Die Macht Des antifen Staatez reidhte allerbings weiter als bie geidhloffene Siedelung, fo befonders in lungarn.

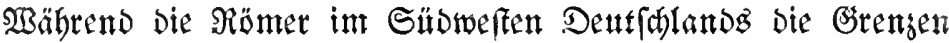

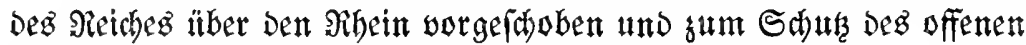

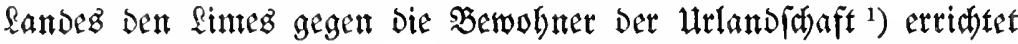
Gaben, bildete im Dfen - von mebi ober wentger vorübergebenden

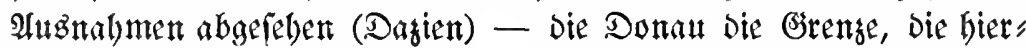
mit gum erfenmal eine igrer vielfeitigen politifben $\mathfrak{A}$ ufgaben erfüllts. Die genannten Provingen befaßen Dementiprediend vor allem mili; tärifichen SGarafter; fie waren $\mathfrak{A b}$ webrs und Puffergebiete gegen bie Ģermanen.

Anz Dem weiten Iazeinanberliegen Der antifen Statgs uno

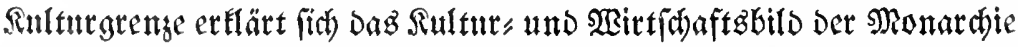
im Slltertum. Die in Den Alpen lebenden Raturob̈lfer wurben roma: niftert, Die in Den Sndeten und im größten Teile ber Sarpatgenländer

1) Ė Darf bei beurteilung Der Sieblungżgefdid)te uno ber llanfänge Der

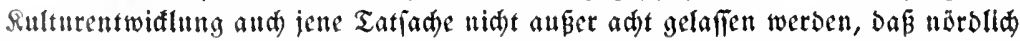

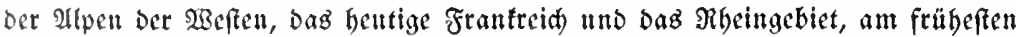
eigfrei maten, wäbreno die Entwidtung in Rorbsentfalano uno ben alpenbergen Durd) Das (Fis tunergleidliđ länger gebemmt war. 
lebenten germanifhen Raturvälker blieben unberührt. Sildlián Der Donau wurben alz römijhe Sulturinjeln Feftungen erridytet,

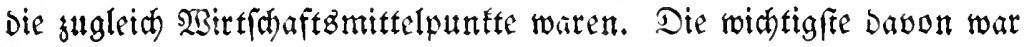
Carnuntum (am Eübufer Der Donal, $40 \mathrm{~km}$ von $23 i e n$ ), ber $P_{u n t}$

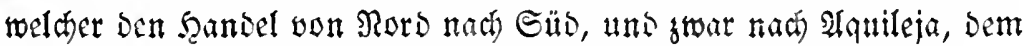
Şauptplatęe an Der Grente des eigentlithe Jtalien, vermittelte. Fin

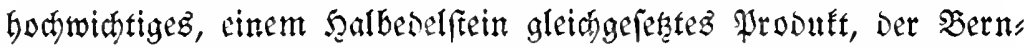
firin, war ber Şauptbandelsartifel; fonft famen Flüperlen, Pelze, Febern in Betratht. Inseres batten bie nördithen, unwirtlichen

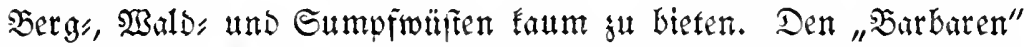

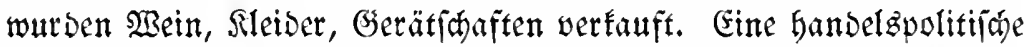
Bebeutung fam der Donau, biejer Eheibe zwijhen römijhen Sultur" vorpoften und Urlandidaft, nid)t jut.

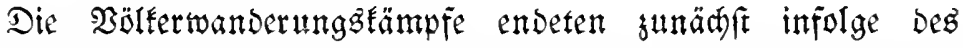

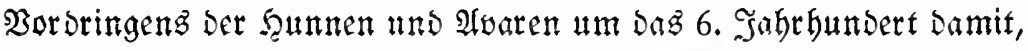

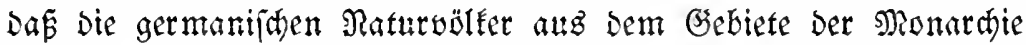
abzogen. Sar bas meftitfe Alpenoorland bis zur Enns blieb in ben Det etros im Bettalfet ses $\mathfrak{\text { Botbett }}$ ifiens oer Rantowirts Şänden ber Bajubaren. Unmittelbar sarauf lę̧t aber ber netter"

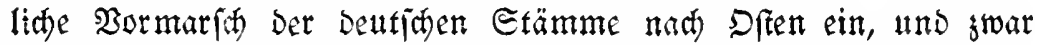
ber Alemannen anf Borarlberg, ber Bajuvaren nach Tirol, ber

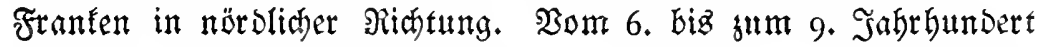

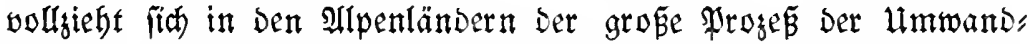

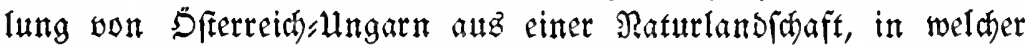
nur vereingelte Siedlungginfeln liegent ${ }^{1}$ ), in bie geithloflene Rulturlanb/haft. Biz bahin war ein gefdloffener Wirfidaftä; färper, D. h. ein zulammenhängentes Neks ländlidber "Sieblungen, nut im Miftelmeers:Bereide Der Mionardite vorbanden gewejen. Nun

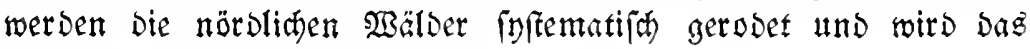
gange land in $\mathfrak{A}$ bat genommen.

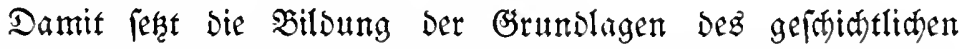

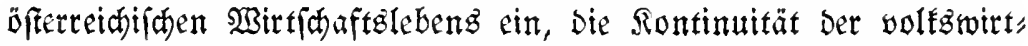
(chaftlichen Arbeit beginnt; Dfferreids/lngarn tritt mit Dem

1) $\mathfrak{O g l .}$ Die $\mathfrak{H}$ beiten Deg 1914 in Den Sämpfen an Der Eave gefallenen, bagnbredenden Gdefrten Dr. A. Gruno in Pendz Geogr. Abh. und Biertel,

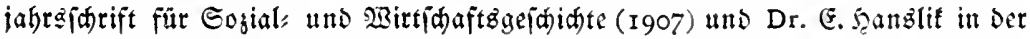

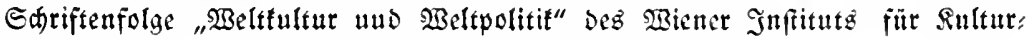
forífung, bei Brudmann, Mänden, im Grídeinen begrifīen. 
Beginne der Befiedung feiner reflitien Gebiete Dard

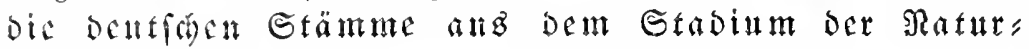

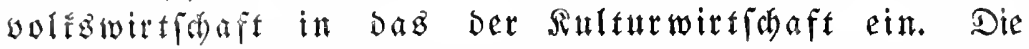
Slaven madien bicfen arnffiteg in Den Gögeren Zuftand ber gefells

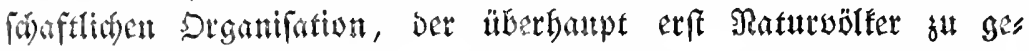

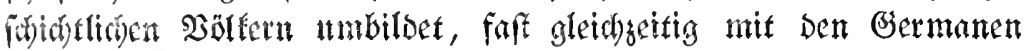

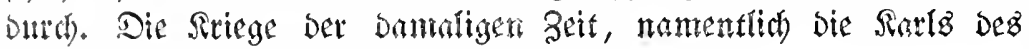

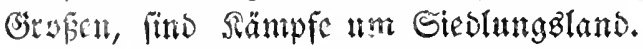

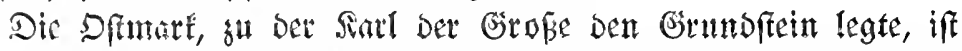

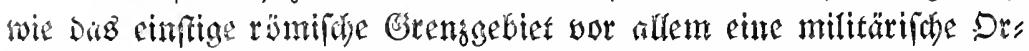

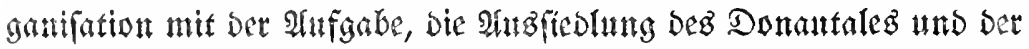

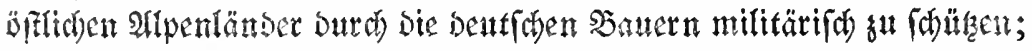

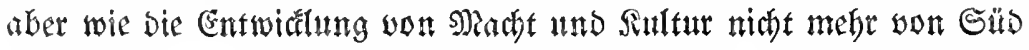
naci) Rord, fonoern won Weft nach Dff fortforitt, erftedfte fich biefe

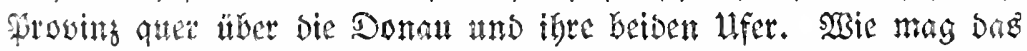

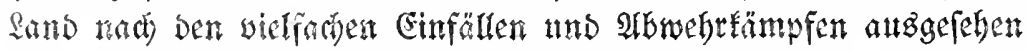

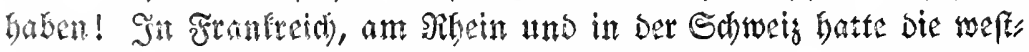
liche sultur bie Grunolage fïr bie neus Entwidung in Berwaltung

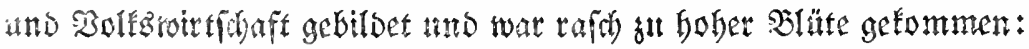
Seter batte man Dutch rumb 500 Sabre cinen gegenfettigen Bernichs tungs:, einen sobren Rofatentrieg gefüht.

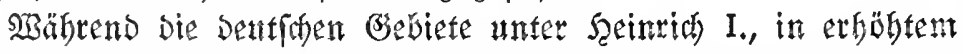

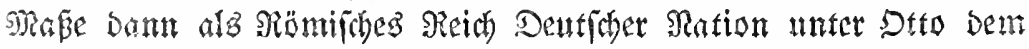

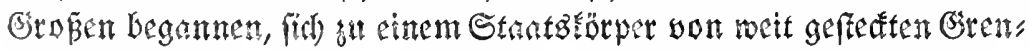

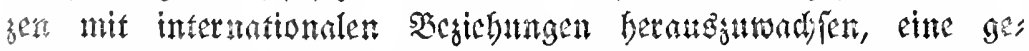

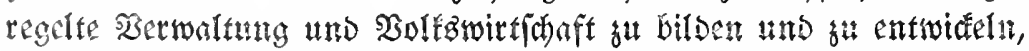
brutfe un 900 anz bem Dften cin netter Sturm baber - bie Magy) sren, ein Steppenudl, bas weder im Dfen wod im Sisefen oom

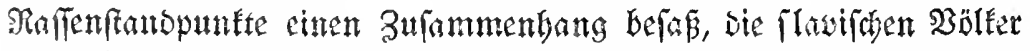

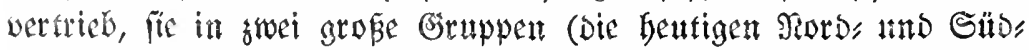

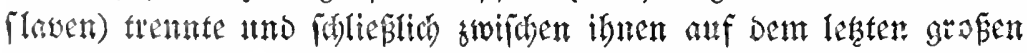
Steppentoren im Serzen Europas, in Der grofen Donatiefebene, feinen bauernoen 230 bnfitis fand.

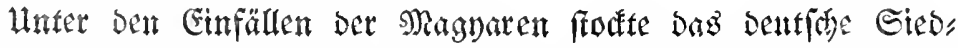
Inngsuert im Dften zeitweilig, biz won newem unter Dtto I. Die Dft: mar gegründet 4 tho 976 feopolo ber $\mathfrak{B a b e n b e r g e r}$ bamit belegnt

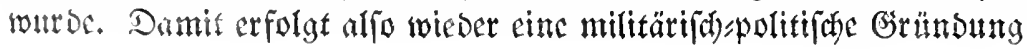




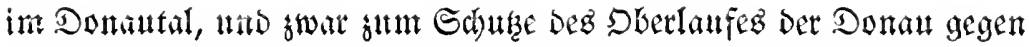
Das untubige Eampfluftige Mieifervolf Der Magyaren, bie erft Friedrict)

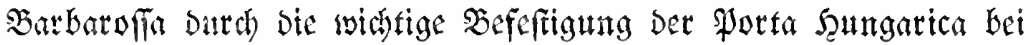

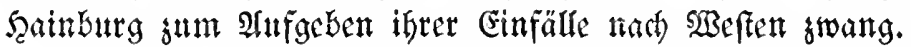

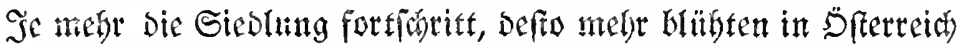

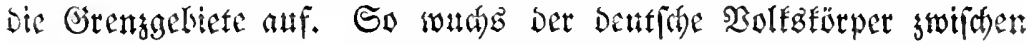
Dem Io. und Dem I3. Jahrhundert sbernals mächtig gegen Dfen und

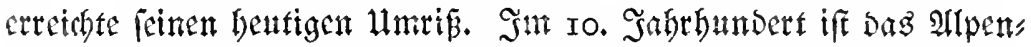

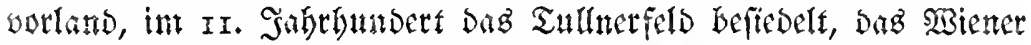

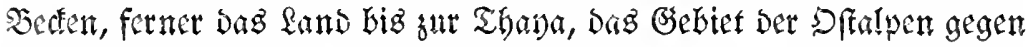
Ungarn, bie weftlide obetungarifhe Tiefebene tho bas fitblidse

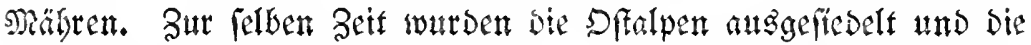

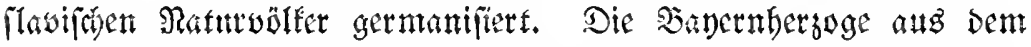

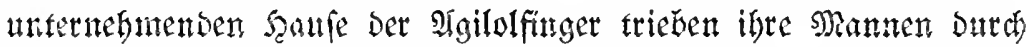
Tirol bis in bie Steiermat und nath Särnfen gegen bie Säbjlaven vor.

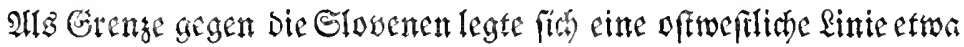

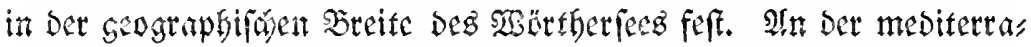
nen Sienge haben fith bie Lavinet wor Den Deuthen bis bente gebalten.

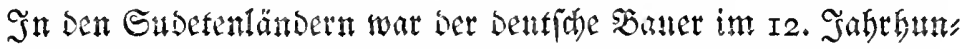

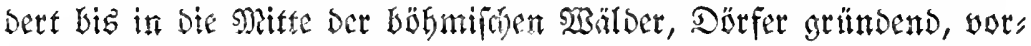
gedrungen. Sint I3. Sarbryatnder legten bie dentionen Siedlet anf

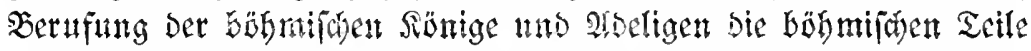
Der Grengmälder um und vermandelten die gebirgigent Teile Sitd,

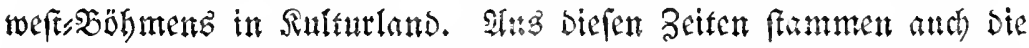

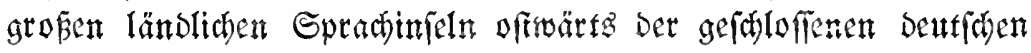
Spract)grenze in böbmen, Sirain thro lingarn.

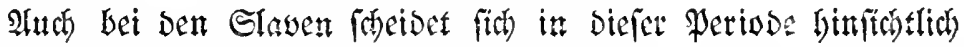
ber Fulfurellen und wirtfindflicien Entwiftung Raturs lind Ges f

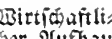
(her $\mathfrak{A}$ Iufball ientionen.

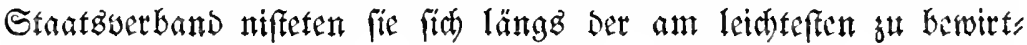

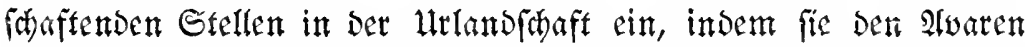
und Dent abgiebenden Germanen auf Dem Fufe folgten. So gewannen

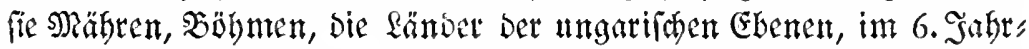
bundert bie Dftalpen, im 7. Das Dinarifhe Gebirge. Die cinteimilate romaniferte Sevolferung wutrbe im Simpf getötet oder im Frieden

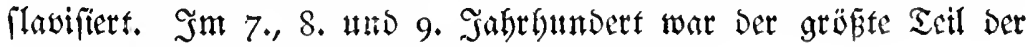
Monardje von flavijón Stämmen bejtedelt. 
Ilß im 9. Jubrhundent bie Magyaren längß Der Steppengebiete cinorangen, wurbe die flovifhe Bevölkerungsdede in Den zentralen Efrenen Der Monardjie vernid)tet. Natr jenjeitz Der ftarken natür,

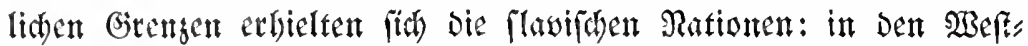

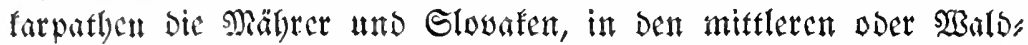
farpathen bie llftrainer (Dutthenen), im SüDen jempettz Der Drau bie

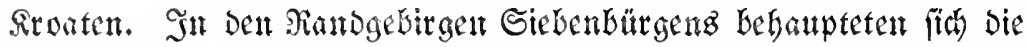

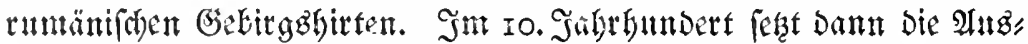
bildung ber politifact und nationalen Individualitäten ein, wobei aber über Den widytigfer Dorgang, Den Des 1 berganges yom Ratur, sum Sulturgufand, feine Radridnten vorliegen.

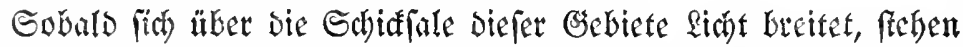

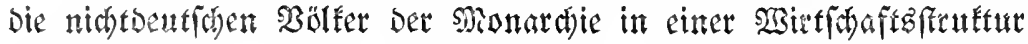

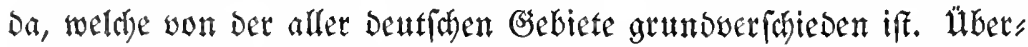

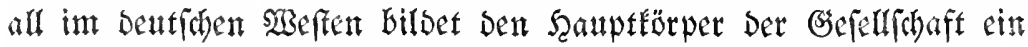

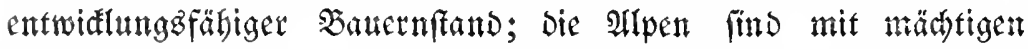

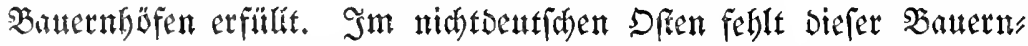
fand faft gang. Dagegen entfanden in Den Tiefebenen, in und rund

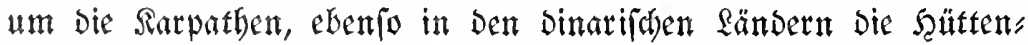
anbäufungen im Stile ber ofteuropäifhen $\mathfrak{B o ̈ l f e r . ~ D e r ~ G e g e n f a ̈ ~}$

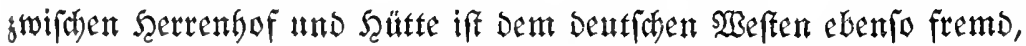

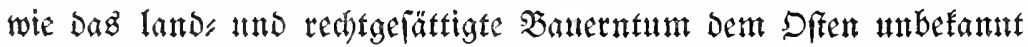
ift. Diefe Grundlagen Dez in ber Folge an mantien Stellen und z̆ manthen Beiten etwaz ver"

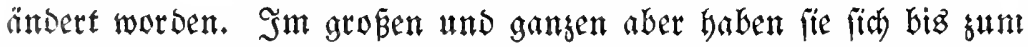

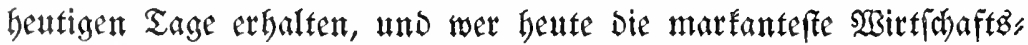

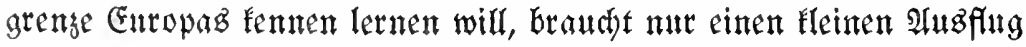
auf 30 biz $40 \mathrm{~km}$ won $23 i e n$ nat) Dem Dften fut unternebnen, wo a Der Mard die gefdloflene felbiändige banernwirtidaft

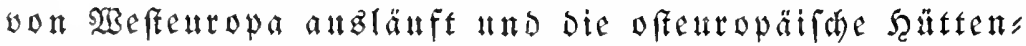

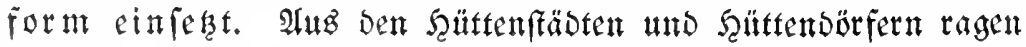

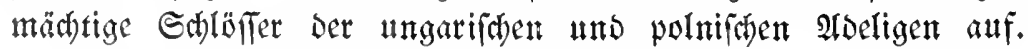

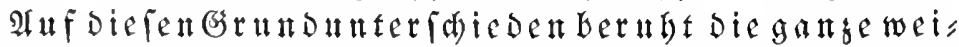
tere Entwidung Des Wirtiflaftalebeng Der Monardie.

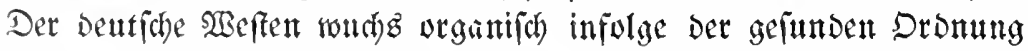

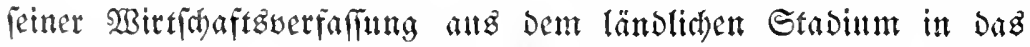

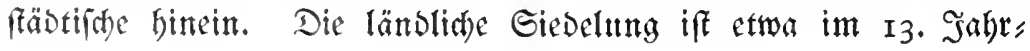


bundert beendet. Dis fäbtif be beginnt. IUlentbalben in Dentidgen fanden erbeben fith inmitfen Det woblhabenden gutgebanten Dörfer

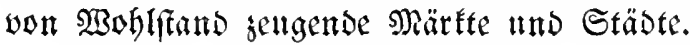

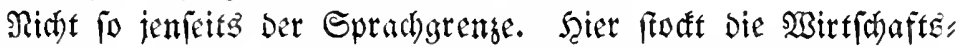
entwidlung, ba die fogialen und rechtlichen Boratsjefzungen für

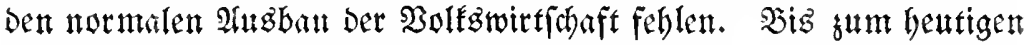

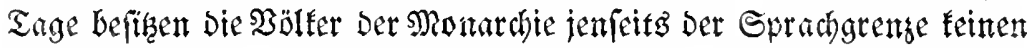

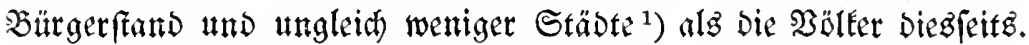
Sn Den öftichen Märften und Stäbten fiedeln Dentiche unb Sttben, bie ber umgeberiden fandbevälferung atational und fulturell fremo gegenüberfteben. Errft beute beginnt fith) biefer auftand fa ändern.

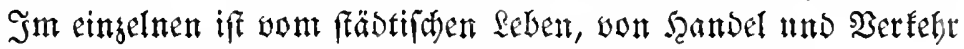

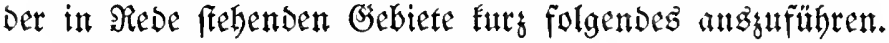

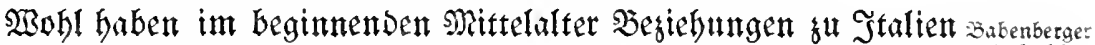

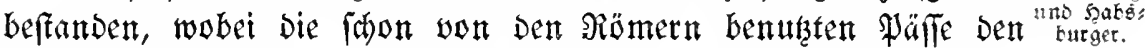

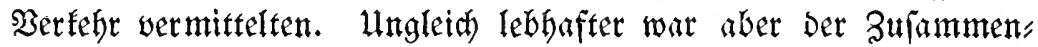
bang mit bem politif(t) bedeutfamen und wirtichaftlid) aufblübenden

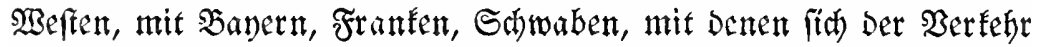

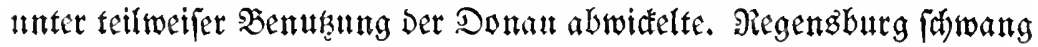

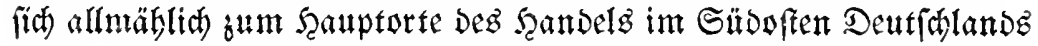
auf. Die Regengburger Stiftăgeren betrieben in $23 i e n$ und Enng eine Fattorei.

Die Maffe Der Sevölferung lebte, wie tiberall in Enropa, won

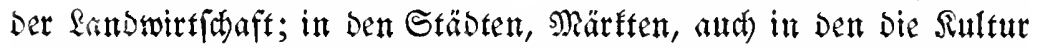
mächtig fürdernden Ilöftern wurde Şandwerkßarbeit geleiftet, aber vorwiegens lofal verwertet.

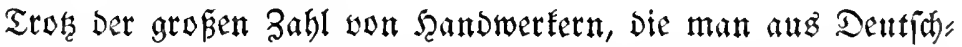
land tno Stalien begog, und ber vielen Bünfte, die es gab, fehlte es aber an Betrieben, die für Den Export gearbeitet hätten ${ }^{2}$ ).

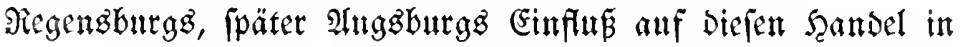
und mit ber Dftmart ging anzerorbentlid weit. Serzog feopold VI.

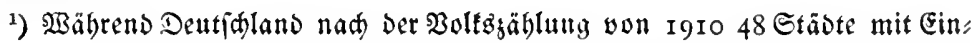

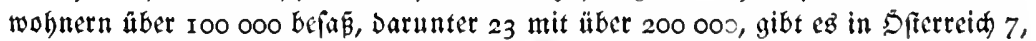

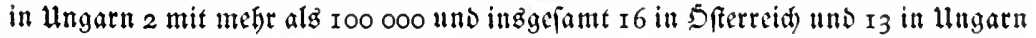
mit mebr als 50000 Einwobnern. Rur brei in Sfferreid und bubapeft in llngarn baben mefr alż 200000.

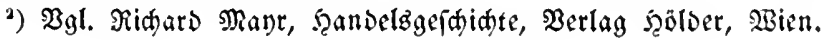




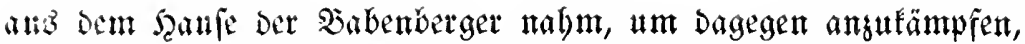

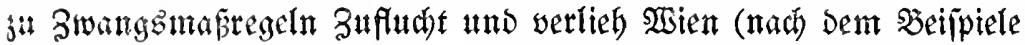
Bencbigg) bas Stapel 4 nd Rieberliggerectr, um wenigftenz Den

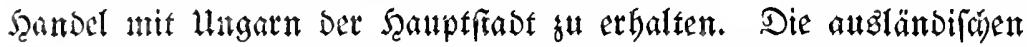

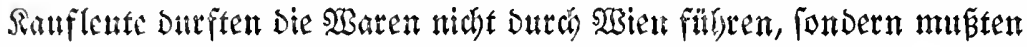

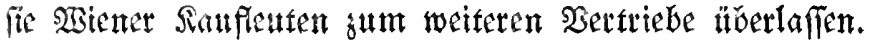

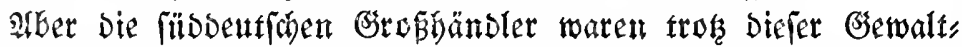

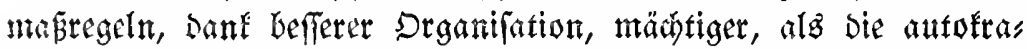

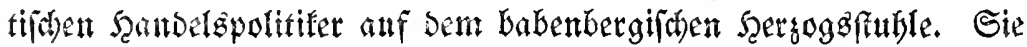

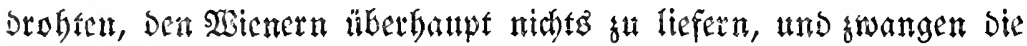

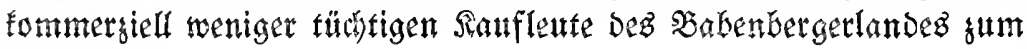
Nach $\mathfrak{g e b e n}$.

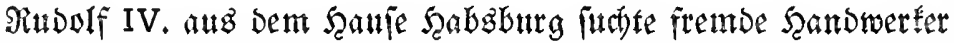

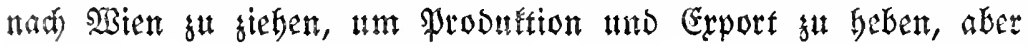
erfolglog. Sie W3iener Sauflente tradseten vielmebr wieder, Dent

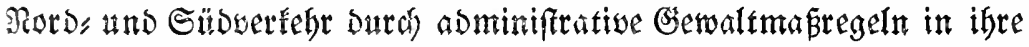
Sornd fub befommen, inden bie auswärtigen Rauflette mur bie Strapen Wuer Şontafel, Subenburg und Den Semmering, mit Dem Intgangs" punkte Wien, benuben Durften. Den Borteil batten nur einige SBienter

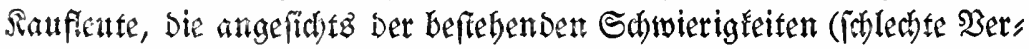

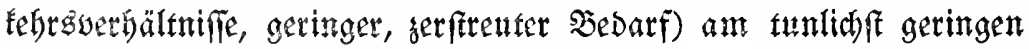

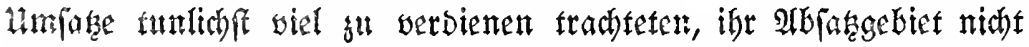
ermeiterten, weil fie nibista ristieren wollten; für Die Allgemeinbeit blieb Der Borteil aus, Denn eine Belebung Des Berfebra trat niát ein.

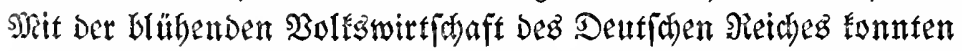
(ich) Demnad), wie oben angefüht, Gerwerbe und Şandel in Den öfers

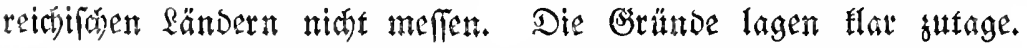

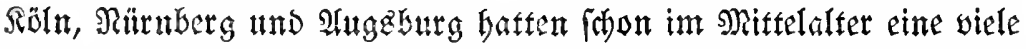
Soundert Sabre alte, mebr oder wentiger unterbrotjene Entwiatung

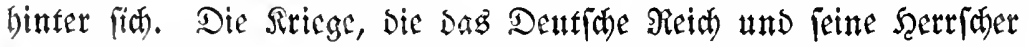

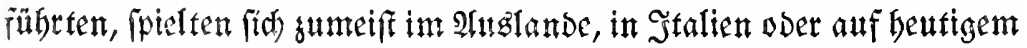
üferreidifhen Gebiete, fowie im flavifhen \$renten ab. Son den unmittelbaren Berbeernngen Der mittelalterlichen Sriege blieben bie bentichen Şauptgebiete und Die Dortigen Ergengungzitätten, Die nod) bagll in engerem 3urammentyange mit Dem bochentwifelten

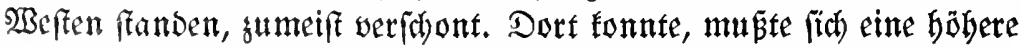
Siultur entwifeln. Daher war Dort Der Bebarf itberbaupt, aud jener 


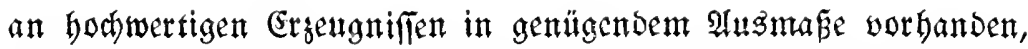
Dementiprectend die Probuftion entmiăelt, wä̈rent in ben öfer,

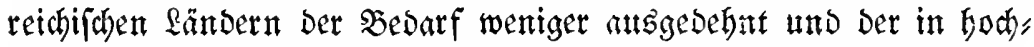

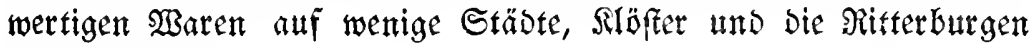
gerftreut $\mathfrak{w a r}{ }^{1}$ ).

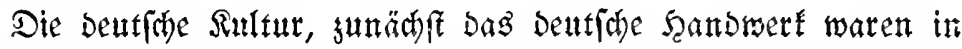
Den fänbern Der bentigen Donammonardje das beifpielgebenve und

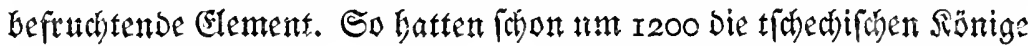

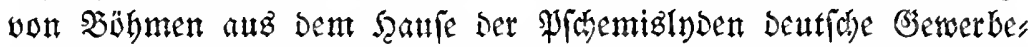
treibenbe nach Prag berufen, Denen now beute der Beftand dez Dentich,

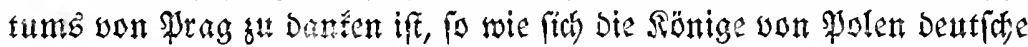

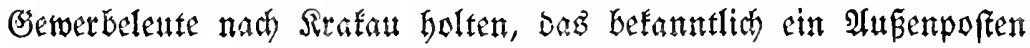

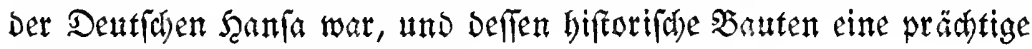
Deutide ?enaifance aufmeifen.

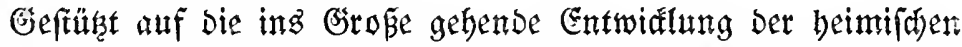

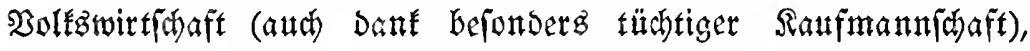

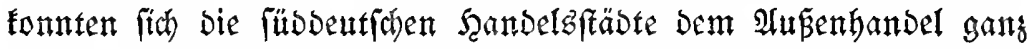
anbers wiomen als fum Beifptel खien uno nübzten baber bie

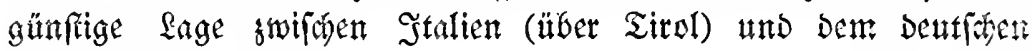
Norden träftig aus.

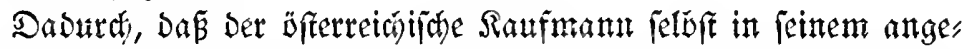

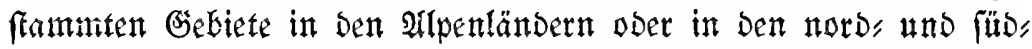
ungarifaen Gebieten Dem zerftrenten bedarf angefista der beftehenden Berfegrshindernille wentger intenfiv nachgeben fonnte, wurben alle

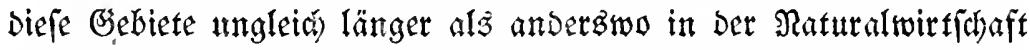
belaffen, faft folange, biz dar Bertehr modernen Stils, namentlić

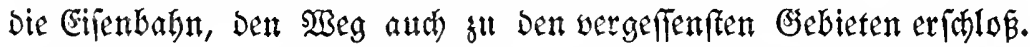
Der Borteil, Der Damit verfnüpft war, beftand in Der längeren Ers

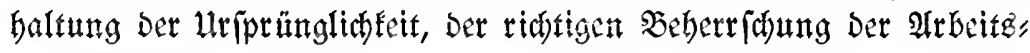

1) Sebreid) iff an ber Şand Der mittelalterliçen Baubenfmale ;. B. cin

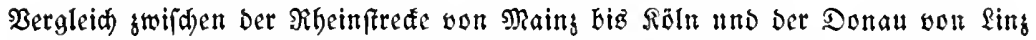

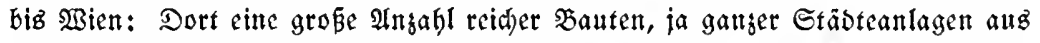
romanifher uno gotifher Beit, bie auf bie hobe Entwithng jener Gebiete fonon im

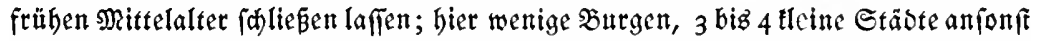

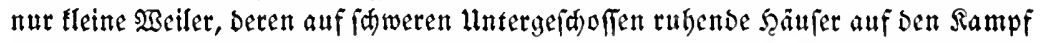

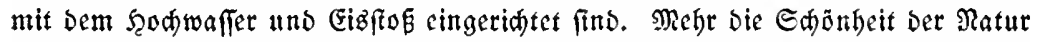
uno ber ftillen, hohen 2 Balsberge iff eB, bie bier bie Etromfabrt im Strubens uno Ribelungengan forie in Der $\mathscr{B}$ adjau angiefeno uns interellant geftaltet. 


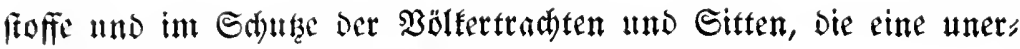

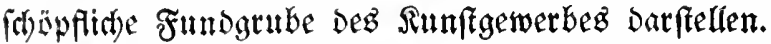

Saifer Maximilian I. Gat ben Wienern nath Der Erwerbung won Trieft weder bas Privileg Dez Straßßen noch Dez Stapelzmangez

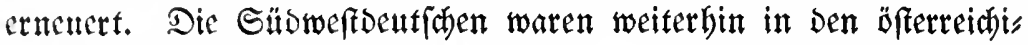

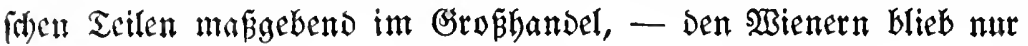
ber Sileintandel.

Unter Sarifer Max̧imilian I. und Sarl V. traten nitht fut unters

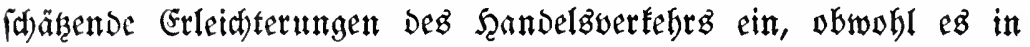
Dem Reiche, "in bem bie Sonne nicht unterging", Dafür wieder an Zollgrengen wimmelte. Bom autofratifden Maddftanopuntte war

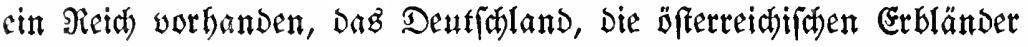
uno bie Niederlande umfä̧te; aber es war in ungäglige Sondergebiete jerriffen. Maximilian fann allerbings für fich in $\mathfrak{A}$ njpruth nebmen,

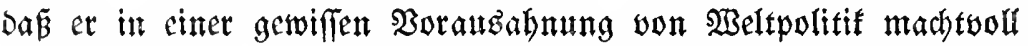

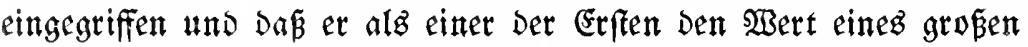
IbFatzgebietez für die Produftion erfannt bat. Daher futhe er entgegen ben fonftigen Tendenzen gerade vieler Rauflente die Sinder,

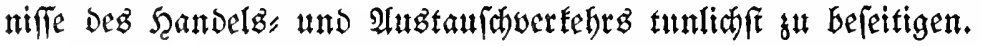

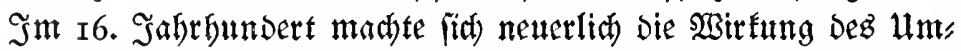
ftandeg gelteno, Dẩ die öfterreichifhen (Frbländer nach Der geographi"

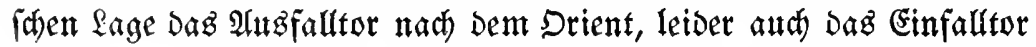
aus Dem Drient waren. Die Dsimaneneinfälle beginnen, nachdem Romftantinopel und Der $\mathfrak{B a l k a n ~ i n ~ b i e ~ S ̧ a ̈ n d e ~ D e r ~ T u ̈ r k e n ~ g e f a l l e n ~ w a r e n . ~}$

Wieder muß Dag Donaureich innerbalb feiner eigenen Grens zen einen Srieg über fien crgeben laften. Bis äber Wien, ja bis gegen ఏberöfterreid, jieben die Ģorden, allez wernichtend, mordent uno plündernd. Saum ift diefe Rot teilmeife vorüber, ohne

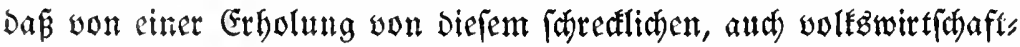

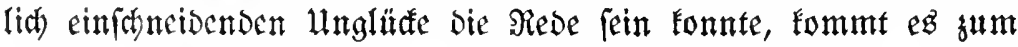
30 jälrigen Srieg, in Dem Den öfterreidjijhen Erbländern ein lo weit, gebender $\mathfrak{A n t e i l}$ befdieden war, Der unter anderem Der Donall entlang,

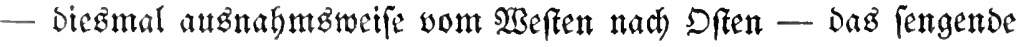
und brennende Seer Torftentons biz fnapp yor Wien fübrte.

खsenn aud biesmal die Erblande in ifrer Gefamtheit nicht fo (idredlid) litten wie bie Deg bentigen Deutichland, fo waren Dod

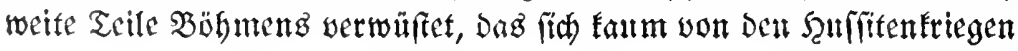


erholt hatte. Dann aber fam wieder ein türtijaer Srieg, Der netterlid biz nad) Ungarn und biz vor Wien Drang. Erft im \$affaromizer Friedent wird die Türennot jum Ende gebrad)t. Snfolge diefer fortwährenden Dpfer an batt uno Blut geriet bie kulturelle und wirtfaraftlidse Entwiatung weiter Gebietziteile inz Stodfen.

Ratier Reopold I. veriuthte burdh bandels" und exportpolitifde

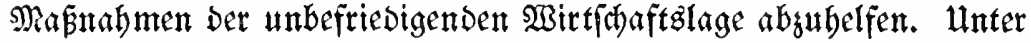
feiner Regierung wurden von S. S. Bed)er, Der aus Surbayern ftammte,

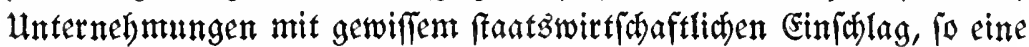
Seidenfompagnie, Dann Das Manufafturbans am Wiener Tabor, gegründet. Die Unternebmungen bewäbrten fĭh nid)t. Ëz feblte Der rid)tige probuftive Boben als $\mathfrak{B}$ afiż für Den Exportbetrieb.

Unter Saifer Sarl VI, wurben Trieft und Fiume in Freifäfen umgerwandelt uno abgefeben vom abjaluffe dez bandelapolitifa) fo wiatigen Paffarowiker Friedens I7 I9 eine Drientalfompagnie für die

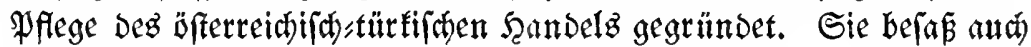

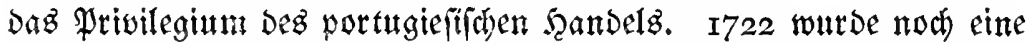

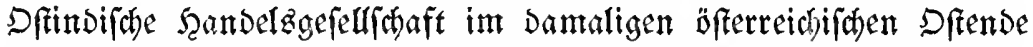
gegründet, Die aber I73 I im Wiener ßertrag Der Ronfurreng Englandz und Franfreidy geopfert wurde. I740 ging aud bie Drientalfom, pagrie ein, fowie die fpäter gegründete ägyptifale und eine jweite Dftindifore Sambelsgefellichaft. Shliejlich wurben bie fpäter er" worbenen öfterreidjifłen Solonien preisgegeben, fo bie Delagoabai, Die Rifobaren uno ber ḩafen won Mangalore in Sïbindien.

Diefes Febllathgen bababurgif(c)er Exportpolitif jener Zcit ift

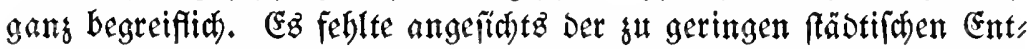

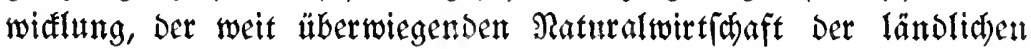
Diftrifte an genügeno grobem bedarf uno baher aud an genügens

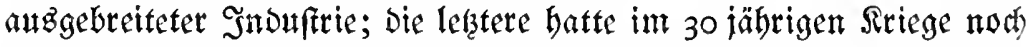

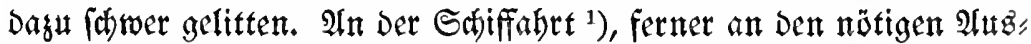
landbegiebungen mangelte es ebenfallż. Die etwähnten Brünoungen

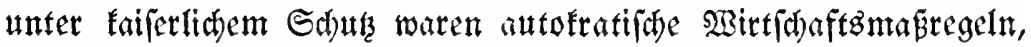

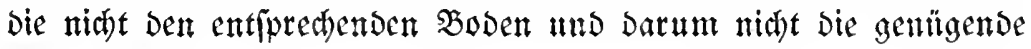

1) Raifer Rarl VI., Maria Therefía und Sofef II. förderten labbaft Den Şafen won Trieft. SMan tann Trieft Das lebendige Dentmal Maria Therefáa mennen. I790 verfügte zwar ber Şafen über eine Sdiffahrtabemegung vou 6000 Sdiffer - aber nur 6\% bavon trugen bie dfterteidifae Flagge. 
encrgifhe llnterftitz̧ung bei Den Saufleuten fanden. England, Frank" reich unb bie Riederlande waren ba als die Erben Spanienz und Por, tllyals gang anders geftellt; Dort war bas welttundige Sntereffe ber Saufleuti Das treibende Ëlement.

Tumete so: lomifation

surd) Bie

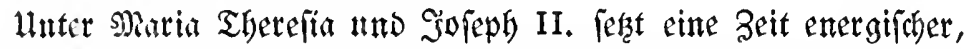
innerer Solonifation anf Deuticher Grundlage ein, wobei bas Der,

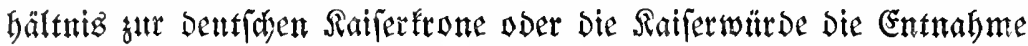
won Soloniften ans nid)t babsburgijhen \&ändern weifgebend erleich),

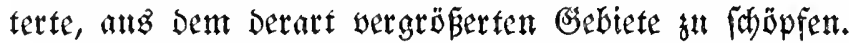

Die $\mathfrak{B a t e r n}$ auz dem SBeften follten beifpielgebend auf die magy)

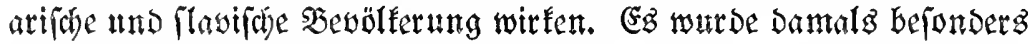
bie Serpfiangung ${ }^{1}$ ) von Samaben an bie Sübgrenge Dez Banats tno nath Slavonien, ferner won Franten nad Saltzien und Der Buforina verfügt. Diefe weittragenden Maß̈atabmen fonnten aber nur teilweife Grfolg ergielen. Die Eintwanderer genoflen fwar ge"

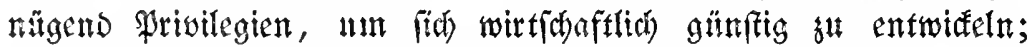
ohne Borrechs wären fie eben nidyt ins fand gefommen. 2 ber Den Sacibart ofme Grund und Boden oder mit fut gering bes

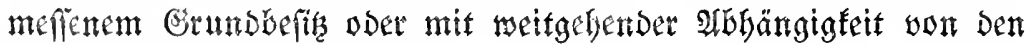

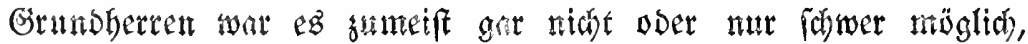
ans bem beiplele ber wirtfhaftlia böberfebenoen Einmanderer Nusen gut zieben; eg feblte ifnen Dagu an Den notwendigen materi; ellen Sorausfegungen. So entwifelten fïh zwar bieje Dafen, aber

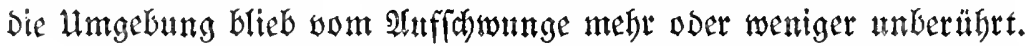

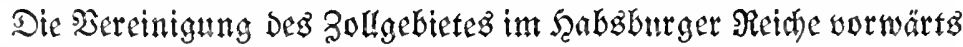
gu bringen gelingt erft I775. Samals murben wenigftens bie bentfisen,

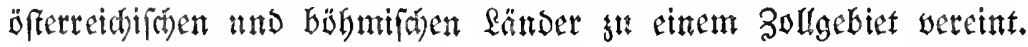
Ungarn (mit Slavonien, Dem Sanat und Siebenbärgen) bilbeten

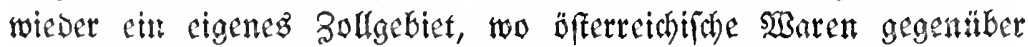
Den mit einem 30 prozentigen $23 e r f$ olle bebafteten fonftigen (Fin

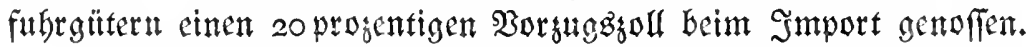

Die Bolpatente Jofefz II, von I784-I788 Dienten nicht mut Den

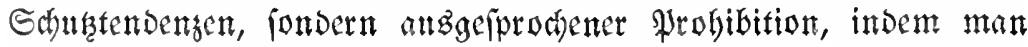

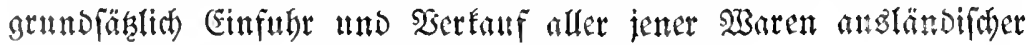
Serfunft verbot, bie im Sinlande ergengt wurben.

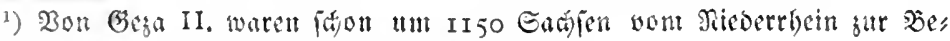
fiedung Eickentügens ing fant gertfen worben. 


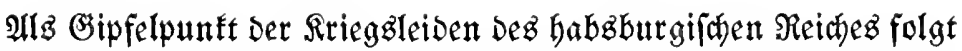

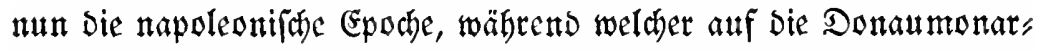
dyie eine bejonderz fdjwere laft entfiel. Woulfommene Zerrüttung

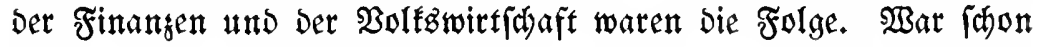
I740-1790 Die Staatzifuld won 45 auf 400 Millionen Gsuldon

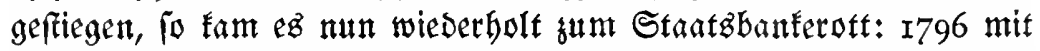

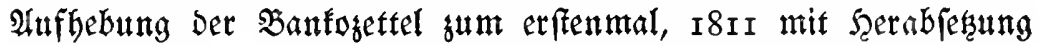
Dez Nenntwertez Dez \$apiergeldez und Der Rupfermünzen auf Den fünften Teil zum zmeitenmal, I8I6 zum Driftenmal.

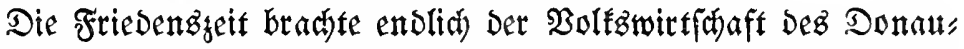

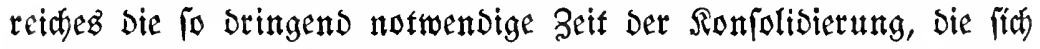

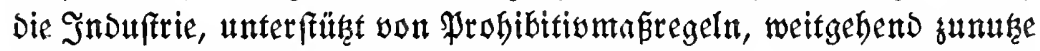

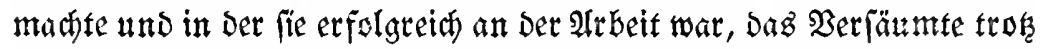

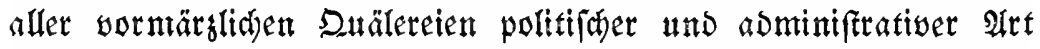

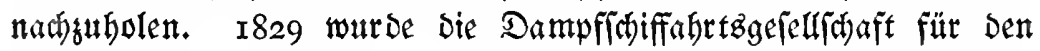
Donauverfegr gegründet. Der Dampferwerfegr auf Der (Elbe und

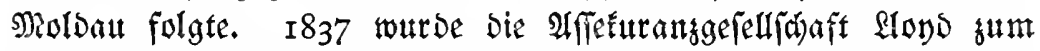

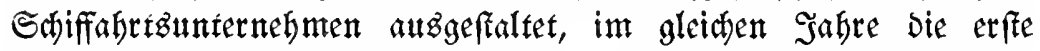
Eifenbahnlinie Floridzoorf-WBagram, I854 Die Semmeringftede

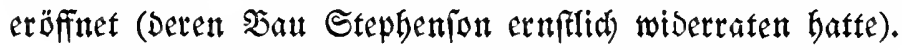

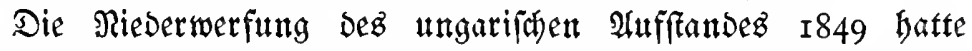

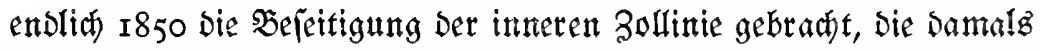

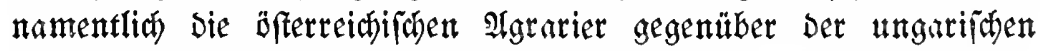

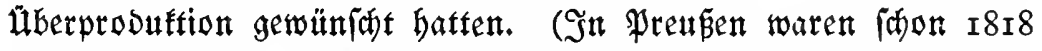

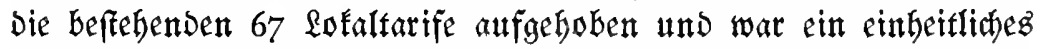
3ollgebiet geida fenen worden.) I85 I traten an Stelle Dez bizherigen Derbot

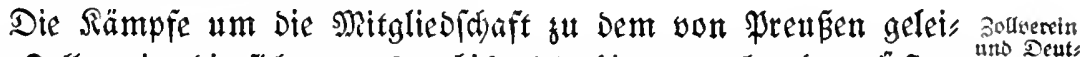

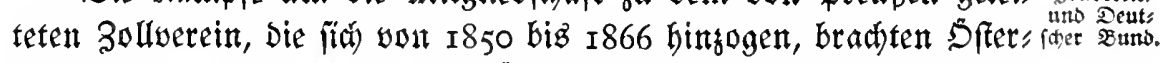

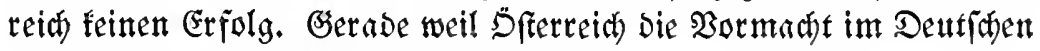
Bunde behauptete, widerftrebte Preuber.

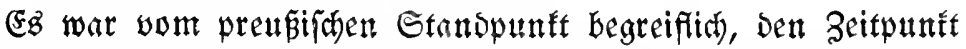

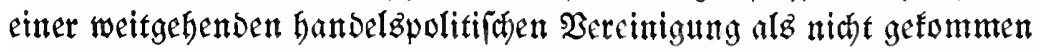

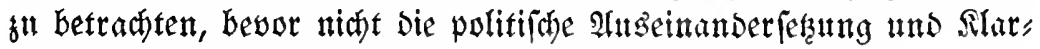

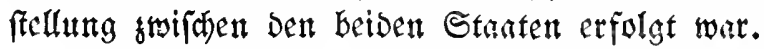

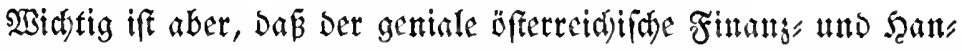

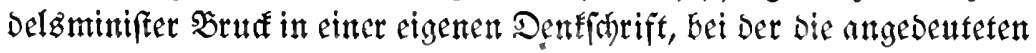


politifach Miotive matürli(b) nidat auker adjt gu laffen find, folgende Brunbfäge atffitlte:

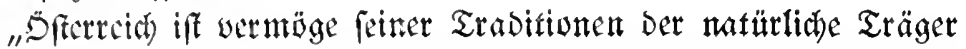

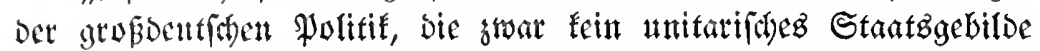

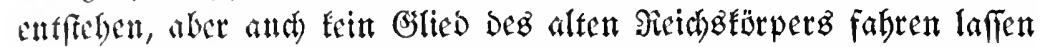

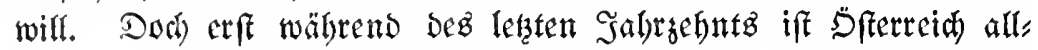

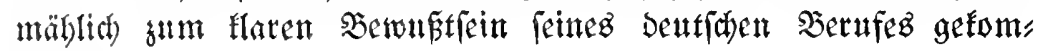
men..."

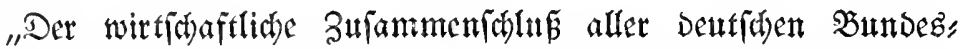
fracten ift Der Bobu, in welchent Dag geiftige, nationale und fon,

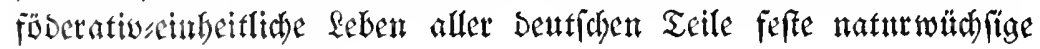

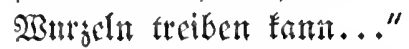

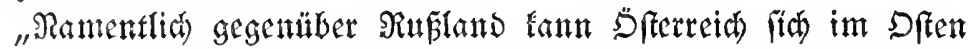

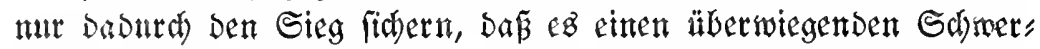

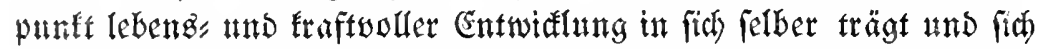
sum 3entrum aller Fragen böberer Gefttung fïr Das weite Donat= gebiet macht. Die freie intenfive Serwegung Der Dentfichen Rultur,

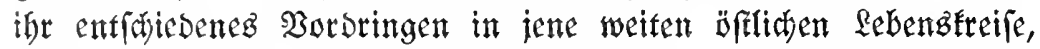

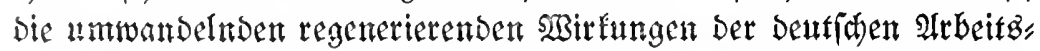
uno Beiftebfraft, ber Deutidyen Sitfe und Befittung, Darin allein liegt bie Damernde föfung jenter Fragen im Sinne Der gefamtfaats (it) $e_{\text {en }}$ Politif..."

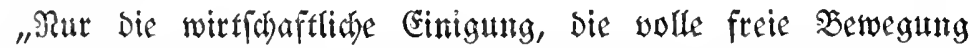

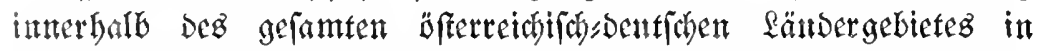
Siederlaffung, Etwerb, Scandel und Berkebr witrd mit Sidherbeit แnd ant $\mathfrak{r a f h e f t e n ~}$ gum Biele fübren..."

Die Denffertift wurde won Saifer Frang Sofef fantfioniert und

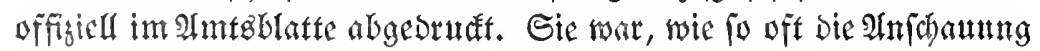

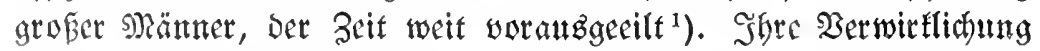

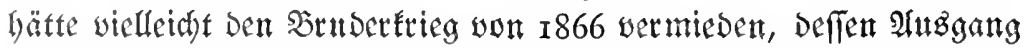

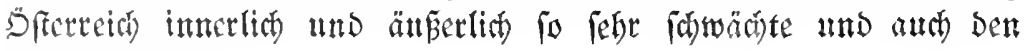

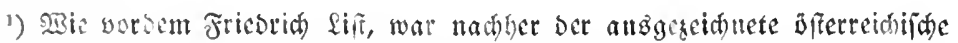

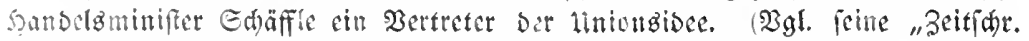

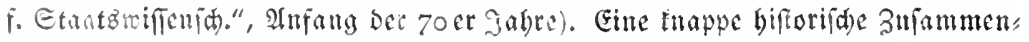
frellung ter Edidfale ber Zolunioniber entbalten: Whilipposid, Fin Birt"

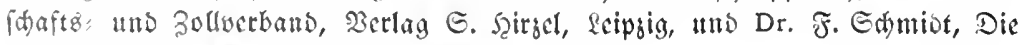
3ollocreinigung, Gogiale Sultur I915, 4. Seft. 
außen= uns Gandelspolitilă bebenflithen Dualismus im Gefolge batte.

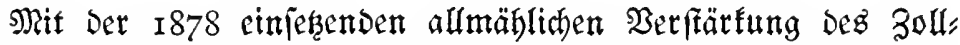

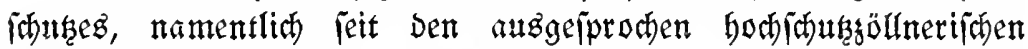

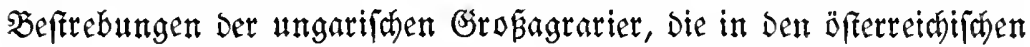
willige Bundesgenollen fanden, geftaltete fith jebe $\mathfrak{A}$ uggleid)ser"

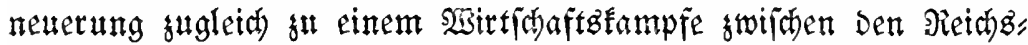
teilen. Smmer gab das parteipolitifa befler und jalagfertiger geleitate

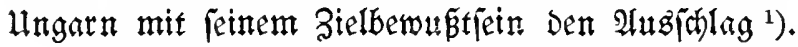

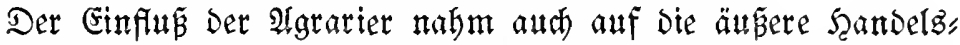
politif Der Monardie weitgebenden Einflus und eridwerte in Der

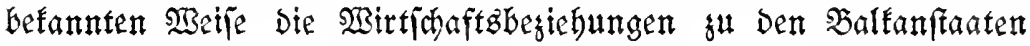

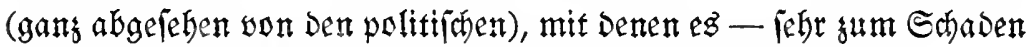
Des indufriellen Exportes - nebrmals za Zollfriegen tam.

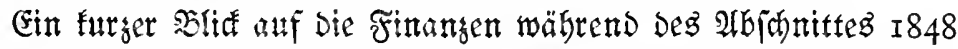

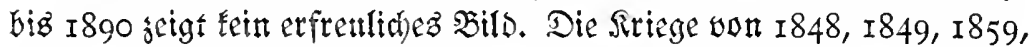
I866 (mit Frantreich, Sarbinien, Prenßen und Stalien) Erathten Die Finangen Eegreiflidermetfe in beflagensmerte Unordinng uno mathten jeweils Das eingeleitete Reformwerk zunithte. Die Maffe Der Stants,

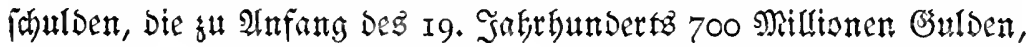
I848 über I000 betragen Gatten, fellten fin I 884 insgejamt auf 3290 Millionen Gulber. Die Srutben wären nod böber gewejen, wenn man fith nidht I855 enfichlofinn bätte, Die Stantababnen, die 377 Millionen Guldon getopet Gatten, um I53 Millionen Gulden

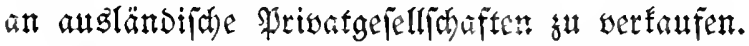

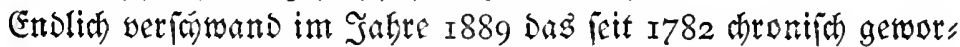

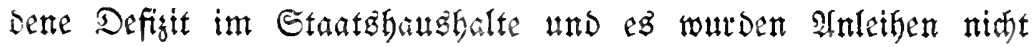
megr für bie bebeçung won Feblbeträgen, fondern für Snveftitionen aufgenommen. Sie Gejamtichulben Der Monardie Eetrtiger I9I4

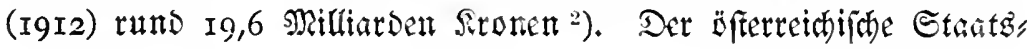

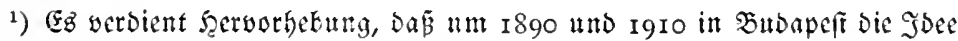
einer mitteleuropäijăen 3ollunion erwogen, aber bann fallen gelafien wurbe.

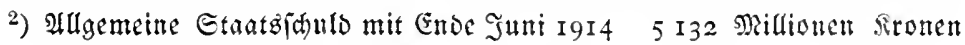

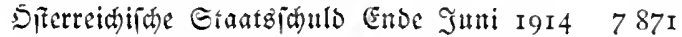
Ungarifide Etaatsidulo Etand v. I9I2 obne

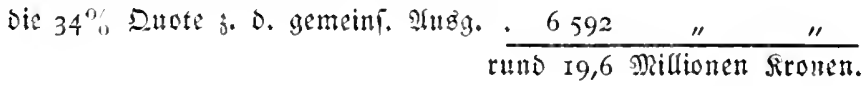


voranfdalag I9I4/I9I5 begifferte find auf 3,46 Milliarden Sronen, ber ungarifote allf 2,26, fulammen 5,72 Milliarden ${ }^{2}$ ).

Seit man alfo won einem Beginn Sfterreids fprecten fann,

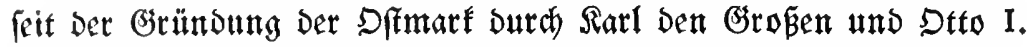
ift biefe, wie baz anz ihr bervorgegangene Reid in erfter Reibe ein Rriegzlano gewefen, Deffen Gekiet fhon in Der Bölferwanderungs; geichichte, aber aud nady her wiederbolt Durdh feindlidye Einfälle volkz;

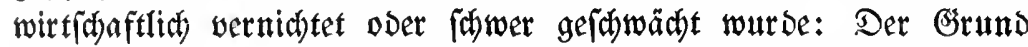
Dafür ift vor allem, Dáz Der Grobteil feittes Gebietes (öftlid) Der \&inie Dangig-Wien-Trieft) itl geographifdher uno ethnograpfiffuer

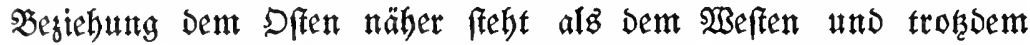

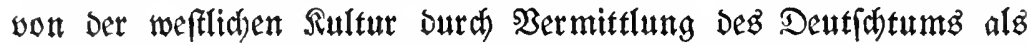

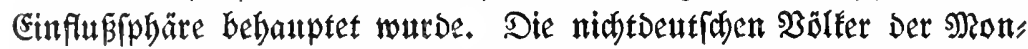
ardie entbefren Dez auffchanngfäbigen Bauernftandes und bleiben jabrhundertelang binter der Dentichen, D. i. Der wefteuropätichen,

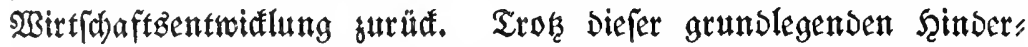

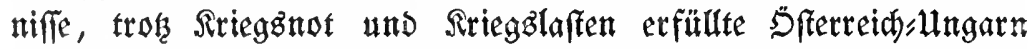

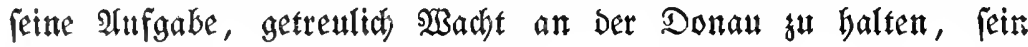
Territorium im Zufommentang mit Der weftlichen Sultur fub bes Gaupten uno gegen Den Dften uno feine Borftöße zu verteisigen, ia felbft ein Sollwert gegenüber Dem Dften fut fein.

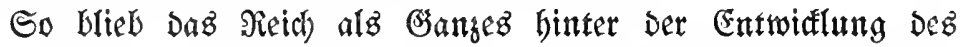
SBeftens zurüaf, uno aud Das Tempo Der Evolution mander Der

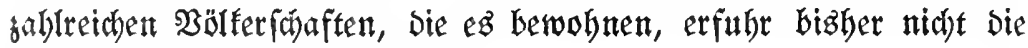
wünichenzwerte Befhleunigung.

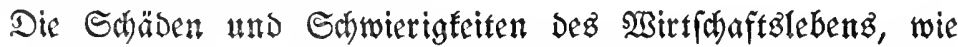
fie beute beflagt werden, laffen firh fordon in ben älteften Beiten uno immer wieberfegrend feftfellen; weitblifende Gerrforder ftanden nur

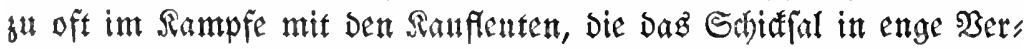
bältniffe gegmungen uno die Dabar nur ful oft geneiggt waren, nad) Regierungzfduts, Priwileg uno Berbot fu rufen, ftatt felbft woll und

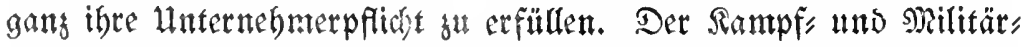

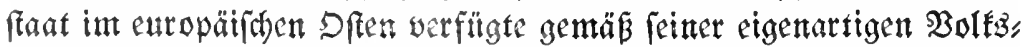

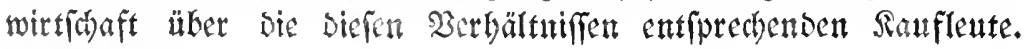

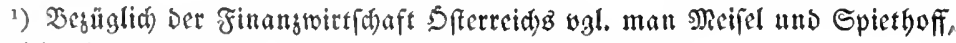
Sffereide Finangen und ber Sirieg, Dunder und Şumblot. 


\section{Die Reute.}

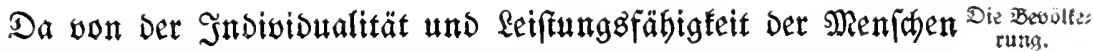

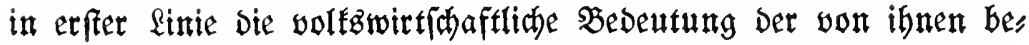
wohnten Ģebiete abhängt, foll zunächft von Der bevölferung ier bereitä geographifíh ffigsierten Donaumonarchie gehandelt werben.

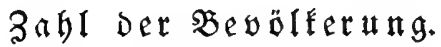

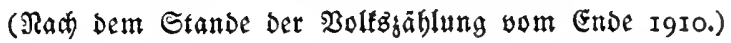

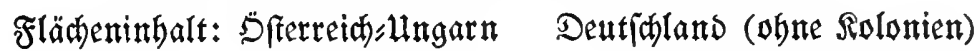
$676615 \mathrm{qkm} \quad 540857 \mathrm{qkm}$

$\mathfrak{B} \in \mathfrak{O} \mathfrak{I} \mathfrak{E} \mathfrak{x} \mathfrak{n} \mathfrak{g}$ :

\begin{tabular}{|c|c|c|c|}
\hline & in Sfftertei & $\begin{array}{l}\text { in llngarn (mit Iroas } \\
\text { tien uns Slavonien) }\end{array}$ & in D. Reicfslanden \\
\hline 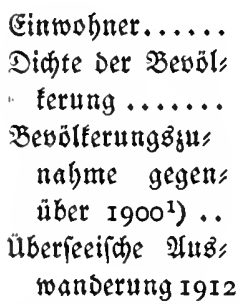 & $\begin{array}{c}2857 \text { I } 934 \\
95,2 \\
0,88 \% \\
\text { I3 } 2227\end{array}$ & $\begin{array}{c}20882487 \\
64,2 \\
0,81 \% \\
120516\end{array}$ & $\begin{array}{c}\text { I } 93 \text { I } 802 \\
37,7\end{array}$ \\
\hline
\end{tabular}

\begin{tabular}{|c|c|c|c|c|}
\hline & in Dftert. Ang. & in Deutialand & RuÉland & Stalien \\
\hline 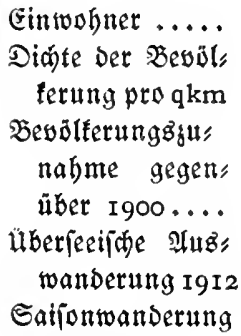 & $\begin{array}{c}0,87 \% \\
252449 \\
350-400000\end{array}$ & $\begin{array}{c}64925493 \\
\text { I20 }\end{array}$ & $\begin{array}{c}2,1 \% \\
\operatorname{tund}_{3} 80000\end{array}$ & $\begin{array}{c}0,63 \\
403306 \\
\text { tund } 300000\end{array}$ \\
\hline
\end{tabular}

1) Siterteid) und Ingarn haben bwar bohe Geburtģiffern, aber aud eine Gohe Eterblidfeit. 
Mationalitäten in Millionen Eintoobern.

\begin{tabular}{|c|c|c|c|c|}
\hline & it Sfterreid) & itt llngarn & $\begin{array}{l}\text { Sn Bosnien } \\
\text { t. Serfegow. }\end{array}$ & $\begin{array}{c}\text { in Sfterreids } \\
\text { Ungarn }\end{array}$ \\
\hline Gefantbevälterung . & 28,6 & 20,9 & 2 & 52 \\
\hline Dentidfe $\ldots . . . .$. & 9,95 & 2,03 & & I 2,00 \\
\hline Mayyaren ......... & - & 10,00 & & 10,00 \\
\hline 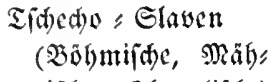 & & & & \\
\hline riface, Slovatif(x)e) & 6,43 & 2,00 & & 8,47 \\
\hline Polen $. . . . \ldots . .$. & 4,97 & 0,04 & & 5,00 \\
\hline 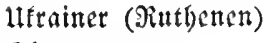 & 3,5 & 0,5 & & 4,00 \\
\hline Slovenen ........ & $I, 25$ & 0,09 & & 1,35 \\
\hline Serbosßroaten .... & 0,78 & 2,94 & 1,96 & 5,543 \\
\hline 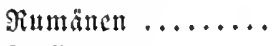 & 0,275 & 2,95 & & 3,22 \\
\hline Staliener ......... & 0,77 & 0,24 & & $I, O I$ \\
\hline
\end{tabular}

Es ift faum fu bezmeifeln, Dấ unter Dem Einflufle Der Ber, waltung in llngarn, ferner als Folge Des Das Miagyarifhe energilat

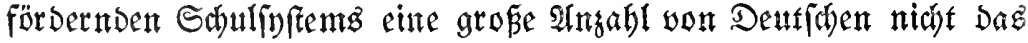
Dettifhe als umgangsjpradye angegeben hat, fondern Das Magya

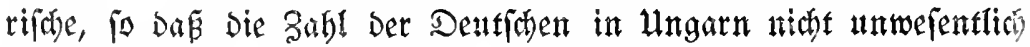

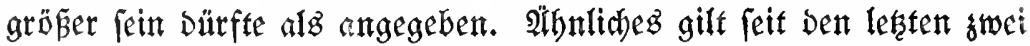

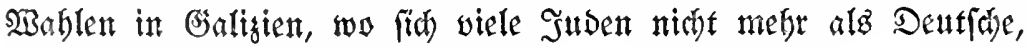
fonbern als Polen eintragen laffen.

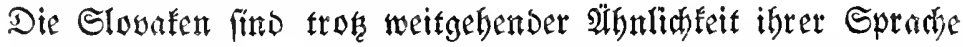

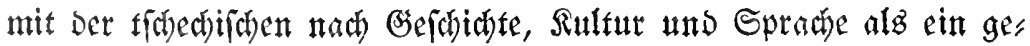
trenntez $\mathfrak{B}$ olf

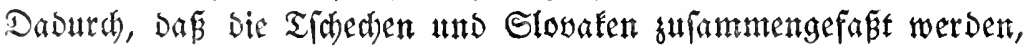

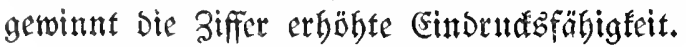

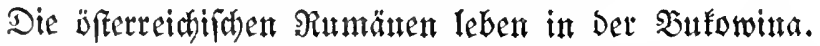

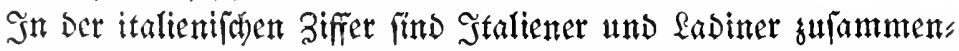
gefaß̧, obwobl es fith bier um swei verfátedene Bolfzftämme bandelt. Die Labiner, bie in Sitdtirol leben, fitrthten fit vor ber Stalianifierung mebr als vor Der Germanifierung.

Stt Ungarn Gerricht Das Magyarenttm gegenüber Den anderent

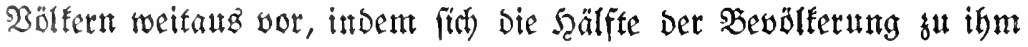
befent. Die in Dffungarn lebenden Sfefler fellen zwar einen Teil Des magyarifhen Boltes Dar, finto aber Duth vielfacte folfloriftifare Eigenteiten gefentzeichnet. 


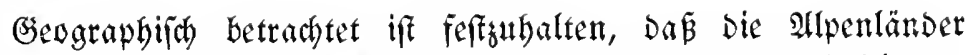

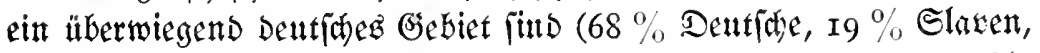

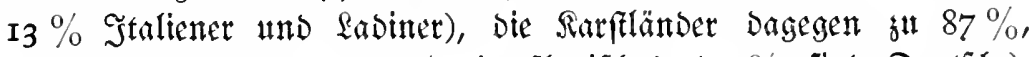

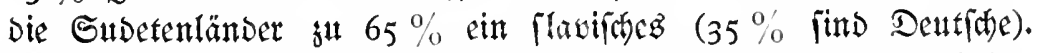
Die Nagyaren leben im Mittelpuntat llnganta, ber ungarifhen Tiefebene.

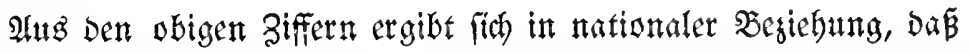
Das Dentichtum mit feinen I2-I3 Millionen Seden fort ein Biertel Dle
Deutyduen.

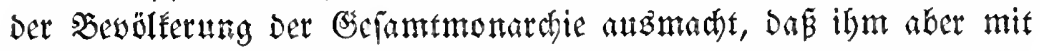

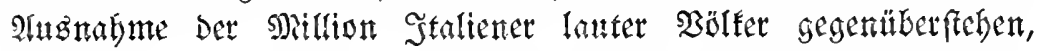

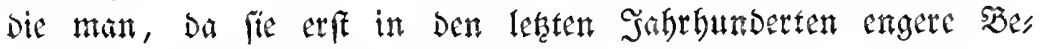

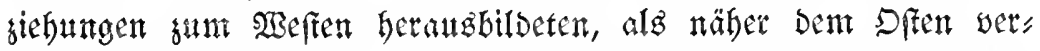

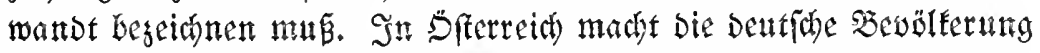

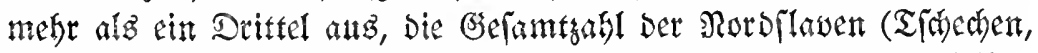

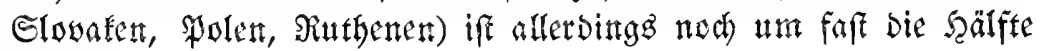
gräß̈̈r.

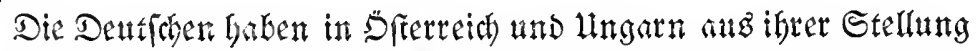

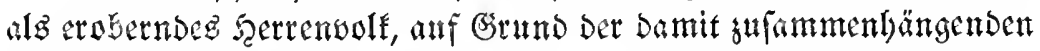

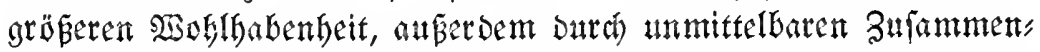

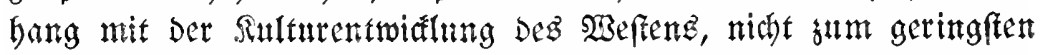

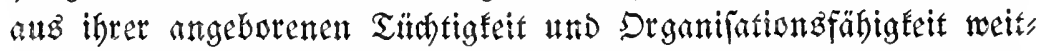

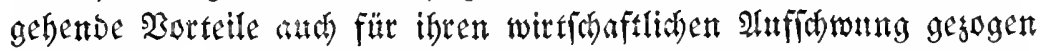

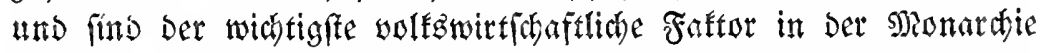
geblieben. Mit berechtigtem Etols weifen bie Deutfichen Darauf Gin,

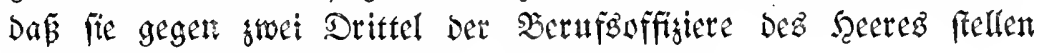
und Den grë̈sten Teil ber Steutern leiffent ${ }^{1}$ ).

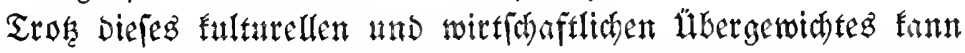

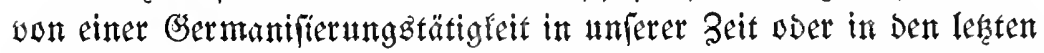

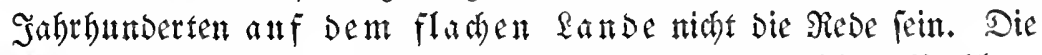

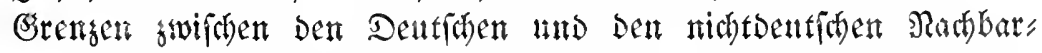
völeern find feit ber \&anbthame eigentlid unverändert geblieben.

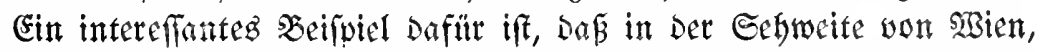

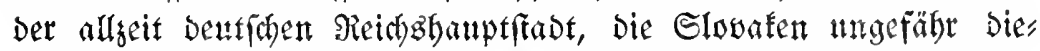

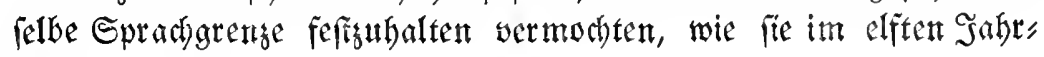

1) Die Deutidet gablen in Dfterreich wou Der Grundfenter $54^{\circ}$ "won ber Gekändefenter $70^{\circ}$, won ber Werionaleinfommenfener rund $80^{\circ}{ }_{0}$. 
huttoert feftgelegt wurde. Sie füblen fith aud alz nationale Slaven,

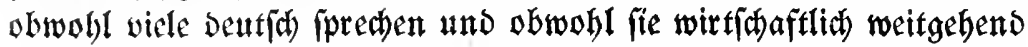

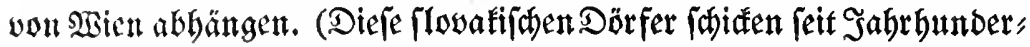

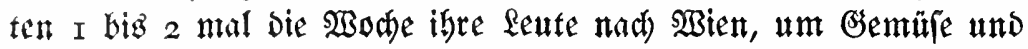

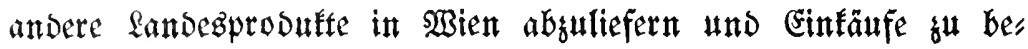
forgen.)

Anders als auf Dem flachen Rante, wo bie Sprachgrenge unver" ränt blieb, ifte es in Den Etäbten, welde felbft in Den flavifhen Rrons lätnoern bis in there zeit einen vorwiegend ober wenigftens weits gebeno bentfden Sharafter bemabrt baben. Sobald bab fremde nichtoutifibe Element Der bleibenden Stüke und Itnlebnung ents

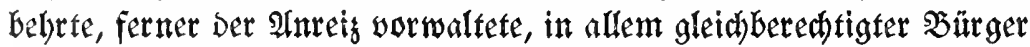

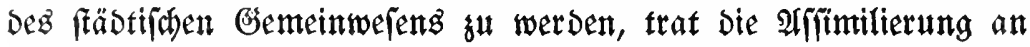

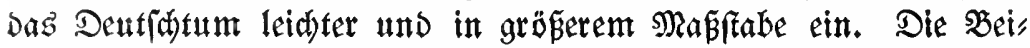

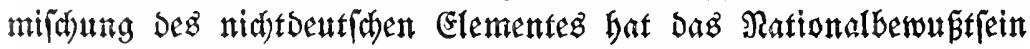

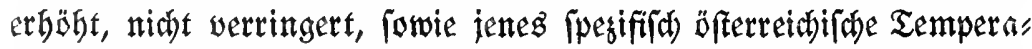

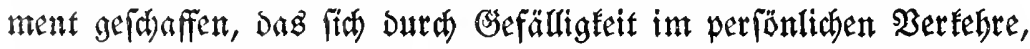

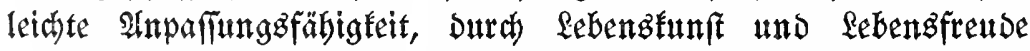

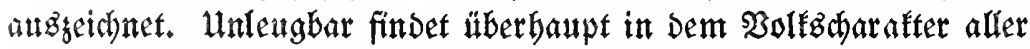
Sewohner Der Donaumontartie, aud) Der Deutfden, Der Einflús

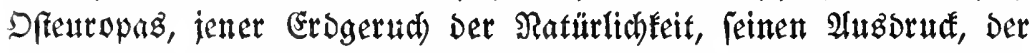

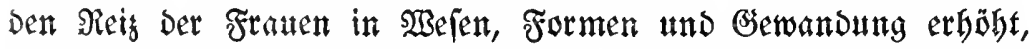

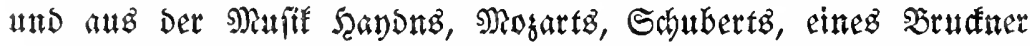

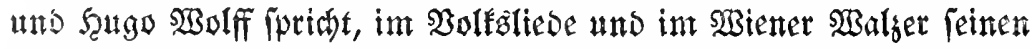

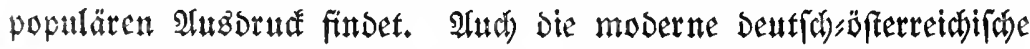

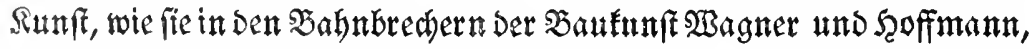

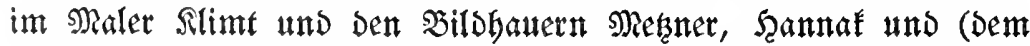
flowatifhen) San llprta, wie in Der entzüftenden Sleinfunft unter Füfrung ber Wiener Iunftgemerbefhule und Der Wiener Werf, ftätte am glängendffen verförpert wird, fprid)t diefe Sprad)e. WBien feleft ift als Stabt bie Berförperung bielés an Dfteuropa gemahnenden Dentfotums und fellt mit feinem regen Geiftes, uno Sinnfleben

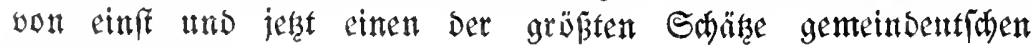
Sulturbefitzeg dar.

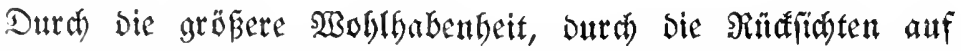
Dic Derwaltung Des $\mathfrak{B e f t i z e}$ an berweglichen und unbeweglichen Gütern

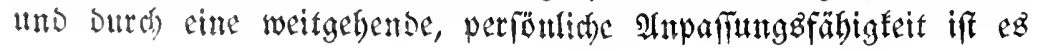


aud in Der Monardie vor allem Der Deutfac und Sube, Der fich bei SFolierung in frembnationalen Gebieten am leid)teften, oft idon in Der sweiten Generation affimiliert ${ }^{1}$ ). Diefer $\mathfrak{B o r w u r f}$ wird ja mit Recht aud gegen Den Dentichen und Suben 2 (merifas und Englands erboben, wo fie leicht das Engländertum annebmen. Eż feaft eben

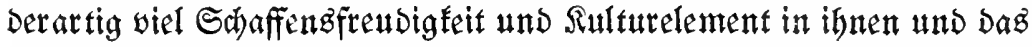
Verlangen, felbft auf Dem fernften Poften an ber geiftigen unb wirts

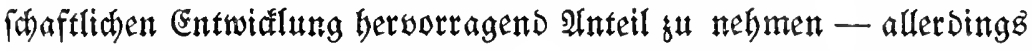

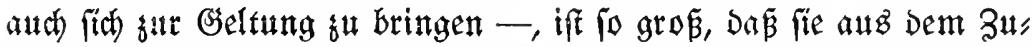
lammenhange gerifler, Dant einer gan aużgezeidneten Fähigfeit, frembe Verbältniffe ridftig zu beurteilen und zu verfteben, forwie fid) innen angupaffen, ifre eigene Bolkgugebörigkeit leiant gang verlieren. Gerabe die Sentidnen Der Monardie mü̈te man wegen

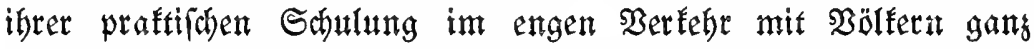

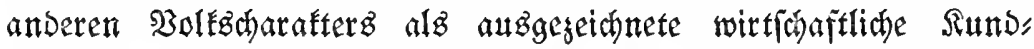

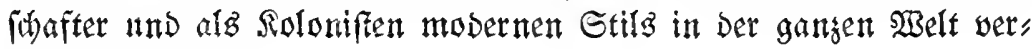
wenden fönnen.

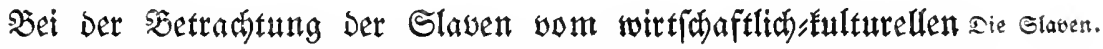

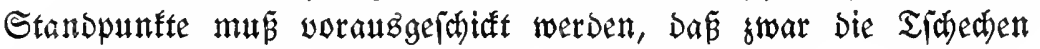

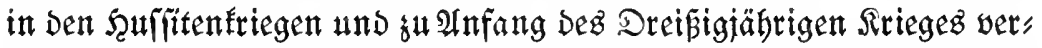

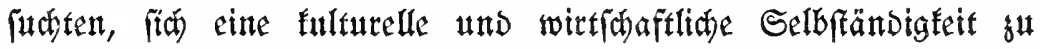
erringen, ofne jebod ben gewänfoten Erfolg gut ergielen. Ferner nebmen Die Polen vor and nath Der Zertrümmerung ibres Rönigtums unter Führung ifrer Ariftotratie eine befondere Stellung ein. Sonft

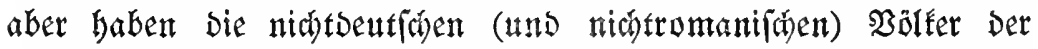
Monardhie bis gum Jahre I848, Dem Sahre Des Beginnes Der politif(hen Bejreiung Des Bürgers und Saaterntums, bie Eulturelle und wirtfhaftiche Entwictung Dez Deutidtums alz Maflen

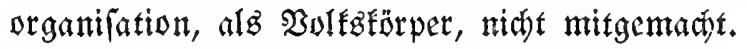

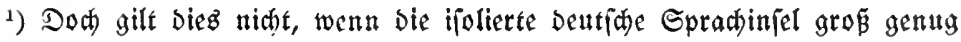

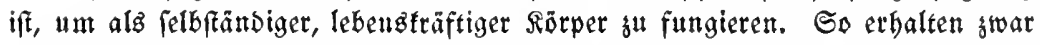
Die zableiden Deutjaen in Bubapeft feimen Dentiden Sdulunterridyt, fondern mur einen magyarifhen, aber ibr Dentfatum bleibt bis auf bie in dffentlichen

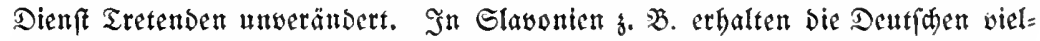
fach nut froatifhen Sauluntertidi, aber Die Betreffenden find in $23 e f e n$ und Wirtfhaft - bis ję̧t wentgfens - Deutiale geblieben, obwohl die jüngere

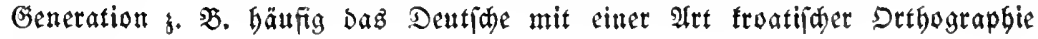
fdreibt. 


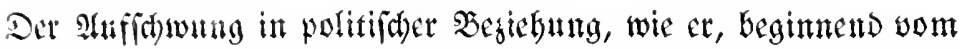
Sabre I848, Dant Dem Parlamentarigmug und Der Durdfeşung

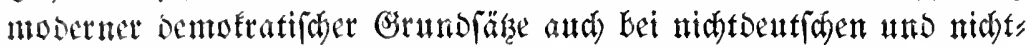

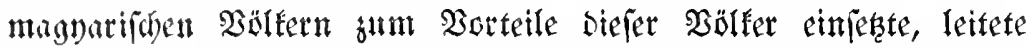

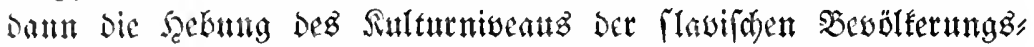

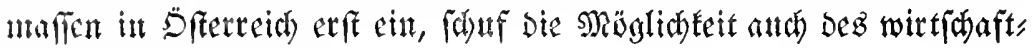

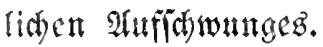

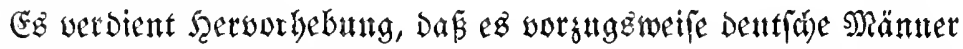

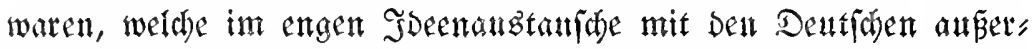

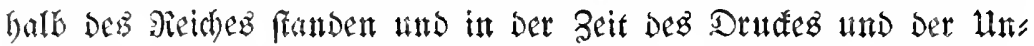

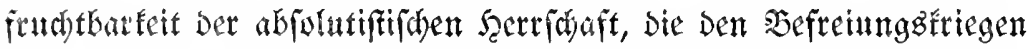

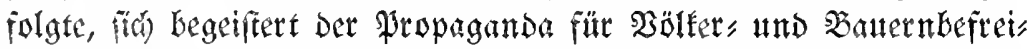

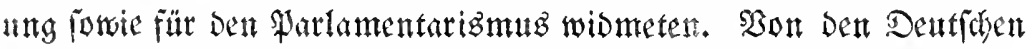
¿ibernabmen bie alíget begeifternnggfrendigen Magnaren, Die Sroaten, Die Tf(t)echen Den Fratheites und Entwidtungzgedanfen.

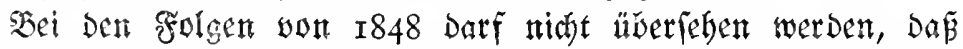

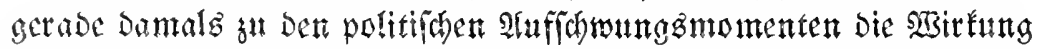
Der bald Darauf (1855) einfezenden wollen Entwidfung Der modermen

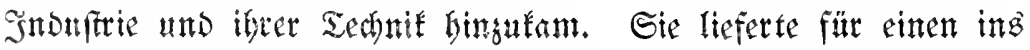

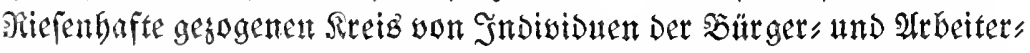

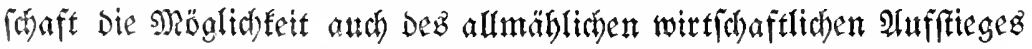
atif Grund Der erlangten poltifiden Red)te.

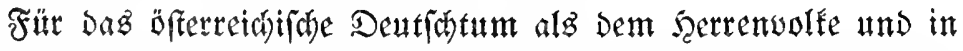

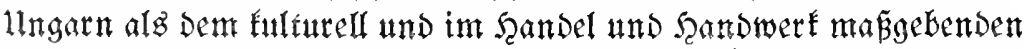

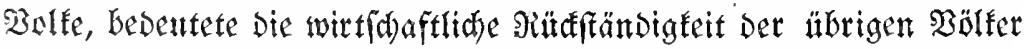

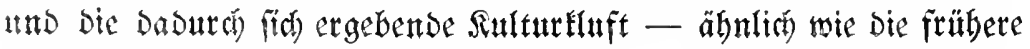

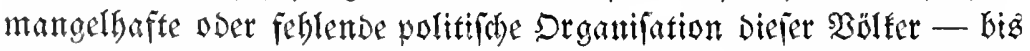
I848, ja bis in bie fedsiger Sabre injofern einen Sortetl, als bie leşteren weitgebend wou Der im modernen Beift geführten Pros Duftion unb bem Srandel bet Deutiden abhingen.

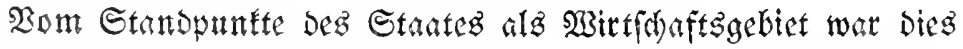
feit jeber ein tieforeifender Mangel ${ }^{1}$ ) - obate Dafe ber Zufand ber

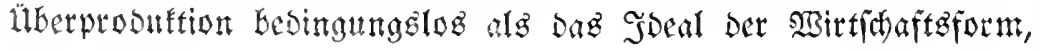

1) Daż iff ja aud Der Grund, warum g. B. Die habsburgifden Saifer bejdlof, ren, bie Einwanberung won beutiden Elementen in groben geidloffenen Maffent in Den weridjebenen Reidgteilen Durdognfübren. 
nod) Dagut für bie verfefrsarne Zeit vor 1848 , gepriejen werden joll -, und es batte biefe Einfeitigfeit ber wirtfanffliden Entwiaflung ifte

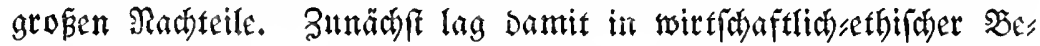
jiefung immer wieber bie Gefably wor, fith auf eine gemiffe mono"

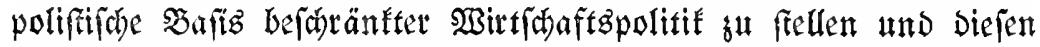

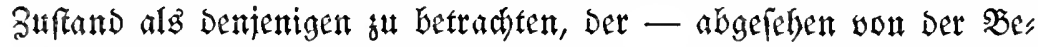
quemlinfeit - bie befien Borteile bietet. $\mathfrak{A}$ bgerehen won anderen.

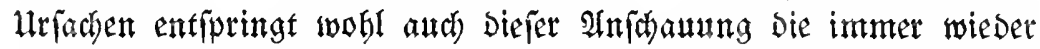
auftretende Tendeng zut Abjperrungspolitif Der mabgebenden wirt, forbaflichen Sireife iat Diferreid).

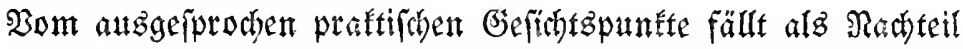

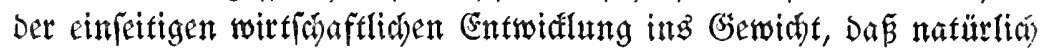
Die Deutfhen vormiegend die Stantalaften zat tragen hatten und bie

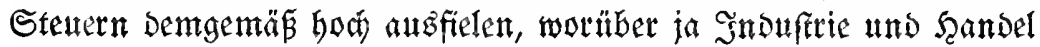

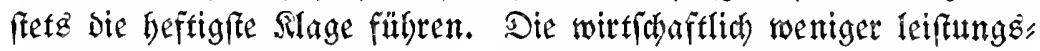

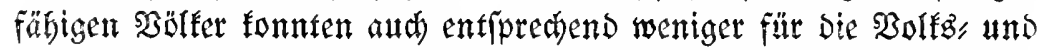
fonfige Siloung aufwenden; bamt wieber hängt bis in unjere Tage

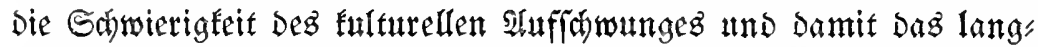
fame Tempo in Der Steigerung Des Bedarjez und des Sonfums bei ben

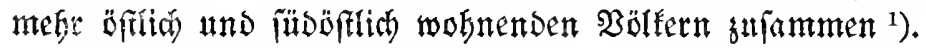

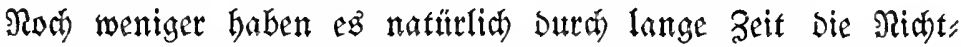
Deutflien fumege gebradbt, eigene Snduftrien zu entwiafeln; fie waren

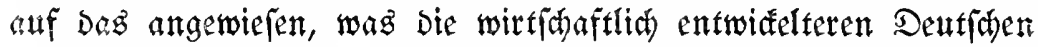
bei ifnen an Snveftitionen mad)ten uno ifnen an induftriellen $\mathfrak{b e t r i e b e n}$

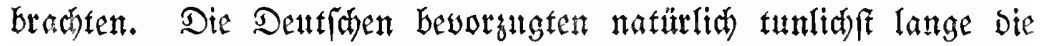
Deutfaren Gebtete, weil bort bie arbeiter fulturell uno wirtifaftlict böber franoen, ferner weil fie bod naturgemäß lieber ifre fonnatio" nalen Gebiete, Denen fie in Spracbe, Sitte und Sebensauffaflung näber ftanden, fat entwidteln bereit waren als andere. Erft als in Den

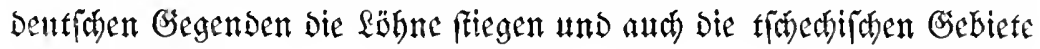

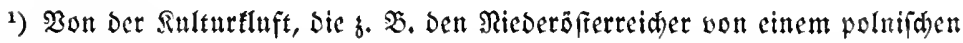

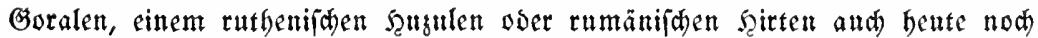
trennt, tann fïh Der Ridftenner Der Berbältniffe taum einen Begrifi maden.

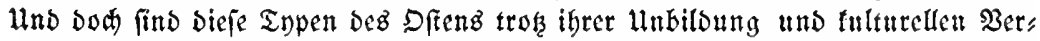

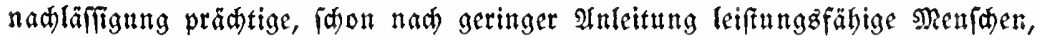

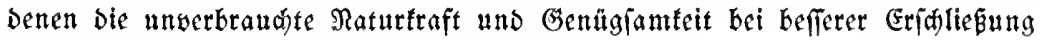
ifrer Gebiete ankerorbentlid gugute tommen müßten. 
burd) eine Berbefferung Der Eandwirtifa aft und Dez Satulwejenz eine für bie Snduftrie beffer verwendbare Bevölferung erbalten batten, berüffichtigten bie beutichen Unternehmer in fteigendem Make auth

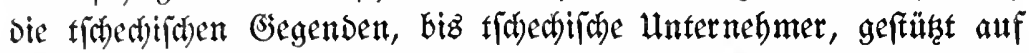

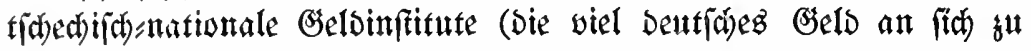
gieben vermod)ten), felbft Grünoungen vornabmen. Bor ungefähr

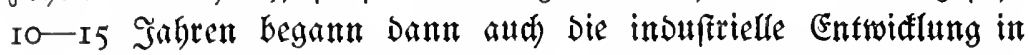
Den polnifden Gebietïa (Bergwerfe, beionders Petroleum), vor"

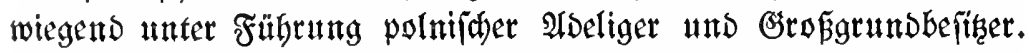

In Ungarn griff bie Regierung felbfit ein, Daz Tempo ber Ent”

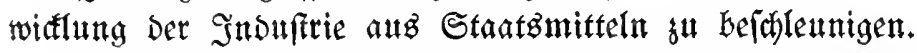

Man möd)te bie geforilderte Ericheinung "nationale Slaufar ber bolkşwirtid)aftlid)en Entwidtung" nennen.

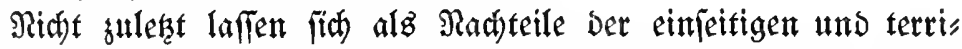

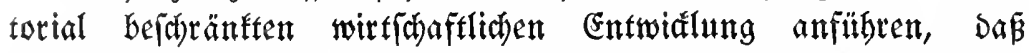

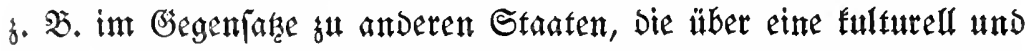

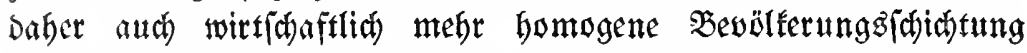
und eimen Dementjprect)enden Sonfum verfïgen, in Der Mronardjie

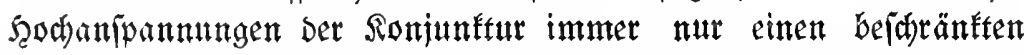
Sreiz betreffen, waz fich Daber in Den guten Swirüngen Der Maffe

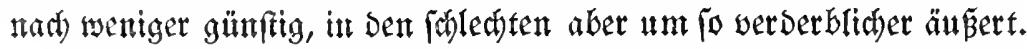

Die Tifhecten ftellen Den am weiteften vorgeidtobenen Slaven: fomplex in Zentraleuropa vor, Da boú) Die Wenden im heutigen Sïnig" reide Sadjen, bieje l̈berbleibjel der eimftigen bevölkerung, wegen ihrer

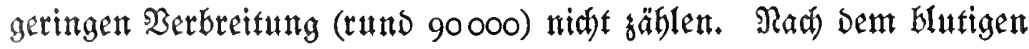

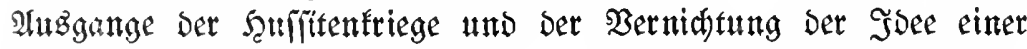

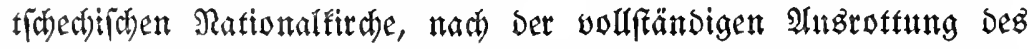

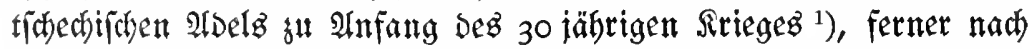
Den Berberungen Dez 30 jährigen Sriegez waren bie T(d)edhen im wefentlichen zu einer Nation von Sileinbautern gerworden, won benen

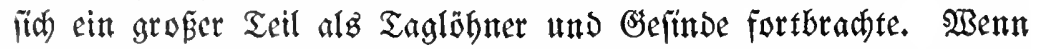
iaton bis fum Sabre I848 eine weitgehende Sammlung Des tiche"

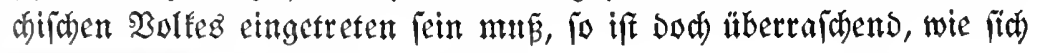

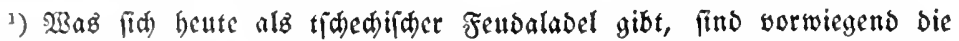

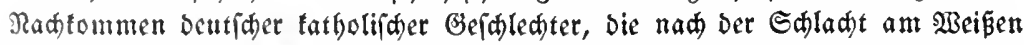

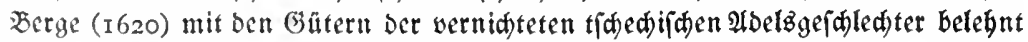
murber. Frang Nayer, Berlag Braumăler, Bano II, Seite 292 ff. 


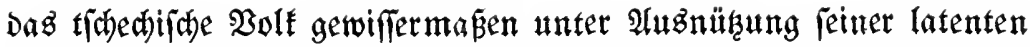
Energien während Der lez̧ten zwe Menichenalter entwidelte, fobald

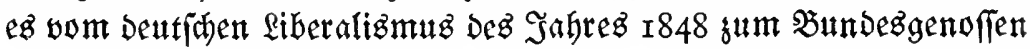
für Den Rampf um politifhe Rechte uns felbftändige Entwiatung aufgerufen worben war. Gz beburfte bei biefem tüchtigen, in jener

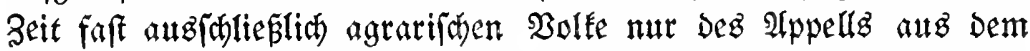

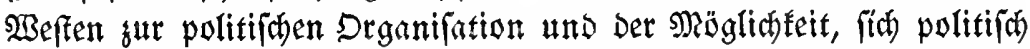

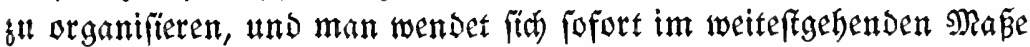

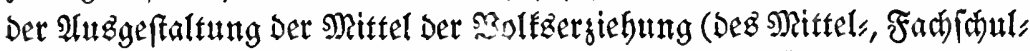

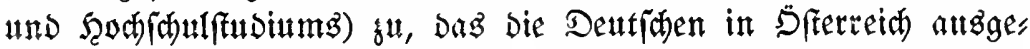
bildet batten. Mit Der politijaen Drganifation, mit Der Wiederber, ftelung Dez şlaubenz an fíh felbft, an bie nationale Miffion ift Der

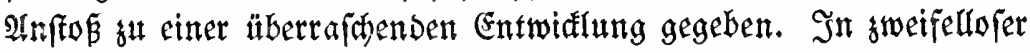
übertreibung and in Dem $\mathfrak{B}$ efteben, ibre nationale Drganifation fo

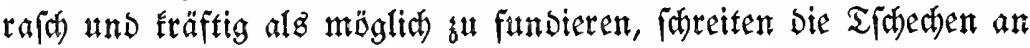

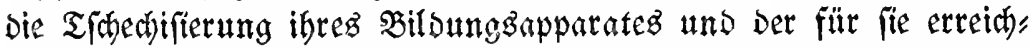
baren $\mathfrak{B e r w a l t u n g , ~ v i e l l e i t b ) ~ a u d ~ u m ~ e i n e r ~ m o ̈ g l i c h e n ~ f p a ̈ t e r e n ~ R e a t t i o n ~}$ von möglidfft langer Sano entgegenzuarbeiten. F̧ bandelt fich Dabei obne Bweifel um eine Sulltur, Die vollfänoig vom Deutichen

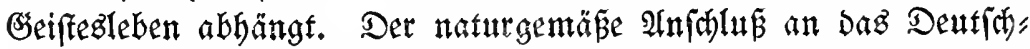
tum wirb leider burd die Politif zum Shaben auth Des Thathentumes unnötig erfhtwert. Dow wird gewiés bie zeit frither ober fpäter bie beftegenden übertreibungen bejeitigen.

Das gefteigerte nationale Dolkgbemü̈tfein und Selbftgefühl

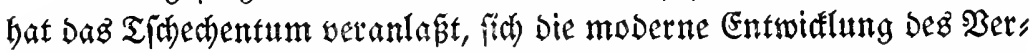
fefrz, Gebanfenauztauldes, Der verfatedenartigften Drganifations;

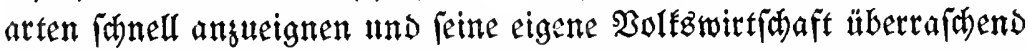
gu organifieren. Die Entwidlung ift aber, wie nodhalz betont wer Den

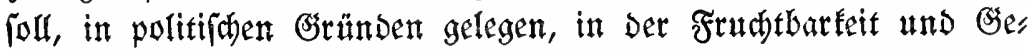
faltungatraft Der modernen Demotratic und Den SBandungen int

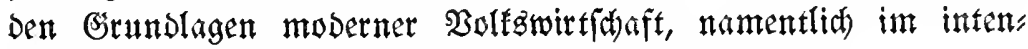

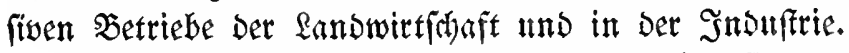

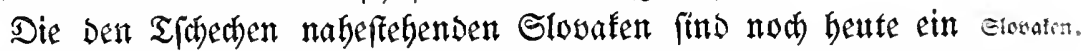

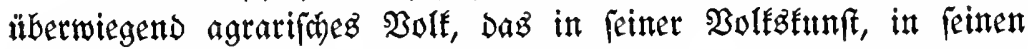

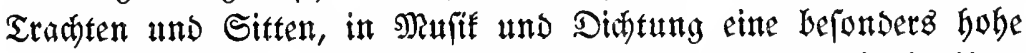

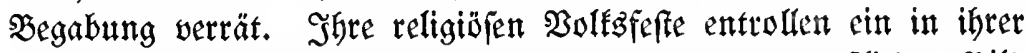

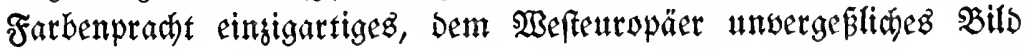


uth verbienen ben Ramen folfloriftifher lebender Sebengwärdigs

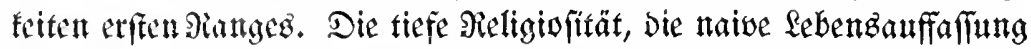

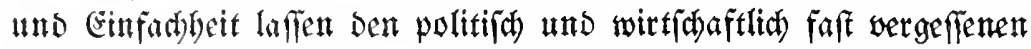

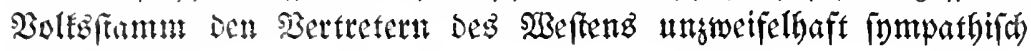
erfideinen.

qolen.

Betradtet man bie Polen, fo ift biefe hodtalentierte Ration wohl ant maifen baourch charafteriftert, Das fie Das an bas Mittelalter ges

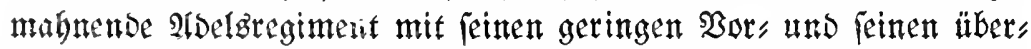

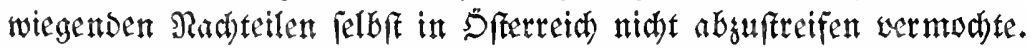

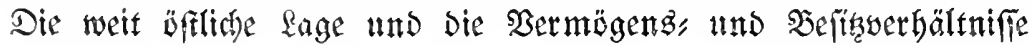
verhimberten, abgefeben won Den heftigen, immer wieber die Sluft erweiternden Eriftengłämpfen, eine genügend enge Berührung Der Maffe bez Polentumes mit ber Deutihen Multur. Ga waren mur

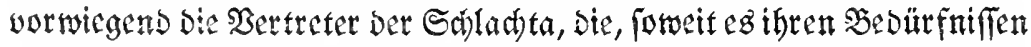
unb Der Befeftigung igrer perfönliden Nadyt Fonventerte, fith bie

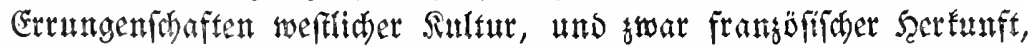
aneigneten. Die Maffe Des Bolkes Gatte gar nidhts ober mur febr wenig Dawon. Eerft Die Mobertie Zeit mif ifren Tendengen und Mitteln, breite Slaffen ber Bevöleerung Der Entwiatung zughführen, Eat bier eine nate Entwithlung eingeleitet.

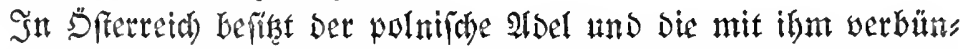
Dete Snterfigents Dant aubgezeidneter polififder Drganifation uno Der

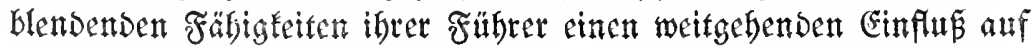

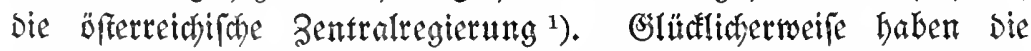

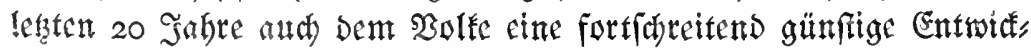

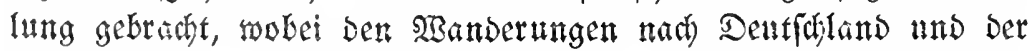

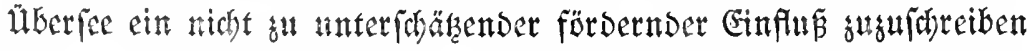

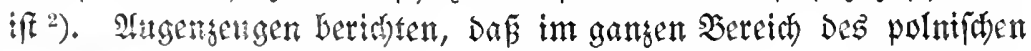

1) Deutide, Jataliener uno Polen bilbeten bisber in ber Regel bie Mas

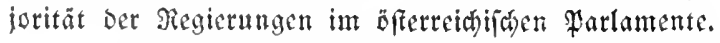

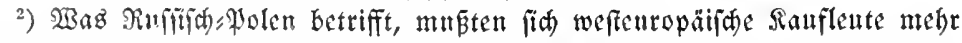
ober weniger raft flar barüber werben, weld)e (Ebancen Der Rapitalinveftition

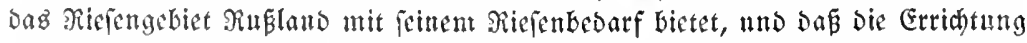

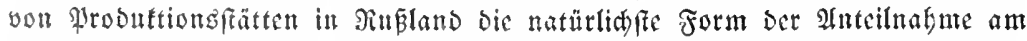

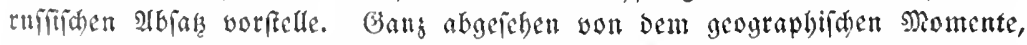

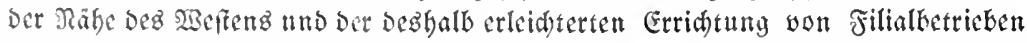

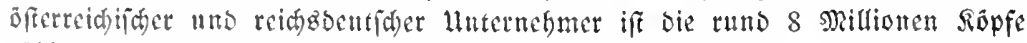

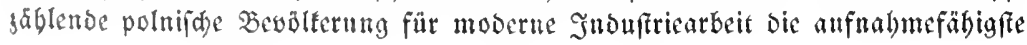


Galigien eine gerabeğ einferzte, bie in ben leşten 4-5 Sahren bejonders erfreulidse Formen

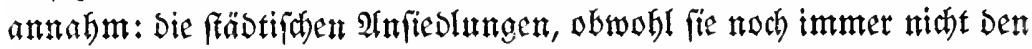
Ramen von Städten fübren, waren in ganten Siertela und Straß̃en

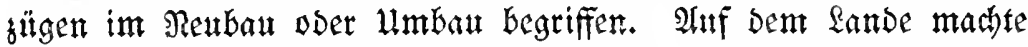
gleithseitig Der bätterliche Mittelbeftis (biz 40 ha) erfrenlid)erweife im

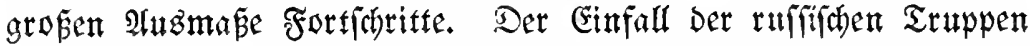
unb \#berbaupt ber Jitieg in Galigien baben biefe vielveriprectende Entwidlung leider geradegu ausgelörtht.

Die Ulfrainer, die als Telle ber rand 36 Millionen jählenden ufratnifuen Pation Dftgultigien, Den Norben Ungarns uno Teile Hfrainer, Der $\mathfrak{B}$ tewwina bewofnen, fino Gente nod, went man bie Mafle des

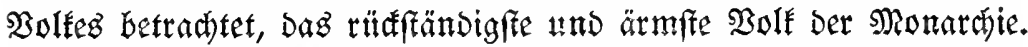

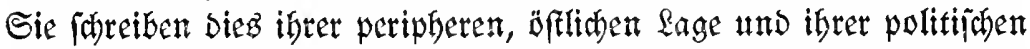
Ibbängigfeit won Den \$olen su. Die getftige leiftungsfähtgfett uno Regfamteit der Gebildeten, die auberorbentlitbe Begabung aller

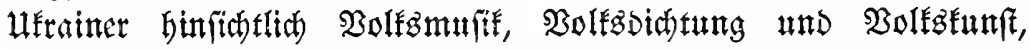
Die guten Erfabrungen, bie man mit ruthenifaen arbeitern in Deutids,

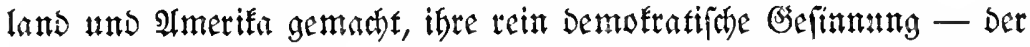

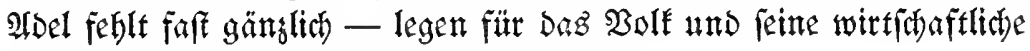
BermendEarfeit eit gitnftiges Bengnts ab.

Die Slovenen werfügen ebenfalls nicht äber einen nationalen elonente 2roelfand. An feiner Stelle fptelt bie Sntelligens, weitgebend die Getits

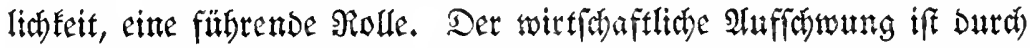
Den alfut geringen llmfang Der Nation ano bie wenig günftigen

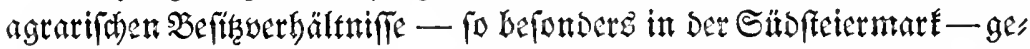

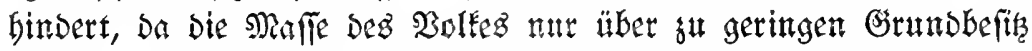

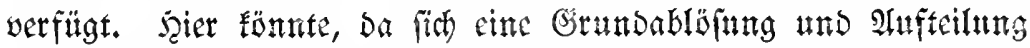

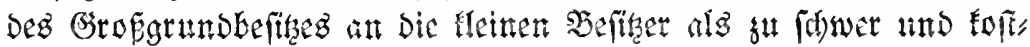
pielig erweifen Ditrfte, nut die induftrielle Entwitung belfen. Diefe

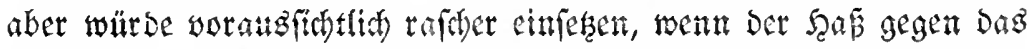

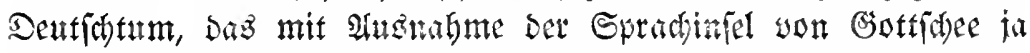

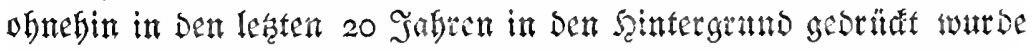

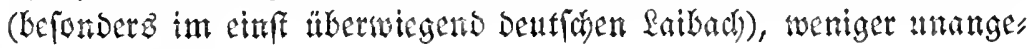

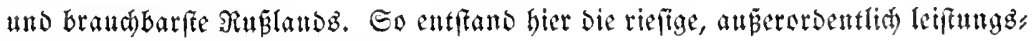

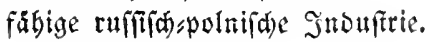


nehme Formen annähme uno Daher bie Betätigung Dentfden Rapi, falg erleidterte. Soviel über bie vorwiegend ober teilweife öfter" reidificten $\mathfrak{B a ̈ l f e r . ~}$

Magnaren. Die Magyaren weifen in einem gewiffen Grabe äbnlidje $\mathfrak{B e r}$ hältniffe auf wie bie \$olen. Aluf Der einen Seite frebt bie mähtige

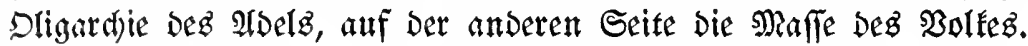

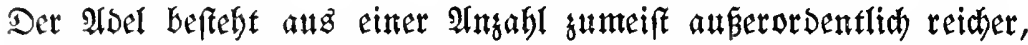

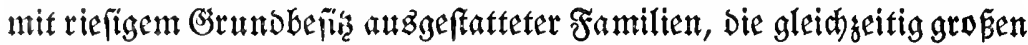

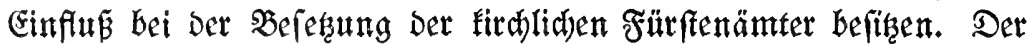
bie Freibeif liebende auferorbentlich liebenswürbige, gewinnende uno

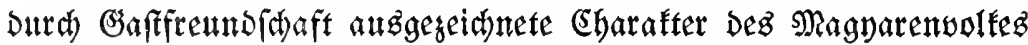

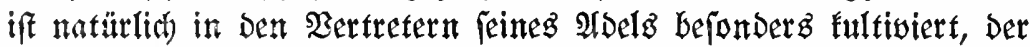

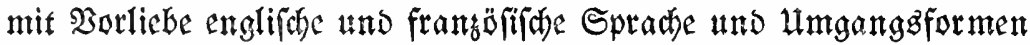
pflegt. Der magyarijare ad hel hat ez glänzend verftanden, fïh Den

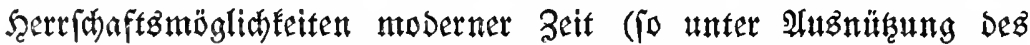
Parlamentariamns) angupaffen ${ }^{1}$ ) und bat Meifter Der Politił heroor,

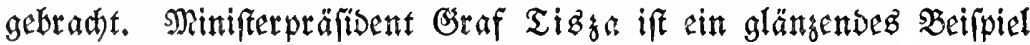
magyarifher Fähigtetten auf Dem Gebiete Der Politif und Der poli, fijhen Drganifation, jener F̋ăfigkeiten, die bie Führer Der meiften

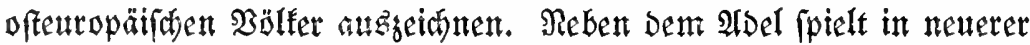

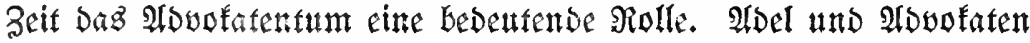
find Die herren Des Landes; die Mrafle des Dolfez hat am Parlamen tarismus keinen berwusten and roirffamen $\mathfrak{A n t e i l . ~}$

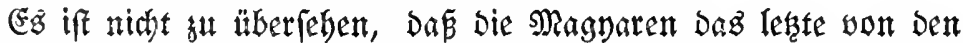
Bölfern fimb, bic innerbalb Der Grengen Der Geutigen Monaraie

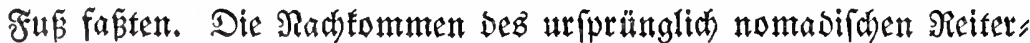

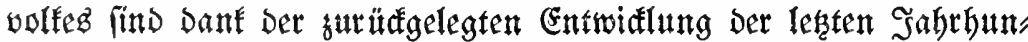

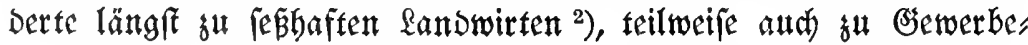

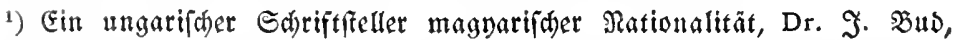
(prid)t find über bie Magnaren unb bie Irt ifrer Serridaft wie folgt ans: „Die

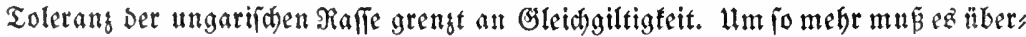

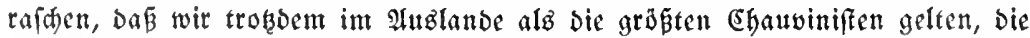
Die Fremben oerfolgen und mit Feuer uns Sdtwert magyarifieren. In biejem Punfte toird bie affentlide Meinung nut von Den $\mathfrak{B e r l e u m b u n g e n ~ u n f e r e r ~ F e i n d e , ~}$

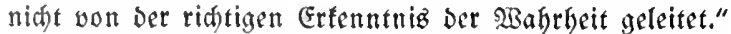

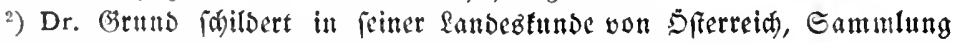

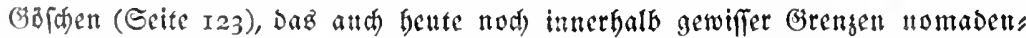
hafte leben ber Bewobner Der Dorffäbte in Den magyarifhen Teilen Ungarns, 
treibenden und Fabrifarbeitern gemorben, obwohl Das Stuben"

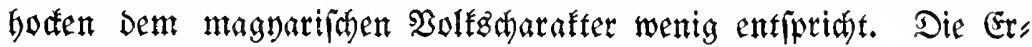
Kenntnis von Der Eigenart Des magyarifden ?aturells in Diejem

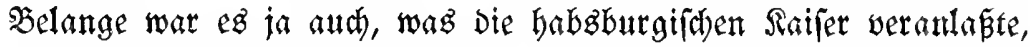

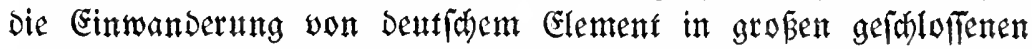
Maffen nach lungarn fu vermitteln. Abgefehen von Den Dentichen liegt Der Şandel weifgehend in Den Şänden Der Jitsen, ähnlid wie im rükftänoigen Ğđigien.

Dbwobl Die ungarifhe Regierung Die Entwiatung von Snouftrie uno Gewerbe mögliaff nad ben magyarifathen Gebieten zul lenten fuht, gieht bie Sinduftrie Deutide uno flovafifhe Gebiete vor, weil fith Diefe $\mathfrak{B o ̈ l f e r ~ l e i d h t e r ~ i n ~ D e n ~ M a h m e n ~ m o d e r n e r ~ i n d u f t e l l e r ~ D r g a n i s ~}$ fation einfügen und nidyt wie Der Mingyare an feinent feben in Der Pugzta bängt, bas in unferen Tagen niddt nut ant Romattił ver"

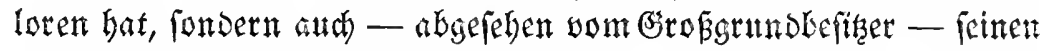

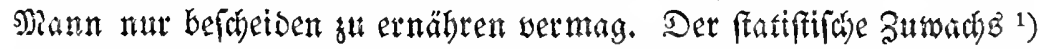

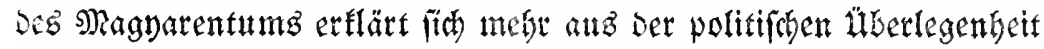
und Dem Injhlü von Bertretern Der Fremonationen (Deutfder, Slaven ufw.) namentlid) in Den Städten. Sn Der grweiten Scälfte

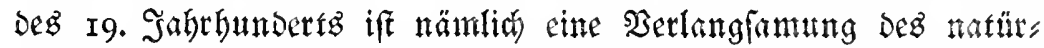

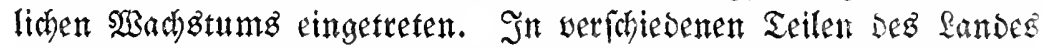

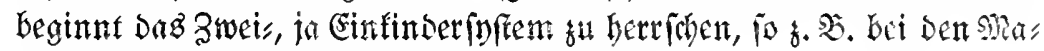
gyaren in manden \$lattenieegegenden ${ }^{2}$ ).

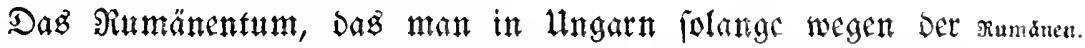
unbefriedigenden wirtiftaftliden 2erböltniffe wenig beadytet bat,

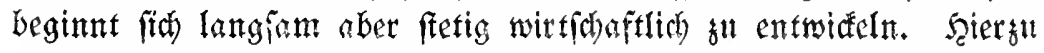
fommt, Dẩ bei Den Rumänen Der Sinderfegen ein ankerordentlid retcher ift ${ }^{3}$ ), weit grëper alz bei Magyaren unb Dentiften. Da Die

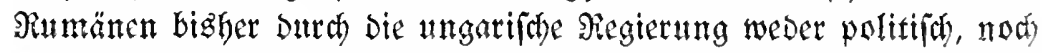

wo Die Bürger wãhreno Der Feldarbeiten in Der wärmeren Jabreg̉jeit weit

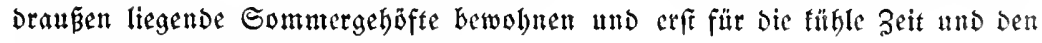
Winter in Die Dorfftad gurúdfebren.

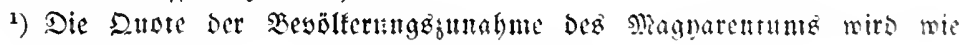
folgt angegeben:

$$
\begin{array}{ll}
\text { I } 880-\text { I } 890 & 57^{\prime \prime} " \\
\text { I } 890-\text { I } 900 & 7 I^{\prime \prime} \\
\text { I } 900-\text { I } 910 & 80^{\prime \prime} "
\end{array}
$$

") $\mathfrak{B g l}$ Publ. Der Platteniecsommititon.

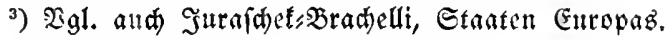

Piffor, Probultweträte Dfferreidsungarns. 


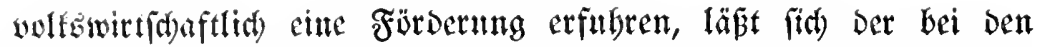

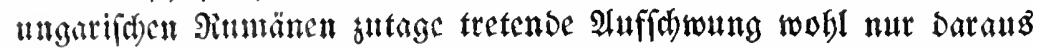

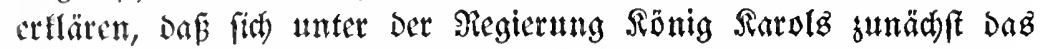
Bewnßtfein Deg sinmänentums im Rönigreid)e polififd und wirt"

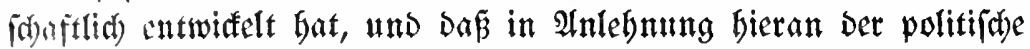

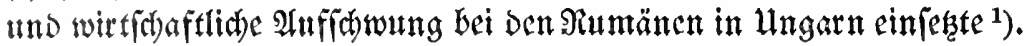

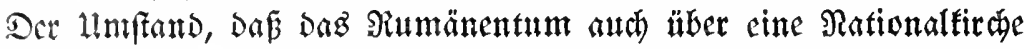
werfïgt, bat die politifaje Entwiaflung sweifellos weientlich gefördert.

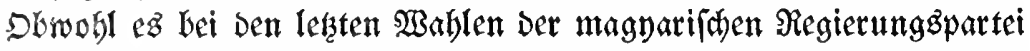

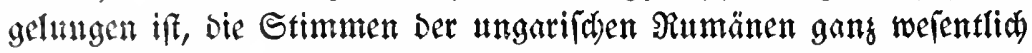

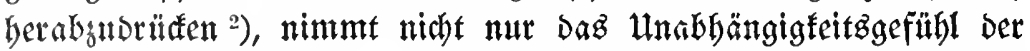

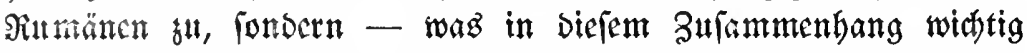

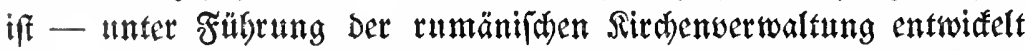

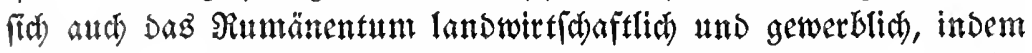
ez ftändig Das Snftem nationaler Ireditinftitute, bejonbers ber Bolkz" banfen in auferorbentlich anerfennengwerter $23 e i f e$ ausgeftaltet.

Die Serben find Dablelbe Bolf wie Die Sroaten; beide fprect)en biefelbe Sprache, mar find fie fird)enpolitifh getrennt, indem bie Serben

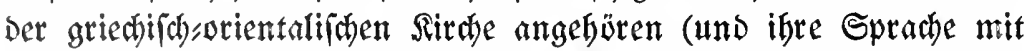
ber Enriflica foreibent), während bie Sroaten fatholifa fint. Die Sroaten, vielleidy nod mebr bie Serben, fino nicht nut politifa), ronbern auts wirtida aftlich auterorbentlich veranlagt.

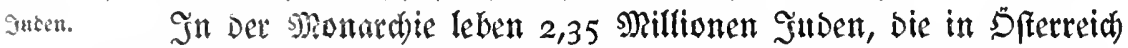
rund 5 , in Ungarn rund $4 \%$ Der Bevälfermug ansmadjen. Sie be"

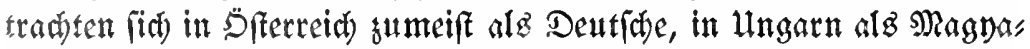
ren. Wäbrent fith die Suben in Den oftgalisifach Dörfern, wo fie in birbter $\mathfrak{A}$ fited geminuen die Snduftriellen und Sauflente jübifater Şerfunft in Der übrigen Monarbje ftänbig an Bebeutung, die in mandben $\mathfrak{B r a n d}$ cn,

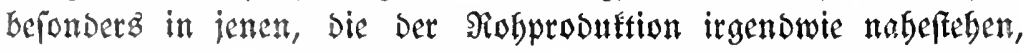

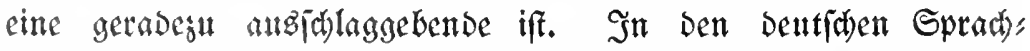
infeln ber Subetentänder bilben bie Suben eine wertwolle Stühe Des Deutidutume.

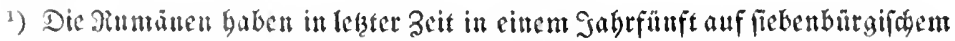
Boben augf befilz erworbin.

2) Bgl. Diz 2Bente non Gcotuz Biator (W3atfon), verlegt bei Confable. 


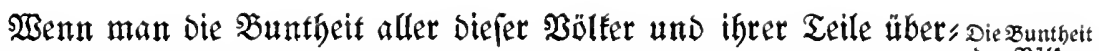

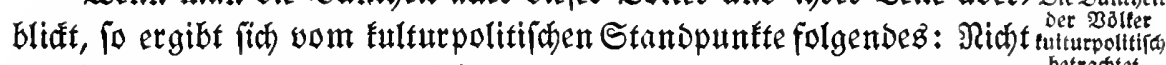

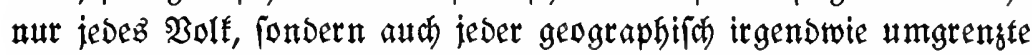

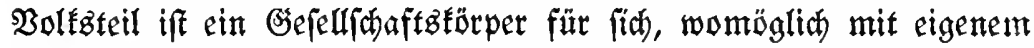
Dialefte, eigenen Sitten, Tradten. Wiser fïh nidft alg Soldat poer

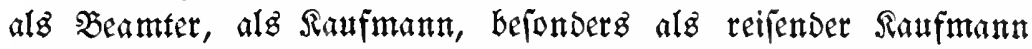

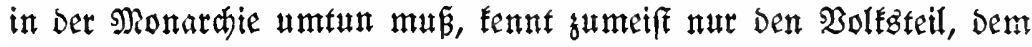
er jelbft angefört. So hat ber Deutifae auz dem Alpenlande zumeift

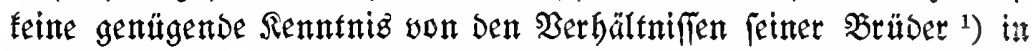
Norbbägmen oder im böhmerwald, nod weniger von denen in Sieben: bürgen, im $\mathfrak{b a n a t , ~ i n ~ G ̧ a l i z i e n ~ o b e r ~ i n ~ b e r ~} \mathfrak{b u f o r w i n a . ~}$

Ez gibt aud faume eine literatur doer Drganifation, bie bie Bölfer und igre Teile einander nathe brädte, bie నenntnis vermittelte -

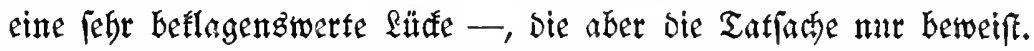

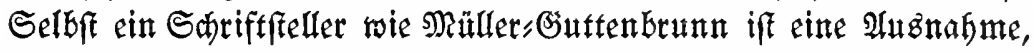

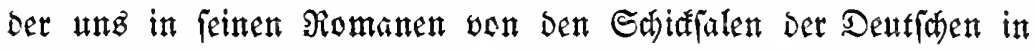

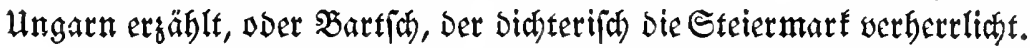

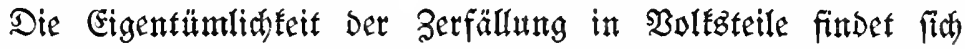

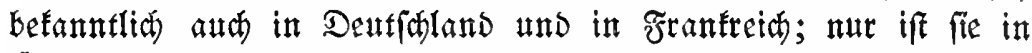

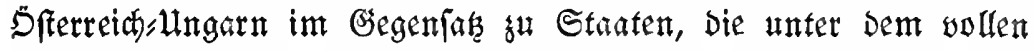

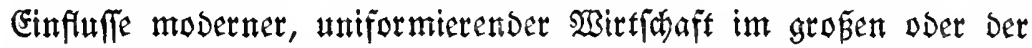

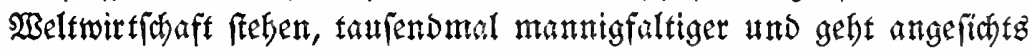

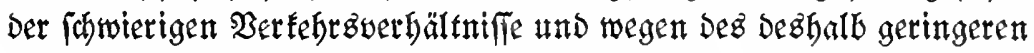

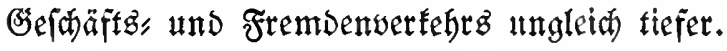

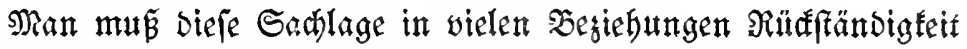
nennen; fie beseutet aber gleidyseifig, wenn mant geredht fein will, ungeheure moralijhe und füntilerifore $23 e r t e$.

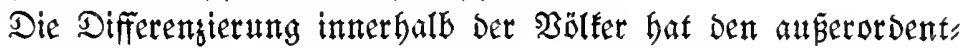

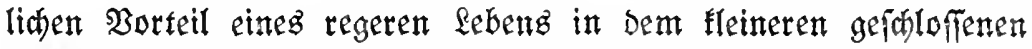

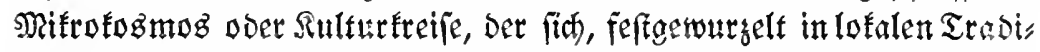

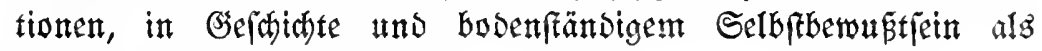

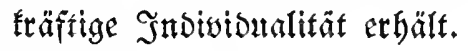

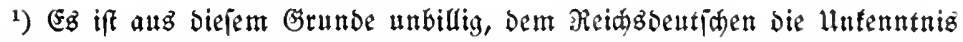

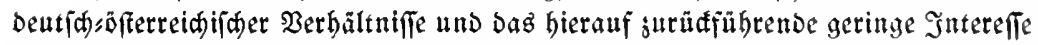
an Dem harten Shidial ber Dentid), Dfferreider vorjuwerfen. Wir Deutid,

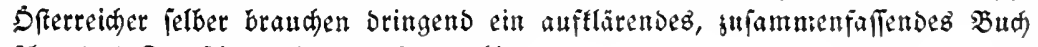
aber bas Dettfdutum in ber Monardie. 


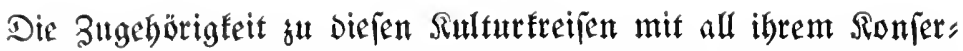

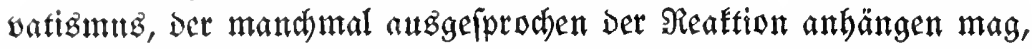

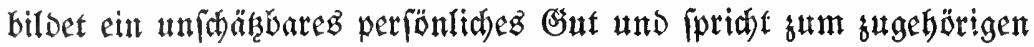
Inbividum eine eigene, zum Serzen gebende Sprache. Sie mag Die Maffe Der Bevölferung in vielen Begiebungen wom Fortichritte

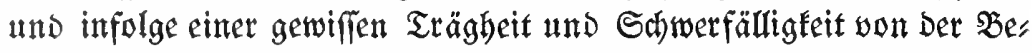
tätigung bochgefpannten Erwerbsfinnes abjaliefen. Uber fie betwahrt

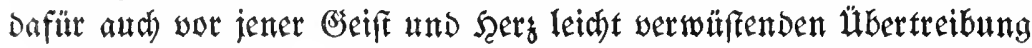
Des Erwerbsfinnes, Der verftänonizlofen Sudht Des Gelomadhens, DeB afemlofen $\mathfrak{B e t t e n n e n s}$ am nidhts anderez als Geld und Gut

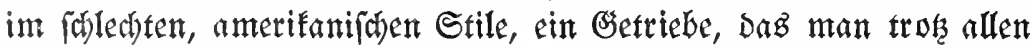
Sitbetriebleşens von Sorten uno Siräften vom perfönlidsen uno nationalen Stanbpuntat als fulturlofe ober wenigftenz Eulturarme übertreibung bezeidynen mutp.

Das Richtige liegt natürlich, wie Ḧberbaupt im $\mathfrak{e}$ ben, in Politif

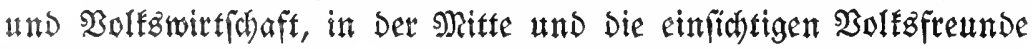

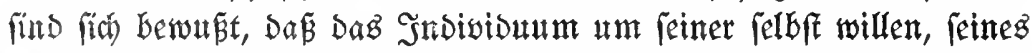

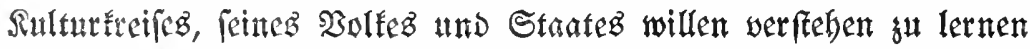
bat, Daß́ bei allem notwendigen Nobernismus auth ber Ronjer,

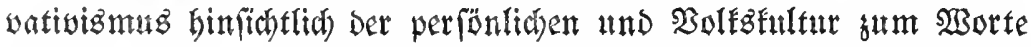
Fommen mur. Die Bewafrung Des Rationalen und wertwoller

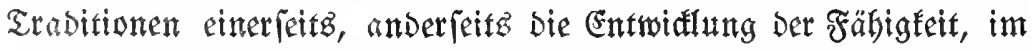

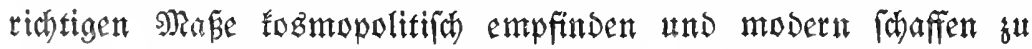
föntren, Gat baber aut Das Grunbpringip Der Sittutrföbernng Der Ronartyie gu billon ${ }^{1}$ ).

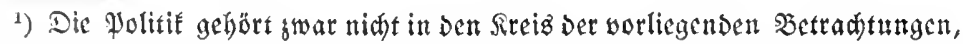

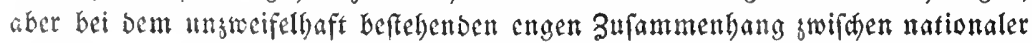

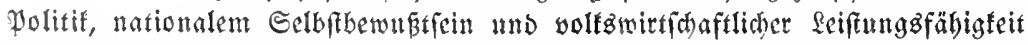
fei furs folgendes bemetft: Die Bölker anf Dent Doden Der Donaumontardie, Die ein

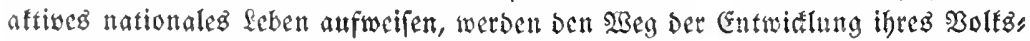

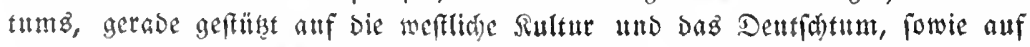
Die imernationalen Errmagenfaften mobener Drganifation, unaufbaltiam

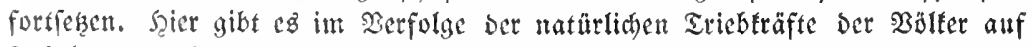

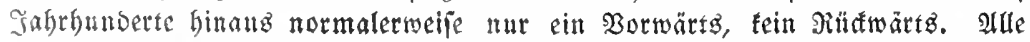

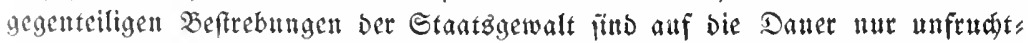

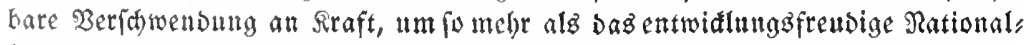

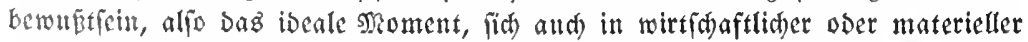

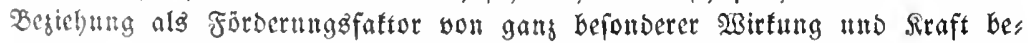

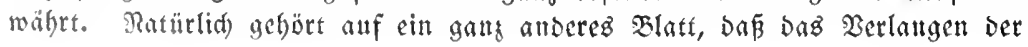




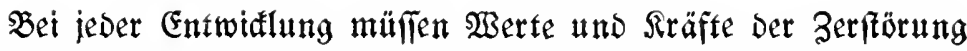

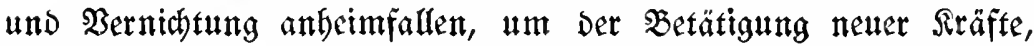

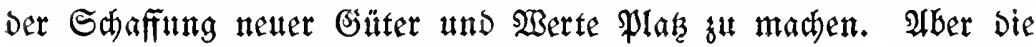

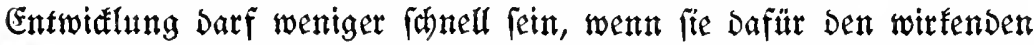

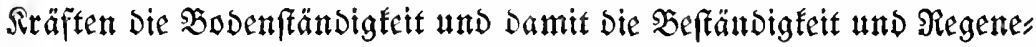
rierungża widłlung in vielen Teilen Der Monardie bişher ein langlames, gegebe"

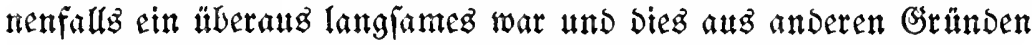

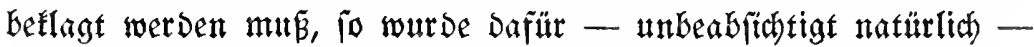

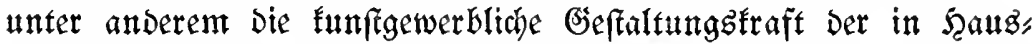

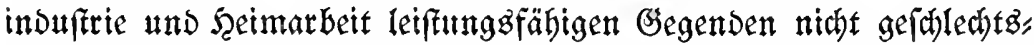

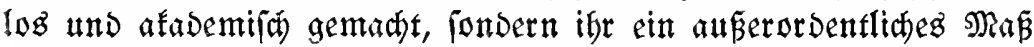

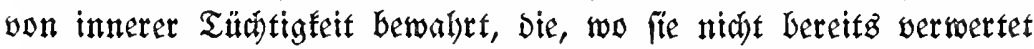

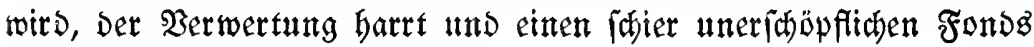

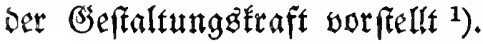

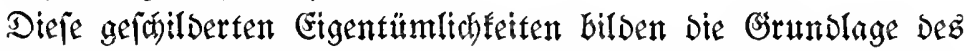

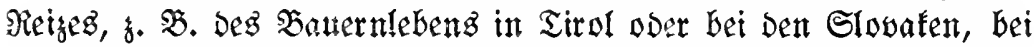

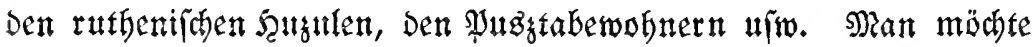

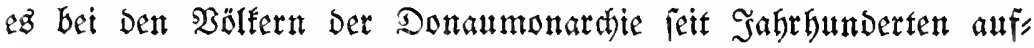
geipecicherte Uurfraft nennen ober einen

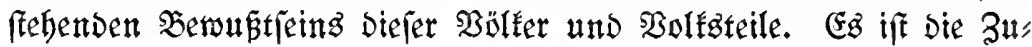

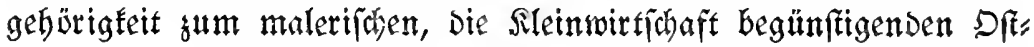

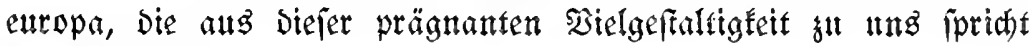

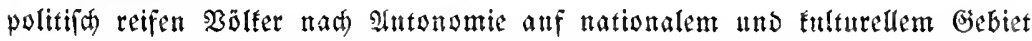

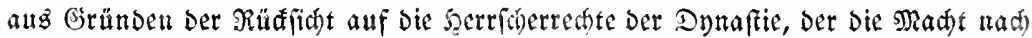

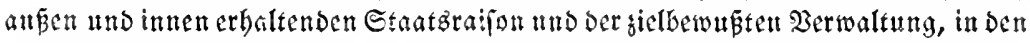

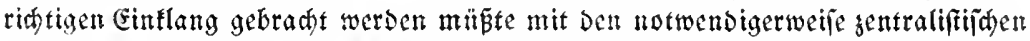

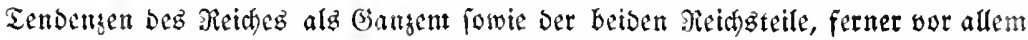

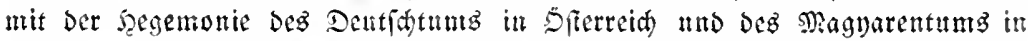

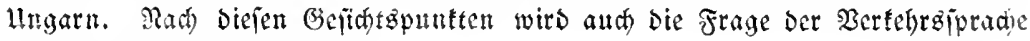
in Softerreid) ju regeln fein.

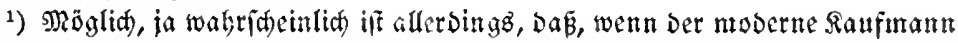

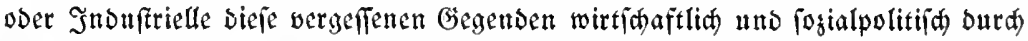
Einfübrnng neuer Grwerbszmeige ju erid)lieben fommt, bie Trabition ber $\mathfrak{H}$,

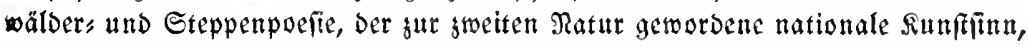
ganz ober zum größten Tetle ferben wirb: aber bie angeborte Erfindungzgabe,

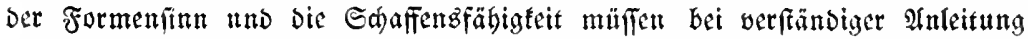
eine verwenbbare und entwituluggäăgige Grundlage inbuftrieller uno gemerb,

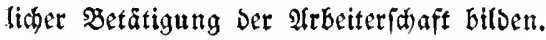




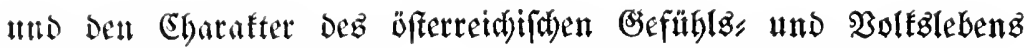
¿tberbant erflären bilft.

Ein Beifpiel bereitż weitgebender abgefbloffener Entroidlung und

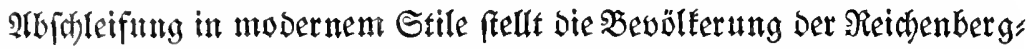
Bäblonfer Mittelgebirgż: Diftrifte Dar, wo bie lofalen und nationalen

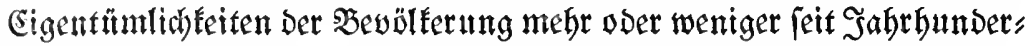
ten Diefelben geblieben find, wo aber Durd) Die Berübrung auch Der entferntefen Tăler mit Dem $\mathfrak{B}$ edarfe Dez $\mathfrak{B e l t m a r k t e z ~ - ~ e i n e ~ B e s ~}$

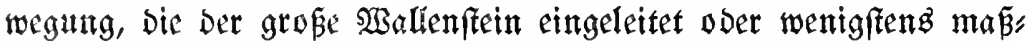
gebend gefördert hat - eine millionenfache betätigung in Der $\mathfrak{D e s}$ hanolung won Seinen, Wolle, Banmwolle, Metall, Edelftein, ESlas, Solg ufw. geforafien wurde.

Sn nod)maliger 3ufammenfaffung witb man fagen łönnen, Daß fïr die Donaumonardie in Fulturpolttif(der Defiegung Der

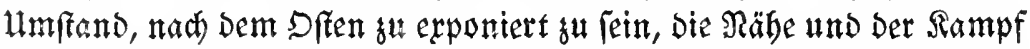

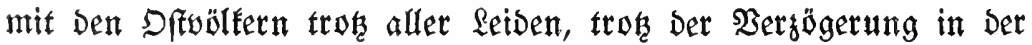

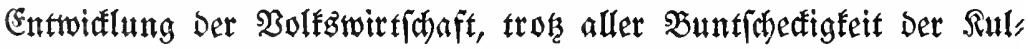
turverbältniffe bet allen Nadteilen auth Feine Dorteile gebabt hat: Eg ift biz in unlere Tage eime unendiche Menge natürlicher Bolkztraft

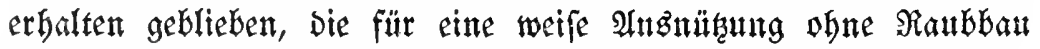

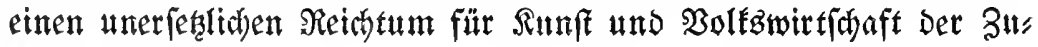
funft barftellen.

Für bie moderne Snduftrie Bedentet diefe Differengierung und Sndividualifiernng - wobei fidt viele Gebiete gang ober weitgebend im Stabium Der Raturalwirffaft befinden-vom Standpuntt Dez Ber"

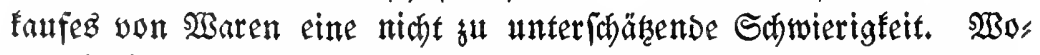
möglich jedez Tal in den alpen, im Sarft, in Den Sarpathen will gemäв feiner nationalwirtidjaftlichen Trabition eigens ausgeftattete $3 a r e n$

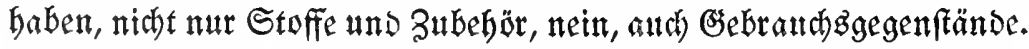

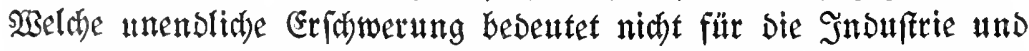

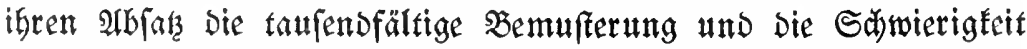
in ber beftellung Der ridftigen Reifenden Ginfithtlid Spraden und Poltegftitten!

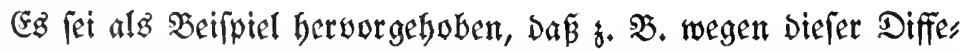
renterung Des Bedarfes eine D̈ferreidjifhe Rerzenfabrif beute nod Gumberte Formen mit allen notwendigen Unterteilungen führen

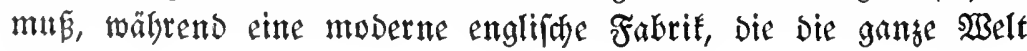


bebient, fid infolge Der Nivellierung Des mobernen internationalen

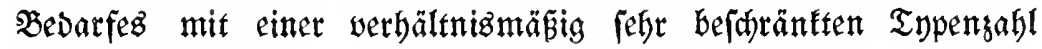
brgnügen $\mathfrak{k} \mathfrak{n}$ nt.

Das Sammeln bes auberorbentlich zerfplitterten betmiftien

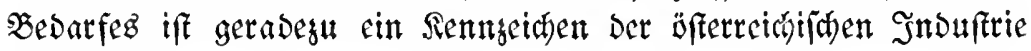
geworden.

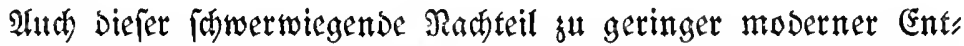
wifflung hat natürlich auf Der Gegenjeite für bie Jnouftrie uno Den

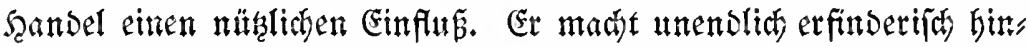

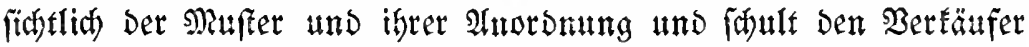

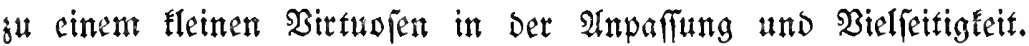

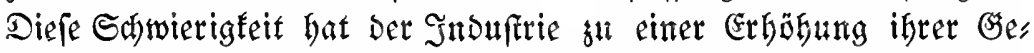
ftaltungatraft, was bie sannigfaltigfeit betrifft, werbolfen uno bes

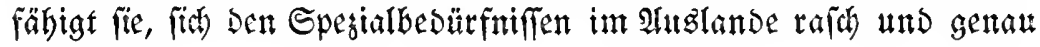
angupanen.

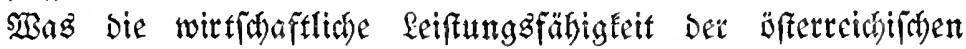
Bölfer betriffit, liegt léiber verläßlid)es, Detailliertes Material nid)t vor,

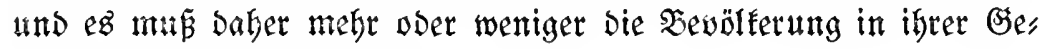
famtheit betraditet inerben.

Eine Statiftił Der Erwerbżätigen, ferner ber Dafugebörigen Erwerbebetä

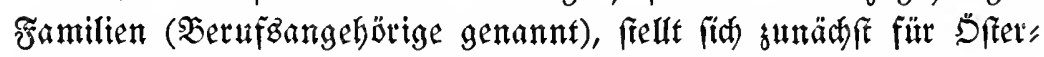
reid) (tad) Den Jahren I900 und I910), ferner für Ungarn (I900) uno

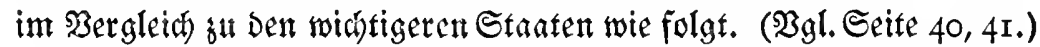

Someit man fich auf sie ziffern Der Statiftif verlaffen Eann, bielt I 900 Dfterretd) mit $51,5 \%$ Der Ermerbgtätigfeit - von Der Ges famtbevalferung geredinet - Den Reford, an zweiter Stelle feftit Frantreid) (I906) mit $51,3 \%$, an brifter Stelle Stalien nit $50,1 \%$, während. Ungarn and Deutichland mit rund $45 \%$ einander unges fähr gleichtomment.

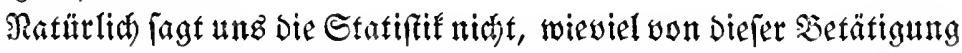
eine ftänbige ober Durd bie Ungunft Der $\mathfrak{B e r h a ̈ l t n i f f e ~ o d e r ~ b i e ~ E i g e n ~}$

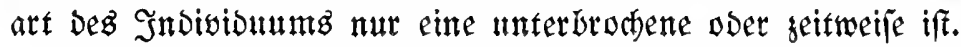

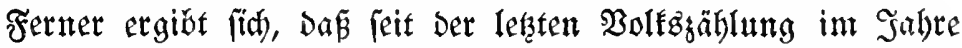

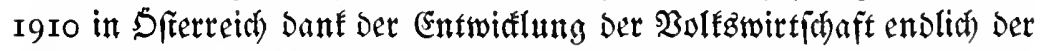

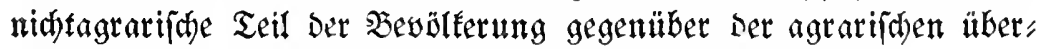

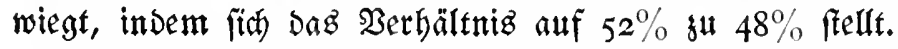

Für Ungarn liegt bie Biffer nichit vor, aber es ift wohl aud bier 
Erroets:

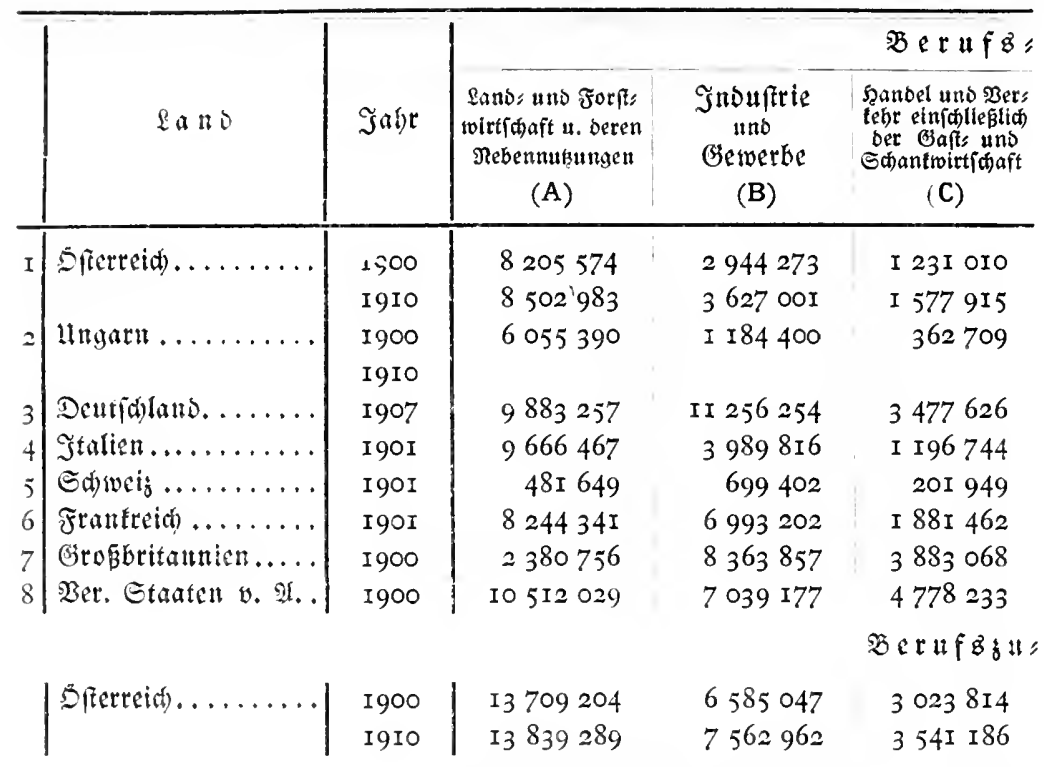

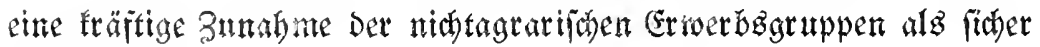
anğtnetremen.

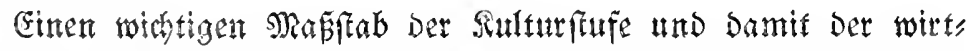

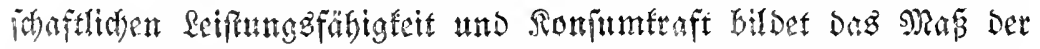

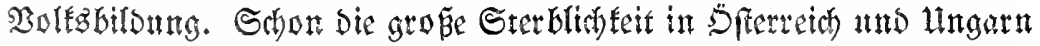

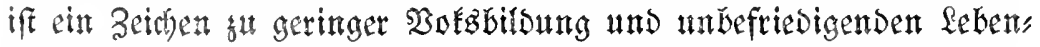
frandarda. Die Sterblichlett betritg I902-I906 in Sthweden 15,2, in Ëngland I5,7, in Dentfaland I9,4, in Sferretch 24,2, in Ulngarn 26, I

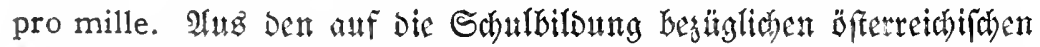

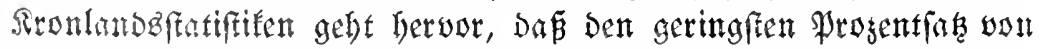

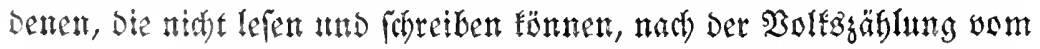
Sabre I9Io (mämliche und weiblidge zufammengenommen) Boralbery $(0,8)$, Dberöferreti $(1,72)$, Böbmen $(2,12)$, Tird $(2,38)$ und Nieder"

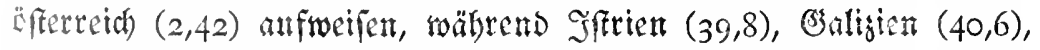
Butusina $(53,8)$ und Dalmatien $(62,8)$ mit exfarefenden Biffern

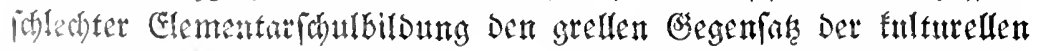

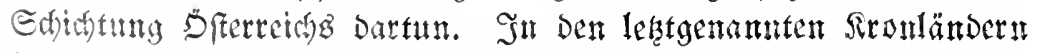

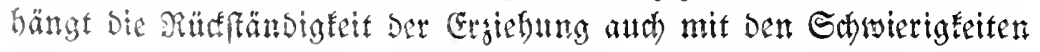


tätigkett.

\begin{tabular}{|c|c|c|c|c|c|c|}
\hline \multirow{2}{*}{$\begin{array}{l}\text { Dffentlider uno } \\
\text { Milltärotente, } \\
\text { freie Berufe, } \\
\text { Ber!sflofe } \\
\text { (D) }\end{array}$} & \multicolumn{5}{|c|}{ Bon je roo fallen auf die Berufg̈laflen } & \multirow{2}{*}{$\begin{array}{c}\text { Bon ber Ses } \\
\text { Tamtbetolles } \\
\text { rung twaren } \\
\text { ertoerbztátig } \\
\% \\
\%\end{array}$} \\
\hline & A & $\mathbf{B}$ & $\mathrm{C}$ & $\mathrm{D}$ & $A-D$ & \\
\hline I 727739 & 58,46 & 20,87 & 8,72 & 12,25 & 100,00 & 51,5 \\
\hline \multirow[t]{8}{*}{2310577} & 53,08 & 22,64 & 9,85 & I 4,43 & 100,00 & 56,1 \\
\hline & 68,6 & 13,4 & 4,1 & & & 45,9 \\
\hline & 35,2 & 37,5 & 12,4 & & & 45,5 \\
\hline & 59,4 & 24,5 & 7,4 & & & 50,1 \\
\hline & 30,9 & 44,9 & I3,- & & & 46,9 \\
\hline & $4 I, 8$ & 35,5 & 9,5 & & & 51,3 \\
\hline & $13,-$ & 45,8 & $2 \mathrm{I}, 3$ & & & 44,0 \\
\hline & 35,9 & $24, I$ & 16,3 & & & 38,4 \\
\hline \multicolumn{7}{|l|}{ 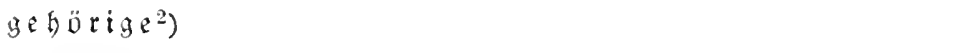 } \\
\hline 2832643 & 52,43 & 25,18 & I I , 56 & 10,83 & & \\
\hline 3627363 & 48,44 & 26,47 & 12,39 & 12,70 & & \\
\hline
\end{tabular}

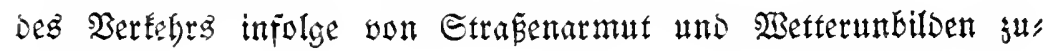
fammen.

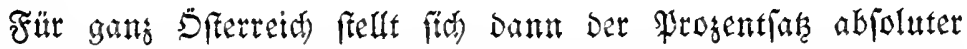

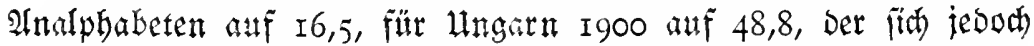
I910 anf $41,8 \%$ verminderte; in Sroatien und Slavonien betrug bie 3iffer $43,7 \%$. Wäbrend in llngarn im $\mathfrak{W e f t e n ~ ( i m ~ G e b i e t e ~ b e r ~ f r a ̈ n ~}$

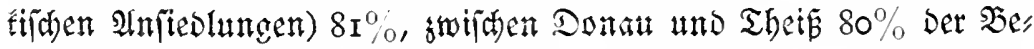
bölkerung lefen uns foretEen fänen, ift bies in Siebenbürgen nur mebr bei 50\% Der Fall. In erfier Stelle feben bie Deutfan, bann die Nagyaren; von ben ungarijhen Rumänen umb Sroaten Eann aher nitht eirmal ber vierte Teil lejer und joretben.

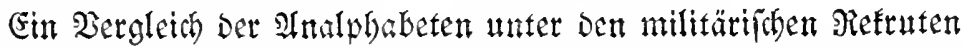
(nach) Dem Taufeno) ferllt Djterreid) unter Den angegebenen Staten (nak) Scidmanta I9Ij) in folgende Rangorbmung:

1) Etatifi. Jafrbud) für Das Deutide Reid, Inbung.

2) Şumbourg, Dieberuffitie uno pojiale Glieberung Der Bevolterung, Etas :ififite Nonatgidrift XIX. 


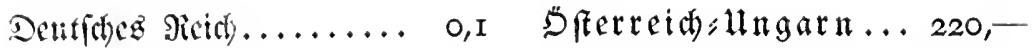
Sdiweden .......... 2,3 Stalien ........... $366,-$

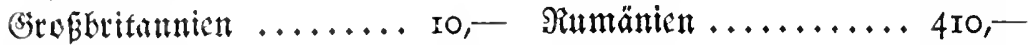
Franfreid $\ldots \ldots \ldots \ldots \ldots$ 33, - Serbien .......... 436,

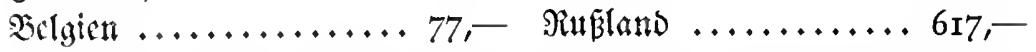

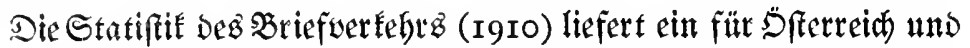

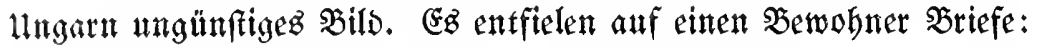
in Grobjbrifannien .... II5 in ber Styeiq....... II3

Sonfam pro Ropf Der

\begin{tabular}{|c|c|c|c|c|c|c|c|c|}
\hline & \multirow{3}{*}{$\begin{array}{l}\text { Batens } \\
\text { gatttng }\end{array}$} & fand & \multicolumn{3}{|c|}{ Siferreid) = Ungarn } & \multicolumn{3}{|c|}{ Deutfaland } \\
\hline & & $\left|\begin{array}{c}\text { Entroofnar } \\
\text { iii Mitliomen }\end{array}\right|$ & \multicolumn{3}{|c|}{51,34} & \multicolumn{3}{|c|}{64,90} \\
\hline & & $\mathfrak{I a \mathfrak { h } \mathfrak { r }}$ & $\left.1900^{1}\right)$ & $\left.1906^{1}\right)$ & I9I $2^{2}$ ) & $\left.1900^{1}\right)$ & $\left.1906^{1}\right)$ & $\left.1912^{2}\right)$ \\
\hline I & \multicolumn{2}{|c|}{ 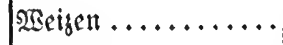 } & 97,6 & 86,2 & 126,8 & $9 \mathrm{I}, \mathrm{O}$ & 94,4 & 87,6 \\
\hline 2 & \multicolumn{2}{|c|}{$\Re \circ g \mathfrak{g e n} \ldots \ldots \ldots$} & 43,6 & 68,0 & 80,5 & $I 47,6$ & I 43,5 & $I 40, I$ \\
\hline 3 & \multicolumn{2}{|c|}{ 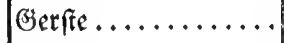 } & 38,6 & 49,8 & 66,7 & 65,9 & 82,5 & 97,0 \\
\hline 4 & \multicolumn{2}{|c|}{ ந̧afer $\ldots \ldots \ldots \ldots$} & 53,2 & 54,4 & 75,2 & I I 4,7 & I 20,6 & I IO, 4 \\
\hline 5 & \multicolumn{2}{|c|}{ Maiz $\ldots \ldots \ldots \ldots$} & $84, \mathrm{I}$ & I 18,2 & 87,6 & 24,7 & I8,9 & $\cdot$ \\
\hline 6 & \multicolumn{2}{|c|}{6 Rartoffeln $\ldots \ldots \ldots$} & 278,0 & $\begin{array}{l}337,5 \\
(1905)\end{array}$ & $\cdot$ & 604,6 & 592,6 & 656,1 \\
\hline 7 & \multicolumn{2}{|c|}{ Fleird) $\left(\right.$ I9I0) $\left.{ }^{3}\right) \ldots$} & - & $\cdot$ & 29,9 & $\cdot$ & • & 52,6 \\
\hline 8 & \multicolumn{2}{|c|}{ Raffee............. } & 0,90 & 1,02 & $\cdot$ & 2,85 & 3,03 & 2,53 \\
\hline 9 & \multicolumn{2}{|c|}{ Rafao.................. } & 0,03 & 0,07 & • & 0,32 & 0,56 & $0,8 \mathrm{I}$ \\
\hline Io & \multicolumn{2}{|c|}{ Tee $\ldots . . . \ldots \ldots$} & 0,02 & 0,03 & - & 0,05 & 0,06 & 0,06 \\
\hline I I & \multicolumn{2}{|c|}{ 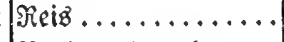 } & $\mathrm{I}, 7$ & $\mathrm{I}, 7$ & $\cdot$ & $2, I$ & 2,7 & 2,4 \\
\hline 12 & \multicolumn{2}{|c|}{ Berbrandigfuder ... } & 7,3 & 10,4 & 13,0 & 12,3 & $I 6,8$ & I9,2 \\
\hline I3 & \multicolumn{2}{|c|}{$\mathbb{S a l}_{\xi} \ldots \ldots . . . \ldots$} & 12,8 & I $4, \mathrm{I}$ & I 4,8 & $\cdot$ & $2 I, 8$ & 24,6 \\
\hline I4 & \multicolumn{2}{|c|}{ Bier (in sitern).... } & 44,4 & 38,8 & 42,4 & $\mathrm{I} 20,8$ & I I 2,0 & IOI,O \\
\hline I5 & \multicolumn{2}{|c|}{ WBein (in litern) ... } & I 4,0 & - & - & 5,9 & ; & $\cdot$ \\
\hline I6 & \multicolumn{2}{|c|}{ Zranntmein (i. \&itern) } & I0, 5 & . & - & 6,3 & 6,1 & 5,4 \\
\hline I7 & \multicolumn{2}{|c|}{ 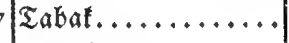 } & • & . & $\mathrm{I}, 23$ & $\mathrm{I}, 6$ & $\mathrm{I}, 5$ & $\mathrm{I}, 7$ \\
\hline I 8 & \multicolumn{2}{|c|}{ Petroleum ......... } & 4,68 & 5,22 & 6,2 & I 6,8 & 17,2 & 17,3 \\
\hline I9 & \multicolumn{2}{|c|}{ Steintoble,... . } & 400,0 & 440,0 & 520,0 & 1800,0 & 2066,0 & 2321,0 \\
\hline 20 & \multicolumn{2}{|c|}{ obrannfoble ...... } & 402,0 & 424,0 & 584,0 & 860,0 & 1058,0 & $r_{328,0}$ \\
\hline $2 I$ & \multicolumn{2}{|c|}{ Eijenerge .......... } & • & $\cdot$ & 109,0 & $\cdot$ & $\cdot$ & 640,0 \\
\hline 22 & \multicolumn{2}{|c|}{ Robeifen $\ldots \ldots \ldots$} & 32,9 & 29,6 & 53,4 & 162,0 & 198,0 & 253,0 \\
\hline 23 & \multicolumn{2}{|c|}{ Batmmolle ........ } & $\cdot$ & $\cdot$ & 4,35 & 5,54 & 6,28 & 7,56 \\
\hline 24 & \multicolumn{2}{|c|}{4 IIute $\ldots . . . \ldots \ldots$} & . & . & $\mathrm{I}, 08$ & $\cdot$ & . & 2,28 \\
\hline
\end{tabular}

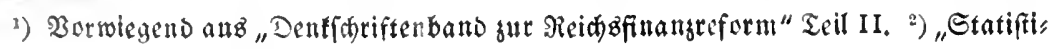


in $\mathfrak{B e l g i e n} \ldots \ldots \ldots$, $\ldots$, in Stalien ........ 34

in Şolland ......... 96 in Ungarn........ 30

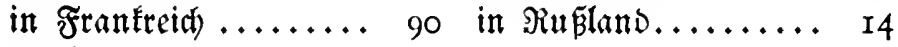

in Sfterreich ......... 60

Die Sonjumftatiftif Der widstigeren Berbrauchgartifel in Der Sonfum Monardjie im Bergleidje mit verf(j)iedenen anderen Staaten Europas ergibt folgendeg $\mathfrak{B i l l}$ :

Bevölfer ung in kg uno fiter:

\begin{tabular}{|c|c|c|c|c|c|c|c|c|c|c|c|c|}
\hline \multicolumn{3}{|c|}{ Frantrcid) } & \multicolumn{3}{|c|}{ England } & \multicolumn{3}{|c|}{$\Re \mathfrak{n} \mathfrak{l a n o}$} & \multicolumn{4}{|c|}{ Stalien } \\
\hline & 39,60 & & & 42,19 & & & 120,65 & & & 32,48 & & \\
\hline $\left.1900^{1}\right)$ & $\left.1906^{1}\right)$ & I9I2 $\left.{ }^{2}\right)$ & $\left(1900^{1}\right)$ & $\left(1906^{1}\right)$ & I9I $\left.2^{2}\right)$ & (900') & $\left.1906^{1}\right)$ & $\left.1912^{2}\right)$ & (1900') & $\left.1906^{1}\right)$ & I9I $\left.2^{2}\right)$ & \\
\hline 200,0 & 216,0 & $27 I, 0$ & I 53,8 & . & 144,9 & 57,8 & . & 107,2 & I 39,0 & I 56,7 & 190,6 & I \\
\hline 32,0 & 34,0 & 32,4 & 2,4 & • & $I, O$ & 147,6 & 142,0 & 242,7 & . & . & 3,9 & 2 \\
\hline 21,0 & 24,0 & 28,8 & 56,7 & 57,0 & 57,6 & 28,4 & 33,0 & 77,6 & . & - & 7,3 & 3 \\
\hline $98, \mathrm{r}$ & 120,0 & 137,8 & 83,6 & 76,2 & 89,6 & • & . & 165,0 & . & • & 20,8 & 4 \\
\hline 20,0 & 22,0 & 28,7 & 68,7 & 56,4 & 42,2 & 3,7 & . & I 8,5 & 56,0 & 72,0 & 76,6 & 5 \\
\hline 310,5 & $\begin{array}{l}360,6 \\
(=905)\end{array}$ & · & 87,0 & 109,2 & • & 165,5 & . & · & • & • & • & 6 \\
\hline$\cdot$ & . & 33,6 & . & . & 47,6 & $\cdot$ & . & 21,6 & . & . & 10,9 & 7 \\
\hline $2, I$ & $\cdot$ & 2,8 & 0,32 & . & . & 0,63 & . & • & 0,5 & . & . & 8 \\
\hline 0,46 & 0,60 & $\cdot$ & 0,50 & 0,55 & . & $0,0 I$ & 0,02 & . & 0,02 & 0,04 & - & 9 \\
\hline 0,03 & 0,03 & . & 2,8 & 2,8 & . & 0,5 & 0,5 & . & . & . & . & IO \\
\hline 2,7 & $\cdot$ & . & 4,6 & 8,9 & . & · & . & - & . & . & . & II \\
\hline $\mathrm{II}, 7$ & I 4,9 & · & 39,7 & 37,1 & . & 5,7 & 7,2 & . & 3,3 & • & $\cdot$ & I 2 \\
\hline • & . & II, 3 & . & • & . & • & . & . & . & . & 7,16 & I3 \\
\hline 24,2 & . & . & 141,7 & . & . & 4,2 & . & . & 0,5 & . & $\cdot$ & 14 \\
\hline I IO, 8 & . & . & I, 8 & . & . & · & . & . & 85,8 & . & . & 15 \\
\hline 8,7 & . & . & 4,7 & . & . & 4,8 & . & . & $\mathrm{I}, \mathrm{I}$ & . & . & 16 \\
\hline 0,97 & . & . & 0,89 & 0,89 & . & . & . & . & 0,48 & . & . & I7 \\
\hline$\cdot$ & ! & • & . & • & • & . & . & . & . & ; & . & I8 \\
\hline 1190,0 & 1260,0 & I 480,0 & 4150,0 & 4080,0 & 3830 & I 50,0 & 150,0 & I 90,0 & I 50,0 & I90,0 & . & I9 \\
\hline$\cdot$ & • & . & . & • & • & . & . & $\cdot$ & . & . & . & 20 \\
\hline$\cdot$ & • & • & . & • & • & $\cdot$ & . & . & . & . & . & $2 I$ \\
\hline $68, I$ & • & . & r9I,I & I99,4 & • & 27,4 & . & . & $6, I$ & . & . & 22 \\
\hline • & • & · & $\cdot$ & $\cdot$ & • & $\cdot$ & • & • & · & • & • & 23 \\
\hline$\cdot$ & • & • & $\cdot$ & $\cdot$ & • & $\cdot$ & . & · & • & • & • & 24 \\
\hline
\end{tabular}

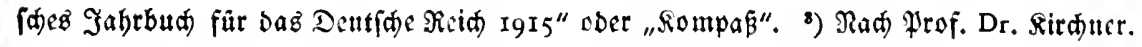




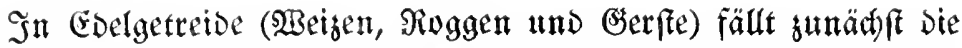
anjerorientlitye Stetgerung Dez Ronjumb in Den Safren I900 bis I9I2 auf und ertlärt biz ful einem gewiffen Êrabe Die ungünfitge Geftultung bes beimifhen Exportez in biejen Produften. Die Bes völferung hat fich beffer genährt und hat gemäß ben befferen Erntes

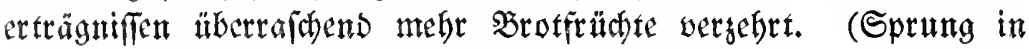

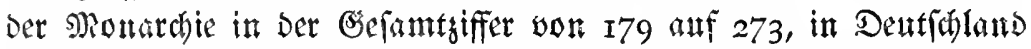
trur von ratid 304 auf j24, in Franfreid yon 253 auf $332 \mathrm{~kg}$.) Das fleifdeffertoe, mat won Der Getreibeeinfubr lebende England ift mit rund $200 \mathrm{~kg}$ unerändert geklieben, während Rubland mit Der Menge

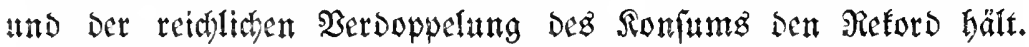
(Bei Der öfterretdifthen Biffer ift Der Einfodbeit balber angenommen,

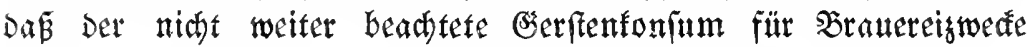
Durd Den Sonfum won Maiz sut menfaliden Sabrung wie er im Süboften Ungarnz erfolgt - ungerähr angegegliçen werde.)

An Dentichland, Frantreidy and gar æubland gemeffen, bat Der Sonfum an Edelgetreide Der Monardie nod immer nidht Das Durds"

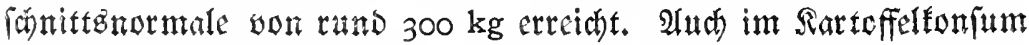

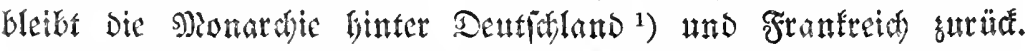

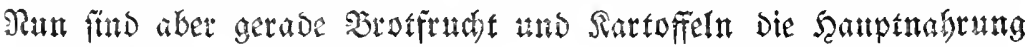

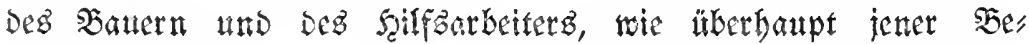

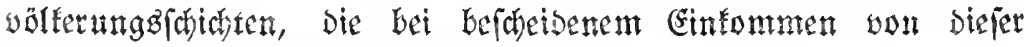

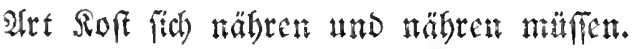

Went aber for bu beim Somftm von Brotfrutht und Sartoffeln

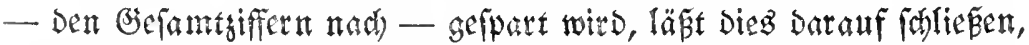

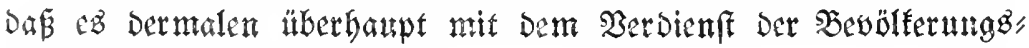

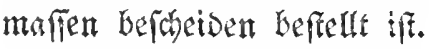

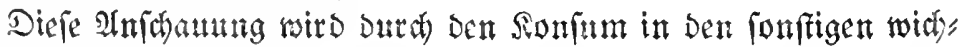
tigen Sonfuntartiteln befiatigt.

Der Sionfan won Fleifd ife Der niedrigfte unter Den vier gröbten

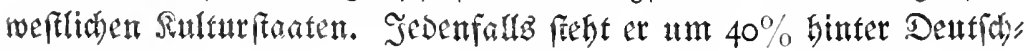
land furüd.

Stidgproben bei Der ländlid)en und arbettenden Besülkerung befrätioen bie Sachlage. Der Balter, o. B. in Den Deutfach arpen

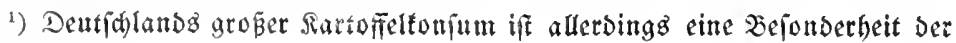
Bolfzernăgrung. 
gegenden, if̧t faum ein

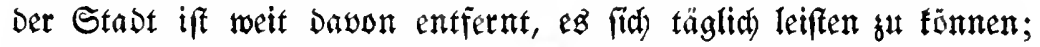

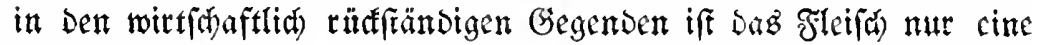
Feiertaggłoft. Unter anderen umftänden wärde mat in ber Monarafie mit Dem Biebftand bei Der faft vollfändigen Eperrang ber Grengen fohon längft nid)t mely altsegetomment fein.

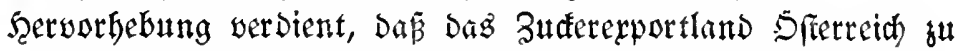
Den iparfamften Ionfumenten von Buder gehört (ähnlth wie Rußs land), was allerdings weifgefend auf Die bohe Beftetterung Diefes

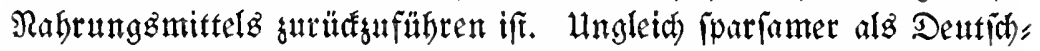

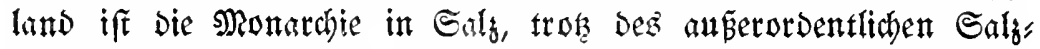

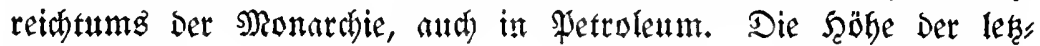
teren Biffer in Dentifhland iff trok Des Dortigen größern Sonfums von eleftrifdem lidbt nath Infitht Der Fad leate nidft auf Den $\mathfrak{B e r}$ braud won Sotoren, fondern aur die böbere Sittlut, Das bedütfntis nadh ausietchender beleuthtung auth auf bem flachen Sambe zurüt,

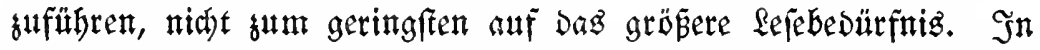

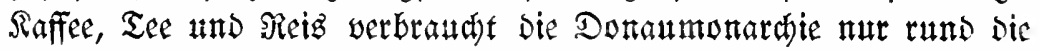

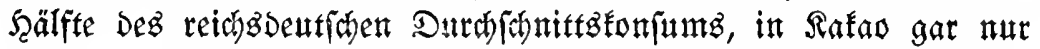

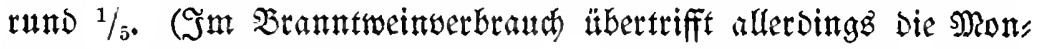
archie Deutfoland.) Der Sonfum in Baumwolle uno Sute ${ }^{1}$ )

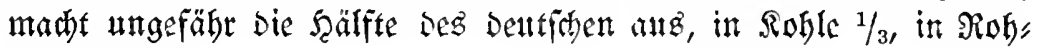
eifen $1 / 5$.

Die obigen Biffern werden es begreiflich eridteiten laffen, wenn jener Teil Der bevälferung Der Monarchie, Der als \$rodusent uno Sonftment modernen Stils in 20-22 Millionen Sïpfe gejdänt wird, wobei bie Dentiden in

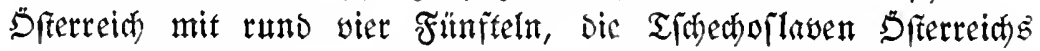

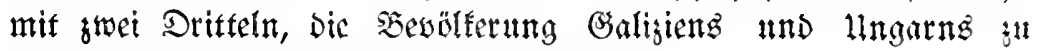
einem Drittel in ßechnung geftellt werben.

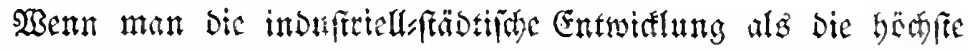
modertte Entwiflung anjeft, ergibt fith, wie gering biefe Ents

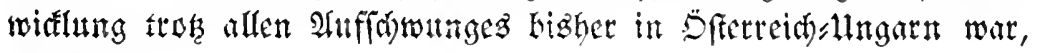

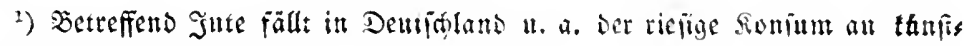
lidjen Düngemitteln féfe ins Gewidt, für seren 2ierjans ungebale smengen won Cäđen gebrautrt merben. 


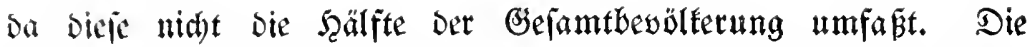

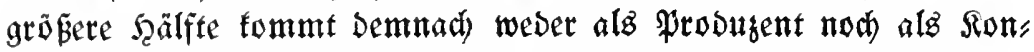
futment in Stile wollentwiftelter moderner Staaten in Beftadt.

Dof e ez in ber Monardjie an vollatif befriesigender Betätigung,

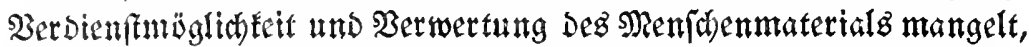
gegt, abgeperen won bent wenig befriesigenden Daten Der Sonnjum

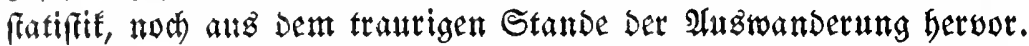

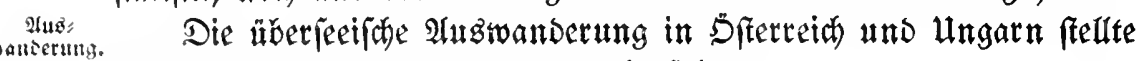
(iin) in Den Sahten 1910-1912 wie folgt:

\begin{tabular}{|c|c|c|c|}
\hline & I910 & I9II & 1912 \\
\hline aus Dfterreid & $\ldots \ldots \ldots 138915$ & 90134 & 128866 \\
\hline $\mathfrak{a} \mathfrak{a} \mathfrak{l} \mathfrak{l n g} \mathfrak{g a r n}$ & .. 130025 & 87757 & 140559 \\
\hline $\mathfrak{z} \mathfrak{a} \mathfrak{a}$ & & $17789 \mathrm{I}$ & 269425 \\
\hline
\end{tabular}

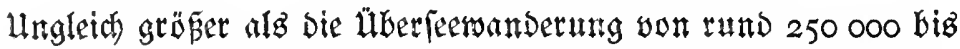
270000 Siappen ift bie Fontinentale Saifontwanderung. Man fann

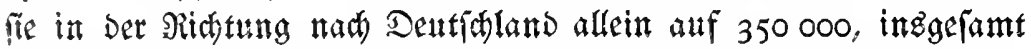

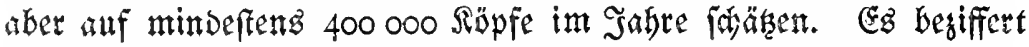

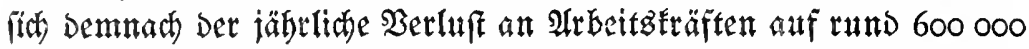

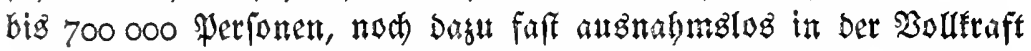

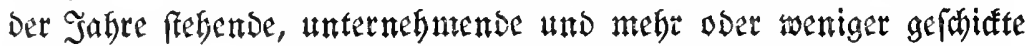

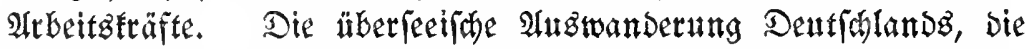

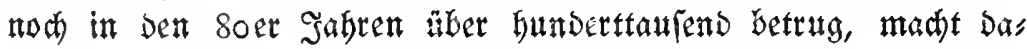

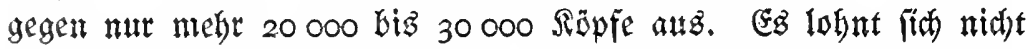

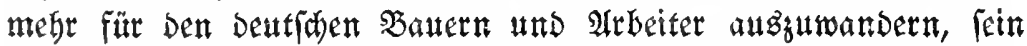
Saterland gibt ifjm genng Berdienti.

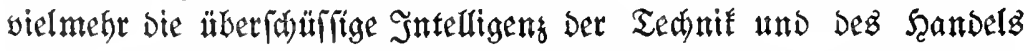

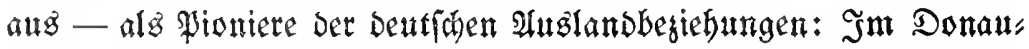
reide flammert fith bie Sintelligeng im Begenteil zumeift an ben beimiticten Serd.

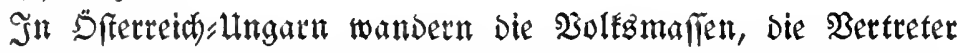

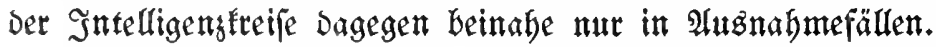

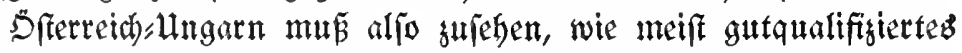

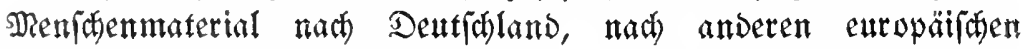
Stanten und aad) Den Bereinigtent Staaten augwandert, $\mathfrak{m}$ in

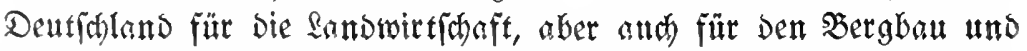

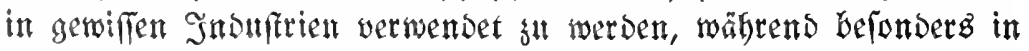

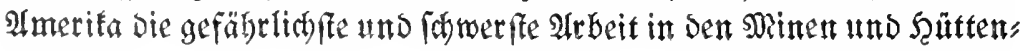


werken von Bürgern Der Monardhie bejorgt mird. Weil Den $\mathfrak{A r b e i t e r n}$ in Der Seimat feine genügend ftabile ober genügeno begahlte arbeit

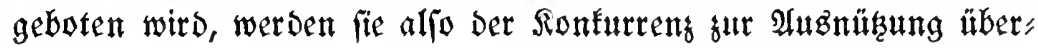
Iaffen.

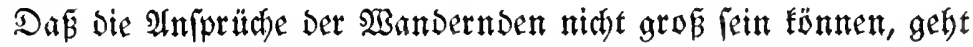

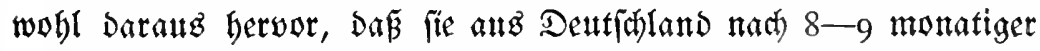

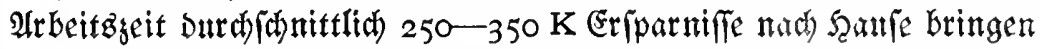
(bie aus $\mathfrak{A m e r i f a}$ Geimfebrenden allerbing mehr ${ }^{1}$ )).

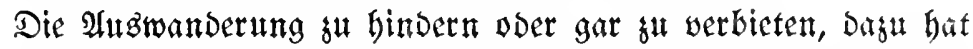

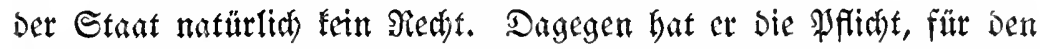

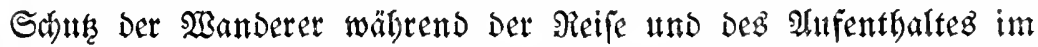

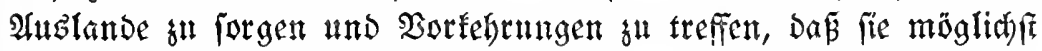

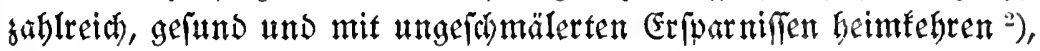
Daßj biejenigen, weldhe nichat beimtebren fönnen, gern und eifrig den fteten Zulammenhang mit ber alten Sceimat pflegen. Aber bie Tats

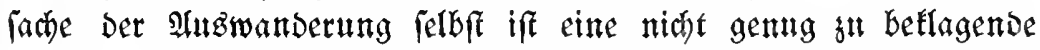

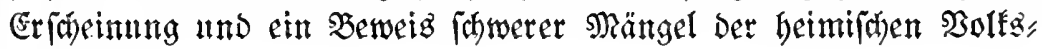
wirtichaft.

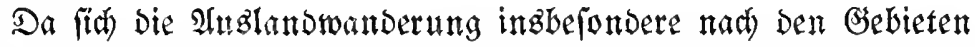

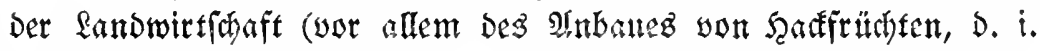
Rüben und Sirtoffeln) und Der Snomftrie richtet, fann eben nur bie

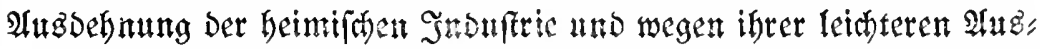
Dehnunggfähigfeit wor allem biefe, ferner die bebung ber Şntenfität unjerer eigenen fandwirtfant Dem übel entgegentritent ${ }^{3}$ ). $\mathfrak{A} \mathfrak{j}$

1) Deu Huterifies tim 2Banbergiele uns im Erfolg ber Dortigen Arbeitşs

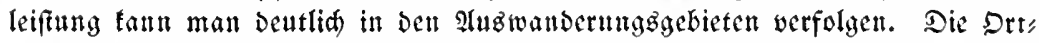

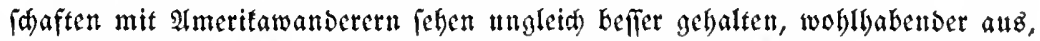
als Die Dörfer Der "Sadjengänger"; Die アaifeijenfaffen und Sparfaffen Der erferen find auffalleno reid, was von ben lez̧teren nitat gillt.

2) Die Gelbfeimienoungen ans Amerifa bilden âlnlia, wie in Stalien, aud in Der offerreidif

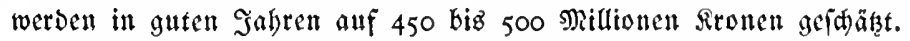

3) Die T(d)eden, bie nod) wor I5 Sabren in gropen Maffen tad Amerifa wanderten, tun siez faft gar nidht mehr. Sie finden in Sfterreid Dant ber Ents

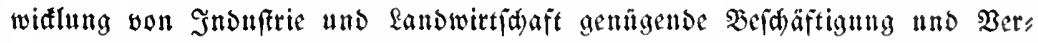
wertung igrer Arbeitätraft. Dagegen bat Die Sanderbewegung inmer mebr

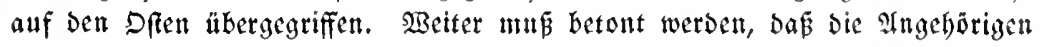

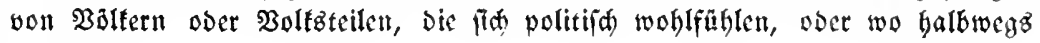


grundlegende $\mathfrak{A}$ grarreformen, fo notwendig fie in vielen weiten Teilen

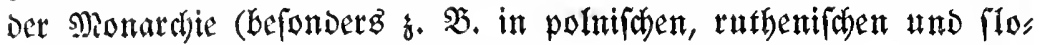

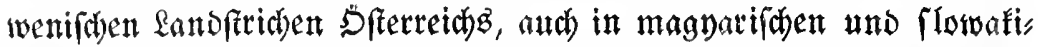

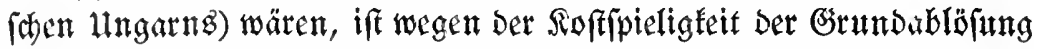
und ber fonftigen, u. a. Der parlamentarifhen Seinderniffe Der Durds, fïlbung (bejonbers wegen Der Schwierigfeit Der Drganifation Des

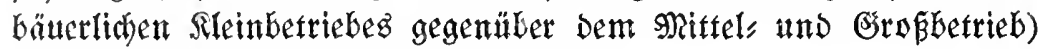
in abjebbarer zet wobl fanm gu hoffen.

Goslalpolitif แกto Irbeite̊s

Anf Dem Gebiete Der Sogialpolitif find aud in Der Monardie, bes

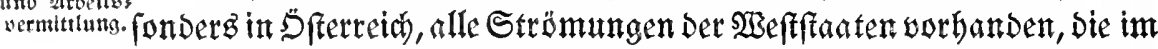

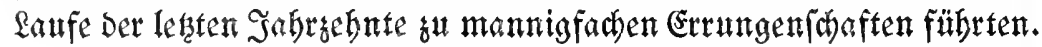

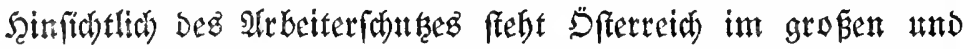
gangen auf ber Şöhe Deutfhlands und nimmt an allen bezüglicten internationalen Bereinbarnngen teil. Die Gerwerbeinfpeftion ift in beiden Staaten befriedigend entwidelt. Dem âbjhluffe ber öfter"

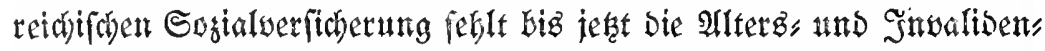
verficherung, bow fteben feit Sabren Regierungsoorlsgen in parlas mentarificer Bebandung, die aber infolge Der mit politifásen \$artei, fragen zufammenbängenden Schnierigfeiten, fo Der Serficherung Der Selbfändigen in Sleingewerbe und fanuwirffofaft, nicht fut einem Ende gefübrt werden lonnter.

Die Arbeitguermittlung ift, wie in faft allen übrigen Staaten,

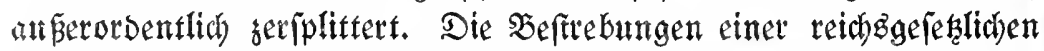
Regelung fropen auf Den \$artifularizmus oer Sronlänoer, welde

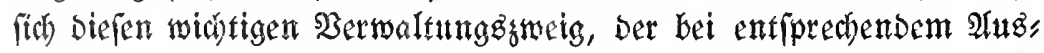

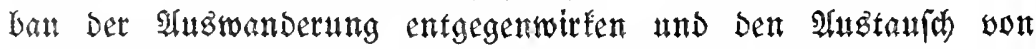
Irbeitzłraften zwifhen Den cingelnen Gebieten föroern, fowie fut inneren Solonifation führen fönnte, nisht entgeben lafien wollen;

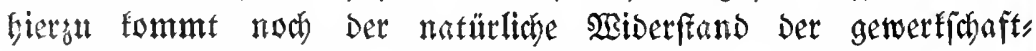
lichen 2irbeiterorgntifationen uno äberbaupt aller beftehenden Irbeits" vermittlutgseinriatungen. Fine mufterbafte Drganifation Des $\mathfrak{I}_{\text {s }}$

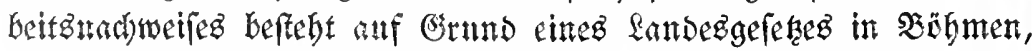

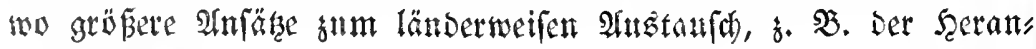

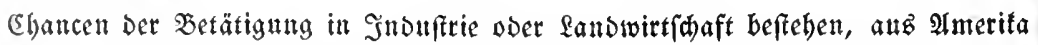
wieber heimtommen, fo bie Polen, Slowaken, Dalmatiner, während jene, bei Demen Dies nid)t zutrifft, Der Secimat anf immer Den Rüden febren, wie bie Utrainer uno gemifle Gäblaven. 


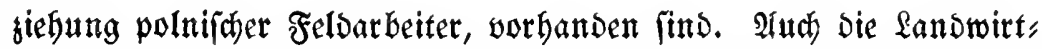

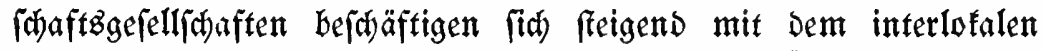

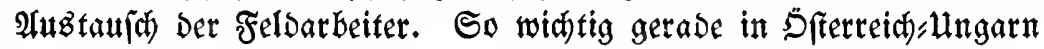

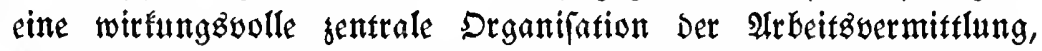

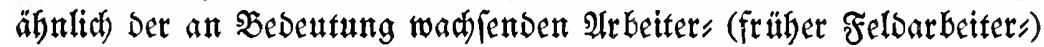

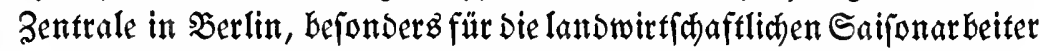
wäre, mu艿 igr Fehlen lebgaft bedauert werden. -

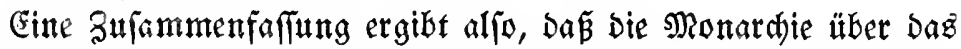

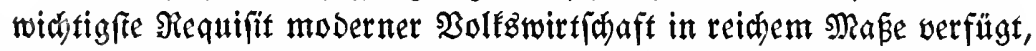
über bie Mienjajenfraft, noch baga über rältige, arbeitzfreudige und

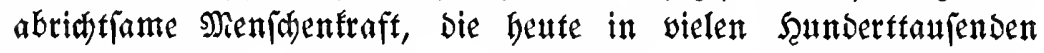

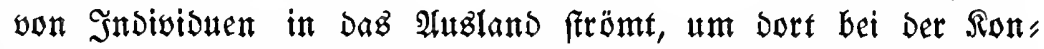

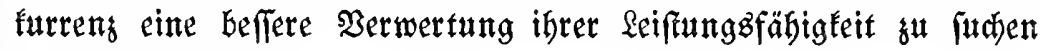
and fu finden ${ }^{1}$ ).

Dieje Menffenmaffen find aber entweber Geute fhon im moder" nen Iandwirtfanaftliden Betrieb (Bögmen, Mähren und Rieder,

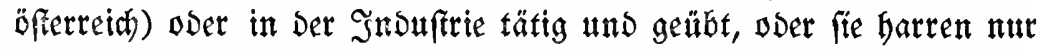

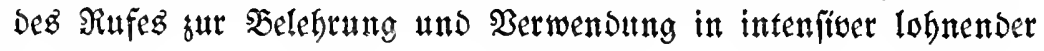
Urbeit.

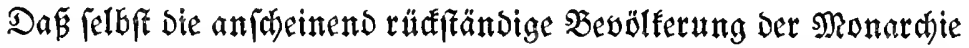

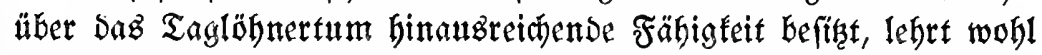

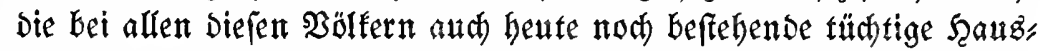

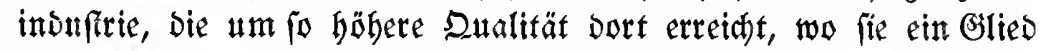

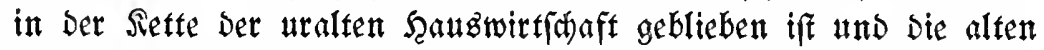

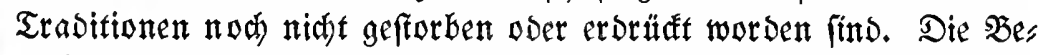

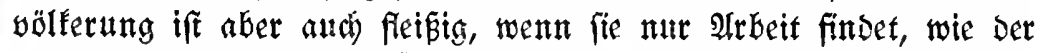
Utmftano berweiff, Daß in Sffterteid) won 28 Millionen Einwognern 16 Mitlionen einen $\mathfrak{b e r u f}$ auzäben, aljo rund 56,2\% Der $\mathfrak{B}$ evölferung.

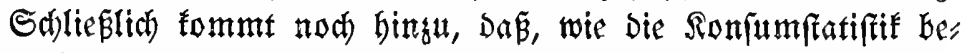

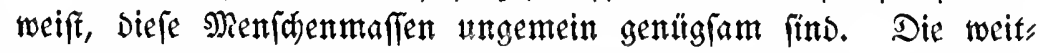

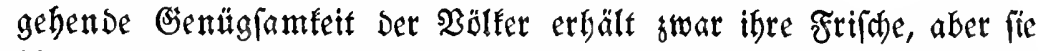

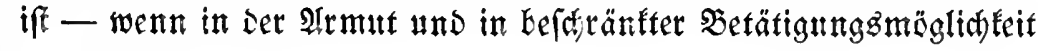

1) Die bei $\mathfrak{B e r w a n d t e n ~ u n d ~} \mathfrak{e} e \mathfrak{f a n n t e n}$ einlangenden Gielobeträge wirten

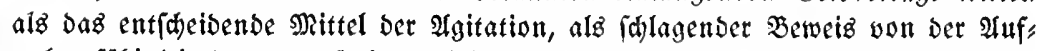

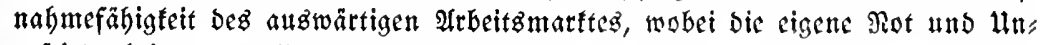

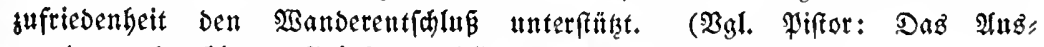
wanderungzproblem. Bei Braumatler im (Erígetuen begriffen.)

Ptfor, Produttiofräfte Dfferteid)/lingarnz. 
begränDet - Eetne Föorberin Der Sultur, ja felbft auj Die Dauer feine

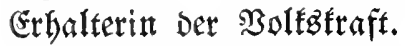

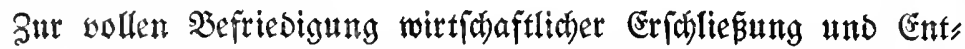

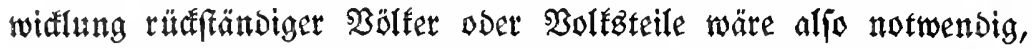
erbüten Sebarf fur Deatung zu befhaffen. Dann wird Den Unter, nebmern genügend Inreiz zut Snveftition für ifr Sapital und ifre Fäßfigfeiten geboten werden, Den Arbeitern aber mebr arbeitgegelegen,

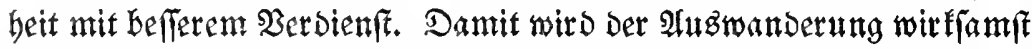
entgegengewirkt, der Sttandonfum neu gehoben, bamit im Sreislanf

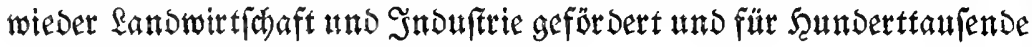
nene 2 trbeitzgelegentheit belchaff.

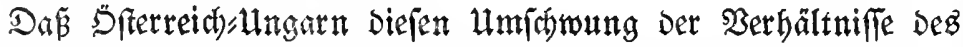

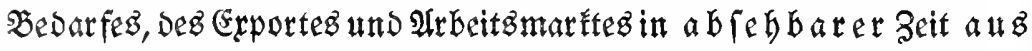

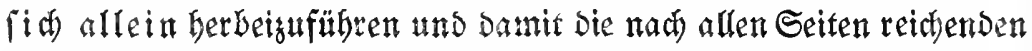
Rulturflifte rafdeftens zu befeitigen und anşugleichen imftande fein wird, ift latoer nicht ansunebmen.

\section{Dic Sandwirtidaft.}

\$enn man won Der Gefamefläd) Der Monardj: angefähr $15 \%$ für anwirtlithe und Eaum vermenbbare Territorien (Şodgebirge,

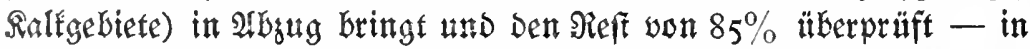
Ungarn ift das Perbältnis nod) günftiger, sa nur 5,19\% als \$oland

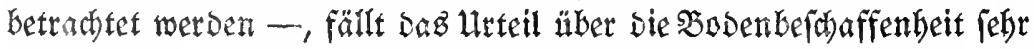

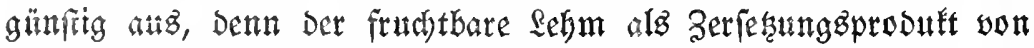

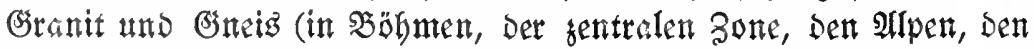

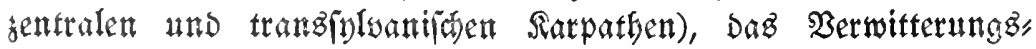
produtt des Sandfteing, Der Gumusteiche Ton uno fhlieflith Der

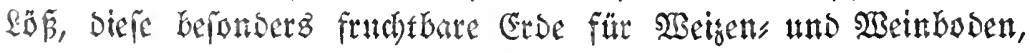

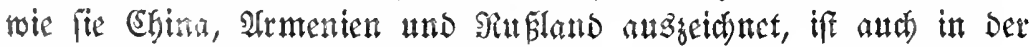

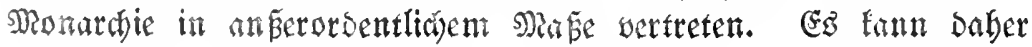

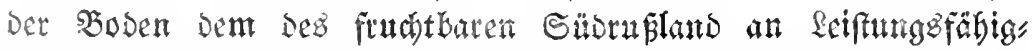

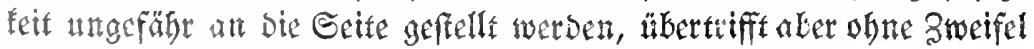

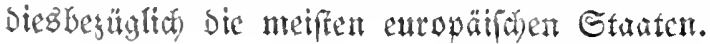




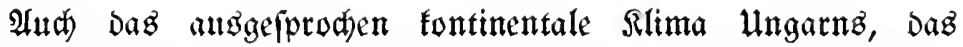
Durd) anbaltende Dürren DDer Feudtigfett Die Entwidlung Der Felds

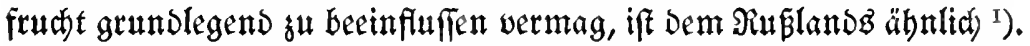

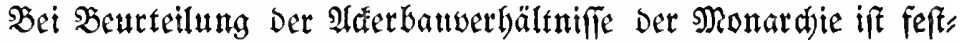
Aderbau.

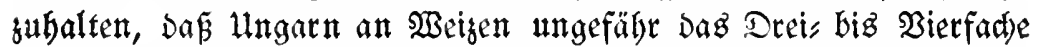
won Dem produstert, was D̈ferretd erntet, währent in Roggen uno Şafer wieder Sfferreid) ungefäbr Daz Doppelte von Der ungarifhen Ernte einbringt. In (Gerfte ${ }^{2}$ ) feben bie Mengen in beiten Teilen Deb Reichez ungefäbr gleidh. Nais, Der allerbings für ben menld)lidjen Şenú im allgemeinen nicht ober nur wentg in $\mathfrak{b e t r a c h t ~ f o m m t , ~ i f t ~}$ Dagegen Dant Dem wärmeren Silima ein ganł überwiegend ungarifarer Artifel. Şervorbebung verbient bie bebeutung böhmenz begügliđ

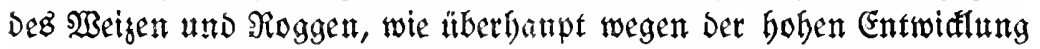

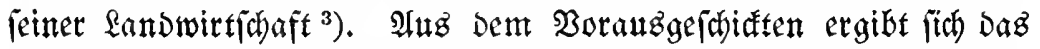

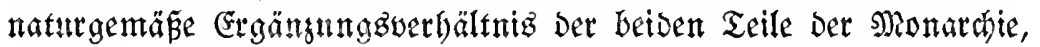

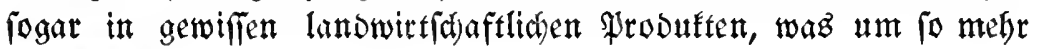

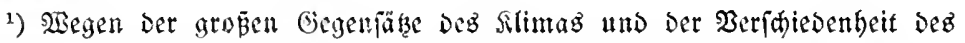
Bobens erforbert bet landmirtid)aftlid) Betrieb in Hngarn meitgebende Sd)ulung

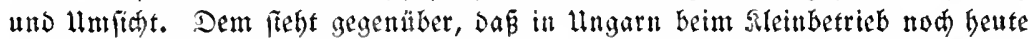
Die Dreifeldermitfidaft mit Brade Die nteift verbectete Detriebzimeife ift. Die Erntes

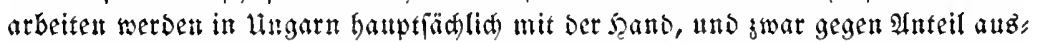
geführt; fo erhält Der Ednitter ein Zebntel bis eit (Êftel obne Betöftigung. Die Sageslöbne werben für Das Jabr I9Io im Durdichntt wie folgt angegeben:

\begin{tabular}{|c|c|c|}
\hline 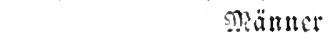 & Fratien & Sinber \\
\hline gisinter.......... I5I & I04 & 71 \\
\hline sommer.......2276 & 177 & II 7 \\
\hline 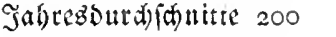 & I36 & 94 \\
\hline
\end{tabular}

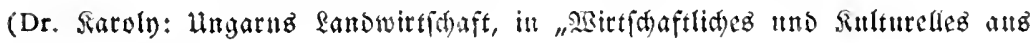
ungarn".)

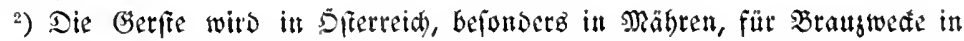

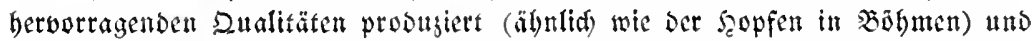
bie zud)t Der Saatgetfe nach ben neueften wiffenfdaftlid)en Methoven betricben.

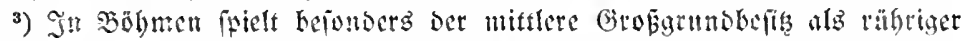

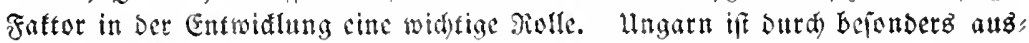

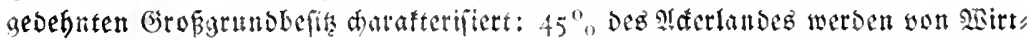
fdaften mif über roo ha bearbeitet, $31^{\circ}$, won folden mit über 1000 ha. Faft

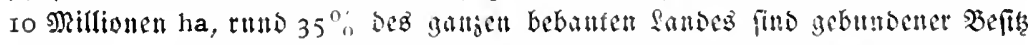

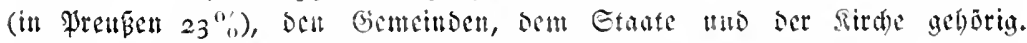
I 352000 ha gebiren in Fiocifommitio 9I Familien. Ein grober Teil bes ges

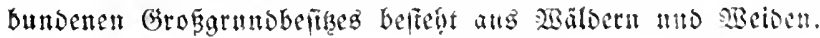




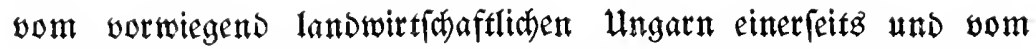
äberwiegend induftriellen Dfterreid) als Gangem andererfeits gilt.

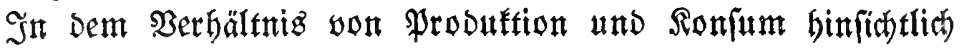

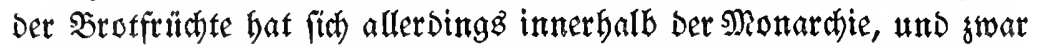
gerabe feit $\mathfrak{B}$ eginn ber leţten Şandelsuertraggära (I906), eine bebeut" fame SSandlung vollzogen.

Rotwendige Erftartung Der \&ans"
wirtichaft.

Wähtemb Die Monarchie früher ein giemlich bebentendes Exports lano für Rörnerfrüthte soar und zum Seifpiel in Den Sahren I906 แnD I907 für 5 und 3 Millionen Rronen Weizen, für 60 und 50 Millio" nen Sironen Gerfte, im Sahte I908 für I $1 \frac{12}{2}$ Millionen Sronen Mais exportierte, iff in einem früher fo wirdtigen Exportartifel, Der Gerfte, eine ftänbige Serminderung ber $\mathfrak{A}$ Bgfubr eingetreten, wäbrend in Weižn, Roggen, Şafer, ja logar in Mais größere ftändige Smporte

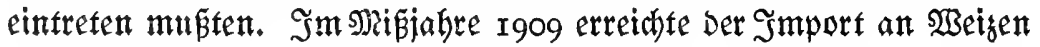
eine Menge won über 7 Miffionen Bentner im Merte von rund I 50 Millionen Sronen. Dast wurbe nody für ro Millionen Sromen

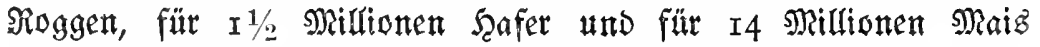

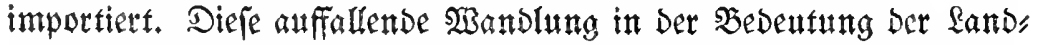

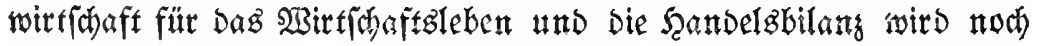

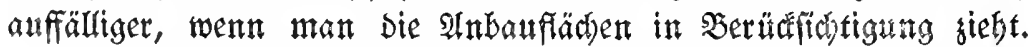

Dant Dem fteigenden Bedarfe, Danf Der Steigerung Des Şelt" markfpreifez, am meiften aber wohl wegen Der Steigerung Des zoll

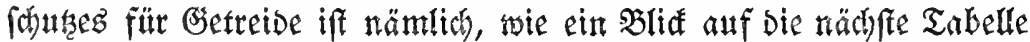

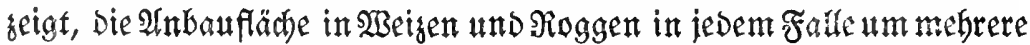
I00 000 ha bis eimfdrlieflid) I9I gewadten, wäbrend fie in serfte

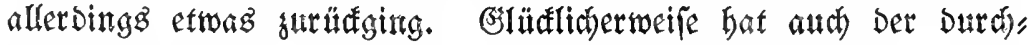

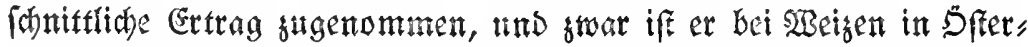
reidh in ben Sabren woth I90 bis I9I2 yon II,2 alt I5, in Ungarn won I0,2 anf I3 geftiegen, in Roggen von Io,6 anf I4,6 int Dfterteich tumb von 9,8 anf 12, I in Ungarn. Troh Der Steigerung infolgr

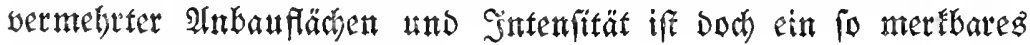
Bleibendes Defizit eingetretent.

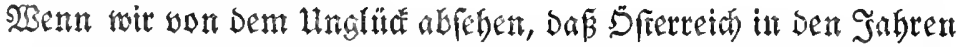
I909, I9I3 uno I9I4 (h)lechte Ernten, teilweife fogar Mifjabre gehabt

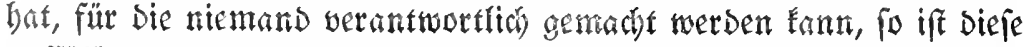
aufiälige Wendung im Endeffert eben eine Folge Der Steigerung Des Sonfums. Die Erflärung für biefe auferordentlidhe Eridgeinung iff 
vor allem Darin $\mathfrak{z} \mathfrak{u}$ fudhen, Daß

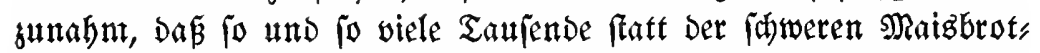

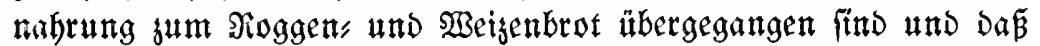

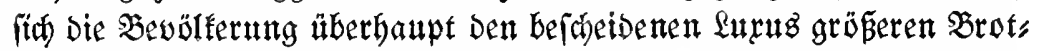
fonjums gönnte (F. o.). Die Zollerböbungen von I887 betrugen bei Weizen erft 200, Dann r906 weitere 75\%, bei Roggen erft 200, Dann

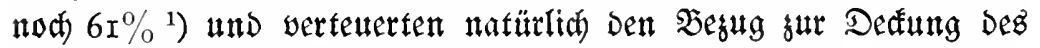

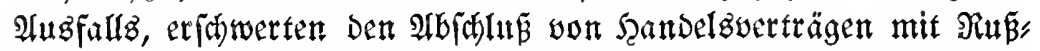
land und Den balfanftaaten, verteuerten und eridswerten Dadurd Die Siebzutht und brachten Den Saatptworteil Dura bohe Preife jener persentuell geringen Zahl von Grunobefitern, die Den Getreidebau

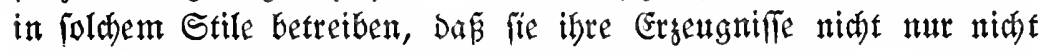
aufzebren, fondern ben überiañ in Den Saandel bringen. Die Zabl Diejer Grunbbefïzer wiro gegenüber Den äbrigen Produgenten auf

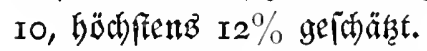

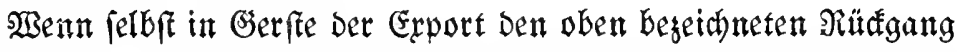
erlitten hat, fo ift bies wieberum in erfer Sinte auf Den feeigenden Bedarf im Snlande, fonft aber Darauf guräaquführen, baß fich bie

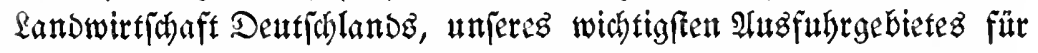

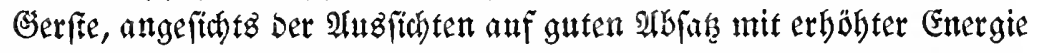
auf bie Produftion diefer Frutht warf und feither die Gerfte fretz mehr felbft điefert. Die gefdjilderte ningünftige swandung Der Sachlage und

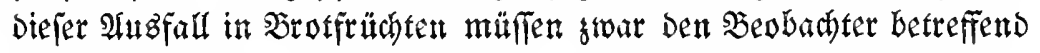
Bergangenteit und Gegenwart mit Ungufrtedenteit erfüllen, aber nid)t unbedingt mit Bejorgnis fïr bie Zutunft. Das \$3idhtigfte, Der Boden, feine Eignung, Das ßlima, alles if ja migletch günftiger als in anderen Staaten vorganden und fundigez Feldarbeitermaterial (bie Monardie als Gefamtbeit genommen) mebr vorbanden als anderstwo.

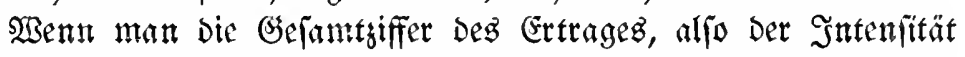
Des Setriebes für Die verichiedenen Getreidegattungen in Der Monathie mit Denen anderer Staaten vergleicht, ftellen fie fid fütr Den Seftar Dem Sabregourafónitt nach in Zentnern wie folgt:

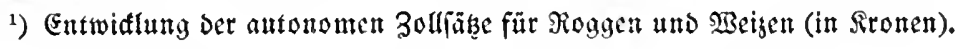

\begin{tabular}{|c|c|c|c|c|}
\hline & I 878 & 1882 & 1887 & $\mathfrak{a b}$ I906 \\
\hline & frei & 1,20 & 3,60 (Etetgetung um $200^{\prime}{ }_{0}$ ) & 5,80 (weitere Eteigerung um $6 \mathrm{I}_{0}^{\circ}$ ) \\
\hline
\end{tabular}




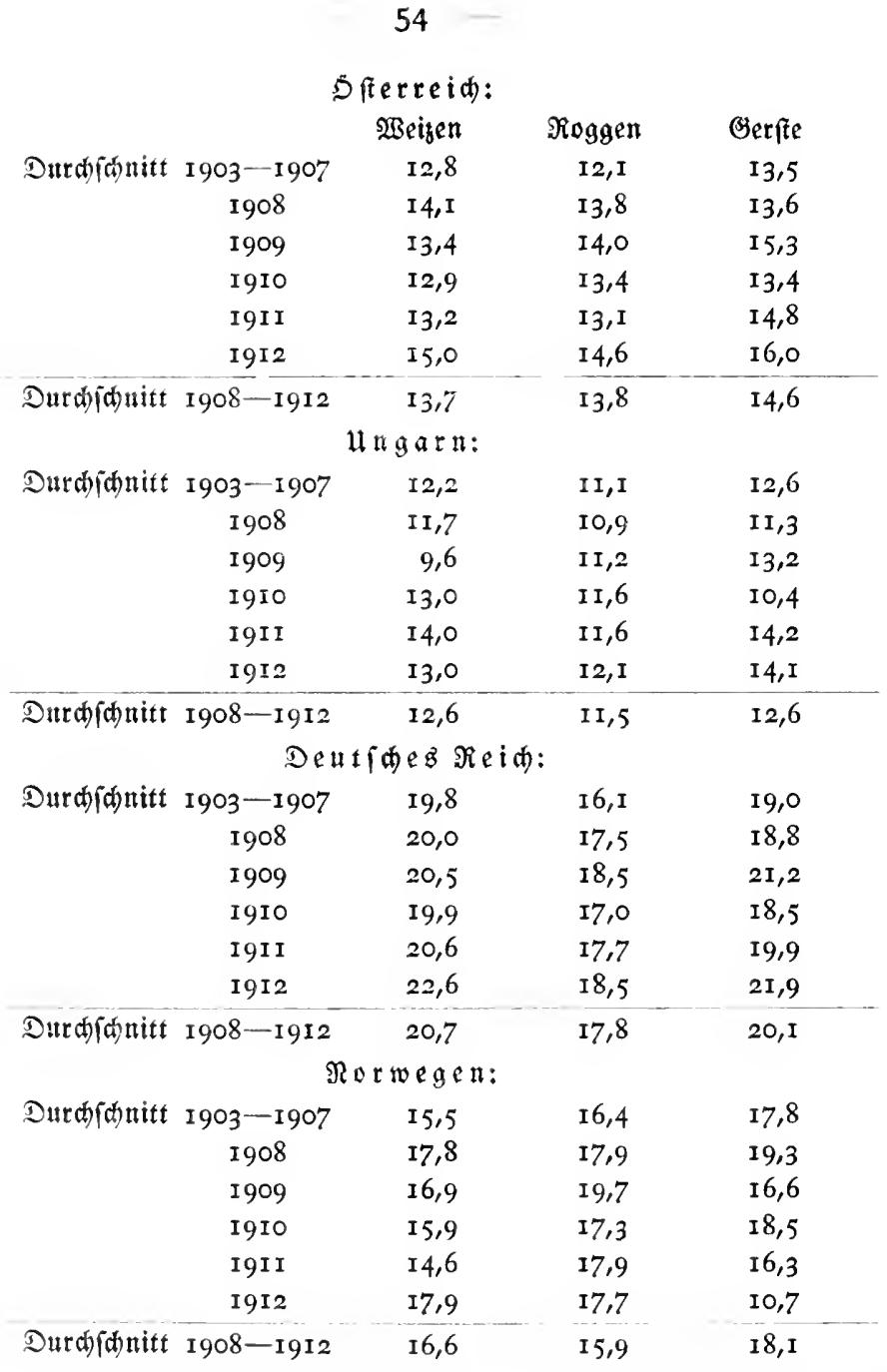

(EB zeigt Die 3ufammentellung, wie fehr ungarn nod in Der extenfiten ${ }^{1}$ )

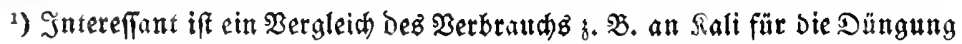

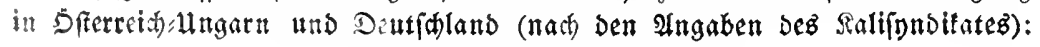
auf $\mathrm{I} \mathrm{km}^{2}$ nutgaten $\mathfrak{B}$ odens in $\mathrm{kg}$

\begin{tabular}{|c|c|c|c|c|}
\hline & 1900 & I9IO & I9I 2 & I9I3 \\
\hline Sfterreich. & 12,4 & 64,3 & I02,8 & I 14,2 \\
\hline 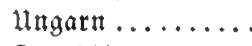 & 0,5 & 6,1 & 17,1 & I 8,8 \\
\hline Dentidtano ...... & 334,4 & $1025, \mathrm{I}$ & 1321,9 & I 529,3 \\
\hline
\end{tabular}




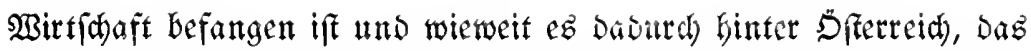

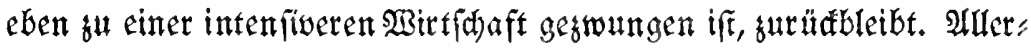

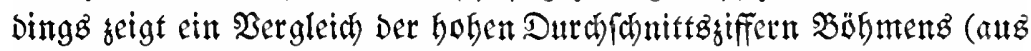

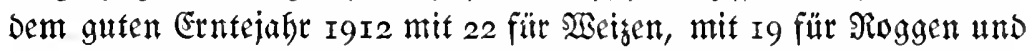

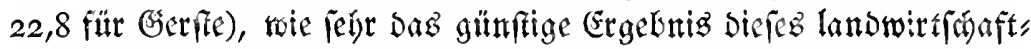

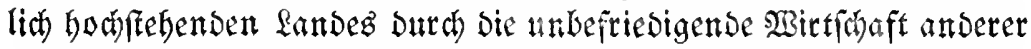

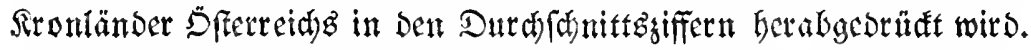

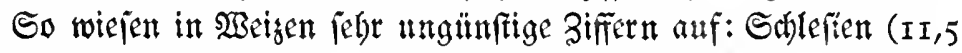
Bentner), Eteiermarf (II), Dalmatien $(9,6)$ und Srain $(7,3)$; itt

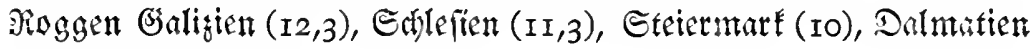
$(8,8)$, Jirain $(6,2)$.

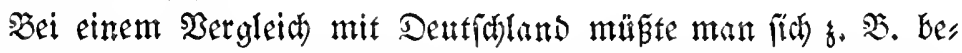

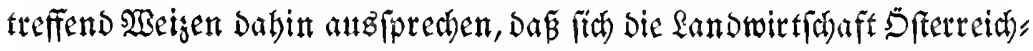

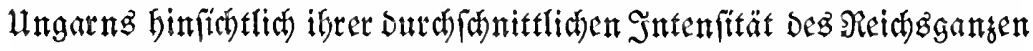

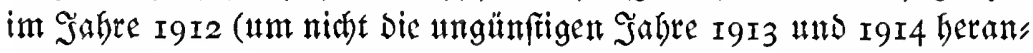

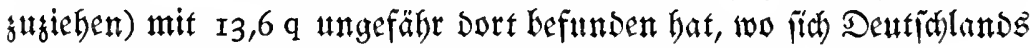

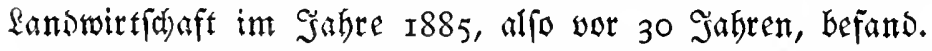

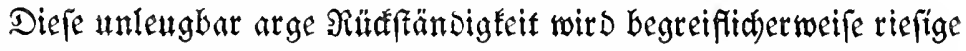

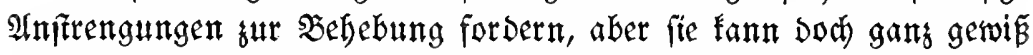
fark gemilbert werden, wobei als bie widftigften Mitfel ungsweifelf aft Die $\mathfrak{Y}$ df

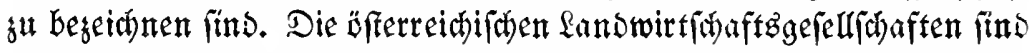

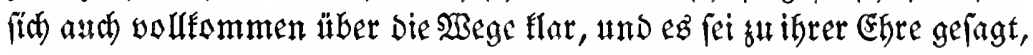

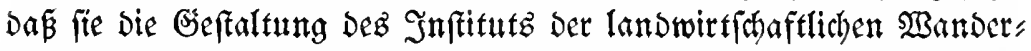

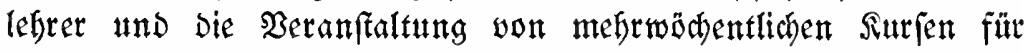
bereits in Der \$raxis Stehende als sringend notwendig begeidynen. Die unbefriesigende Geftaltung unferer Şandelsbiland, noch megr

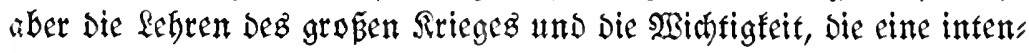

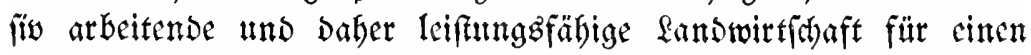

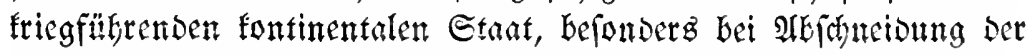

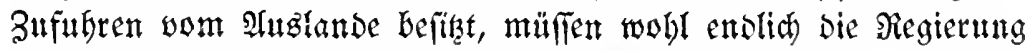

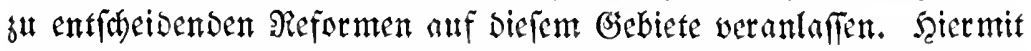
iff natürlich nicht die Fortfersung Der Politif Der \$robibition gemeint,

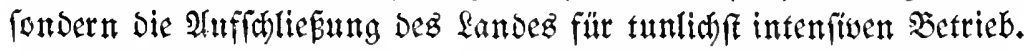

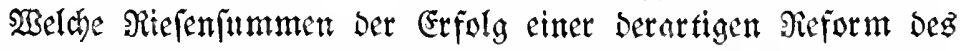

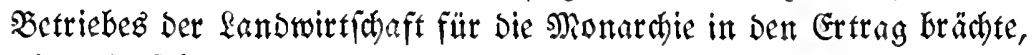

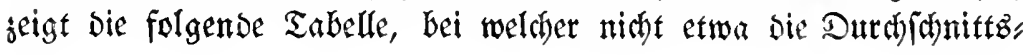


erträge Dentifhlandz ober gar Şollanós oder Selgienż (Die lez̧teren befisen eine fut wenig umfangreiche landwirtichaft) als Soeal ans genommen fino, fondern mebr ein Mittelgebiet wie Norwegen, Daz

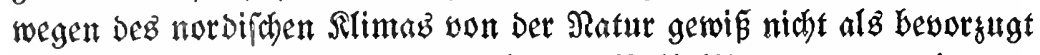
gelten fann, aber Dafür eine gebiegene Volfabildung und weit vors geidrittene moderne Sá)ulung ber Eanowirte befiţt.

\section{Die möglíne Bermebrung bes Ernteertrages in 5 ftereich}

\begin{tabular}{|c|c|c|c|c|c|c|c|c|}
\hline \multirow[b]{2}{*}{ Betretbeart } & \multirow{2}{*}{ 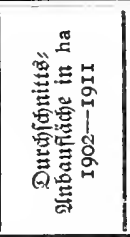 } & \multirow{2}{*}{\multicolumn{2}{|c|}{ 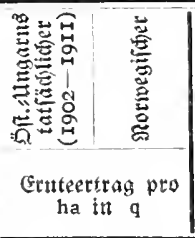 }} & \multicolumn{2}{|c|}{ 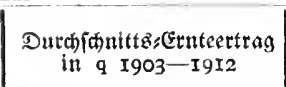 } & \multirow{2}{*}{ 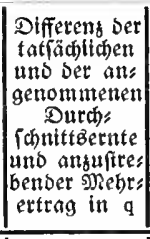 } & \multirow{2}{*}{ 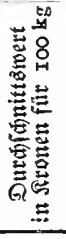 } & \multirow{2}{*}{ 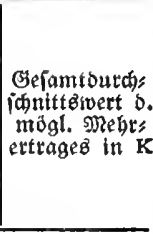 } \\
\hline & & & & Fatfädlidget & $\begin{array}{c}\text { Nady Den } \\
\text { Ergebnifien } \\
\text { Norwegens } \\
\text { anges } \\
\text { nommener }\end{array}$ & & & \\
\hline Beijen. & 4840706 & $\begin{array}{l}12,8 \\
\text { (in } \\
\text { Sitert. } \\
\text { I3,3) }\end{array}$ & I 6,0 & 60322606 & 77451296 & I7 I28 690 & 19,2 & 328870848 \\
\hline Roggen & $3064345 \mid$ & $\begin{array}{l}\text { I2,I } \\
\text { (in } \\
\text { Dfietr. } \\
\text { I2,9) }\end{array}$ & I 6,2 & 37770853 & 49642389 & II 87 I 536 & I 4,6 & I773 324426 \\
\hline Serfite. & 2329958 & $\begin{array}{l}13,3 \\
\text { (it } \\
\text { Sitert. } \\
\text { I4) }\end{array}$ & 17,9 & 30979035 & 35847758 & 4868723 & 12,7 & 61832782 \\
\hline Sgafer... & 3017005 & II 5 & 15,3 & 34695558 & 46 I6o I77 & II 4646 I9) & 13,3 & I 52479433 \\
\hline Maiż ... & 3263540 & 13,5 & $\left.16,5^{1}\right)$ & 53824045 & 55148953 & 7 I 89534 & 14,7 & 105686 I 50 \\
\hline
\end{tabular}

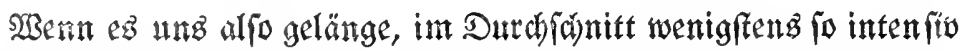
zu arbeiten twie Norwegen, fo würde Diez bei Zugrundelegung von

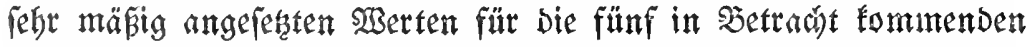

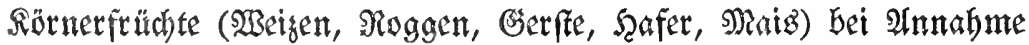
Derfelben Antaufläche, wie fie von I902 biz I9I I in ßerwendung ftano, einen Mebrertrag won ẗber 800 Miruionen Tronen im Sabr ergeben.

Begreiflid)erweife wärbe fithon bie Şälfte einen glänzenden

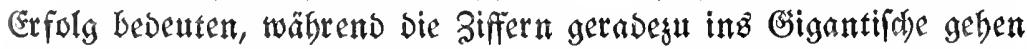

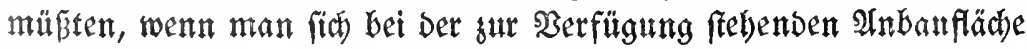

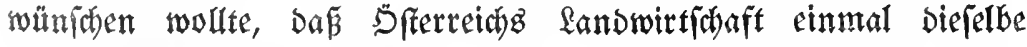

1) Iuf Den ungepägren Ertrag won 16,5 q wie in Den meiffen Getreibearten Rorwegents erbäht. 
Intenfität ergiele, wie dies bei Dettffhland im Sabre r912 Der Fall war.

Dann Fönnte Sfterretcos rung Des Eigentonfunts fulaffen wird, wieber in gröperer Menge Getreide an Deutfaland ju liefern, Das I9 3 bet einer Ernte von

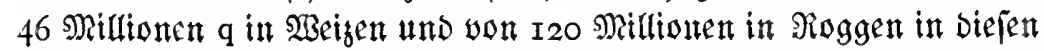
beiben $\mathfrak{B r o f f r u ̈ d}$ ten grwar für 220 Milltonen Mark exporticrte, aber

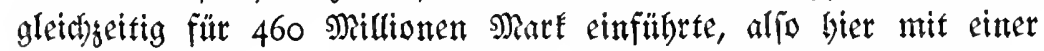

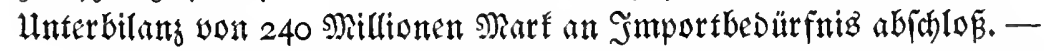

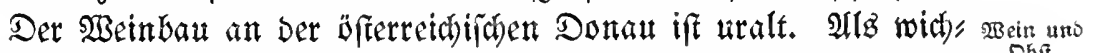

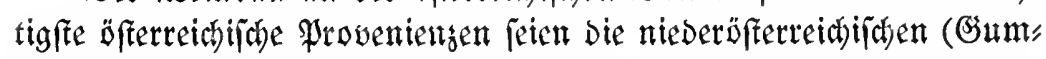

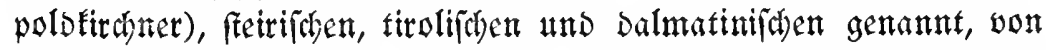

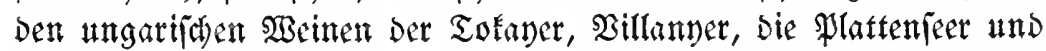
Siebenbttrger Wetne. Die Reblaub bat zwar Der Weinproduftion auperorbentlichen Schaden zugefügt, Den Ertrag auf ungefähr ein Drittel verringert, aber Dafïr Die Mobernifierung und Egali;

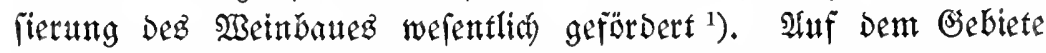
Der Dbftudyt wird trok Der teilmeife ẗberaug günftigen Dorkedin gungen und glängenden Erjolge bie DualitätBproduftion gegenüber Der Mallenproduftion nod) immer fu wenig geförbert.

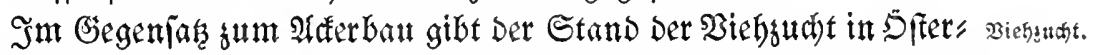

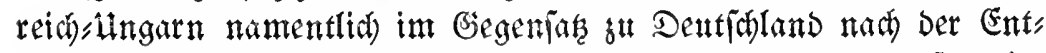

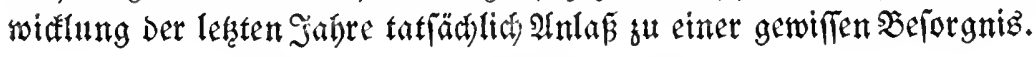

\section{Beftand an Rinbern unb Sctrocinen}

in D̂ferreiás) Alngarn

in Deutifiland

\begin{tabular}{ccc|ccc} 
3r. Dej. & Rinder & Sdweine & I. Des. & Rinder & Ed \\
I890 & 8643936 & 3549700 & I 892 & I7 555834 & I2 I74 442 \\
I900 & 95 II I70 & 4682654 & I900 & I8 939692 & I6 8076 I4 \\
I9I0 & 9 I60609 & 6432080 & I9I2 & 20 I58738 & 2 I 885073
\end{tabular}

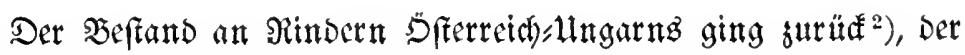

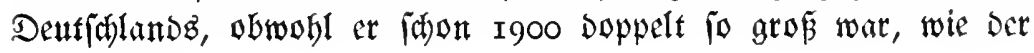

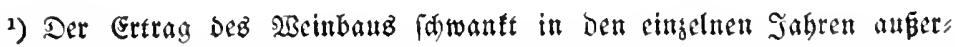

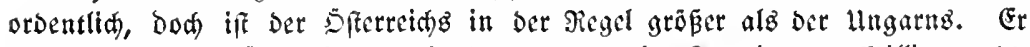
betrug (I912) in Sperreid) 4,0, in Ultgarn 2,7, in Seroatien 0,5 Nillionen hl.

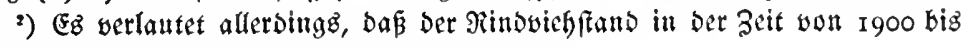
rgr4 infolge Der boben Fleifdpratie geftiegen jei. 
Der Monardjte, watt) a um weitere I I20 000 Stük. Der Beftano an Schmeinett ninme auf ber erferen Sette $\mathfrak{u m} I, 7$, auf Der grweiten tm 5 Millionen Etüt $\mathfrak{g}$ t.

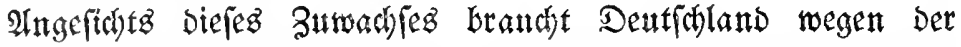

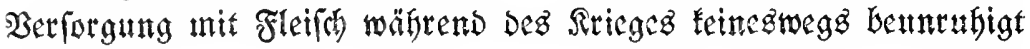
jut feit.

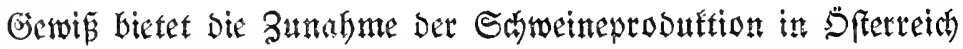

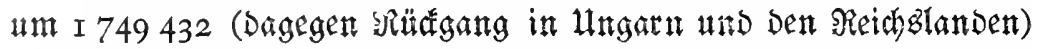

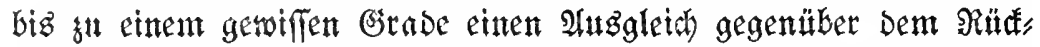
gange an Rinbern. Dem ift aber gegenüberzufalten, Das Dem

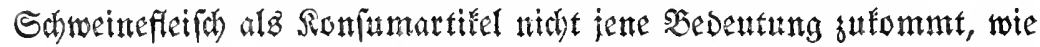

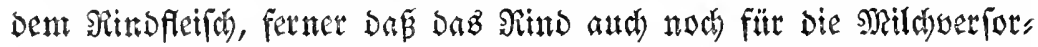
gung, als Zugtier ttwo roegen Der Rebenprodufte, inzbefondere

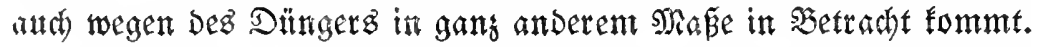

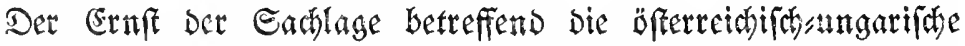

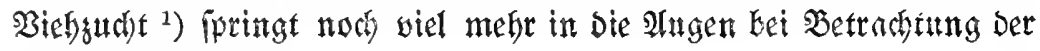

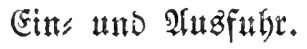

Biebeinfuhr and

\begin{tabular}{|c|c|c|c|c|c|c|}
\hline \multicolumn{7}{|c|}{ 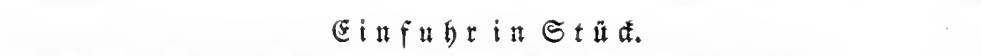 } \\
\hline \multirow{2}{*}{$\mathfrak{S a \mathfrak { h } \mathfrak { r }}$} & sum & $\begin{array}{l}\text { Shlachten } \\
\text { Swlat }\end{array}$ & Sdineine & Sthafe & Pferde & $\begin{array}{l}\text { Fleifan, } \\
\text { frifaes }\end{array}$ \\
\hline & ভtüta & $\begin{array}{l}\text { Bert in } \\
\text { Mill. Sronen }\end{array}$ & \multicolumn{3}{|c|}{ Menge in Stüđ } & $\mathrm{q}$ \\
\hline I 900 & 74036 & $I_{3}$ & 84109 & 23299 & 3579 & $35 \mathrm{O} 2 \mathrm{I}$ \\
\hline I903 & 94308 & 19 & 145262 & 21625 & 3057 & 38 I 28 \\
\hline I 905 & 88060 & $2 I$ & I 7 I 727 & I $873^{I}$ & 3844 & $29 c 45$ \\
\hline I906 & I 8877 & 5 & 81352 & I3 286 & - & - \\
\hline I908 & 3636 & I & 6855 & 7148 & 4502 & I 026 \\
\hline I9I I & $595 I$ & 5 & 5832 & 7934 & 6929 & 65855 \\
\hline I9I3 & 23457 & I I & 2439 & I2 636 & 5045 & I2 202 \\
\hline
\end{tabular}

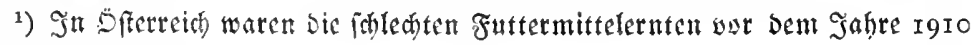
beînders abträglidx.

Jit Ungarn fülyet man alz günftigez Moment ar, baß man mit Grfolg baż typifate ungarifde Eteppenvieh Durds Pflege bez fith rafder entwidelnden rot"

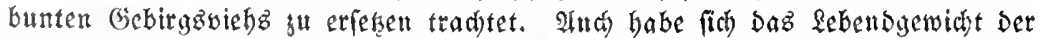

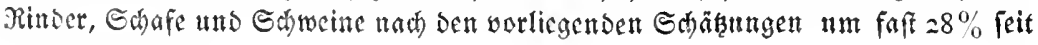
I 896 vermetrt. 


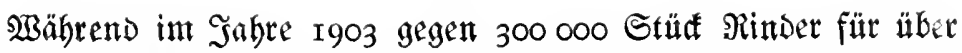
I Io Milfionen Sironen ausgefübrt wurben, maat (idd nummehr ange" fid)t

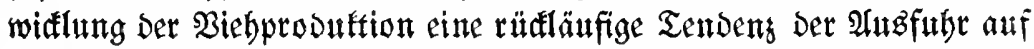
55000 Stüt zum allerbingz erböbten Preis von 30 Millionen Rronen geltend. Die Mronarchie ift aber gar nidbt weit bavon, ifre verfïgbares

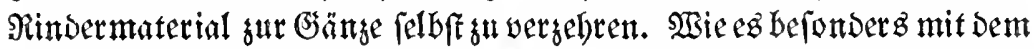
Beftande Des Rindvieb) nach Dem Siriege ausfeben wird, wo bie fletich, nabrung Dez Milfionenbeeres einen gans anterorbentlich forcierten Mekroerbraud mit fích brad)te, außerdem Der Biebland Galigiens

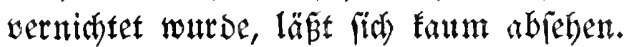

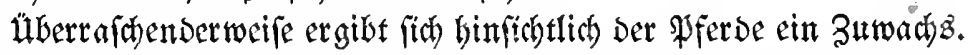
Der Grund ift, Daf trok freigenden Genuffes von Prerdefietich bet Det ärmeren Bevölerung eben nur ber 2 bfall an Pferden won Der $\mathfrak{B e}$

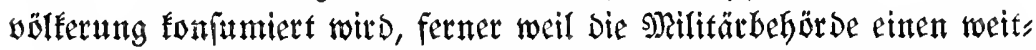
gebenden Einfun auf bie Pflege unt Entwidtung Der \$Ferbegut nimmt.

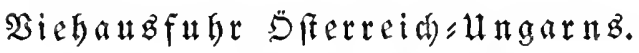

$\mathfrak{I} \mathfrak{u} \mathfrak{B} \mathfrak{f} \mathfrak{h} \mathfrak{t} \mathfrak{i} \mathfrak{\mathfrak { S }} \mathfrak{\mathfrak { t }} \mathfrak{\mathfrak { u }} \mathfrak{d}$.

\begin{tabular}{|c|c|c|c|c|c|}
\hline \multicolumn{2}{|c|}{$\begin{array}{c}\text { Rinber } \\
\text { sum Saladten }\end{array}$} & Sdroeine & Sdafe & Pferde & $\begin{array}{l}\text { Fleifa, } \\
\text { frifa)e }\end{array}$ \\
\hline Stüa & $\begin{array}{c}\text { Wett in } \\
\text { Mill. Sronen }\end{array}$ & \multicolumn{3}{|c|}{ Mettge in Stü } & $\mathrm{q}$ \\
\hline I 56320 & $6 I$ & 7290 & 44400 & 66 I 52 & 14040 \\
\hline 277219 & III & 6373 & 92249 & 62 I06 & I9 256 \\
\hline 200947 & 87 & I 785 & 46432 & 69243 & 30136 \\
\hline I26 644 & 65 & $85 \mathrm{I}$ & 36683 & - & - \\
\hline I68754 & 59 & 21789 & IOI 892 & 50109 & I2 823 \\
\hline I 8456 & I I & I 254 & 9408 & 40483 & II 830 \\
\hline 55298 & 30 & 2126 & 39920 & I9 I 58 & 10803 \\
\hline
\end{tabular}

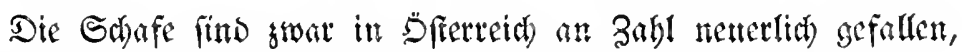
in Der Monatedie aber won ro,7 Millionen anf ro,9 geftiegen.

Foricht man nach den Gründen Der unbefriedigenden Entuidłnth

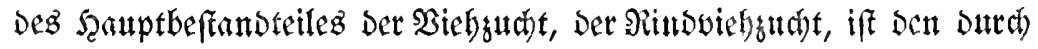

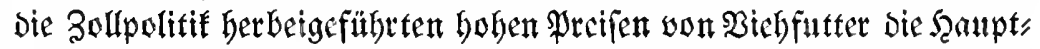

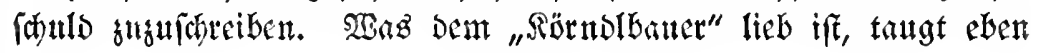




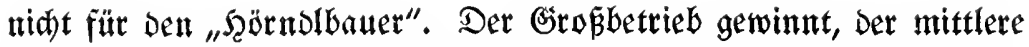
"no fleinere betrieb, Der fïh früher Der Scaltung von einigen Stǘt Bieh wiomen fonnte, werliert, weil bie eigene Probuftion an Futter nicht auseredt, Das Zufaufen von Futtermitteln aber wegen Der hohen

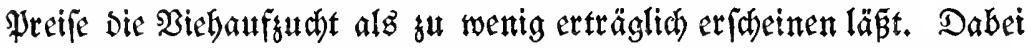
merben nad) roie vor die an fidh febr wertwollen Diente ber fundigen \$artung Des Biebes gar nitht beredinet.

Die Biefmaftung lohnt fíd) äberwiegend nut mefr auf induftrieller

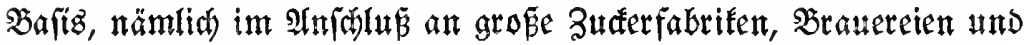
Brennereien, wobei bie $\mathfrak{B e r w e r t u n g ~ D e r ~ \Re e b e n p r o d u f t e ~ d i e f e r ~ B e t r i e t e ~}$ und Die Dïngergewinnung sumeift die Şatptrolle fpielen.

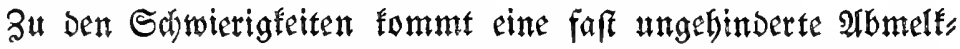

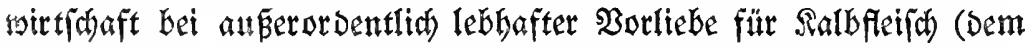

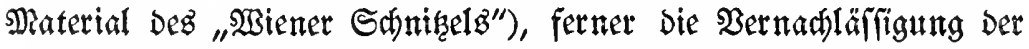

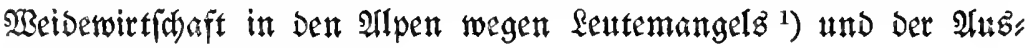
Debnung Der Sagogründe.

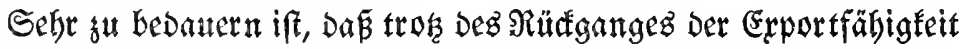

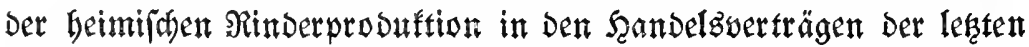

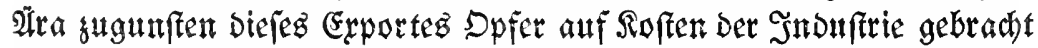

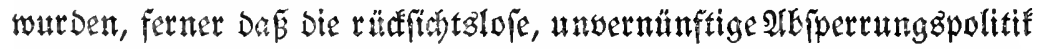
bejonders gegenilber Serbien sine Berfdürfung fatt eine Erletwterung

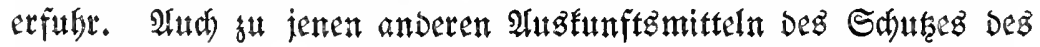
Geimifáden Biefftandeg, Der Einfuhr von gefrorenem fleifd wentgfens für Den SEedarf Der ärmeren Bolfzichidten, Eonnte man fich nicht ents

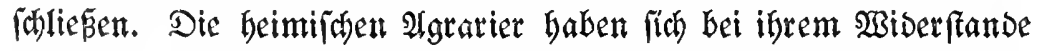
auf Daz Beifpiel Dentifblands aubgeredet, Das aber über einen

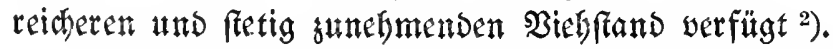

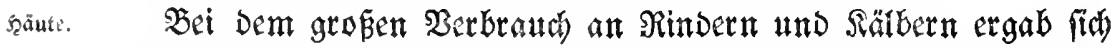
in Rindşäuten and Ralbfellen I9 3 ein Export von je rumb 30 Mill:

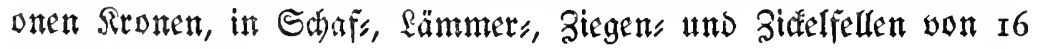
Millionen Sronen.

Eier. Ginen widffigen aglarifden Exportartifel Der Monaraje bilden

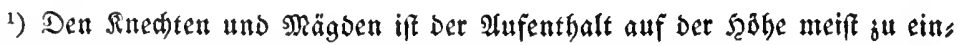

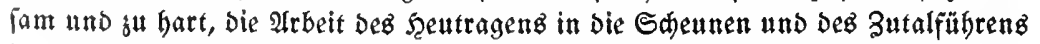
im 23 inter (mit Salitten) ju fdurer geworben.

$\left.{ }^{2}\right)$ Sie fübt fin erfolgreid) auf Die Einfubr won rulifider Futtergerfte, Die

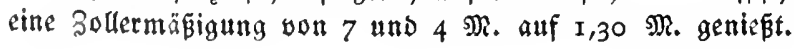


(Eier, von Denen Dfferreid in Den Sabren I9I2 und I9 3 je fïr rund 140 Millionen Sironen ausführte, bie weitgehend ans Găliģen ftammten.

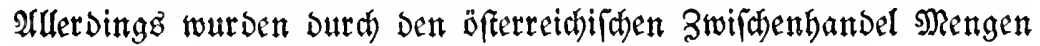

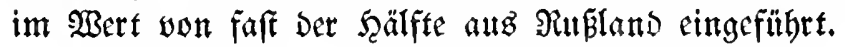

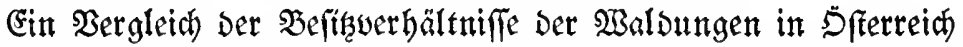

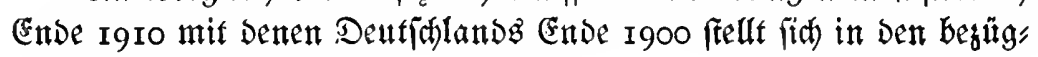
RBald: liden Biffern wie folgt:

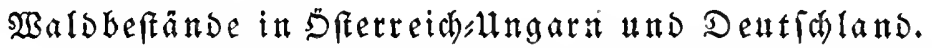

\begin{tabular}{|c|c|c|c|c|c|}
\hline fänber & $\underset{\text { ha }}{\text { Gefamtfoche in }}$ & $\begin{array}{l}\text { Gefamte } \text { Balds } \\
\text { flüte in ha }\end{array}$ & $\begin{array}{c}\text { Inteit ant } \\
\text { oer Gefamt: } \\
\text { flähe }\end{array}$ & $\begin{array}{c}\text { Stuatagforfie in } \\
\text { ha }\end{array}$ & $\begin{array}{l}\text { Inteit an } \\
\text { ber Gefamts } \\
\text { Waloflädee }\end{array}$ \\
\hline Dftert & 30000518 & 9768290 & $32,6 \%$ & 726448 & $7,4 \%$ \\
\hline Hngarn & 32541100 & 8948875 & $27,5 \%$ & I 3 I3 242 & $14,7 \%$ \\
\hline \$fterr.:llng. & 62541518 & 18717165 & $30 \%$ & 2039690 & $12 \%$ \\
\hline Deutífland & 54085760 & I3 995869 & $25,9 \%$ & 4430090 & $3 I, 6 \%$ \\
\hline
\end{tabular}

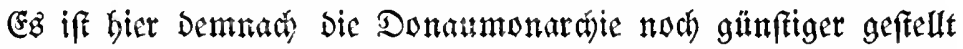

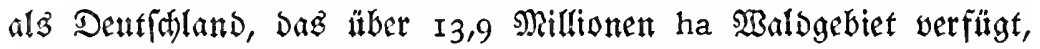

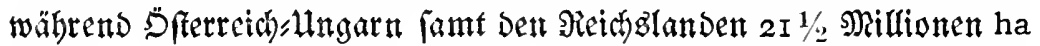

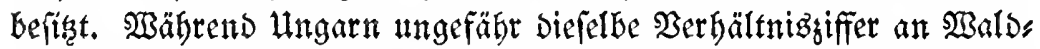

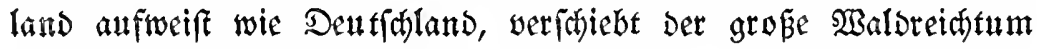

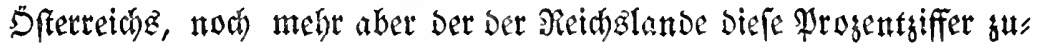
gunften ber beramtmonarchie.

Sibgejehen won Der Menge Dez vorbandenen Material's, Der

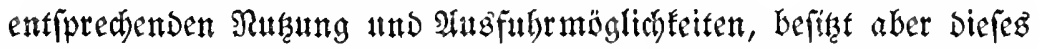

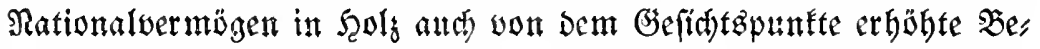

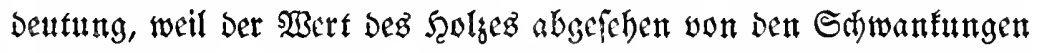

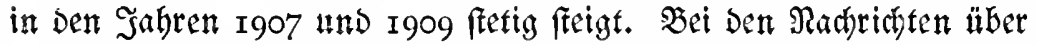

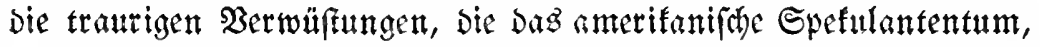

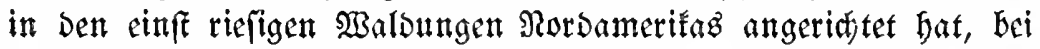

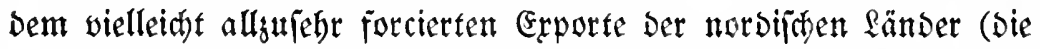

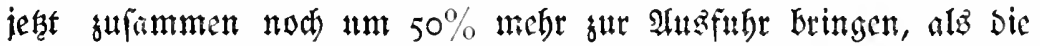

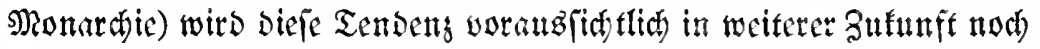

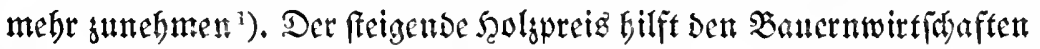

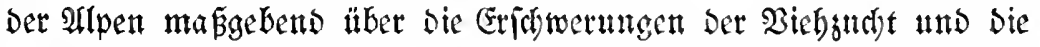
Sdymälerung ibrez Grtragez Dutch Die hohen Getreidepreife bintweg.

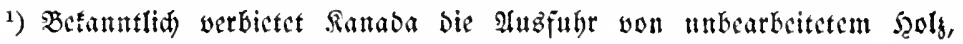

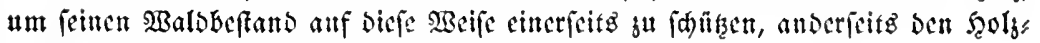
bearbitungslobn ocr eigeneu $\mathfrak{B}$ evölfernng ju crbalten. 


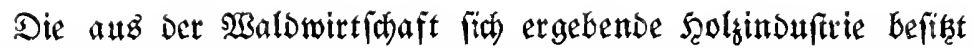

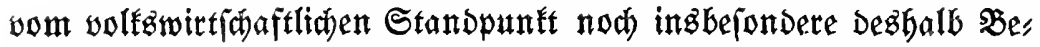
Deutung, weil fie febr bänfig gang abgelegenen Gebieten, die fonft

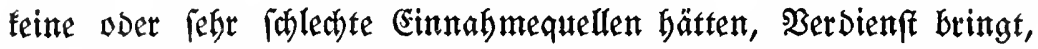

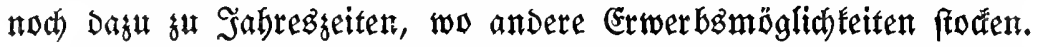

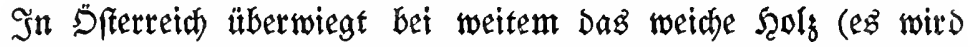

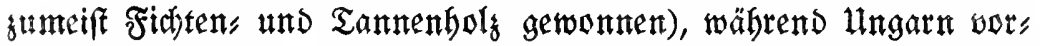

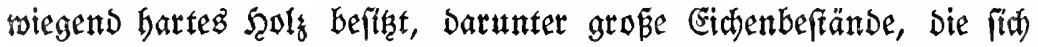
belonders in Slavonien Durch Dualität, anter und Menge aus",

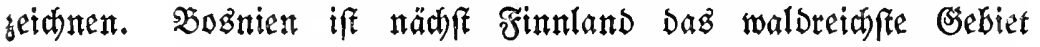
(Europas, wo fich äbnlict) wie in Den nordöftichen Siarpatben tod Urwäldor, namentlich an $\mathfrak{B u c h e n , ~ b e f i n d e n . ~}$

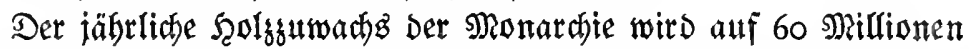

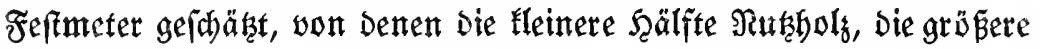
Brentholg iff.

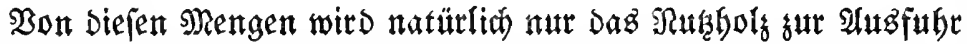

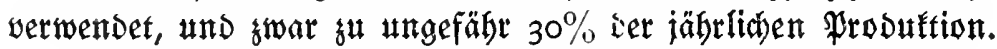

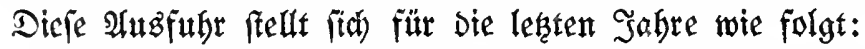

Sfitereidy

\begin{tabular}{c|c|c}
\hline Iabi & $\begin{array}{c}\text { Menge in } \\
\text { I000 q }\end{array}$ & $\begin{array}{c}\text { Wert in } \\
\text { Millonen Fronen }\end{array}$ \\
\hline I905 & 39033 & 247 \\
I907 & 41999 & 276 \\
I909 & 37701 & 227 \\
I913 & 38432 & 259
\end{tabular}

Damit ift Şols näd) Zut bufte Der Monaruie geroorden. Entiprectend Den Mengen Des Urpro"

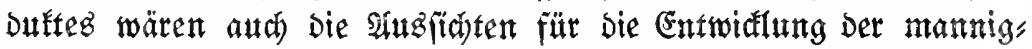
faltigen bolguerarbettenden Snduftrien auperorbentlád günftige.

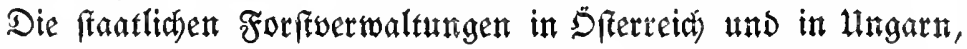

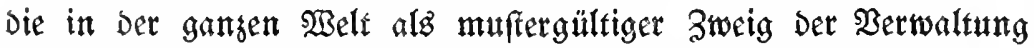
gelten, find eifrig beftrebt, Das ifrige zur Scebung Der Waldwirtid)aft

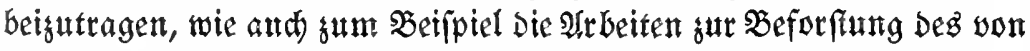
Den Benestanern im Mittelalter für ifren Flottenbał verwäftetent

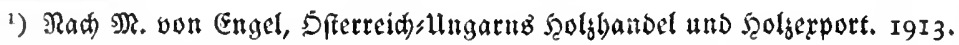
Bon den angegebenen 3iffern fullen rumb $32 \%$ auf Sperreid, I $8^{\circ}{ }_{0}$ auf Utrgarn. 
Sarfes günftig fortjäreiten. Mit Dem feigenden Werte Deż Mationals

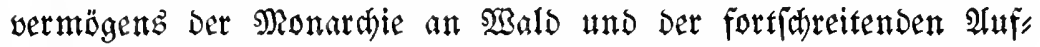
flärung wird die Strenge Der Forftauffitht bered)tigterweife funehmen und freigende unterftüksung bei ben Interefienten felbft finden.

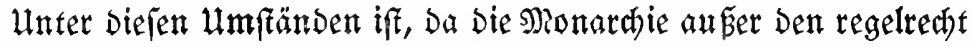

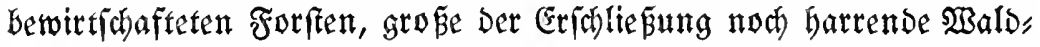

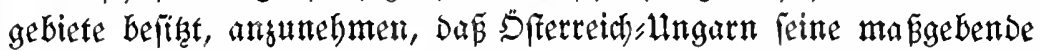
Stellung als Şolgprodusent mindeftens für Das nähfite Dierteliabr, Gundert als gejichert betrahten Eann.

Im Zufammentang mit Der Fonftuirtfhaft fai furg bie Sagd эage.

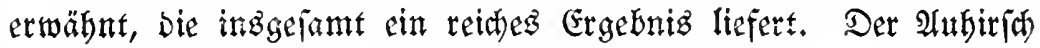
Der Donauniederungen, die OSemie \#nd Der Auerhan Des Şodgebirges, fowie Der $\mathfrak{B a ̈ r}$ in Den Sarpathen verbicnen als \$ejonderbeiten Servor, bebung. Geider fübrt ber teilruetife leibenfáaftlitje Sagbbetrieb, bes fonders in Den alpen, fur fortfar citenden Bauernlegung, ba mur in Tirol

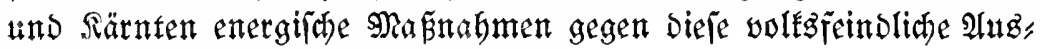
artung Des Sportbetriebes beftehen.

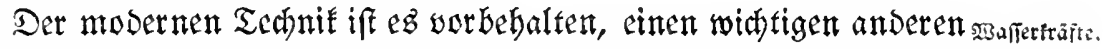

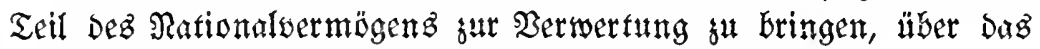

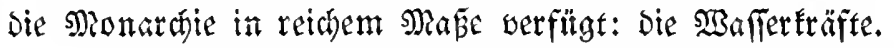

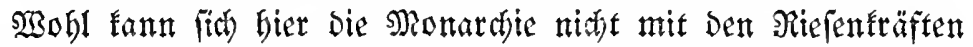
meffen, äber Die z. B. Der Biftoriafall Des Sambeft:Flntfes allein mit feinen 35 Millionen HP verfïgt. Inth Die Dereinigten Staaten feben mit ifrem riefigen Siräftereid)tum (Der Niagarafall weift allein 3 Milli, onen verwertbare HP auf) gewtflerntäen auberbalb Der Sonfurteng.

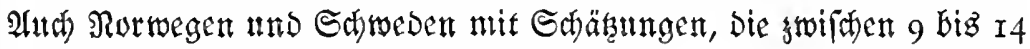

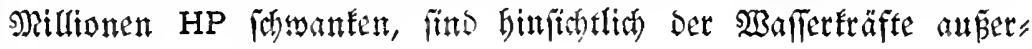
orbenflict) reichlich bebacit.t.

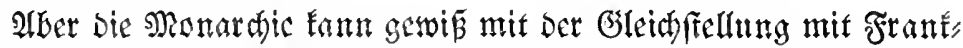
reidh uno Ştalien, auf Ornnd won ungetäht 5 Millionen Turbinen HP, fufrieden jein. (Engelmann ${ }^{1}$ ) 亿 auf maximal 4 Millionen HP. Sng. Riegl nimmt Diefe Biffer fogar

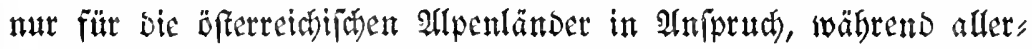

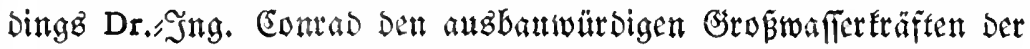

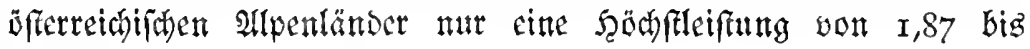

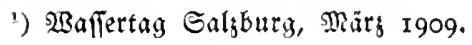




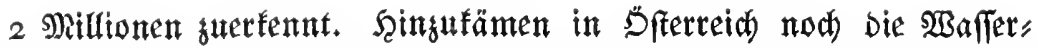
fräte im Süben, beponders in Dalmatien, wo fich Das gröpte öfter, reithif(t)e 3 sert mit $40000 \mathrm{HP}$ bereitz im Betriebe befindet, ferner

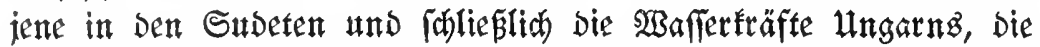
nach Dem Motion I 700000 HP veranichlagt werden ${ }^{1}$ ).

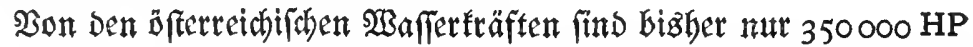

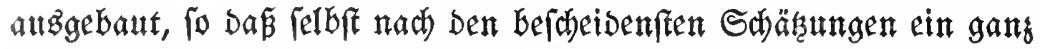

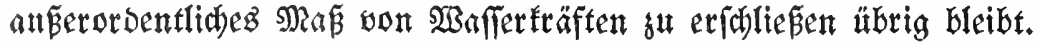

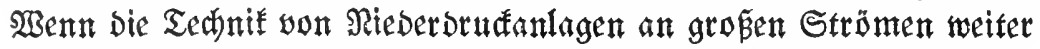

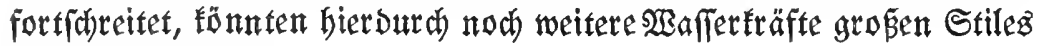
eristofien werden.

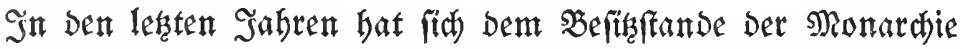

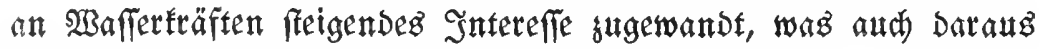
Gervorgebt, Dá bie Eifenbahnuerwaltung im Sabre I906 einen şaffertatafter anlegen liés.

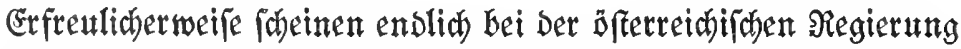

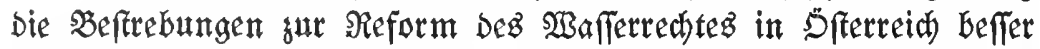
in Bug zu fommen, Die auterer ber Enteignung wegen agrarifder

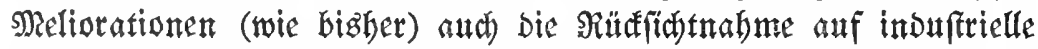

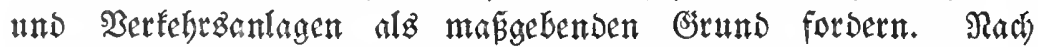

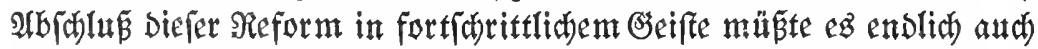

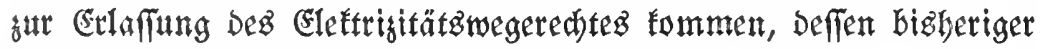

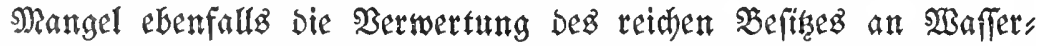
fräften und Danit Die Entwidtung Der Snouftrie grundlos er, frbert und gebemmt hat.

\section{Dis Inoultris.}

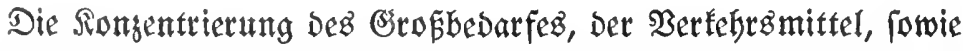
Jage ber

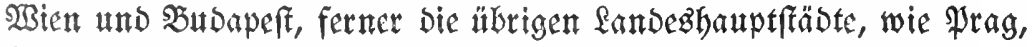
Brän, Trieft, Osras, Zagreb (अgram), fu induftriellen Zentren auzge"

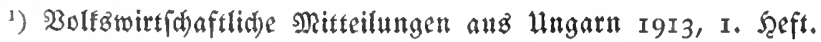


ftaltet. $\mathfrak{A}(\mathcal{B}$ bod induftrielles Gebiet ragt aber weiter Das Elbegebiet mit

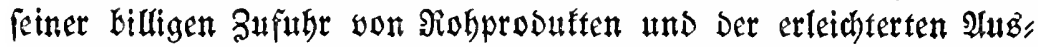
fubr nach Şambarg berwor, fu Dem Dann Die betriebretchen Ery

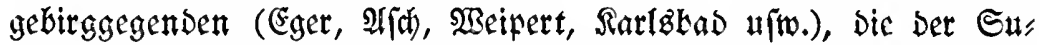
Deten mit Reichenberg als Zentrum, ferner Daz fid) unmittelbar an,

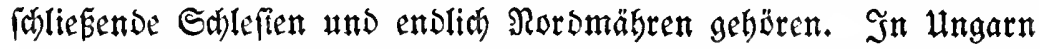
verdienen die Sinduftriezentren won Temeguar und Prepburg,

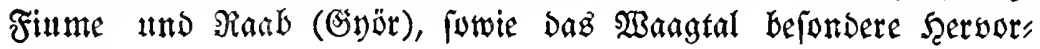
bebung.

In allen biefen Zentren und Sebieten baben meift uralte uns fpesifiche Insuftrien ifren Sił̧.

Nun bat aber Durá Die Susgeftaltung Der Inoufrien und bie Erweiferung Der Setriebe, Die in Den Etäbten immer fónerer Plat fanden, in Den leften Jabrgehnten eine Mbwandertng befoniers aus

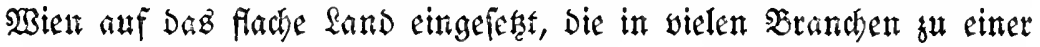
weitgebender Degentralifation gefüfrt hat. Dies wirft vom Stand, punte Der Irtbeiferatbbiloung und Der Sdjaffung genügent grobe:

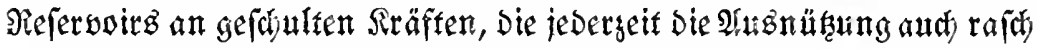
und furg auftretender Sonjunfturen ermöglțen wärben, für mandie

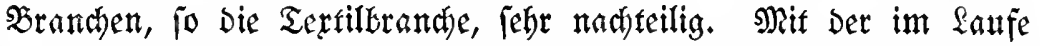
Der Beit eintretenden Berdichtung Der Inouftrie auf Dem flatyen

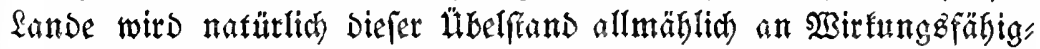
Eeit werlieren. In Dentidiland ift Diefes Ḧbergangsffabium bant ber weiter vorgefdriftenen Entwitflung Der Jnduftrie äberwunden. Wrienz Mobe und Sonfeftion, Sunftgetwerbe und Tertilsubehör, Die Prager Majđtnen, und feine Şandfhubinduftrie, Die Bränner,

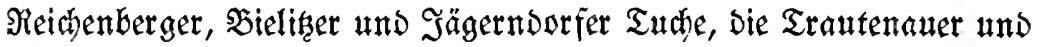

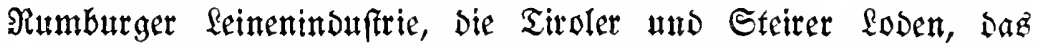

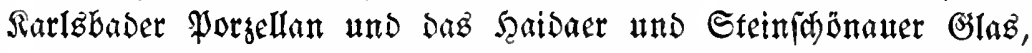

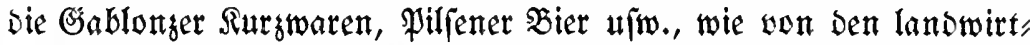

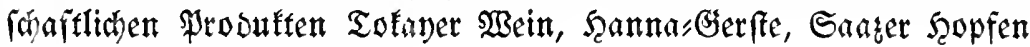
Gaben Weltuti gewonnen.

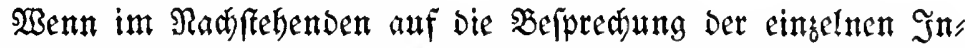
Duftriegweige eingegangen wirb, Fännen felbftrebend mar bie widjtigeren und intereffanteren berauggegriffen und aud ba nur flüdtig bebandelt

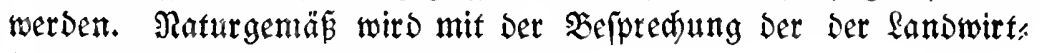
(f) aft näherftebenden 3weige begonnen.

$\mathfrak{P}$ tifor, Prosuftiotrăfte Sfterreit):Lingarnz. 


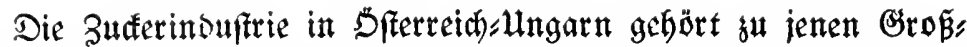

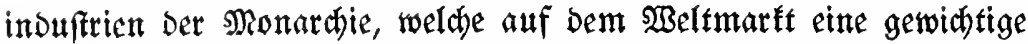

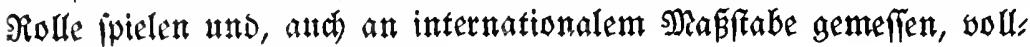
fommen anf Der Şäbe fteben.

Die Zutferimbuftrie in Dfterreid ift auz einem landwirtf(t)afflid

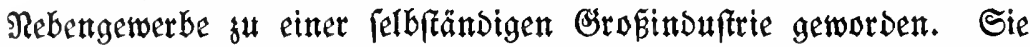
bat aber ihren zalammentang mit Der fandwirtidhaft feinesmegs

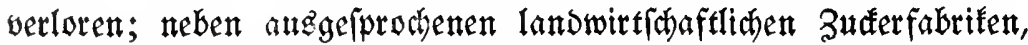
Deren Aftien yorgugşweife rübenbauenden fandwirten gehören, find in Dfterreich aud die won Snduftriellen geletteten ober unter Dem

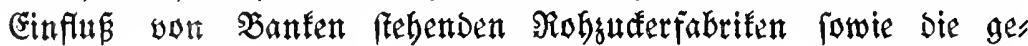
mifhtan Fabrifen (joldhe, Deren Rohłuffererzeugung einer Raffinierie angegliebert ift) Durd auggebehnte DFonomien im landwirtichaftlichen Intereffenfreifi feft veranfert; gleidjes fann von ben Unternebmungen Der ungarijaen Sanduftrie gejagt werden.

Bon Den Landwirten wurben jwar gegen bie Zukerinduftrie

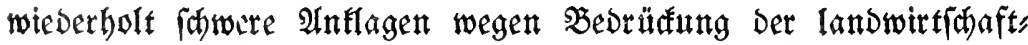

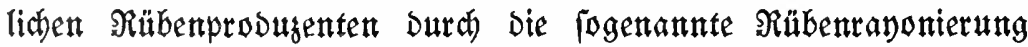

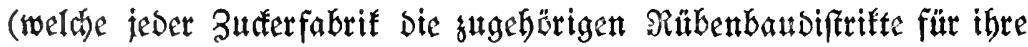

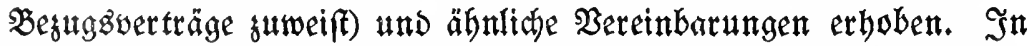

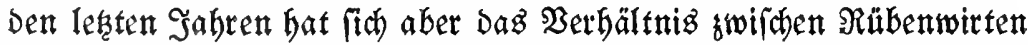

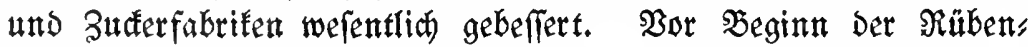

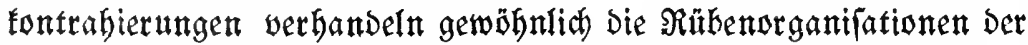
Snouftrie mit Denen Der fandwirtictaft, was tros manther Reis

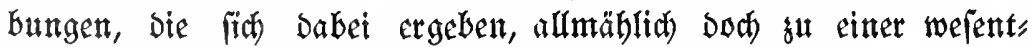

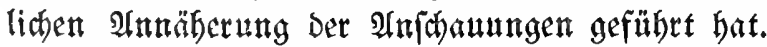

Die Sandwirtifaft bat aud in ber Tat Der Buferinduftrie, nid)t

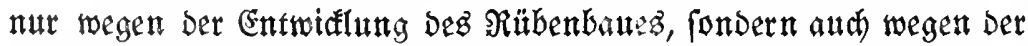

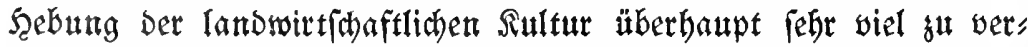

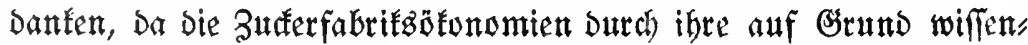

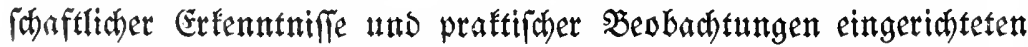
Mufterbetriebe auf bie Sandwirtichaft Der Hmgebnng anregend und befruthtend wirkten.

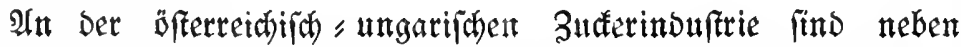
Snouftriellen und fandwirten auch bervorragend Banten beteiligt,

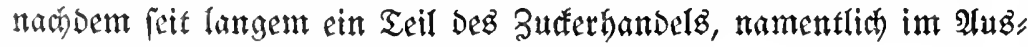

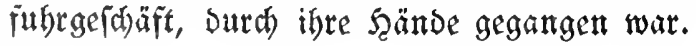




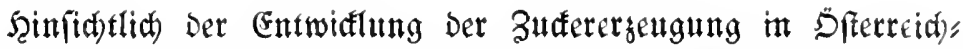
Ungarn fei erwähnt, Daß Die Rübenverarbeitung in Sfterreich) Ilngarn im Sabre I854/55 2,8 Millionen q betrug, im betriebsjabre I890/9 a auf 68,6 Millionen q ftieg uno in ben lef̧ten Sabren

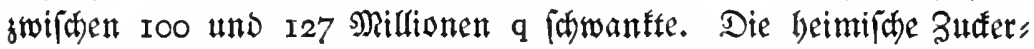
erzengung Defte im Setriebsjabre I 854/55 nur ungefäbr ein Drittel Des rund eine balbe Million q betragenden Zutferverbraudes. Für Den äbrigen $\mathfrak{B}$ edarf forgte Der aus Den Solonien eingefïfrte Rofre suder, Der meift in Der Monarchie raffiniert wurbe. Sajon nath jefhn Safren wurbe aber Der auf Das Doppelte feigende Berbrauth

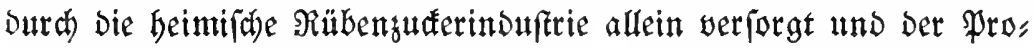

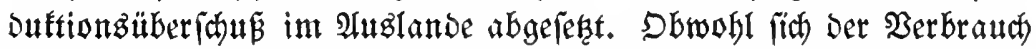

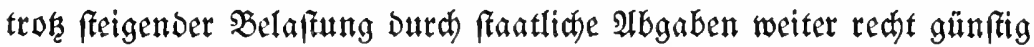
entwidfelte, nötigte Das Emporid)nellen Der Ersengung on einem ers

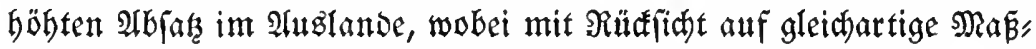

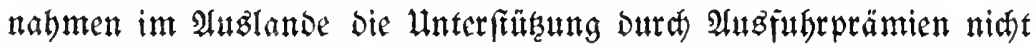

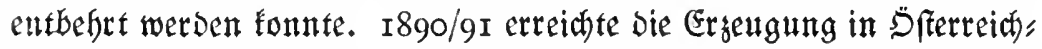
Ungarn 7 Millionen q bei einem Snlanosiverbrand won nicht gand 3 Mituionen q.

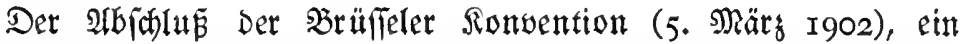

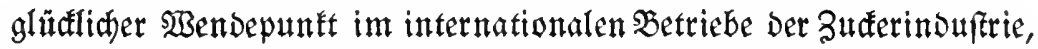

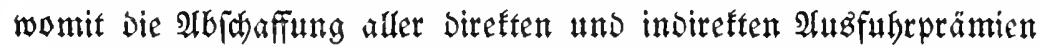

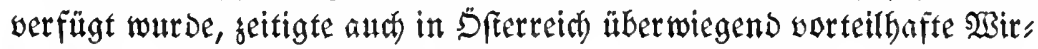
knngen. Die Befürdtungen, die man vielfăh wegen ungünfitiger

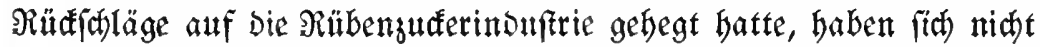

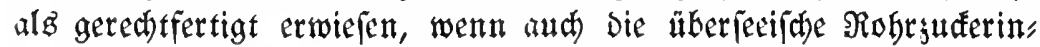
Duftrie Durd) Die (Erföbung Des 2 Seltmarftpreifes, Der nid)t mefr Durd prämiierten Zuder fünftlid) Gerabgeorüat wurbe, einen außeroroent" lichen Auflchung genommen bat ${ }^{1}$ ). Die Butferergengung hat I9I3/I4 und I9I4/I5 in s̈fterreich) je II,7 Millionen q Betragen, wähteno bie bezüglichen Biffern für llngarn 5,2 unv 4,5 Millionen q

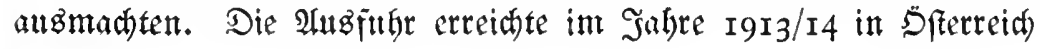

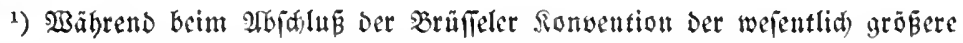

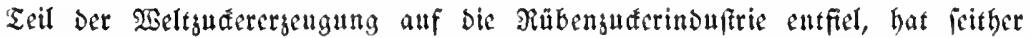
bie Rohrguterergengung wieder Derart jugenonmen, Daß̧ von Der Gefamtergengung von I8,6 Millionen Tonnen im Betriebsjahre 1913/14 9,8 Millionen Tomen auf Rogrzuđer uno nur 8,8 Millionen Tonnen auf Rübenłuder entficlen. 
6 Millonen q, in Ungarn 3,5 Millionen q, Der $\mathfrak{\text { Berbrauth }}$ in Sfterretits 5,2 Millionen q und in Ungarn 1,6 Milfionen q.

Eine Erfoließ̧ung neuer Gegenden für Den Rübenanbau ift in Sfterreth, won Galifien abgejeben, weder fut erwarten noch möglid, Da bas rübenfähige Sand in Böbmen, Mähren, Sdylefien und Rieders

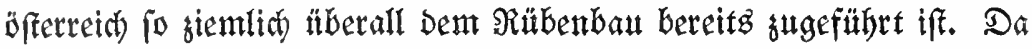

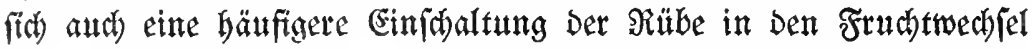

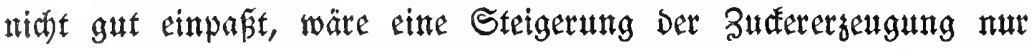

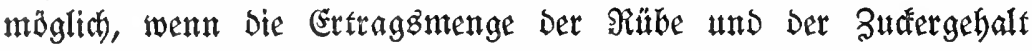

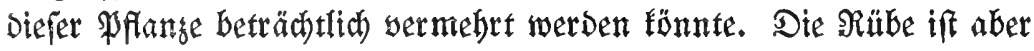
Gente in Der Monardyie eine fo hodgegüd)tete Pflange, Daß Die Steige" rung ibrer Eeiftungzfähigkett nur mit Nähe und Geduld und unter Antwendung Der volítommenften Bühtungsmethoden möglid) ift,

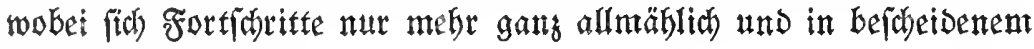
$\mathfrak{A} \mathfrak{u} \dot{B} \mathfrak{m a} \mathfrak{e} e$ einftellen.

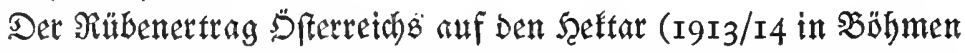

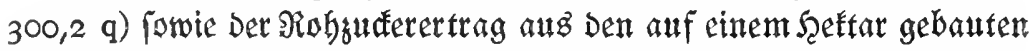
Rüben (I913/14 in Böbmen 50,4 q) fommt im Durdfichntft Dem Des

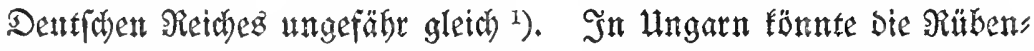

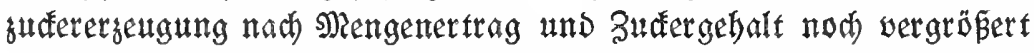

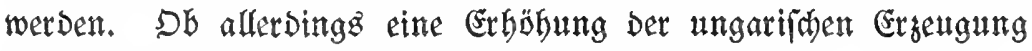

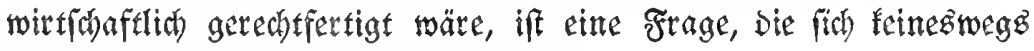
leidht und eintwandfrei beantworten lä̈ŕt.

Die eittiflägige induftrielle Fandorganifation, Der Zentralvelein

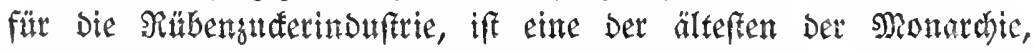

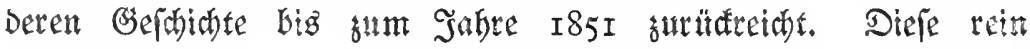

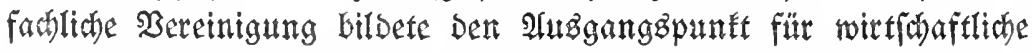
Bereime und Grütdungen verfotedener Art, won Denen bejonoers

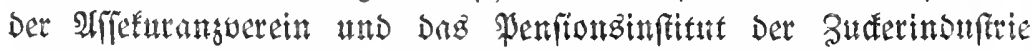

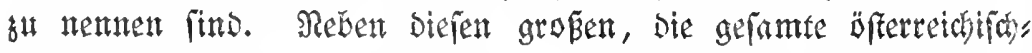

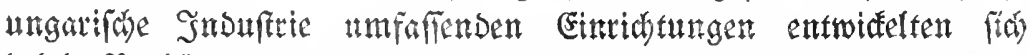

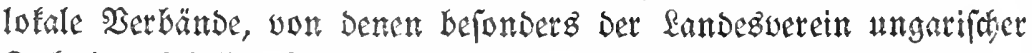

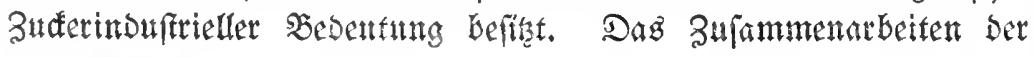

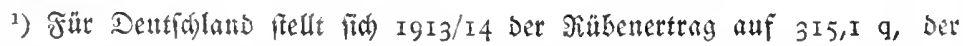

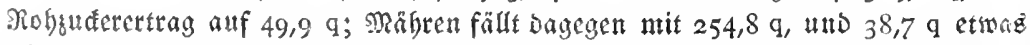

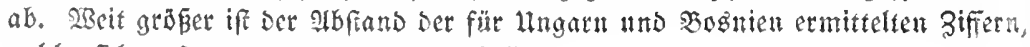
melde fich auf 218,6 q uns 30,3 q fiellen. 


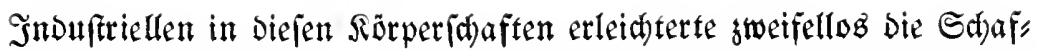

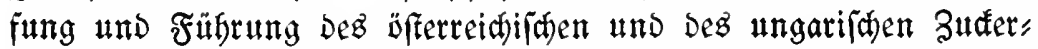

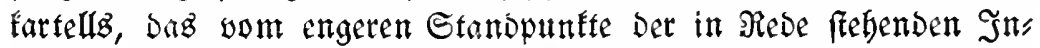

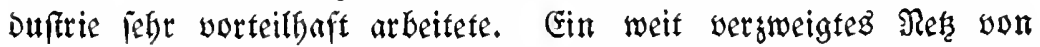

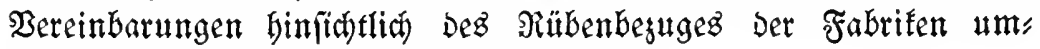
ipannt faft sie ganzen Rübengebiete.

Beim $\mathfrak{B r a n g e w e r b e}$ Der Monardie treten die einzelnen Stadien Der Betriebzentwiflung in auffälliger Form Gervor. Pon Der ḩaus;

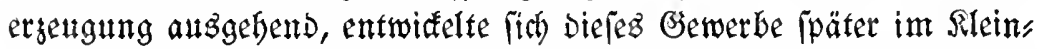

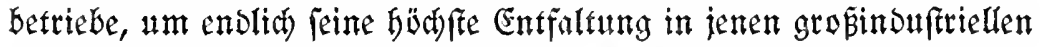

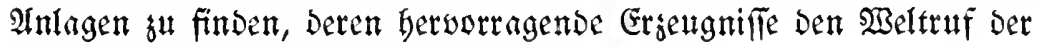

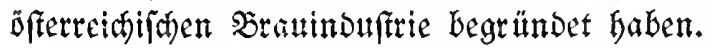

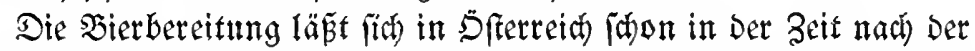
33ölferwanderutrg nadhei Steiermarfz eine Irt Gerftenbier brante, Dem Die bieräfnlidien Pros butte Der Elaven in Böhmen und Mähren an bie Seite zu fellen find.

Damals fanto auj Dem fiacten Eande daz Eelbftbereitunggredtat

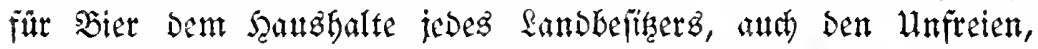

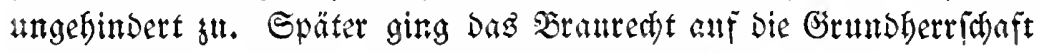
über, bei Der Der Banter feinen bierbebar

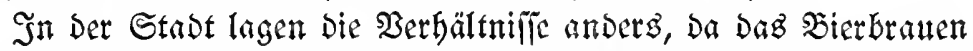

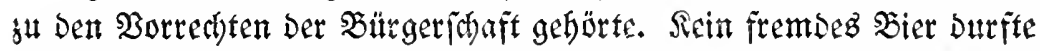

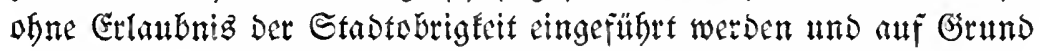

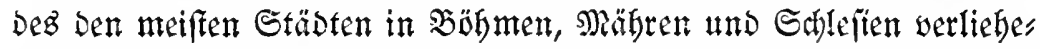
nen jogenannten Meilenredteg im Umfang einer Meile von Der

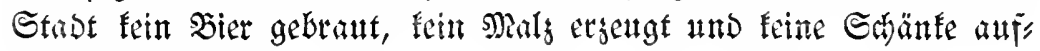
gematht merden.

Die brangeredtigfett wurbe in ben Stäbten mit bejonderen braus

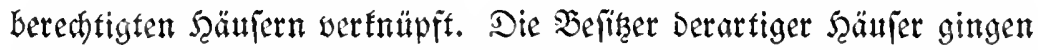

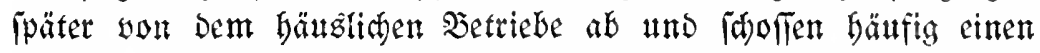

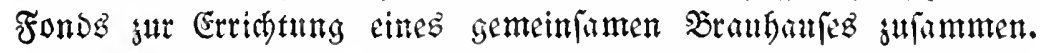
So entfanden in viclen Städten, namentlid in Bögmen, Mä̆fren und

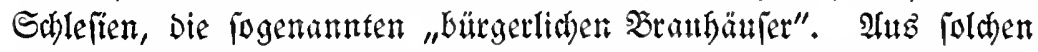

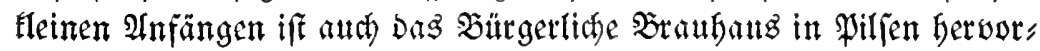

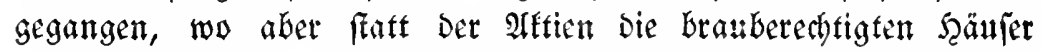

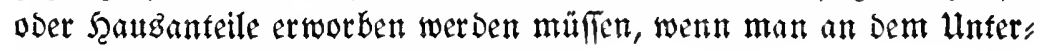
nehmen 2 nteil gewinnen will. 
Sn Pieder, und Dberöfterreidy wie in Den Alpenländern twirfte Der Entwidung Des braugewerbez die Weinproduftion uno Der frark Beintonfum entgegen.

Eine einfhneidende Änderung im Brauereibetriebe trat ein, als

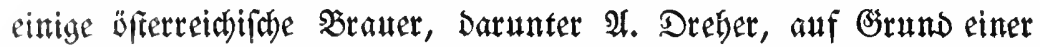
Studiemeife nach England zum modernen Gropbbetrieb übergingen,

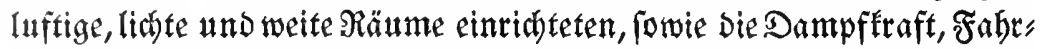

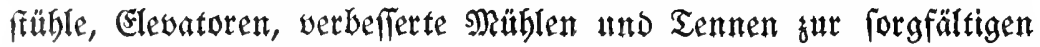

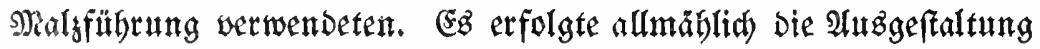
Der Subhäufer mit rationellen Rüfrwerfen, Die Einfübrung werbeflerter \{äuteranlagen, Die Anwendung von Bentrifugalpumpen fur Fỏrberung

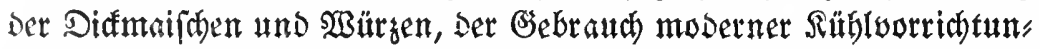

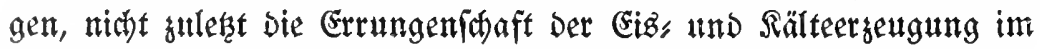

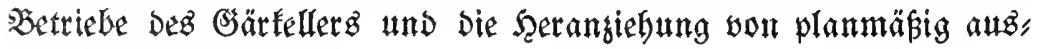
getwäblten heferaffen.

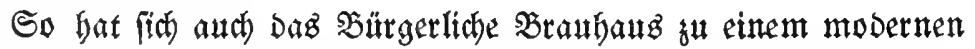
Riefenbetrieb mit allen modernften Errungenjthaften Der Tect)nil ent"

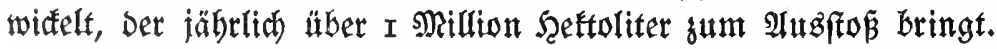

Sinfichtlity Der Menge Der Produttion (bie allerbings in Den lesten Sabren etwaz zurüaging), reibt fich Die Nonardjie mit 25 Nitlio" nen Scktolitern im Sahre r9r2 binter Deutfaland (76 Millionen Setto" liter) uno Grop̈britannien (6o Millionen Seftoliter) ein. $\mathfrak{A} \mathfrak{n f f a ̈ a l l i g ~}$ ift Das ftarke llberwiegen Der Rleinbetriebe befonders in $\mathfrak{B}$ öfmen und Den Ilpenländern, wo es nad) Der leşten Betriebszählung immer nod) faft trulend $\mathfrak{B e t r i e b e ~ g a b , ~ b i e ~ m u t ~ b i s ~} 20$ Perionen befhäftigten, eine

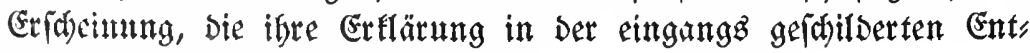
widtung Deg $\mathfrak{B r a n g e w e r b e z ~ f i n d e t . ~}$

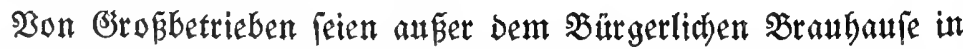

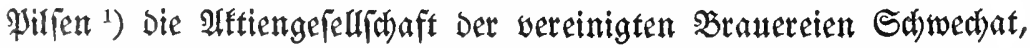
St. Marx, Simmering:Dreher, Mautner, Meithel mit einer Befamts ergeugttng won $\mathrm{I} 1 / 2$ Millionen Settoliter angefübrt.

In Ungarn befteben mebrere Grobbetriebe, won Denen die be" Deutendften, Die beiden Brauereien in Steinbruth, jebe eine Erzengung won rund 700000 hl aufweift. Der $\mathfrak{B i e r a u s f u b r ~ D e r ~ M o n a r b i e ~ i m ~}$

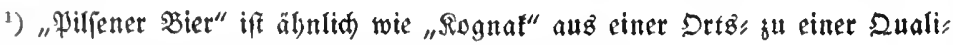

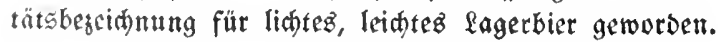


Sabre I9I3 im 2 Berte wont rund I9 Milliunen Sronen febt ein (Einfuhrs wert won I,2 Mitlionen Sronen gegenïber.

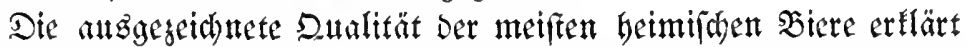

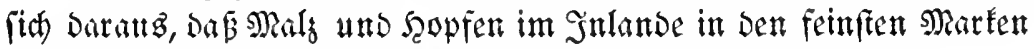
gemonten werben $($ F. H.), bie ez in ber Welt überbaupt gibt.

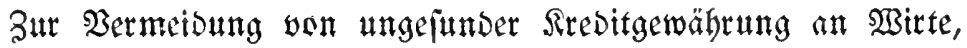
weld)e Durd Die gegenteitige Ronfurreng Der Bierbrauereien in Den

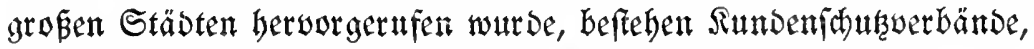
Die Den $\mathfrak{B e r b a n d e b r a u e r e i e n ~ g e w i f f e ~ E n t f a ̈ a ̈ b i g u n g e n ~ f i t h e r n . ~}$

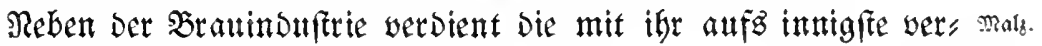
fnüp fte Malginouftrie befonocre Erwähnung.

Danf Der Bobenproduftivität, Der türdtigen fommergiellen uno ted)nifden \&eitung Der Betriebe Diefer $\mathfrak{B r a n d}$ e ftebt Die Malsfabrifation namentlich in Mähren, Stufe. Die vorgüglid)en Gerftenqualttäten Mä̆hrenz (Şanna tnd bie - Tiefebene Des Mard)gebieteg)), Die Proventenzen Böhmenz, ferner Ungarns baben Den Malzprobuften Der Monardie einen Borrang

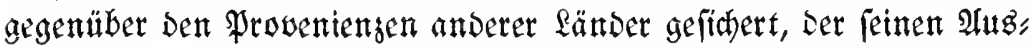
ortat in Dem großjen Export findet, welder im Sabre I913 einen $\mathfrak{3 e r t}$ won 57 Millioner Mronen erreichte.

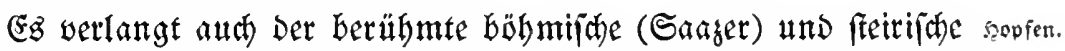
Şopfent (Erwähnung, an ben fith als mittlere Dualitäten bie Sorten

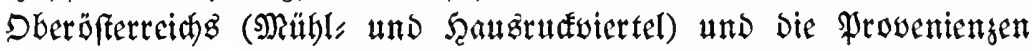
aus Tirichis in Mähren anjhließen. Sn Den berworragenden Marken

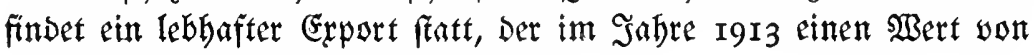
39 Millionen Mronen repräßentierte.

Die Spiritusinduftrie Der Monardute fteht bimfthtlith ihrer Epititues.

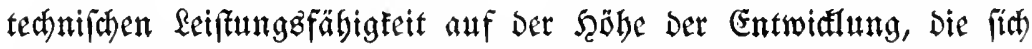

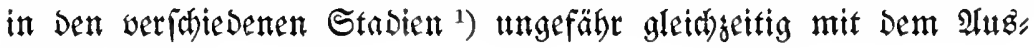
lande vollog.

1) Tie Entwidlung ift, turs gefdilbert, folgende: Erft Erzengung von खein, uno Getreibejpirtus, Dann um bie Mitte beg XVIII. Jahefunbertg auz Sartoffeln; ftatt Diretier Fetterung Die Anmendung von Dämpfen, fpäter=

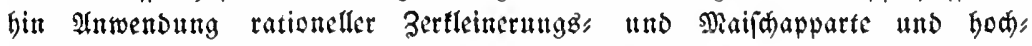

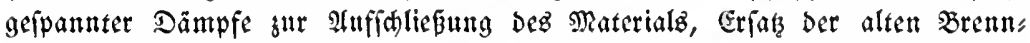
blafen Durd fontinuterlich arbeitenbe Deftillierapparate, welde nadi Dent neueften Sonftultionen fogar die Gerwinnung eines raffinterten Produltes 
Die Sandwirte erfantten bald, Daß̃ Der Anbau Der Sartoffel und ine $\mathfrak{B e r a r b e i t u n g ~ a u f ~ S p i r i f u s , ~ D i e f e ~ F o r m ~ D e r ~ S n o u f t r i a l i f i e r u n g ~ D e r ~}$ Eandwirtiandt, Dent Ertrag wefentlich feigere, zumal gerwiffe, fonft weniger günftig verwertbare $\mathfrak{B}$ öben für Den Sartoffelbau $\mathfrak{B e r w e n d u n g ~}$ finden köntten.

WBiter ftellt Die beim Sartoffelbrentert als Rätfand rejultierende Sallempe cin wertwollez Frnttermittel bar, daz die moderne Biebs mäftutig in gropem Stile geftattet. So fellt bie Spiritusinduftrie

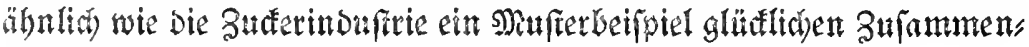

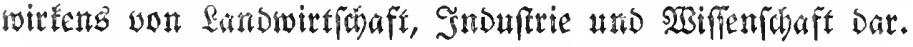

Sn Erfentnio Der bebeutung Der Sartoffelbrennetet für \&ano;

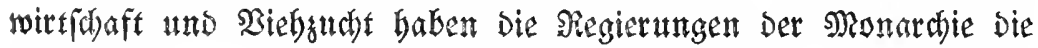

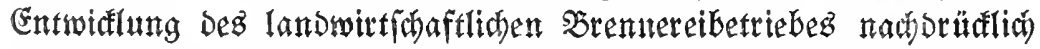
gefördert und Duth Gewäbrung won Bonififationen Dieje Betriebe gegen bie unter wefentlich günftigeren bedingungen arbetrenden in Duftriellen Spirtusfobriten fu foühen gefucht ${ }^{2}$ ).

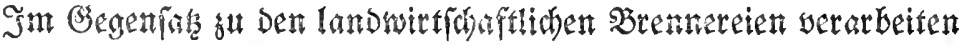

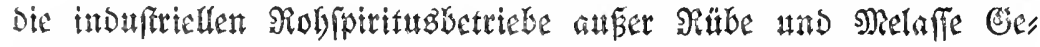

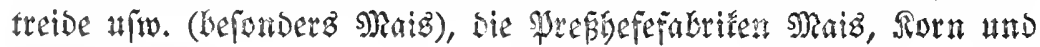

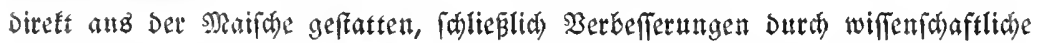

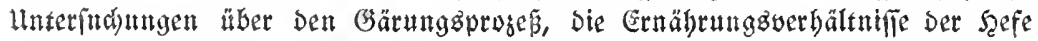

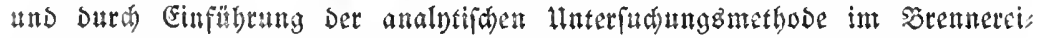
laboratorim; fratt Fubrung Des Setriebes anf rein empirifser jene auf toiffer

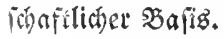

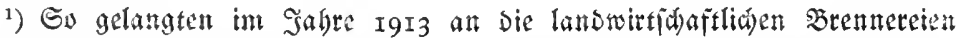

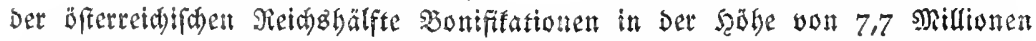

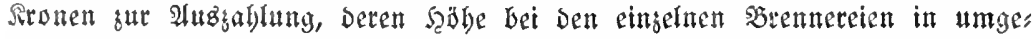

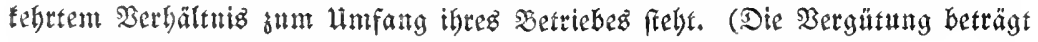

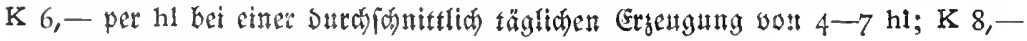
bet 2-4 hl und K ro,- Det einer (Ergettgung bis jul 2 hl.)

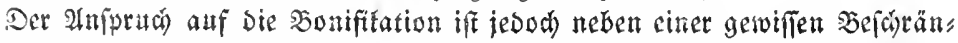

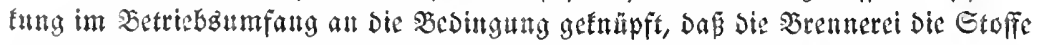

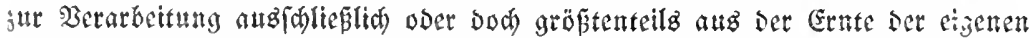
Eandwirthaft ziebt, Dagegen Die bei Der Spiritusergengung getwonnene Sdjlempe

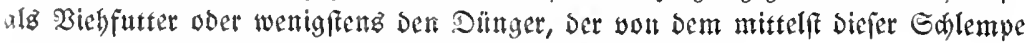
gefütterten Bieh berrührt, an biefe fanowirtidaft abgibt.

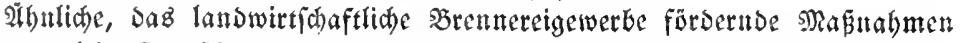

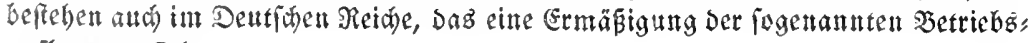
atrlage vorfebt. 


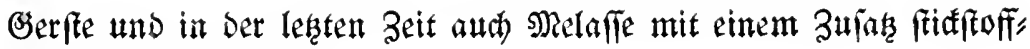
baltiger $S_{\mathfrak{n}} \mathfrak{b}$ fintzen.

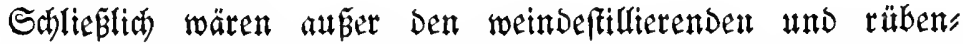

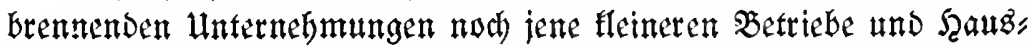

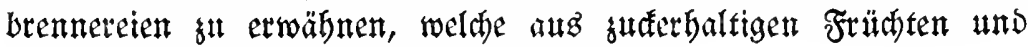
Treftern Dutulitätäbananntwein Gerfétlen.

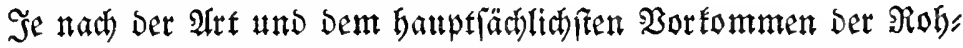

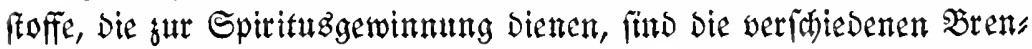

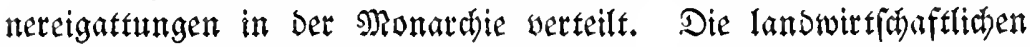
Sartoffelbrentereien finden firh wegen Der ausgedegnten Siartoffels

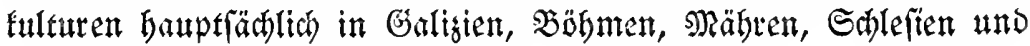

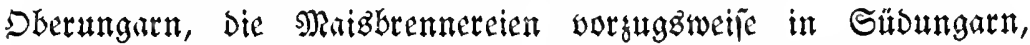

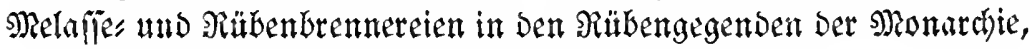
D. i. in $\mathfrak{b o ̈ h m e n , ~ \Re a ̈ h r e n , ~ S d h l e f i e n ~ u n d ~ D b e r u n g a r n . ~}$

Die \$repgefefabrifation Gat ifren Sits in Der Rähe Der groß̈en

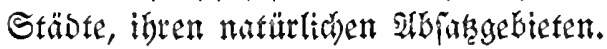

Die Probuftion ber Monardite fteft mit einer Sabregergengung

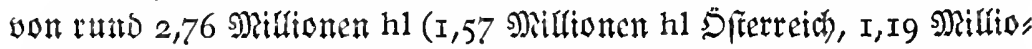
nen hl lingarn) ant fünfter Stelle tno wird in Der (Ergetigung war vour

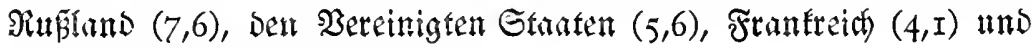
Deutifdrano $(3,75)$ itbertroffen.

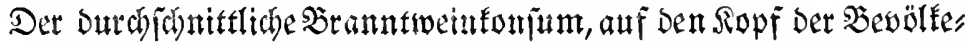

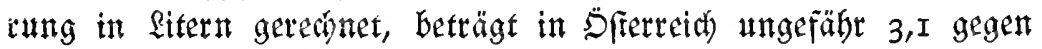
2,8 in Deatiffland ${ }^{1}$ ).

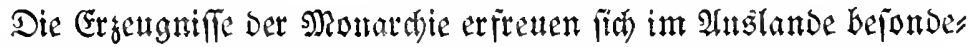

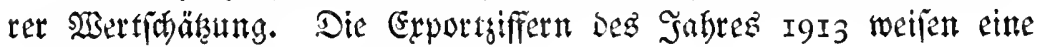

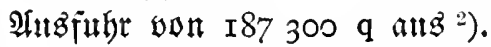

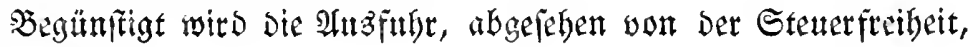

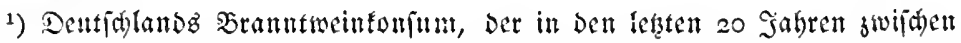
3,8 biz 4,4 liter per Ropf gefdwante hatte, ging im Etenerjabr r9Io um 1,4 flter

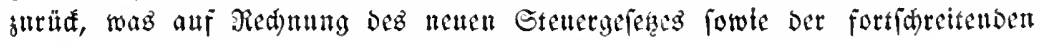

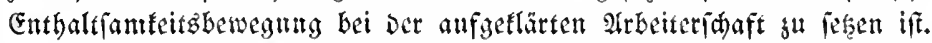

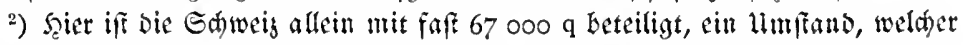
bei Den frengen Boridriften, welde bie cibgenofitide Regierung bejüglid) Der Dualifät Des einjufübrenben raffinierten Produltes erlaffen bat, soppelt in bie פiagid ale fällt.

In zweiter finie findet ein Simport mad) Dentid)lano (3 I 000 q) unb nad Den $\mathfrak{B a l f a u f f a a t e n ~ f i a t t . ~}$ 


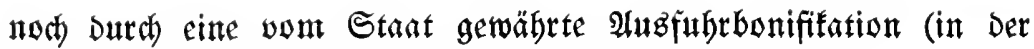
Betriebsperiode $1912 / 13$ rund 2 Millionen (Tronen) ${ }^{1}$ ).

Zut befferen $\mathfrak{B e r t r e t u n g ~ i f r e r ~ S ̧ n t e r e f f e n ~ G a b e n ~ b i e ~ b e g u ̈ g l i c h ~ D e s ~}$

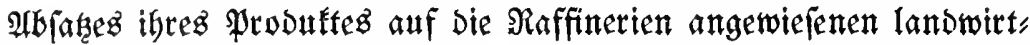

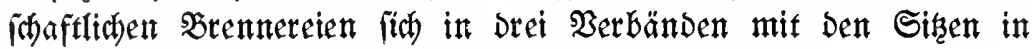

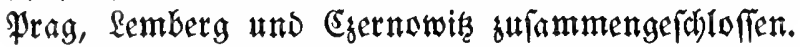

Diejen $\mathfrak{B e r b a ̈ n t b e n ~ f t e b t ~ d i e ~ i m ~ S a b r e ~ r g I ~ I ~ i n g ~ l e b e n ~ g e r u f e n e ~}$ Drganifation Der induftriellen Brennereien und Raffinerien Dez wefts

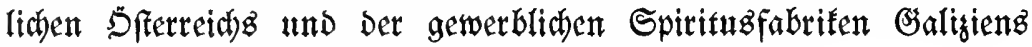
"nD Der Saforwina (Daz Spirifuzfartell) gegenüber.

Die moberne Mählentorofindufte mit Dem intenfiven $\mathfrak{B e r}$

fahren Der weiteftgebenden Reinigung Dez $23 e i s e n s$ and Der möglid/fen Trennung Der Meflprodufte (nämlich) bis zat $83 \% 1 / 2 \mathrm{~kg}$ Mebl), thahm won Ungarn ifren 2 tusgang, wo 1836 in Sopron Die erfite Dampf" mïble entitand und fpäterbin mit Der Erfindung und Einfellung

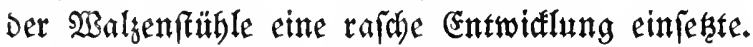

Die ungarifare Mähleninouftrte übertrifft die öfterteidifhe an

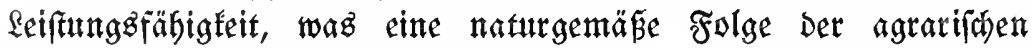

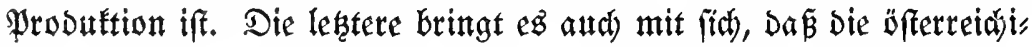

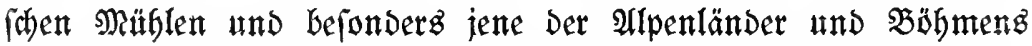

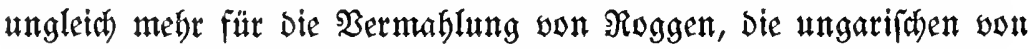
Weizen und Maiz eingerichtet find. Die Mübleninduftrie in lngarn ift befonders in $\mathfrak{b}$ Hapeft, $\mathfrak{A}$ rab, Temebuar und Effeg vertreten, während in Dfferreid) neben einzelnen Sroßnmühlen in \$rovinzftädten Die Wiener uno Prager Mühlen vor Der übrigen einheimiłhen Ron

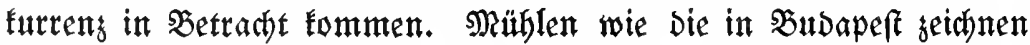

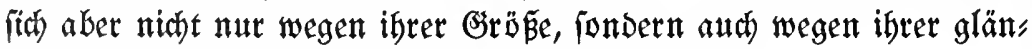
senden modernen majhinellen (Einridhtung atts ${ }^{2}$ ).

Alz feinergeitiger bejonders förbernder Faftor für bie ungarifóde

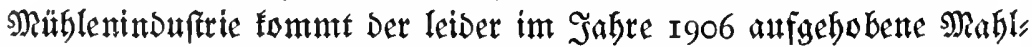
verkebr in Betradt, Der Die ungarifden Mählen inftand gefebt batte,

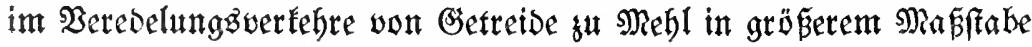

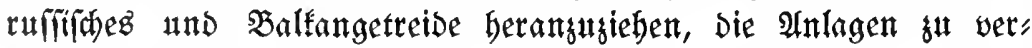

1) Sn Deutidland wird meben Erftattung Der $\mathfrak{B e r t a u f z a a b g a b e ~ e i n e ~} \mathfrak{B e r}$

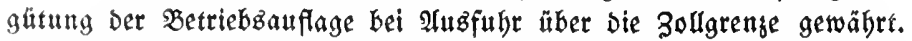

2) Die neun groben Busapeffer Rühlen mit eitnem Stammapital von fait 24 Millionen Sronen haben $19068 \frac{1}{2}$ Millionen q Meiten wermablen. 


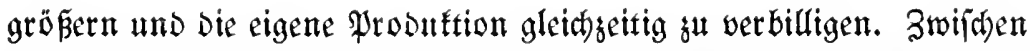

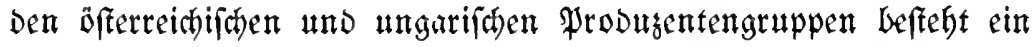
Streit Darüber, Daß bie ungarifthen Mühlen als teilweifen Er ją̧ für

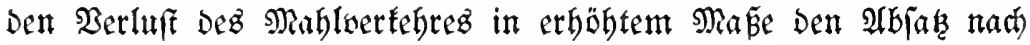

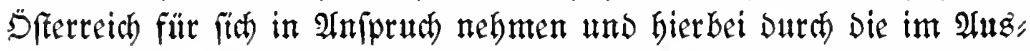
gleid)gefege nominierte (an fid) abnormale) Bleiá)fellung bes Fradt: fakeg won Getreibe uno Mehl weitgehend unterftüht werben.

Sfferreich)

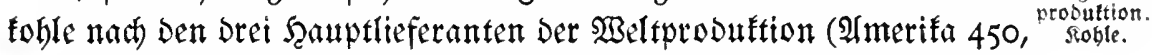
England 264, Deutifland 255 Millionen Tonnen) an Der Epize ber Sieferanten mittlecer Bedeutung, inbem ez I9I2 mit 5 I Millionen Frantreich, Rußland und Belgien übertraf.

Die Förberung an Braunfoble betrug im genannten $\mathfrak{J a f r e ~} 34$ Millionen $t$, gegenüber 80 Millionen $t$ in Deutfoland, die an Steins foble 17 , I Millionen $t$ gegenüber 177 Millionen $t$ in Dentialand. Bei Braunfoble beftebt im Gegenją̧e fur Steintogle Der Borteil,

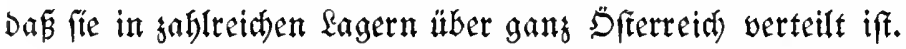

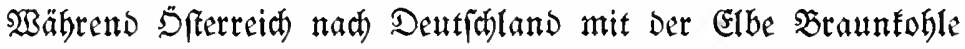
angführt (70 Millionen q), bestebt ez bafür faft bie Doppelte Menge an Steintohle $\mathfrak{e}^{1}$ ) won Dorther. WBenn Ginfithtlith Der Ergiebigfeit vom mittelbähmifach Steintohlenlager behauptet wird, Dẩ ez in roo biz I50 Sabren erłhöpft fein Dürfte, ift Dagegen Die fonftige Föroberung an Braun und Steinfoble nodh nicht einmal bei Dem grö̈stmögliden Umfange angelangt. Sn S̈fterreid) und in Ungarn wird febr äber Die

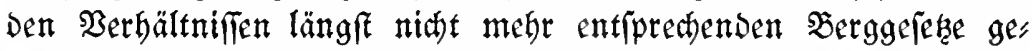
flagt, Deren nadteteilige Wirfung fïh natürlich auf allen Gebieten Der Bergwerfzeroduftion gelteno madt.

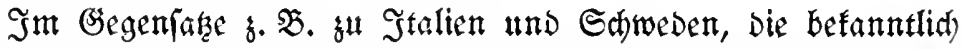
feine Roble bejizen, iff Demnath Die Monardie mit Material fur Ex" geugung aller Irt won Rraft reichlich verieben, Denn fie verfügt über Roblenlager und Rejervoirs an Wallerfaft.

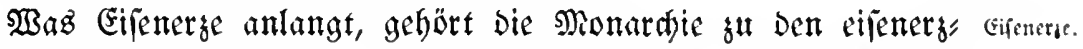

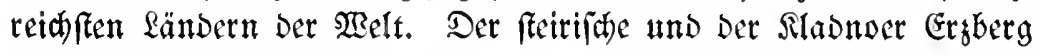

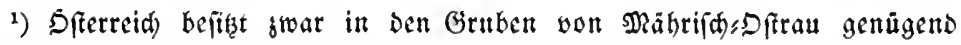

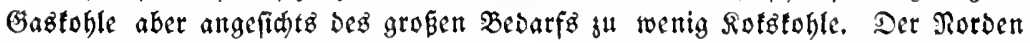
importiert Das fehlende Duantum aus Deutidland (Rubrgebiet), Der Süben aนs Englano. 
fino Tagbaute von grof̧em umfang. Bum Stanopunfte billiger moderner Berwertung befteht allerbingz bie Erfwherung, Dap (itd) Die jur Burbtttung notwendige Sioble in Der Regel nicht, wie in Dettichs, lano, in unmittelbarer Rähe Dez Gifenerseg vorfindet. Es hat Daher

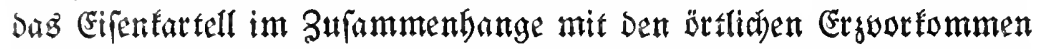
ben Betrieb anf Die mit Den mobernfen Erforberniffen auBgeftatfeten

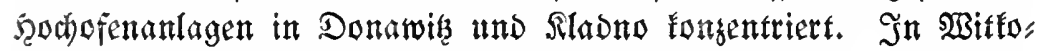
wił̧ (Mähren) werden auf Grund Des Sohlenvortommens vorwiegend

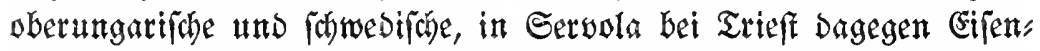

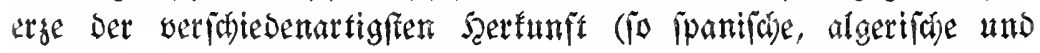

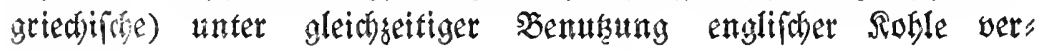
arbeitet.

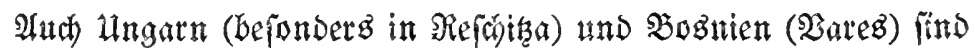
reici) an Eifenerglagern.

Dabei befint Die Mronarchie Sager, die wegen gümftigerer $\mathfrak{B o r}$ fommen an anoeren Slägen Dergeit nod nicht abbaufähig find, eine

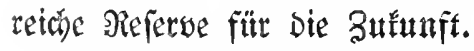

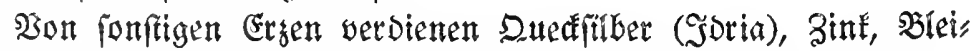
erge und Pechblende (\$adium) Gervorgeboben zu werden.

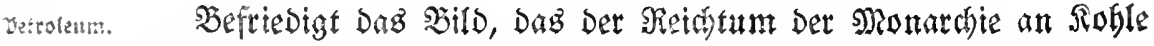

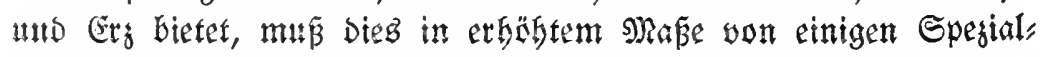
produften gelten, ïber weldye die Monardie in Maffe verfügt, io

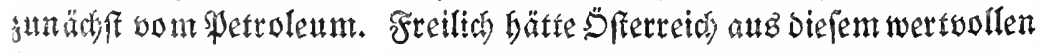

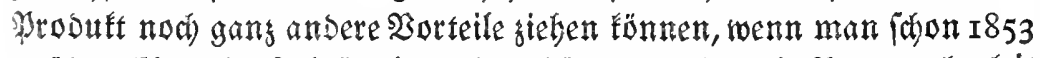

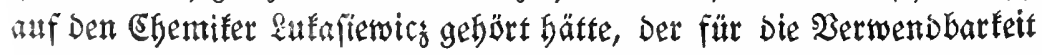
bes Petroleums eingetreten war. Man madyte fid aber infolge ungtt:

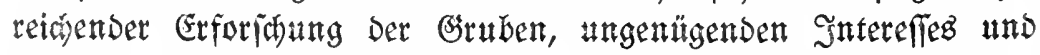
mangelnden Sapitals nicht fofort an bie Exploitierung, fondern über"

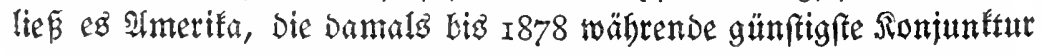
auşunüsen, two Gohe Preife und Riefengervinne su ersielen waren ${ }^{1}$ ).

Sn ber Gerwinnung von Erdöl, Dag im internationalen Ģüter" austaufd fetgende Bebentung gewinnt, feht bie Monardje mif

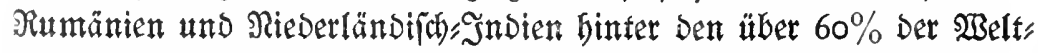
förberung befterefenden Beteinigten Staaten und Rußland an Dritter Stcule.

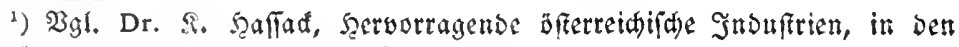

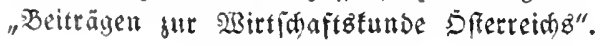


Die Berwinnung von Groül im Sarpathengebiete bat fidh nod in

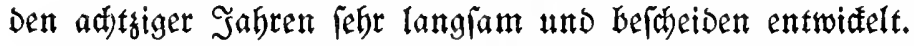

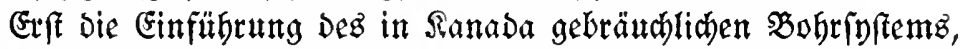

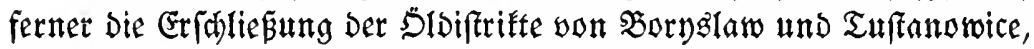

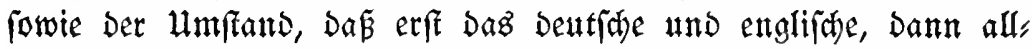

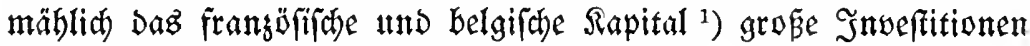
in Der Petroleuminduftrie vornath, bradten die bebeutame Ent" widflung Der Snduftrie mit fid

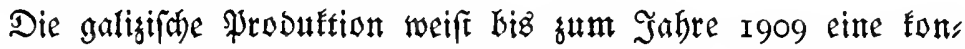
ftrnte Steigerung auf und wuch $g^{2}$ ) von 6000 q im Sabre 1878 auf über 20 Mitlionen $q$ im Sahre I909 an. In Den barauf folgen

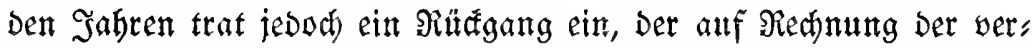
minderten Ergiebigfeit in Den Dldiftriften Boryslaws: Tuftanowice zh

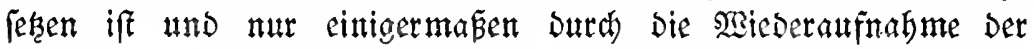
Arbeit in vielen Sdjädten, bie feinergeit als nid)t lufrativ aufges geben worben waren, gemildert wutrde.

Die Dlgeminnung erfolgt Dank Der vervollemmmeten $\mathfrak{B}$ dye, tednif meift im fogenannten britten Scorigont, in eimer Tiefe wont

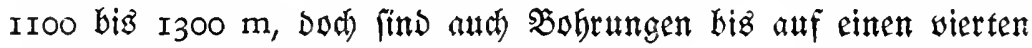
Scorignt worgetrieben unb Tieren bis fall $1500 \mathrm{~m}$ erreid t worben.

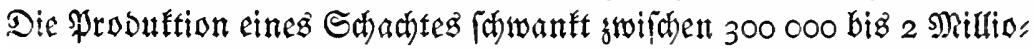
ten Bentnern jährlich, Dod fommen bei mandien Bobrlöbrern Tages: produftionen von 3000 bis 5000 Zentnern var $^{3}$ ).

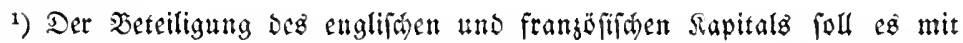

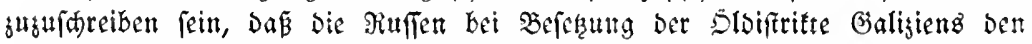

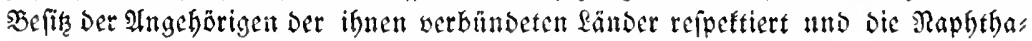
gebiete und Raffinerien nut wentg befrbabigt baben. Die Probultion war für

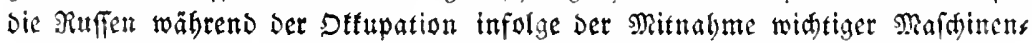
teile Durch Die Dfterreiner fo gut wie unmögliá gemađt worden.

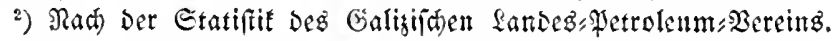

3) Die internationale Probuttion bat gegenüber Galtzien ben Borteil Der weit geringeren Tiefe Der bobrungen, to Bafu wan penniploanifhen yon runb $600 \mathrm{~m}$ Tieje, Sumänien vou zumeif $250 \mathrm{~m}$ Tiefe, ans̆nabmetweife von $600 \mathrm{~m}$. Die Bobrtopten fiellen fit in Galigien je nah Tiefe

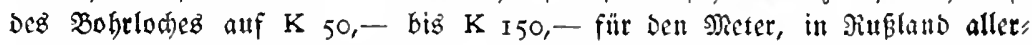
bings auf 1000 Rubel (ba wegen Des Gefreinsuanfallez bie bobrlöd)r mit einem Durdmefter son I4-i9 3oll worgetrieben weroen müfen), in Pennipls wanien wegen bez weiden Befteins auf $\mathrm{K} 25$, - biz $\mathrm{K}$ 100,-. In Rumänien

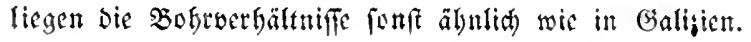




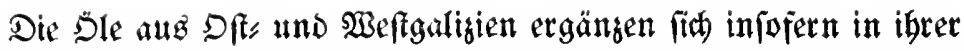
(bemifa)en 3ufammenfeg̨ung, als bie erferen neben viel Paraffin wentg Bengin und howflammende Samieröle enthalten, wäbrend bie leşteren Dagegen meift paraffinarm, Dafür ungemein reich an Bengin und ziemlich afphalthältig find. Sie liefern Sdmieröle von niebrigem Flammpuntt.

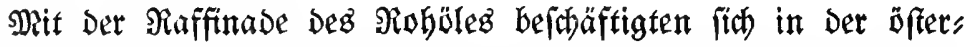

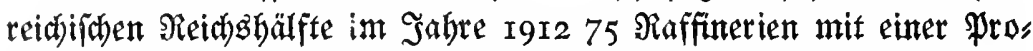
buftion für Den Snlandzłonfum von $r, 8$ Millionen und einer ftener, freien Erzengung (für Den Export) von 4,8 Millionen Zentnern.

Wetfer gibt eż in Ungarn und Bog̈nen etwa I5 Raffinerien.

Uriprünglich waren bie öfterreidhifhen Raffinerien infolge ibrer

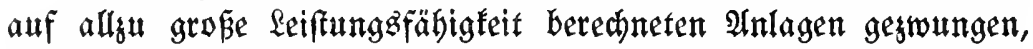

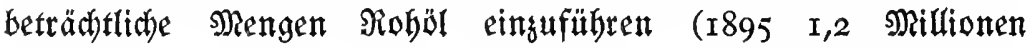
Zentner); Dod) Gatte mit Der Stetgernng Der Snlandsproduftion die

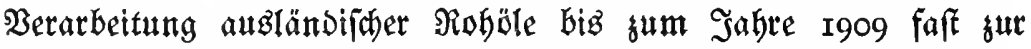

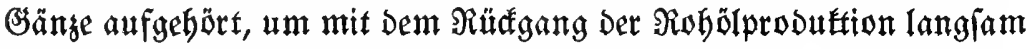
wieder anfufteigen (im \afre I9I3 I9I 000 q).

Der Gefamtfonfum S̈ftertetchllingarns an Petroleum errecidte im Sabre I9I3 rund 3, I Millionen q. Der Berbraud betrug Daher im gleichen Sahre etwas über $6 \mathrm{~kg}$ für Den Sopf, Dem ein Petroleum= verbrauch in Deutichland won etwas mebr als i7 kg für Den Ropf gegentuber(tegt ${ }^{1}$ ).

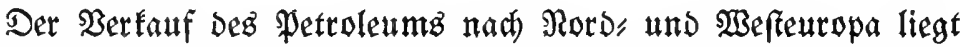

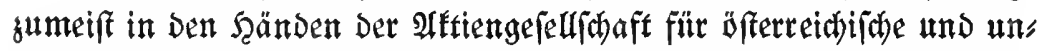
garifare Mineralölprobufte (Dlex) und ifrer Tod)tergelellddaften in Deutfaland, Şolland, Sthreig und Belgien, Die über grofere Refervoits anlagen in Den $\mathfrak{A b}$ [ą̧̨ebieten verfïgen.

Die Berjorgung Der Balfanländer erfolgt teils über Die Donau, teill über Trieft und Finme ${ }^{2}$ ).

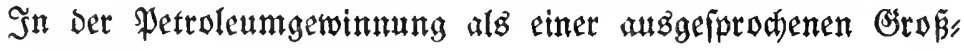

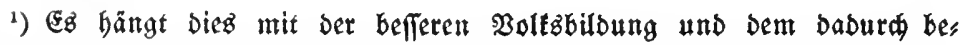
bingten größeren liđtbedürfnis ber Bevalferung auf Dem fladen lande in Deutf́land zu[ammen (f́. o. bei Roním).

2) Der Export Der Monarajie betrug im Jabre I9I3 an raffiniertem Petros leum 2,8 Millionen q, an Sd)mierälen 1,5 Mirlionen $q$ und an Bentin ca. 1/2 Mils, lion q. Davon nady Deuffaland rund I,8 Millionen q, 670000 "nd 342000 q. 
induftrie war von jeber bie Tendent gur Songentration vorberridnend. Das öfterreidjifde Rartell iff aber in Sabre I9I2, nitht fuleg̨t aus

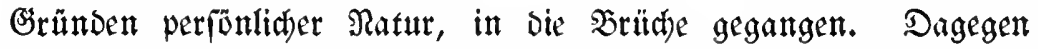
fam ez mit Dem mähtigen amerifaniíchen Sartell, Der Standard Dil

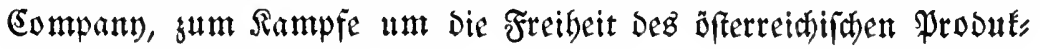
tionsgebieter.

Die $\mathfrak{A m e r i f a n e r}$ trad)teten Dag won innen bereitg erfolgreids in Shina, Sapan und Sndien verwendete Tanfipfem eingufübren, Daz Darin beftebt, Das Petroleum Durd Serteilungszagen - ähnlid

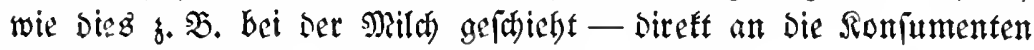
abzulezen und fo ben Bwifhentandel auszulahalten.

Frft trift eine $\mathfrak{B}$ erbilligung Deg Produftez ein. Sobald Die ßon,

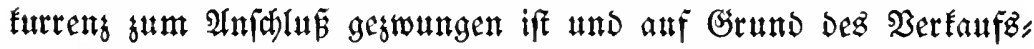
monopolz aud ein $\mathfrak{P r o d u f t i o n s m o n o p o l ~ g e f d a f f e n ~ w u r d e , ~ f e i g e n ~}$ Dann bie Preife.

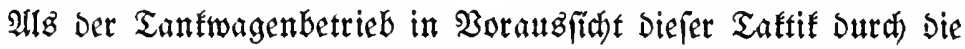

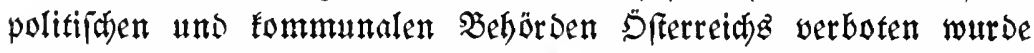

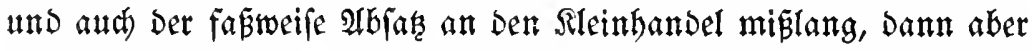

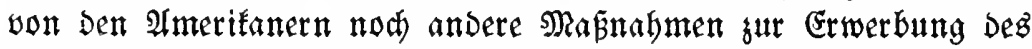

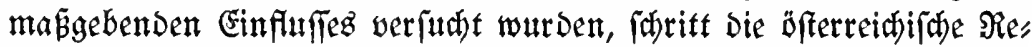

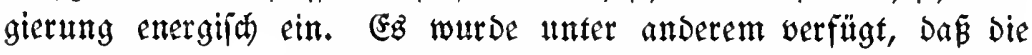
Errictung von Petroleumraffinerien nur auf Grund bejonderer Rongeffionen geftattet wirb. Die Folge bavon war, Dẩ die

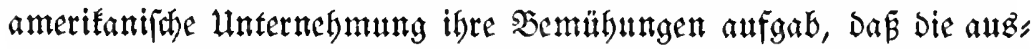
ländif( )

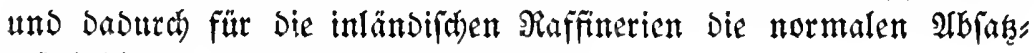
möglich keiten wieberbergeftellt wurbeti.

Es ereignete fith fomit Der intereffante Fall, Da ba baz fonft Den modernen Sringipien Der Gewerbepolitif wenig entipred)ende Son, seffionsinftem - ein überbleiblel ber Probibitiopolitif früberer

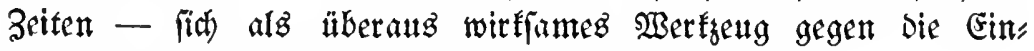
miffung Dez norbamerifanifđen Riejentartells erwieg.

Während D̃ferreid) Dutr(y) Den Reidftum an Petroleum und ßengin Grogas.

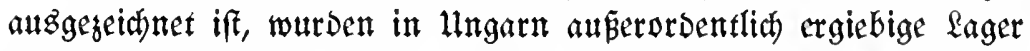
an ErDgas erbobrt. So in Ris Sarmaz (tägliche Ergiebiateit eines $\mathfrak{B o b r l u d}$ es $864000 \mathrm{~m}^{3}$ (Gaż), Mayar

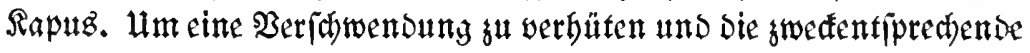


Berwertung Der angebofrten Lager für Den geeigneten Zeitpunft

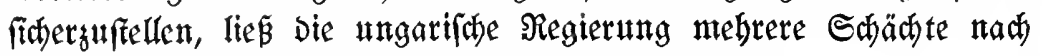

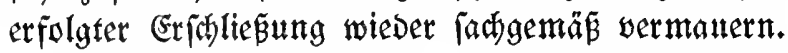

Sals.

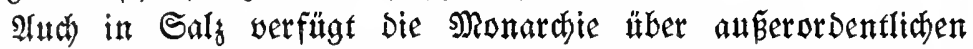

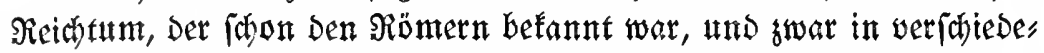

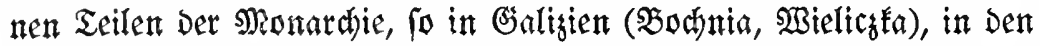
Ilpen (Şallfatt, Şallein, Şall) ${ }^{1}$ ), in Ungarn und in Sognten. Der Şert Der \$roduffion belief fid I9I3 auf rund 80 Millionen Sronen.

Bon fonftigen in grö̈eren Mengen vorbandenen Mineralien feten unt guelen. nod Radlin, Miagnefit und Graphit (allerbings minderer Datalität), yon Steinen Marmor, Porphyr, Granit und Srbiefer berwors geboben.

Şierber gebören audh bie Mineralquellen uno Säutrlinge, an Denen bie Monarchie fo reich iff und won Denen Sarlabad, Marienbad,

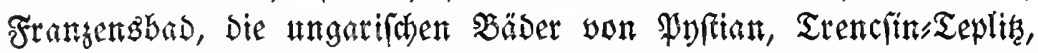
Mebadias die betannteften find tnd 2 seltruf genieben. Das Rabium von Soachimserbal ift die nentefte Speztalität.

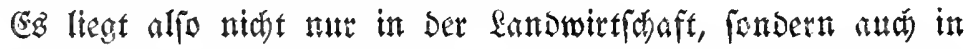
biefen Belangen, wor allem in Sohle, Etien, Petroleum, Salz difw.,

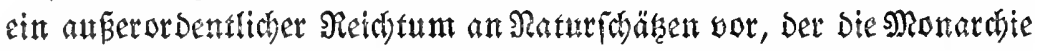
id)on Geute mit in bie erfe Reibe Der bebentenden Probuftionsfättent Des Siseltuertebrez frellt.

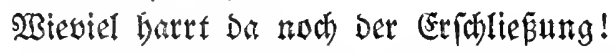

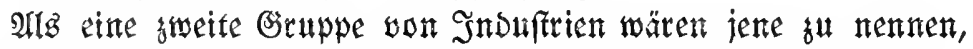
vie vorwiegend bodenfändiges Material verarbeiten, die Eifentnduftrie,

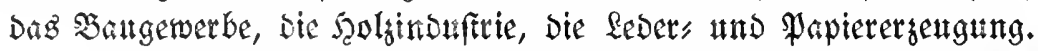

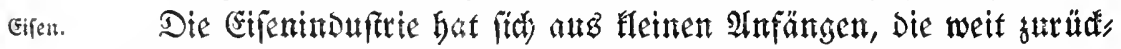

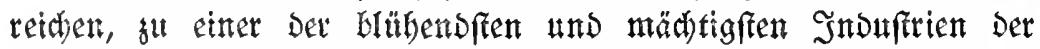

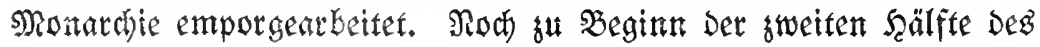
I9. Sabrfunderts wat igre Produftion eine red t befdeidene. Die

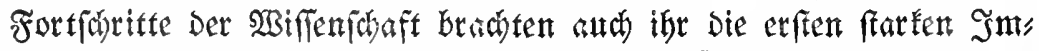
pulfe: Das Beffemerverfahren ermöglidy te bie ulberführung scs Roh, eifens in ichiesbaren Eifengur, Das Thomaguerfahren die Ent"

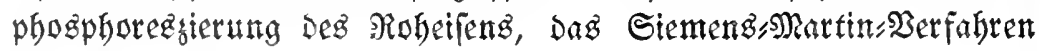
sal, $\mathbb{E}_{\mathfrak{a}} l_{\mathrm{s}}$.

Caton ber Rame beutet auf Den 3ujammenbang mit bem lateinifaen 
Die Serftellung von Stabl burd Berfamelgung von Robeifen mit

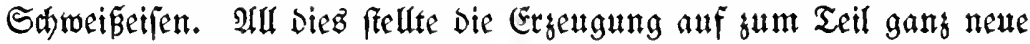

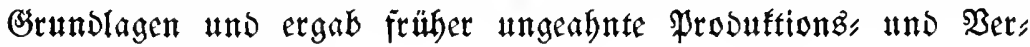
wendunggamöglictetetten.

Şierğ fommt infolge Des Eingreifenz fatarer Periönlidfeiten ( Rarl $\mathfrak{B t t f g e n f t e i n ) ~ D i e ~ B e r e i n i g u n g ~ i n ~ e i n e r ~ g r o B a n g e l e g t e n ~ o ̈ f t e r , ~}$

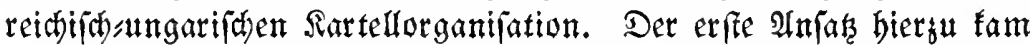

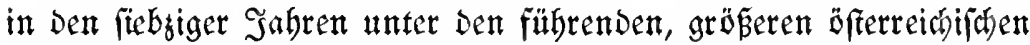
ख̉erten zuftande, als bie Eijenpreife Durd) übertriebene Sonfurren tief gefunten waren und fat empfindlidjen Berluften gefübrt batten.

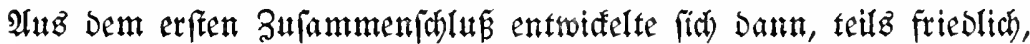
teils unterbrochen Durdh heftige, aber furge Sonkurrengfämpje, jener enge Bulammenialus, Der beute eine glängend geführte und Daher Die mäd)tigfte Drganifation ber beimifhen Snouftrie geworben ift.

Mögen freilich Die fonjumierenden Snduftrien über bie ungenü

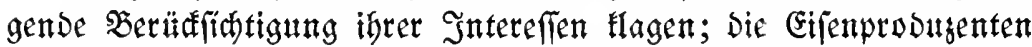
fönnen won ibrem engeren Standpuntit auf Die gang ungebeuren Er, folge hintweifen, bie fie Der Regierung, Dem Parlament und Der Sffents

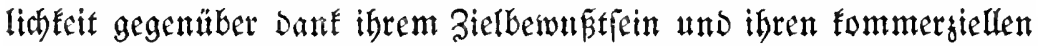
Fäbigketten errungen Gaben. Das Eifentartell ift ein Mufterbeifpiel

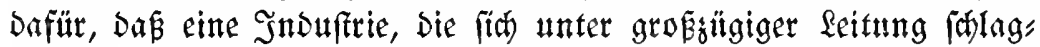
fertig organifiert, Die Regierung uno Das Parlament gerabefu zu fwingen vermag, die Sntereffen biefer Induftrie in befonderem Grabe

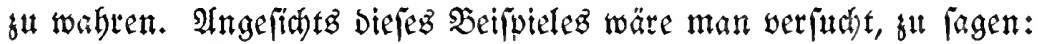

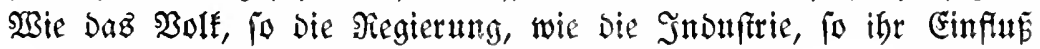
lno Demgemä́ Die Snduftriepflege Dez Staatez.

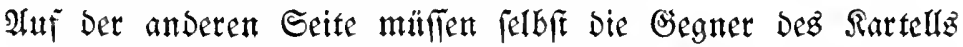

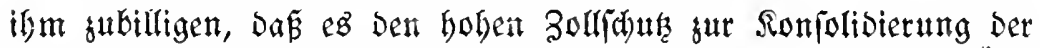
Eifens und Sd)werinduftrie gefdidt und umfithtig verwendet bat uno

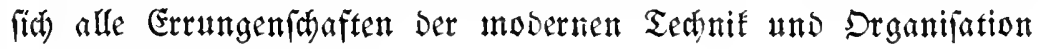
grof̧zügig zuntutze mactite.

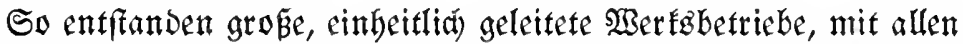
boúmodernen Şilfizmitteln aubgeftattet, erfolgte die Stillegung vers altet eingeridfteter ober foldter Untermebmungen, Deren Fortführung auz irgendrwelden anderen Grünben, \&. B. wegen Nongelz Der nötigen

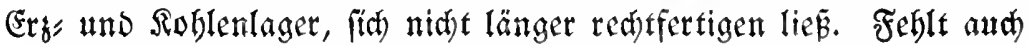

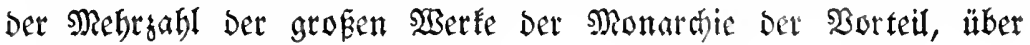


(Er

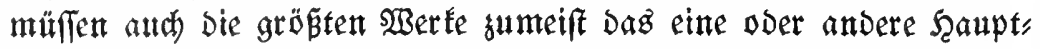
produtt auf teurem SWege herbeiführen, fo haben Dody Die großjen Ery

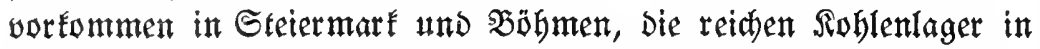

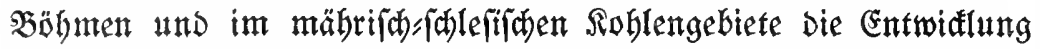

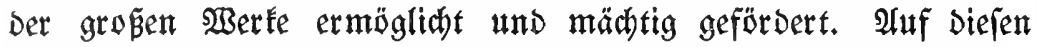

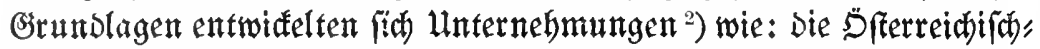

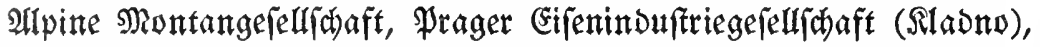

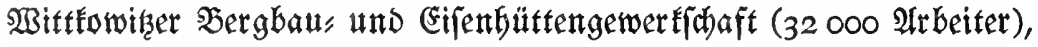

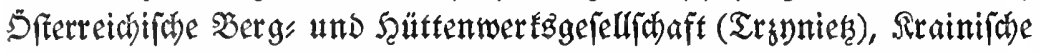

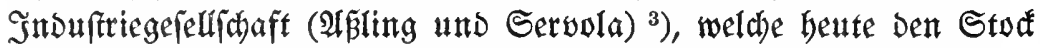

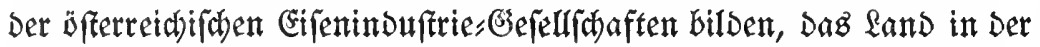

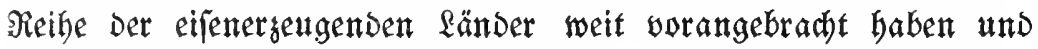
io siemlith Durctireg mit mobernften elettrifhen Anlagen ver" jeben find.

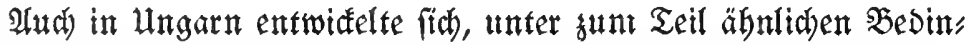

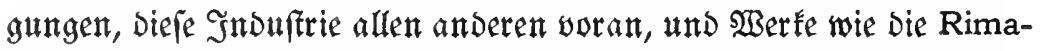
murany Salgotarjani Vasmü R. T. vas és acelgyar Ozd, Die SiBerte

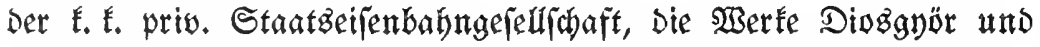
zolyombrezo, bie dem ungarifhen Staate gehören (ber aljo indireft

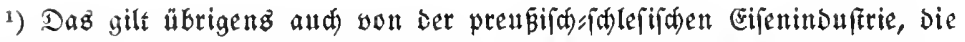
an ibrem Size nur über reidjes Borfommen von Soble berfügt, Eifener aber eins fübren mußs. Da fie fid nid)t nur mit ber Robeifenergengung, fonbern aud mit Der mannigfaden Bereblung befä̧t, blüten die Betriebe uno ergeben fogar eine hähere Disidende als $\%$. . Die wefffälifaten.

2) Bin Bergleich) Deš Erträgniffes Der widstigeren Gefellfdaften ergibt folgendes bill :

\begin{tabular}{|c|c|c|c|}
\hline & & $\begin{array}{l}\text { Angagejablte } \\
\text { Dibibenbe: }\end{array}$ & $\begin{array}{c}\text { Gewinn wom aftien= } \\
\text { Eapital (Tantiemen } \\
\text { und Dividenden): }\end{array}$ \\
\hline Berg: und Şütentwerfe & I9I2 & - & $\mathrm{I} 8,8 \%$ \\
\hline Rimanutany salgos Sarianer & 1912 & - & $22,6^{\circ}{ }_{\circ}^{\prime}$ \\
\hline Alpine Montan & IgII & $21 \%$ & $25 \%$ \\
\hline MIpine Montan & I9I2 & $26 \%$ & $\%$ \\
\hline Prager Eifeninduftrie & $1911 / 12$ & $40 \%$ & $45 \%$ \\
\hline
\end{tabular}

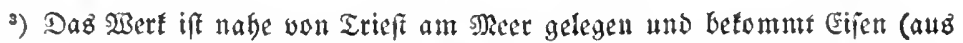
Spanien und 2 lgerien) und Roble (aus England) auf bem sectwege jugeführt (โ. ०.). 


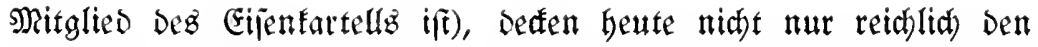
Geimifaen ungarifaen Bebarf, fondern find aud), wie bie ôfers

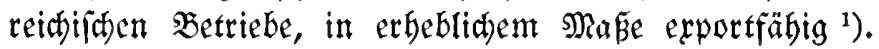

Attch die Eijenwerke Bosniens und Der Serzegowina blühen auf: Das Ëł Eifenwert Zenica, weldjes vorwiegend Stabeijen ergeugt.

Die inländifâe Snduftrie verforgt beute Den gangen beimifach

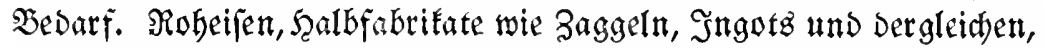
Fertigfabrifate wie Stabeifen, Träger, Schienen, Slecte, Drahtfiften, Drabt uno $\mathfrak{A}$ hnlibes ${ }^{2}$ ) werden in gropen Mengen uno in befter

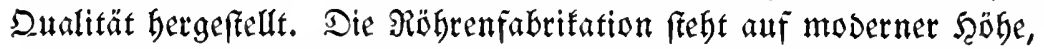

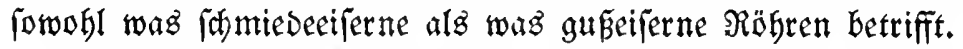

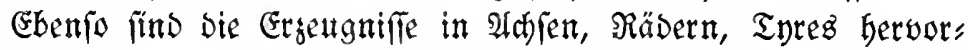
ragend; unter ben Blechen nefmen Feinblecke cinen bedeutenden

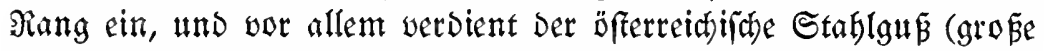

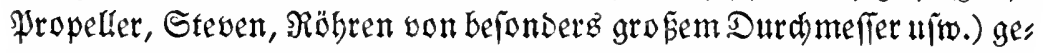

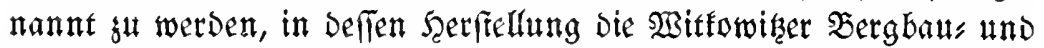

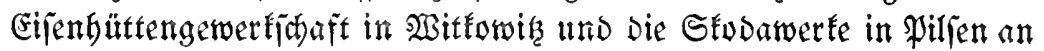
erfer Stelle freben. IIut) die vollfommen moderne Anlage futr Şer: fellung von Pangerplatten im Wittowitzer Eifenwerke ift muftergültig.

\$3ofl bleiben die Produftionzmengen, inzbefondere z. $\mathfrak{b}$. Dez Robeifens, Ginter ienen anberer fänoer uno binter ben Riefenpro, Dutenten, iv Den Bereintgten Staaten, Englans uno Deutfdland, ferner binter Frantreidy uno Rußlano gutrïf; aber immerfin Fann bic Monardyie mit ifrer Stelle als fechjtgrößjtez Robeifen erzengendez

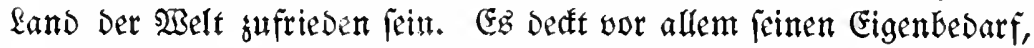
und nur fïr Gjteß̧ereten reicht itt guten Beiten die Selbfterzeugung

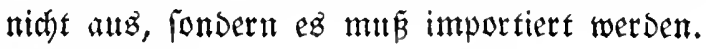

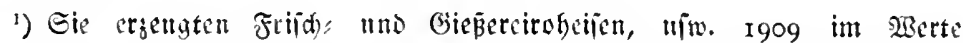
von faft 43 Sillienen Sronen. Iluf Die Rimamutanyer entfallen von ber

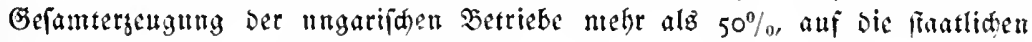
rund ein $\mathfrak{B i e r t e l .}$

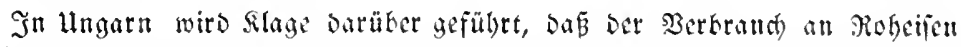

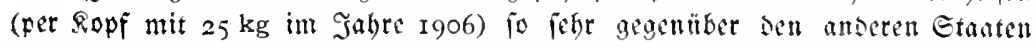

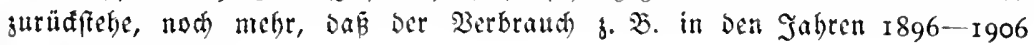
unverändert blicb.

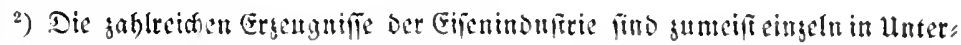

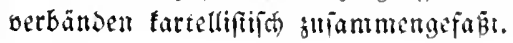


Die ittländifhe Eifeninduftrie fann im Export fpesiell nach Dem Drient und nad Stalien erfolgretd) mit Dem Anglande fonfurrieren.

Die Erzengung von Majajinen bat mit Den wom Eijenfartell bes frimmten Materialpreifen und Dem bejđhäntten Sonfumm ${ }^{1}$ ) zu tämpfen.

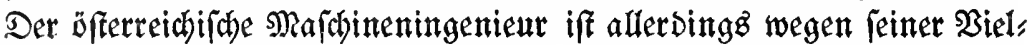

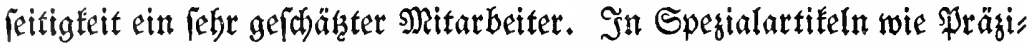

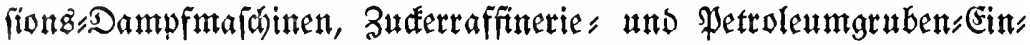

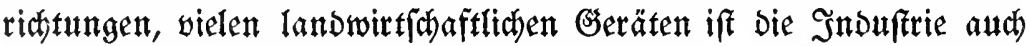
exportfäbig. Die hobe ted)nijhe Entwidtung Des Sofomotiven und Waggonbaues Darf ebenfalls nicht unerwähnt bleiben. (Der $\mathfrak{A}$ şafur

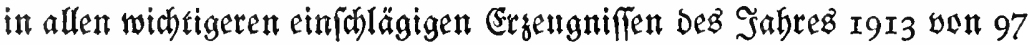

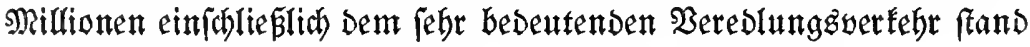
allerbings eine (sinfubr von 155 Miflionen gegenüber.)

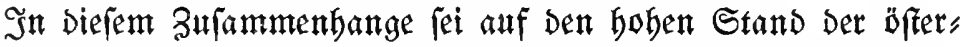

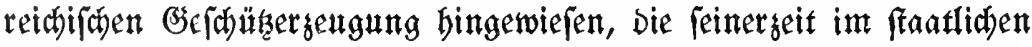
Betriebe bie beritbmten Udbatubłanonen aus Stablbronge - eine öfterreichifhe Spegialität - ergeugte und nummebr burch bie $30,5 \mathrm{~cm}$ Mörier und bie $42 \mathrm{~cm}=5$ faubizen Der Stodawerke (bie im Frieden ro 000 Itrbetter beldäftigen) netterlich befonders berüfmt wourbe. Sie, bie grofe Waffenfabrif in Stenr (bie Erzenger Des Mannlicher" Gewebres) fowie die Patronens und Muntionsfabrifen betreiben einen grö̈en Export nach allen Teilen Der $23 e l t$.

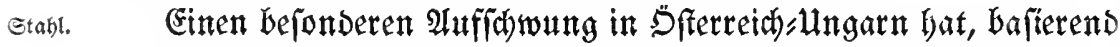
auf uraltem Şandwerfabetrieb, bie Stablergeugung genommen, die im Jahre I9I3 äber 2,6 Millionten Tonnen lieferte. Die Snduftrie

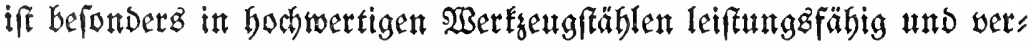
fügt über eitten grổen Export nach Dentfdaland, England and Den Bereinigten Staaten. Sonft feien nod) als weltbefannte öfterreichifáe Irtitel Emailgefritrr, Senfen und Sidjeln genannt.

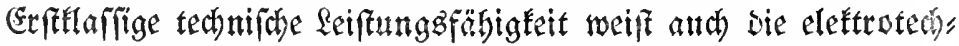

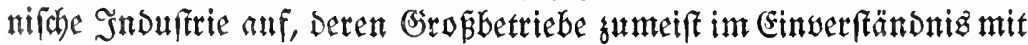
Den reidjobeutichen Ulnternérmungen gegrändet wurden, mit Denen fie

1) Der Sionfum Der Mafdineninduffrie in Dfferteid) (1902) uno in Ungarn (1899) Warafterifiert (iid wogl am beften ourd ben $\mathfrak{B}$ ergleid an worbandenen

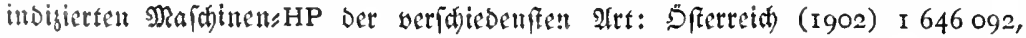
Ungarn (i 899) 262070 , zufammen I 908 I62 gegenüber Deutfd)land 3357000 (1895), \& Millionen (1907); beibez obme elettrifhe Motoren. 
in einer $\mathfrak{A r t}$ geiftiger Union $\mathfrak{B e r e i n b a r u n g e n ~ w e g e n ~ D e r ~}$ Berwertung von Patenten und betreffend Den $\mathfrak{A b}$ fat verfnüpfen. Sie fiehen auds

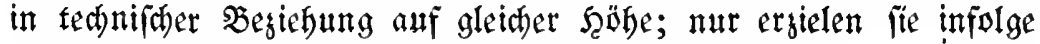

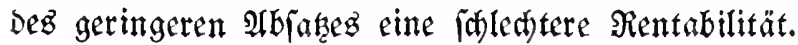

(Finen bejonderen Rang auf Dem Gebiete Der Majhinenergengung nimmt in Ulngarn Giang \& Eo. ein.

Da won Der Şoljwerwertung idjon in anderem Zulammentange (bei Der Forftrirtfataft) Die Rede war, fet hier Die holginduftrie mit igren

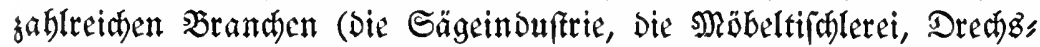
lerei, Böttherei, die Erfaugung von Fournteren, Parfetten uiro.)

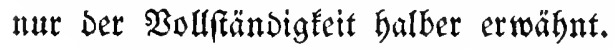

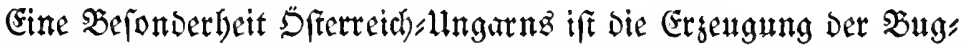
holgmöbel, die ğl einem WBeltartifel geworden find. Sie hängt won Dem $\mathfrak{O}$ orbandenjein bichter Iungwäloer von Rotbuche ab, beren Stämme fitch) für Das Biegeverfahren bejonders eignen. Die forg: fältige bearbeitung und \$olitur fomie Die gute Sonftruftion firjern Den Erzeugniffen felbft vor Den billigen amerifanifoen Mnflenerzeug: niffen weitgehenden 2 orgug. Der Export in Bugholzmöbeln belief (ith) r9r3 allf rund 22 Millionen Sironen.

Beachtung verdient, Daß trok der ftarf and vielfältig entwidfelten

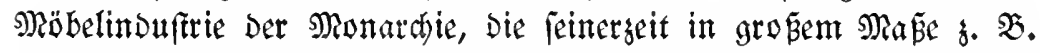
auch nach Deutjhland erportierte, nummebr Das Deutjhe Reich in fteigendem $\mathfrak{R a} \tilde{\beta} e$ Gebrautb)

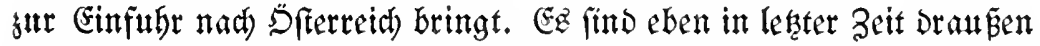

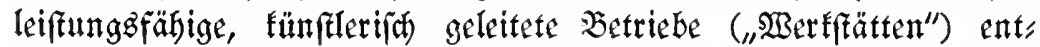

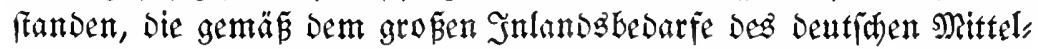
frundez Möbel in febr gefälliger form uno in gutem, modernem,

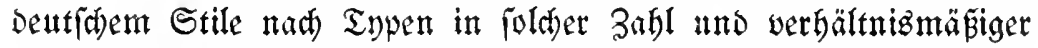
billig ergengen, baż fie - banf ber gropinduftriellen Drganifation -

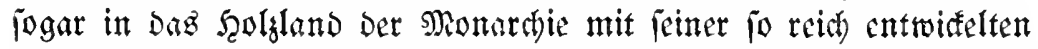

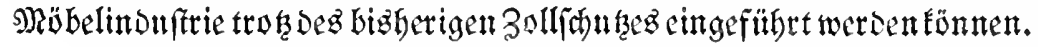

Die Sederimbuftrie Der Monardie verfügt in reidem Mǘ über bie widtigften Rof

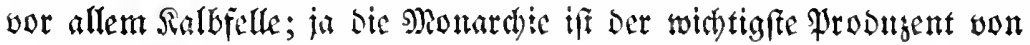

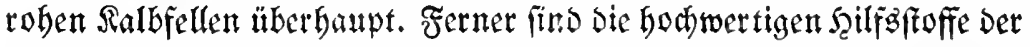

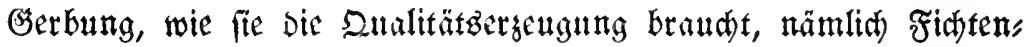

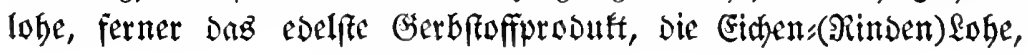


befonderg reidhlith vorbanden. Şiergu fommen Dann nod) die ungari,

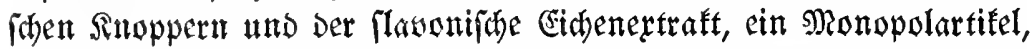

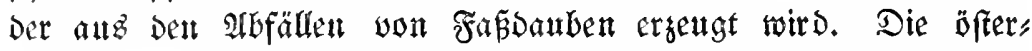

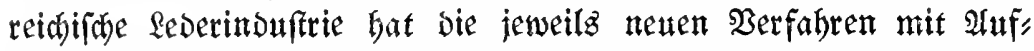
merfamkeit verfolgt und redtzeitig Stubien angeftellt ober bie Gins fïbrung aufgenommen (fo fatt ber birubengerbung jene in ber Flotte ober $\mathfrak{B e r f e n f}$, aud Die einfadye und fombinierte Ebromgerbing), ja

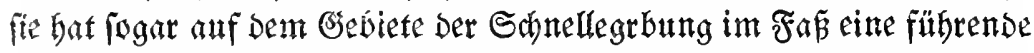
Rolle erworben. Diejes Derfabren, bas mit Inwendung won farten Extraften und Daber bejonders raft) arbeitet, bringt ein Erzengniś won febr bohem ipesifijhen Gerwidht, allerbings won geringerer Sualität auf Den Marta.

Trotz Diefer Bemühungen und trok des retalichen Rohmaterials Gat bie Rederinduftrie, die eite alte und auperorbentlid verbreitete Induftrie ift, nut binftithtlith ber Ergengung von Soblleber eine grobe

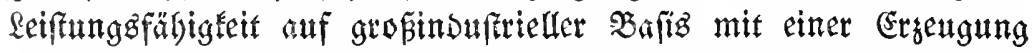

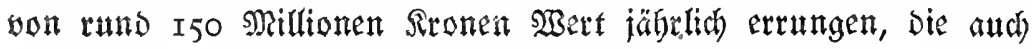
rand ein Duantum won Io Mirlionen Sronen, und fwar nad) Den Balfanftaten, exportiert.

Die Ergengung von Dberleder Dagegen, bie meit überwiegend auf Der 2 erwertung von Ralbfellen bertht, ift nitht, wie man ans nebmen follte, ein Nonopol Sfferretchs, fondern Deutichlanbs getworden.

Esz gelang auf biefem Gebiete in Deutifhland einigen, allerdings wenigen Setrieben, Die Erzengung auf groß̈induftrieller $\mathfrak{B}$ afis anfón

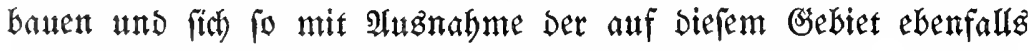

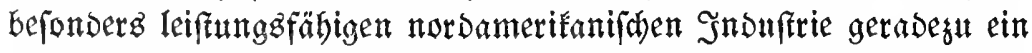
Weltmonopol fat fithern. Der Betrieb auf befonders groper $\mathfrak{B a f t}$

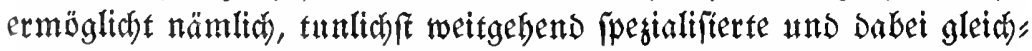
artige Sortimente aus Den Maffen Dez ?ohproduftes gul fdaffen uno

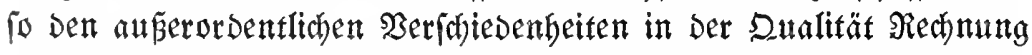
fut tragen, bie dem tierifach Produft anbaftet. Mit Dem reidbaltigen, gleichartigen Sortiment bängt aber Der leid)tere Ilbfą tnd Die beffere Rentabilität zulammen.

Durch Diefe umftände haben sie Deutfalen Setriebe einen Eaum

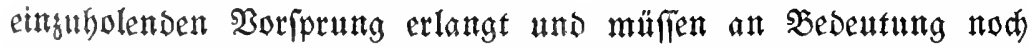

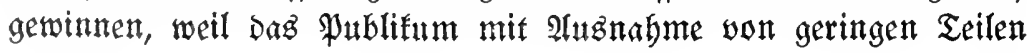




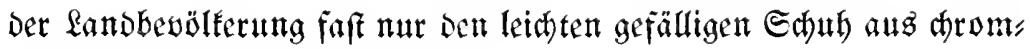
gegerbtem Dberleder verlangt.

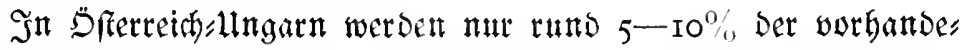
men Ralbjelle werarbettet.

Şerworbebung verbient and Des gro als in Deutfaland verarbeitet werden, und Dás namentlity Die qualis tatio fo hochftebende jübamerifanifore uno jübafrifanifoche şaut (in Dfterreids

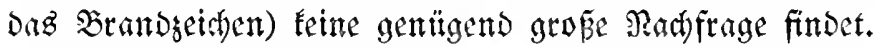

2atá) Die (Ergeugung won Balanterieledern hat faft fat Gänge Dentfaland Durth feine Fabrifen an Rgein und Main an fid gezogen.

Mährend vou Den verarbeitenben Induftrien bejonderz bie Ers zengung ies Damengalanteriefdihes eine $23 i e n e r$ Spegialität won

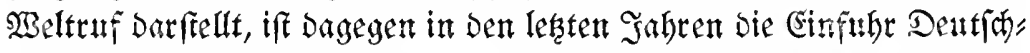
lands in Strajentichuben mit 24 Millionen Sironet rajher geftiegen

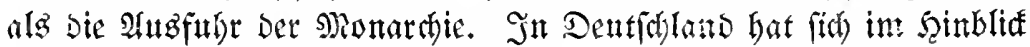

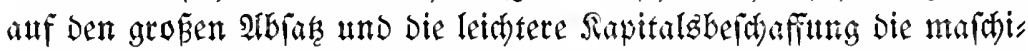
nelle (Frzengung eben früber tnd rafher als in Sfterretd entwidelt

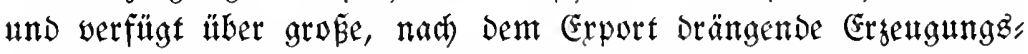

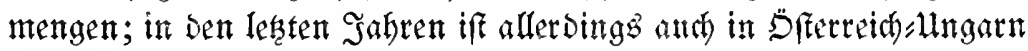
trok - oder vielleid)t gerabe wegen - Dez ungenügenden Zollez eine Reife höd)ft modern eingerid)teter, leiftungżähiger Eduhfabrifen entftanden.

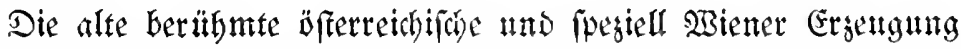
won Sebergalanteriemaren, Die frark won Der Serliner (bejonders itt

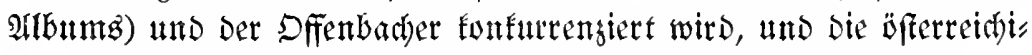

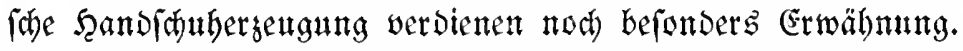

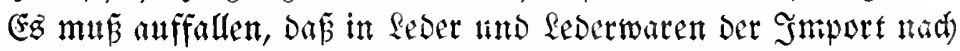
S̈ftertetch uno bejonders jenter Dentfolanos ber Jahre I909 bis I9I3

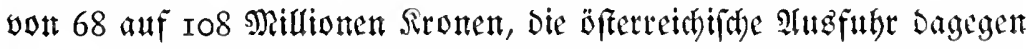
nur von 66 anf 90 Sillionen fiteg (llnteridsted 40 gegentiber 24 Millionen).

Unter Den fablreidfen Zweigen Des induftrellen Grob̈betriebez

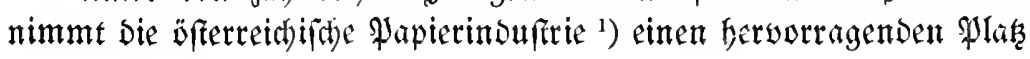




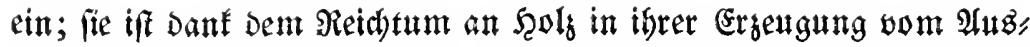

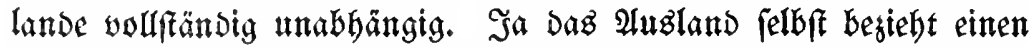
groben Teil fetnes $\mathfrak{B e d a r f z}$ an Rohftoff autz Der Monard)ie.

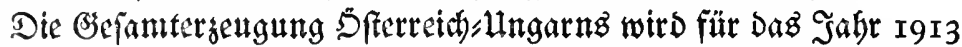

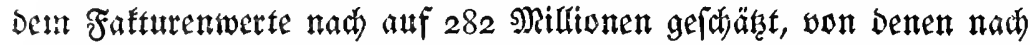

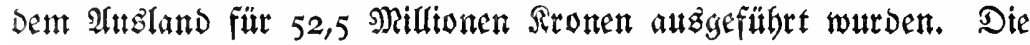
Sapievinduftrie befräfftigte I908 rund 4I 000 Seamte und 2 trbetter

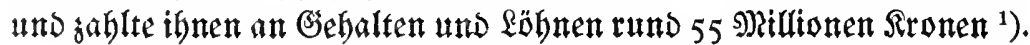

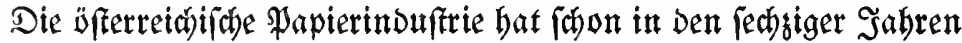

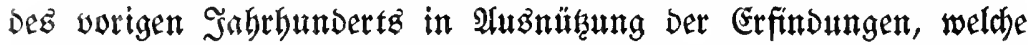

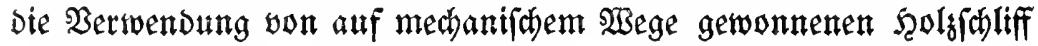
uno won chemifty erzengter Belluloje ermöglichten, eine beachtens;

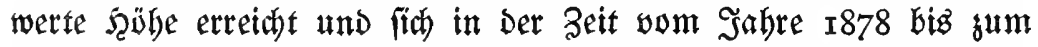
Sabre 1907 Der Ergengungsimenge nach veroreifadt. Dies tif um io mebr anguerfenten, als ja bie Papierinouftrie in engem sulammen,

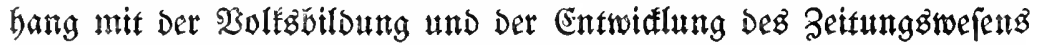

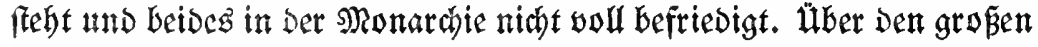
Wrojentfas an Mrnalphabeten in Der Monarhie und Den Mangel eines

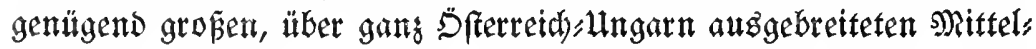

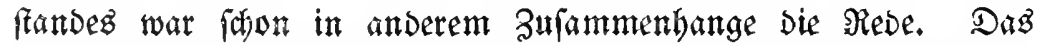

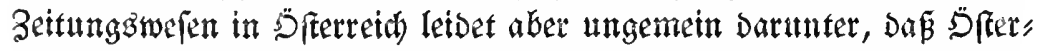

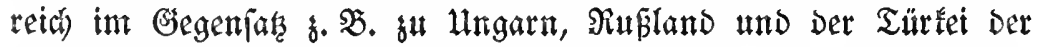
eingige elropäif

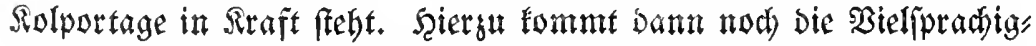

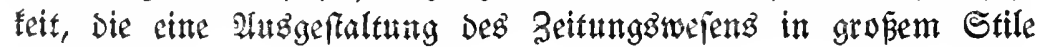
ericivert ${ }^{2}$ ).

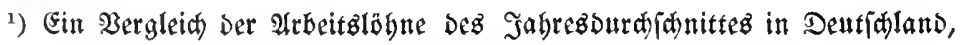
D̈ferreich un Ungarn ergibt folgendeg $\mathfrak{B}$ illo:

\begin{tabular}{|c|c|c|c|c|}
\hline & \multicolumn{2}{|c|}{ Deutialand } & Diferreids & Ungarn \\
\hline r900 & MR. 666,15 & K $800,-$ & & \\
\hline 1908 & ME. 840,20 & K roo8,- & $\mathrm{K} 770,-$ & \\
\hline I9I2 & MA. 981,88 & $\mathrm{~K} I \mathrm{I} 28,-$ & K $880,-$ & $\mathrm{K} 920-$ \\
\hline
\end{tabular}

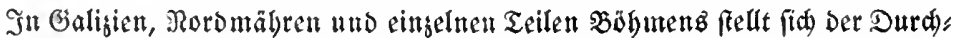

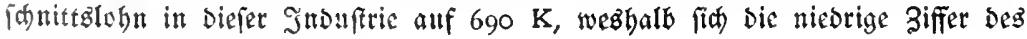

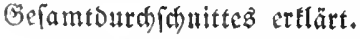

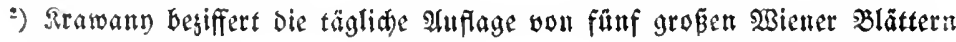




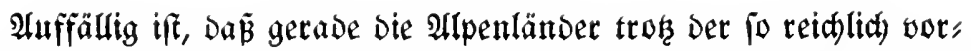
handenen $\mathfrak{B a ̈ l b e r ~ u n d ~} \mathfrak{B a f f e r t r a ̈ f t e , ~ D e n ~ w i d ) t i g f t e n ~} \mathfrak{B o r b e b i n g u n g e n ~}$ für bie Papierinduftrie, nur eine geringe ̧ałl von Setrieben Der in Rede frebenden $\mathfrak{A} \mathfrak{n}$ aufwetien.

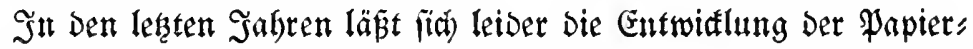
induftrie, wie aus der nachftehenden Tabelle und bejonders aus bem Bergleid) mit Deutfalland hervorgebt, nidht fo günftig an, wie man

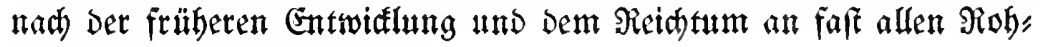
materialien erwarten mäste.

\begin{tabular}{|c|c|c|c|c|c|c|}
\hline & \multicolumn{3}{|c|}{ Dfterteins ungarn } & \multicolumn{3}{|c|}{ Dentialand } \\
\hline & \multicolumn{2}{|c|}{ Ersettgungṡmenge } & \multirow{2}{*}{$\begin{array}{c}3 \mathfrak{m} \\
\mathfrak{w a d} \mathfrak{z}\end{array}$} & \multicolumn{2}{|c|}{ Erzeugungżmenge } & \multirow{2}{*}{ 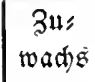 } \\
\hline & 1907 & I9I3 & & I906 & I9I2. & \\
\hline \multirow{4}{*}{ 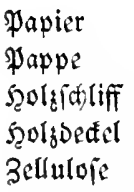 } & $3716360 \mathrm{q}$ & 4279 I $47 \mathrm{q}$ & I $5, I \%$ & I2 $632500 \mathrm{q}$ & I6 II 4 I $3 \mathrm{q}$ & $27,5 \%$ \\
\hline & $269330 \mathrm{q}$ & $501523 \mathrm{q}$ & $86,2^{\circ} \%$ & I $794300 \mathrm{q}$ & 3695 I27 q & $106 \%$ \\
\hline & & & & & & \\
\hline & $4702350 \mathrm{q}$ & $5727855 \mathrm{q}$ & $22 \%$ & $10320600 \mathrm{q}$ & $17000000 \mathrm{q}$ & $64,7 \%$ \\
\hline jufammen & $8688040 \mathrm{q}$ & $0508525 q$ & $20 \%$ & $24747400 \mathrm{q}$ & $37000000 \mathrm{q}$ & $50^{\circ}$ \\
\hline
\end{tabular}

Die öfterreid)i(já)

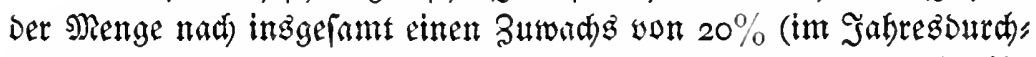

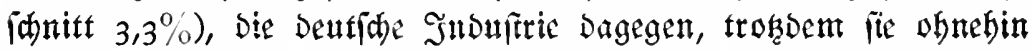

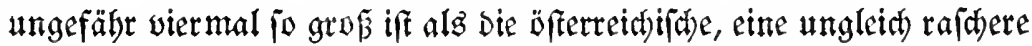

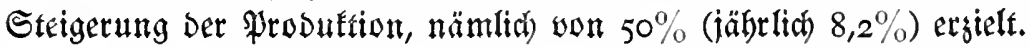

im Sabre I9I5 mit 366200 gegenẗber 397400 Exemplaren im Jabre I 908

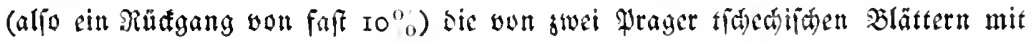
I 90000 gegenüber 125000 . Dic fünf gröpten Bubapefter Blätter baben Dagegen cine Tagezanflage you 936500 , alfo von faft ciner Million, faft steimal fovid

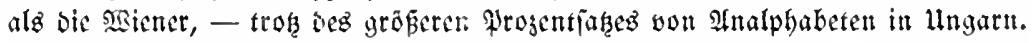
Da liegen bic Borteile Der Solportage in materieller Begielung - ob fie nid):

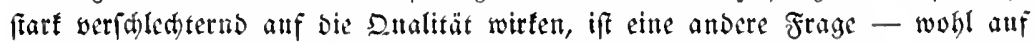

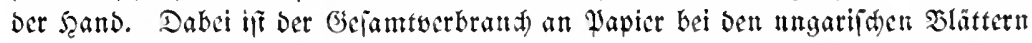

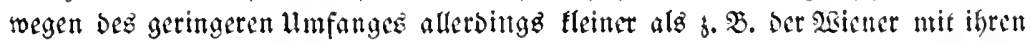

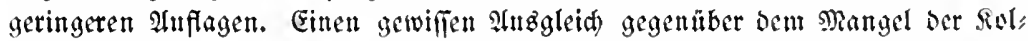
portage bietet in Dfferreid) Das weit umfangreidere Jnjeratenge(d)äft, Das wieber

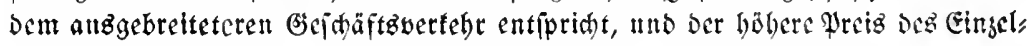
blatter.

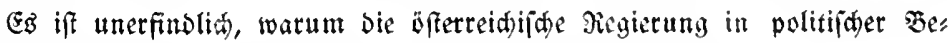
biebung frenger uns vorithtiger fein mus als bie ungarifhe. 


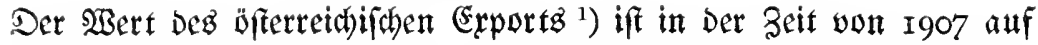
I9I3 von 55000000 auf 52000000 Rronen gefallen. (Der Menge nad) trat eime Steigerung won $12 \%$ ein.) IInferdem weifen bie bent" fonen 2 ftiengefellidaften Der Papterfabrifation eine um ungefäbr $3 \%$

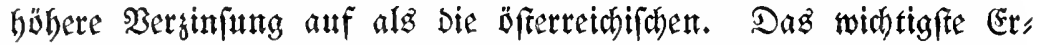
fowernis Der Enfwidtung ift vor allem Der geringe Bedarf, Der auf

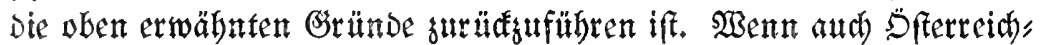
Ungarn unter Den 37 für Die \$apierergengung in Befrad tommenden Staaten an fiebenter Stelfe febt, fo ftellte fidh Der Papierverbrauth per Sopf im Sabre I9I3 in England anf 27,6 , in Sdweden anf 23,7 , in Norwegen auf 22,3, in Deutfhland auf 21,3 , in Dfterreich auf II,5

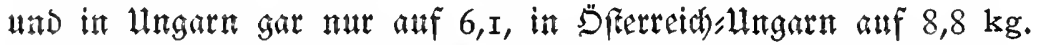

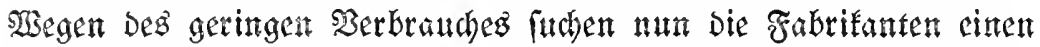

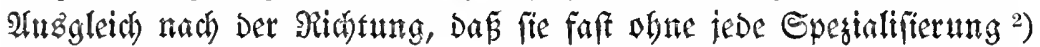

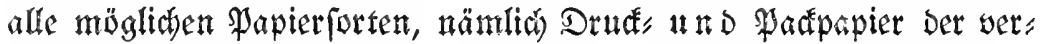
frjtedenen Sorten forwie \$appe, erzengen. Der häufige Sisedjel ver" tewert natürlich die \$roduktion. Şn Fommergieller Begiegung soird getlagt, Dấ unter Den Firmen Feinerlei Srganifation betreffend Den Ahbah beftebe; als ein günftiges Moment if bagegen aufer Dem

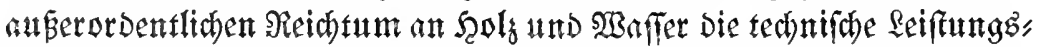
fäbigkeit zu bezeidnen, wobei Die gute Dattität Der Ware aud nod

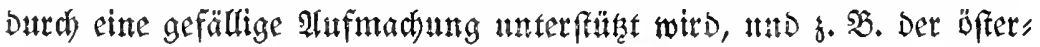
reiraifon Marke im Drient aus diefen Girunden vielfach fogar bei Heinen nadreiligen Sreigunteridieden Den Vorzug wor ber Son" furreng fingert.

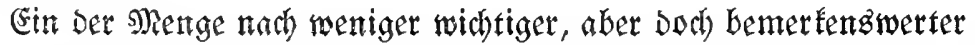
öferreidifiner Spegtalartitel ift Das Bigarettenpapier.

1) I9I3 cxportierte Deutaland in Papier allein 2,5 Millionen Bentner, Dfterciolulngarn mur 608000 q, alio cin Birtel.

2) Die ins Ricenbafte fich entwidelnbe amerifanifore grosultion, bie fitt

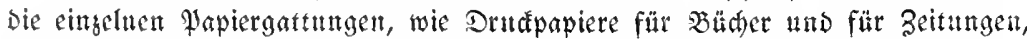

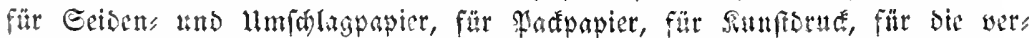

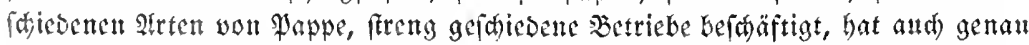
geregelte, fïr jeben eimgelnen Urtifel beftimmte llfancen und bettachtet als Mindel: quantum für normale 2 fufträge DaB Gewid) von eitter englifacn 20 me $(907 \mathrm{~kg}$ ),

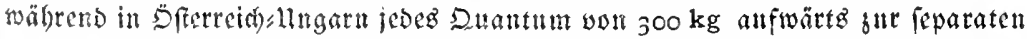
Erzengung übernommen wird. Die Imterifaner j̈brtreffen an Epesialifierung fogar bie deuffere und englifate Jituftrie. 


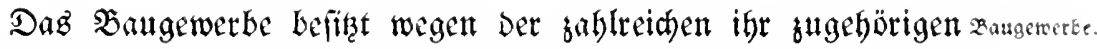

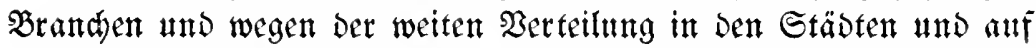
bem fladen Eande jowie wegen bes 3tiammentanges mit ber induftri, elfen Sonjuntur hervorragende Bedeutung in Der Dolfzwirtidaft jedes Staateb. Zu ben Bangewerben zählen rund 30 veridhiedene Bran, cín, unter Denen die Banmeifter, Tifd)ler, Shloffer und Zimmerleute

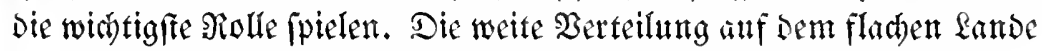
bängt mit Der berüffithtigung Der lotalen Sroduttion in Zement, Zies

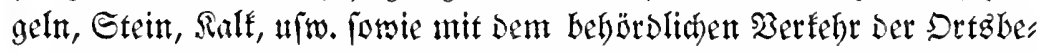

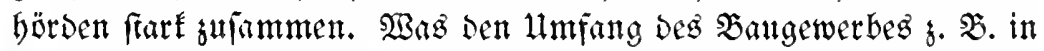

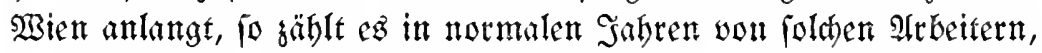
Die anf Dem baute felbft befdäftigt fitto, rund 300000 , welde 3 abl bei gufen Ronjuntuturen bis auf 400000 unb Darüber fetgt.

Betreffeno oen 3ufammenbang mit Der inoufriellen Sonjunftur

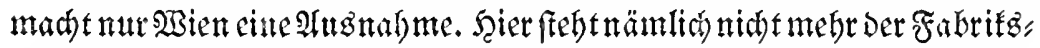

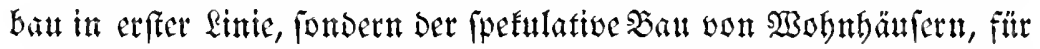

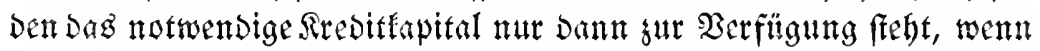

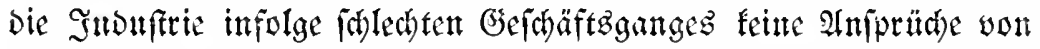
Sedentung an bie Geldquellen bez andeg fellt. Sn 2 Sien folgt alfo

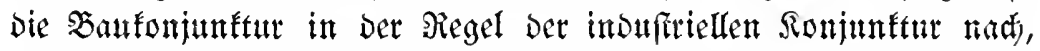

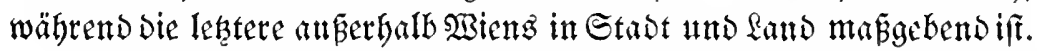

Die Snouftrie flagt febr

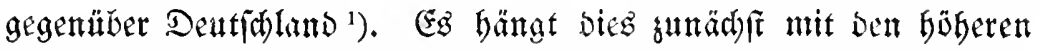
Preifen dez Eifenfarteúls gufammen, weld)es für Tä̈ger und Etab" eifen für Den Metergentner in Sronen im 2 ergleid) mit berlin folgende Preife verlattgt ${ }^{2}$ ):

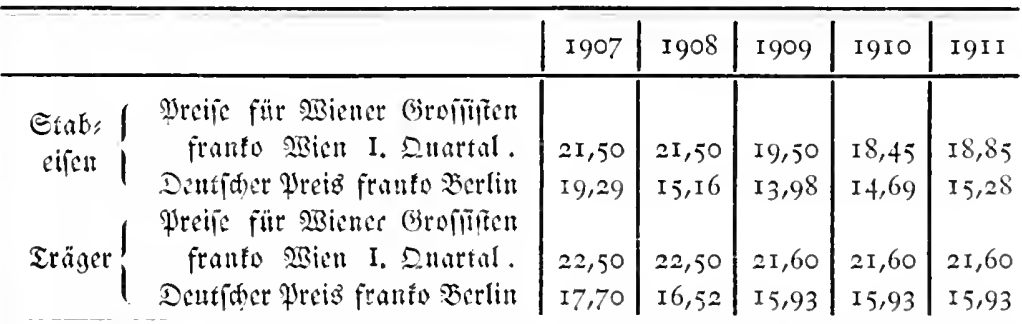

1) Ein Unternebmen ließ in Deutichlano uno Sferecids Den gleiden Fabrits"

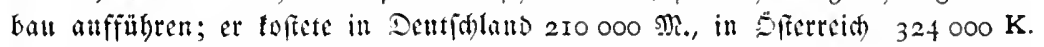

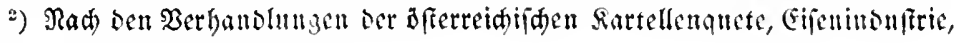
Inni I9I2, Eeite 46I, 465. 
Der zoll wird vom Eifentartell zwar nicht woll auzgenüht, aber Die Differen Diefer beiden widftigen Maffenartifel per Bentner von runo $2 \frac{1}{4}$ biỏ $3 \frac{1}{2}$ Sironen bei Stabeifen und von rund $4 \frac{1}{2}$ biz $5 \frac{1}{2}$ Rromen bei Trägern fällt natürlid nidyt unbedentend inz Esendidt.

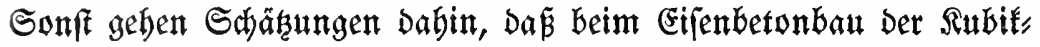

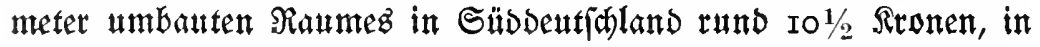
Snneröfterreid aber I4\% Sironen Fofte. Fin Bergleid Der Biegels preife per Taufend loco Baufelle ergibt folgende Unterichiede ${ }^{1}$ ):

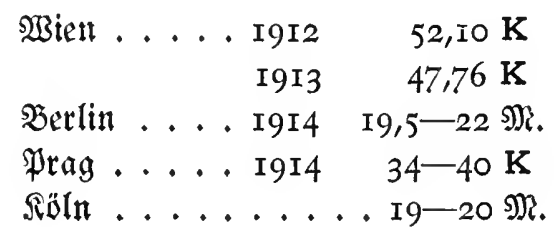

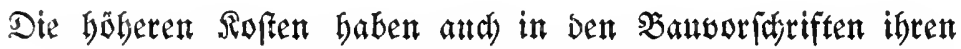
Grund, bie fitenger alz in Dentfaland find, whne bas biez nach Anglage Der Fad)lente motiviert wäre. So werden $z$. $\mathfrak{b}$. in $\mathfrak{E e t o n}$ und Ëifenbeton nur niebrigere Spannungen als in Deutialand geftattet; fratiften Forberungen ber Sebörden, befonders auf bem Gebiete

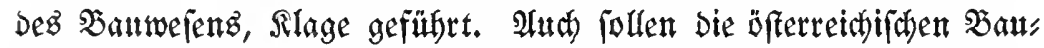
fïmen wentger gut nit mobernen Bebelfen auzgeftattet fein wie

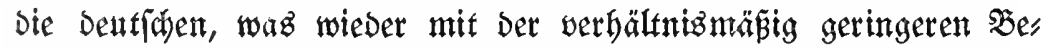

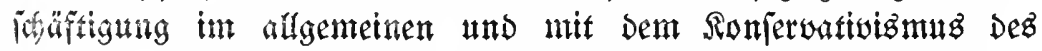
weniger geidhitfen $\mathfrak{B a u h a n d w e r k e r s ~ z u l a m m e n h a ̈ n g t . ~ W a ̈ h t e n d ~ i n ~}$ Sfferreid) eben bie Snonftriefirmen, weldye als Sefteller wornebmen laffen, fid bejonders peinlith äberlegen müffen, wie weit fie angefid)te Der weniger nad)haltigen Roniunfturen mit Erweites

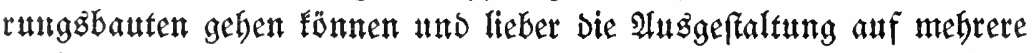
Perioden verteilen, fann man in Deutifhland wegen Der gegenteiligen günftigeten Sad)lage weithergiger vorgehen. $\mathfrak{A} \mathfrak{a z}$ Der Darauz für bie Bauinduftrieunternebnungen fich ergebenden reibhaltigeren $\mathfrak{B}$

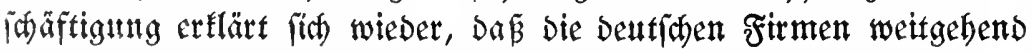
mit Typen für Die Banführung arEeiten, waz entiprechend birriger tommt. E\& feflt aljo fogar bier an genügend weitgebender Spes

1) Radi Dem Rompás I9I5 II. $\mathfrak{B D}$. 


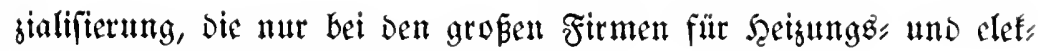
trifase ŜIffallationen eingetretent iff.

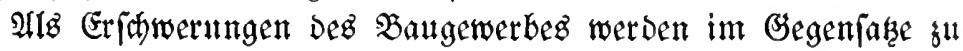

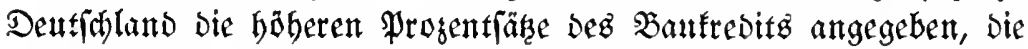
mit normal ro-I2\% begeidynet werden, für Daż ungünftige Jaht r 913 aber s. $\mathfrak{3}$. mit $18-20 \%$.

Şervorbebung verbient bie weitgebende bejtaftigung won reidg:

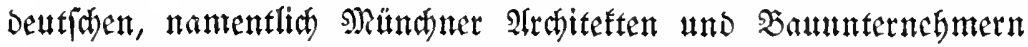

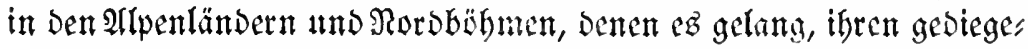

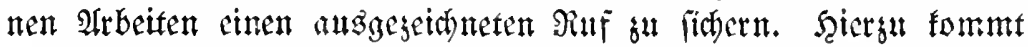

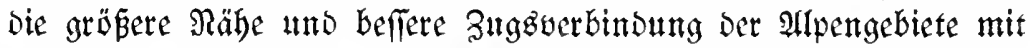

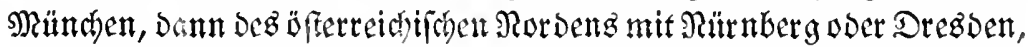

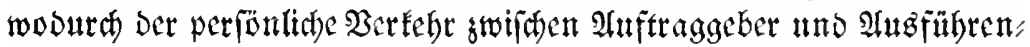

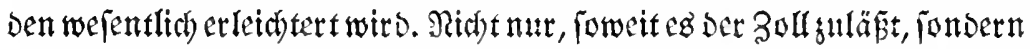

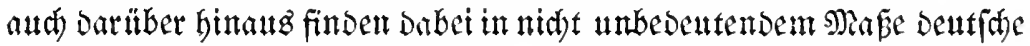

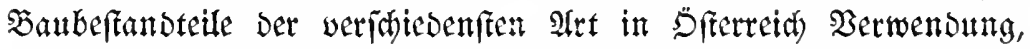

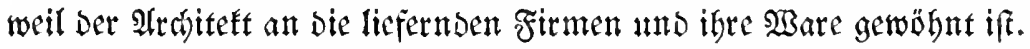

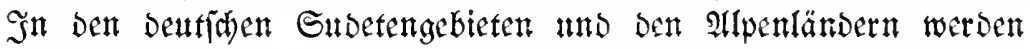

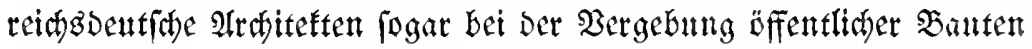

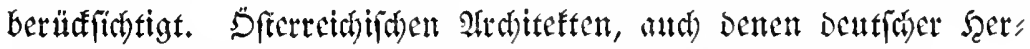

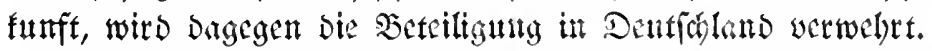

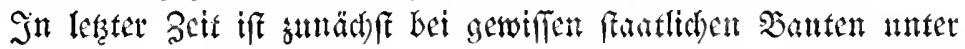

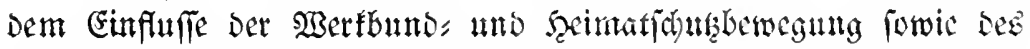
Deutf

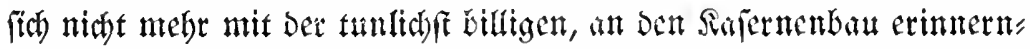

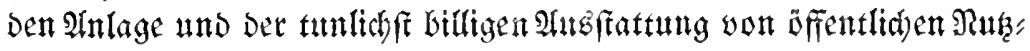
bauten begnägt, fondern unter Fübrung bes 2atbeitenminifertums

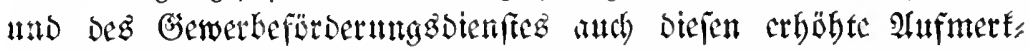

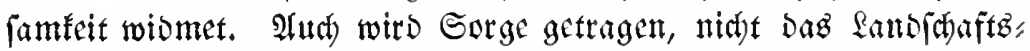

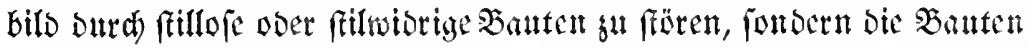

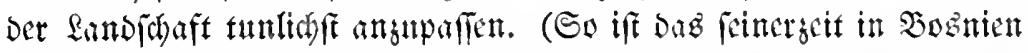

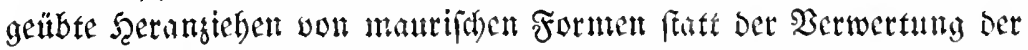

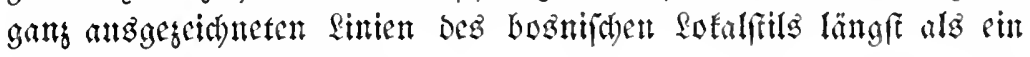
(G) werer Febler ertantrt.)

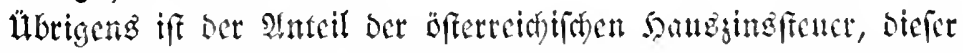

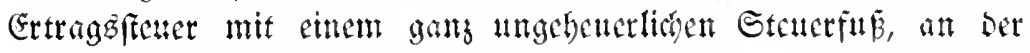
kahmlegung bez sfferteidfif 


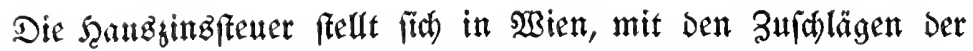

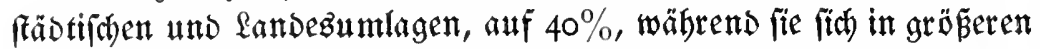

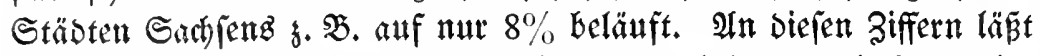

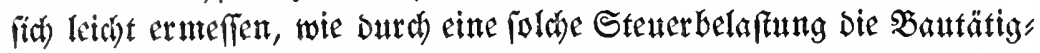

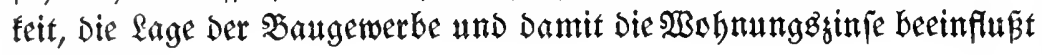
werben ${ }^{1}$ ).

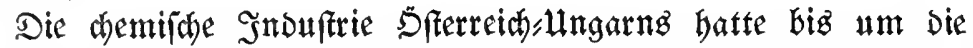

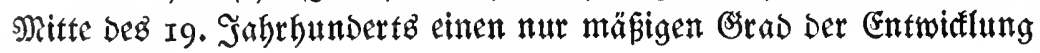
aufgutueifen.

(Frft Durch Die (Finführung anderwärtz bereitz mit Erfolg Durchs gefübrter $\mathfrak{B e r w o l f o m m}$ mungen und $\mathfrak{B e r b e f f e r u n g e n ~ w o n ~}$ Berfabres arten ift in Den leşten Dezennien eine anjegnlidhe Steigerung Der

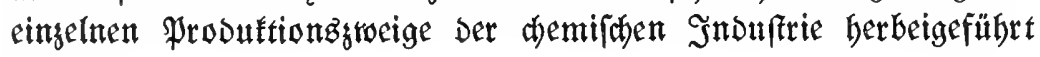
worden.

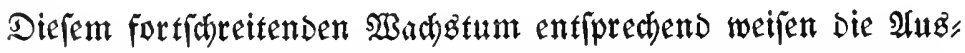

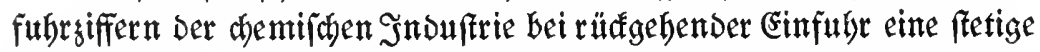
Steigerung auf (G̈efamtaubfutbr I9I3 über 58 Millionen Rronen).

Die Entwiłlung Der eingelmen 3neige ber chemifhen Snduftrie

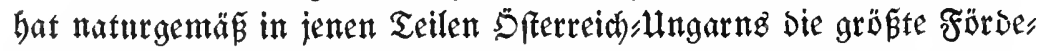
rung erfabren, wo die an Drt und Stelle worfommenden Robprodufte Die Gründung beftimmter Snduftrien von vornberein lufratis ers (cheinen liesen, ober wo günftige Eifenbahnoerbindungen ober vors

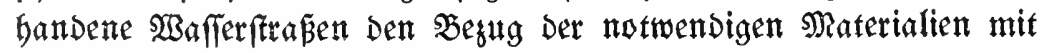
geringen Roften ermöglidyten.

So Gat bie bedentende Sobainduftrie Der Monarthie eine Pro"

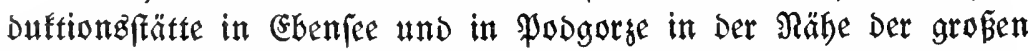
Salgbergmerte in futavac (Bognien), wo die Sole in einer $14 \mathrm{~km}$

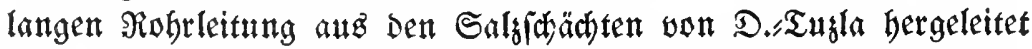

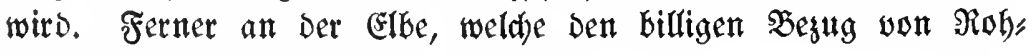
materialien aus Dentichland geftattet.

Reben Der bereitż genannten Soda befä̈t fïh) Die öfterretchijade

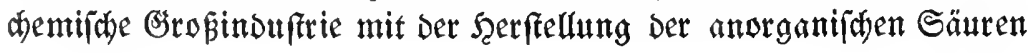

1) Inbangzweife fei bemert, Daßj fid) einez ber größten Biegelwerte ber

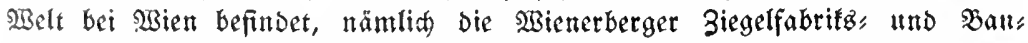

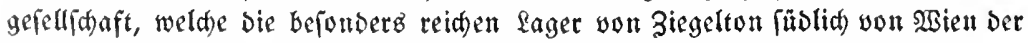
Berwertung zuführt. Dab şietter Biegelfartell ergengt in guten Sabren ratb 300 Millionen Ziegel. 
wie Satwefeliäure, Salpeter, und Salzläure, ber Erzengung von

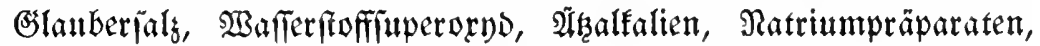

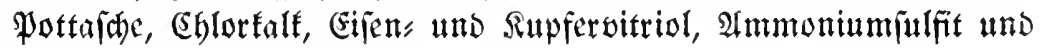
f(d) wefelfantent $\mathfrak{A m m o n i a f .}$

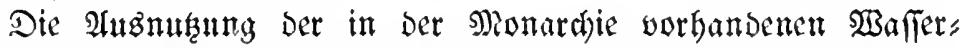
fräfte bat bie Entwidtung Der Ergengung von $\mathfrak{A}$ luminium, Sarbo:

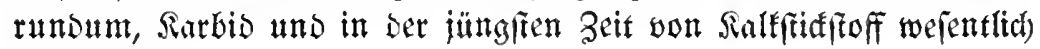
geförbert.

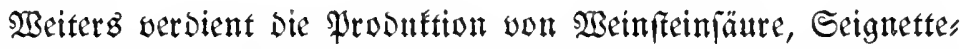
uno Sintlaugenjal Erwähnung, ebenjo die von Farben uno faten,

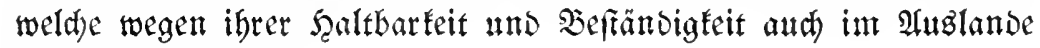
$\mathfrak{A n e r k e n n u n g ~ f i n d e n . ~}$

Die bei Der Petroleumraffination fin ergebenden Zwifanen probufte und Rübftände find Gegenftand einer intenfiven Berarbei, tung, bie fich worğthģweife auf bie Gewinnung von Gafolin, Sigroin, Blan und Treiböl, die verichiedenen Eorten von

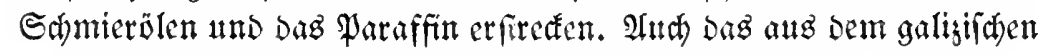
Erowatys gewonnene Berefin gehört in Diefe Gruppe.

Die Erzengnifle Der Fettwarenimbuftrie, wie Matgarin, Elait Margarinbutter und ijamals fowie bie Pflanjenfette verbienen Er" wäbnung. Aluci) bie Ergengung von Eeifen, Serzen und Toilette"

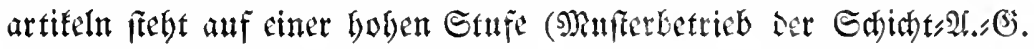

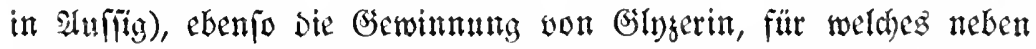
anderen Berwendunggatten in Der leşten Zeit ein erböhter Bebarf bet ber Serftellung won Sprengitufien beftebt. Zut Serftellung von

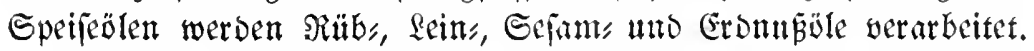

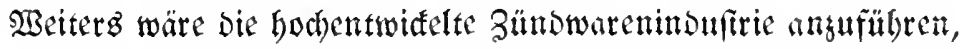

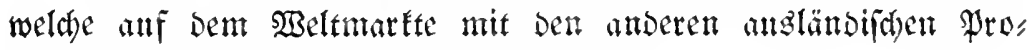
veniengen erfolgreid) in $\mathfrak{B e t t b e t w e r b}$ tritt.

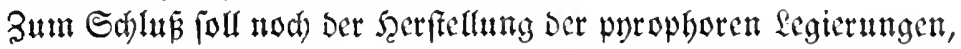
namentlict) Des Bereijeng, gebatht werben, weld)eg als Zündfein bei Den Tafdenfeuergungen ausgebreitete $\mathfrak{B e r w e n d u n g ~ g e f u n d e n ~ b a t , ~ u n d ~}$ Der aus Sfterretd bervorgegangenen Serftellung von Präparaten für

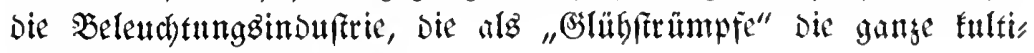
vierte Grbe erobert gaben.

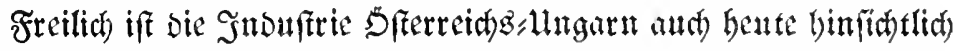
Der Ergengung won fänftliten Furbftoffen und Farbenpräparaten vor, 


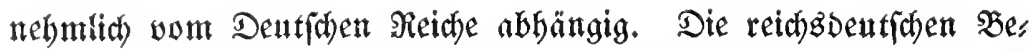

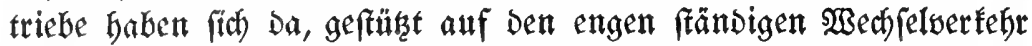

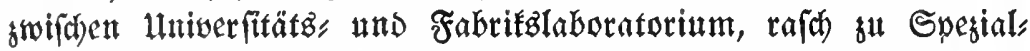
betrieben Der 23 eltproduftion entwiffelt, Die alle fur Fabrifation

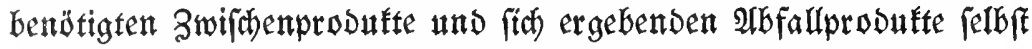
ober in unmittelbar angeffiloffenen $\mathfrak{F a b r i f e n}$ werarbeitent.

Das geringere Angebot an wiffenifafaftlithen Mitarbeitern, Die

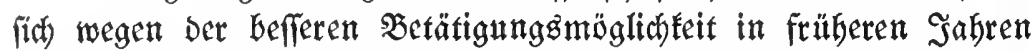
lieber nad Dentfaland gerwendet Gaben und nodi Gente namentlich in ber Farbeninduftrie Gersorragende leitende Stellutngen ein

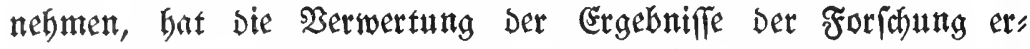

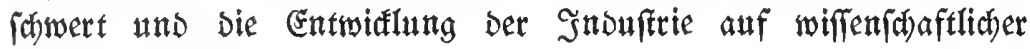
Bafiz vergägert.

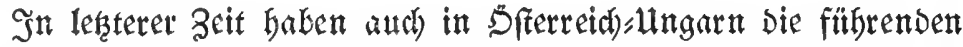

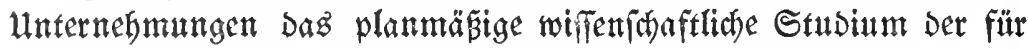

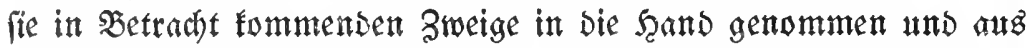
eigenen Mitteln Dazu beigetragen, Daz Gebiet Der wifien

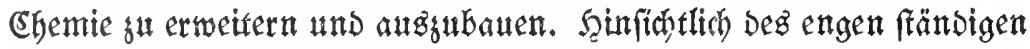

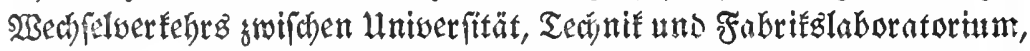

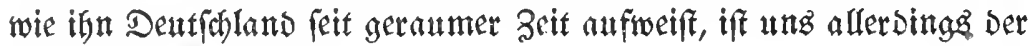
Reitgobertifte vorats.

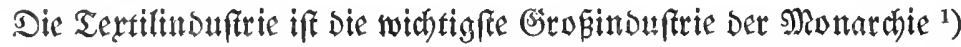
und berubt bet Der Berarbeitung won 230 lle tmo Flath a anf Der

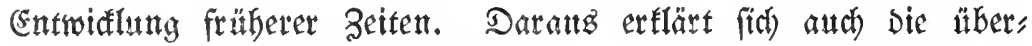

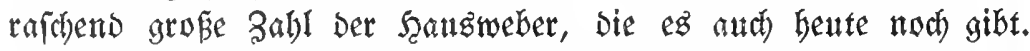
Der naturgemäß groß̉e $\mathfrak{b e d a r f ~ a n ~ T e x t i l i e n ~ G a t ~ b i e ~ E n t w i f t u n g ~ D e r ~}$ induffriellen (Ergengung weitgehend unterftübst, wobei allerdingz atth

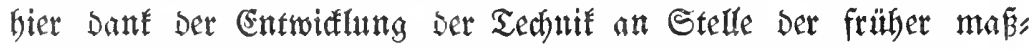

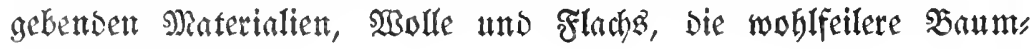
wolle trat.

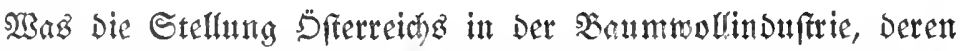

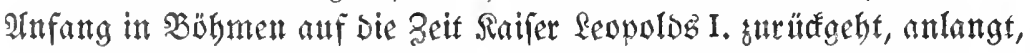

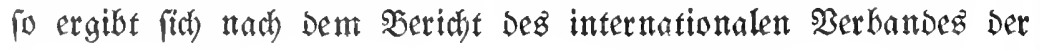

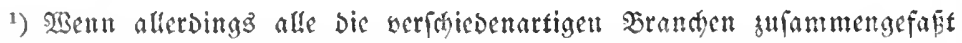
werden, die s!m Sangerwerbe gerechnet werden, erweift fih biefes den Gefants 3iffern แad) a!s a!tzaebreiteter. 
Banmwollpinner und Weber für bie Beit vom I. September I9I I biz fum 3I. 2\{uguft I9г3 folgendez:

\begin{tabular}{|c|c|c|c|c|}
\hline & \multicolumn{2}{|c|}{ 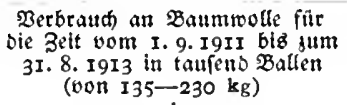 } & \multicolumn{2}{|c|}{ 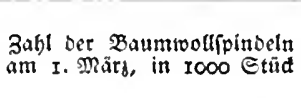 } \\
\hline & I9I I/I 2 & $1912 / 13$ & 1912 & I9I 4 \\
\hline Grogbritannien ...... & 3765 & 3825 & 55165 & 55972 \\
\hline 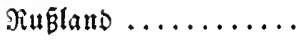 & 2035 & I 942 & 8800 & 8950 \\
\hline Dentfaland......... & I 770 & I 580 & 10599 & II 405 \\
\hline Frantreich .......... & 988 & 987 & 7400 & 7400 \\
\hline Sfterreid sllngarn..... & 864 & 837 & 4718 & $494 \mathrm{I}$ \\
\hline Jtalien ............. & $8 I_{3}$ & 744 & 4622 & 4600 \\
\hline
\end{tabular}

Die Spindeln Der Monardie gebören faft jur Şälfte Firmen, die zunädjf für ben bebarf ifrer eigenen Webereien uno bergleiden arbeiten, babei aber Den Bebarf ifrer Finalbetriebe Durdauz nidht

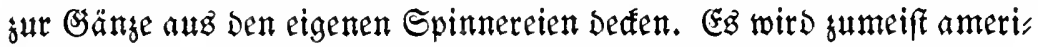
fanifthe uno oftindijhe, aber auth ägyptifate Baumwolle verarbeitet.

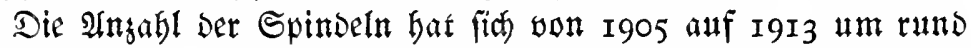

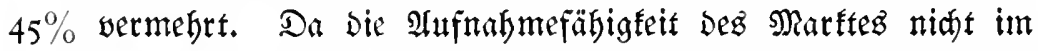

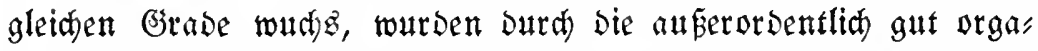
nifierte Epinnerbereinignng wieberbolt gan wejentlicte Einjarän" fungen Der (Ergeugung Durchgeführi, gleid)seitig Der Erport organifiert.

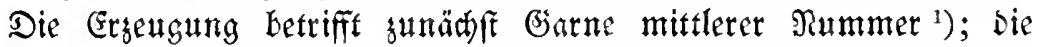
Dualität wird Danf Den modernen Setriebzanlagen alz faft surat) wegs etwas höher als jene ser reutichen ober engliften Gane frebeno begeichnet.

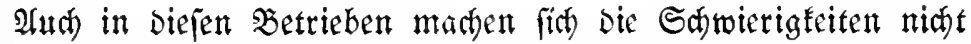
genügender Spezialifierung geltenb, da in Spterreids gerabe infolge

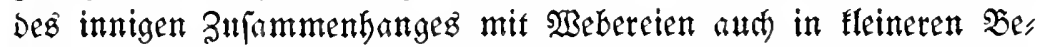

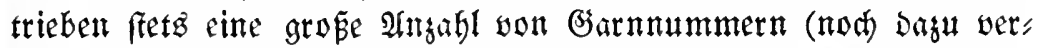
ífiedener Dualifät) Gergeftellt wird, wäbrend fïh) bie Erzeugung Der eingelnen Betriebe in Englano befantlid) nur auf wenige Pammern

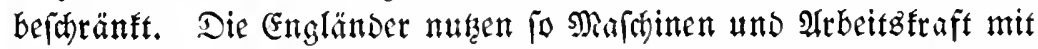

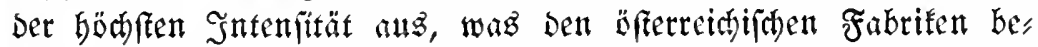
Deuteno wentiger möglid iff. Şiergu fommt als weiteres (Erjetwernis

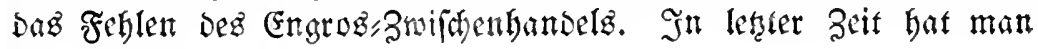

1) Die ungarifde Epinnerci ergeugt banptiänlidh bie Rumern I4-24.

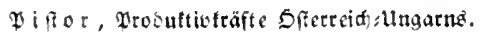




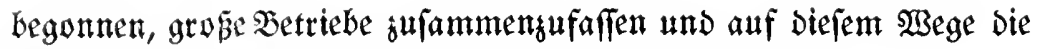
Errzengunggbebingungen fu regeln und zu verbeffern.

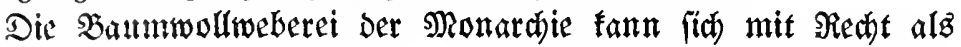
roibetici.

eine Dualitätżinduftrie bełeichnen. Illem Intahein nach bängt bier Die höberwertige Radjfrage aud in Den weiten Schidhten Der $\mathfrak{b e}$

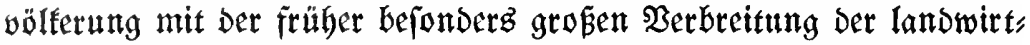
(d)aftlidyen Seimarbeit und Der Damit verbunbenen Materialtenntniz

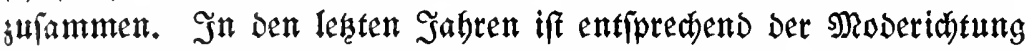

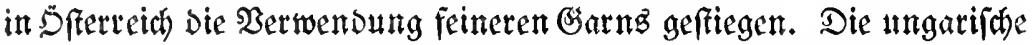
\$eberei ergengt worwiegend gröbere, roh appretierte ober auth uns

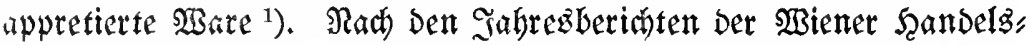

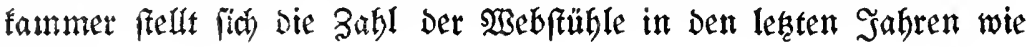
folgt:

$\begin{array}{lrr} & \text { Dfferreid) } & \text { Ulngarn } \\ \text { I9I0 } & \text { I40000 } & 8000 \\ \text { I9II } & \text { I45000 } & 8000 \\ \text { I9I2 } & \text { I55000 } & 9000 \\ \text { I9I3 } & \text { I60000 } & \text { I0 } 000\end{array}$

Den $23 e r t$ Der Ër zeugung Dürfte man auf gegen ein halbe Milliarde

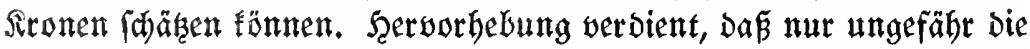
f̧älfte Der Stühle Saumwolle allein verarbeitet, während für bie übrigen aud) nod andere Textilien, wie Wolle, feinen, Seibe, wermendet

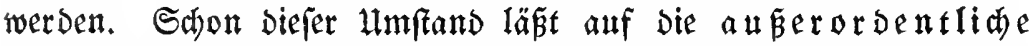

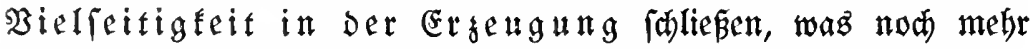

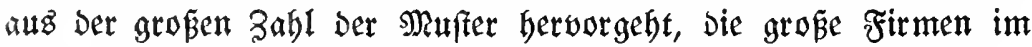

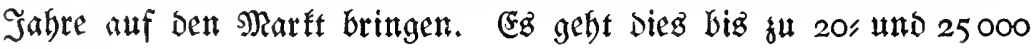
Defiling.

Fine nidht unbedeutende Erfdrerung Deg Gefhäftsbetriebes liegt Darin, Dá bie Fabrifen Den Engroghandel - poweit nicht in Der Rob" weberet Die Manipulanten eingreifen - fämtlid in eigener Regte

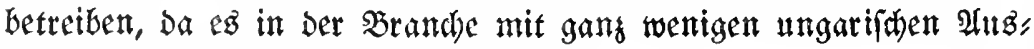
nahmen Engrofititen nicht mebr gibt.

Der Bebarf ift angefidhte Der nationalen, fultutellen, ja audb Det

1) Die ungarijale Spinnerei uno $93 \mathrm{eberei}$ exportiert fu $75-80 \%$ nach

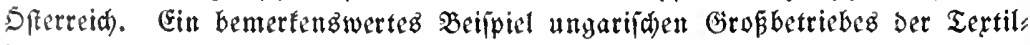
inoufric iff die "Magyar Tertilioar" in Moflabegy (ungarifae Elovatei) mit über 3000 Arbeitern uns einer jährliden Erteugung won 25 Millionen Rronen. 


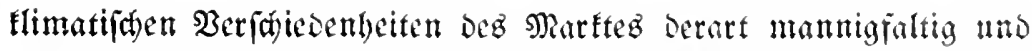
individualiffert, Daß bie Jnouftrie Daz birefte $\mathfrak{A}$ rbeiten mit Den Detailliften vorgiebt. Sie bat baburd allerdings ben widtigen 20 ,

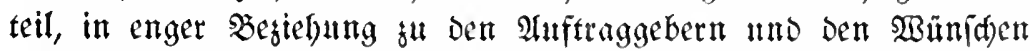

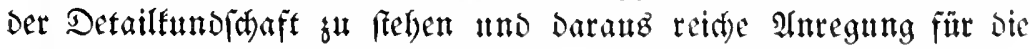
Bemulfetung żu fhöpfen.

Finen Beweiz von Der feifunnggërähigkeit Der Batmmollweberei liefert bie geringe Einfuht, die I9I3 faum $3 \%$ ber inländilchen (Er:

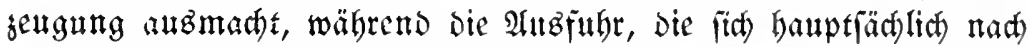
Dem näheren Drient ridftet, gegen 70 Millionen Sronen betrug.

Für bie öfterreidfifthe Stifereitnduftrie in Porarlberg fpielt Der

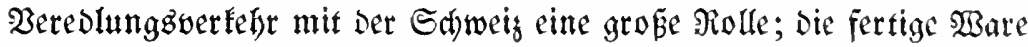

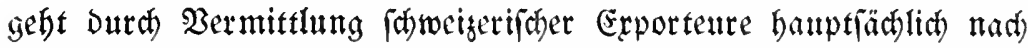
Amerifa. Raum minder bedeutend ift die böhmifhe Stidereimbufrie; ebenjo gentept die bühmijhe Stidereträpheimbufre, die an vielen

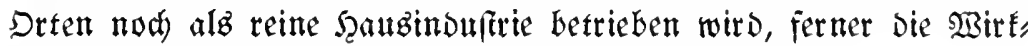
warenimbuftrie und Zengoruterei bered tigteg anjehen.

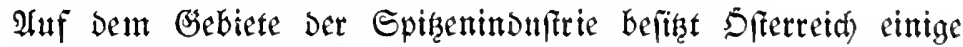
alte und angelebene Fabrifen, weld)e alle Arten won Mafdinempipen erzengen. Sm lez̧ten Sahrzehnt wurde von Staatz wegen ber Seim" arbett, Die bejonderz in Böhmen, Irain und Dalmatien betrieben

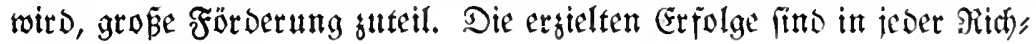
tung befriedigeno.

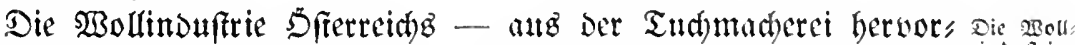
gewadjen - verfügt und Sägerndorf für Modetwaren, in Reid)enberg für glatte Tutbe;

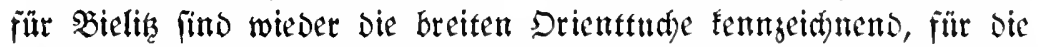

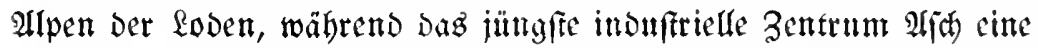

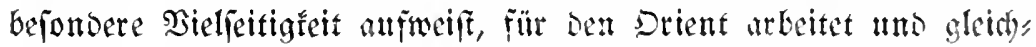

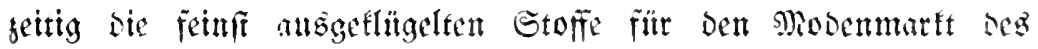
Wefteng liefert.

Die Spinnerei und 23 berei feten infolge bes ungemein jet"

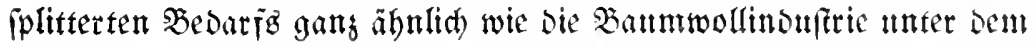
Betchen auberorbentlither Mannigfaltigket, was ants

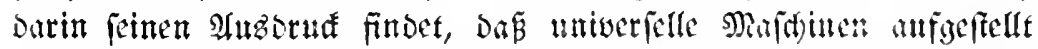
werben mäffen, währeno bag atuslans feiner Betrieb ungleth mebr fpestalifiets. 


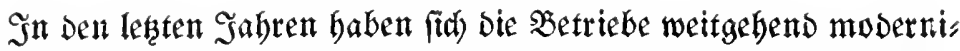

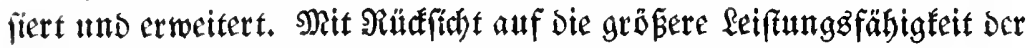

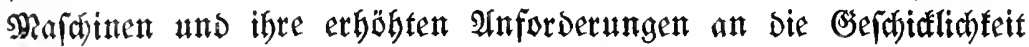

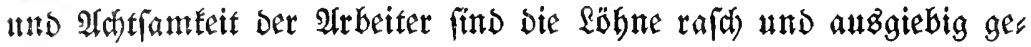
ftiegen - feit I890 am 50\% und mebr ${ }^{1}$ ). Sn vielen Gebbieten und

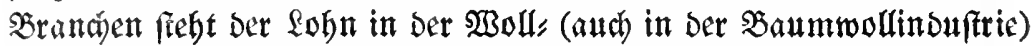

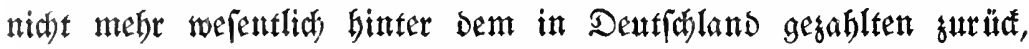

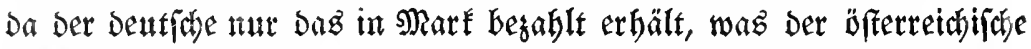
in Sronen befommt. Dafür wird Der Deutfhe artbeter als leiffungs"s

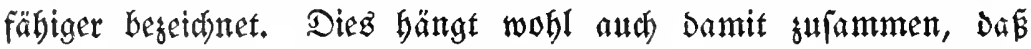

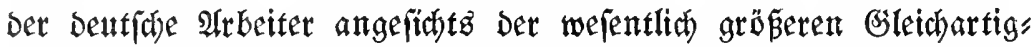
Feit deb Bebarfz länger gleichartig forturbeiten und fith allf bie Irrtitel beffer einfoulen fann.

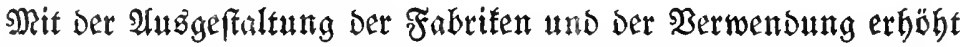

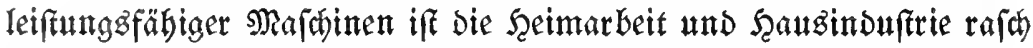

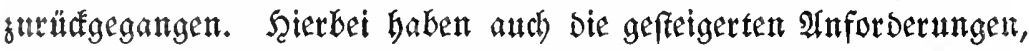

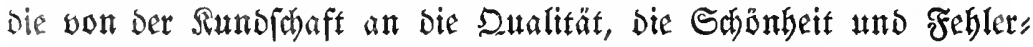
lofigkeit Der Ergengnifle geftelút werben, mitgewirtt.

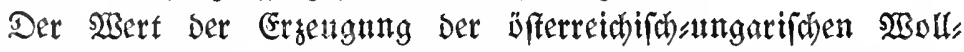
weberei wito won der Brünner Şandelstammer für bas Şabr IgI I

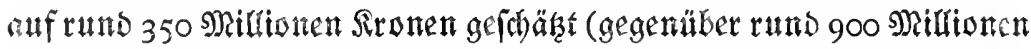

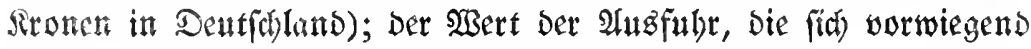
nach Dem balfan und Der Sevante ridftete, besifferte fith I9I2 aui 62 Millionen Sironen, Denen eitte Einfubr von 32 Millionen (vor, roiegend aus (England) gegenüberfitand.

Inth in Der 230 dinduftrie geigt fith biefelbe Erjofeinung wie in

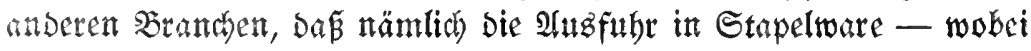

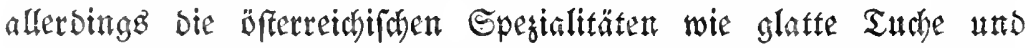

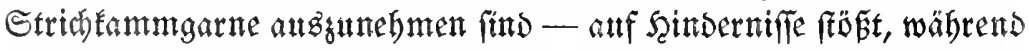
Der Export yon Modewaren, wo Der Sefthmad und nitht die firenge

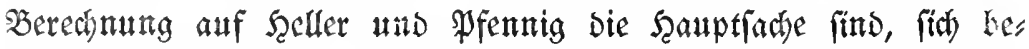

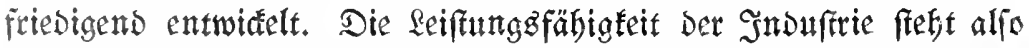
anzer Zroeifel, und nur die hohen Geftehungzłoften (böbere Preife

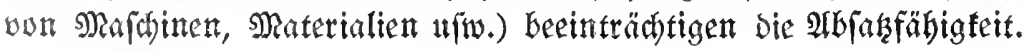

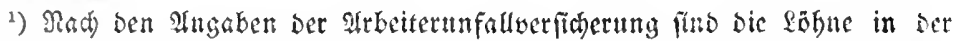

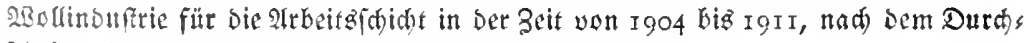
innitte beredinet, won $\mathrm{K}_{2}$, I4 nuf $\mathrm{K} 2,66$ geftiegen. 


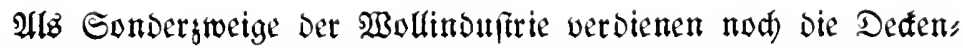
und $\mathfrak{R a ̈ b e l f t o f f i n d u f t r i e , ~ f e r n e r ~ b i e ~ T u ̈ d y e r s , ~ f i l l y ~ u n o ~ T e p p i d j i n d u f t r i e ~}$ bejonderer Gränähnung.

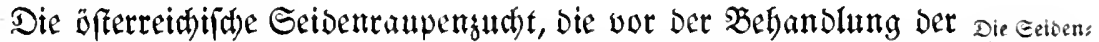

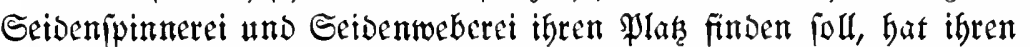
Si⿱⺈ in Säbtitol, im Rältenlande und in Dalmatien, leibet aber wie intuptrie. Die

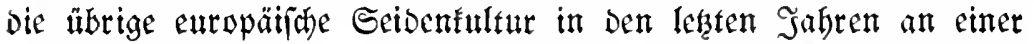
Stagnation. Dura die immer mäatiger werbenbe Sonfureng ber

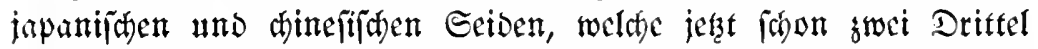
Der gefamten SBeltproduttion angmacten, werliert bie europäija

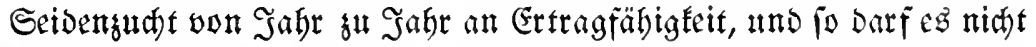

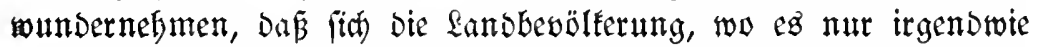
angebt, anderen Sulturen zumendet. Sm Sabre IgI2 wurben in ben

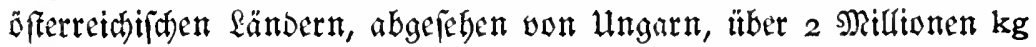
Sofons fabrigiert, welde cinen Wert won faft so Millionen Sironen

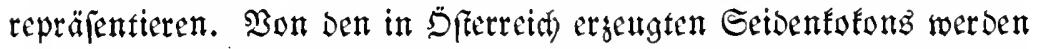
ungefähr $30 \%$ ausgeführt und nur ber Reft wird im Smlande vers iponnen.

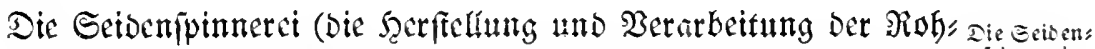

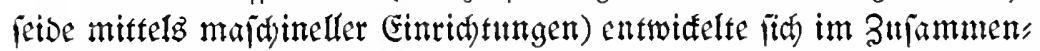
ipinnerei. Gange mit Der Rofonprobuftion in Den fübliden fändern Der Mons

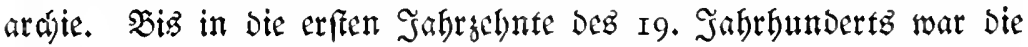

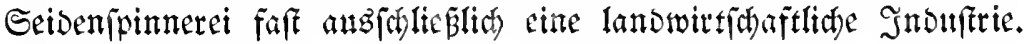

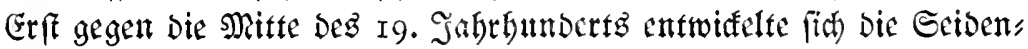

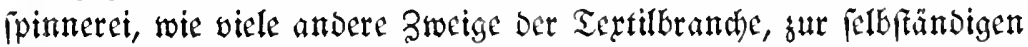

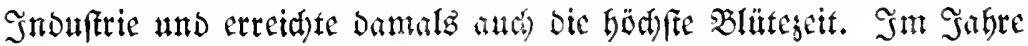

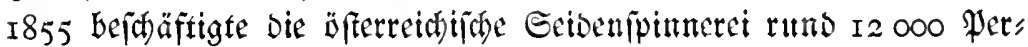
fonen, int Sabre I 870 aber nur mebr 8300 . Dieje Zahl ift fet ther won

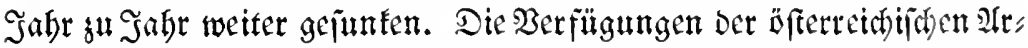

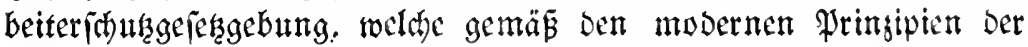

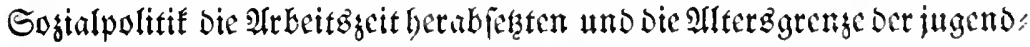

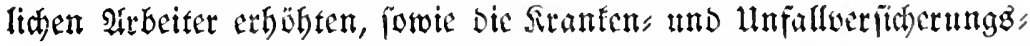

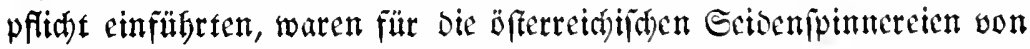

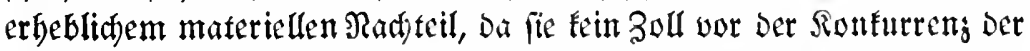

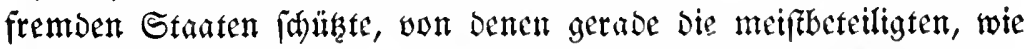

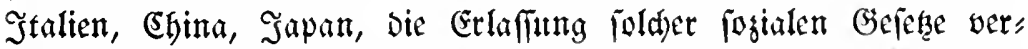
meiben, ferner mit weit tiebrigeren Iöhnen arbeiten als Sfterreta). 


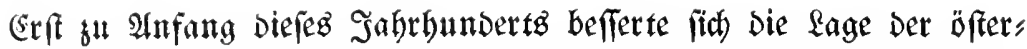
reirfirthen Seidenfpinnerei, alz bie Regierung Dem 2 ntrag Der ver"

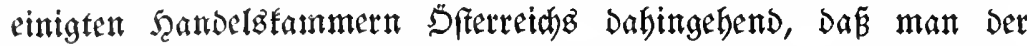

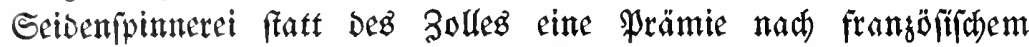
Mutter gewähren follte, ftattgab. Gegenwärtig befteben in Diferreid)

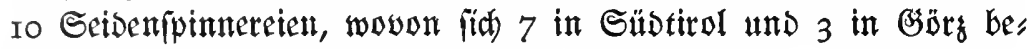

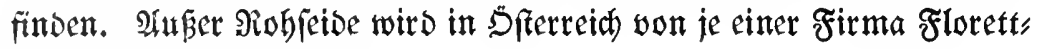
und Sinnffeide ergengt.

Die Setoenweberei war bis in bie fiebriger Safte Deg vorigen

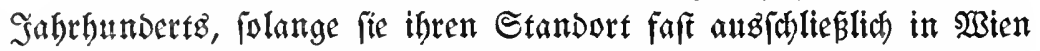
hatte und in - gemäp Den hentigen 2 nj Sitzmaße betrieben wurbe, eitre Derart blïhende Snduftete, Daß der

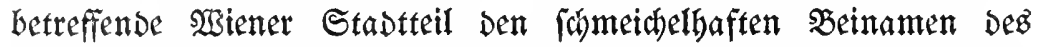
"Sriflantengrundes" gugelegt erbalten hatte. Ulm Das genannte Sabr berum ftrebte nun sie Setbenweberei nad) IHBdebnung, die für fie

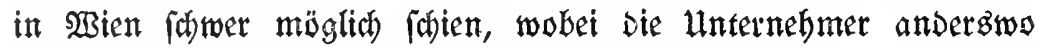

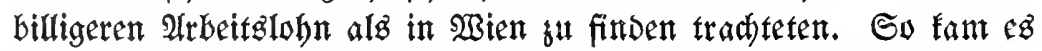
zat einer faft vollfänbigen Dezentralifation ber Seidentinduftrie, die erfit in ben leşten Sabren infofern wieder zufammentütat, als bie

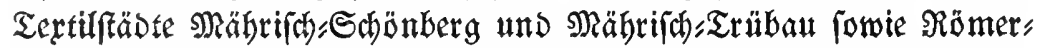
ftabt bei llberjëblungen oder bei Reugrünoung won Betrieben bevor" fugt werden. Die betreffenden Unternebmer hatten bierbet eine

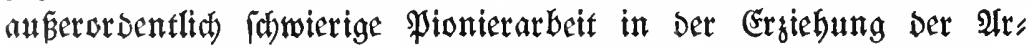
beiterid)aft fu leiften; fie fanden gmar billigere föbne, waz bet ber

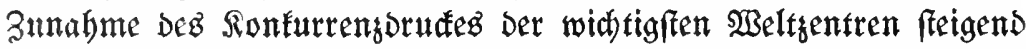
notwendig geworden war, aber die Degentralifation - ju Der

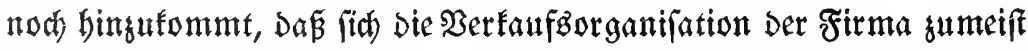
immer nod in Witen befindet - bebeutet gerabe gegenüber bem lons

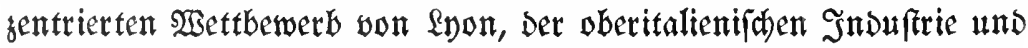
bejonders ber reictsobentichen Sonfurreng, nämlich Sirefelos, einen

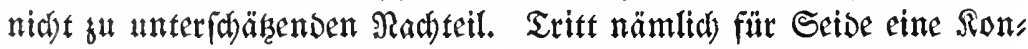
junftur cin, uno follten Daber bebeuteno mehr Arbeiter alz ga gewöhn licher zeit eingeftellt werben, fo feblen fie Den Betrieben, weil es an einem großjen Refervoir an gejd)ulten arbeitern mangelt und

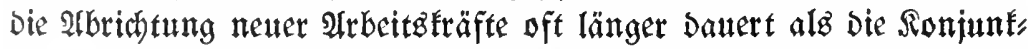
tur. Auch ergänzen fith binfichtlich brr Ronjuntur bie glatten Seiden: fioffe und die Seidenjamte, und die atrbeiter finden baher felbft bei 
getrennter Erjeugung Durd) veriftedene Betriebe jeweils bet anocren Firmen $\mathfrak{B e r w e n d u n g . ~ N u r ~ b i e j e r ~ l l m f t a n o ~ u n o ~ b e r ~ u n g l e i c h ~ g r o ̈ b e r e ~}$ Snlandabjąz fönnen ben ungebeuren $\mathfrak{A}$ trfichwung ber wett jüngeren Srefelder Seidenindufte ertären, wo man anf Grund des Jnland: $\mathfrak{a b j a z e z ~ f a j o n ~ l a n g e ~ a n ~ d i e ~ w e i t g e b e n d e ~ E p e g i a l i f i e r u n g ~ i s h r i t t . ~ E o ~}$ tetlen fith dic Dentfden Firmen im wefentlidien in Erjenger won Sileider, oder Bluten, oder Sirawatten, oder Sdirmftoffen, von

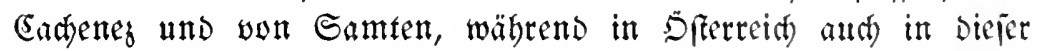
Brand)e (mit geringen Iftsnabmen für Srawattenftoffe) faft jeber Betrieb alle Artikel ber mobernen Seibentmbufricerjeugt, ferter fowohl in batto wie in Salbjetoenwaren. Şicră fommt, sab

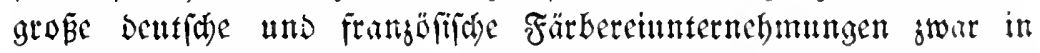
DFferreid) etnen mobernen Brobbetrieb eingerid)tet baben, ier bie

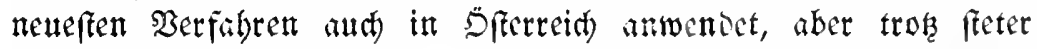
Fortfaritte in manchen Epejialifäten bod crfolget(ber in ben Miutter" betrieben arbeitet.

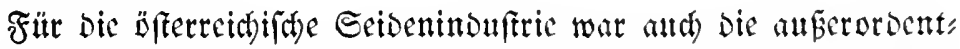

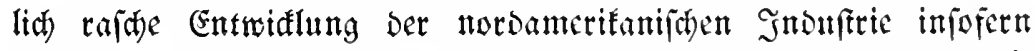

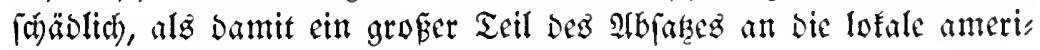
fantifhe Eraengung abgegeben werden mußte.

Der Wert ber Gejamtproduftion won Seibenwaren in Sperreid beträgt ungefähr roo Millionen Sronen, fo Dá̉ Sfterreid) unter Den Şanptfaaten Der Seideninduftere gegenwärtig bie fiebente Stelle cinnimmt, Da eg won Den Bereinigten Staaten von Amerifa, Frant"

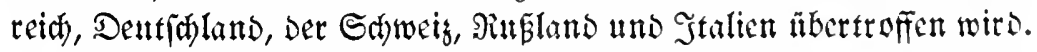

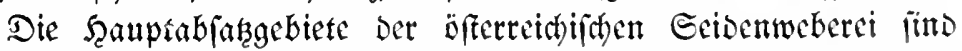

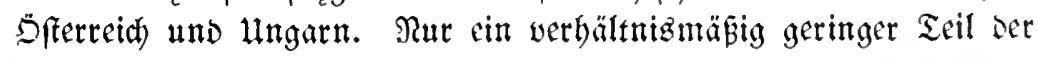

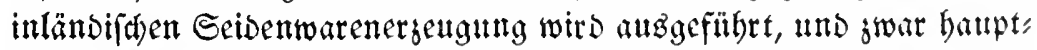
(äblta) Sirawattenfoffe und andere äbnlidge Ergettgnifle, bei weldent

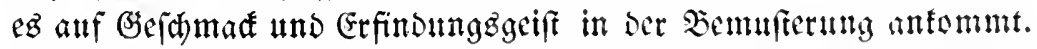
Dem Gejamterport im Jabre I9r2 von 16 Milltonen Sronch fians cint

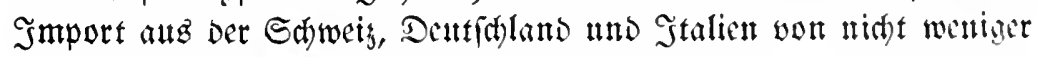
alg 53 Miflionen Siromen gegentiber.

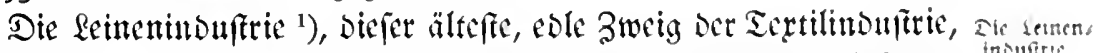

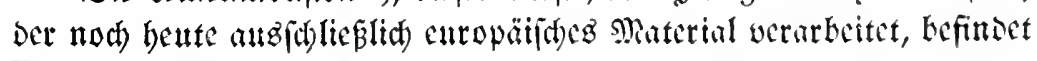

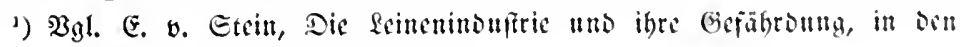
Edriften bez Bercing fïr Eosialpolitil Ig00. 


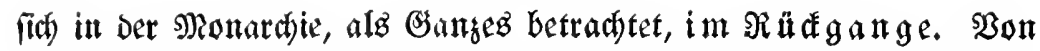

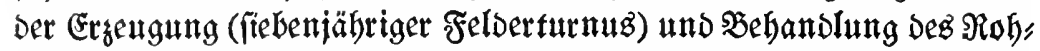

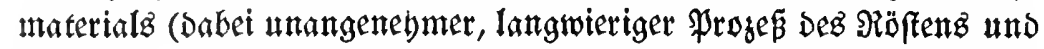

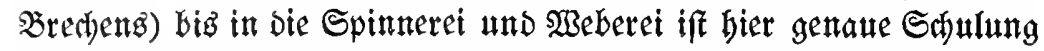
tnd Erfabrung ber Beteiligten Die Borausfez̧ung. Sn Den Tagen

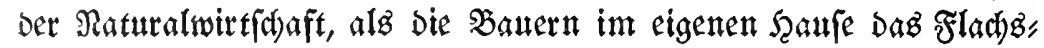
matertal verarbetteten, waren fie anmittelbar an ber Ģäte Des Fladj fes

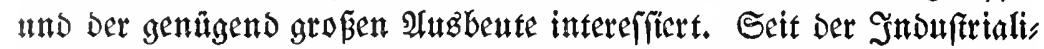
fierang Der Beberei find diefe Bestebungen zwifhen landwirtf haftlicher Produftion und gewerblicher $\mathfrak{\text { Berarbettung weitgebend geftört }}{ }^{1}$ ). So ift Dic (Finforäntung Des Flachbanbaues in Der Monarchie ${ }^{2}$ ) trok

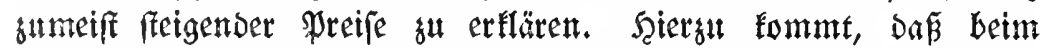

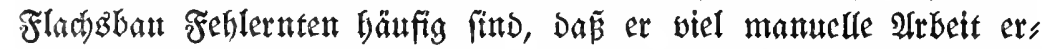
fordert, bie Der Bauer immer forwerer aufbringt, und wenig

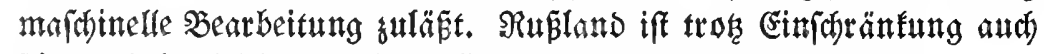
feiner Inbauflähe der Şauptlieferant won Fladys geworden.

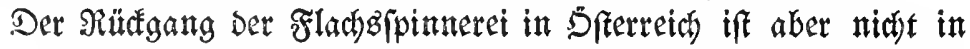
erfer Sinte auf Den Rüfgang Des eigenen $\mathfrak{A n}$ baus an Flad)s

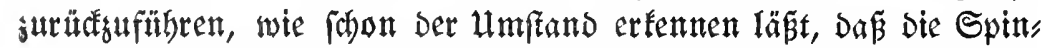

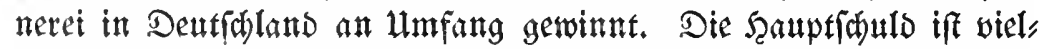
mebr bie gegenüber Dem ?achbarreiche geringere Sauftraft in ber Monarchie, die fith fo weitgebend wie möglid) Der Berwendung won Textilien atts dem Surrogate der Baumwolle zumendet. Die

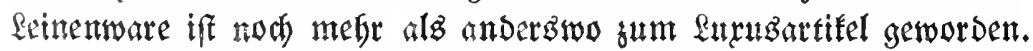

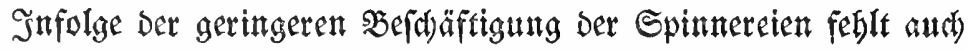

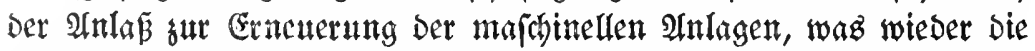

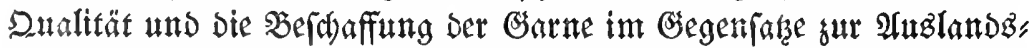

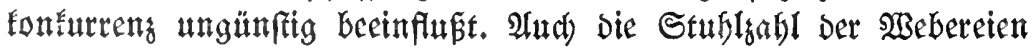
Gat, it Der Geramtheit betrad)tet, faum żtgenommen. Ëz ift nur an

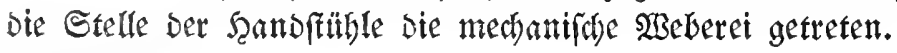

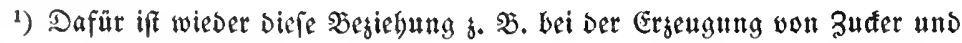
Epiritts eingetreten $\left(\boldsymbol{F}_{0}, 0.\right)$.

2) Rađ Dem Annuaire international de Statistique Agricole, Rome I9I4:

\begin{tabular}{|c|c|c|}
\hline Inbanfläche in ha & I903 & I9I I \\
\hline in Sfterreid ......... & 66568 & 388 I 3 \\
\hline llngarn.............. & 20872 & 15769 \\
\hline 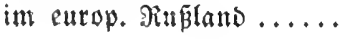 & I 559939 & I 301365 \\
\hline
\end{tabular}




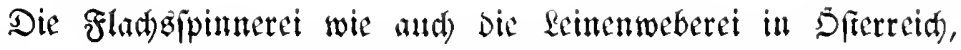

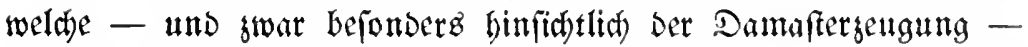

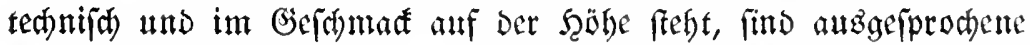

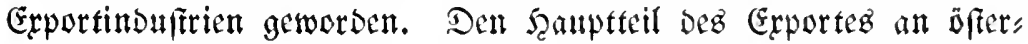
reidifingen Seinendamafen begieben bie Bereinigten Stanten von

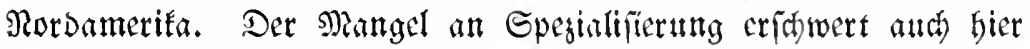
Das Gefääft und werringert Den Geminn.

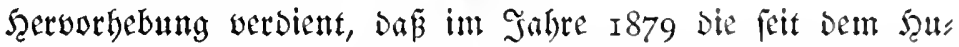

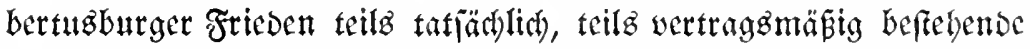

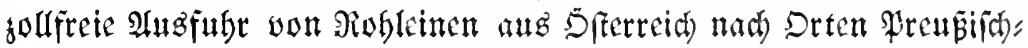
Shlefienz und Sabjenz gut vollfänoigen Iafbebung fam. Damit wurbe binfidytlid Seinen ein feit alters ber beftebendes bebiet gewerb:

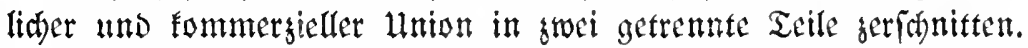

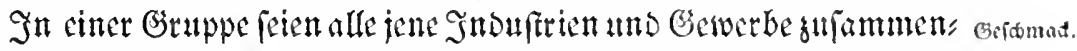

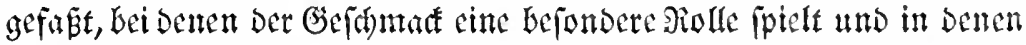

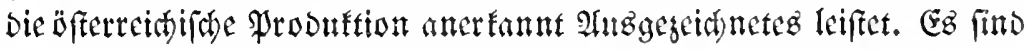

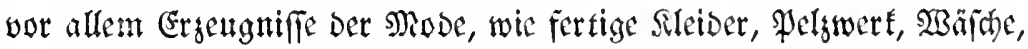

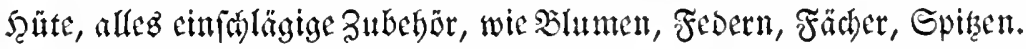

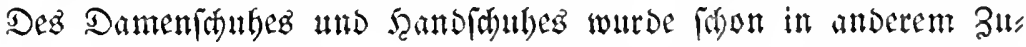

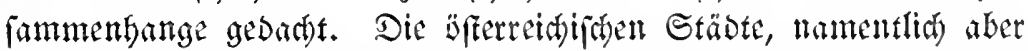

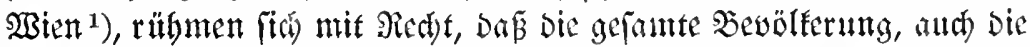
minder bemittelten und bejonders ifre weiblichen Bertreter, auf ge"

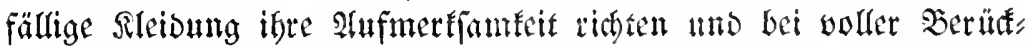

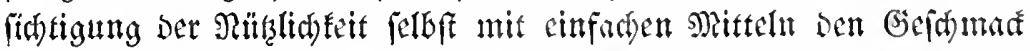
zut Geltung bringen. Dabei ift Der Gefomat viel rubiget uno

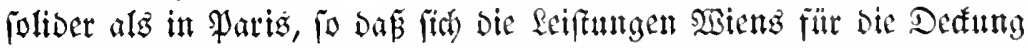

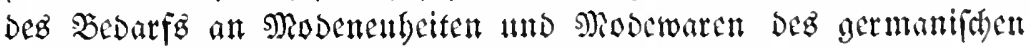
Mitteleuropaz beffer eignen als bie von Frantreich und Pariz.

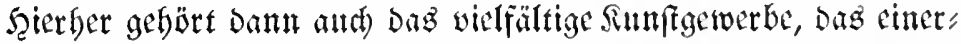

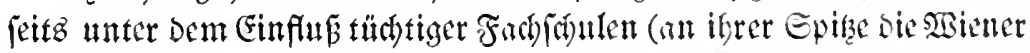

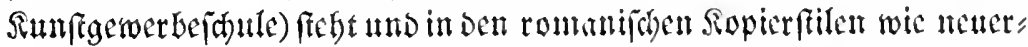

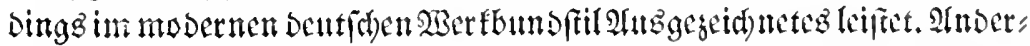

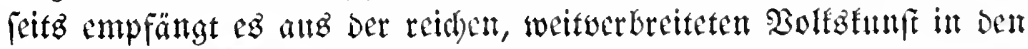
verfatedenen Gegenden mannigfaltige, won ridbtiger Materialbeats

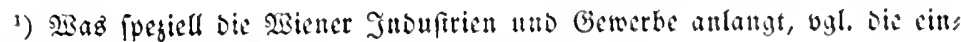

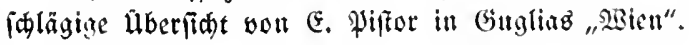


beitung ausgebende Anregungen. Die Leifungen Dez öfterreithifden

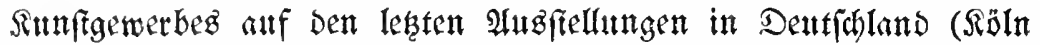

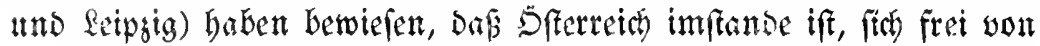
Den llbertreibungen Der erfen 2 erjuthszeit richtunggebend aut Dem

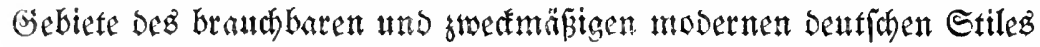

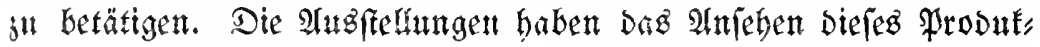
tionssweiges netiersingz gehoben. Şoffentith erkennen Dies die

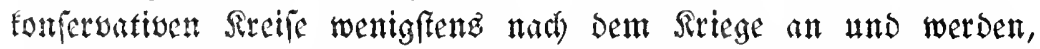

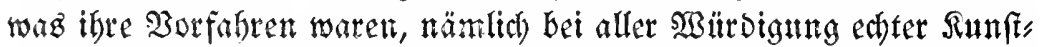
betätigung Der Nergangenbeit, Näcene anth Der originalen Sunft Der Zett, in Der fie leben, fitt sie Sïnftler und bie Sunftgetwerbler vor"

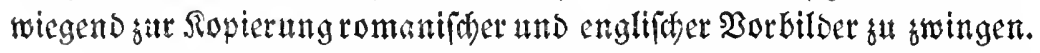

Waz im befonderen bie berithmte Porgellanindufterie und bie

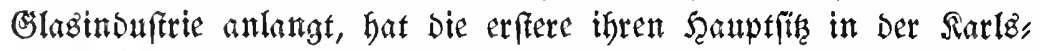
baber Gegens, währenb hinfichtlich ber lez̧teren neben ben vorwiegend Den Snlandbbearf verjorgenden Tafelglazfabrifen die Scoblglas",

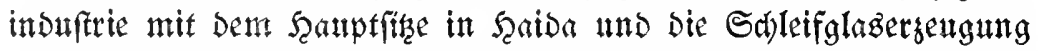

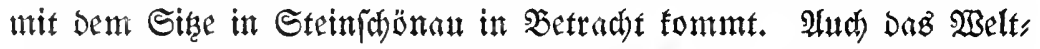

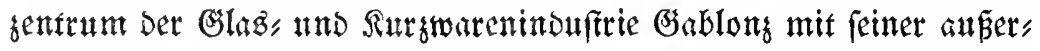

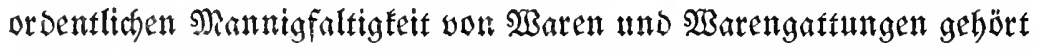

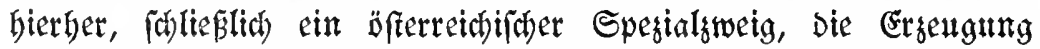
eleftrifaer GSläblampen. Die Deutiche Porzellan, and Glabinduftrie

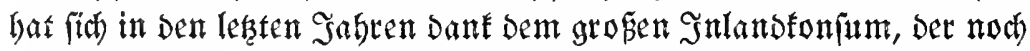

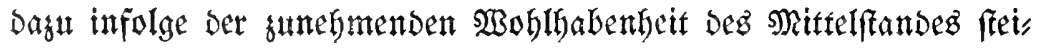
geno Godrwertige \$aren verlangt, wiel rajder entwidelt als bie öfter" reichifde. Bemerfenswert ift bie glänzende Entwidtung Der beutiden Porzellanindufteie in Selb, bart an Der böbmifhen Erenge, wo mit

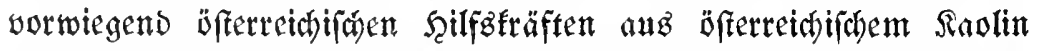

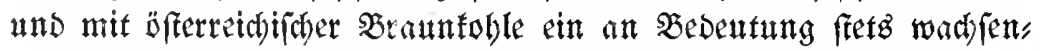

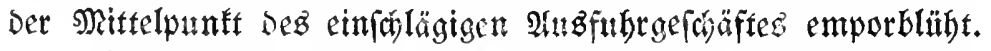

Die Eetfangen altf Dem Gebiete Der Metallwaten, befonders

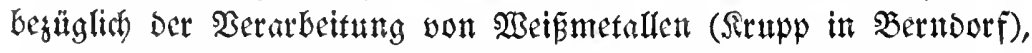
Bronge, ber Scolzgalanteriewaren, weldye lestere weifgebend in ber

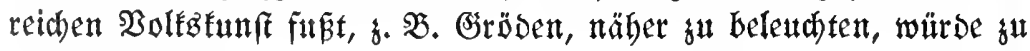
weit führen.

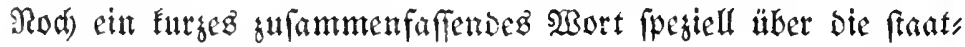

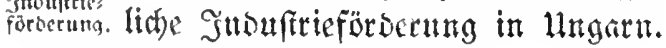


Sie wird feit Dem Jabre I 881 anj Grund von Gejegen plan:

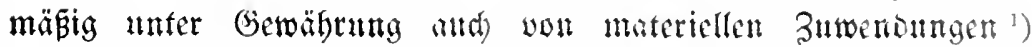

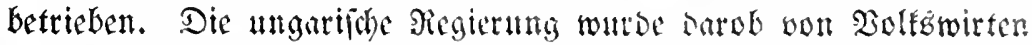

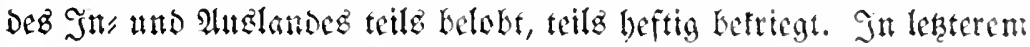
Sinne wurbe betont, Daßj bie Subventionierming mit Gids mobenen

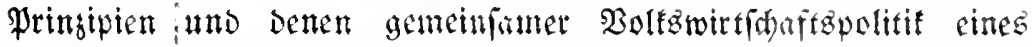
Staatzganzen wiberfteite. Dhre bie theoretifate Esite oer Frage weiter fu berühren, muté gefagt werben, daj Den Bemilfungen Der

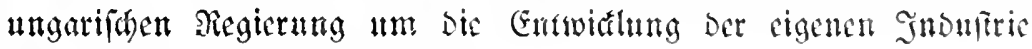
Der Erfolg ritht abjupredyen ift.

Die Entwiálung Der ungarifaen Inoufrie wäre angelid to ser

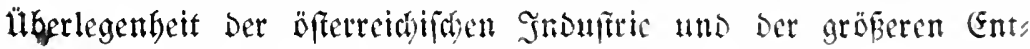

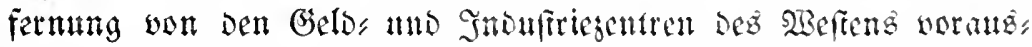

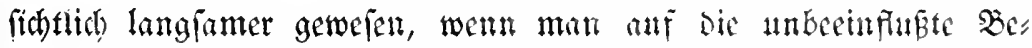

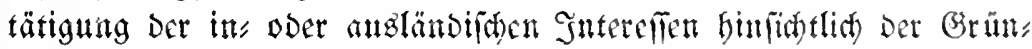
Dung von Fabrifen gewartet bätte, uno wenn nidit bie Piegierung ourd ibre Snitiatioc fowie bie moralifás uno matertelle Föbernng

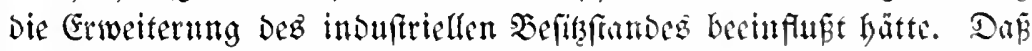

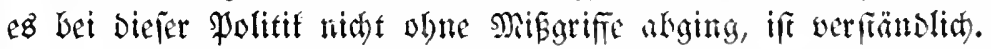

Die Subventionżtätigfeit becinflüt naturgemǟa Den ganger $\mathfrak{B e r}$ waltungsapparat und bie induftulle Förbernngğtätigket fowohl ses

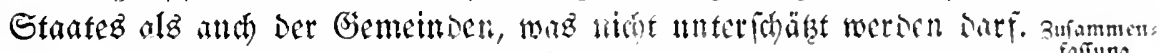

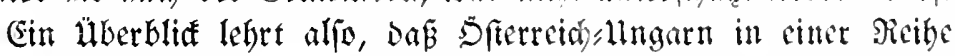
Faffung.

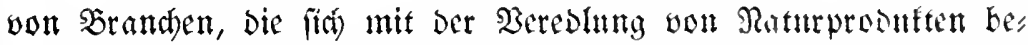
faffen, befonderz auf Dem Gebiete Der Rabrungsuttelinduftrie, Dann weiters in ber Textils, Reocrs uno Papierinoufterie surs cinen

1) Rad) ben antliden Berlantbarungen raren wen i 881 - I910 felgenoi Unterftüz̧ungen gewährt:

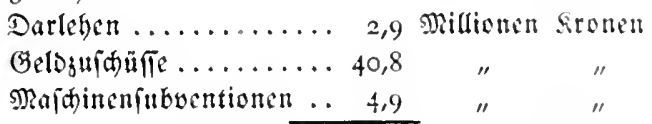

Zufammen 48,6 Nillionen sronen.

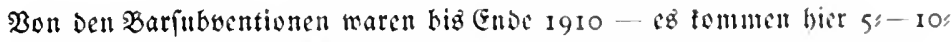
jăbrige Ratengablungen in Betradt - I6,6 Millionen Sronen ausbejablt.

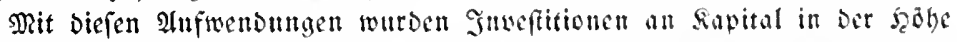

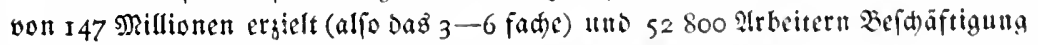
gegeben. Die Sabeesproduttion oer in Rebe Rebenden Betriebe wirb von Der

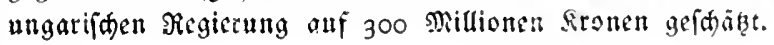


belangreidyen Export über Die Grengen Der Monardile binaus feine Reiftungsfäbigkeit beweift, Dak weiters in diefem Sinne bejon"

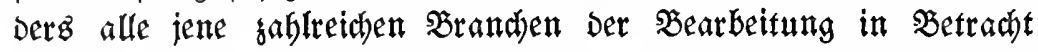
fommen, die abgefeben vom Sunftgerwerbe bauptfädylich Durch ge"

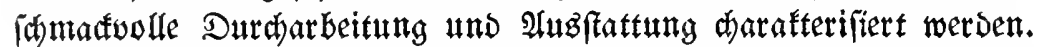

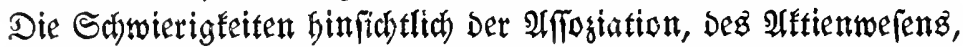
Der Gohen Befteueru! $\mathfrak{g}^{1}$ ), Der reaftionären Sewerbeoronung, vor allem

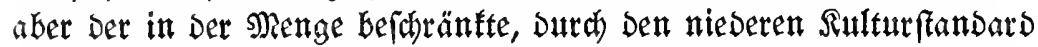

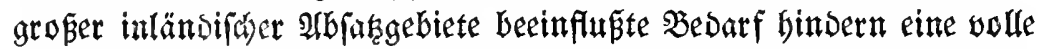

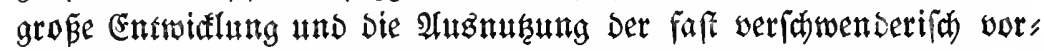

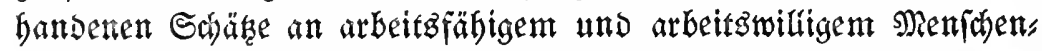
material fowie an Bobenproduften und einfalägigen Şalbfabrifaten.

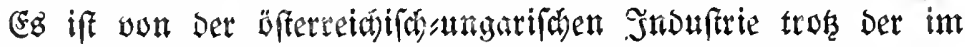

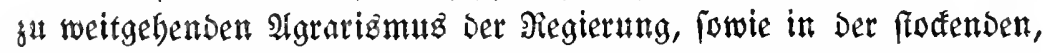

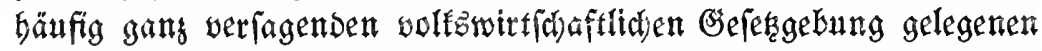

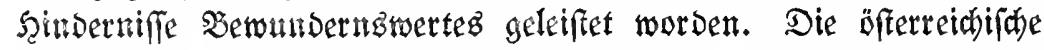
Snduftrie batte babei auch nod mit bem gu geringen Entgegen"

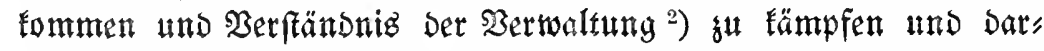

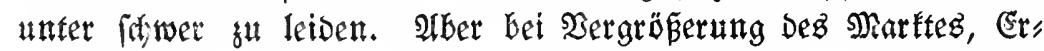
letaterung Der Spescialifienung, Sebung Dez Sultur, und Derdienfts

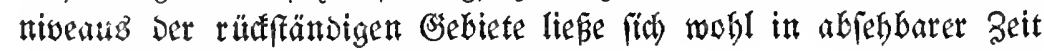
DaB Berfäumte nadholen.

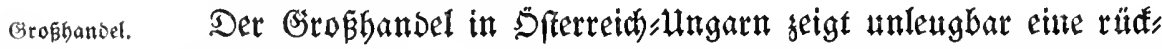
läufige berwegung. Daz gill vor allem von ber Textilbrande, wo Der Engroffift früber eine ungleich größere ఇolle fpielte. Biele von ben

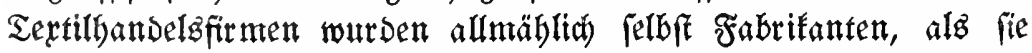

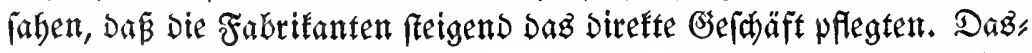
felbe gilt für die Eifenbrandje, wo nut bie mit dem Eifentartell in engerer Fühlıng ftebenden Firmen übrig blieben. Shre Babl bürfte in Der gangen Nonardie 30 faum erreiden, won Denen fidt) 7 in Wien

1) Prilippovid) weift allerdingz in einem $\mathfrak{A} u f f a k e$ (Steuern in 5 ft. uno

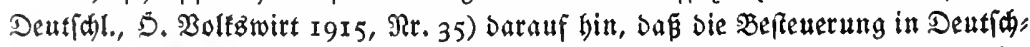

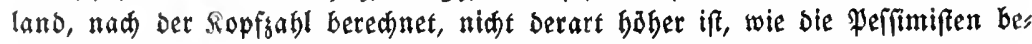
Gaupten (

2) Im Nai rgI I wurve in Dfferteid eine grobe Sommiffion gur Durds

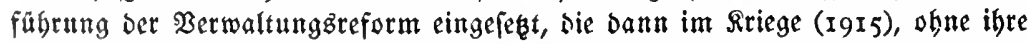

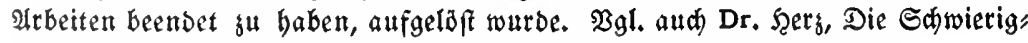
Eeiten ber induftriellen Produftion in 5fferreid, $\mathfrak{B r a u m u ̈ l l e r , ~ S \$ i e n . ~}$ 
befinden. Alud) Der Şandel mit unedlen Metallen liegt in Den Şänden von nur 5 biz 6 gropen Firmen, Der Srogenhandel in Denen von

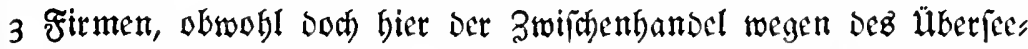
verfebre eine anbedingte Rotwendigfeit Durftellt. Sm Erporthandel

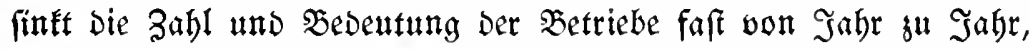

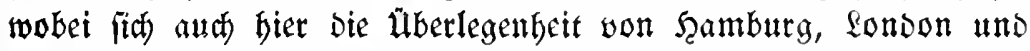

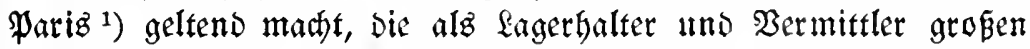
Stils Den Betrieb Des Grob̧handels in Der Monardie an fid fieben.

Die rüflälifige Tendeng beftedt fogar aut Dem Gebiete bes Şandels

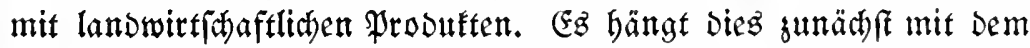
I903 verfügten gefeşlichen Berbot Dez Terminthandels in Dfterreich

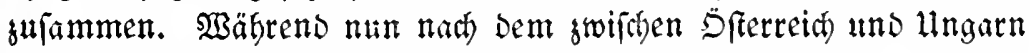

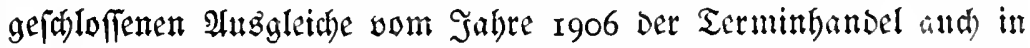
llngarn verboten werben follte, gefdah bies bigher nitht, forbern

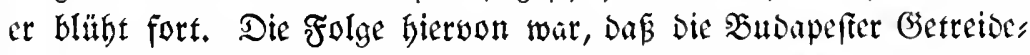

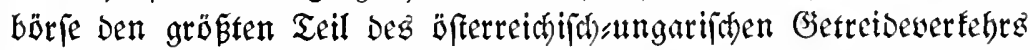
an fith fog und auth eine Reibe von Wiener Getreibegroffirmen nath Bubapeft abwatberte. IHf Der anberen Sette nabmen bie lanos wirtid)aftlid)en Genoffenifhaften auf Grano Der Parole Des Sampfez gegen Den Zwifhentyandel Den Berfauf Der Genoflenichaftzprodutte

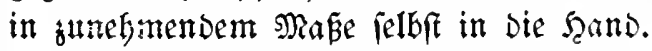

Dicjer Rüfgang bez Grob̧handela ift Eein günfigez Symptom, namentlich wenn man bie Erjheinung mit Der Webeutung Des Sandels in Deutfáland oder gar in England vergletdit, obwobl fich in auth Dort Teile Der Brobinduftrie funebmeno Dem bireften Befdäfte

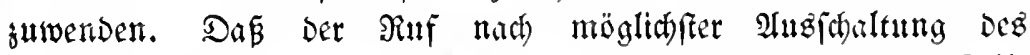
Zwifhengandels won weiten Sreifen erboben wird, und jogar Teile Des Programmes einer politifanen Partei in Sfterreith biloet, fann

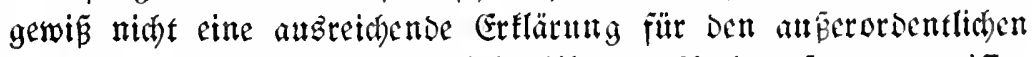

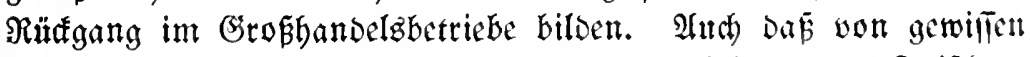
Feitmen Des Şandels behauptet wirb, man bringe dem Zivijhen= handel wegen äbler Erfabrungen, die nit $i$ mm gemad t wurben, ju

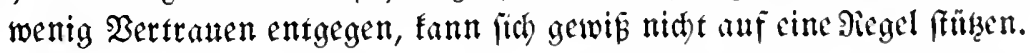

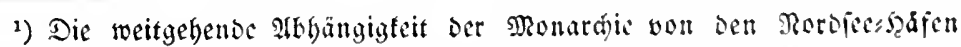

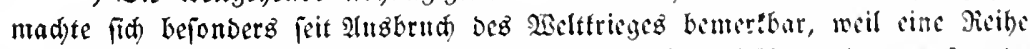
von Branden, gewögnt an bic Beriorgung ourd ietle Bäfeu, obme yeuñgente

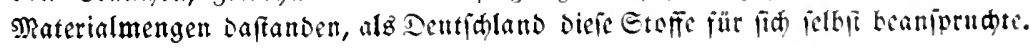




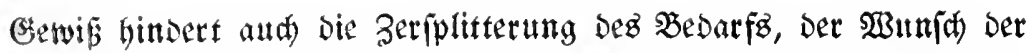
Fabrifanten, äber bie SB̈̈njhe ber Sunden funlidjft unmittelbar

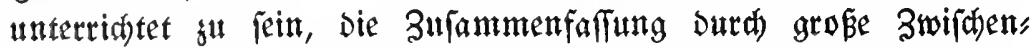

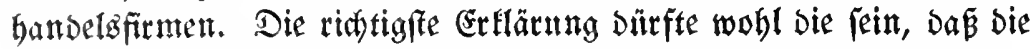

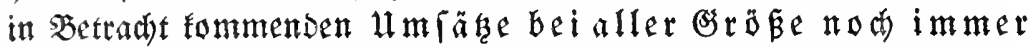

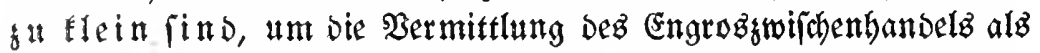

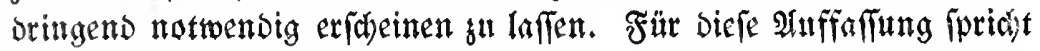
wobl aud), baz ber Sanfmannzbetrieb Der induftriellen und gewerb" lidjen Erzeugung, Der Großs, und Rleithandel, Der Rommiffions; uno Agenturbetrieb regellos nebens und gegeneinanoer arbeiten, ja baf

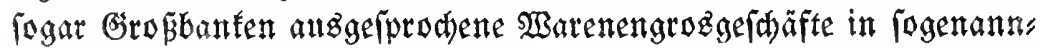
ten "\$Z̉arenabteilungen" Getreiben. Man gebt auf Grund Der $\mathfrak{B e}$

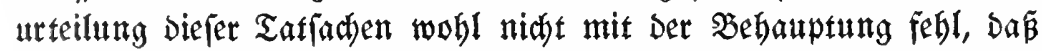
Der Nangel einez Elühenden, gut organifierten Zwifhenbandelz, Der Dod Den Fortjaritt Der Produftion fu fördern und Den Derkeranth fll feigern vermag, - gerabeź ein Merfyeiden begrengter Wirts (đ)aft uns \$irtf(t)aftzpolitił bebentet.

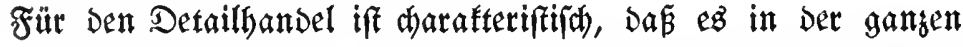

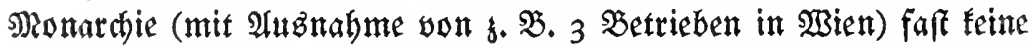

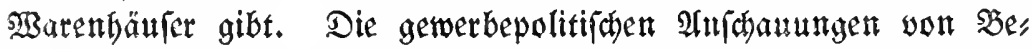
hörben uno Parteien find gegen fie; aud Daz Publifum gieht Den Spezialiften im Detailfandel Dem jentraliftícten Srobbetrieb vor.

Dem Grobjandel ift in Den Banfen, beren Einflü auf bic Rartellbiloung immer mebr wäd) fit, anth infofern ein widjtiger Ron, furrent erwadjan, weil bie Rartelle febr oft Den Berfauf ben Ees treffenden $\mathfrak{B a n k e n}$ übertragen.

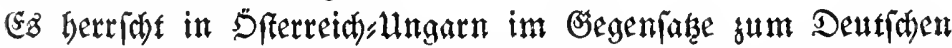

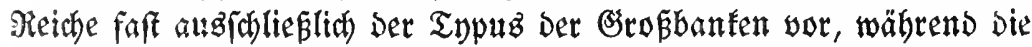
vorber vorbandenen mittleren $\mathfrak{B a n t u n t e r n e b m u n g e n , ~ b i e ~ a l s ~ f i n a n s ~}$ gielle Mitarbeiter auffeigender, mittlerer und lleiner Betriebe uts leugbat grofe bebeutung befízen, nod) rafduer alz in Deutfalatio in Rüdbillong begriffen find. Die öfterreidjifdjen $\mathfrak{B a n f e n}$ mit einem im Sabr I9 I I 295,6 Millionen betragenden Rapitale und Rejervefonds itt Der Şöbe yon faft 500 weiteren Millionen Sronen fellen, abgefeben von thren internationalen Begiegungen, einen achtunggebietemben Faftor Dar.

Eartafís. Şierğt tommen Dann nod) Die Sparfaffen, Deren Rapital füt 
r912 in Ungarn allein, gemeinfam mit bem bet Banten, faft mit

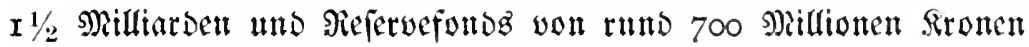

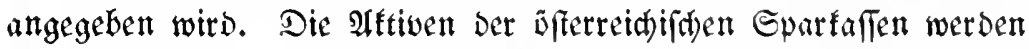
für I9 I mit faft 7 Milliarden begiffert; bie Summe ber Eparcinlagen in llngarn belief fich auf $\mathfrak{t h} b \mathrm{er}$ Milliarben.

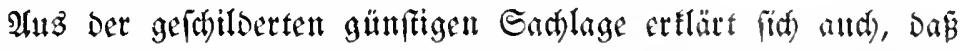

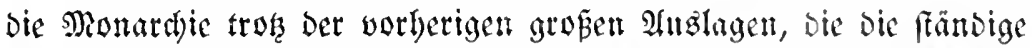

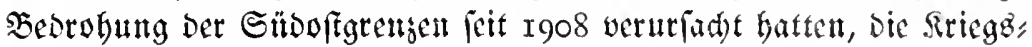
anletben eigentlith leid)t aufbrad)te.

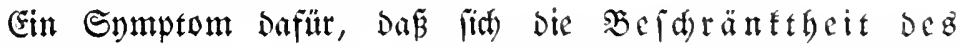

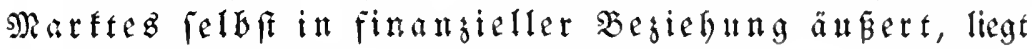

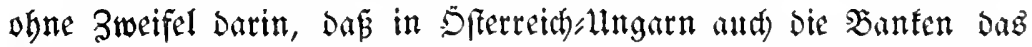
Einlagengeid)äft im Stile won Spartaflen betreiben uno auf biefe

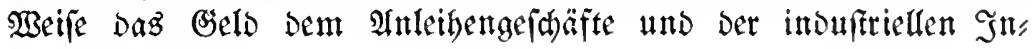
weftition zufübren.

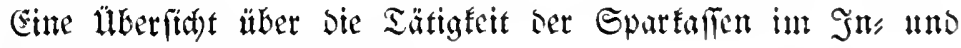
Inslanbe fitlt fit) wie folgt:

\begin{tabular}{|c|c|c|c|}
\hline & $\begin{array}{l}\text { Ginlagenguthaben } \\
\text { in Miltionen Sronen } \\
\text { überbaupt }\end{array}$ & $\begin{array}{l}\text { In Fronth auf } \\
\text { Den Fopf Det } \\
\text { Bevölferung }\end{array}$ & $\begin{array}{l}\text { Sonti auf le } \\
\text { I00 Eintrober }\end{array}$ \\
\hline Deutidjlano ........ IgI I & I 8680 & 352 & 35,02 \\
\hline Dfterreich $\ldots \ldots \ldots$ I9ro & 62751.45 & 222 & 22,83 \\
\hline Ungarn .......... IgrI & 4 II $3 j^{3 \mu 1.10} 388$ & 195 & $10,4 \mathrm{I}$ \\
\hline Groß̈britannien ...... I9Io & 5301 & I 8 & 30,42 \\
\hline Frantreida . . . . . . I I909 & $5 I 49$ & I3I & 34,85 \\
\hline Stalien ........... rgro & 3920 & I 12 & 22,05 \\
\hline
\end{tabular}

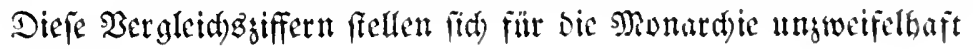
febr güutftig.

Die Donammonarbie weift nod) cinte befannte intercllanti Befonderbeit auf, bie beiben fraatliden Poftiparfaffen. Der Umfatz

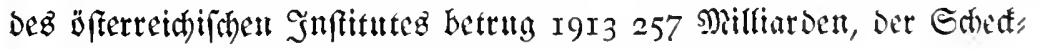
verfehr gegen 34 Mitliaroen (I9I4 liber 36 milliarben).

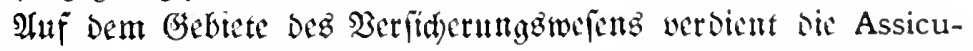

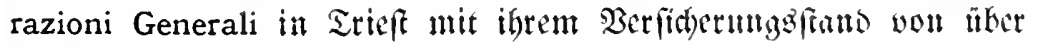

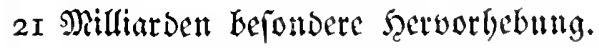

(Sharafteriftifh für Siferreid) einer feitz die ungünftigen byorographifacm, anserfeits bie oro, 


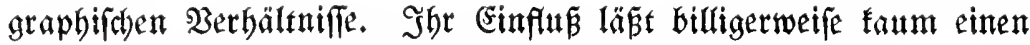

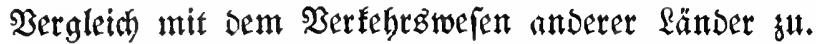

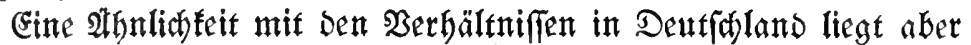
infofern vor, als bier wie Dort ber Sdyerpunft Der agrarijhen Pro" Duftion int Dften bes landes liegt. Der 2 seften ift auf Den Smport

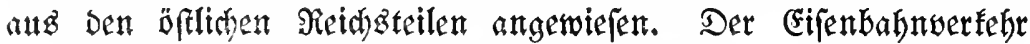
wird wefentlich Durch Den Donaurweg fonfurrengiert.

Die nicht genügend günftigen hybrographifden Der Mangel an billiger Zufubr von Gättern Durd) bie Ranäle beetn, trächtigen natürlich bie Entwidtung Der Eifenbabnen, wenn auds nicht fo lebt wie die orographiften.

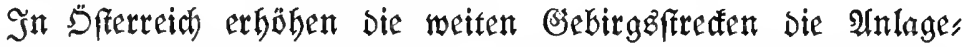

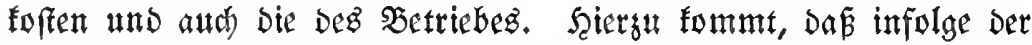

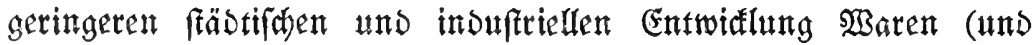

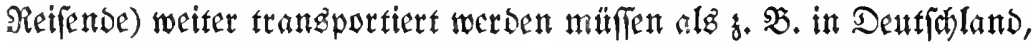
wobei natürlich Die Frad)tbelaftung Der Waren innerbalb Der geges

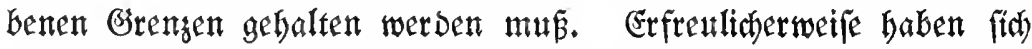

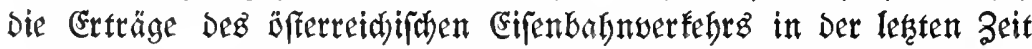
febr gebeffert, da bie Verginfung im Sabee I9 13 anf 3,53\% geftegen

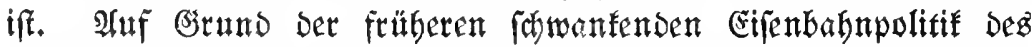
Staates fateben die öfterreichifden

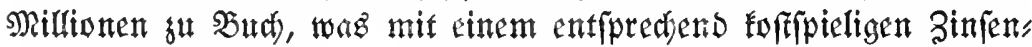
Dienft werbunden ift. Die früberen Privatbahnen trachteten, im

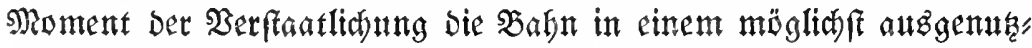
ten Zuftano zu übergeben, was bis vor furgem auberordentlity grope

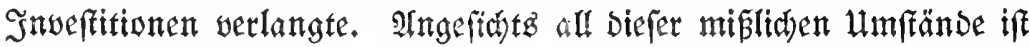
Das heutige Erträgntz obne Zweifel ein fehr befriebigendes zat nennen.

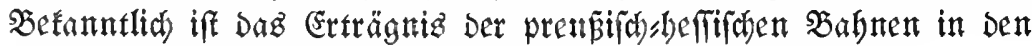
leţten Sabren etwas (anf $7,17 \%$ ) gefallen.

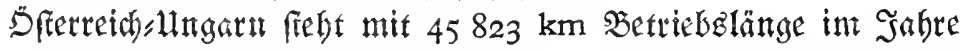
I9I2 in (Europa binter Deutichland (mit 62700), Ginter æiutaland (mit 62000 ) unb Ginter Frantreid) (mit 50000 ) an vierter Stelle. Die 3ahl ber geleifeten Tonnentilometer betrug in Dentfuland 20 Mitliar:

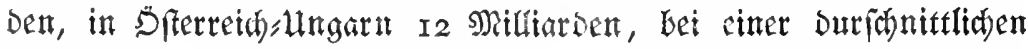
Einnabme per Tonnenfilometer won 2,55 Pfentig gegen 4,63 Seller.

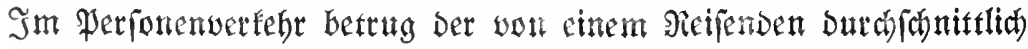

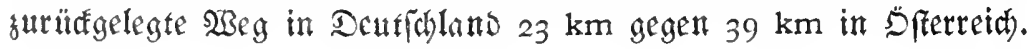




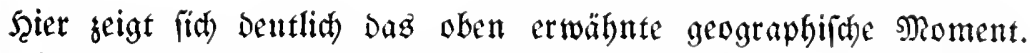

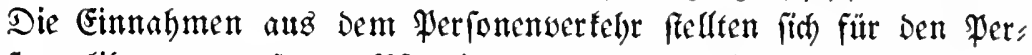
fonenfilometer auf 2,53 \$fennig gegen 3,18 Şeller. W3irb erroggen,

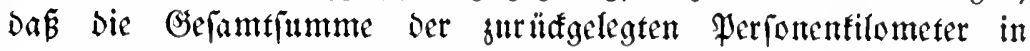
Preuken 25 Milliarben gegen $5-7$ Milliarden in Dfferreid, betrutg,

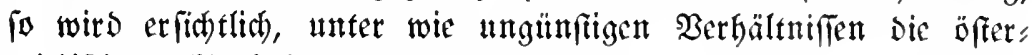
reidififaen Gifenbahnen arbeiten mälíen.

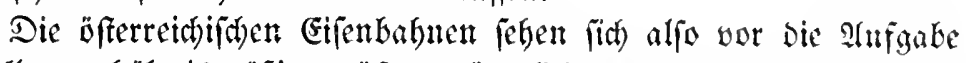

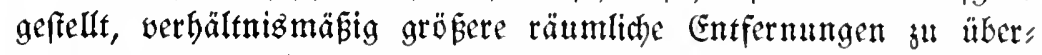

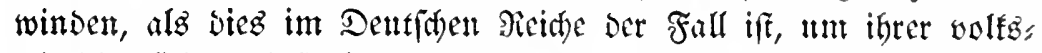

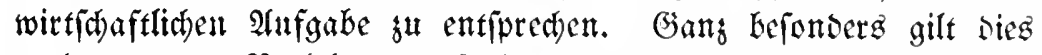

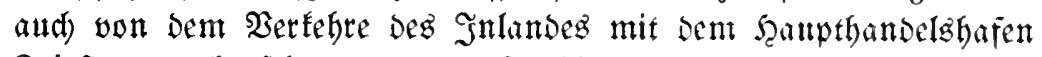

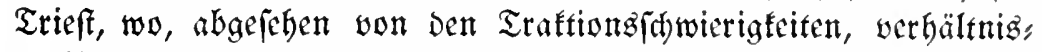

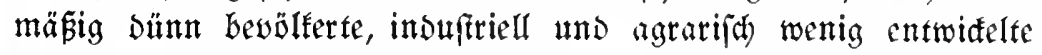

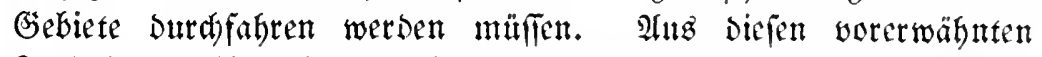

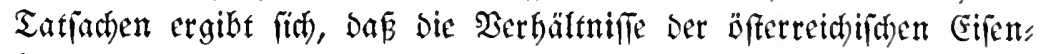

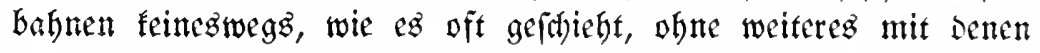

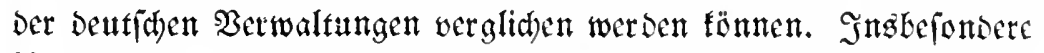

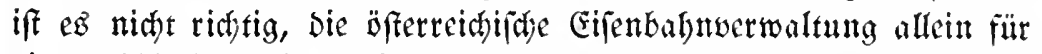

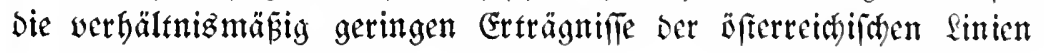
verantwortlid fu madien.

In Ungarn fekgte mit Dem Jabre I876 die Perive Der Berfants

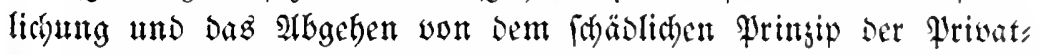
bagnen mit fantlider Żinfengarantie ein. I888 Gringt bann Barog mif füfrnem Griff Feinen Zonenturif jut Einfübrung, ber eine gans

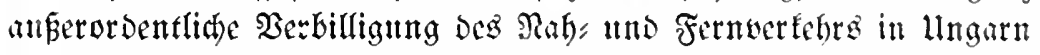

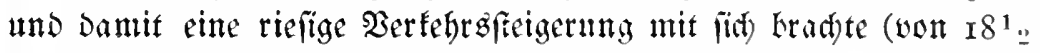

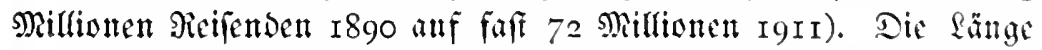
Der Etantabahmen befrug I9I I $S_{123} \mathrm{~km}$, bie ber Verwaltumg beg Staates unterfétenden 2 isinalbahnen $9498 \mathrm{~km}$, bie ser Privat: bahnen $8367 \mathrm{~km}$.

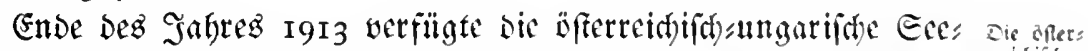

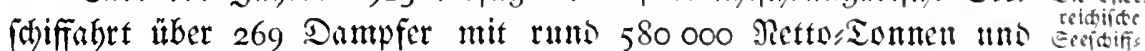

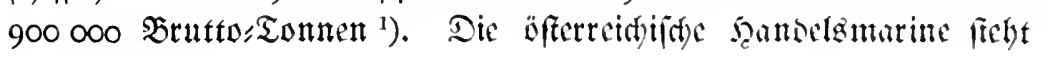

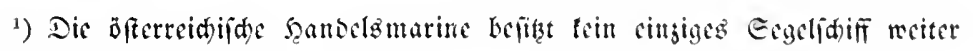
Fahrt mehr.

Pt ff or, Prosultioträte Sftereids) ungarne. 
Demnath an zelnter Stelle und wird auper von England, Nord, anterifa, Deutidaland, Porwegen, Fraufreich und Stalien aud von Griechenland, Scolland und Sabeden äbertroffen.

Dic gettanten Staaten find entweder joldje mit ausgefprodten maritimer Sage, fo Dá̧ fie nur oder faft nur mit Şilfe Des Meers berkehrs erreid)t werden fönnen, ober fie fins, geftüz̨t auf reides

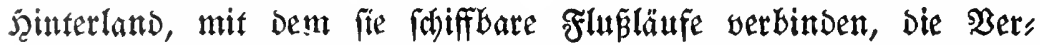
mittler sez Smport" und Exportwerkefrä, oder fie befízen eben die Flotte aus citter großen Beit expanftuer Solonialpolitif und baben ire feit jefer gepflegt.

Fürt Den öfterreidfifhen Seeverfebr fehlt eg faft an jeber biefer

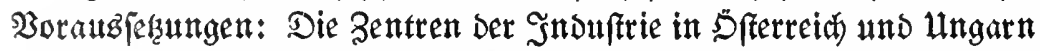
liegen weit ab won Der Meeresłäfte, die Bwifhengebiete find gebirgig und induftriel rünftändig; die Nieberlafinng von Snouftrien an Den Meeresgebieten leşte enft in Den lez̧ten ro- r5 Sabren ein.

Errf Das I9. Jahrbundert mit feinen Erfindungen in Dampfs 低iffahrt und Eifenbahnuerfebr, diefen Mitteln bodymoderner $\mathfrak{B e r}$ Eefröpflege und Berfebrgorganifation, hat bejonderz für Trieft die Srundlage Der vollen Entwialung gebradt.

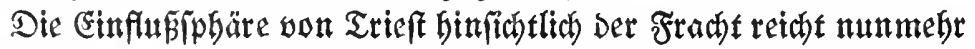
bis in bie Begend won $\mathfrak{P r a g}$ und Dank Der Tauernbahn bis in bie Oegend won Nürnberg und Mannheim. Damit hat Trieft nidyt nur

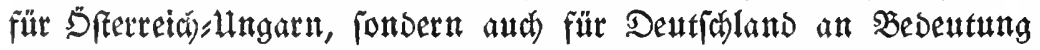
gewonnen; es ift auth binfict tlich Der Lanoverbindungen ein inter" nationaler Safen geworben.

Ez zeigt fith, Dấ Trieft, erft mur im Mittelmeere bebeutend unv Sïbfrüctes unb Rolonialwarenhandel aus bem näberen Driente betreibend, erfit auf Smbien übergreift, itt Den leşten I5 Sabren aber

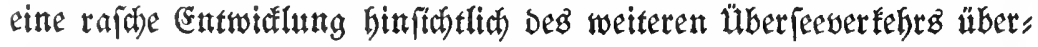
Gaupt nimmt. Şierbei iff ihm Fiume, energif won ber ungariforen Regierung geförbert, fretig nachgefolgt.

Trieft Fam im Sabte I9I2 Ginfictitlich Der Smports uns Exports mengen ungefähr Şaure gleith. 23on I9I2 auf I9I3 iff bie Biffer um rand $14 \%$ geftiegen ${ }^{1}$ ).

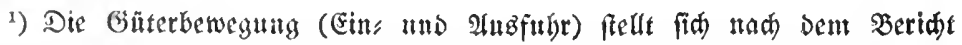
Der Şandelałammer in Trieft für Das Jaht 1913 in Mill. q wie folgt: Marieille 98, Genua 74, Bremen 7x, Trieft 34,5, Benedig 26,7, Fiume 20,98. 
(Finen widtigen Wendepunft Der öferreidifhen Ediffabrt uno einen Beweiz ihrer Entwidlung ftellt bie im Jabre I906 verfügte

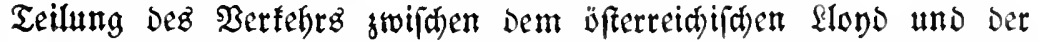
jungen, mit Der Şamburgsłmerifas linic tmo Dem Bremer flond in enger $\mathfrak{B e r b i n d u n g ~ f t e h e n d e n ~} \mathfrak{A}$ ftros: Americana Dar.

Die lez̧tere übernahn Den Berkefr nad) Porbamerifa, währemb betreff's SüDamerifaz eine Teilung vereinbart wurbe. Dagegen blieb Dem öfterrethijhen Gloyd Der Sinienverłehr nad) Dem näberen uno ferneren Dften biz Egina und Sapan.

Der ofterretaifthe floys bat in Der leţen zeit eine jebr günftige Entwiłlung genommen, bie fid aud in Der Divioendengablung aus",

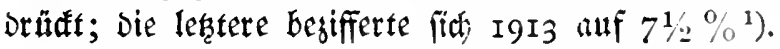

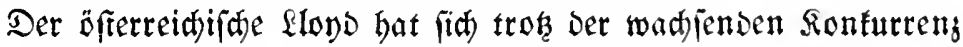

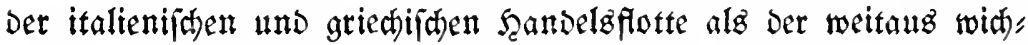

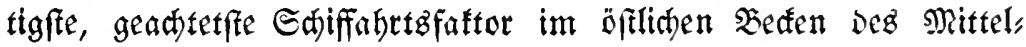
meereg für Den $\mathfrak{B e r k e h r}$ mit Sleinafien uno Ägypten betautetet. Die

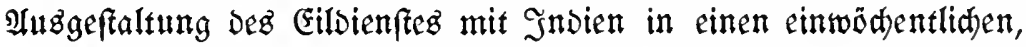
mit Shina und Sapan in einen I4tägigen, wurbe allerbings ourch Den Srieg aufgehalten.

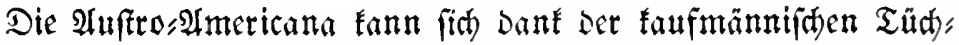

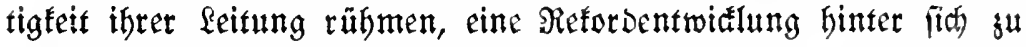
baben, indem fie in ben Jabren ibres beftandes (I904-1913) Den $23 e r t$ ifrer flotte von I $1 \frac{1}{2}$ auf 30 Millionen Sronen $\mathfrak{y o b}$, und Den Gefamt, werkefr an Ģütertonnen von $230000 \mathrm{t}$ auf äber I Million (flono I $1 / 2$ Millionen) ${ }^{2}$ ).

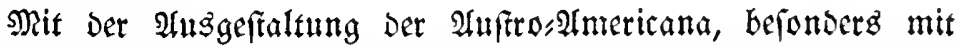

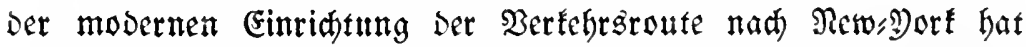

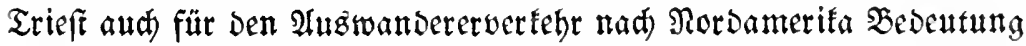

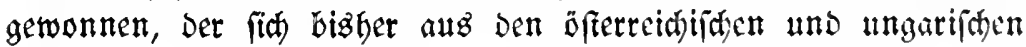
Ałzmanderungzgebteten weit äberwiegend äber Şamburg und Bremen berwegt hatte. Die befebenden Rartellwercinbarungen Des Saiffabrtpools Gatten Trteft, won Dem man annebmen modhte, bar

1) Der flono verfügt Dermalen über cime Flotte won fali 70 Ediffen mit runs 300000 Bruttotonmen, Die Imfrosimericana über faft 40 Ediffe mit runo I 50000 Bruttotonnen.

2) Durd Den Srieg surbe aud bie Eriffunng oer meuen finic ber Ifuftes Americana nad (Ebile (Durd) Den Panamatanal) gefōort. 
es auf lange Zeit feine belangreidye Rolle im Perionenvertebr mit RorDamerifa jpielen Dürfte, ein Rontingent von $4 \%$ zugebilligt.

In $\mathfrak{B u ̈ r d i g u n g ~ D e B ~}$ Berteళ loyaler Ronfurreng für jede wirt"

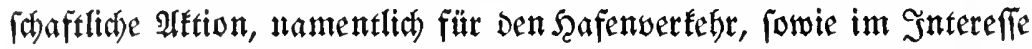

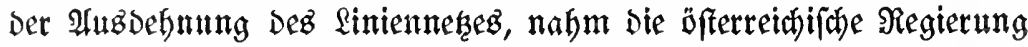
Daz $\mathfrak{a n g e b o t ~ D e r ~ E a n a b i a n ~ P a c i f i c ~ a n , ~ D i e ~ I 9 I 3 ~ e i n e ~ D a m p f e r " ~}$ linie zwifhen Trieft wnd Montreal einridftete und gleidfzeitig äußerft ftrenge Rontroll, und Füriorgemaßnabmen betreffend Den öfterrei,

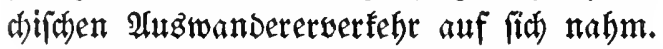

Der Darauffolgende beftige Rampf mit Dem unter Füfhrung won Şamburg und Bremen ftebenden Sdiffahrtżartell endigte in wejentlitben Damit, Daßj betreffz Der Sinie eine Dereinbarung fwijden Der Eanabian und Der $\mathfrak{A}$ trftros 2 mericana bergeftellt wurde,

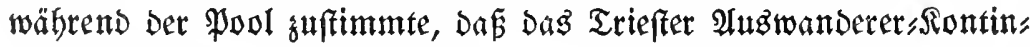
gent erft auf 7 unb alumäblith auf $10 \%$ gebrad)t werden foll. So wurde die Stellung Trieftè erfolgreid gegenüber Der internationalen (nad) Dem Gebote Der Sadblage aud gegenüber Der Deutfden) Sdiffabrt

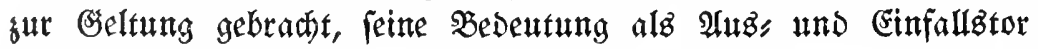

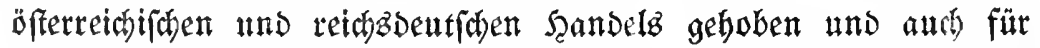
Die Zukunft Die Entroidlungzmöglidbett Der beimifhen Sdjiffatht fithergeftellt. Mit Der Beendigung Der geplanten 2rbeiten Der 2rišs, geftaltung Des Triefter Scafens - namentlich was die Soblenverladung modernen Stilz, Die Derbieiterung Der Riven und Die Dermebrung

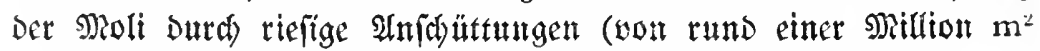
aut Dbetfläche) ufw. betrifft - muß Trieft weiter aufblühen.

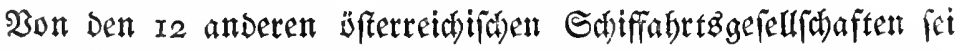
Dit (B) fellifhaft D. Tripcovith und Die Navigazione libera Triestina beruorgeboben.

3wifden Dferreid) und Ltrgarn befteben binfiantlid) ber Sees

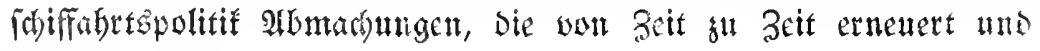
etgänğ werden.

lungarn verfügt über 6 Seejdiffabltzgefelrchaftent. Der Stant hat Die Gefamtiuboention für Safiffabrtżnede auf I Millionen

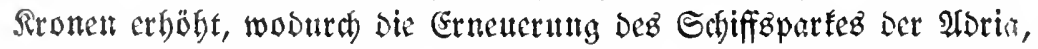

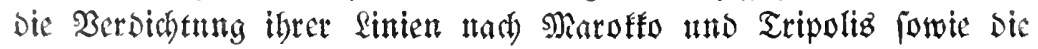

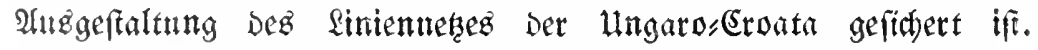

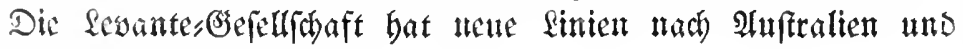

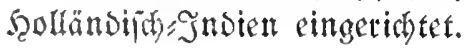


Dringend notwendig für bie weitere Sebung ber öferreinfijhen Seefdiffahrt ift die jeitgemäße, feit I 840 vergeblid) geforberte Reform

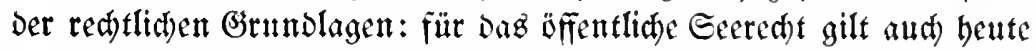
nod) baz won Maria Therefia, Der eifrigen Föroerin Triefts uno ber Geimifhen Sniffahrt, im Sabre I774 erlaflene uno feinergeit mufer" gültige Ravigationsedikt, für Das Privat:Seered bas II. Bud) Deg

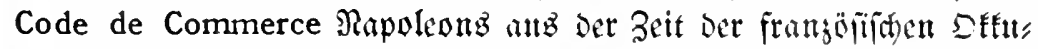
pation Dez Sïftenlandez. Weide Brundlagen fino natürlich gang

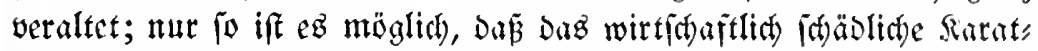
inftem nod) immer gilt, während es eine Gectypothef nid)t gibt. Das Marineförberungagefes vom Jabre 1907 bat ïberwiegeno gün: frige Eriolge ergielt ${ }^{1}$ ).

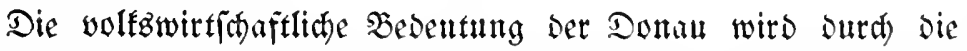

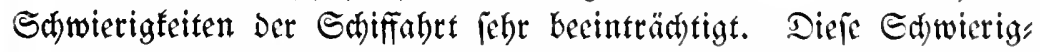
Eeiten wurben erft Durd) bie moderne Sed)niE teilweife bejeitigt.

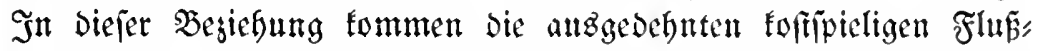
regulierungen in befrad) uno bier vor allem jene jur Sdaffung

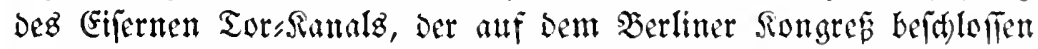
worden war uno I 896 eröffnet wurbe $\left.{ }^{2}\right)$. Die Mäglich feit Deg $\mathfrak{B}$ atteg

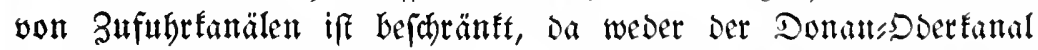

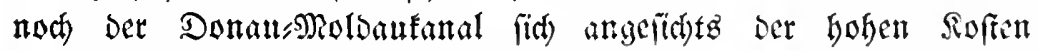
faum je rentieren wärde. Dagcgen veripricht allerdings bie Ber" binsung Der Donau mit Dem アifein eime Erböbung Der bebentung Der Donal alz Wafferweg, weil Dann eine wichtige, billige Durd gangs", route für Den Gäteraustati(t) won Dften mad) SBeften gejdafien wäre.

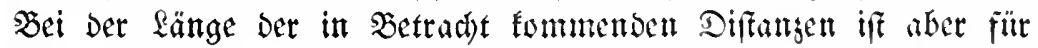
bie Sonardyie eine Borbedingung, Dañ Gier wie anf ber Elbe bie

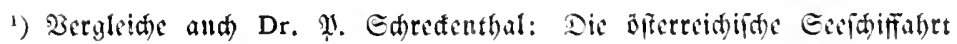

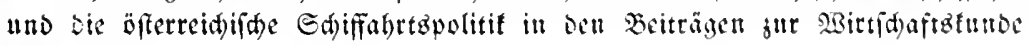
D̈fterreict)8.

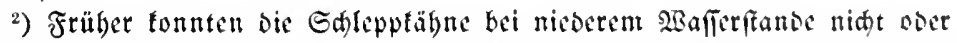
nur bei feidatem Tiefyange Durd) Die Donansataratte remortiert weroen, wezbalb fie oft uns lange in Turn: Severin auf günfigen siafferfand warten แubten. Bor Der Regulierung tonnte Daber ein Shlepper bie Fabrt von Galab nad

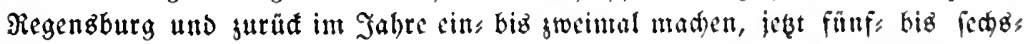

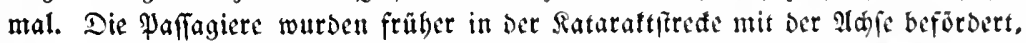
weil große Paflagierdampfer foon mit einem Siefgang yon $1,4 \mathrm{~m}$ bte Strede nur bei günftigem Wafferfand pafficren tonnten. 
garanterte Freibeit von Sajiffabrtzabgaben erbalten uno Damit aud Daz ftantlitye Saleppmonopol abgewebrt bleibt.

Sebenfalls ift für Die Dona mangelz Der Berbindung nad) Weften und Der nod) lange nid)t genügenden Entwiaflung Dez

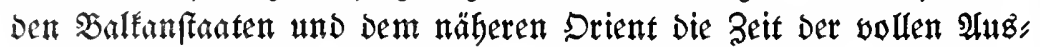
nuthung nod) nicht getommen. Der Bouftündigfeit balber fei berworgeboben, Daß für Den Derkebr anf Der Donat 3 Shiff" fahrtzgefellfhaften zur Berfügung ftehen, bie I830 gegründete

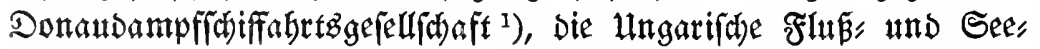

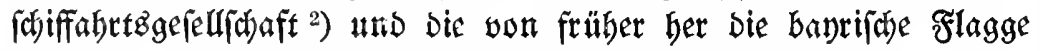

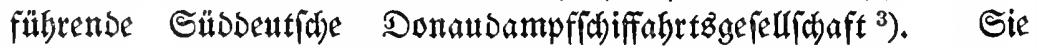
wurde I9 Io von Der ëferreidifjen Regierung aufgetauft, um eine

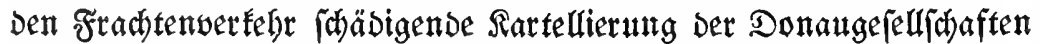
fu verbindern. Bon Dem Fradtenverfebr auf Der Donau bejorgt Die ungarijare Gejellichaft rand $40 \%$.

Der (Elbevertebr mit rund 33 Millionen q Fradjt ift Der Menge

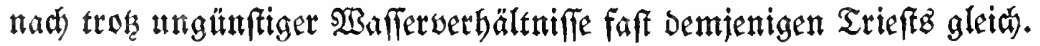

Alle Diefe $\mathfrak{e r k e h r g o r g a n i f a t i o n e n ~ f o m m e n ~ f u ̈ r ~ b e n ~ F r e m b e n , ~}$ verfebr, Dem die Shroeiz und Stalien fo reiche Einfünfte fdron bente verbanken, weitgehend fugute.

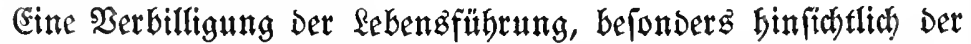
febensmittelwerforgnng (wobei Eejonders Das benad)barte Bayern

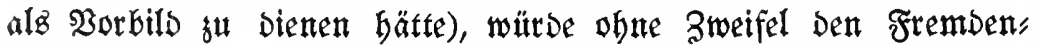
verfebr autf) Der mittleren Slaffen (und fie wirken gerade durd)

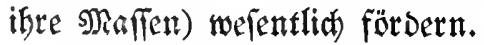

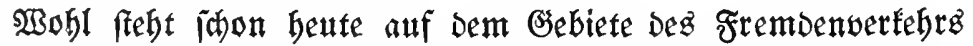
Der Befud) auz Dentfdland an erfter Stelle, aber ez läpat fid wobl annebmen, Daj er nad) Dem gemeinjăm geführten Sir iege einen nam, baften weiteren $\mathfrak{A}$ ufferwung nebmen wird. Rein Teil Der Alpen, überbaupt feine Der bohen Gebirgbłetten in Earopa ift Derartig plan

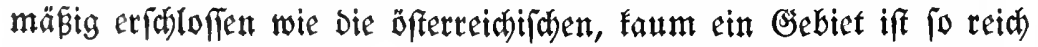

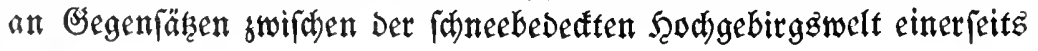

1) Sftienfapital 60 Millionen Srouen, rund 50 Dampfer und 870 Sd)lepper,

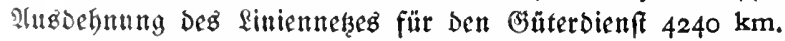

$\left.{ }^{2}\right)$ Rapital to Millionen, runs 50 Dampfer und 275 Matenbode.

3) Die Gefellidaft betreibt nur Den Gütervertebr. Sapital 3 Millionen Mart, I2 Dampfer, 3 Motorfradtłähne (Syftem Bolinder) und II 5 Sdlepptähne. 
und Den nördidgen doer fïbliden Salfalpen, bejonders Den Dolomiten, andererietitg. Der berühmten Seilquellen in Sferreid) uno llngarn

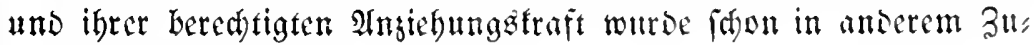
fammentange gebadt.

Ein âweig gang eigenartigen Aeijens, Das anF Dem fulturpolttifáten Stubium der fo verfdhiedenartigen, gumeift ungentein malerifiten,

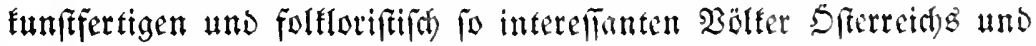

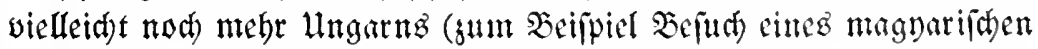
(Enntefeftes, flovafifder ober rumänif(ter Sirctenfelfe), Bosniens uno Der Serzegorwina fu beruben bätte, if unbegreiflidberweile bis bente

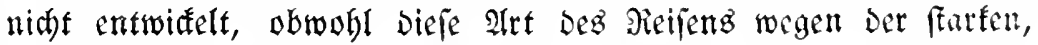

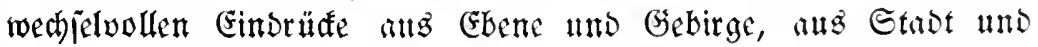

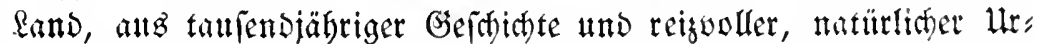

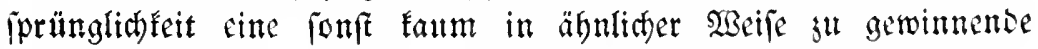
Belefrung, $\mathfrak{A}$ megung und angenehme Erinmerung bietet.

\section{Dic widhtigiten bilanjen.}

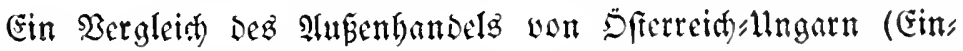

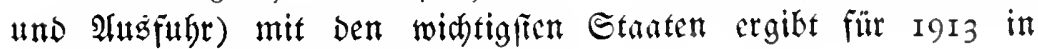
hancelos: bilany. Millionen jolgender Rills:

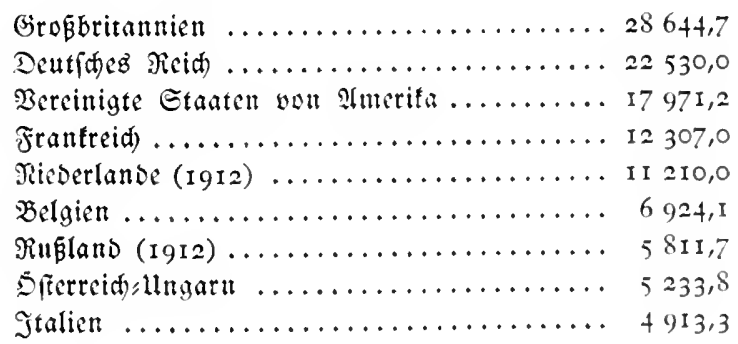

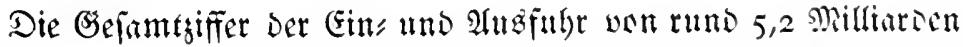

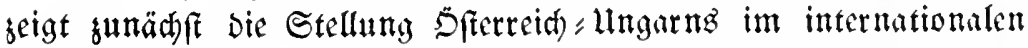

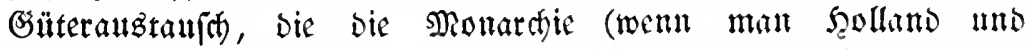

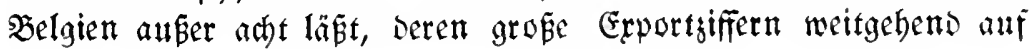




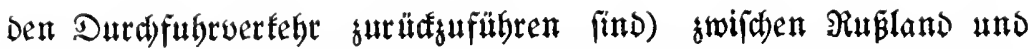
Stalien placieren, wobei wieder Rubland von England, Deutichland, Den Bercintigten Staaten and Franfreid) äbertroffen wird.

STandelabilang Der Monaraie

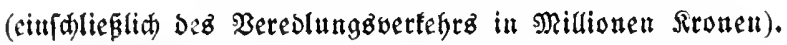

\begin{tabular}{|c|c|c|c|c|c|c|c|c|c|}
\hline & 1903 & 1905 & I906 & 1907 & I908 & 1909 & I9II & 1912 & I9I 3 \\
\hline Einfubr ... & 1936 & 2213 & 24 I I & 2587 & 2467 & $282 I$ & 3275 & 3670 & 3509 \\
\hline $\mathfrak{A} \mathfrak{u} \boldsymbol{s} \mathfrak{f} \mathfrak{a} \mathfrak{r} \mathfrak{r} \ldots$ & 2236 & 2391 & 2598 & 2658 & 2389 & 2475 & 2583 & 2927 & 2988 \\
\hline 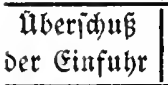 & - & - & - & - & 78 & 346 & 692 & 743 & 521 \\
\hline 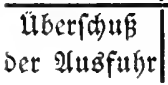 & 300 & I 78 & I 87 & $7 \mathrm{I}$ & - & - & $\rightarrow$ & - & - \\
\hline
\end{tabular}

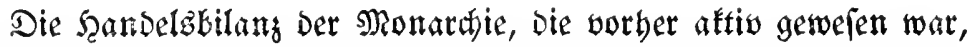

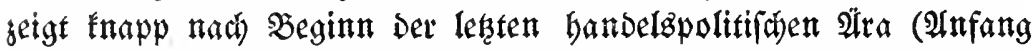
I906) eine langfame, aber Dentliche Sunahme Der Paffíttät, bie

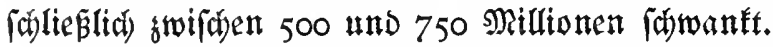

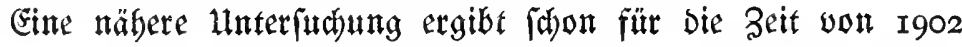

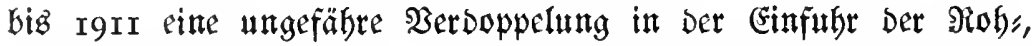

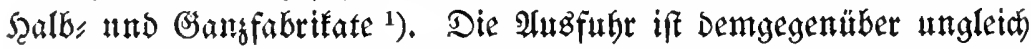
wentiger geftiegen, nur um rund $25 \%$. Weide Mlomente fprechen

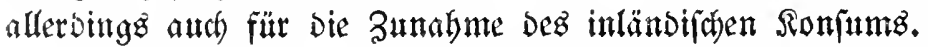

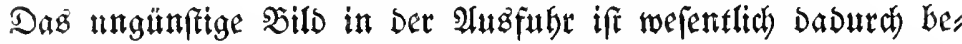

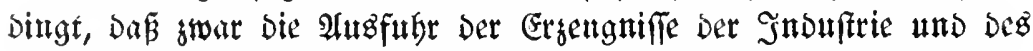
Bergbaues um rund $50 \%$ geftiegen ift, Dẩ aber die Der Ranbrits

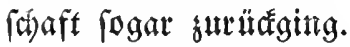

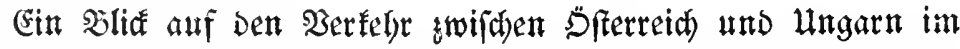

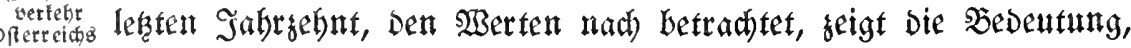

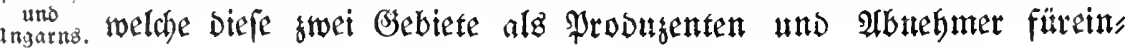
ander befizzent.

1) Wert Der Einfubren in Millionen Sronen:

$\begin{array}{cccc} & \text { Robftoffe } & \text { Sealbfabrifate } & \text { Ganbfabrifate } \\ \text { I902 } & \text { I } 003,5 & 249,1 & 467,7 \\ \text { I9I I } & \text { I } 831, \text { I } & 484,7 & 875,9\end{array}$




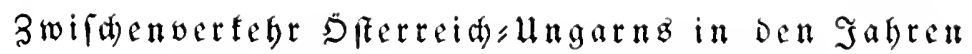

I 903 - I 9 I 3 (in Millionen Mronen).

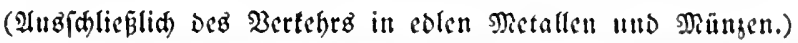

\begin{tabular}{|c|c|c|c|c|c|}
\hline Sabee & 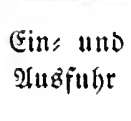 & $\begin{array}{c}\text { Einfubr } \\
\text { aus } \mathfrak{u} \text { ugarn }\end{array}$ & 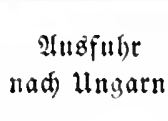 & $\begin{array}{l}\text { Mebrein: } \\
\text { fubr aus } \\
\text { ungarn }\end{array}$ & $\begin{array}{l}\text { Mebraub่fubr } \\
\text { nad) llngarn }\end{array}$ \\
\hline I 903 & I 848 & 944 & 903 & $4 I$ & - \\
\hline I 904 & 1967 & 993 & 974 & 19 & \\
\hline I 905 & I 992 & 988 & 1003 & & 15 \\
\hline I906 & 2272 & 1082 & II 90 & $\ldots$ & 108 \\
\hline I909 & 2592 & I 286 & 1306 & & 20 \\
\hline I9IO & $269 \mathrm{I}$ & 1294 & I396 & & 102 \\
\hline I9II & 2909 & 1377 & 1532 & - & 155 \\
\hline I9I2 & 3040 & I 457 & 1582 & & 125 \\
\hline I9I3 & 2863 & 1380 & 1483 & & 103 \\
\hline
\end{tabular}

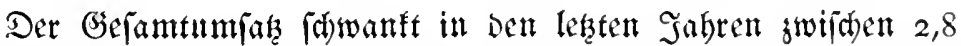

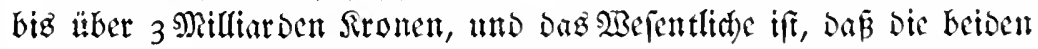

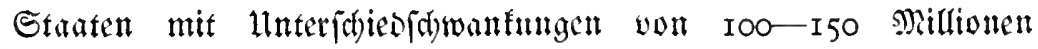
Sironen, waz ungefäbr $3 \frac{1}{2}$ bis $5 \%$ von Der Gefamtiumme entiprid)t, und Daher nid)t ing Gemidyt fällt, foft ju gletden Teilen partigipieren.

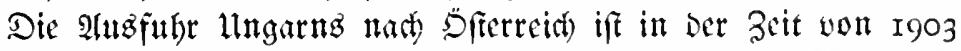
bisz r913 von 944 anf I 380 Millionen, D.i. wm 46,2\% geftiegen, wobei

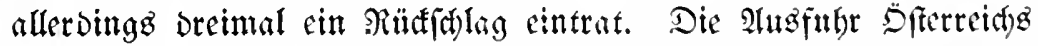
nact) Ungarn ift Dagegen in oer genannten Beit wnattzgefert gefticgen

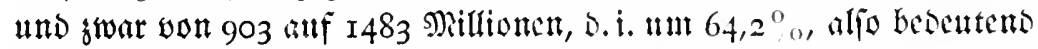

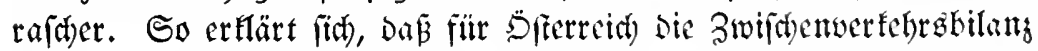

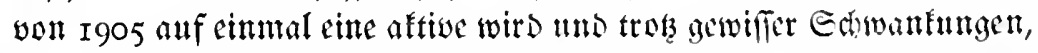
Die mit sen Ernten zulammenhängen, aftiv bleibt. $2 B a \mathfrak{s}$ Die $2 B$ aren

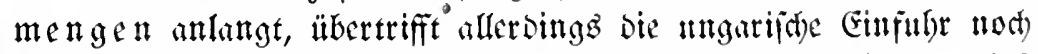

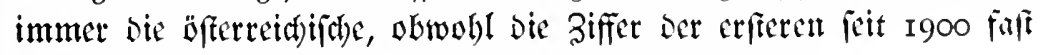
fonftant fällt, weil ber Eigentonfum llngarta fietgt.

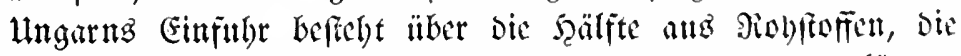

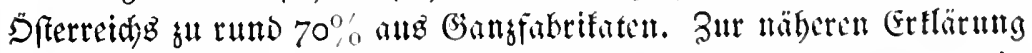

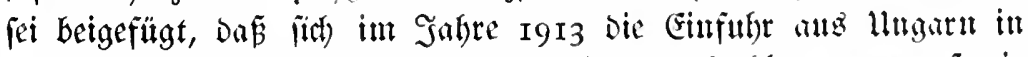
Getretbe, Mals, Seülienfrüthten, Mebl utto Moblprobuten, fowic Reis ${ }^{1}$ ) auf 507 Millionen bezifferte, in Sdlad t: und Zuguieb anf faft

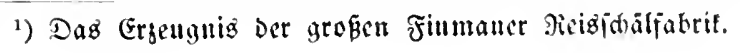


300, in tierifacen Wroduften und in Betränfen auf je rund 50 Millionen Sronen, in Bammollgarnen und $\mathfrak{B a r e n}$ Dagegen auf 32, in Lebre und Reberwaren auf 28 Millionen Sronen.

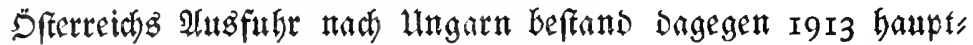
(ät)lids) aus folgenden Sinduftrieproduften:

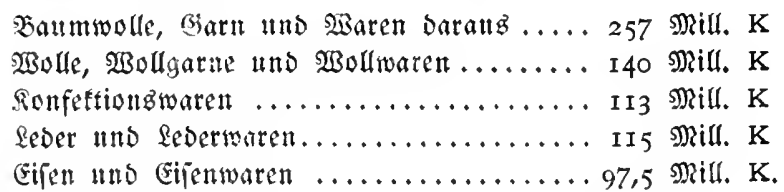

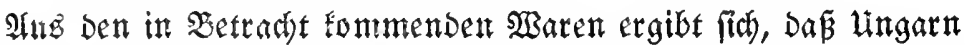
eben fetre worwiegende Agrarprobuftion nicht fo rajh gefteigert bat

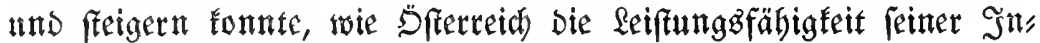
Duftrie, Die baher aud wadbjend nad lungarn importiert ${ }^{1}$ ).

Berfebr ntit dustano.

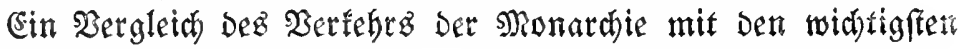

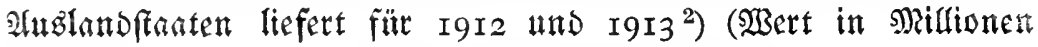
Sronen) folgentez $\mathfrak{B}$ ild:

\begin{tabular}{|c|c|c|c|c|c|c|}
\hline \multirow{2}{*}{$=\ldots$} & \multicolumn{3}{|c|}{1912} & \multicolumn{3}{|c|}{1913} \\
\hline & $\begin{array}{l}\text { Finfuhr } \\
\text { n. Sfierr.s } \\
\text { Uligarn }\end{array}$ & $\begin{array}{c}\text { Iusfunhr } \\
\text { a. SOfferr.: } \\
\text { Hutgarn }\end{array}$ & 3ujammen & $\begin{array}{c}\text { Einfubr } \\
\text { n. \$Fferr.: } \\
\text { Ingarn }\end{array}$ & 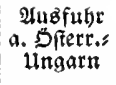 & 3ufammen \\
\hline Deut $\{$ d land $\quad . . .$. & I 405 & III 4 & 2519 & I366 & I I IO & 2476 \\
\hline Grob̧britannien .... & 245 & 257 & 502 & 217 & 270 & 487 \\
\hline Ber. Staaten..... & 349 & 64 & 413 & 323 & 70 & 393 \\
\hline Rnßland $\ldots \ldots \ldots$ & 228 & $9 \mathrm{I}$ & 319 & 202 & 102 & 304 \\
\hline Stalien .......... & I63 & 239 & 402 & 169 & 216 & 385 \\
\hline Brit. Indien ...... & I99 & 63 & 262 & 233 & 95 & 283 \\
\hline
\end{tabular}

Bertebr mit

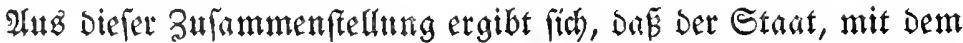

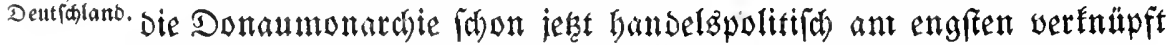

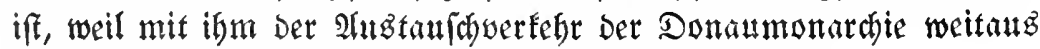
bie gröste Rolle fpielt, befanntlich Dentidyland ift ${ }^{3}$ ).

1) Inalog wie Deuffalands Sulthfrie nad Der Donammonardfie.

$\left.{ }^{2}\right)$ Dhne Beredunggertebr, Edelmetalle, Münsen.

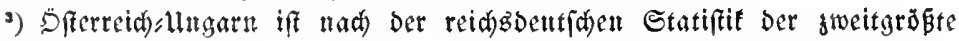
26nebner Dentfdlands, Das I 9 I3 Der Monardie für I I04,8 Mill. Mt. Waren lieferte, und unr England mebr, nämlid für I 438 Mill. Nat.; ant britter Stelle ftebt Ruß̈land mit 880, an vierter Frantreid mit 780 Mill. Mf. WBaz Den Smport nad Dentfdland anlangt, ift allerbings ber ber Bereinigfen Staaten 


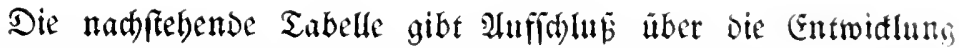

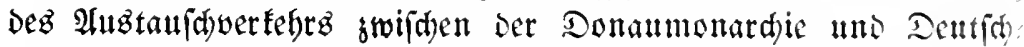
land, forwie über die Aftivität uno Palïtwität biefeg Berfebrg:

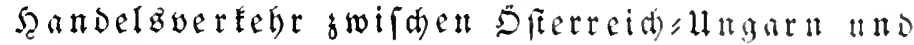
Dentibland ) I902-I9I3 (in Milliomen Sronch).

\begin{tabular}{|c|c|c|c|c|c|c|c|c|c|c|c|c|}
\hline & |1902 & 1903 & 1904 & 1905 & 1906 & 1907 & 1908 & I909 & I910 & I9II & 1912 & $\mathrm{I}_{9} \mathrm{I}_{3}$ \\
\hline $\begin{array}{c}\text { (Einfubr } \\
\text { aแz Beutidjland }\end{array}$ & 659 & 706 & 775 & 820 & 923 & 993 & IOIO & 1082 & II 69 & I 282 & I $44 \mathrm{I}$ & 1397 \\
\hline $\begin{array}{c}\text { 2usfubr } \\
\text { nad) Deutfd)lans }\end{array}$ & 937 & 1024 & 974 & $104 \mathrm{I}$ & 1053 & 1085 & 974 & 972 & 992 & 977 & I I 4 I & I I 43 \\
\hline Gefamtverfebr & 1596 & 1730 & 1749 & 1861 & 1976 & 2078 & I 984 & 2054 & $216 I$ & 2259 & 2582 & 2540 \\
\hline $\begin{array}{l}\text { uberfauk ber } \\
\text { Etnfubr aus } \\
\text { Deutfdland }\end{array}$ & - & - & - & - & - & - & 36 & 110 & 177 & 305 & 300 & 254 \\
\hline $\begin{array}{l}\mathfrak{a b e r i d ) u B ~ b e r ~} \\
\text { Ausfuhr nad } \\
\text { Dentfdlans }\end{array}$ & 278 & $3^{18}$ & I99 & $22 \mathrm{I}$ & 130 & 92 & - & $\ldots$ & - & - & - & - \\
\hline
\end{tabular}

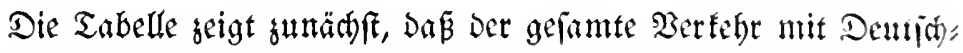
lans vont tund I596 Millionen (I902) auf 2540 Millionen (I913), alio um 59\%, geftiegen iff. Dabei ift intereffant, baß innerbalb sicfer I Iahre Der Export Der Donaumonataie nad) Deutidhlano mit I-I, I

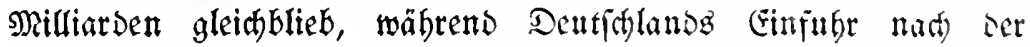
Monardie von 695 auf 1397 Millionen, aljo auf mebr als bas Doppelte, fitieg.

Der $\mathfrak{B e n d e p u n f t ~ f a ̈ l l t ~ m i t ~ D e r ~ n e t t e n ~} \mathfrak{B e r t r a g g a ̈ r a ~ j u f a m m e n , ~}$

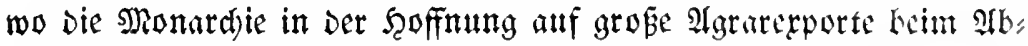

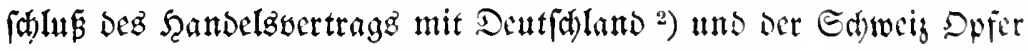

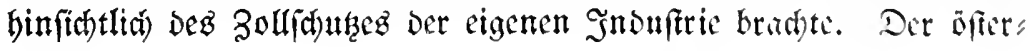

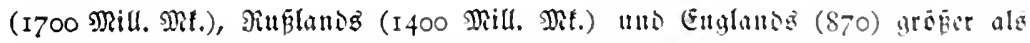

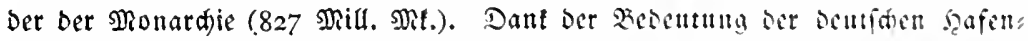

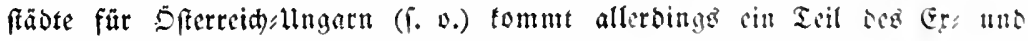
Smports Der Donaumonardie im Bertebre mit Dettiftans nur ald Furdifubr gut in Setradyt. metalle.

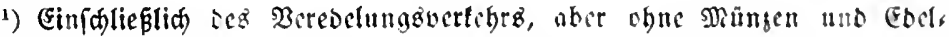

2) Ibge (d)loffen am 25. Tamuar 1905; in Rraf̈t feit I. Miär 1906. 


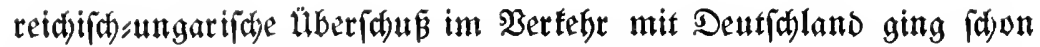

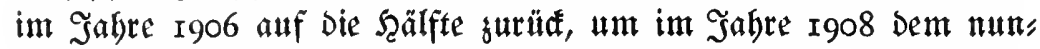
mehr frändig bleibenden Paffítum Pląz za madjen.

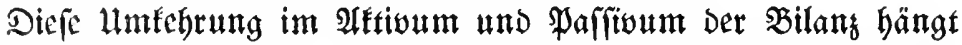
aber gewiß̄ nid)t nur mit Der für Deutfalands Exportinduftrie vorteils hafteren Ģeftaltung Dez Şandelövertragez zulammen, fondern auth

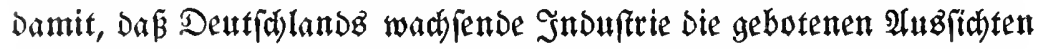

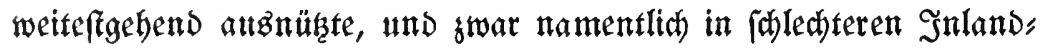
jabren.

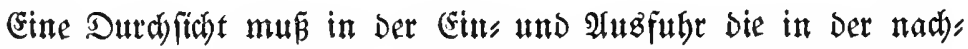
frebettben Tabelle auf S. I26 und I27 aufgeftithrten und etnander

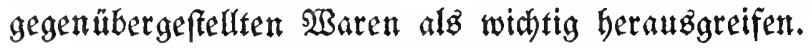

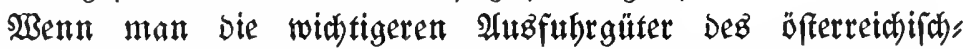

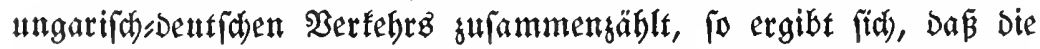

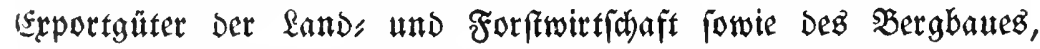

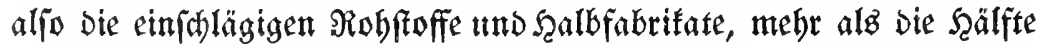

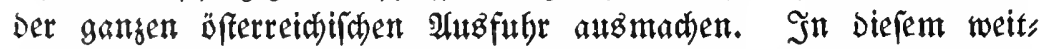
gebenden Maje liefert die Donaumonardje Der Deutfhen Snduftrie

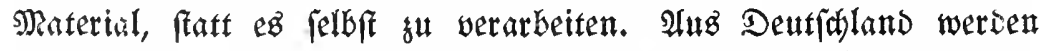

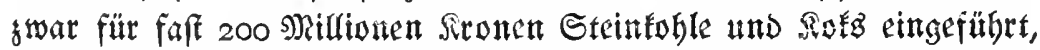
und Durd) Bermittlung Des Deutf(jen überfeebandels Baunwolle

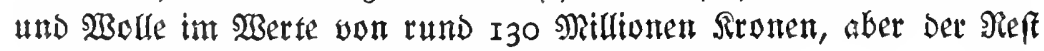
von megr ald I Milliarde find Snduftrieartifel ${ }^{1}$ ).

Die wirtichaftliá)e überlegenleit Dentfdlandz gegenüber Der Domanmonardje gebt aus biefen Biffern am jhlagendfen bervor.

Die Bedeutung Der Deutiden Jndufte ift Daz Ergebniz der befonderen Tüchtigfeit, Des raftofen Fleifes und Der Drganifations"

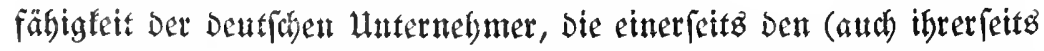

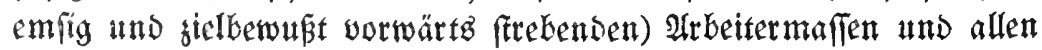

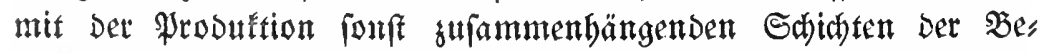
völferung Rerdienft und mit Dem Serbienft Der Esefamtheit Den erböbten

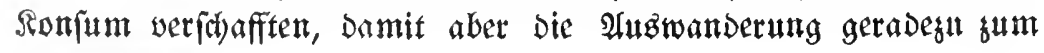

1) Zwirden Dentfaland unto Der Donaumonardie eineríeitz, Dfferreid

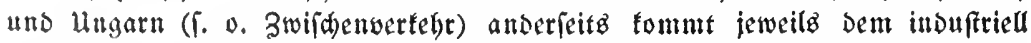

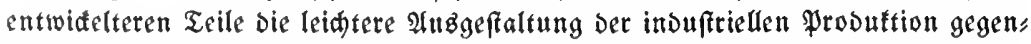

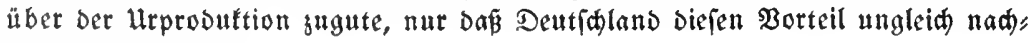

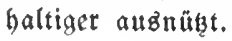


Stillfand bradten. Die worbanoenen Duellen uno Möglidfeiten

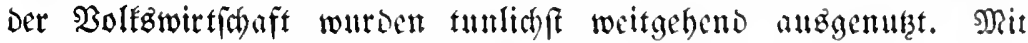

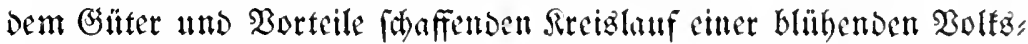

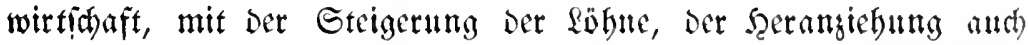

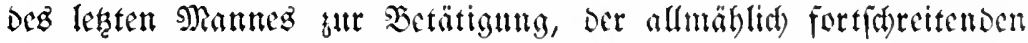

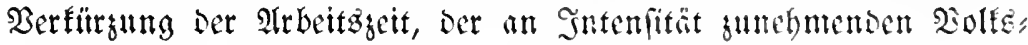
bildung, nidyt gullegt Danf Dem nationalen unb frantlid)en Eelbft: bewneffetn beben fid Sultur und Sonfum. Die bentiche Snous

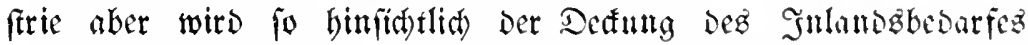
immer leiftungafühiger, anf Dem Weltmarte immer ̈̈berragender "nd unwiberfeglicher ant Ginfun werden milfen. Das ift ja auth Der

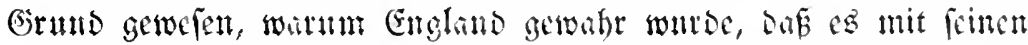

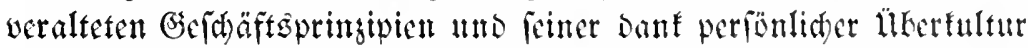

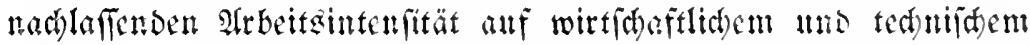
Bebiete von Deutfd)land überfligelt fei; Besbalb cutfolofien fid die

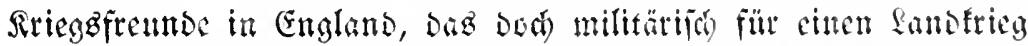

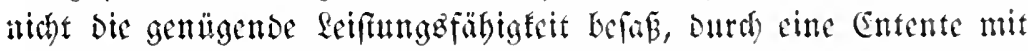

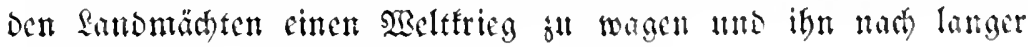
Poebereitung jum Entflammen jut Eringen.

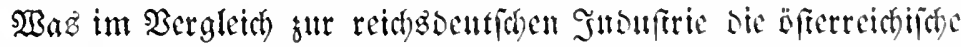
uno igre Entwidfutig betrifft, mus man in Berüdfichtiguttg zieben,

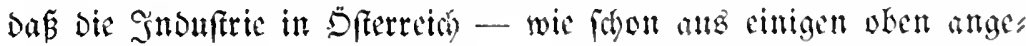

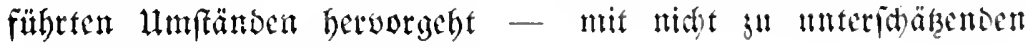
Shwierigketen z̆l fämpjen liat.

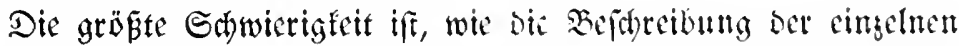

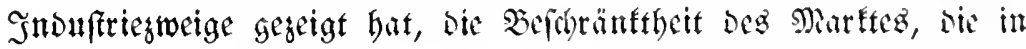
Dem geringen $\mathfrak{B o f l f t a n d}$ Der Bevölfermm, ja in Der Ifrmm tho

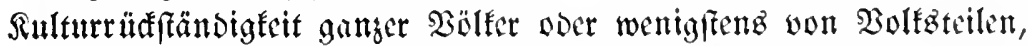
befonders ber agrarifaen, begründet iff, if metter sfiltich fie liegen.

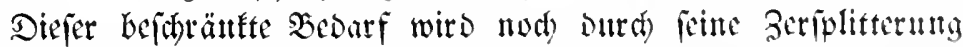

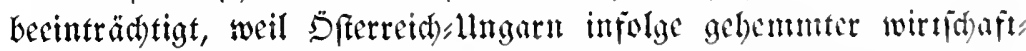
licher unb fultureller Entmiálumg, infolge der Bobengefinltung uno

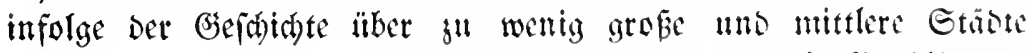
fowie über genügende Berkebrawege verfügt, uno bie Bevilfermis in gang ungewöbnlid hobem Mabe national unb regismal ver,

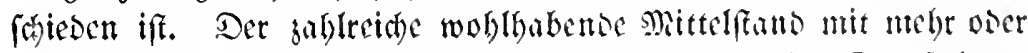

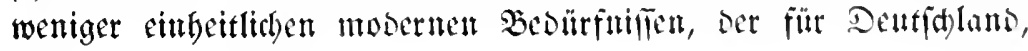


Die widtigften Waren DeB

\begin{tabular}{|c|c|c|c|}
\hline \multirow{3}{*}{ Barenbenenunng } & \multicolumn{3}{|c|}{ 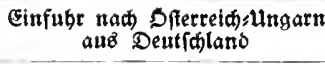 } \\
\hline & \multicolumn{3}{|c|}{ Bert in Midionen Stronen } \\
\hline & 1905 & 1908 & 1912 \\
\hline 1. Agrar $=$ und forftprodutte & & & \\
\hline 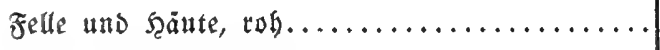 & II & 16 & 25 \\
\hline 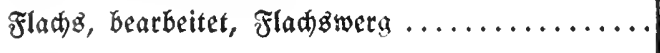 & 9 & 9 & 8 \\
\hline 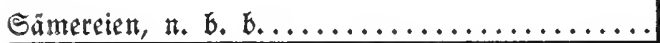 & 9 & II & 14 \\
\hline Snmme I $\ldots \ldots \ldots \ldots \ldots \ldots \ldots \ldots \ldots \ldots \ldots$ & 29 & 36 & 47 \\
\hline 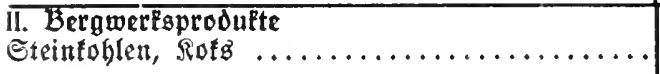 & 95 & 157 & I96 \\
\hline Sumtme II $\ldots \ldots \ldots \ldots \ldots \ldots \ldots \ldots \ldots \ldots \ldots$ & 95 & 157 & 196 \\
\hline Summe I $u$ nd II $\ldots \ldots \ldots \ldots \ldots \ldots \ldots \ldots \ldots$ & I24 & I93 & 243 \\
\hline III. Ilber/eei/des Cetilmaterial u. Jnduftrieprodufte & & & \\
\hline 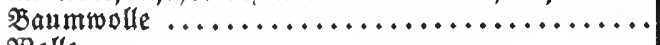 & 28 & 50 & $4 \mathrm{I}$ \\
\hline 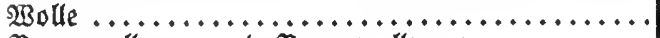 & 66 & 66 & 85 \\
\hline Baumwollgarn uno Baumwollwaren .......... & 12 & I8 & 29 \\
\hline Wollgarne und $\mathfrak{Z}$ Bllwaren $\ldots \ldots \ldots \ldots \ldots \ldots$ & 27 & 36 & 43 \\
\hline 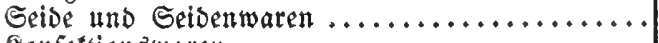 & 24 & 28 & 38 \\
\hline Ronfettionstuaren $\ldots \ldots \ldots \ldots \ldots \ldots \ldots \ldots \ldots \ldots$ & 9 & 8 & 13 \\
\hline 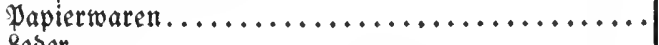 & 22 & I7 & 20 \\
\hline 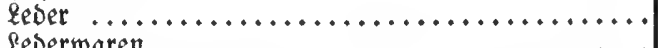 & 24 & 34 & $5 \mathrm{I}$ \\
\hline 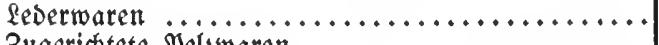 & 6 & 7 & 23 \\
\hline Zugerichtete $\mathfrak{p e l g i v a r e n}, \ldots \ldots \ldots \ldots \ldots \ldots \ldots$ & I3 & 14 & 24 \\
\hline hol & 7 & IO & 23 \\
\hline 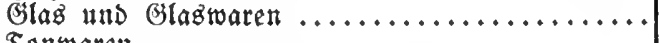 & 2 & 5 & 7 \\
\hline 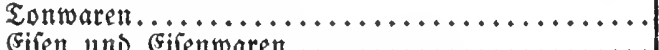 & 4 & 6 & 9 \\
\hline 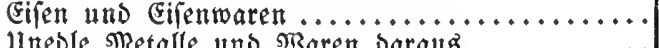 & 25 & 56 & 89 \\
\hline & $\begin{array}{l}53 \\
4 \mathrm{I}\end{array}$ & $\begin{array}{l}59 \\
62\end{array}$ & $\begin{array}{r}72 \\
144\end{array}$ \\
\hline $\begin{array}{l}\text { Majdinen und Ipparate } \ldots \ldots \ldots \ldots \ldots \ldots \ldots \ldots \ldots \\
\text { Golb: tnd Silbertwaren. } \ldots \ldots \ldots \ldots \ldots \ldots \ldots \ldots\end{array}$ & $2 I$ & 49 & $\begin{array}{r}144 \\
42\end{array}$ \\
\hline & 44 & 28 & 42 \\
\hline 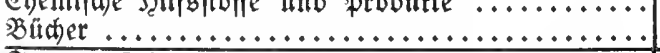 & 66 & 45 & 56 \\
\hline Enmme III $\ldots \ldots \ldots \ldots \ldots \ldots \ldots \ldots \ldots \ldots$ & 494 & 98 & 850 \\
\hline Gejamtiumme von I, II, III................ & $6 \mathrm{I} 8$ & $79 I$ & 1093 \\
\hline Gefamteinfubr $\ldots \ldots \ldots \ldots \ldots \ldots \ldots \ldots \ldots$ & 803 & 993 & I44I \\
\hline
\end{tabular}

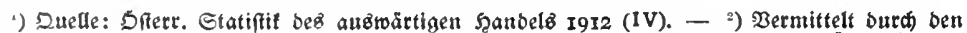

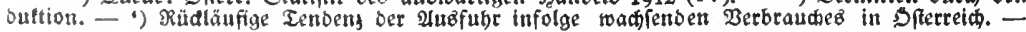




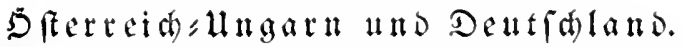

\begin{tabular}{|c|c|c|c|}
\hline \multirow[t]{2}{*}{ Warenhenennumg } & \multicolumn{3}{|c|}{$\begin{array}{c}\text { Sugfube aud ORerreidsungatn } \\
\text { nat Deutidlanb') }\end{array}$} \\
\hline & 1905 & 1908 & 1912 \\
\hline 1. Agrar = und forStprodutte & & & \\
\hline 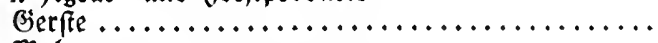 & 66 & 43 & $\left.37^{\circ}\right)$ \\
\hline 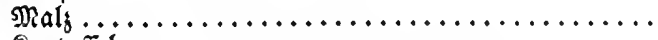 & 30 & 23 & $\left.17^{3}\right)$ \\
\hline 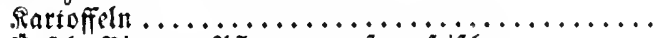 & 4 & 3 & 2 \\
\hline Âpfel, Birnen, Pflaumen uitw., friīh ......... & 16 & II & 12 \\
\hline (Ed)ladtuieh und Pferbe $\ldots \ldots \ldots \ldots \ldots \ldots \ldots$ & 107 & 54 & 39 \\
\hline Geflügel, lebeno tho tat $\ldots \ldots \ldots \ldots \ldots \ldots$ & 15 & I7 & $\left.14^{4}\right)$ \\
\hline 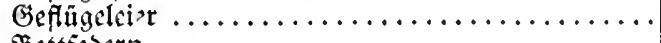 & 85 & 99 & 129 \\
\hline 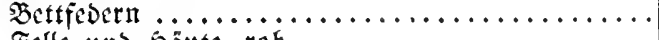 & $2 I$ & I7 & I7 \\
\hline 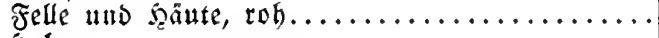 & 49 & 43 & 67 \\
\hline 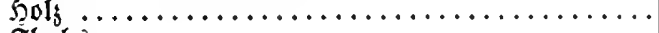 & 125 & 105 & I 14 \\
\hline 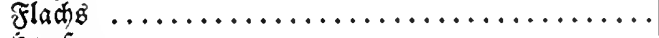 & 5 & 5 & 5 \\
\hline 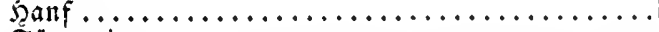 & 3 & 3 & 35 \\
\hline 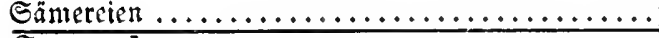 & 12 & 16 & 32 \\
\hline 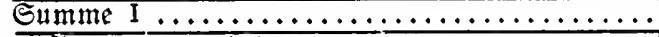 & 538 & 439 & 490 \\
\hline II. Bergwerfaprodufte & & & \\
\hline Eteinfohlen $\ldots \ldots \ldots \ldots \ldots \ldots \ldots \ldots$ & II & 12 & 7 \\
\hline 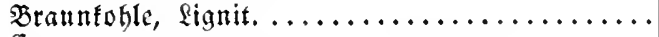 & 63 & 88 & 76 \\
\hline 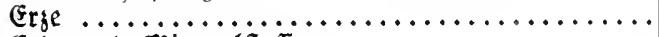 & 9 & 8 & 8 \\
\hline Erd uno Minteralftoffe $\ldots \ldots \ldots \ldots \ldots \ldots$ & I 2 & If & 17 \\
\hline 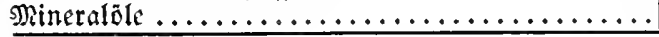 & 5 & 18 & 40 \\
\hline Eumme II $\ldots \ldots \ldots \ldots \ldots \ldots \ldots \ldots \ldots \ldots \ldots$ & 100 & 140 & 148 \\
\hline Summe I $\mathfrak{n} n d$ II $\ldots \ldots \ldots \ldots \ldots \ldots \ldots \ldots$ & 638 & 579 & 638 \\
\hline III. Uber/esi/hes Ccetilmaterial u. Jndultricprodufte & & & \\
\hline 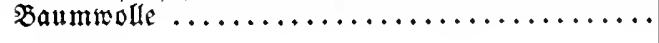 & 6 & 6 & 9 \\
\hline Baumivolfgarme und $\mathfrak{B a u m}$ allwaren $\ldots \ldots \ldots \ldots$ & 4 & 6 & I5 \\
\hline Eeide und Eeidentmaren ................... & 7 & II & II \\
\hline 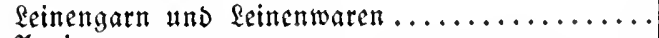 & I5 & I 2 & I4 \\
\hline 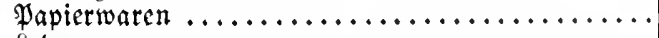 & 2 & 3 & 3 \\
\hline 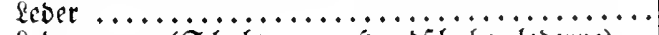 & 4 & 4 & 6 \\
\hline 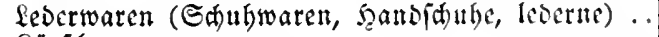 & 17 & If & 14 \\
\hline 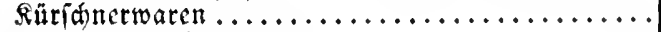 & 3 & 5 & 8 \\
\hline hrol und frolswaten $\ldots \ldots \ldots \ldots \ldots \ldots \ldots \ldots$ & I 2 & 14 & 20 \\
\hline Ğlas und Glasmaren $\ldots \ldots \ldots \ldots \ldots \ldots \ldots \ldots \ldots$ & 12 & I4 & 15 \\
\hline 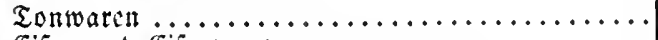 & 6 & 6 & 7 \\
\hline 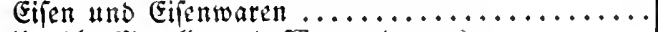 & 6 & 7 & II \\
\hline Uneble Netalle mo $\mathfrak{W a r e n}$ baranz ........... & I7 & 22 & 38 \\
\hline Mafdinen und $\mathfrak{A p p a r a t e}_{\sim} \quad \ldots \ldots \ldots \ldots \ldots \ldots$ & 4 & 5 & 7 \\
\hline Gold" und Silberwaren $\ldots \ldots \ldots \ldots \ldots \ldots \ldots \ldots$ & 36 & $2 \mathrm{I}$ & 84 \\
\hline 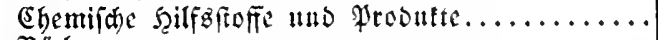 & I9 & $2 \mathrm{I}$ & 28 \\
\hline 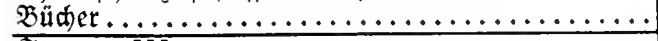 & $2 I$ & 17 & 14 \\
\hline Snmme III $\ldots \ldots \ldots \ldots \ldots \ldots \ldots \ldots \ldots \ldots$ & I9I & $18 \delta$ & 304 \\
\hline Ecfantiumme von I, II, III $\ldots \ldots \ldots \ldots \ldots$ & $8 z y$ & 767 & 942 \\
\hline 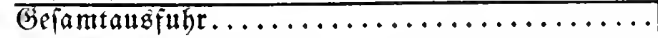 & 1020 & $95^{8}$ & II 4 I \\
\hline
\end{tabular}

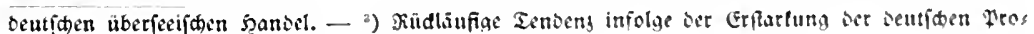

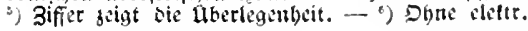


Frantreid), England eine fo widftige Rolle fpielt, iff es wor allem, Der in Der Monardie nut bei Den Deatidhen uns Stalienern, bei Den Thlyed oflawen teilweife, fonft aber wenig ober gar nicht worbanden ift.

Die Zeriplitterung Des Bedarfz Gindert aud bie fo notwendige Spesialifierang, die die englifue Snduftrie vor allem auszeidnet, fie troh Freibandels befäbigt, Dank der Scerftellung von Typen in einer Reibe von Fabrifzstweigen eine tomangebende Rolle allf Dem Beltmarfte zu ipiclen und bie auch Der Deutidjen Snduftrie fut fo großjem Erfolge werbolfen hat.

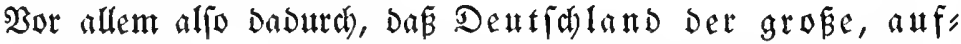

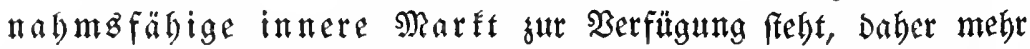

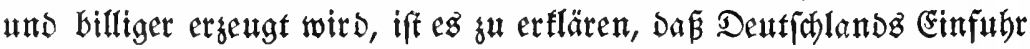

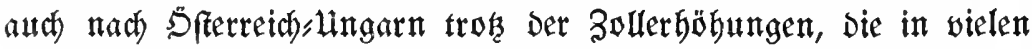
Artifeln im Sabre I906 fattgefunden baben, fo febr geftiegen ift.

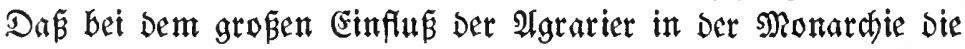

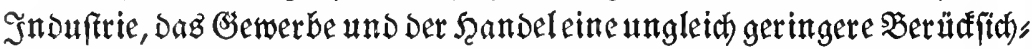

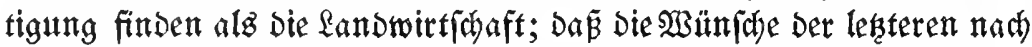

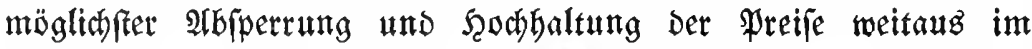
Borbergrund feben (obrobl Der Getreideknjum Der Monardie nur in normalen Beiten im Snlande gedect werden fann und Das, felbe begüglich Der Fleifaprodutte in eintigen Sabren ebenfallz eintreten Dürfte); Daß biaber dic Sandeispolitif, namentlich jente gegenüber

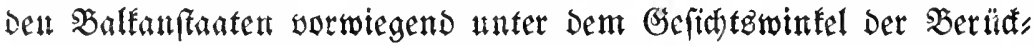

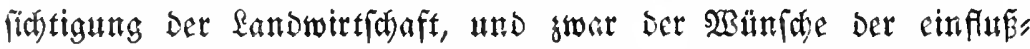

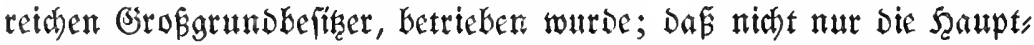
laft Der Steuern auf Den Sedultern Der Snouftrie rubt, fondern vor allent die alftienbeftenernng nad fursfithtiger Auffafinng gebands Gabt unb fo bie notwendige Ifloziation dez Rapitalz im modernen Stil gefindert wird: all biefe Miffëänoe find gegenüber Den geldils Derten Eridwerniffen, wenn fith aud die Wirtung jedes eingelnen llmitandez geltend madyt, nut folde von geringerer Bebentung.

Benn man bie mannigfadten tiefgegründeten Şinderniffe in Errwägung ziebt, Die bizber ber vollen wirtjd)aftlichen Entwidflung

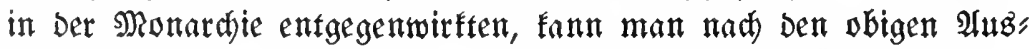
fübrungen Den leiftungen Der Bolfswirtiduaft in S̈fterretch und Ungarn - abfolut betrachtet - Die anerkenmung nicht verfagen.

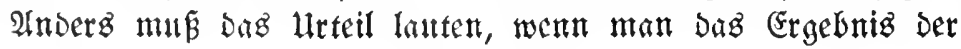




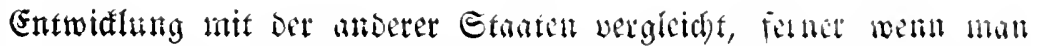

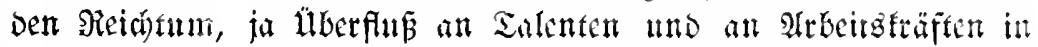

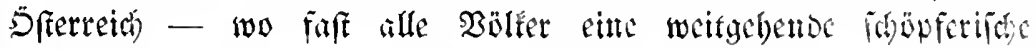

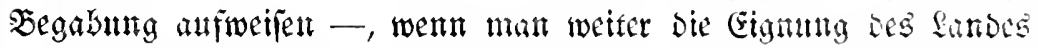
für eine mannigfaltige, infenfioe fanowirtida aft ${ }^{1}$ ), ber Jicichtum an

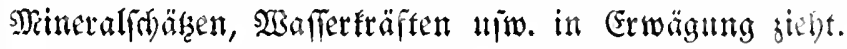

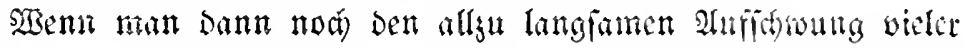

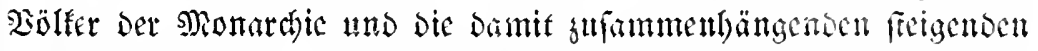

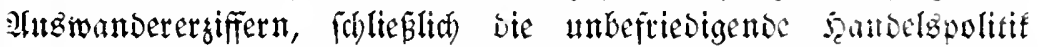

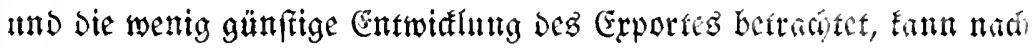

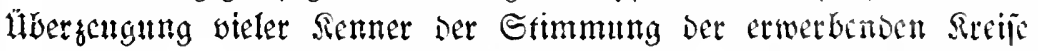

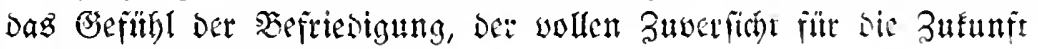
nicht zat Gelunng fommen ${ }^{2}$ ).

Ban Diefer Grundiage atsgebeno, fteft die Fragi jut Beam,

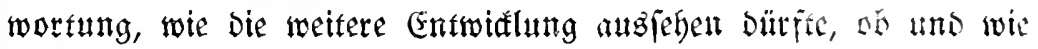

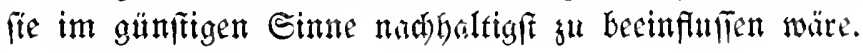

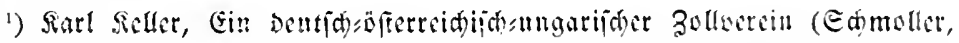
39. Sahrg. 2. 5. I9I5), weif mit Retht Darauf him, Daß sas Etcppentlima ba:

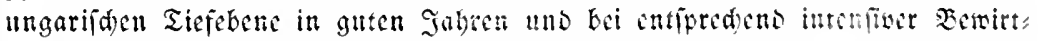

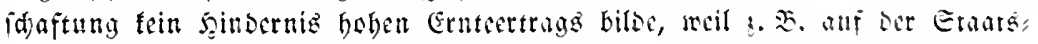

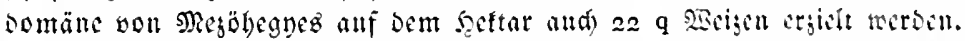

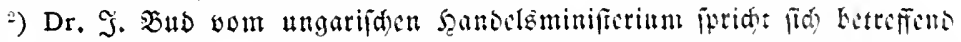

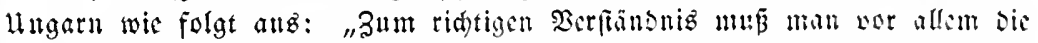
wirtisaftlide Depreffion Eennen, welthe Den lebten Sabren Des XIX. Tabrhunterts

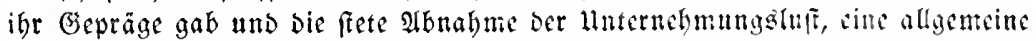
Wirtidaftzfodung unb eimen Dauernoen, fets funchmenoen Berfall in sent

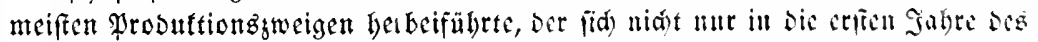

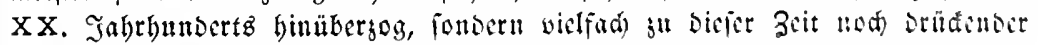

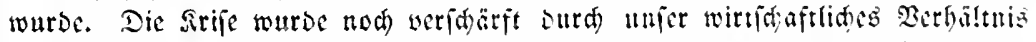

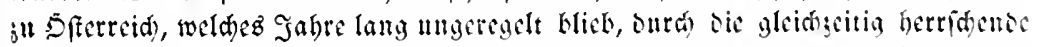

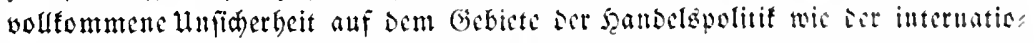
nalen Berträge und Durd Den mit geringen llnterbed ungen Sabre lang mitenoen

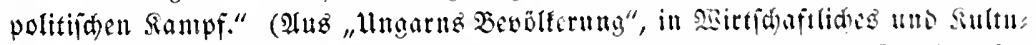

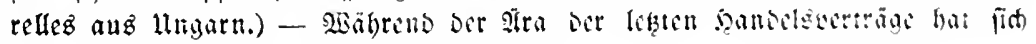

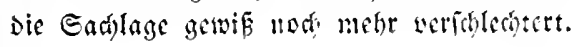


 \\ Dir כutunft. \\ "SRöge uns Der Geift von $1914 / 15$ erbalten Bleiben!"}

Sindenburg.

Die Batrteilung Der Zuftnft von Dferretd

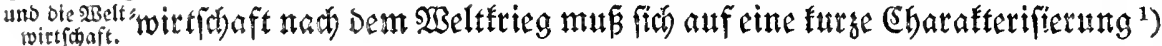
Deg Srieges mit fpesieller Betonnng feiner tiefgebenden weltwirtfd)aft: lishen uno handelspolitichen urjachen und Tendengen ftützen.

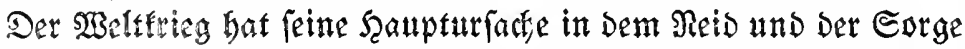
Der Fetnde weget Dez rajhen und mähtigen $\mathfrak{A}$ uf wirtichaft Dentidylands, wegen feines wack jenden, bandelspolitifaen

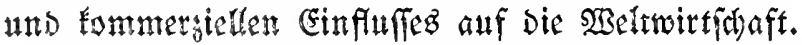

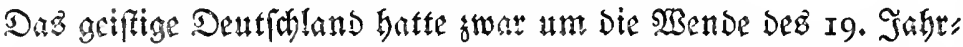
Gundertz Der WeltEultur eine Blitteget bödyfer geiftiger Entwieflung

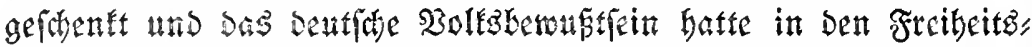
friegen wan 18 I3 bis I8I5 einen weiteren füftigen Impuls ersalten;

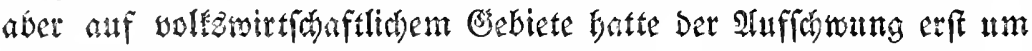

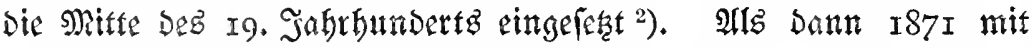

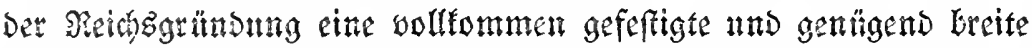
Bafis Der Entridtung gefictert war, begant anf Dem einfigen Ges mengfel won Mittels und Rleinfaaten, Danf glänzenter Drganifation gröpten Stiles unter ber Fübrung von Siffenthaft und mobernfer

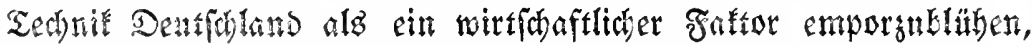

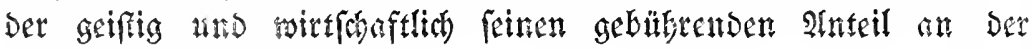
Weltuitufflyaft begelute.

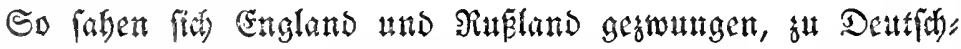

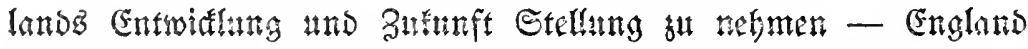

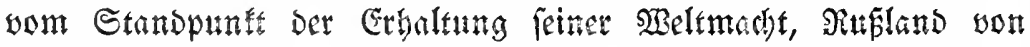

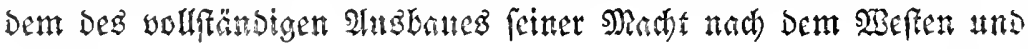

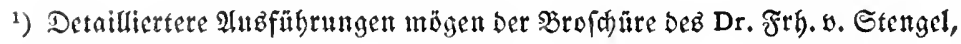
3ut Frage ber wirtichaftliden uno gollpolitifhen Einignng, bei Eallway, ents nommen werbet.

2) EB if intereffant, wic Fricorid \&ift, Der Bortämpfer gegen Englant

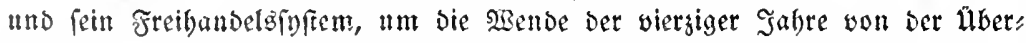

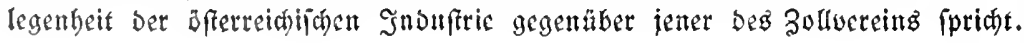


nad) Borberafien, wobei and) Der freie Zugang zum Mittellänoijhen Meere und Damit naty Dem Itlantifonen Dzean fidfergufellen toar.

âs Bertreter Dez Romanentums, nahm and) Frantreid jur Frage Stellung, in feimem Stols won 2 nfang an won Revancheges Danfen geleitet. Die Donaumonardsie und die Türfei fpielten bei

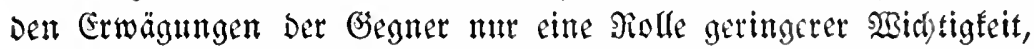

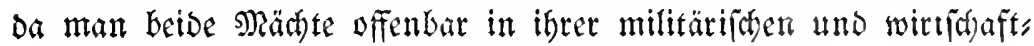

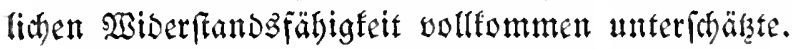

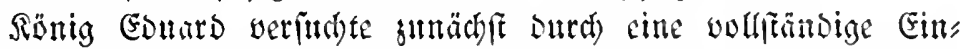
treifungspolitif Deutialland ja แmmthmmern und ez ju erorüden,

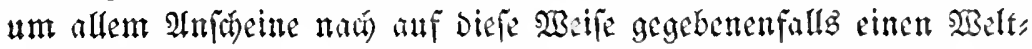
frieg zu vermeiden. Der (Einfreilungaplan wutbe aber Dasurt) nich) untwefentlich geftërt, Daßs Saifer Frans Jofer, ritterlidg und tren, bie an ifn geffelleu Zumutungen ber Seifilfe in energiliácr, feine Dentung zulaffender $23 e i f e$ ablebnte.

(Sitgland entidied fith nun im weiteren Petlant trob allen Ents

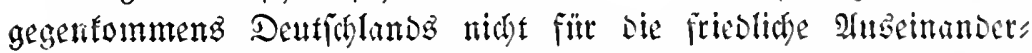

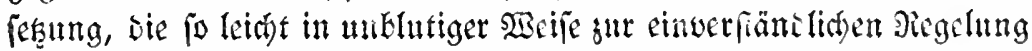
Det MRachtfphären, wenn nötig auj bem Beóiete ber gefamten 2 delts

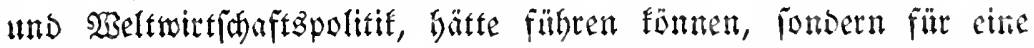

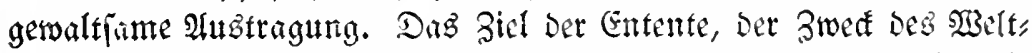
frieges und feiner jubrelangen eifrigen 2orbereitung wort aljo bie

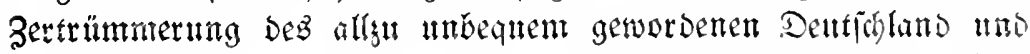

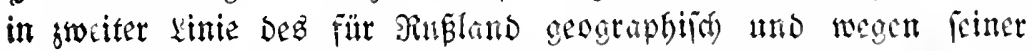

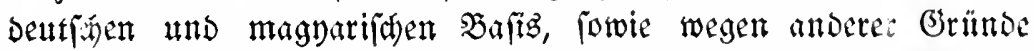

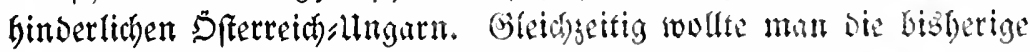

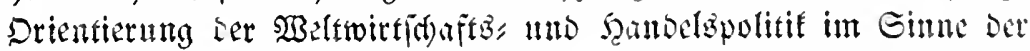

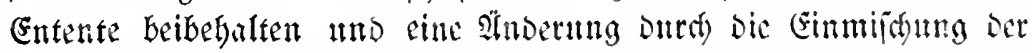

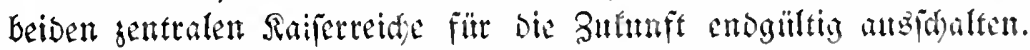

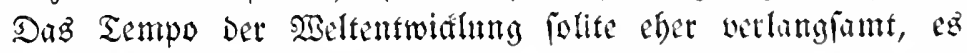

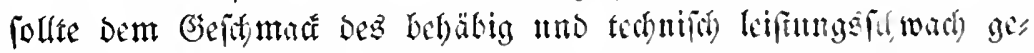

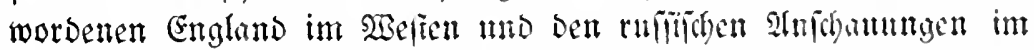

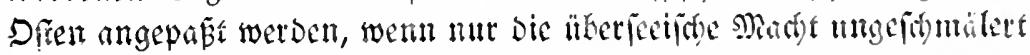

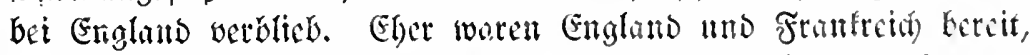
Die \$elffultur Der fóndfenden Siruft eines groben Solfes un Etantes fu berauben, fowie tweite Gebiete Sfterreid) slngarns, sie surd) mebr als ein Jahrtarfend gegen sen Dften erfolgreids wertisigt worden 


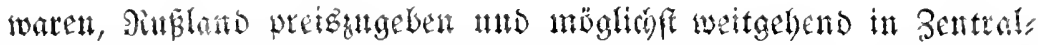
curopa eine balkntartige Sleinfraaterei einstifubren, alg fith bent menen, won Dentichland angeftebtent Sitt's ber Soldpolitif uns

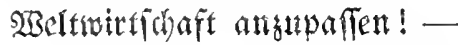

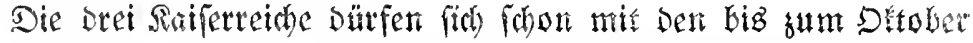
IoI 5 ergielten Erfolgen - von benen eit gut Teil auf bie Reifungs"

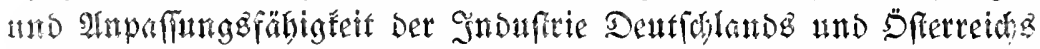

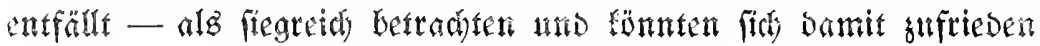

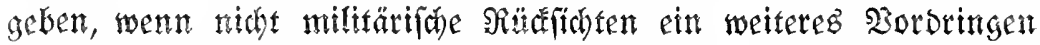

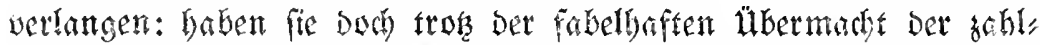
reithen Feinde ihe eigenten Gebiete won Den Arngreifern befreit, ja tent

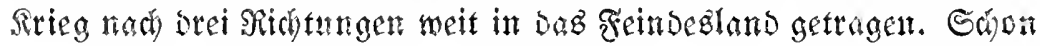
sic ersielten Erfolge bilden, abgefeben won Dem erruigenen Sraft gefübl und bem etröbten Blauben an fich felbft, fowie Dank ber wt

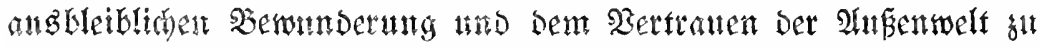
biefer bewährten, webrbaft atierordentlichen Seifung ber Bentrals

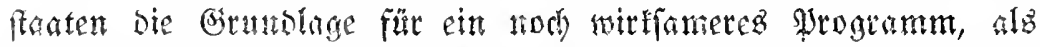

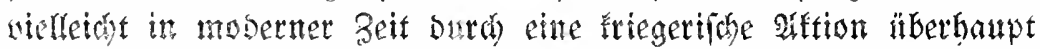

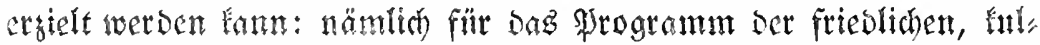

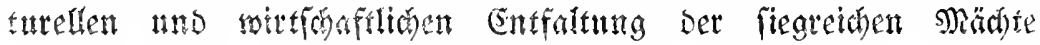
felbft nits ber befrembeten Stanten, fowie Der gegenfetigen Dnts:

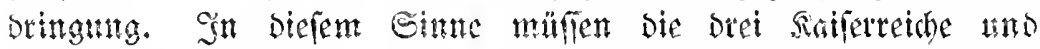

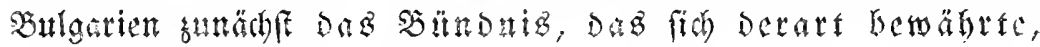

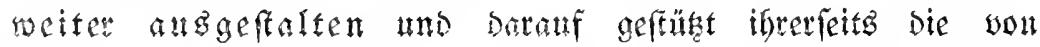
England gelcifete Molitie ber Entente in Dem Sinne verfolgen,

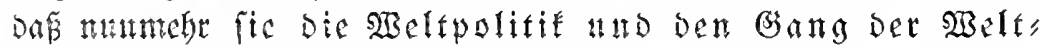

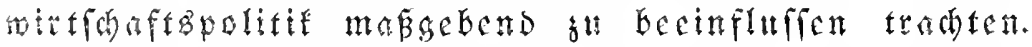

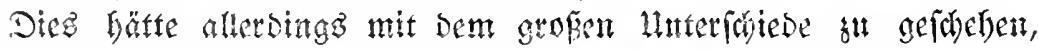

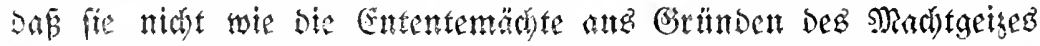

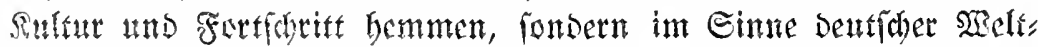

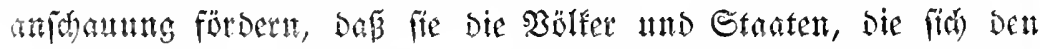

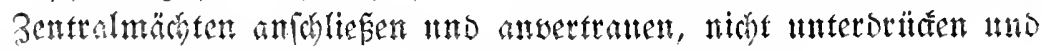
Gefertiger, fondern fie unterftitsen und entwiatin ${ }^{1}$ ).

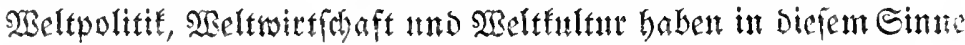

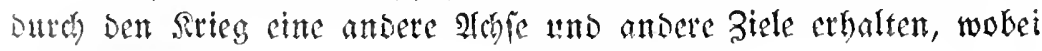

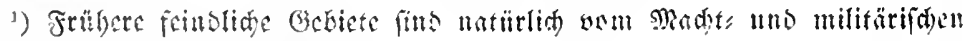

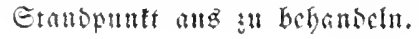




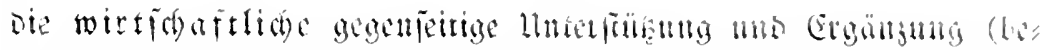

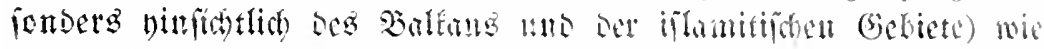

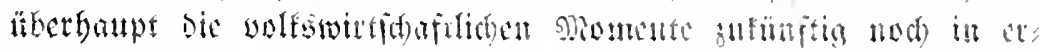

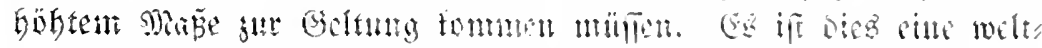

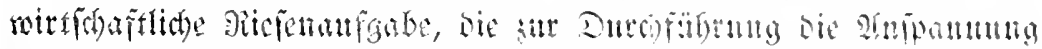

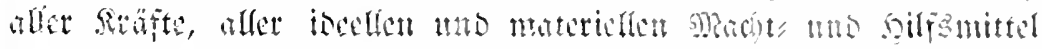

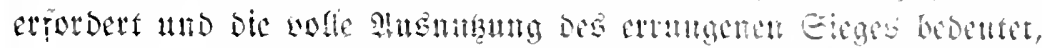

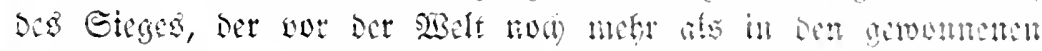

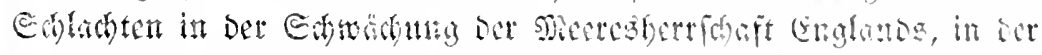

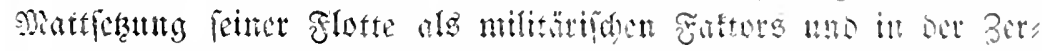

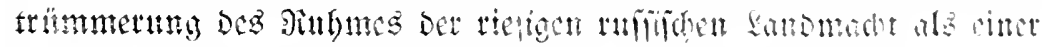

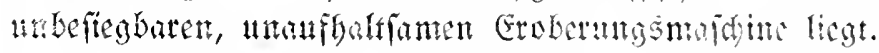

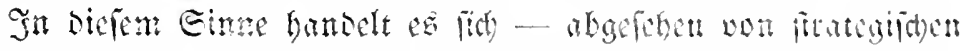

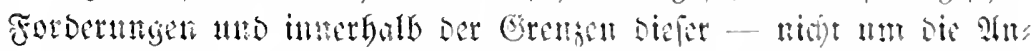

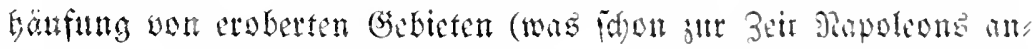

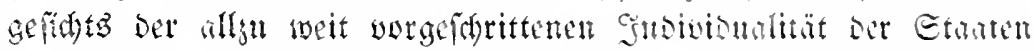

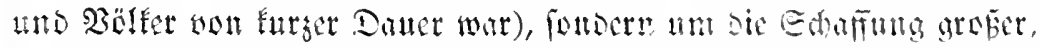

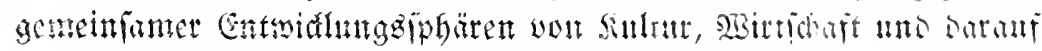

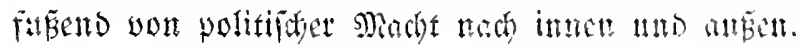

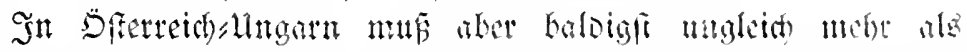

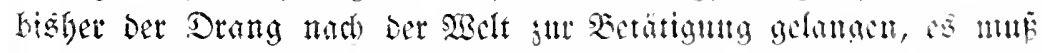

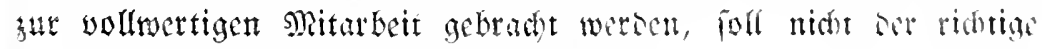
3eitpunft anf immer scrïnmt werden.

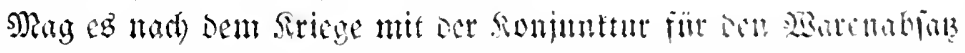

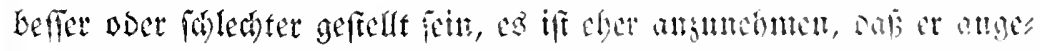

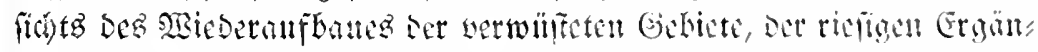

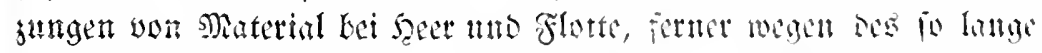

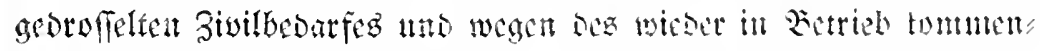

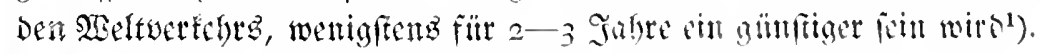

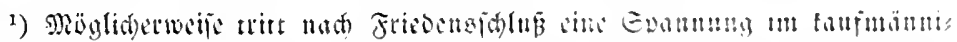

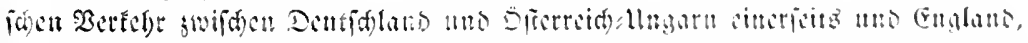

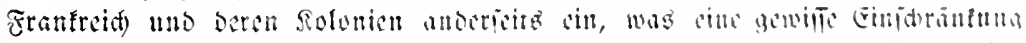

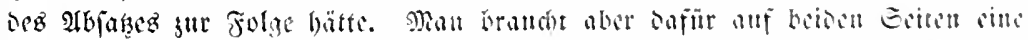

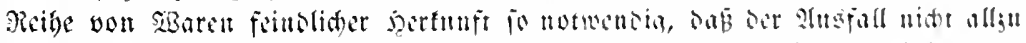

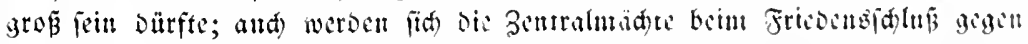

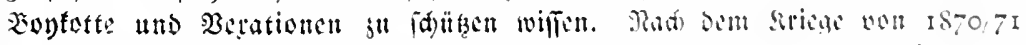

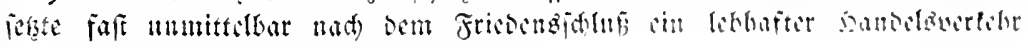
jwifdea Dentialans nus Fratterid cin. 
E马 wird แun vermutlich Die alte Erricheinung Plaz̧ greifen, Daf

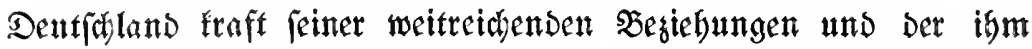
fur Berfügung febenden Bafiz won bodffebender, unters nebmender Bevölferung und leifungzfäbiger Produftion an ben

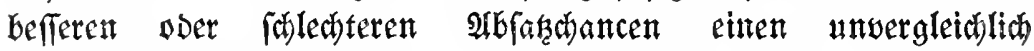
größeren Inteil nimmt, als die Monardjie, wie es fith $\mathfrak{s}$.

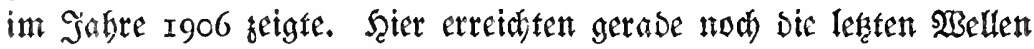

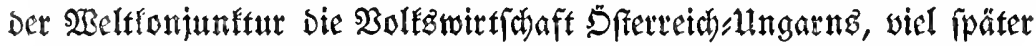
als im fonftigen 2usland; natitlid) Dauerte aud bie ginffige Seeins

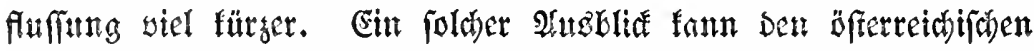
Bolfswirt faum befriedigen und gerade jefit, wo bie alte Donatmon ardie in Diefem 2 Selffriege, Danf Dem Dpfermute und Der Begeifterstng

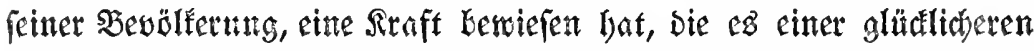

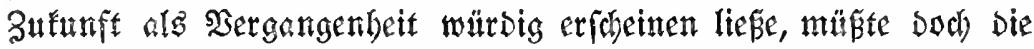

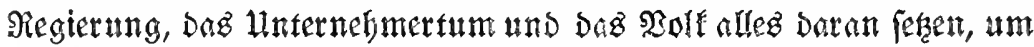

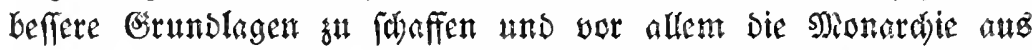

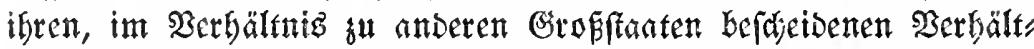

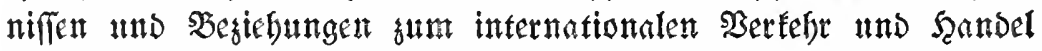

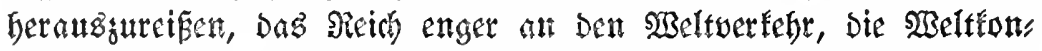
junftulen und Die Damit werbundene günftigere Berteilung Der Rifffen

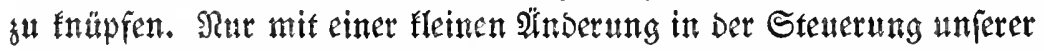

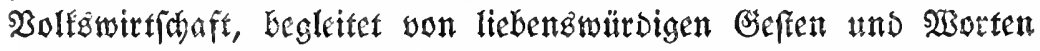

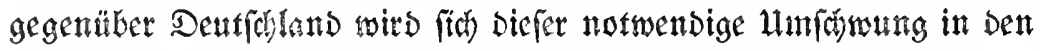

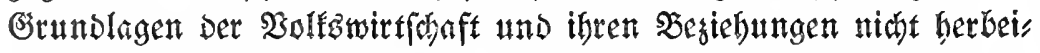

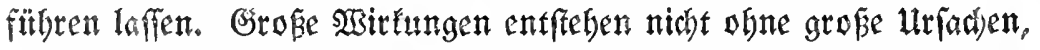
und grofe Berfäumniffe laffen fich nid th Durd cin Sandumbregen

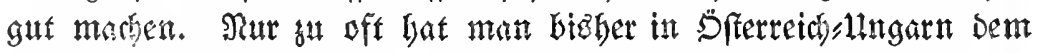
Staat, Der Regierung und Den Eirmelnen vorgemorfen, Daß fie tad

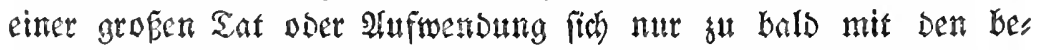
treffenden feifungen zuftieden gaben und bie weiters rotwentige Energie sut vollen Sfugnüzung Der leifungen nidht immer auf"

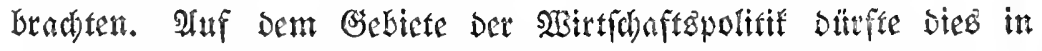

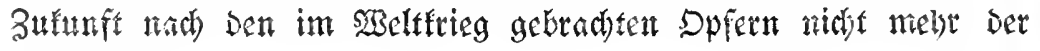
gall rein!

Es ift aber cine grumblegende Ändernng Des Surfes am fo not: wenbiger, als mögliduerweife nad) Der wunberbaren syindfitlle, die

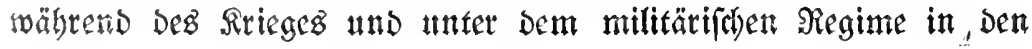


nationalen wats politifonen Sämpfen ber Monardie cingetretit ift, angefact wie won einer Wimbsbrant, ser alte politifde Saber in er,

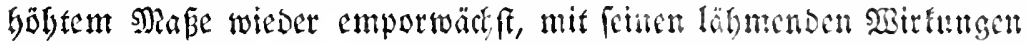

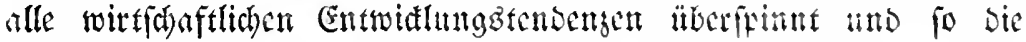
Befteblangen Der Expanjion weitgebeno bemmat. Da fanth nut

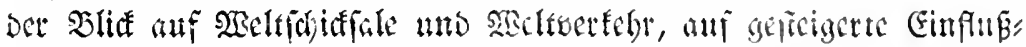

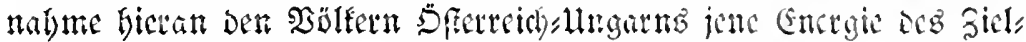

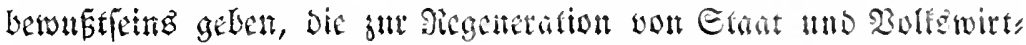

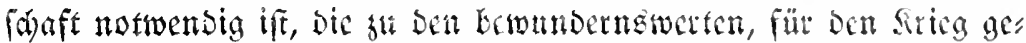

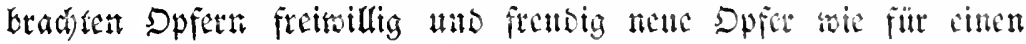

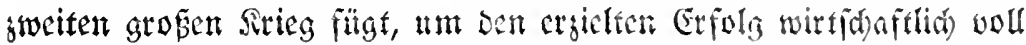

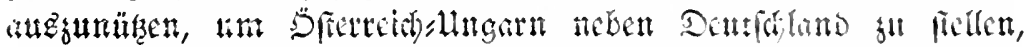

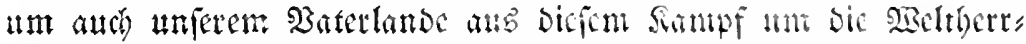

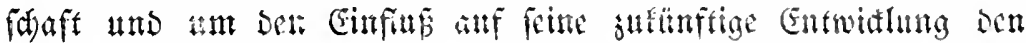

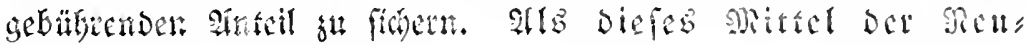

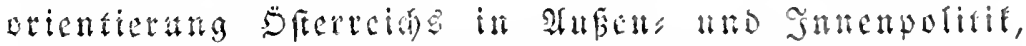

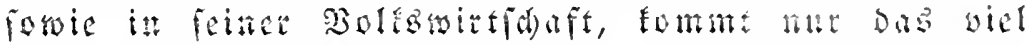

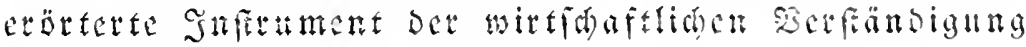

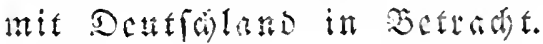

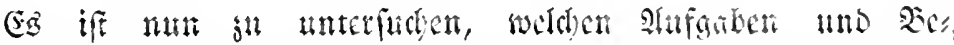

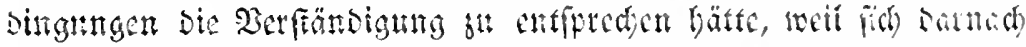

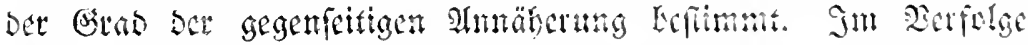

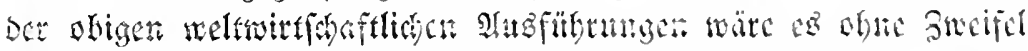

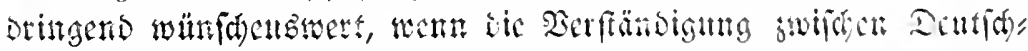

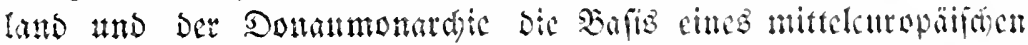

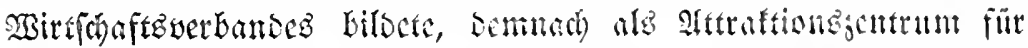

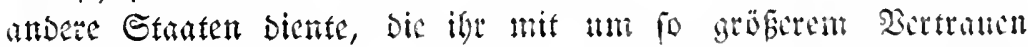

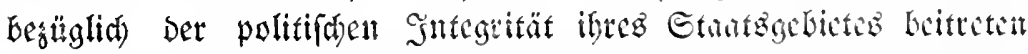
E⿱艹

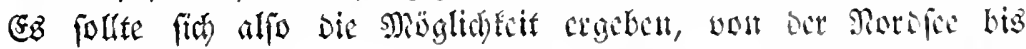

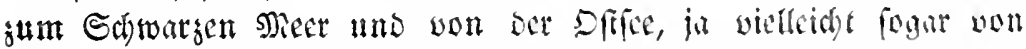

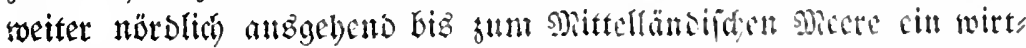
ichaftlich geeintez europäifdes Zentrulgebiet ju farffon, bus wic cin

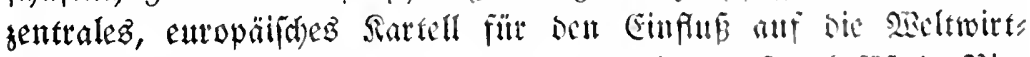
(6)aft alle Bortaile moderner Drganifation im grobiat bejäbe! Sirr

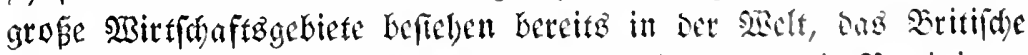

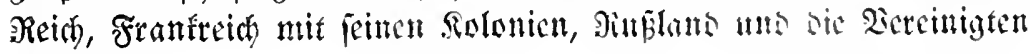




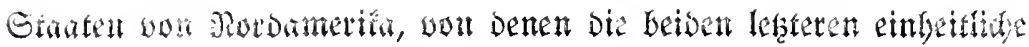

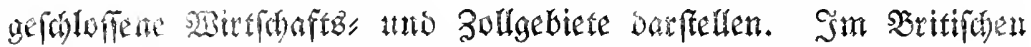

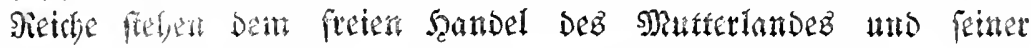

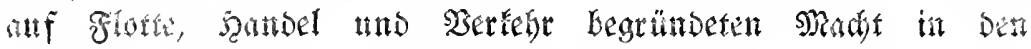

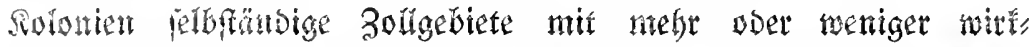

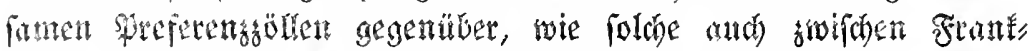
reirh und pinen Solonien gelten. Doch arbeiten betanntlid

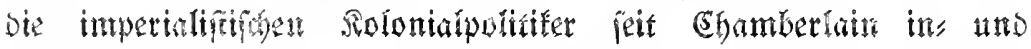

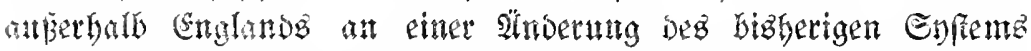

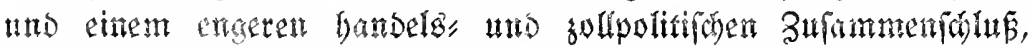

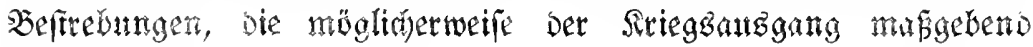
fortsern mirs.

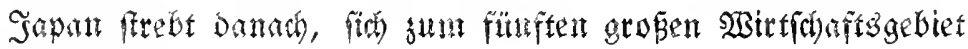
bcrattgrubition.

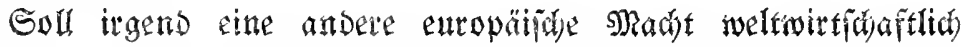
gegentiber diefen Riefenorganifationen mafigebend gu soorte

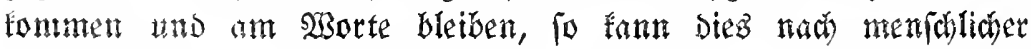

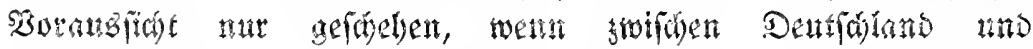
S̈fterreidillngarn eine analoge Drganifation ber gegenfeitigen

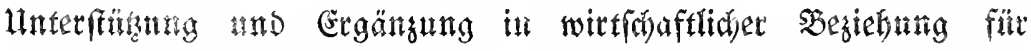

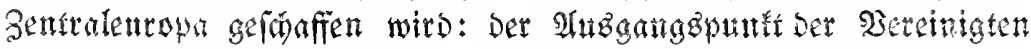

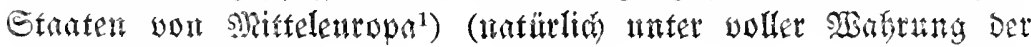
Souverünitäten).

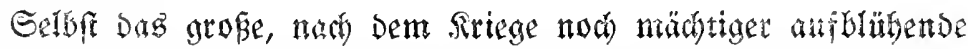

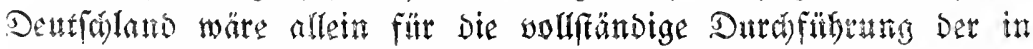

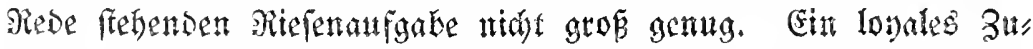
fommenwiren mit bell geetgneten benabbaren foltoren wiro

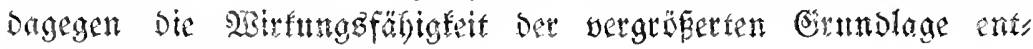
fprechend zut Beltung bringen.

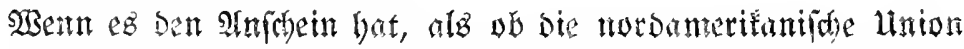

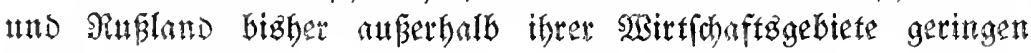
oder überbant Eciten Sinflü nahmen, fo trïgt ebeti, befonders

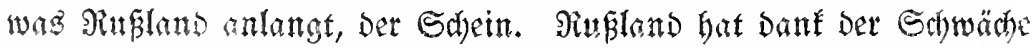

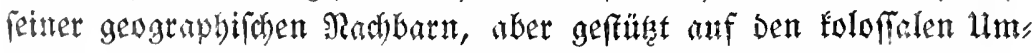

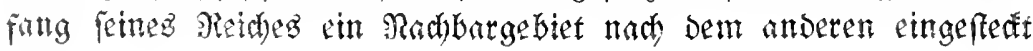

1) Sgl. Ramman, Mittelenropa, bei Geotg Reimer, Betlin. 


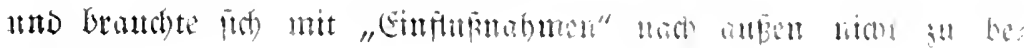
gnttgen ').

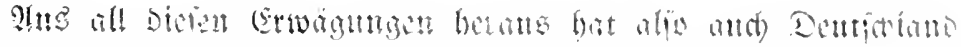

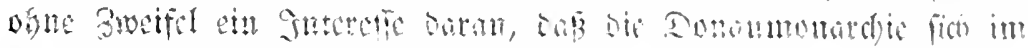

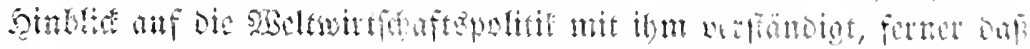

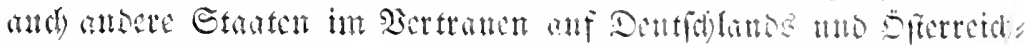

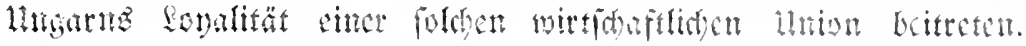

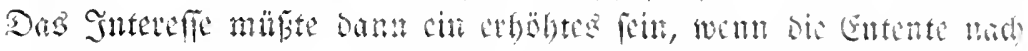

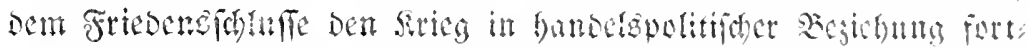

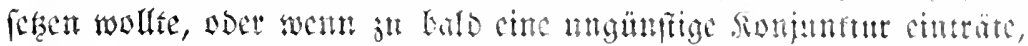

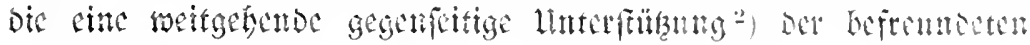

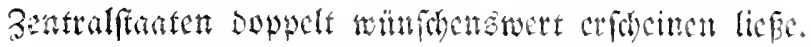

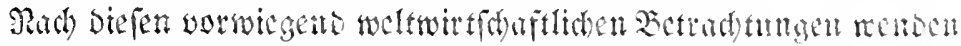

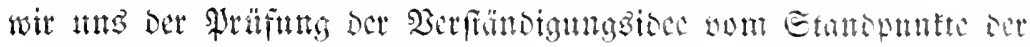

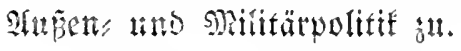

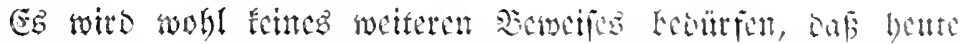

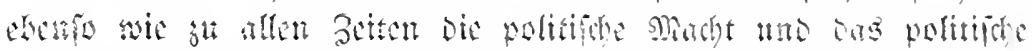

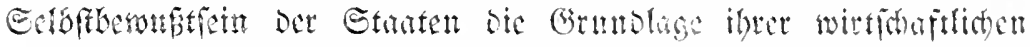

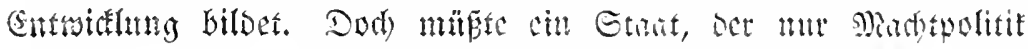

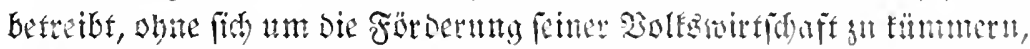

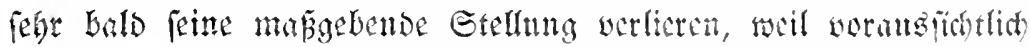

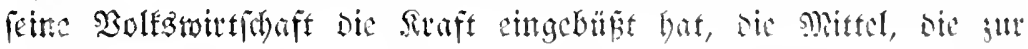

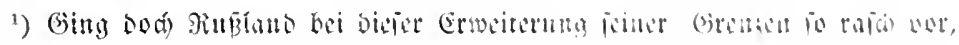

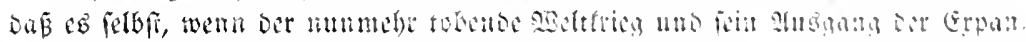

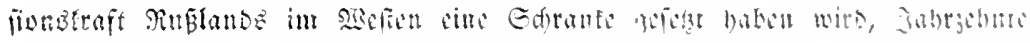

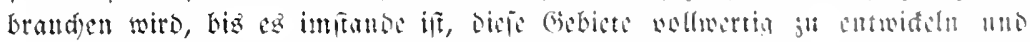

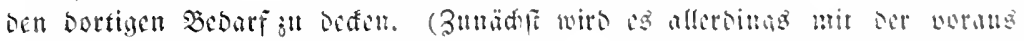

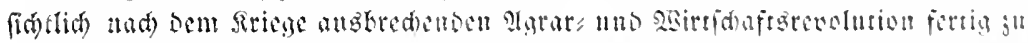

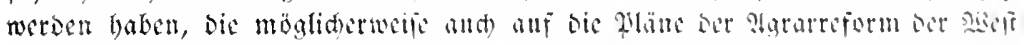

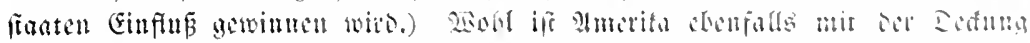

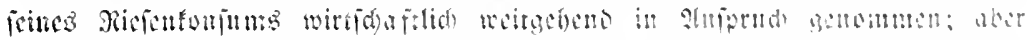

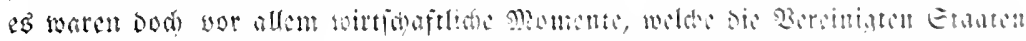

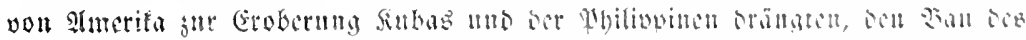

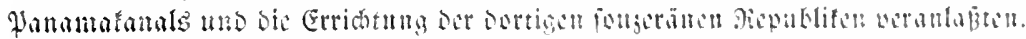

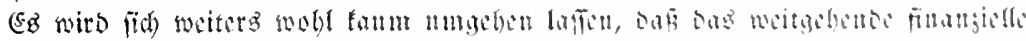

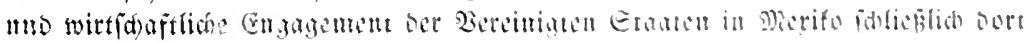

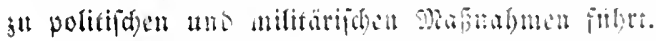

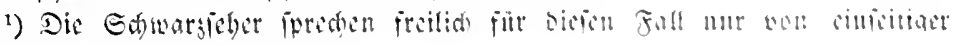

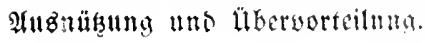




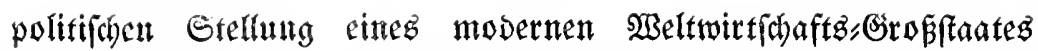

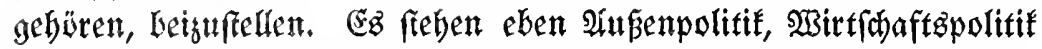

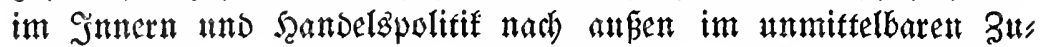
jammenbang uno fömnen wernïnftigermaßen nut nach Demfelben Syftem betrieben wetoen. Sut ein ftarfer Staat, nod beffer mebrere

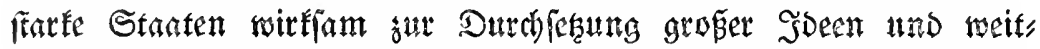
gebender \$rogramme vereinigt, fönten eine wirtunggodle Sandels" politif gegenüber Dem Ifuslande fut Geltung bringen, ober gar voll

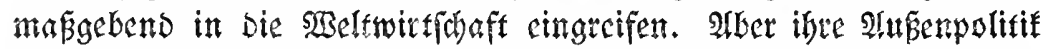

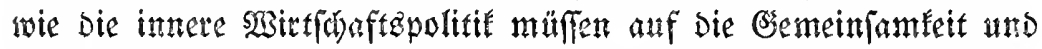
Das gletche \$rogramm abgeftimmt fein, foll nicht fut Frende Der äubern und innern OSeguer bei Der erften Belafungsprobe Die Ber,

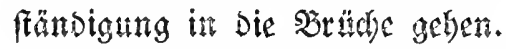

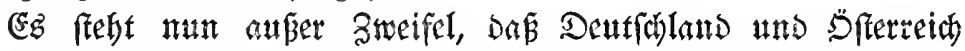
zut 2ltsgeftaltung ibrer politifhen Madd auf Dem Rontinente

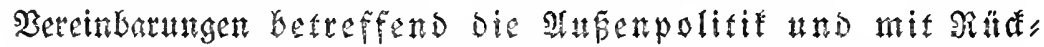

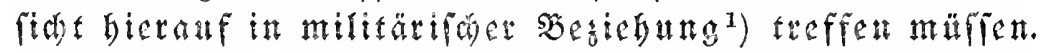

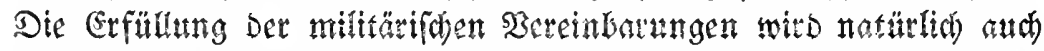

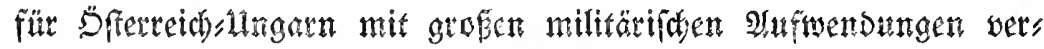

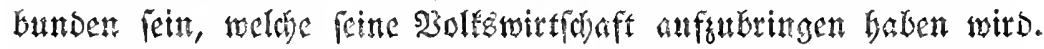
Die Einfalumg Der notwendigen, weitreichenden 3ufagen wirb aber nut bont yon ben Erwerbsterfen ertugen werben fonnen,

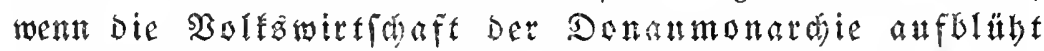

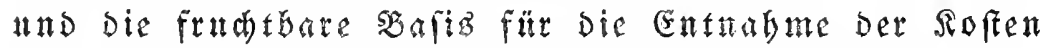

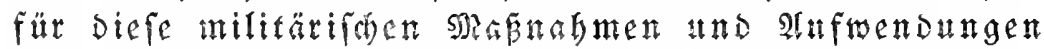
bilbet. Es liegt alfo felbft in Deutfolands militäriforem Sntereffe,

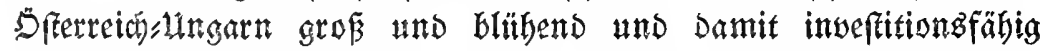
an feiner Seife ż wiffen. Sciervon bängt Der Wert Der Flanfen Dectung Durch Sfterreibusungarn gegenüber Dem Dften uno SïDen,

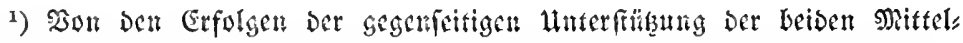

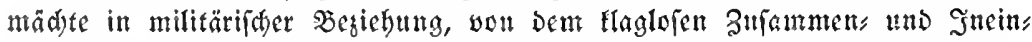
anderarbeiten Der Seere und Seeresteile find felbft bie notorifaen Miesmadaer

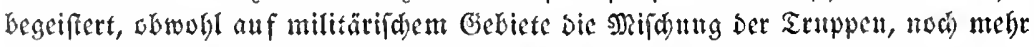
Die Berteilung Des jemeiligen Befeblaredtes biel beiflere Dinge find als bie gemein

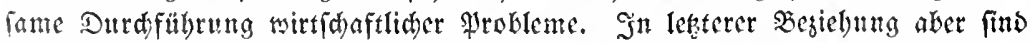

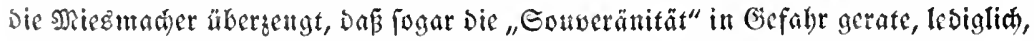

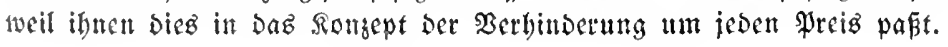




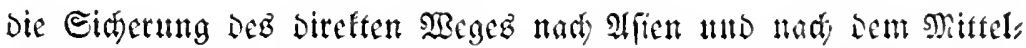

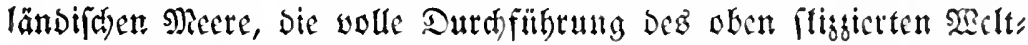

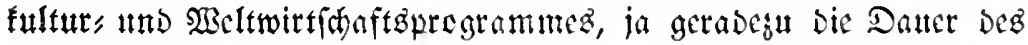
łänftigen Beltfriedens ab, Den Deutfdland nut im Berein mit ciner

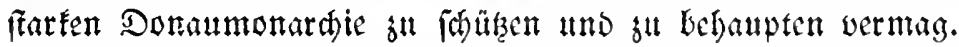

Wenn im worigen Sabrfunderte bie won Diferteid worgeithlagene

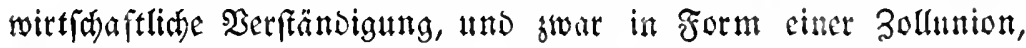
gerabe wegen bes sibiderfandes won Preuben nicht juftande tam,

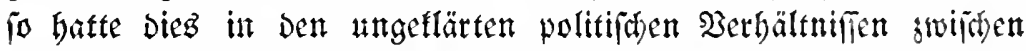

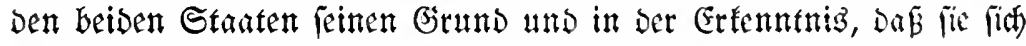
im Zuftande fatarfer politifaer Sonfurreng befanden. Siefe Fragen befchäftigen uns glüalicherweife bente nicht webr, fie find erledigt. Int bie Stelle ber Sonfurreng ifteine in Den geograptifich, fulturellen

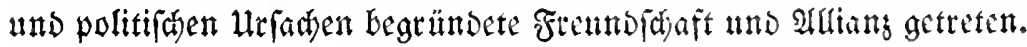

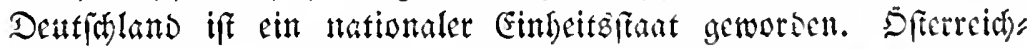

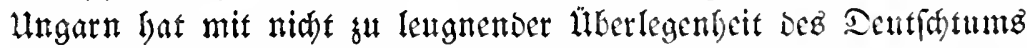

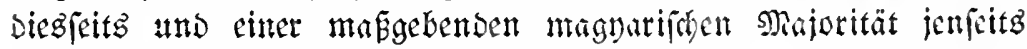

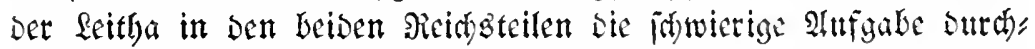

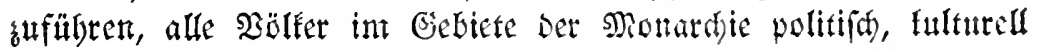

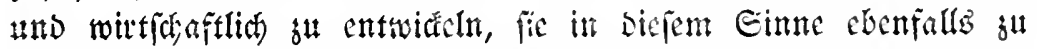
leifunggfähigen $\mathfrak{B o r p o f t e n ~ w e f t l i c h e r ~ S u l t u r ~ s u ~ m a d t e n ~ u n o ~ f o ~ g e g e n = ~}$

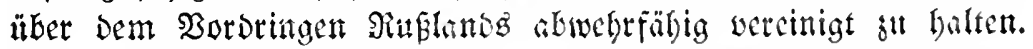

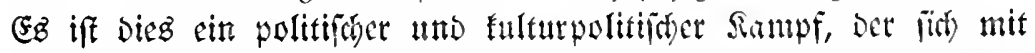

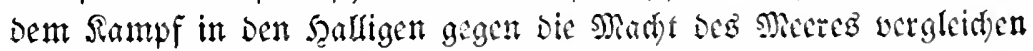

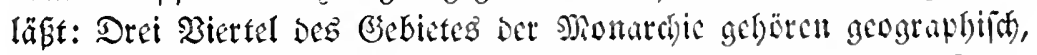

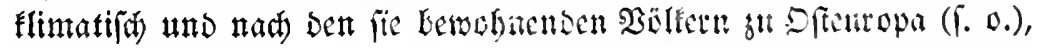

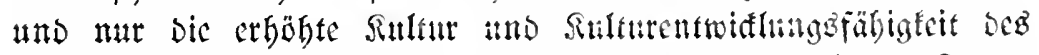
Wefteng haben diefe Gebiete trof fid immer wiederbolenter Forbe"

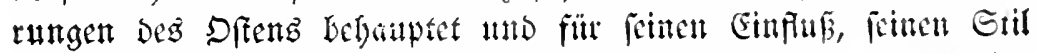

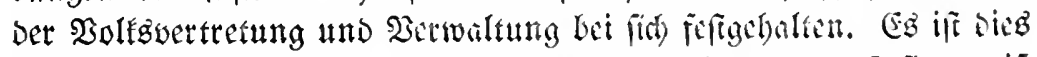

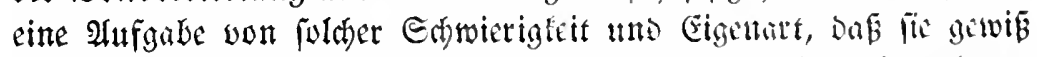

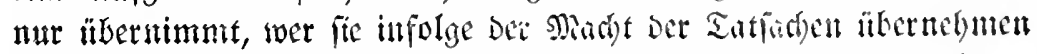

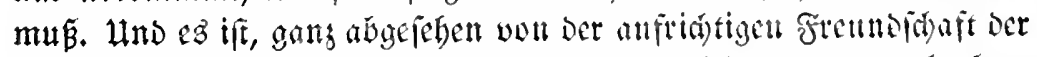

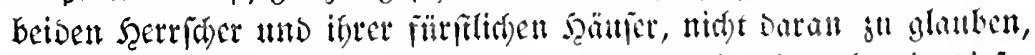

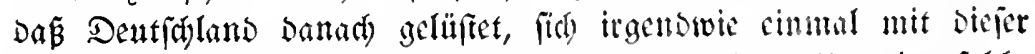
jóswierigen $\mathfrak{A}$ hfgabe birett felbft belaften ju wollen. Ilni citte foldye

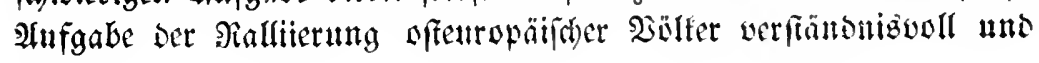




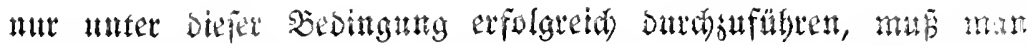

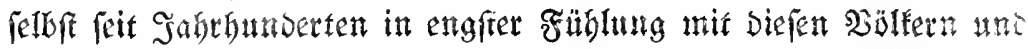

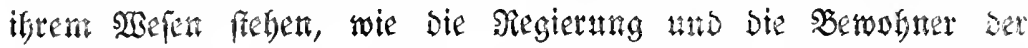
Donanmonarbie, füt welde bie bitteren fefren (b)eret soer gathgentit etit a

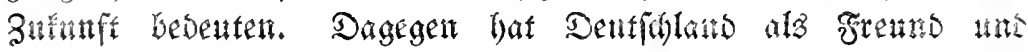

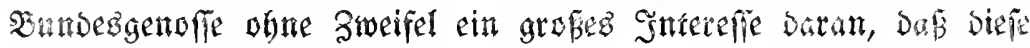

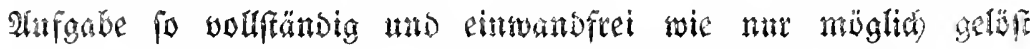

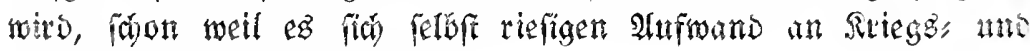

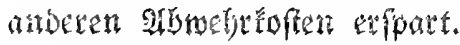

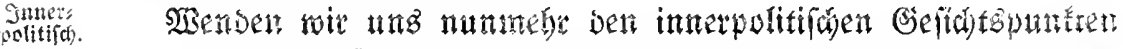

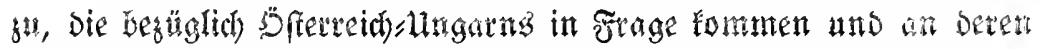

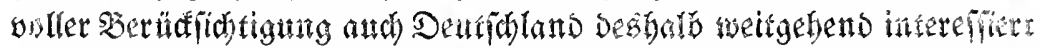

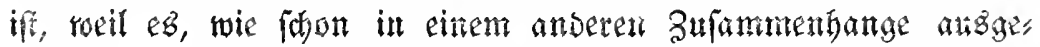

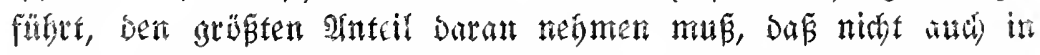

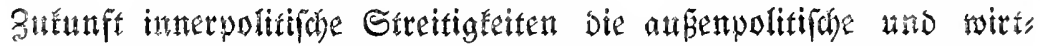

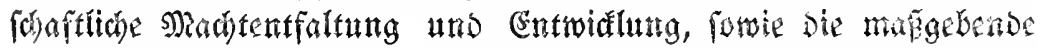

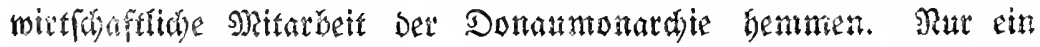

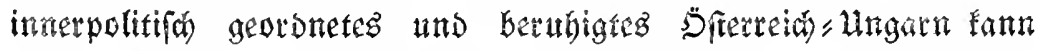

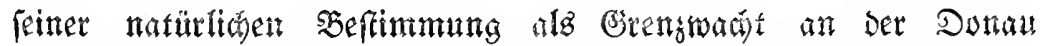
volftommen genügen utts beffer als bisher gleiden Sobrtt mit ber

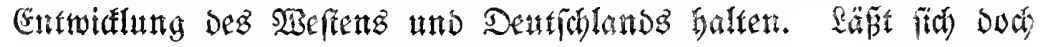

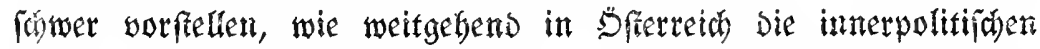

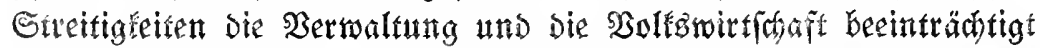

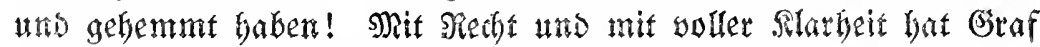

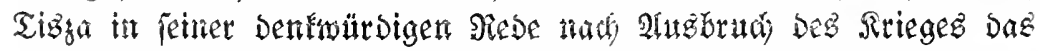

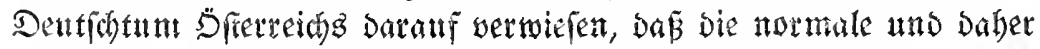

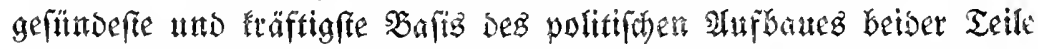

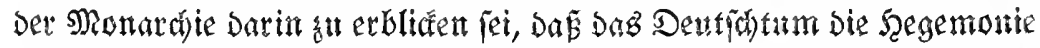
in Dfferretch, Das Mayarentum in ungart befint, und bap die Sprachet:

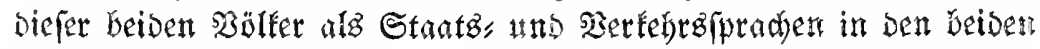
Gebieten zu Dienen bätten. Er Enüpfte Damals Datan Daz Bedauern,

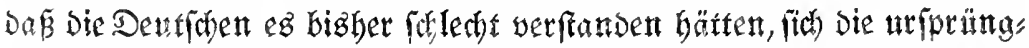
liste Sragemontie auth taffäblich ful erbalten. Mag auth Daz Magbaren tum in mantberlei Bestehungen bei feinen Beftrebungen fut Schaffing

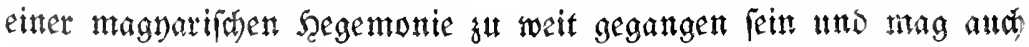
bem Dentfhtum in lingarn mander Eintrag geidefyen fein, fo if 


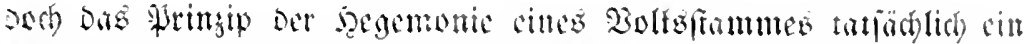

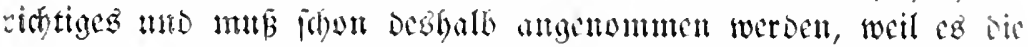

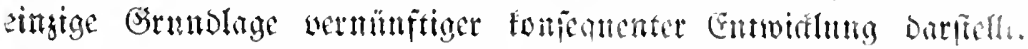

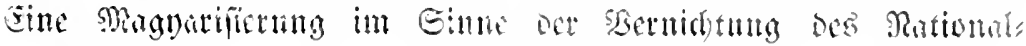

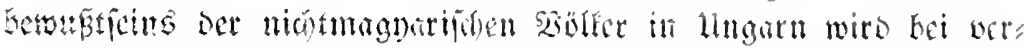

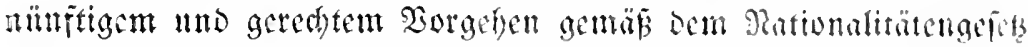

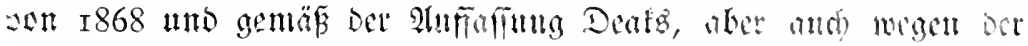

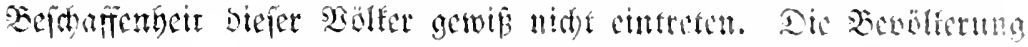

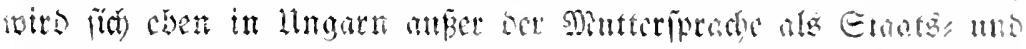

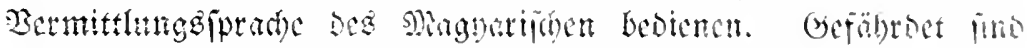

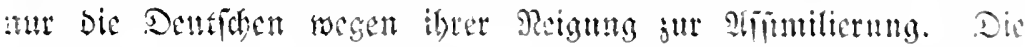

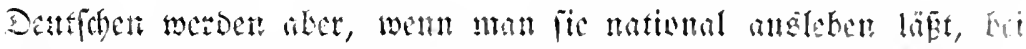

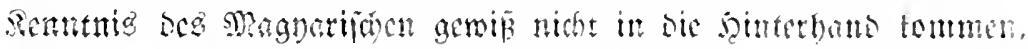

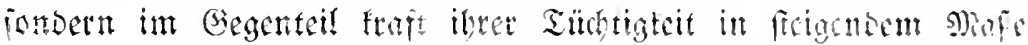

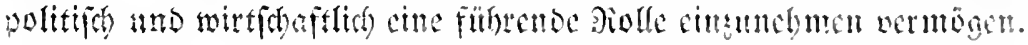

In S̈ferreidh if allerbings vel ber Grumbioe ser Segemunte

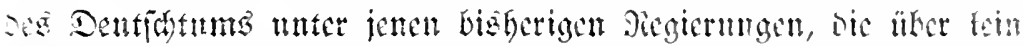

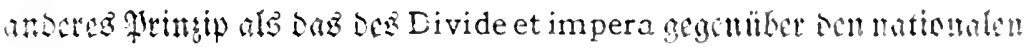

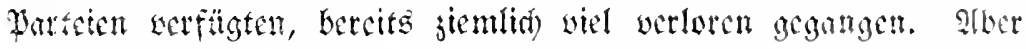

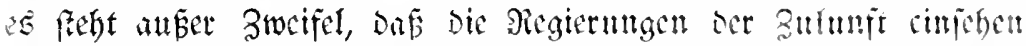

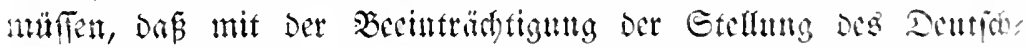

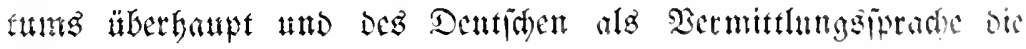
Soffintng anf Bernfigung Der mationalen Sämpfe finft, nidht afor

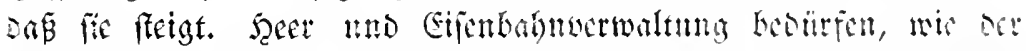

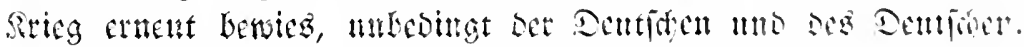

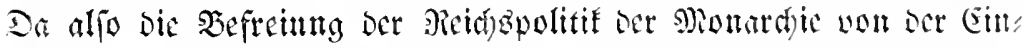

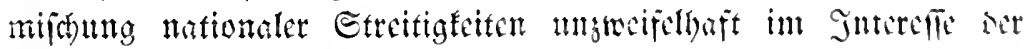

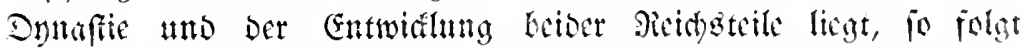
bacats, ba

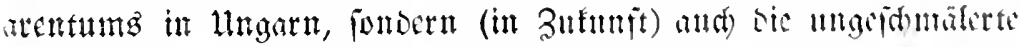

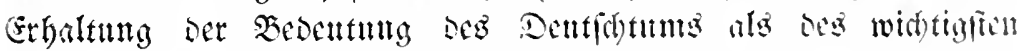

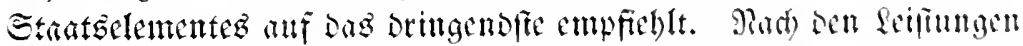

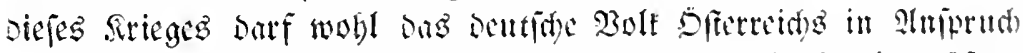

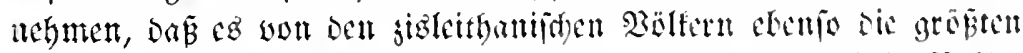

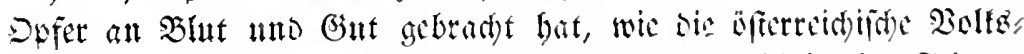

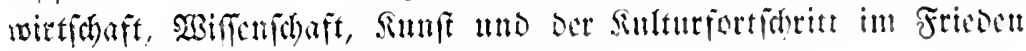

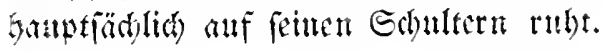




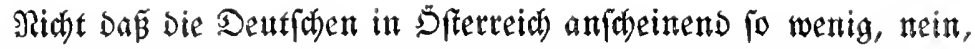

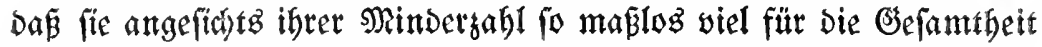
fu leiften vermodten und sermögen, fennzetdnet ihre Bedeutung uno rectffertigt ifre Bevorgugung.

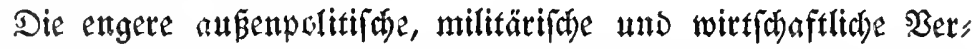

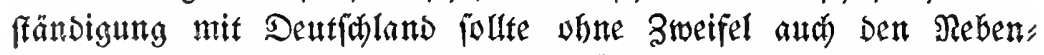

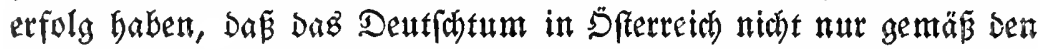

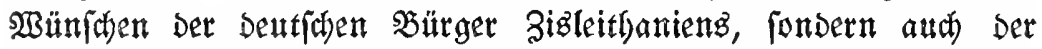
fübrenden Sireife in lungarn geboben unb tunlichft weitgebend wieder" bergeftelt witr.

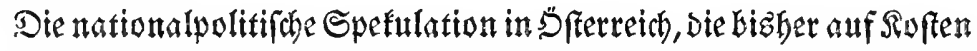

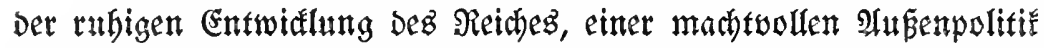

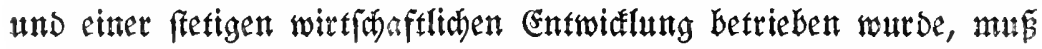
auffören, um fo mefr, als die Gefahr brobt, Daß fie, wie oben aus",

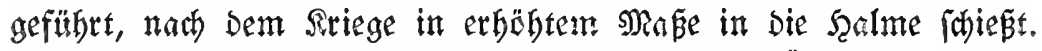

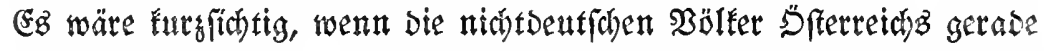
aus Dem Grunde ber Erbaltung Des Deutfatums als wirkfamen

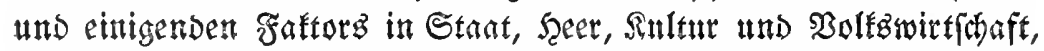

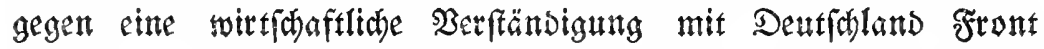

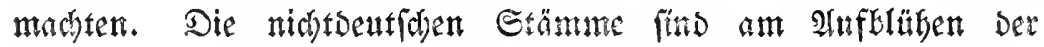
Monnerbie ebenfalls am meiften intereffiert; Die Donaumonards

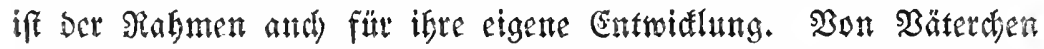
Zat bätten fie nie efwaz Gutez gll erroalten gebabt (man berglethe

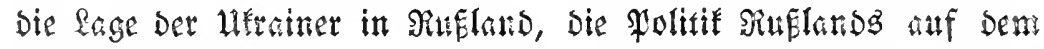
Baltan utro.). Da die Segenonie Des Deutfdume, Deutfuer Sultur und Sprathe einen wefertlichen Fattor für Den Auffidinung

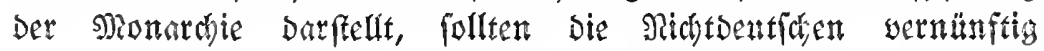
genth fein, biergegen im eigenen Intereffe nibh anğtämpfen.

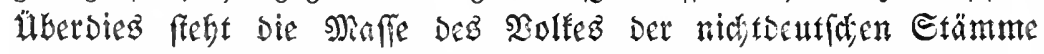
Dem parlamentarifhen und politifhen feader mo ber Berbeg̨ung

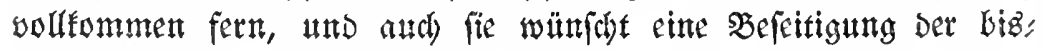
herigen nationalpolitifhen Edyierigkeiten. Die Foroentng iff citte

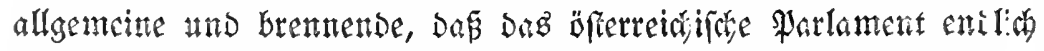
feiret Aafgabe gered werde und sie Tütigket Der Regierung fiel,

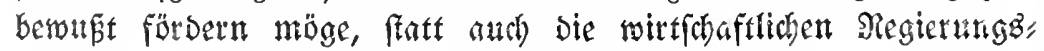
worlagen Dutd Dermefrung Det Sduterigfeiten immer wieder gu

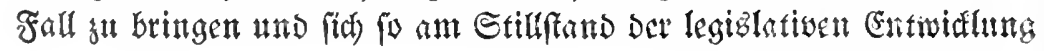


in Den widtigfen belangen mitfathloig fll macten, oft fogar ser

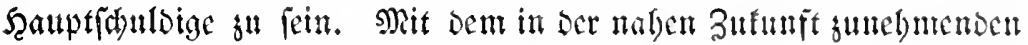

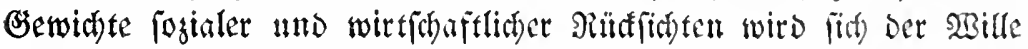

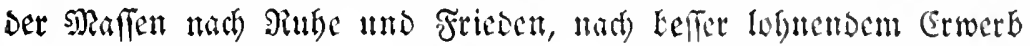

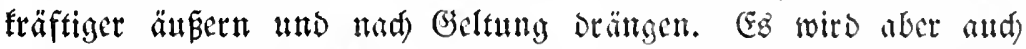
Das Dentfatum im Gegenteile 4 fo metr bereit fein fönnen,

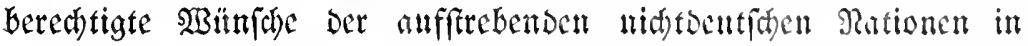

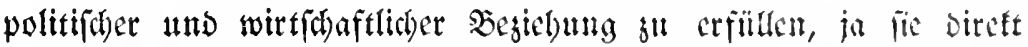

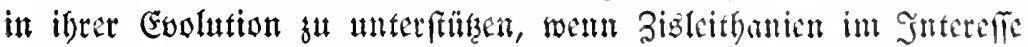

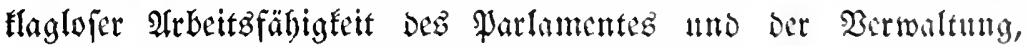

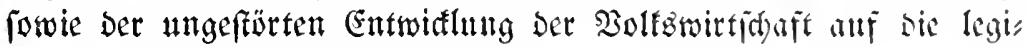
time beutifhe Gimmolighe geftellt wird.

Drdung, bindernislofez Funtionieren der jen,

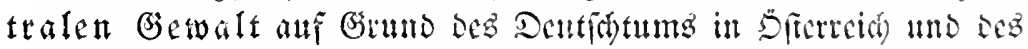

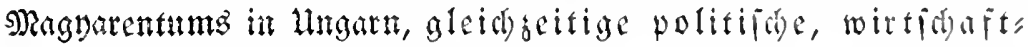

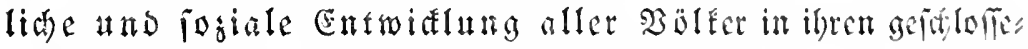

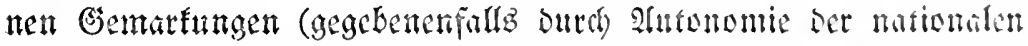
Sebietgate in Enltureten mo territorinlen Fragen) mintion bie

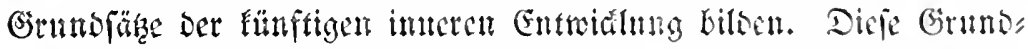

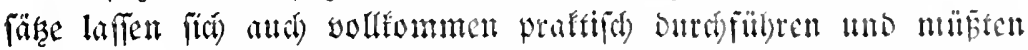

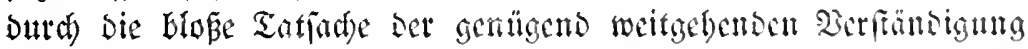

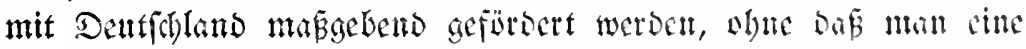

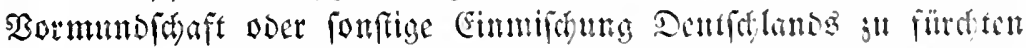

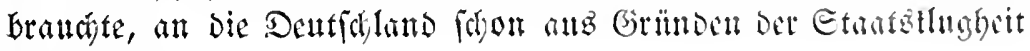

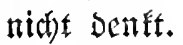

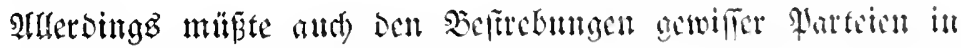

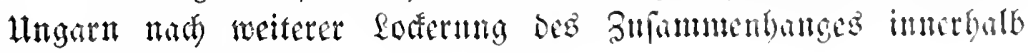
Des Dualisnug Eintall getaut wertin.

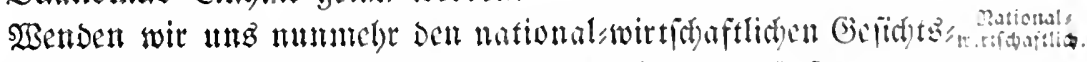

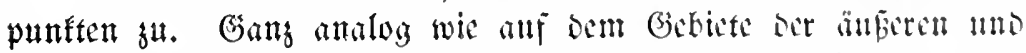

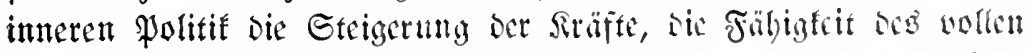

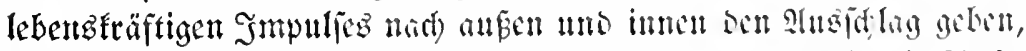

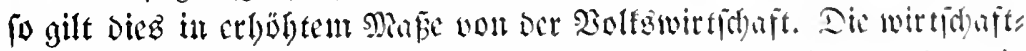

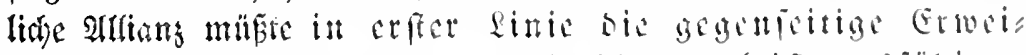

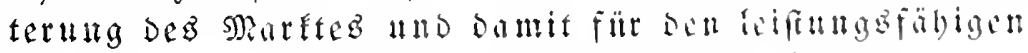

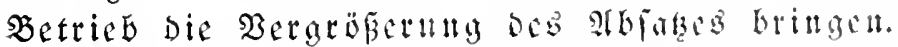

(B) 


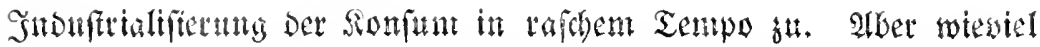

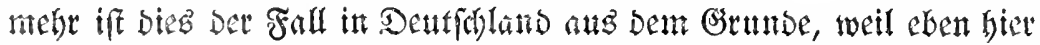

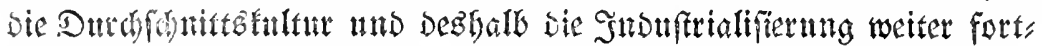
geidritten ift. (5s wärbe alfo für ben Ginfidtlich beftimmter \$3aren

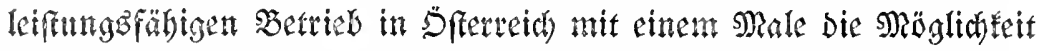

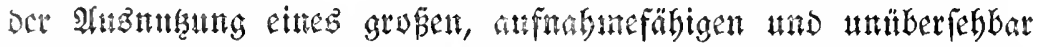

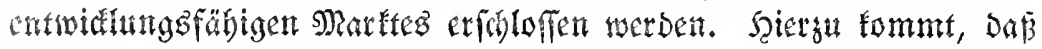

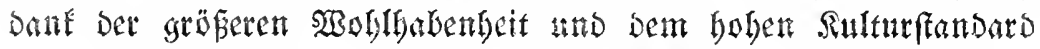

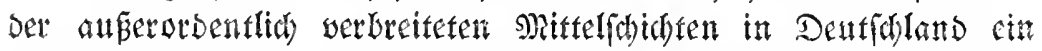

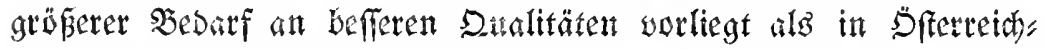

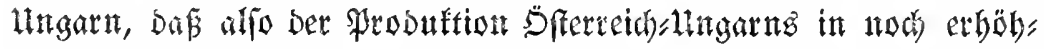

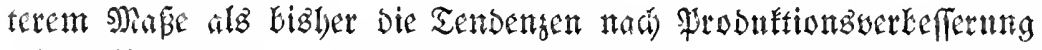

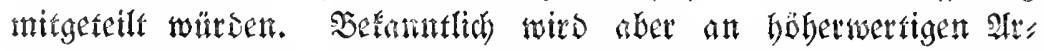

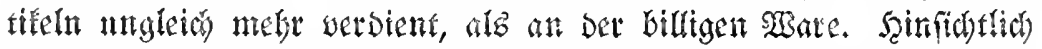

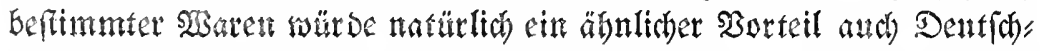

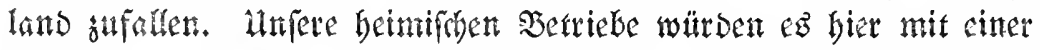

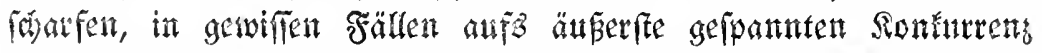

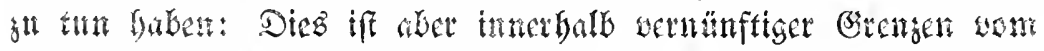

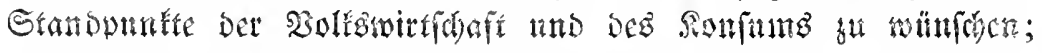

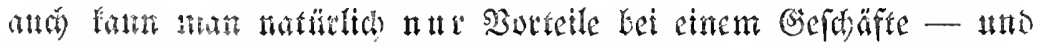

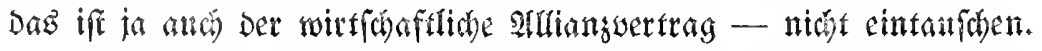

Dentfoland und Sfferretd

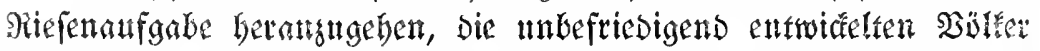

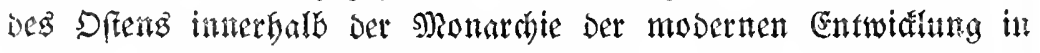

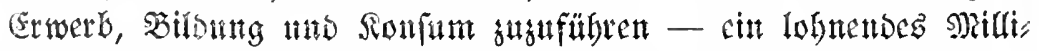
atdenunternetyen, Das alle Sinveftitionen mit mmittelbar ermisg

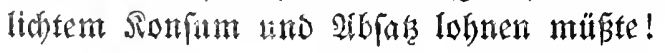

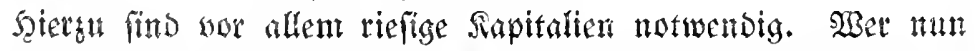

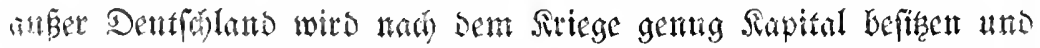

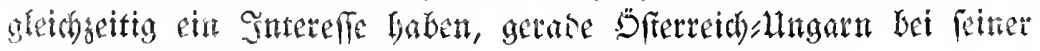

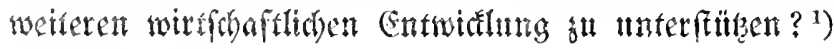

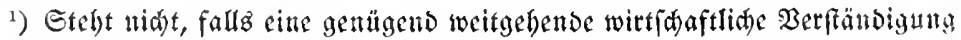

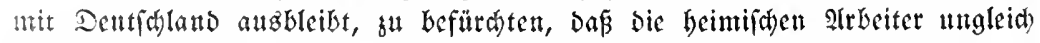

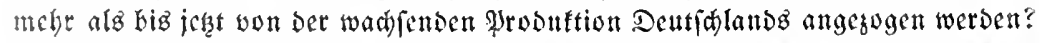

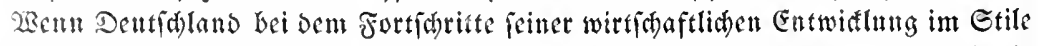
Wmeritas in abfebaret Beit an etwas Mangel leibet, fo fins ez vermutlid bie

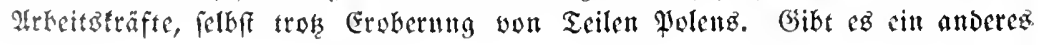




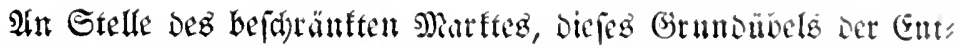

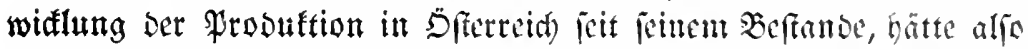

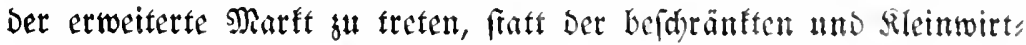

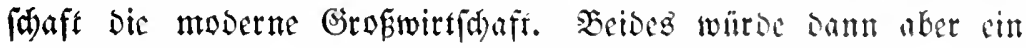

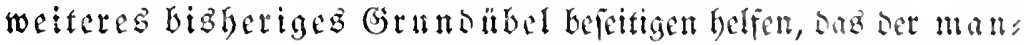
gelnoen oder ungenägenoen Spejialifiernng ${ }^{1}$ ). Sm grofen

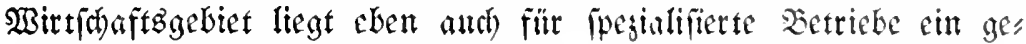

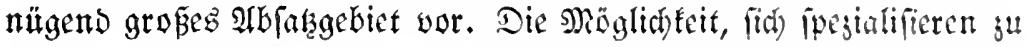

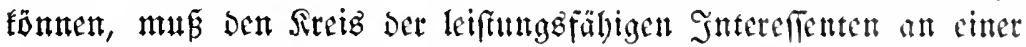

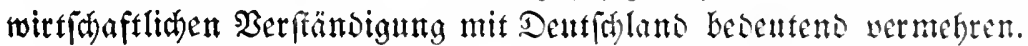

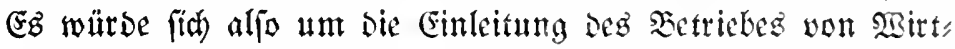

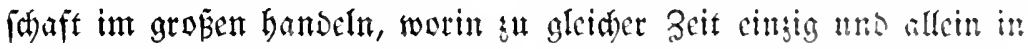

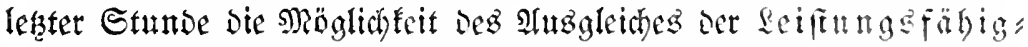

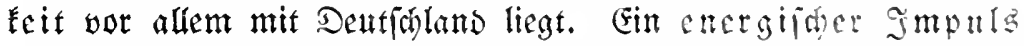
mübte alle soirtichaftichen Sntereflenten er fafen uno würe dicjenigen,

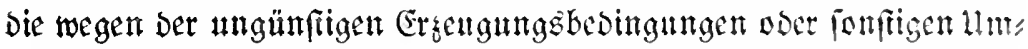

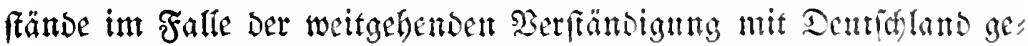

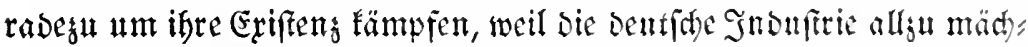

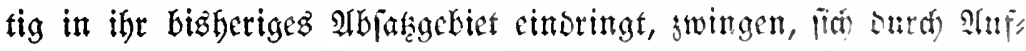
gebot aller Siraft uno fommergielier Erfinemngegank an Febanten.

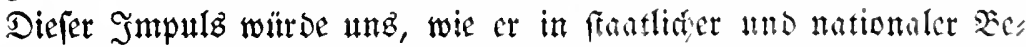

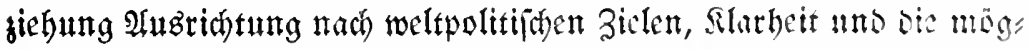
lidff rubige Entwidung ithaft, mit einem Male ang bor Etifluft, sic uns umgibt, befreien uno von vorabserein sic Spfer, sic bic cmergitac

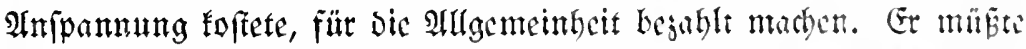

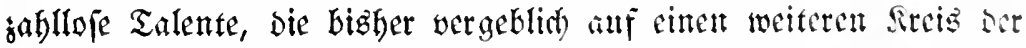
betätigung boffen ${ }^{2}$ ), ber Sotätigung im Smlatio jufübren, fur'

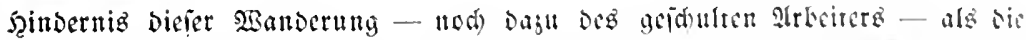

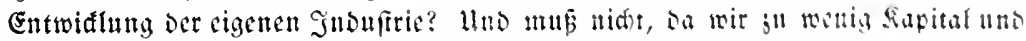

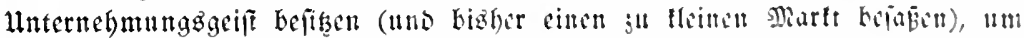

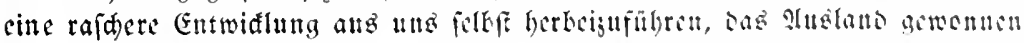

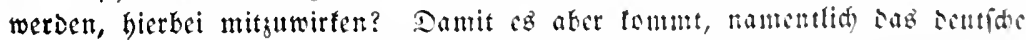

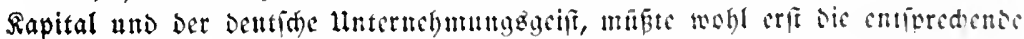

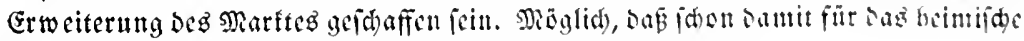
Rapital Der Inteis za größeren Snveftitionen vorbanben ift.

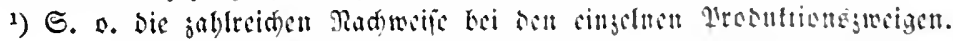

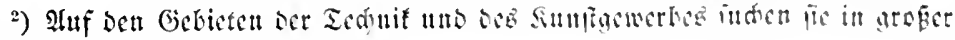

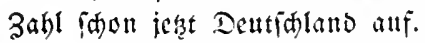

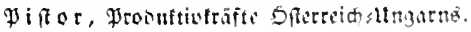




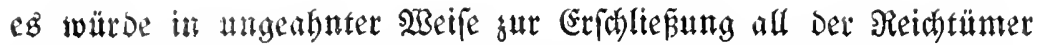

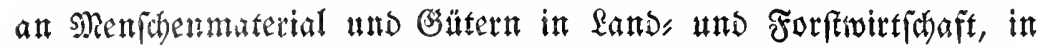

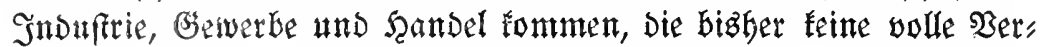

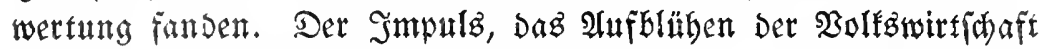
HIt inte wadjende Bebeutung müste auth auf Den Getif unjerer Berwaltung belebend und regelnd witken, müste f(c)lieflich für Soiffenidaft und Runf Den notwendigen, erbübt ertragfähigen

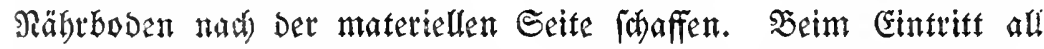
biefer günftigen Momente wärbe vor allem Das Die Siraft fo un:

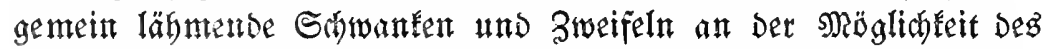

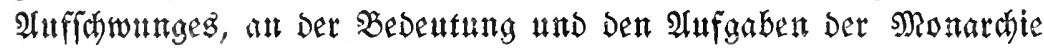

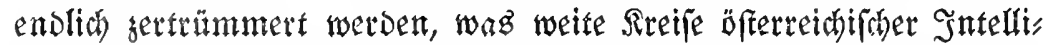

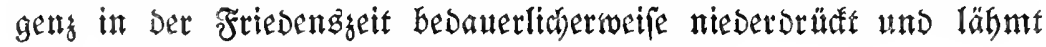
und fie wom Drange nadh Der Welt abfhnüt.

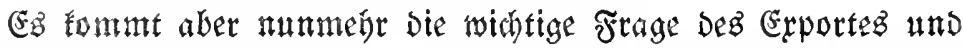

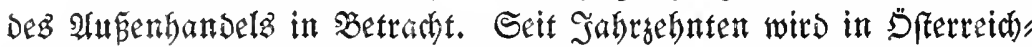

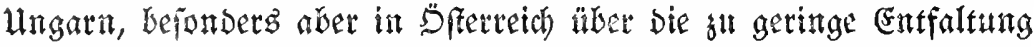
DeB Exportes, ja über Den Riedergang befonders ber Exporthandels" betriebe geflagt, weil fie fets mit Den gröbten und feigenden Sthiterigkeiten ful kämpFen batten.

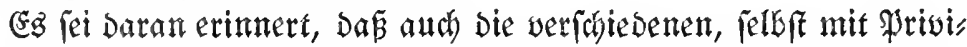
legien ausgeftatteten Exportgefelifichaften Der früberen Sabromberte immer wieder nach furzer febenzzet verforbanden (F. o.). Unternebmer

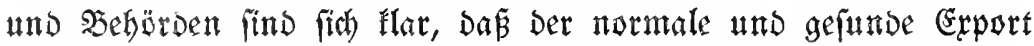
nidf tum feiner felbft willen betrieben werden fann, fondern Dás er im Prinsip unt die Berwertung jener \$robuttionsmengen Darftelft,

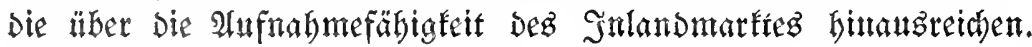

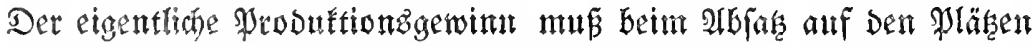
Des Snlandes ergielt werden. Seim Eeport gentigt eB pogat unter

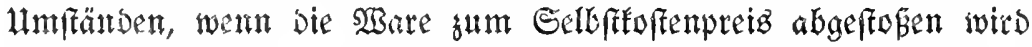

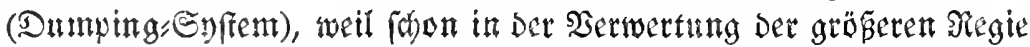

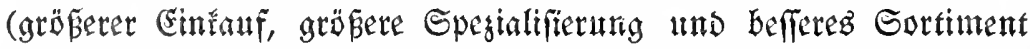
ufro.) ein grofer Borteil liegt. Jeder Teil eines \$ersentes an befferen

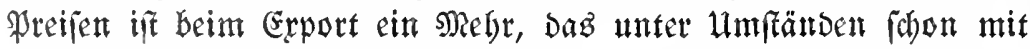
groper Befriebigung eingeheimft wird. Bei diefer Sarblage ifte es

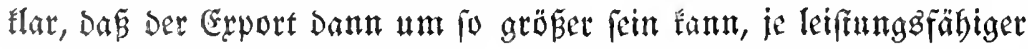
bie betreffende Sinduftrie oder Der betreffende Betrieb - felbft nath 
internationalen Begriffen gemeflen - ili, ie grö̈er ferme Ergengung

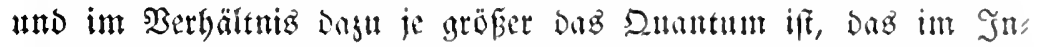

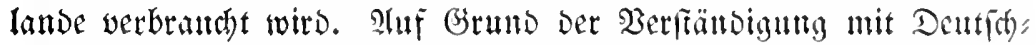
lanó und Darauf fußend ser Bergrößerung Des Marfteg forvis Ber

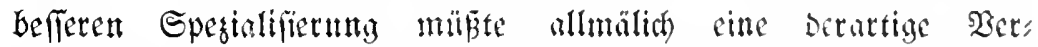

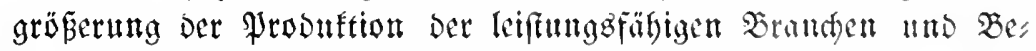

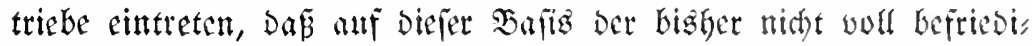

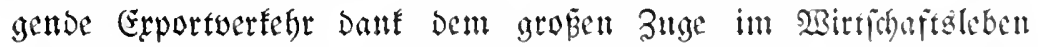
und in ber induftriélen Produftion won felbir einen ganj anderen

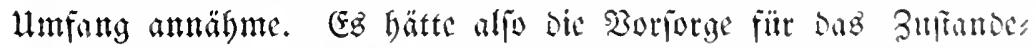
fommen einer entiprechent anfgebanten antians bie wirfampic

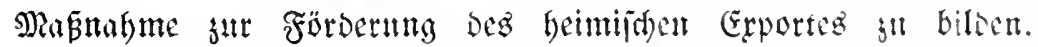

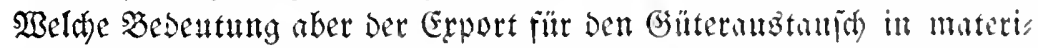
eller, aber and) funft Duth bie enge 2 erbinonng mit sem naben uns

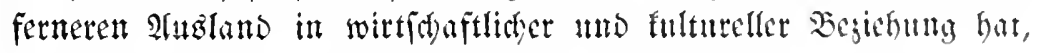
bebarf an biejer Stelle feiner näberen Erlänternng.

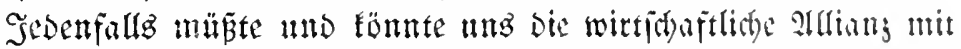

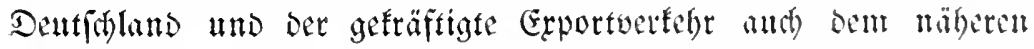

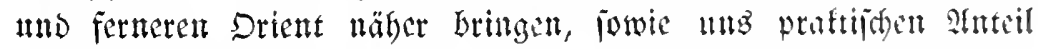

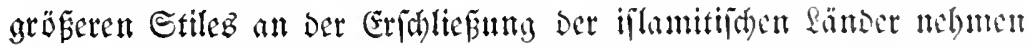
laffen. Wir wïroen bei oci weitgehenden Parallelität umerer Suters

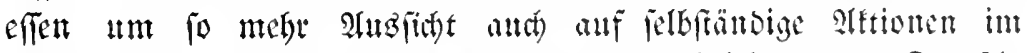
Drient baben, wie wir in begentcil obue Anlebmung an Dentios, land und ogne Berfäntigung gerabe in ifm ben grö̈ten, weil

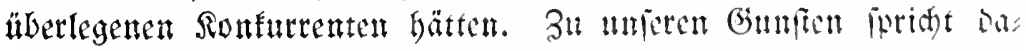
gegen bie günftigere geographifab Rage, ser altere utts enget wirtidhaftlithe Berfebr.

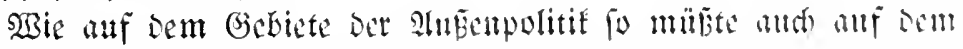

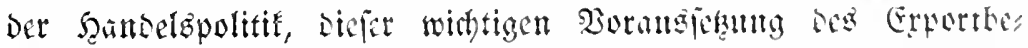

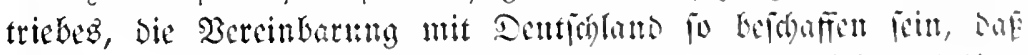

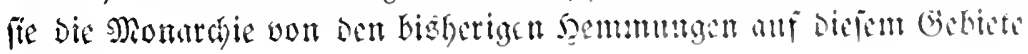
befreit.

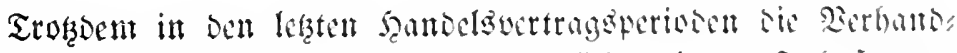
lungen won Det Monatfie immer grünslidfer, fu muferbajt was"

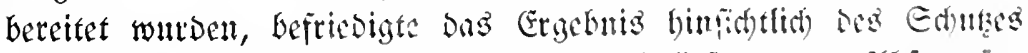

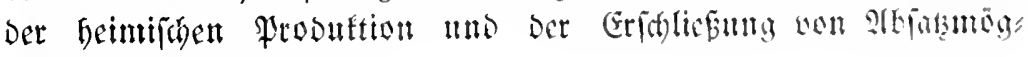
lich feiten immer weniget. 


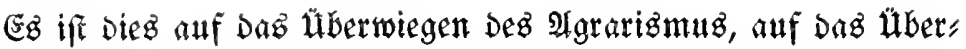
wiegen Der Shuz̧tendengen gegenüber Den Expanfionstendengen, auf Die Bermifinnth mit politifden Strömungen gegenüber Dem

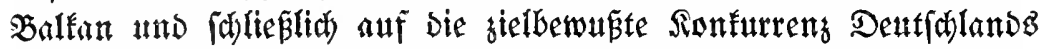

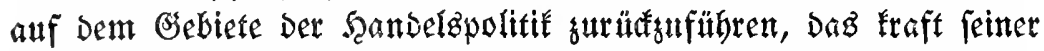

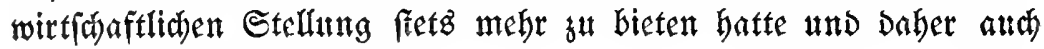
mebr fordern fonnte.

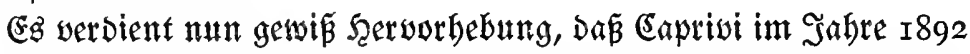

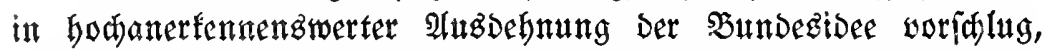

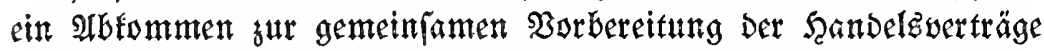

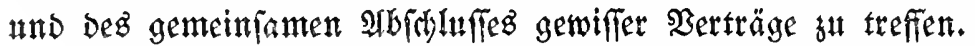

EB Gollte Die Ronfurreng ber beiden Staaten int Den হerbandlungen

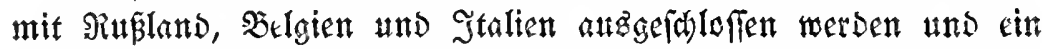
Bertrag Der beiden Stanten mit Den eben genanten nur suftande fommen, wenn erft beibe Alliterten einig geworien wären. Es wäre

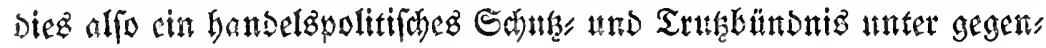
feitiger linterfühung getwefich.

Die Bereinbarang fam niat zuffande; eB bleibe Dabingeftelft,

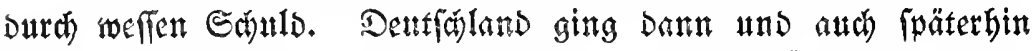

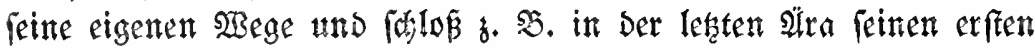

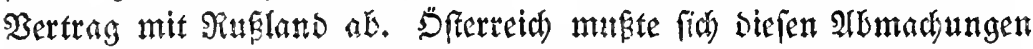

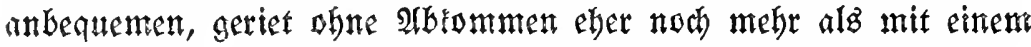

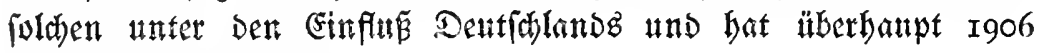
nid)t gut abgefdritten.

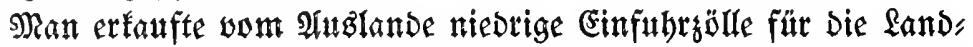
mirtichaft mit sugeftänonifien für bie crleidsterte (Einfuthr in Snduftes probuften, obrobl die frndwirtichaft nidht mebr exportfähig im alten Stile war, gab alio inoufrielle Sutereffen nuzloz preiz.

Die mettere Folge war, Daß́ (F. o.) Der Jmport Dentfalanis nad Der Donaumonardie von Ig,6-I9I3 nn! 5I,I \%, Der Export Diferretchs nur $u \mathfrak{m}$ I2,2\% fiteg.

Mit ben Balfanftaaten binderte ebenfallz wor allem Der 2igrariz"

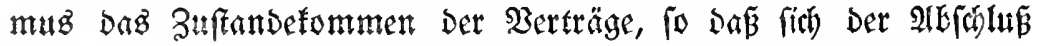

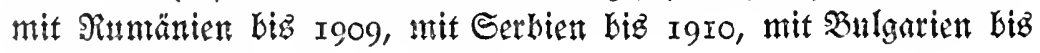
I9I2 bitta1:8gog.

Eine Det widtigfen Bedingungen - und Şoffnungen -, Denen

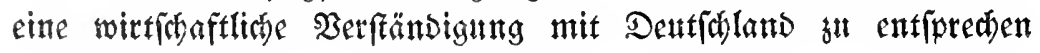


bätte, wäre alfo bie Bereinbarming wegen gemeinfdaftlider

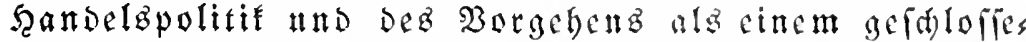

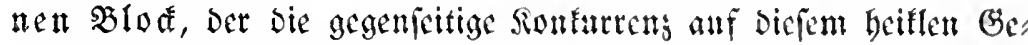

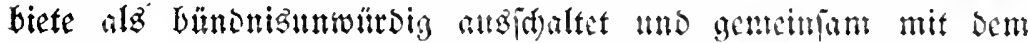

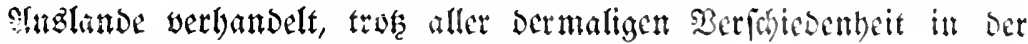
Entwitung Der SHoufrie der beioin Etanten.

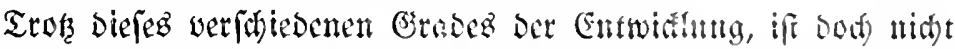

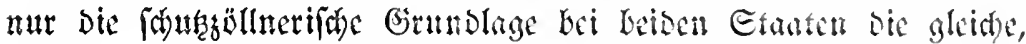

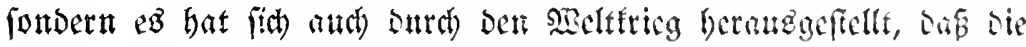

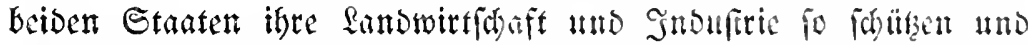

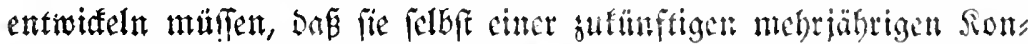
tinentalfperte ourd) (England obne Gefabl uno Eorge entgegenfeben

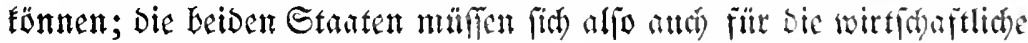

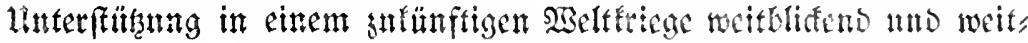

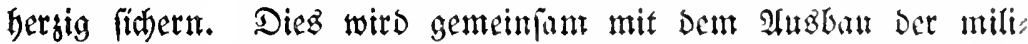

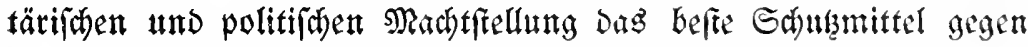
eine Wiederbolang Deg Meltftiegez bilben, alfo anf bas wirfiamfte Den Frieden fichern.

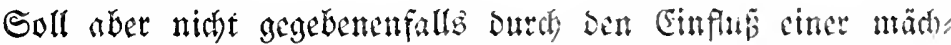

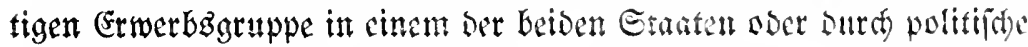

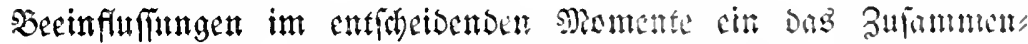

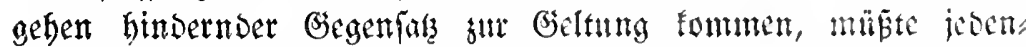

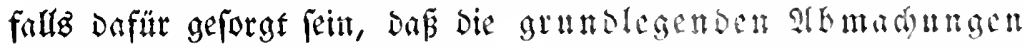
feime berart lofen find, um trgent cimmal bas soirfame

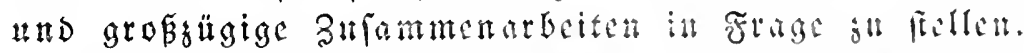

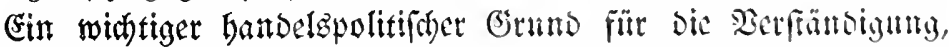

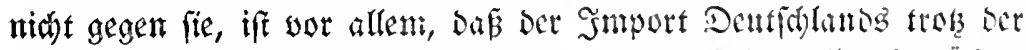

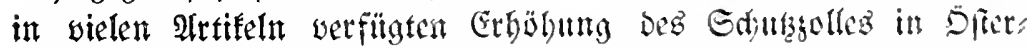

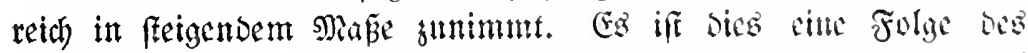

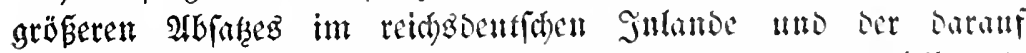

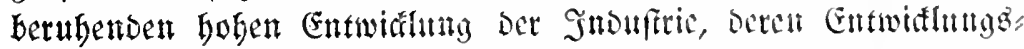

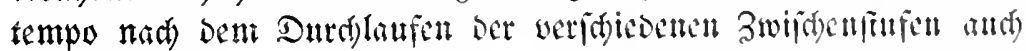

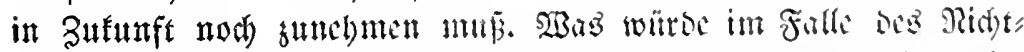
fuftandefommens einer Berftänbigung bei ben mäd) fen Sandels,

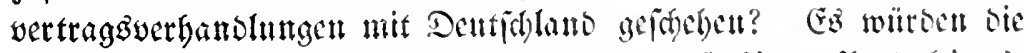

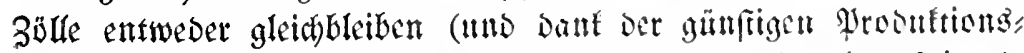

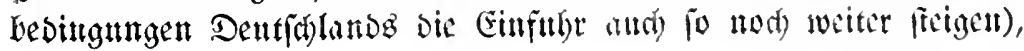




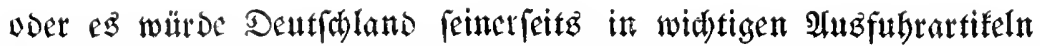
SFferreichs nutr bann won einer Zollerböbung abjeben, wenn ifm bie

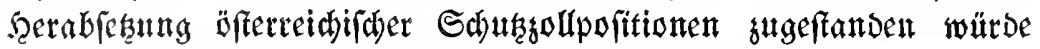
- Das suäbe Dann Den Import nud weiter erleitjtern.

Bei ber an Setrieben bedeutend reicheren und einer rajheren Entwiłlung fähigen Dentfden Snduftrie wärbe die Zabl Der Dentfden

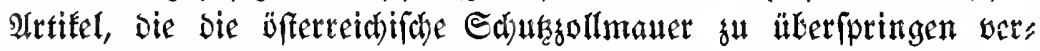

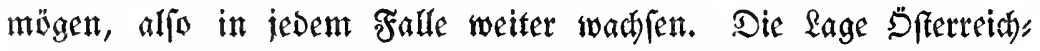
Ungarns gegenüber Dentfhland würde möglidberweife ftets ungün"

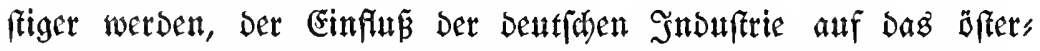

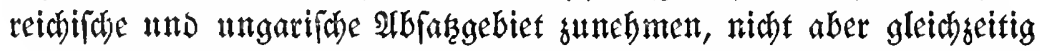
- wegen Des Mangelg an Der entiprenend groben

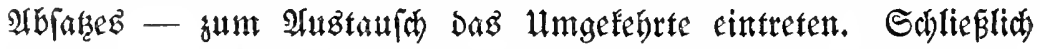
wärde bie gegenfeitige Spannung womöglich eimmal mit cinem zoll, triege endigen. Sft es da nicht beffer, fid gegen die Stfinung bes eigenen Matftes einen Snteil an jenem Marfte zat fid ern, Deffen groper Sedarf, Deffen birlige Şalbfabrifate und bebelfe die Deutfhe Induftrie (d)on bis̆ber fo leifungafäbig gemad)t baben? Für Den Schaden in gewiffen Artifeln wärde Dann eben Der grop̉e Borteil Der tunliaf angebinderten freien 2 ngfubr nach Dem böberwertigen Marfte erfanft werden, an Stelle regels uno rütfichtglofen Sampfez Die Berfändignting won wornberein treten.

Anf eines Ditrfte die moderne Bolfzwirtichaftgpolitif in Zuknth

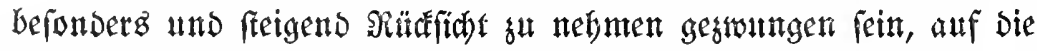

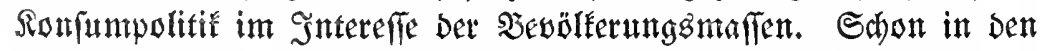

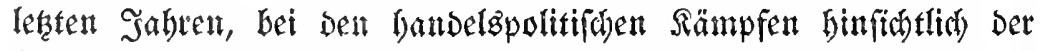

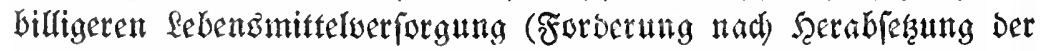
Betreidesölle, nach (Einfutgr von gefrorenem Fleifín ufw.), wurbe won Den Bertretern Der unternebmer gleidsuie Der âbetterfdaft mit zunebnender Energie Darauf bingewiefen, Daß in Dfterreid bie

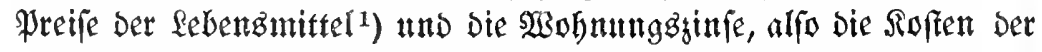
Sebenghaltung, in ein fid fretz verfolechterndez

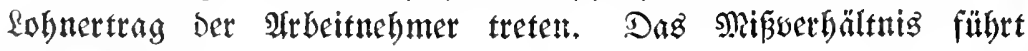

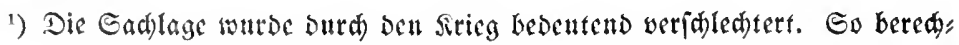

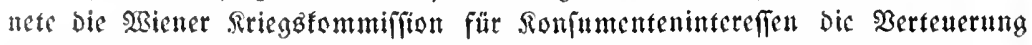
Durd Den Rrieg für Den Dftober I9I5 im Durdjdjutte in: Engthat auf 34 , in Deutialand auf 65,4 , in Dfferreid) auf $121,3 \%$ 


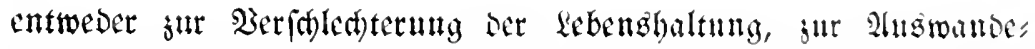

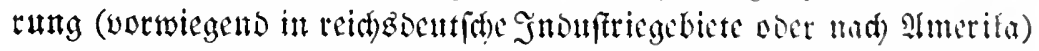
ober jur angiebigen lobnfeigerung tho santr wieser zur Ber, teuerung Der Indufreieartifel.

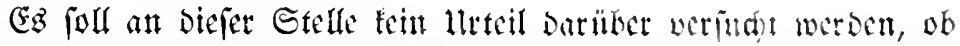

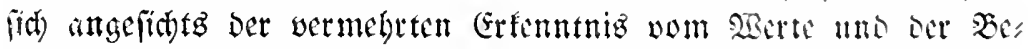
oeutung leifungefäbiger nationaler Sanswirtichaft bie tomum,

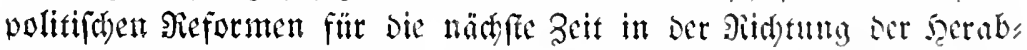

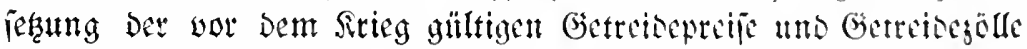

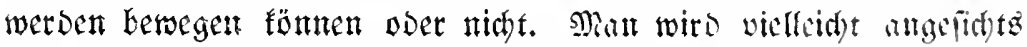

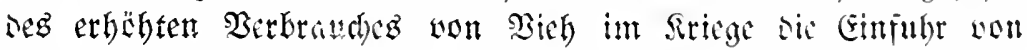

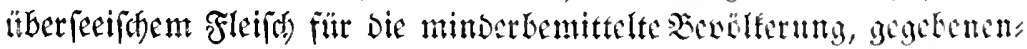

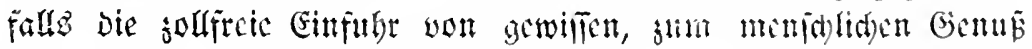
unbrautis bat gemedten Futtermitteln füt die (Erleidfterung Eet

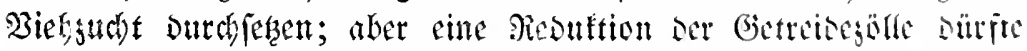

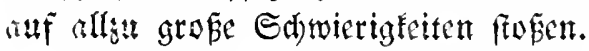

Es wätde alfo Dann vermutid) ju Lohnerbabungen fommen,

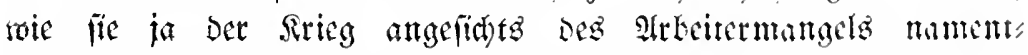

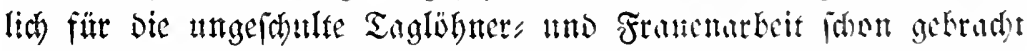

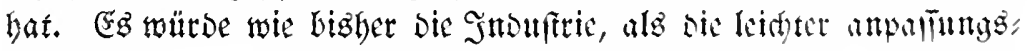

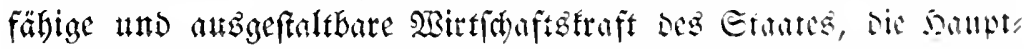

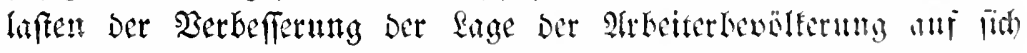

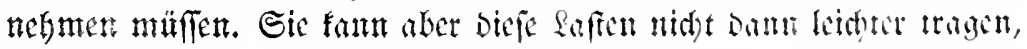

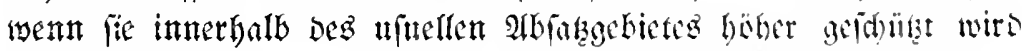
- alfo beim status quo bes 3ollgebirtes mit (erböbutig ser 3olle-,

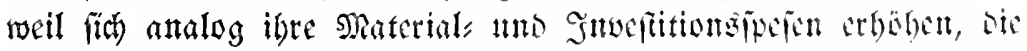

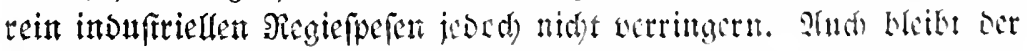

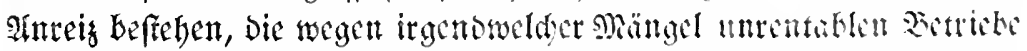

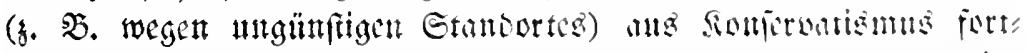

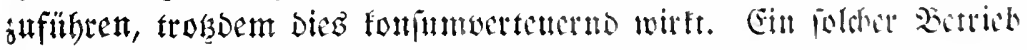

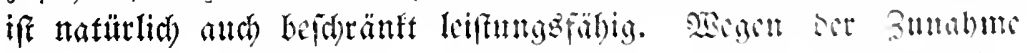

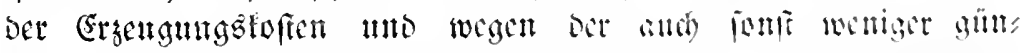

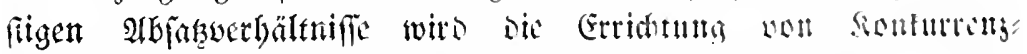

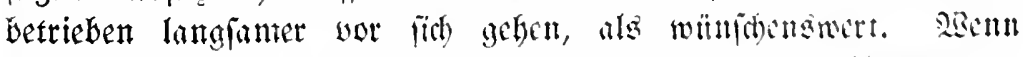

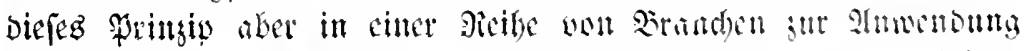

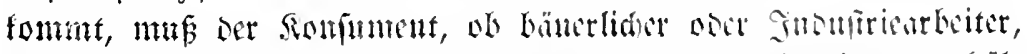

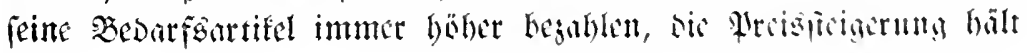


alfo an uno buntí die Forderung nady böheren Einfünften, bejonders

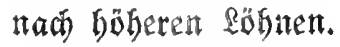

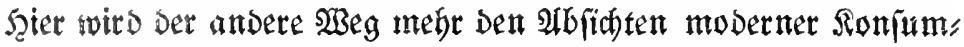

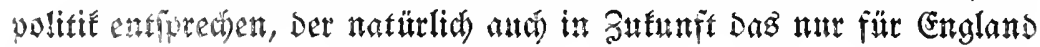

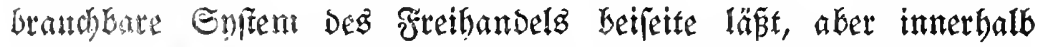
vernünftiger Brengen eine Steüung Der Bolkztwirtidhaft, bejonders ber induftriellen Erzengung, anf Die Erundlage Des erweiterten

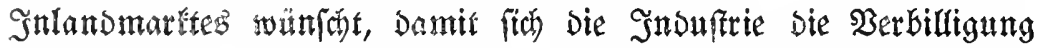

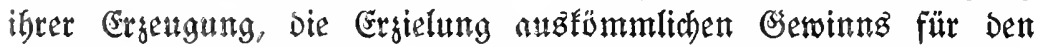
unternebmer uno beflere lobngablung für Den Arbeiter ans Der Bermetrung Deg BeDarfes und aus Der Berbilligung ber Pro"

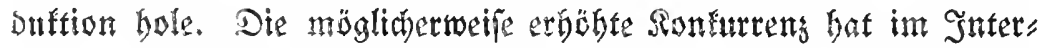

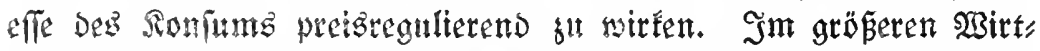

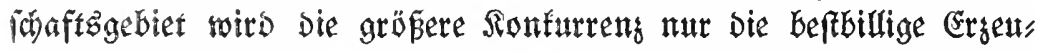
gung befrehen laffen. Dank Der Ronkurreng, Danf Der vermebrtent Wroduftion werben alle Ergengnifle tros erföbter Bölle und trok böberen Ertrages für Den Unternebmer billiger, nidbt teurer fein.

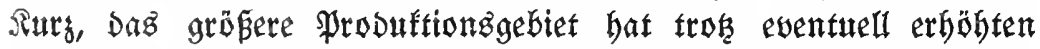

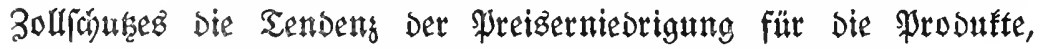

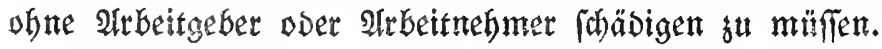

Nan ntöge aber ttidyt im unf́laren Daräber bleiben, Daß̃ Die Forderang moderner Ronfumpolitif, die anf bie Ergielung einez befriedigenden Sebenzftandard der Mafle, auf Sebung von

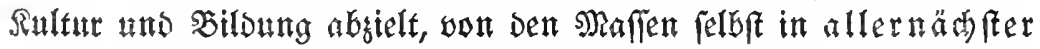
3eit mit gang anderer Sntenfität verareten und wabs

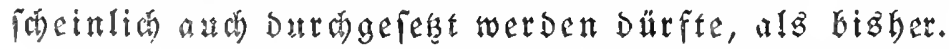

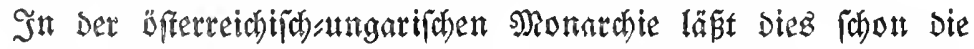

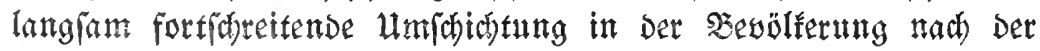
induftriellen. Seite vermuten. Mí Dem vollgogenen wirtfdhaftlithen

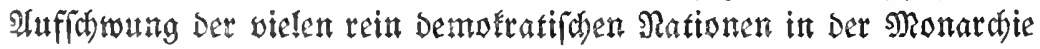
(F. o.) müfen biefe Tendengen eine weitere Hnterfïtsung erfahren. Bor allem twird bies aber bor Sirieg berwerffelligent.

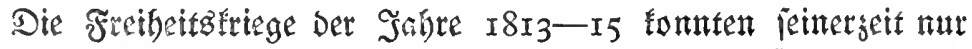

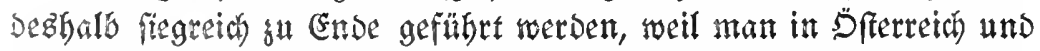

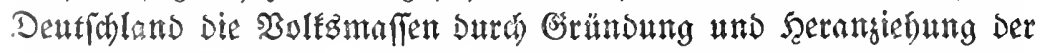

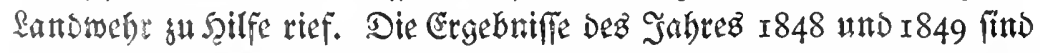

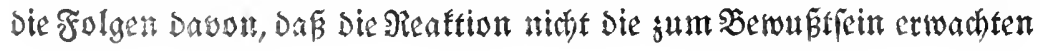


Demokratijhen Sireije Durch Gerwährung von Bolfgevertretunyen be" friebigen wollte. Damals allerbings haben zunäáf vorwiegend die befitzenden Slaffen in Stadt mto Land ifren Anteil erbalten. Die weiteren Sreife waren hierfür vielleid)t nidht einmal reif gewefen.

Der nunmebrige $23 e l t$ uno $20 ̈ l$ ferfrieg, als $\Omega a m p f$ Der Millionen maflen gegeneinanoer, mit feinen riefigen z"l wollbringenden feifungen wird auth bier wieder Madtgefẗble ber Maffen andlöfen, nur mit Dem

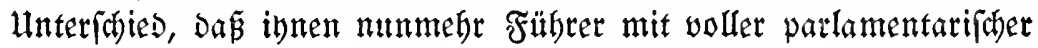
Shulung und bie Dorbilber fortgejorittener Drganifationen fur Berfügung fieben. Fine vernünftige, leifungşähige Sonjumpolitif,

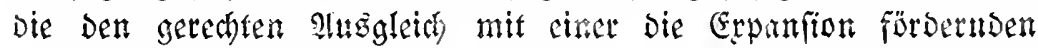

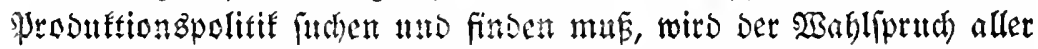

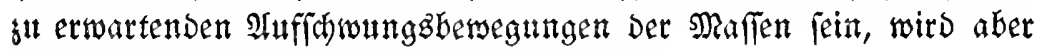

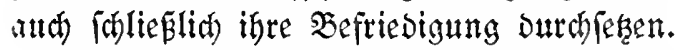

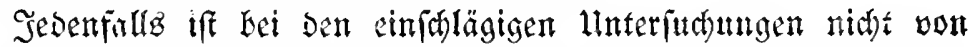
einem Der erörterten Standpunfte allein Dee in Rebe frebende Fragen" fomplex qu bebandeln, fonbern nut won einer gebenden Gefichtspunte aus.

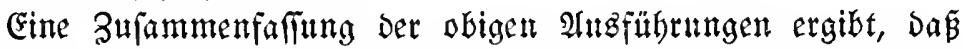

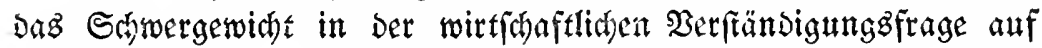
bie Reuordntuy oer $23 e l t p o l i t i k$ und uno innere Politif, atf Marht und Sreftige und bie Nawebr ber

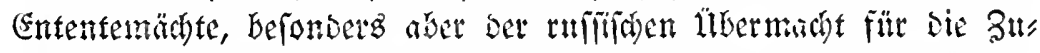

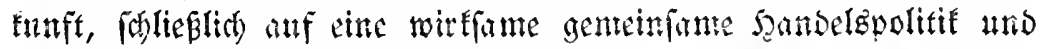

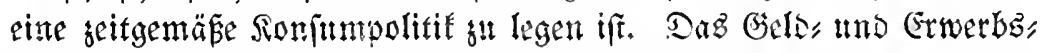
interefie dez Eingelnen hat bei biejem wirtfataftiden llmbildungs",

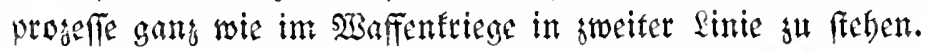

Bemertenswert ift die 2̈̈nerung bes englifacen Solonialpolitifers Sobneftore, ber I903 die Fronge eines beutf(t) Wittia)aftabundutfes bebandelte (Dentifhe Solonialscitung I9I5, Seite 4I) tho fich gails im Sinne ber worfebensen 2tusfübrungen

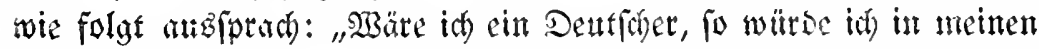

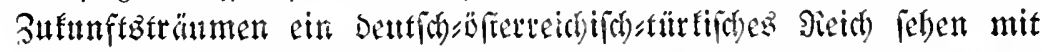

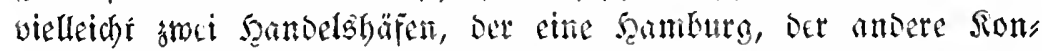

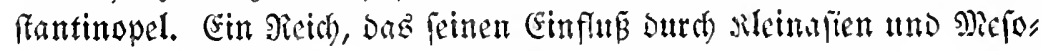
potamien bis über sie bagonobuhn gelteno madben follte. Diefes แnunterbrodjene Smperinm, Das von Der Elbe bis an bie Ufer bes 
Enphrat und Tigriz reithen wärie, wäre Doch gewif́ ein ftolges Biel, wie es citre groje Ration nutr anftreben fonnte."

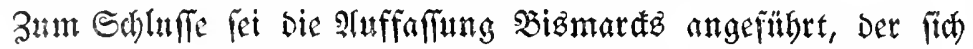
swar I863 (Gedanten und Erinnerungen I. $\mathfrak{B D}$., I7. Sap.) aus nabe" కtegenden Gründen gegen die Zollunion aubgeiproden hatte (j.o.),

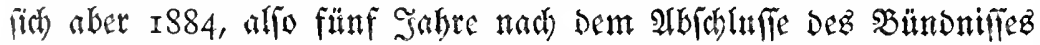

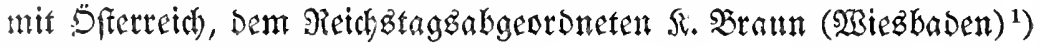
gegenüber wie folgt äußerte:

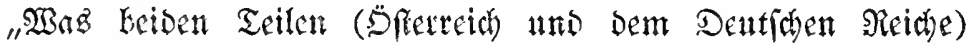

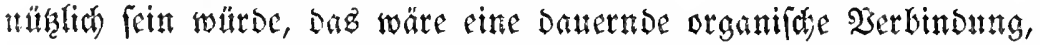

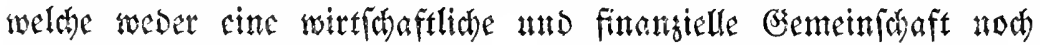
eine wechjelfeitige Sinmijhnthg in innere Fragen mo territoriale Dder partifuläre Differengen anftebt, fondern alles Das anf bas bes

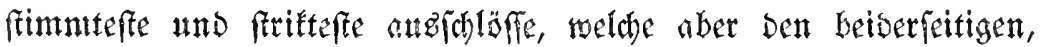

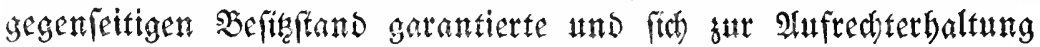

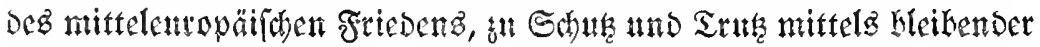
Inftitutionen verpfichtete. Damit wäre nidbt ausgerdjoflen, fondern

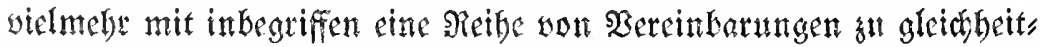

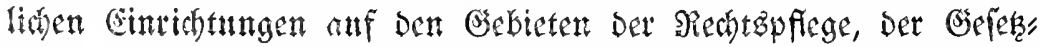
gebung, Der Berwaltung fowie ber wirtfdaftiden und forialpoltifden Dinge, eine 3nfammentwirting, weldhe obne 3weifel fefr fegensecth

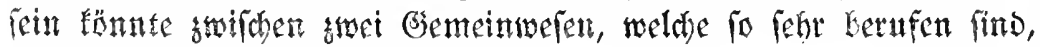
cinchder zut crgänzen."

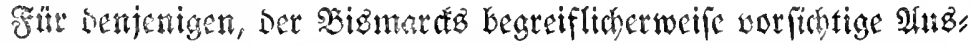
orudéform werfteben will, chthält diefe vor faft 30 Jabren gemnthe

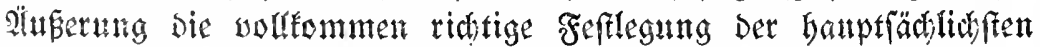
Sefichtepunke für bie notwendige und möglidhe serftönsigung mit

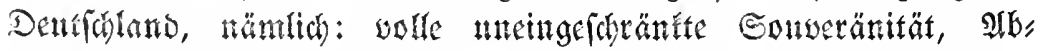

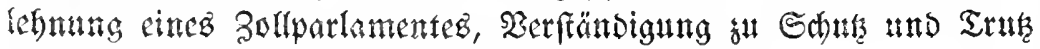
und itber den befinftand, wirtichaftides Sändatis.

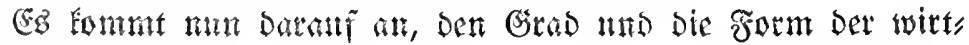

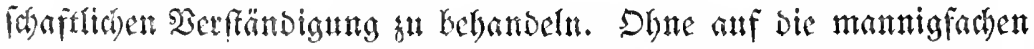
Bartationen, die möglich find, eingugeben, feien bis folgenden Satupt formen beransgegriffen:

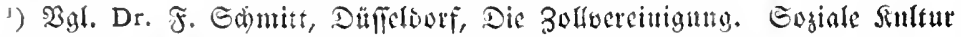

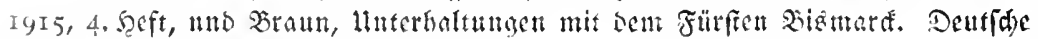
Revue I885, Janturbeft. 


\section{Woirtid)aftlid) $\mathcal{D}_{\mathfrak{a}}$ ftändigung.}

1. Weiteftgebende Form, bie volle zollunion, uno jwar:

I. mit gemeinfanter Sandolspolitif,

2. mit einbeiflid)em, geneinfament bandelşpolitifaem Drgan (weitefigehcnde Form diejes Drganes wäre ein gemeinjamez Bollparlament),

3. mit gemeinjamem 3olutarif,

4. mit ungeteiltem $\mathfrak{W i r t}$ idhaftagebiet.

11. Frleidterte Form, eine möglid) fr weitgehende Finheif, und groar:

I. mit gemeinfamer ḩandelspolitit aber mit Der Söglichteit,

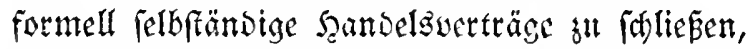

2. mit einfeitliben, geneinfamem Bermaltungsorgan alf $\mathfrak{B} a$ fiz

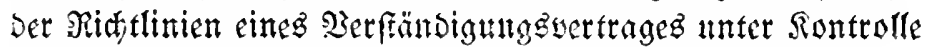
Der Parlamente,

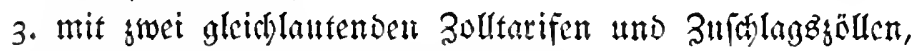

4. mit anglcid)enden 3wifhengöllen.

II. Sebr bejaräntte Form mit möglichfer Grbaltung fes status quo, und juar:

I, mit nur einvetfiänoliá)er Scratoelsopolitif,

2. obne eidi gemeinjames Erefutionorgat,

3. mit felbfänbigen 2imbentolitarifen,

4. mit Durth gegenieitige Prefereng rcougierten 3ällen im Butifhenuertebr.

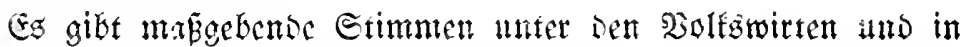

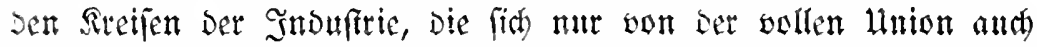
Den wollen Erfolg weripectien. Sur bicif Form fidere die gemeinfame Sendelspolitif, fithere baz gemeinfame Suftrcten gagenüber sem

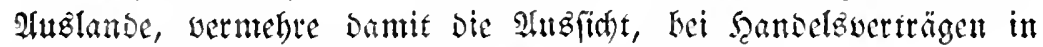
gegempertiger Unterftützang volle Erfolge ju argiclen.

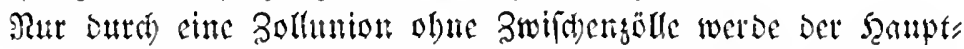

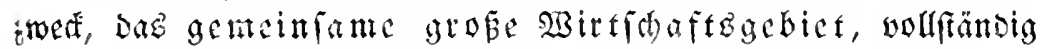

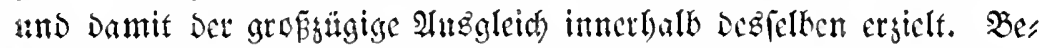

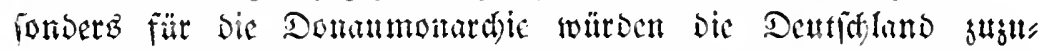
geftefender, Zollcuicorigungen (in Form von crmäpigten Bwild

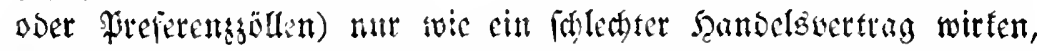

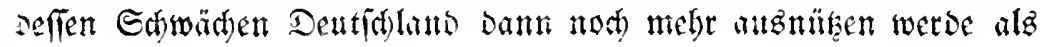




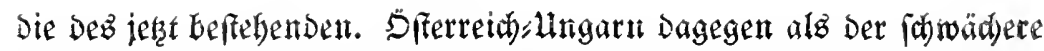
Exportfat werbe won Den Deutiden Bollerniedrigungen ungleid weniger Nuţen gieben fönnen.

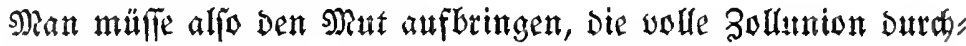

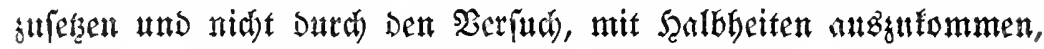

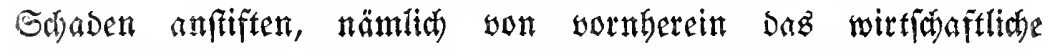
3ufamntenwiten der beiden Stanten auf einem falfhen Syftem "urbaten und bamif ad absurdum fïfren.

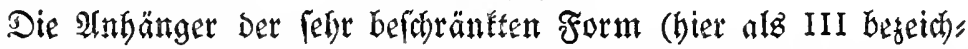

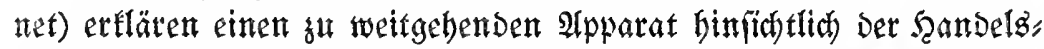
politil nich)t füt nötig; die Deteinbarung won gemiffen Gortudfäken gunitge, fo Dáp bie verantwortlityen Fattoren im gegebenen Falle :

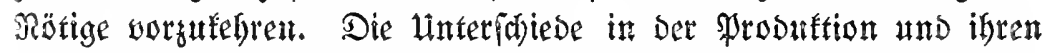
bebingungen feien in beiben Stanten mitrelbar und unmittelbar

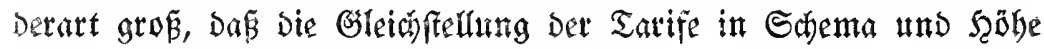
taum Duráfithrbat fei. Die felbftändigen Tarife bätten Daber fo

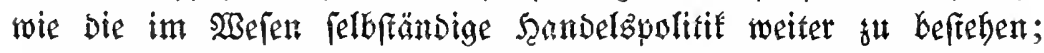

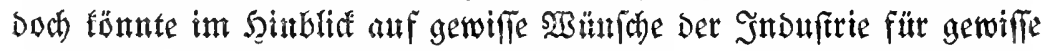
Poftionen (nod) einem Prozentfats oder individnell veriotisden) gegenleitig eine Serabfestung in Form Der Sirefereng eintreten, die allo Dem 2 utulatide nitht zugewendet werden tönnte.

Das lesertere Sylem (in Der geínilderten Form now) Das weiteft

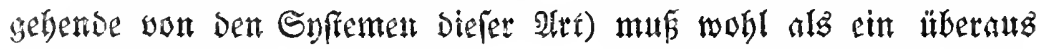
proteftioniftiches begeidnet werden, Das in Sinne wormiegent in

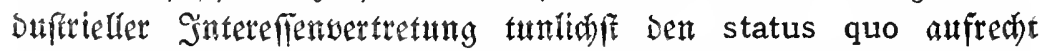

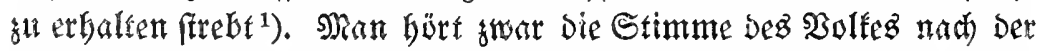

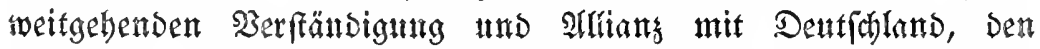
Dringenden $23 n$ ich nach grundlegender 2̈̈nderung ber bisherigen

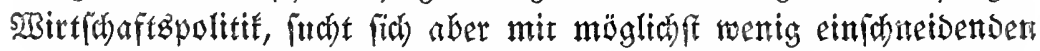

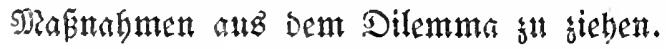

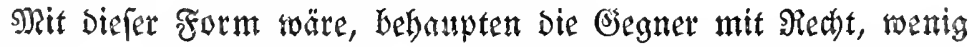

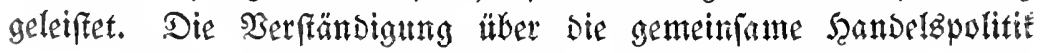
wäre mangels gentigens einheitlicher Bollpoltiti fo lofe tho loafer

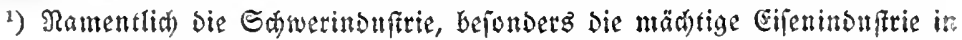

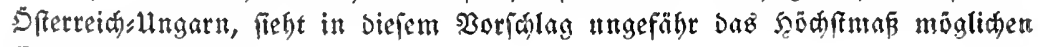
Entgegentommens. 


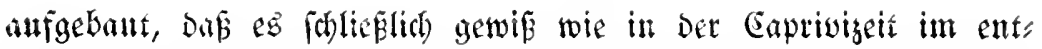

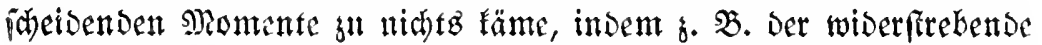
Eeil einfach crflärte, ar warbe mit ben Borarbeiten nidst redtgetfig fertig und fönne baber niơt gemeinfom unterbandeln. Die Prefe" renzen wärben vor allem von Dentfaland tno feiner ppestali, fierten Exportinduftrie anggentift werben fünen, alfo mehr in ber

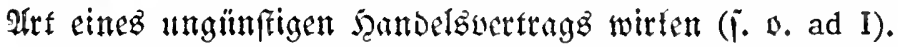

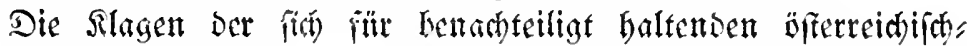
ungarif̧en Inouftrie über bie ungünftige nene Dronung würbent

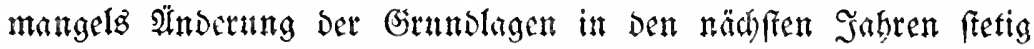

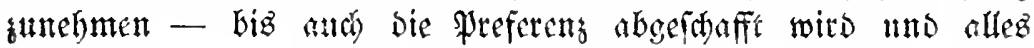
riditig wieber beint alten bleibr.

Das toollen ja won ifrem engeten, begreifliden, went atth nitht gerabe bie arlógemeinbeif genügend berïffidtigenden Efanspunfte Die Berteter Der opponterenden Inonfrien uns ibre Birfel.

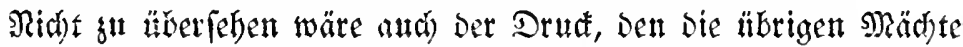
bei jedem eingelnen Şanbelgatrtage anf Den 3weibuno wegen beren Prefereng ansüben würben, fo baß eg fraglits eridicne, ob wegen Des wentig widtigen uno wenig wirfanten Snftrumentes ber Pres

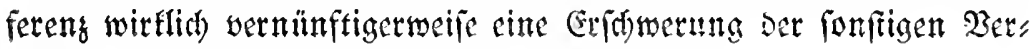
trogbuerbantumgen berbeigerïbrt werten follte.

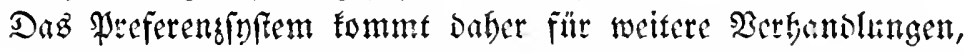

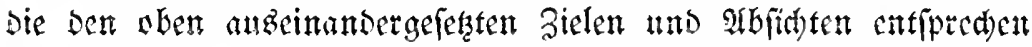

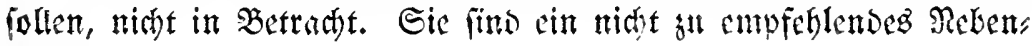
geleife.

Ingefictits Der beftigen Angriffe, die gegen die reine zollumion cryoben wurden, uno ba aud in Deutichlano gegen bie Cingefung

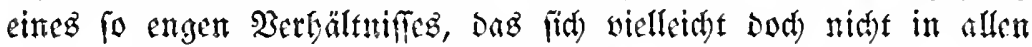

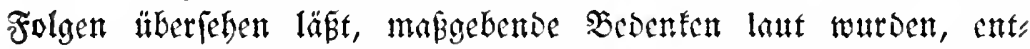

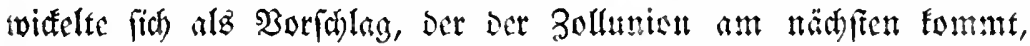
Die als II begeidyete Bariante Der "erleidfterten" Form wirtidyaft" (iơ)er Intants.

Sie bält bie gemeinjame Sambelspolitif alg aberfien brumefat feft unb verlangt gat biefem 3mede bie Eduffung cines Delegierten=

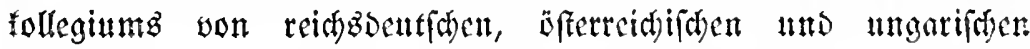
Beanten ber beteiligten Minifterien. Diefes Sollegittm bäte im

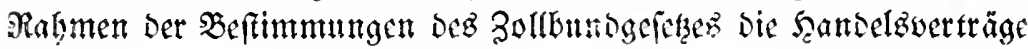


gemeinfam sorzubereiten, die Berbandlungen zu fübren uno abgus

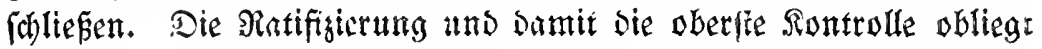
Damn wieder Den \$arlamenten Der drei Etaaten. Bur Erleidrternng

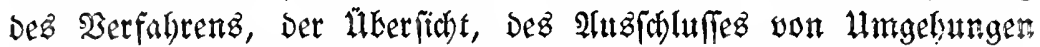
erfellen beide Staaten ia Shema und \$ofitionen gleidalautende Tarife ${ }^{1}$ ), bie aus einem Maximal und Minimilsarife befteben. Soltte Der eitte Der $\mathfrak{B e r t r a g s f t a t e n ~ m i t ~ e i n e r ~ P o f i t i o n ~ D e z ~ M a x i m a l s ~}$

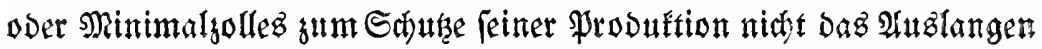

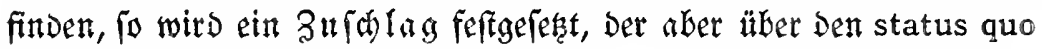
ante Dez früberen antonomen Tarifez dez Stantes nicht gimauz, reichen foulfere ${ }^{2}$.

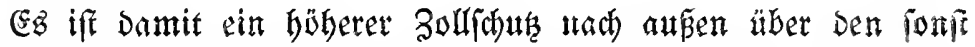
gleid)lattenden Mrarimals nno Minimals Tarif binaus ermögltat.

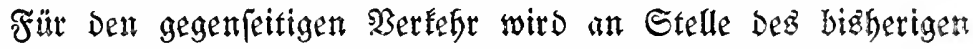

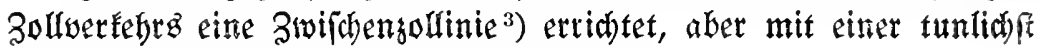
umfangreichen Sifre von zolifreien Gätern.

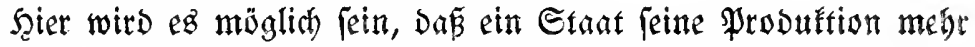

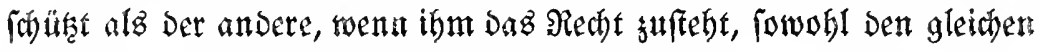

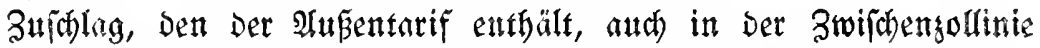

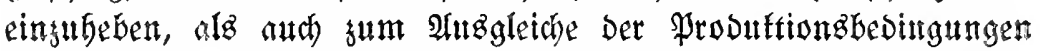
fich befondere 3ufdhläge für Den Bwifhenverfebr augzubebingen ${ }^{4}$ ).

1) Das Prinjip Der Form von "gleidlautenden" Tarifen liegt ja fidon Dem

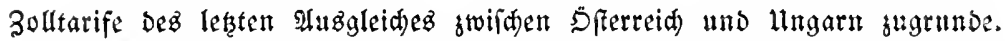

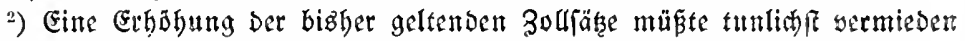

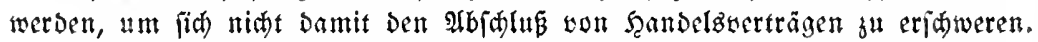

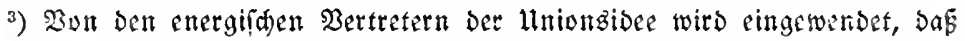

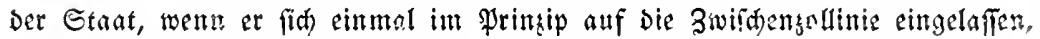

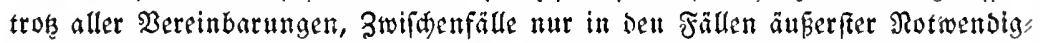

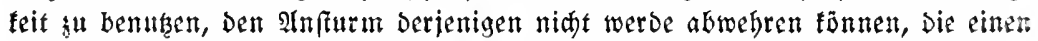

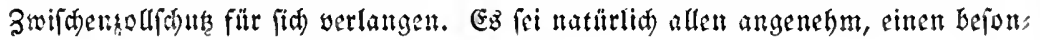
Deren Sđut zu geniesen.

Dem ift entgegentubalten, Daß̧ fid) Die Staaten beim Bertraye unf eit be: (đ) tönten, 3. B. I5-25\% Der Zahl Der Pofitionen.

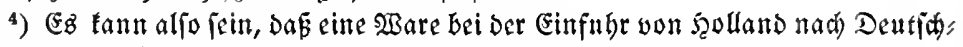

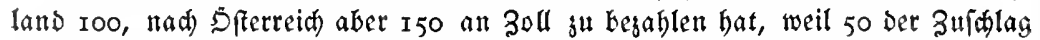

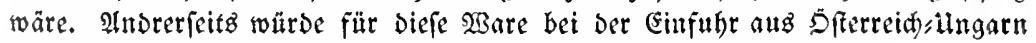
nad) Deutfdland 30, won Deutfaland nad) Sferreids/lngarn aber $30+50$, alio 80 gezaglt werben, wenn 30 Der Zwifdentoll und 50 Der eingeitlide Zujalag wäre. 
Wäbreno Der 2ertrag jwilden Den $\mathfrak{A}$ (literten anf 20 bis 30 Jaber

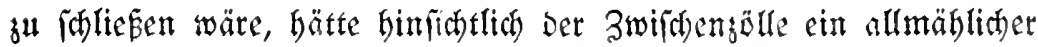
automatifber $\mathfrak{A b}$ bă rath Projentiägen ju erfolgen.

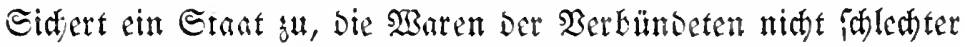
fu Eebandeln als die Englands, Frantreids, Jtaliens, Rnßlands \#no Der Bereinigten Etaten, fo fann ifm ofne weiteres ber Minimals

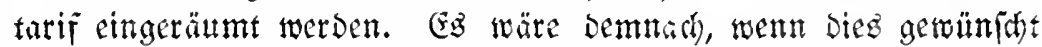
werden jollte, felbft bie Gewährung ber "Neifibegünftigung" möglict).

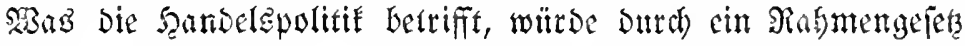

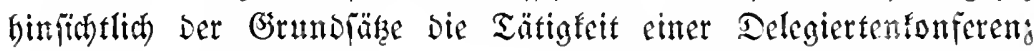

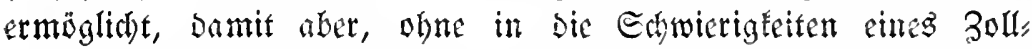
parlantentes fïh ju verftrifked, die Edhlugfertigfett ber gemeinfamen Şandelşpolitif aefît)ert und diefe felbft atif bleibende Grandlage geftellt. Dabet bleibt oen Parlamenten dod bie oberfte Sontrolle gewahtst.

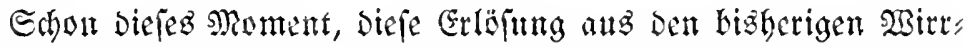

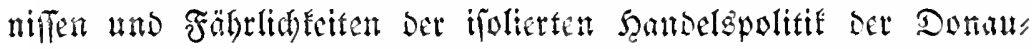

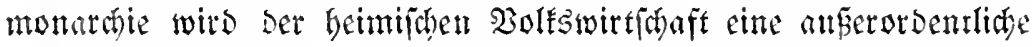
Erleichôtung bietent no bie Inomfrie geneigt machen, eber aui

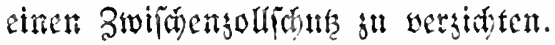

Da alpo bie glatte Zollunion amiateinemb nidyt juftande ju

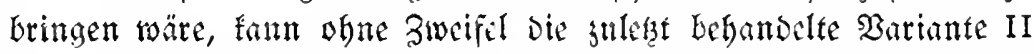

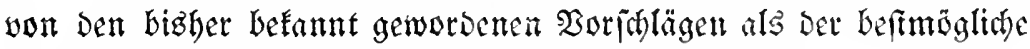
und vieliettigft verwembkare $23 \mathfrak{e g}$ empioblen werben.

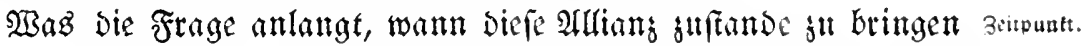
wäre, fo fann fie nut Damit beantwortet werben, Daj man fie

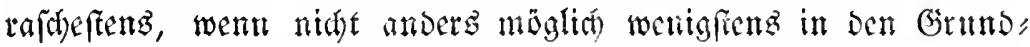
fügen nod wor bem Friebengiduluffe, triter Dach bringen follte.

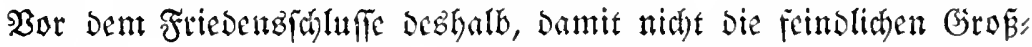

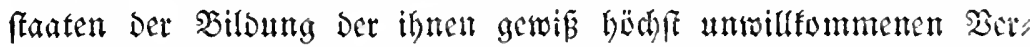

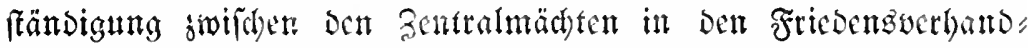

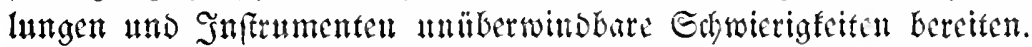

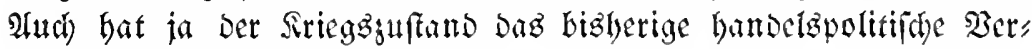

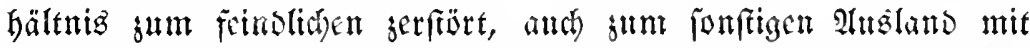

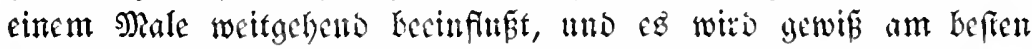
womöglich gleid won wornherein mit cinem temen giegime begonnen. Man bätte bann angẹ̣thts bes burd ben Sirieg erfolgten Erlöjdeng 
Der Şandelzuerträge nut Rubland, Franfteid, Stalien, Belgient, Serbien, Montenegro no Sapan eine einverfändiche Mufbebung Der Berträge mit Den übrigen Stanten Durdłureben, Damif nid

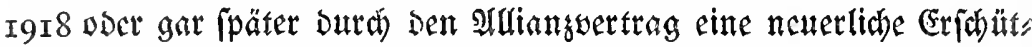

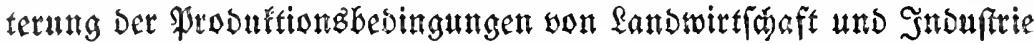
erfolge, die unmittelbar nad Dem Sriege ungleid) geringer wä̈e.

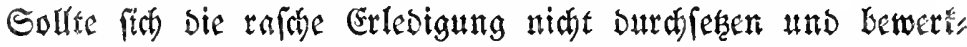

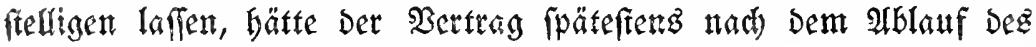
beftegenden Bertrags mit Dentfdland, aljo am I. Samuai I9I8, in Siraft $\mathfrak{g}$ treten.

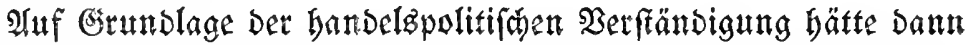

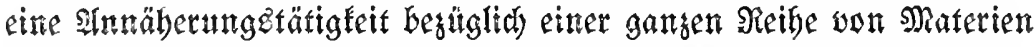

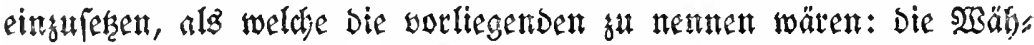

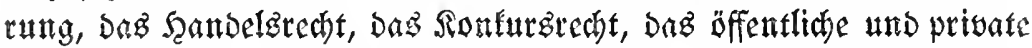
Seeredht, Das Bergredyt, das Sartelumefen, die fogiale Befergebung,

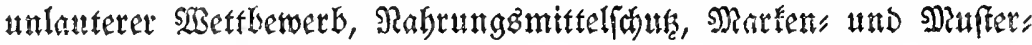
fđun, Die Beterinärgorfariften.

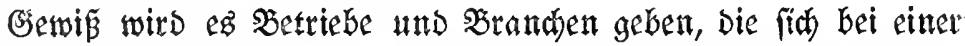
weifgebenden Berfändigung nit Deuticland gegenuber den gün:

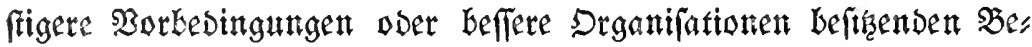
trieben und Sranchen Deutjhlanis nicht bebaupten fönen. Wber wie

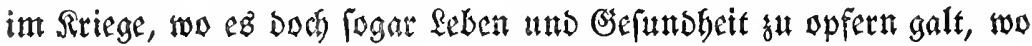

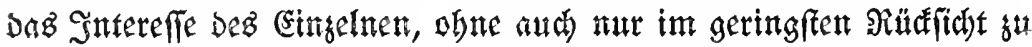

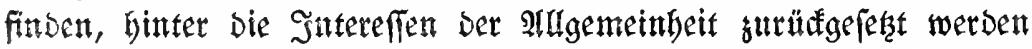
mufte und warde, gilt bies bier bei Der widjtigen Frage Der wirts

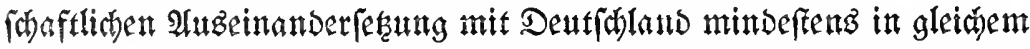

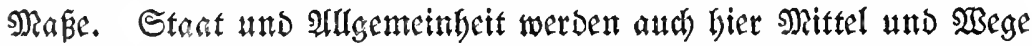
finden, um bei aubfichtzlos ungünftiger Sachlage - wobei es fich

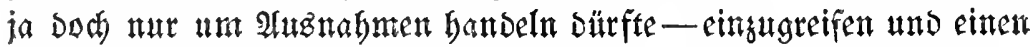

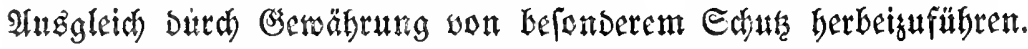
Eingriffe in bie priwatimtereffen find ja fon während bes sirieges in weitem Situma me vorgefommen, und die Sevollerung bat fih an Diere Eingriffe dez Stantez im öffentlichen Sntereffe gewöbnt.

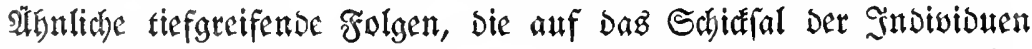

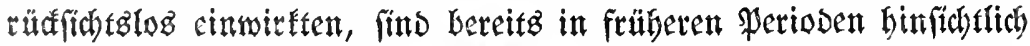

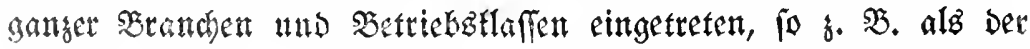
moderne Fabrifs: ans Mafdinenbertiob in einer gatten Reithe 


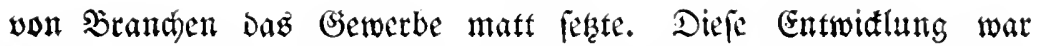
eine nutwendige, allerbings worwiegend vom Sndiviontum ge"

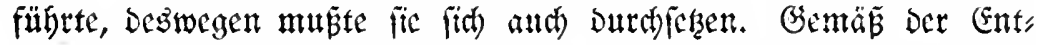

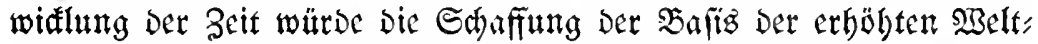
wirtichaft auf beutfocr und zentraleuropäifder $\mathfrak{a}$ lt

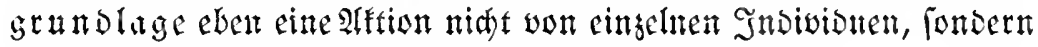
Der $\mathfrak{A}$ llgemeinbeit ful fein baben.

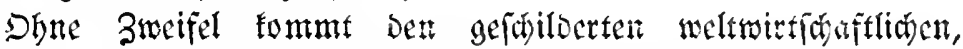

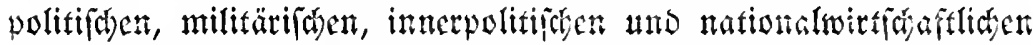

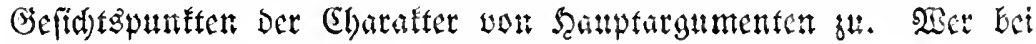

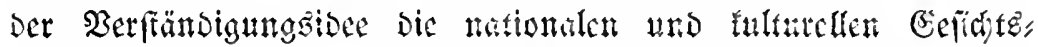

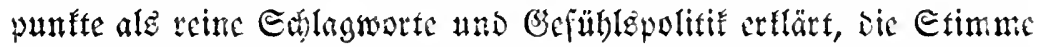
Det Bölfet nidht bört voer börent will voet won wornberein auf Geller and Pfennig Die Rechnung anf Den Tijó gelegt verlangt,

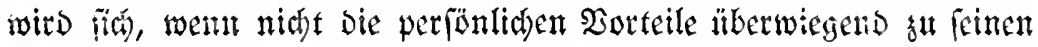

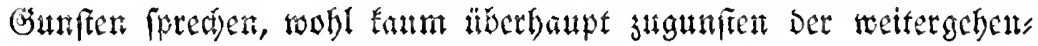

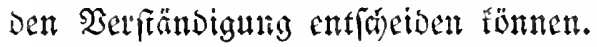

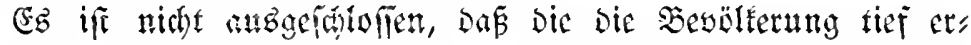

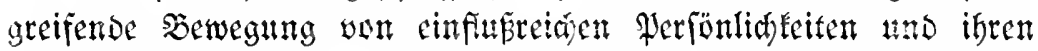
Sonderbünden ähnlid) wie frühere Infäzze und Bewegungen unters

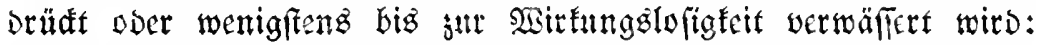

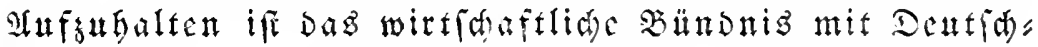

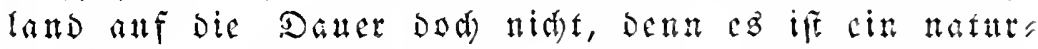

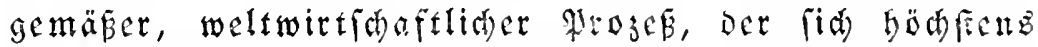

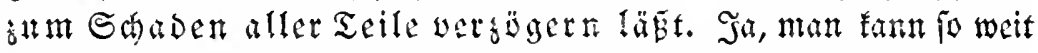

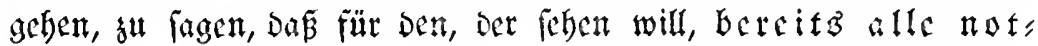

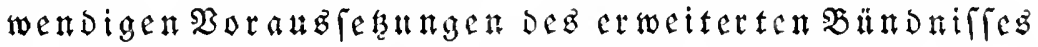

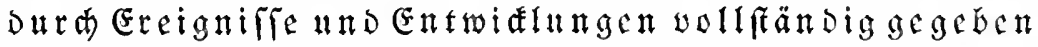

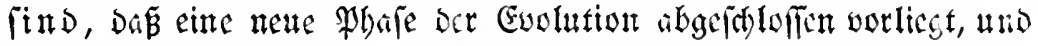
baßj es fich nummebr barm banselt, aud formell bie notwendigen

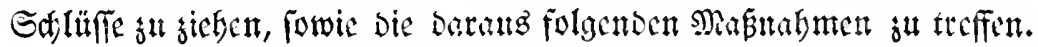

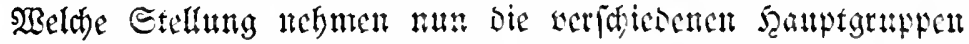

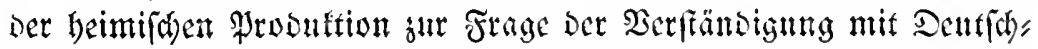

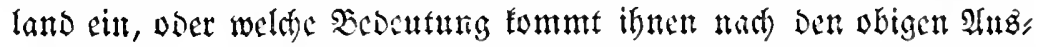

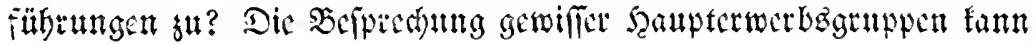

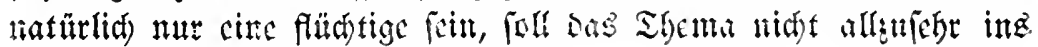
Detail gefportten werden.

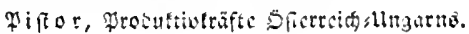




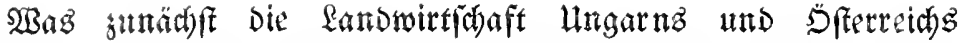

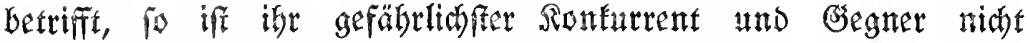
bie Srobuftion einer mit hod moderner Technif intenfits arbet; tettben Eanomintidaft, bie naturgemä́z wegen Der Roften uno

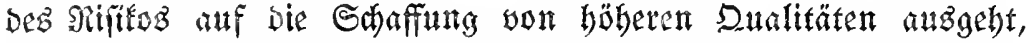

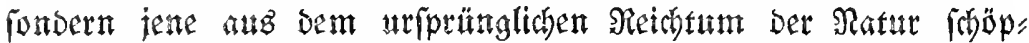
fende Probution, wie fie in Rordamerifa und Argentinten bes trieben wirs. Begen diefe teils anf Raubbat, teils anf Dem

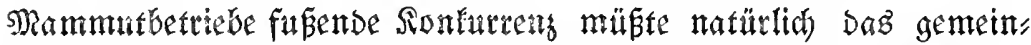

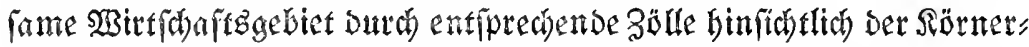

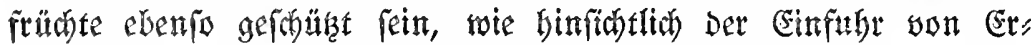

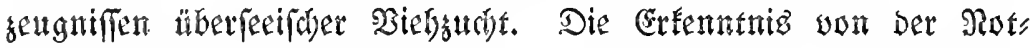

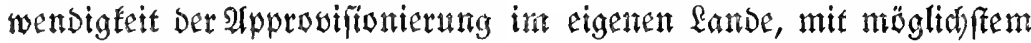

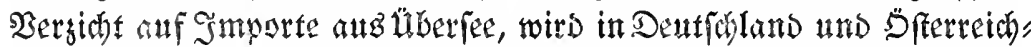

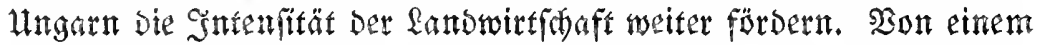

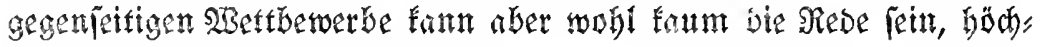

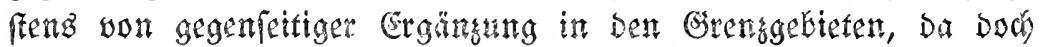

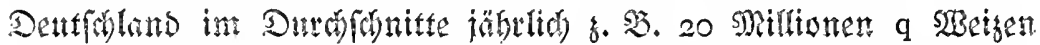

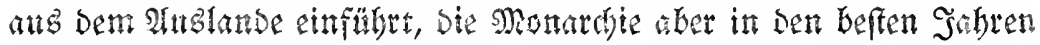

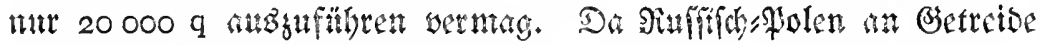

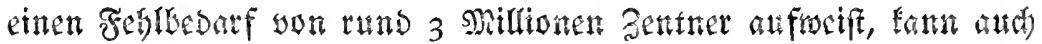

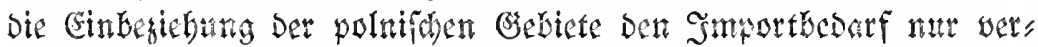

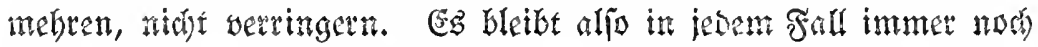

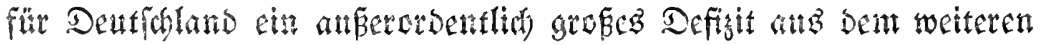

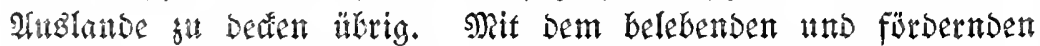

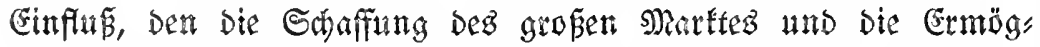
lichung Der Spegialifierung anf Die Lage Der Mebrzabl ber Srandent

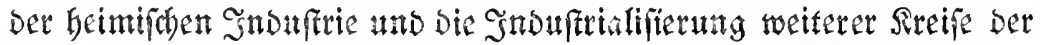

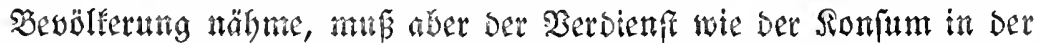

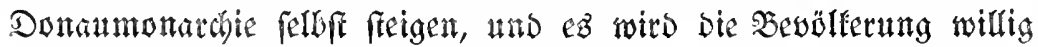

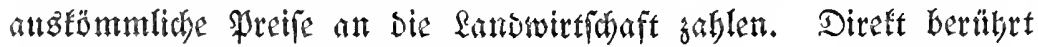

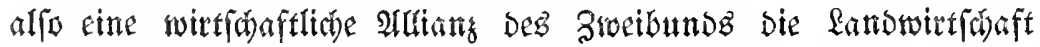

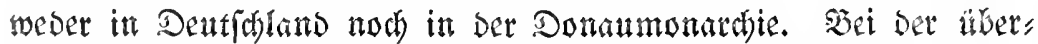

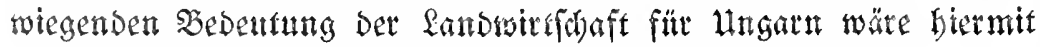
bie Frage für Transleithanten im wejentió)en gänftig gelëf.

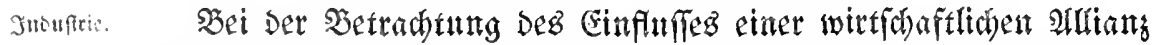

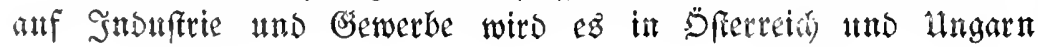




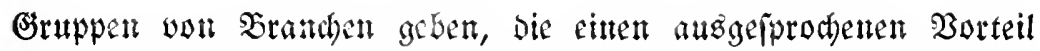
Daraus giegen, foldye, bei benent firit) Sorteil und Rachteil ants" gleiden, tho fuldee, bie anggeiprodyen Darunter letben.

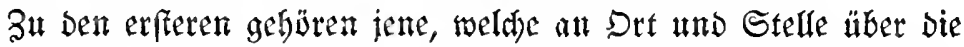
notwendigen und widftigften Rofy und fandwirtidaftzprodufte

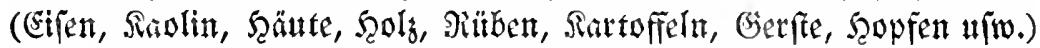

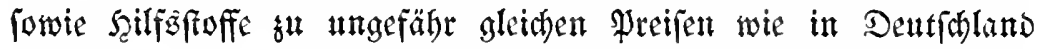

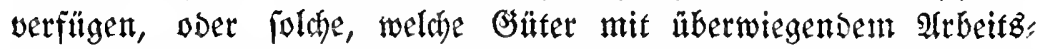
lobn erzengen, und Denen entweder gefáulte atrbetter in genü,

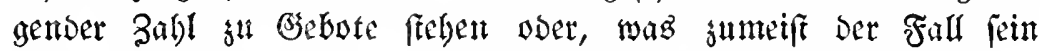
wits, bie über genügend abrichtbares, gentitg jamez artbeitermaterial

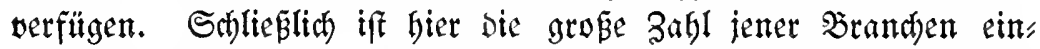

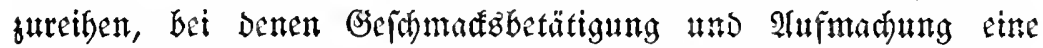

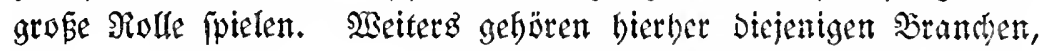

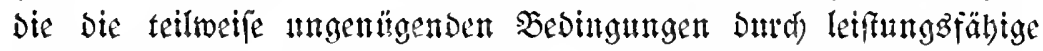
Drganifationen aubgeglidyen boben. Sei all beejen Granpen ber

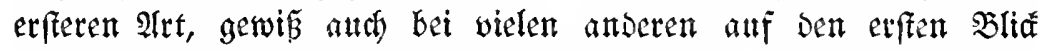

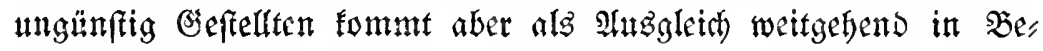

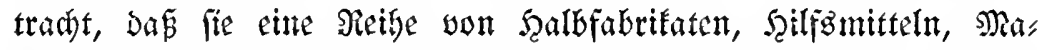

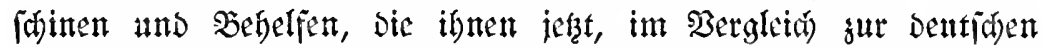

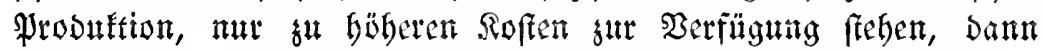

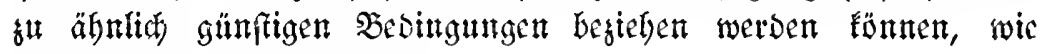

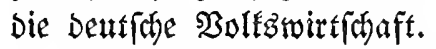

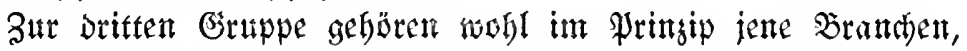

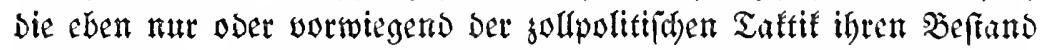
verdanfen. Esz if bet iften getwi

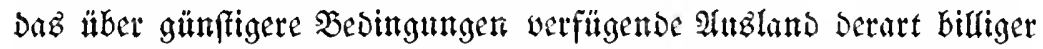

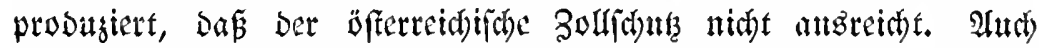
fann Der Fall eintreten, Daßj firi) bie Sonfumenten oder seiter"

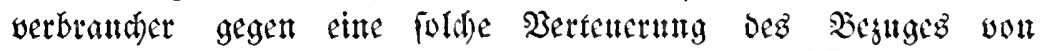
Derartigen reinen Zollītubetrieben mit allen Mitteln femmen uns bei

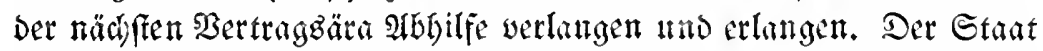

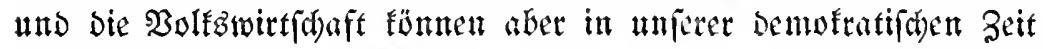

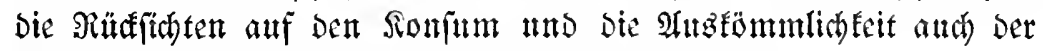

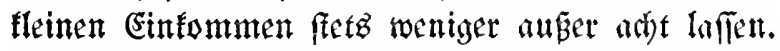

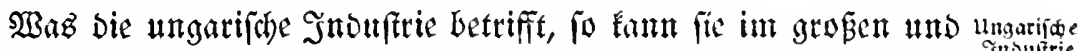
gantsen Den nadbeiligen Folgen eittes wirtichaftlidyen biunoniffez 


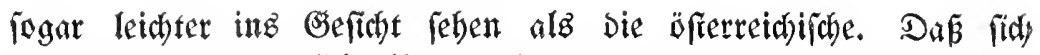

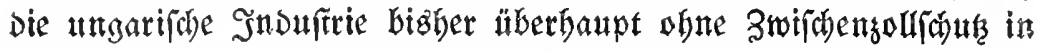

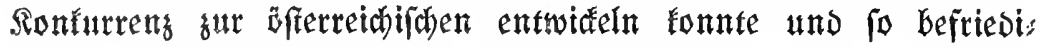

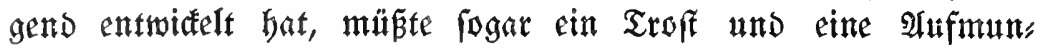

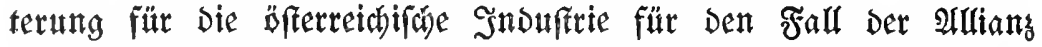
mit Dentfaland fein. Die Subventionierung Durd) bie ungarifde Regierung bat Dod immer nur einen geringen Teil Der Snveftitions: Foften gebeft, und die Subvention frant in ben meiften Fällen nut in untergeoronetem Berbältnis su Den feiftungen, bie der Unters nebmer bei Einfübrung einer Snduftrie in Ungarn gu vollbringen batte. 2Ingefichta Der Ronfurreng in D̈fterreich if in Ungarn an Sndufteren und Befrieben nut entfanden and bann verblieben, sas entweder über günftige lofale oder Frachtverbältniffe voer fonftige fürberlicle Norbedingungen verfügte; aud wurden Subventionen dod nur an leifungzäăbige uns kapifalfeäftige Unternebmer gewäbrt, bie

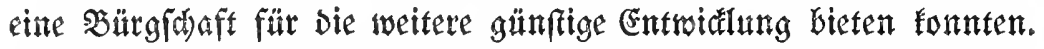
Schließlich ift bie ungarifbe Snouftrie jung und ifre Neugrünonngen

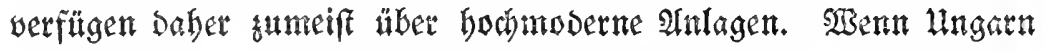

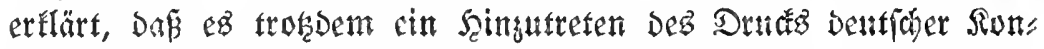

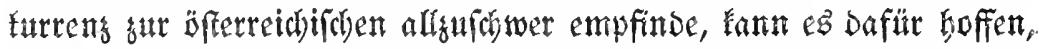

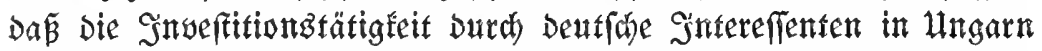

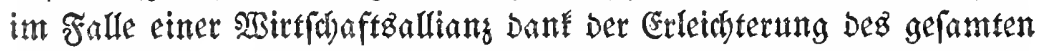
Berfefri, Des gefteigerten gegenfeitigen Sittereflez und Sertratens sunebmen, baber bie ungarijhe Snouftrie wadhjen, abev nidht fas rütgeben wirb. Siefe worwiegend günftige Stellung ber magarifden

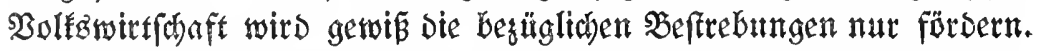
Sïnftlich gesüchtete, auf Rleintwirtid)aft beredhnete Betriebe fönnten für bie tngarifde $\mathfrak{D o l f z}$ wirtfhaft fanm won witflid)em und bleibendem Borteil Fein.

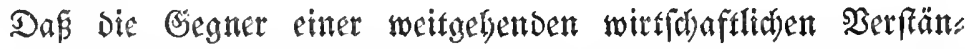
Digung mit Dentichland Das Gefpenft einer Zwifhensollinie zwifhen

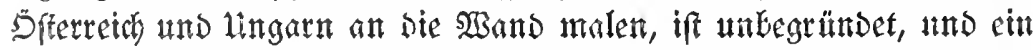

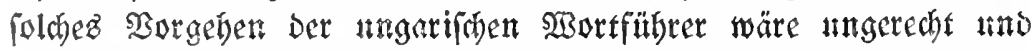

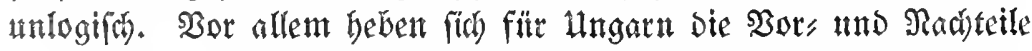
Der gemeinfamen Sisitfohaft mit Drerreich in groben getabe fo anf,

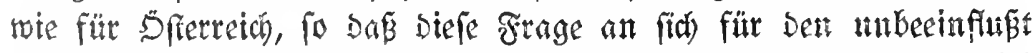

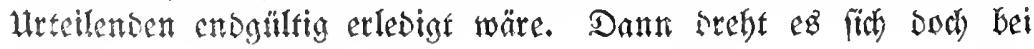


Der gangen aftion um ein Dpfer, ous bie öfterteidaifde uno ungarifthe Snouftrie ber Algemeinbeit, Den weltwirtionaftlitben

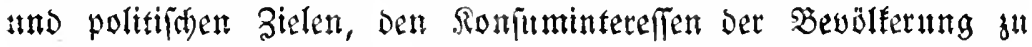

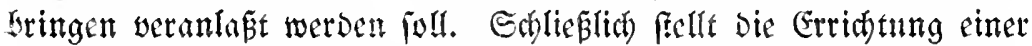

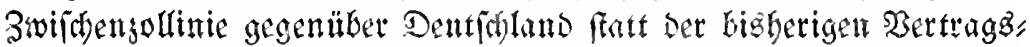

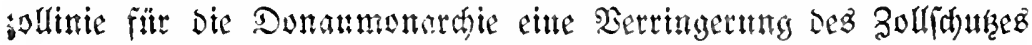
Dar, bie Dod logifherweije von lingarn nidjt mit einer Grichwerung

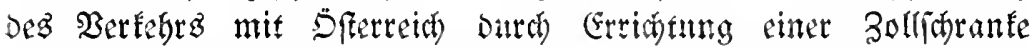

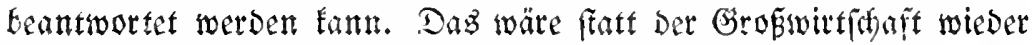

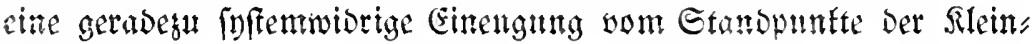
wirtf(b)aft.

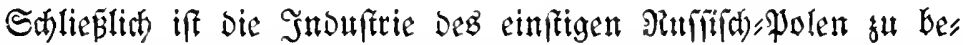

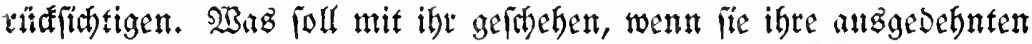

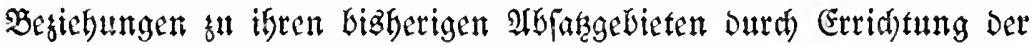

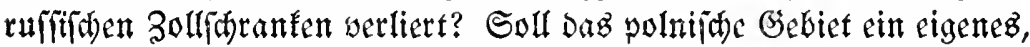

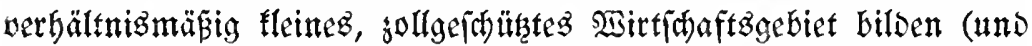
Dort verfümmern), oder foll feine Jnouftric die Erzengniffe auf ben

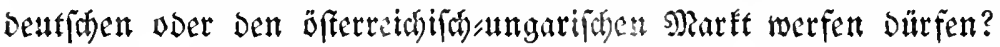

Die Frage Der Erbaltung Der polnifhen Snouftrie und Damit Der withtigften Boblftandsquelle Polens fordert naturgemäß ein

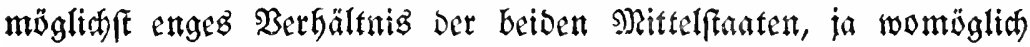
Die Zollunion, um Den Wettbewerb Des nenen Produftiongegebietez leidfter extragen fa lönnen, Dem neuten Sonfurrenten aber einen

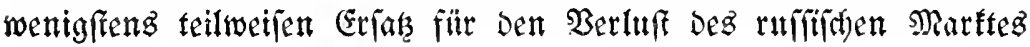
jat bieten.

S'm allgemeinen wiro man, obne in Details eingugeben, anf

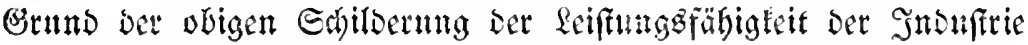

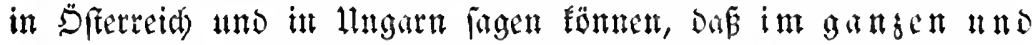
grofen sie gejumte Tertilimonftrie, die Eifen", Etabl, feoce mo Şolginouftrie, bie Papierinonfrete, Das Bangewerbe, wichtige Teile

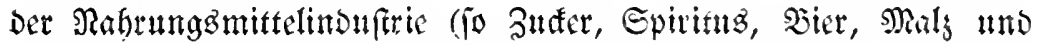

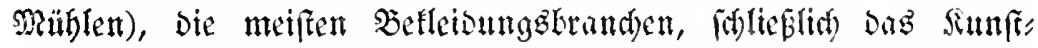
gewerbe int weiteren Einne logut eine reine Bolfunion vertütgen ${ }^{1}$ ).

Das aber fino runo $70 \%$ Der indufriellen uno gerwerblicten

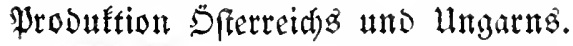

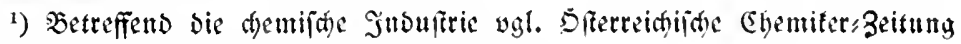

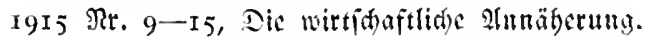




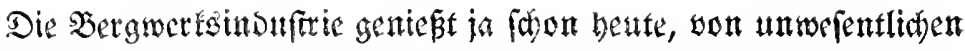

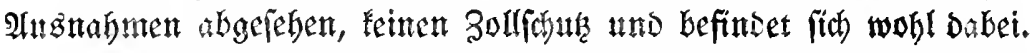

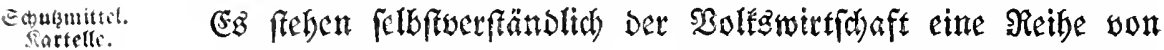
befonoeren Mitfeln zut Eebote, un fith gegen ungünftige Folgen

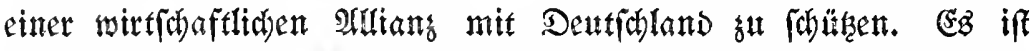
birz namentlith bie Sartellorganifation. Ilnfer widjtigftez Sartell,

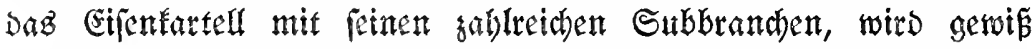

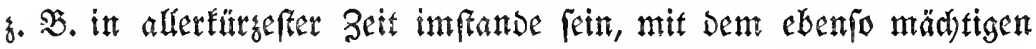

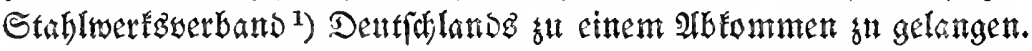

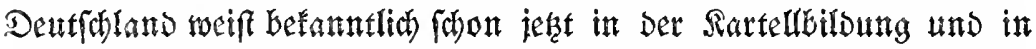
Den fonftigen induffriellen Drganifationen größeren limfang tho befifere

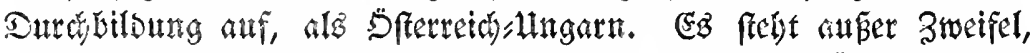

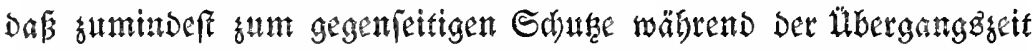

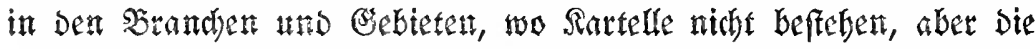

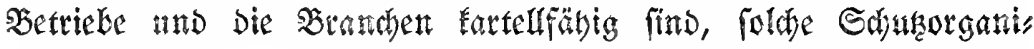

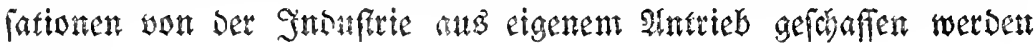
Sürften.

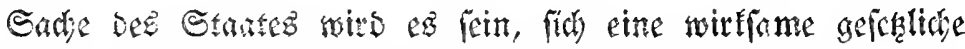
frandhabe gegen

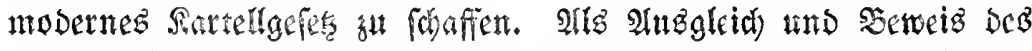

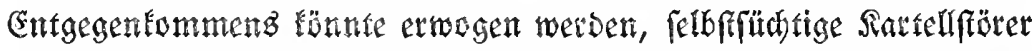

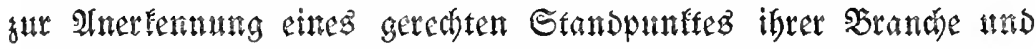

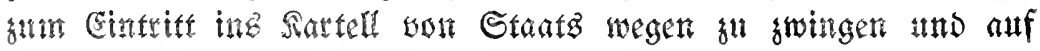

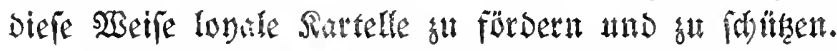

Eirenbabns
fratt.

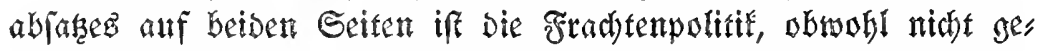

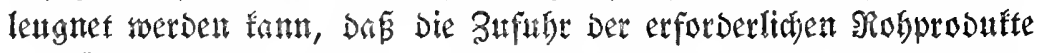

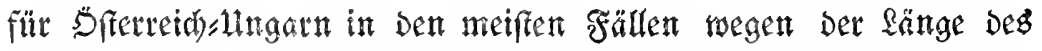

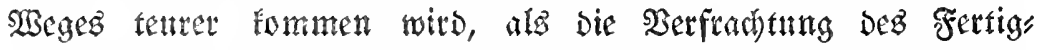

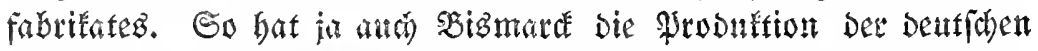

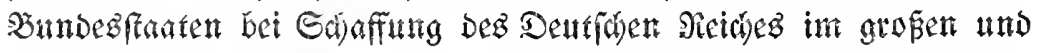

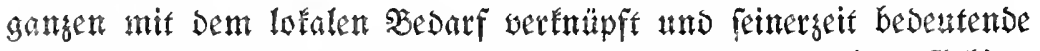

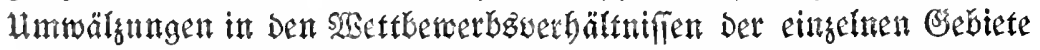

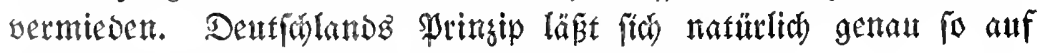

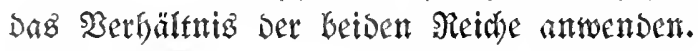

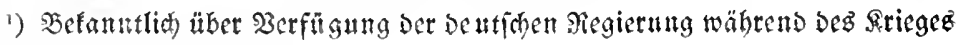
wieder zutranie gefommen. 


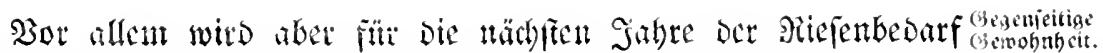

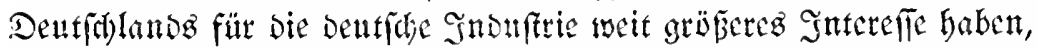

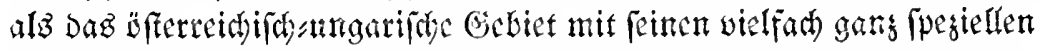

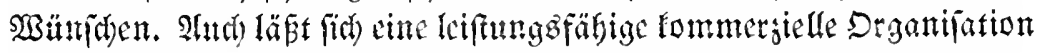

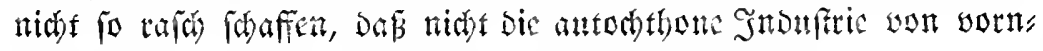

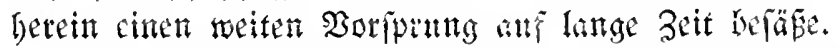

Eineat befonderen Troft gegentber ber \$ejorghiz yor werberenden Vumaftumges
iänigleit.

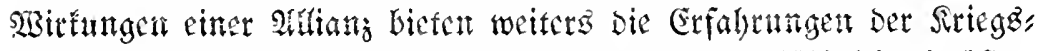

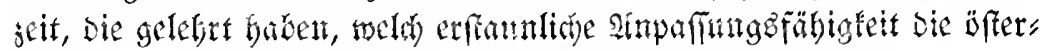

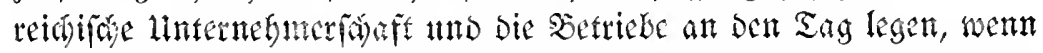

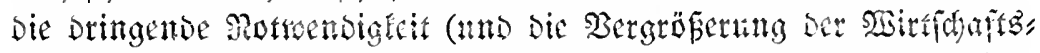

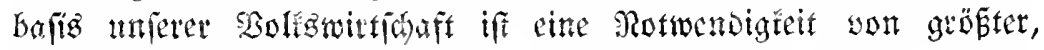

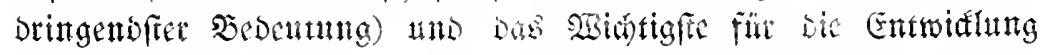

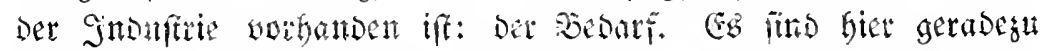

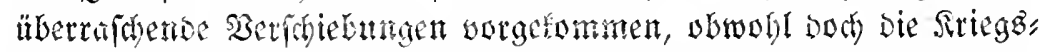

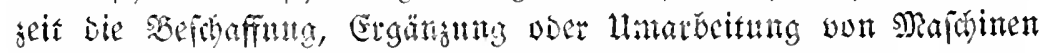

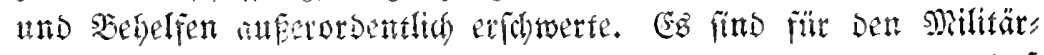

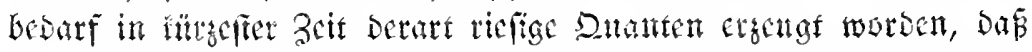

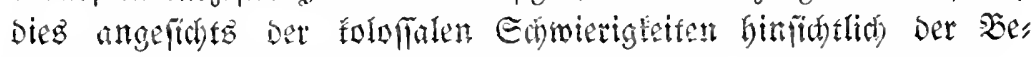

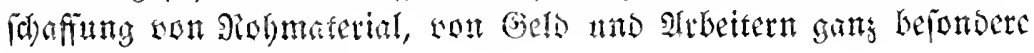
Beaclitung verbient ${ }^{1}$ ).

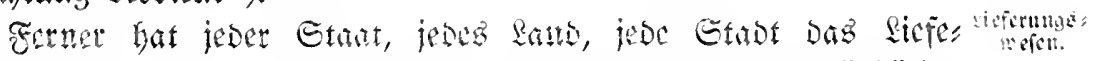

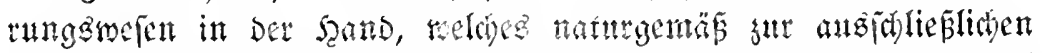

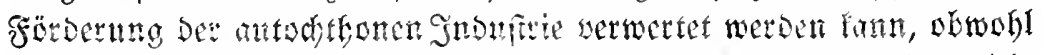

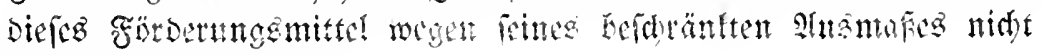

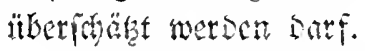

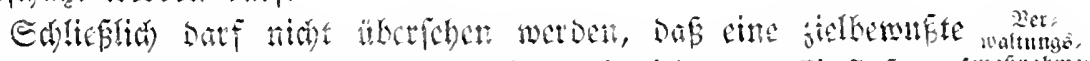

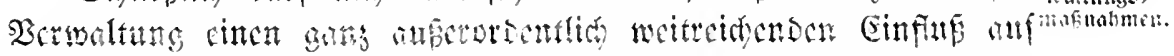

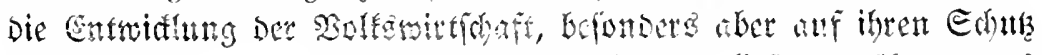

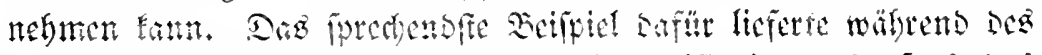

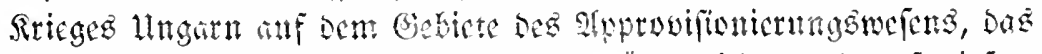

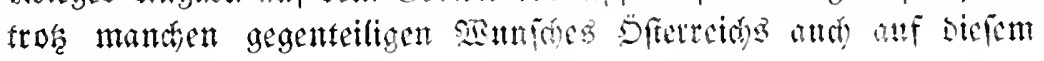

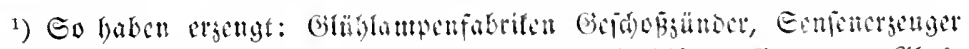

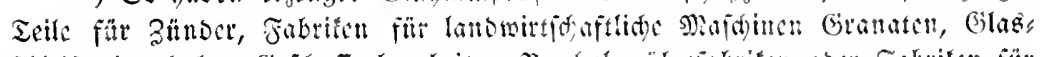

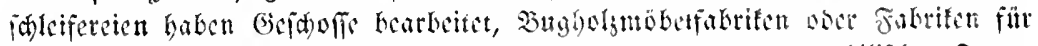

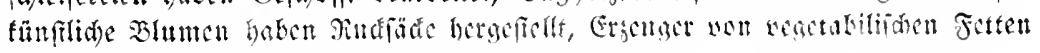

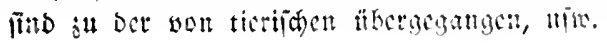




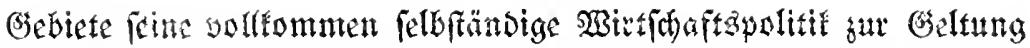
bradjte.

Nenn bann it einer Sranche teines aller angegebenen Mittel

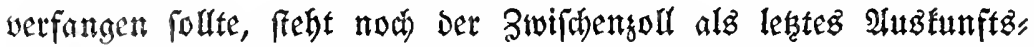
mittel sutr Berfügung. Diefe Bemerk̈ngen Dürften betreffend Den S(t)

3ufanmm, \$fierred biftorifhen, geographifden uno nationalen Schwierigteten in Erioäs gung jebt, bisher eine günfige Entwiflung genommen. W\$obl fant ez fíty mit Dem in Die vorberfte Reife Der SBeltftaaten eintretenden

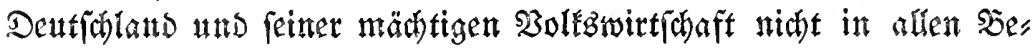
langen meflen. $\mathfrak{A}$ ber es febt idhon beute ftapp hinter Den fübrenden

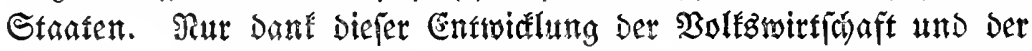

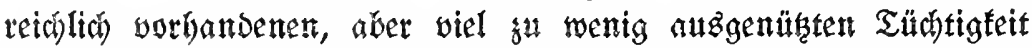

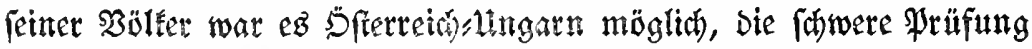

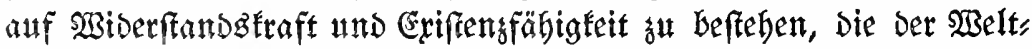

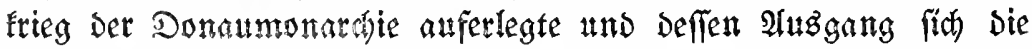

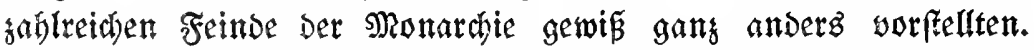
Mit Der Eriegerifonen Eewaltleiftung, Die Die Donnumonartie, geftüţt

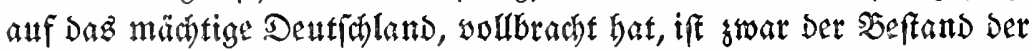

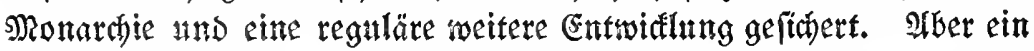

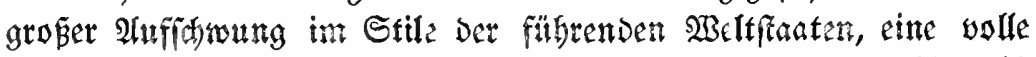

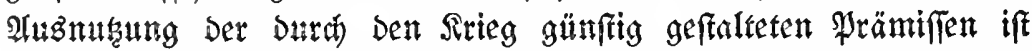

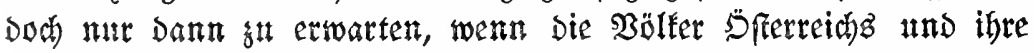

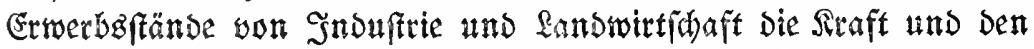

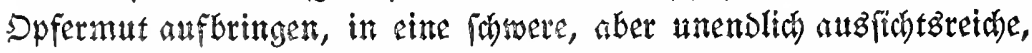

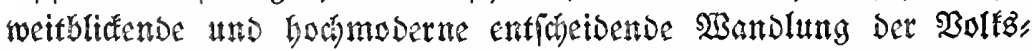

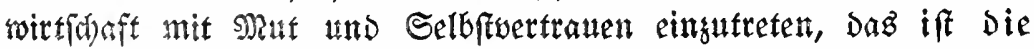

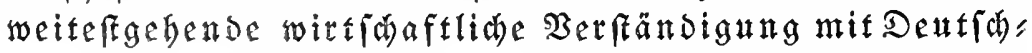
land Hnd bie Shaffung jenes Rernes wirtidafticher

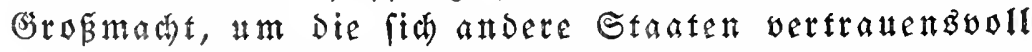
als weitere Teilnehmer Der Alliang gruppieren follen.

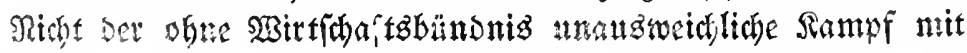
Dentfoland, fondern nur Die vernünftige, alle Shaffenstraft on fpanteros Berfänsigung mit Dentfdland fann für bie Monardie Der richtige 2 Legg für bie Zukunft fein. Dies gilt fowohl für ber gegenfoitigen, swie für Den $\mathfrak{A}$ ts 
Der gemeinfam ğl betreibenden Entroidung Des Drientg auf fultue" politifater Gentudage.

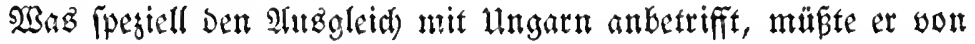

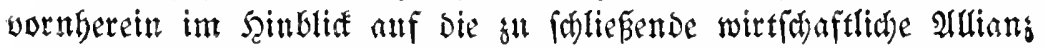
mit Dentfaland worbereitet und bebandelt, aber erft dann jum ends

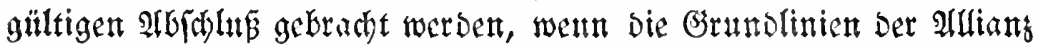
zwifhen Den brei Stataten flargeftellt $n$th feftgelegt find. Die Regelung

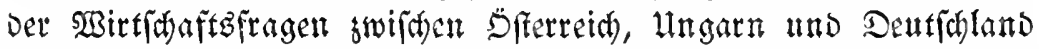
find eit Ģanjeg, won Dem nidht ein Sctl in Der Befandlung abgetrent und felbftändig erledigt werden Eann, ohne damit Den Bulammentang oes Rompleres anföntheben.

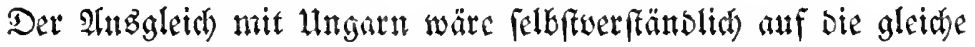

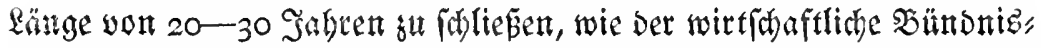
vertrag mit Dentidhland. Die Bulfzintrtichaft betber Staaten verlangt obnebin (chon längf eine Feftlegung Der wirtfdaftlichen Gemeinịams

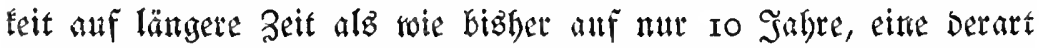

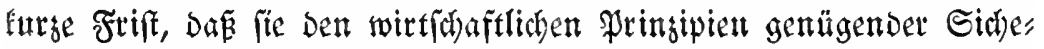
tung von Snoftitionen and vernänftiger (mortifation wiberipridyt ${ }^{1}$ ).

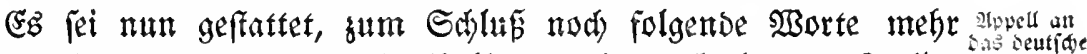

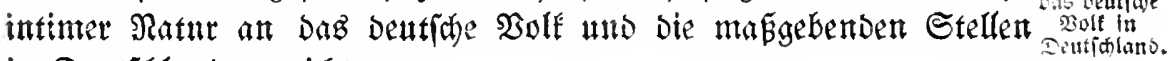
in Deutfaland $\mathfrak{z}$ rifften.

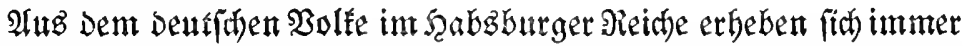

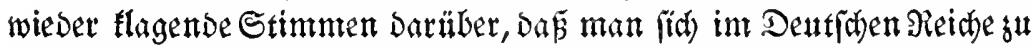

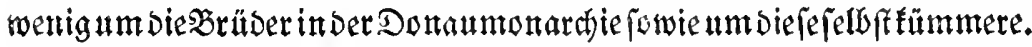

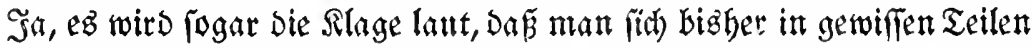

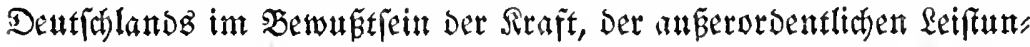

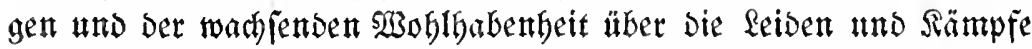

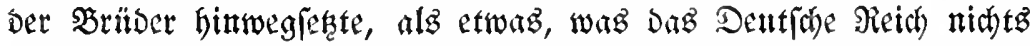
angehe. Die einen erflären biefe Erfajeinnth Damit, Dentichland habe

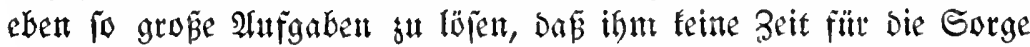

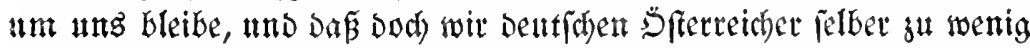
in nationaler und wirtfdaftlid)er S(y)barbeit leiften. Ind wir felbfr feien won jeger in den unz biz aufz tiefite intereffietenden

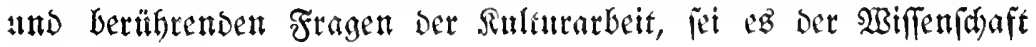

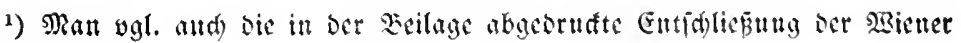
รุanธอไดีลณm 
oder Des Belderwerbez befangen. WBieviel mebr müßte Das von Den Bewohnern eines $\mathfrak{a n d e s}$ gelten, die Den nationalen Rampf nur vom Şöremfagen fennen und im Madjtbetriebe bemmungslofer, grof angelegter Entwidtung feben.

Sn Diefen Gegenjak Der Meinungen folf nidht weiter eingegriffen

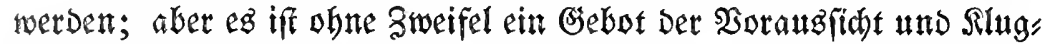

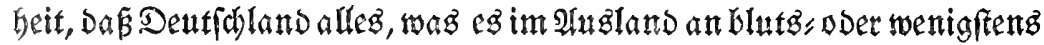
Eulturoerwanden Elementen auf Der ausgerprodenen aftivete,

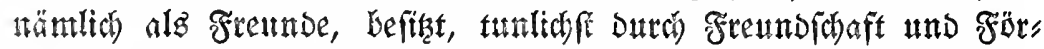

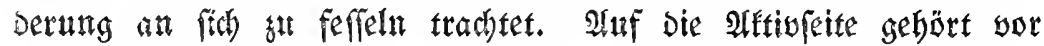
allem Dfferteid) Lngarn mit feinen Dentidten, ands mit feinen Magyaren, Numänen und Slaven ${ }^{1}$. Se feftere Bande Der Freund,

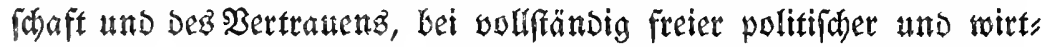

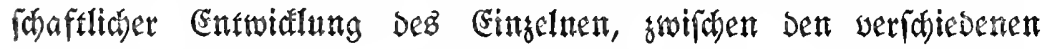

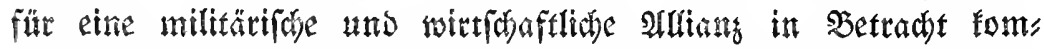
menden Stanten und Staatsgebieten geidhafen werden, um fo grö̈rer

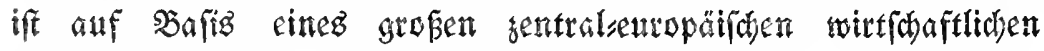

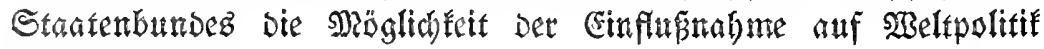

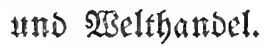

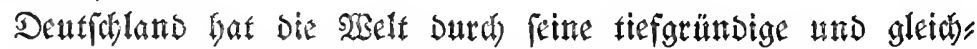

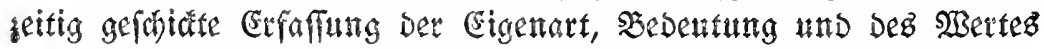

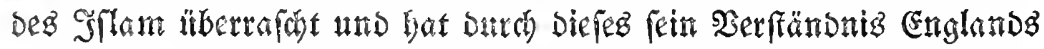
Bormady in Sifen einen nimmer gut gu madenden, fhrweten Shlag

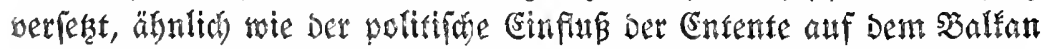
erledigt if. Sngland bat swar in eitnem anberen Sinte als bie ro" mantichen 230 lfer Rolonialpolití betrieben, aber eb haf, ohne anf bie Individualifierung eingugehen, Die farre Suprematie aud Dort Durds" fulesen fortgefaben, wo biefe nicht am Slake wat. Sn ber weits

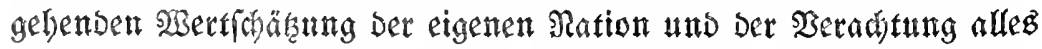
beffen, was nicht englifí) und naí englifinen Sitten falons und flubs

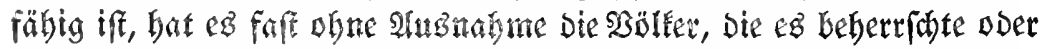

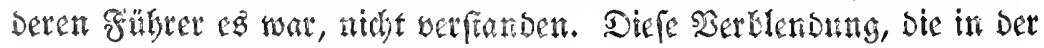
Rage Erobbritantiens begrünset ift und vont "Infulariemug" Fommt,

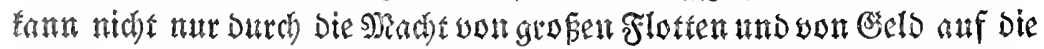

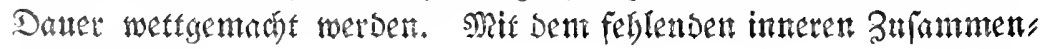

1) Bernht Dod bie moberne Sultut all bicfer Bölfer anf Der Deutiden. 


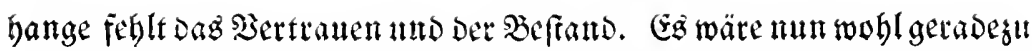
tragifh, wenn Das Bolf Der Didfter mo Denfer zwar metfterhaft Den nahen und weiteren Drient, Das \smanen und Ebinefentum ju erfallen verftitnoe, Dort und it Sitdamerifa gern und weifgehend Snveftitionen vornähme, aher an feinen Stammegbritdern, an Den

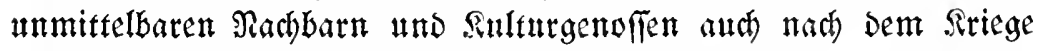
wieder faft achtloz und verftänonisloz vorüberginge. Sm Gegens

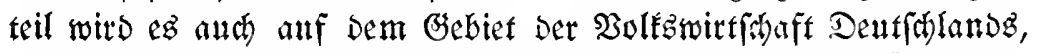

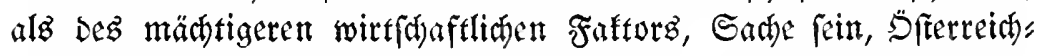

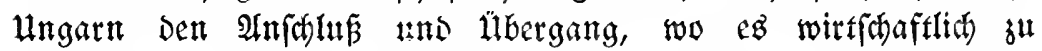
iefr leiben wärde, stt erleithern. Die vollwertige fulturelle tno

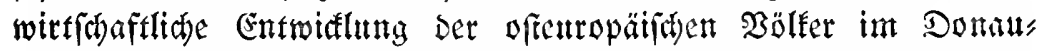

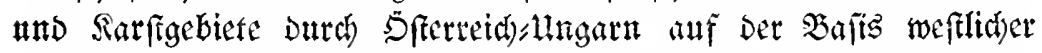
Sultur, fowie beren machtodle 3ufammenfafing gegentiber bem

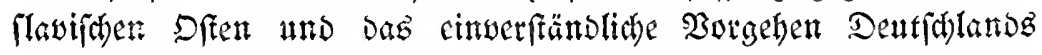
und Der Donaumonardbie it allent Fragen Der äußeren, befonderz

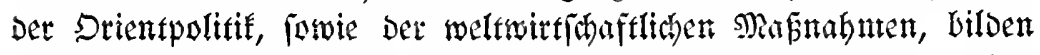
Die Grundlage Der wollen Maddentwidung beiber Statter. Dhne

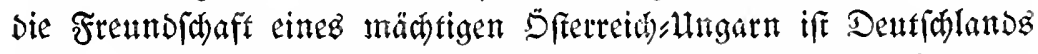

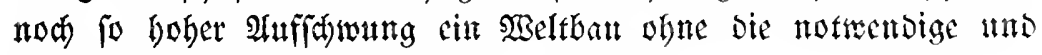

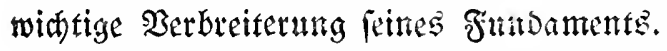

Sommt aber eine gerechte, Daterttie Derfiändigung jufantide, Dann wärde bemiefent werden, Daj bie Ströme won

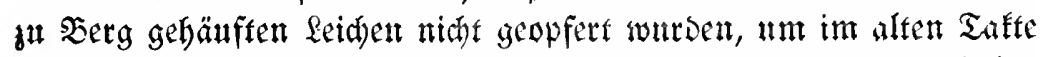
Politif und Sirtichaft zul treiben, pondern un Zentraleuropa auf citte

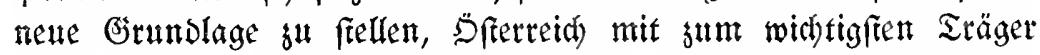
Diejer neuen Dronung und fum hoć)wertigen Teilnebmer ga madjen.

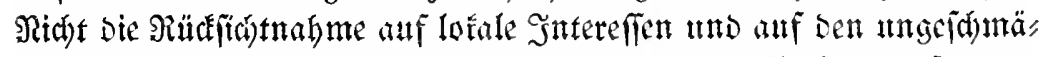

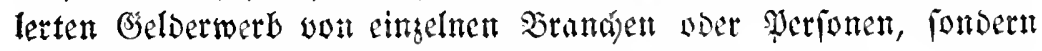

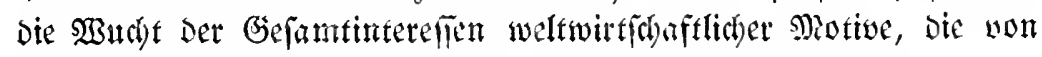

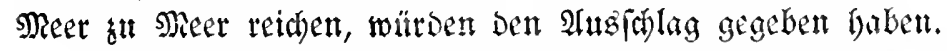

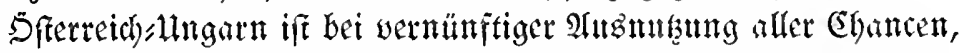
melde bie moderne Sultur, ber Sapitalismus nno Der SBeltverteht

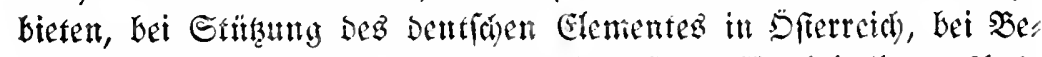

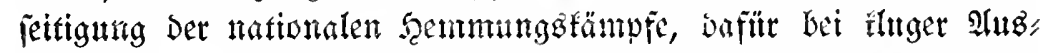
nub̧ung Der Rationalitäten: \&and Der Zufunft, ja ebenfaliz ein Luns mit unbegrengten Möglith feitent. 
Die Monarffie wärde Dutch engere, ntehr unmittelbare Bers

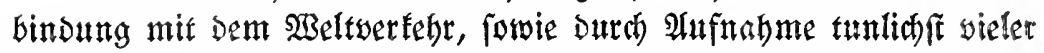
Deutirider Sauffente, Durd engere Durdobringung won Berwaltung

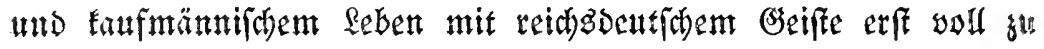
blüben beginnen, Denn eigentfich erff jeş⿰ viden Belangen für Dag Donaureid) Ste rechte Zeit Der Entrwidlung

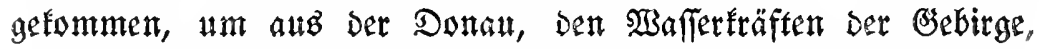
Der Durd Den Binnenverfehr günftiger geftalteten Lage jeines Meeres, auz Der Uriprünglitfeteit, aus Den Talenten uno Der unverbrauthter

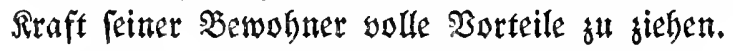

Dann wärde man in ber şelt woll und gant begreifen, rad Dfferteich Ungarn ift:

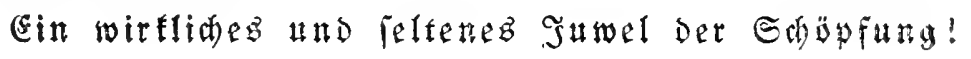




\section{Fundgebung der Wiener Gandelatammer,}

rinftimmig befallofen in der yollverfammiurig am 21 . Oftober 1915.

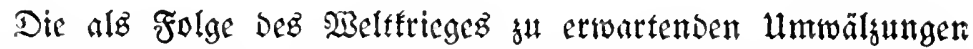

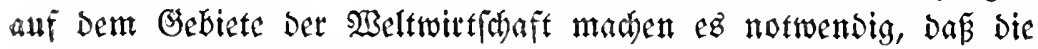
offerreid

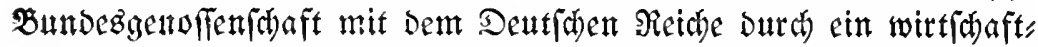

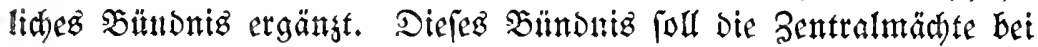

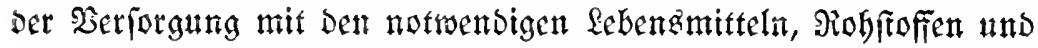
Induftrieprodutten won ibren poltifiouen und wirtichaftlichen Eegnern unabbängiger machen uno sutr nadboritufltderen Bertretung ifrer

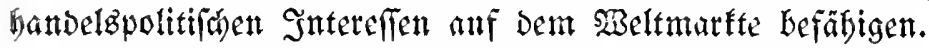

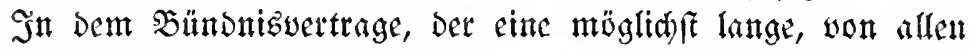

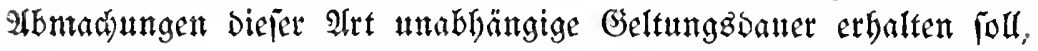

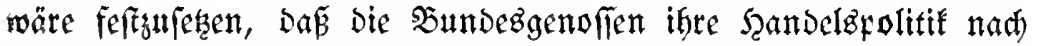

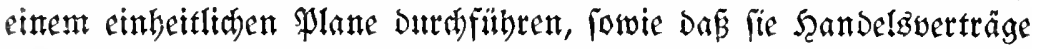
mit sritten Staaten gemeinjam verbandeln und abjáließen werden.

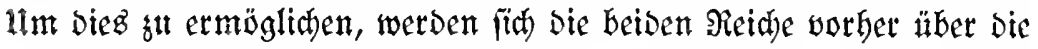
Den $\mathfrak{B e r b a n d u n g e n ~ z u g r u n d e ~ z u ~ l e g e n d e n ~ Z o l l t a r i f e ~ z u l ~ e i n i g e n ~ h a b e n . ~}$

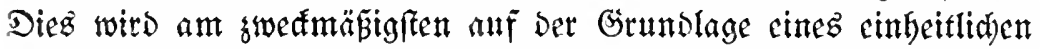

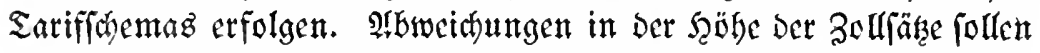

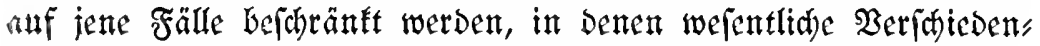
beiten ber wirtid aftlid)en Berbälinifle, insbefondere der Produftions, bebingungen dies crforberlid) madien.

Sm $\mathfrak{B e r}$ kefre Der verbündeten Staaten untereinanber foll wed jel,

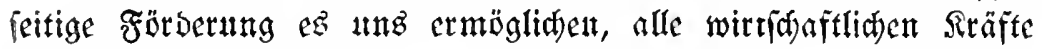

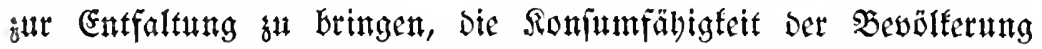

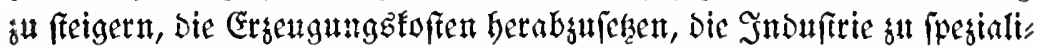

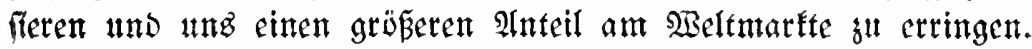

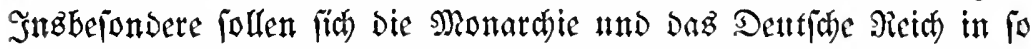

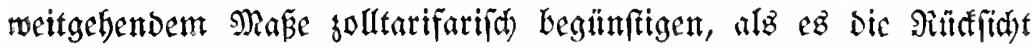

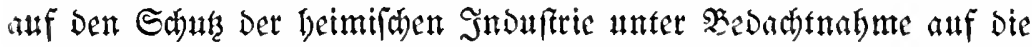

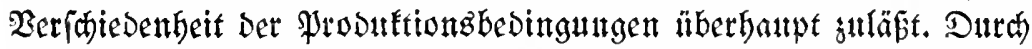

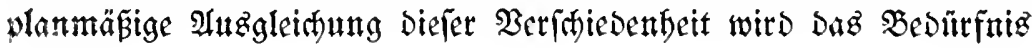




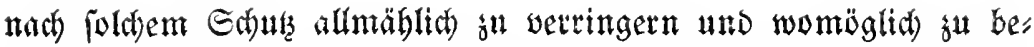

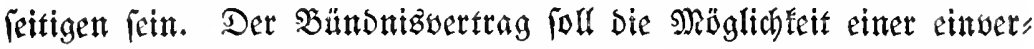
nebmlichen $\mathfrak{A}$ fnalme and brifter Staaten in ein Bevorzugung: verbältris vffenbalten.

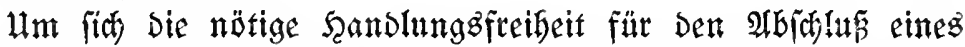

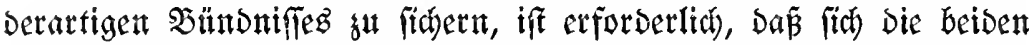
Reiche bereitz wor Dem Beginn Der Friebenswerhandungen äber die in biefen gemeinfant bat vertretenden wirtichaftlitjen Forberungen

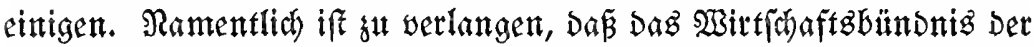
Zentralntäd)te bereits in Den Friebensuerträgen mit briften Staaten

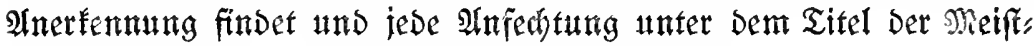
begünftignng won vornberein ausgeichloffen wird.

S̃n Der SMonardbie felbft bilbet eine Der Şauptworausfebungen Der

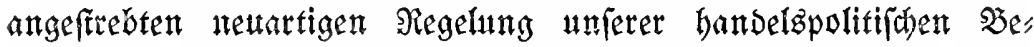

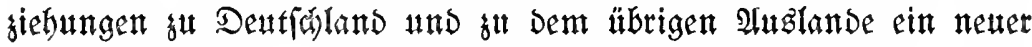

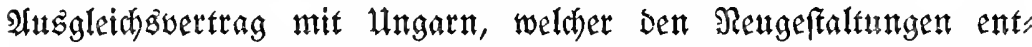

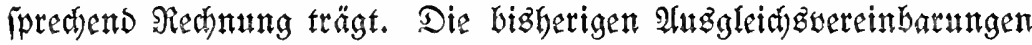

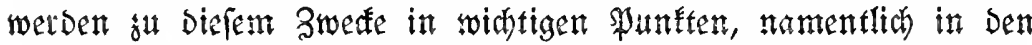

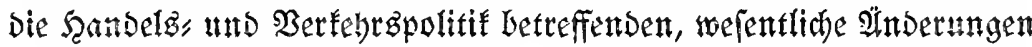
und Ergänğtngen erfagren müffen. Jebenfallz wird biesmal bie oft

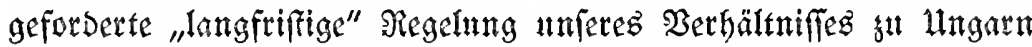
erfolgen nüffer, obne die irgendeine weiter ausgreifende llunge"

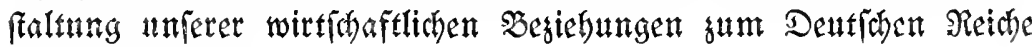
nicht Dentbar ift.

Die Borbereitung Der Den $\mathfrak{A}$ usgleid) betreffenden Arbettent wird

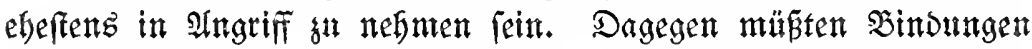

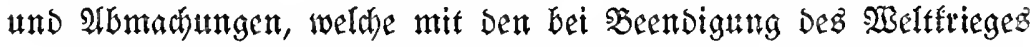
fu erwartenden Rengeftaltungen in WJiberipratu geraten fönnten,

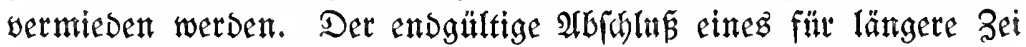

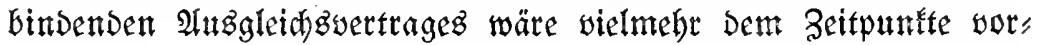

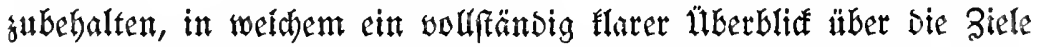

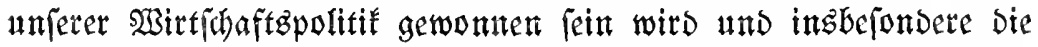

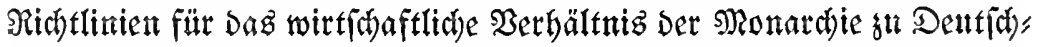
land Durdh grundä̋zliche Berftändigung Der beteiligten Regiennngen feftgelegt find.

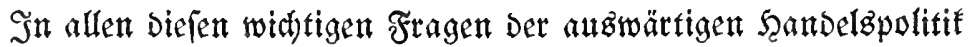

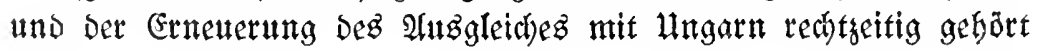




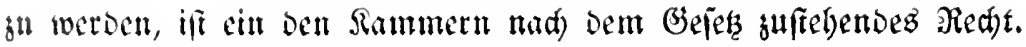

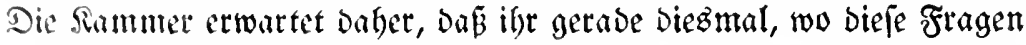

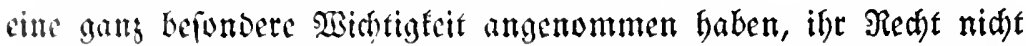
verkürgt werbe, jondern ibr feitens Der Regierung Gelegenfeit gegeben

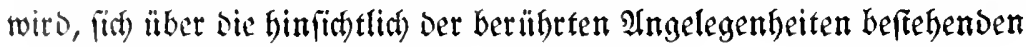

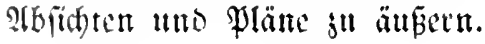

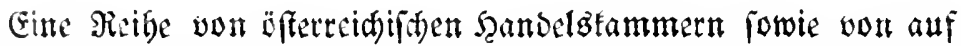

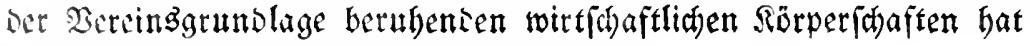
bisber äbuliche Sundogebungen bejaloflen. 


\section{Bisheríge Werôffentliđungen deg $\mathfrak{b e r f a f l e r g . ~}$}

Der internationale Gandelatongrez in Whiladelphía und das dortige Gandelsmuleum (Grandjäze für den kauf= männifhen Huskunftsdienft auf offfentlich = rechtlither Żajis)

Werlag Braumüller

Das fommerzílle Ausfunftawe/en im modernen bettehre Jm Verlage der wiener Gandelsfammer

Durd) Síbírien nad der Güd/er, Reifejdilderungen Verlag Braumüller

Fusgeftaltung der Exportförderung

Im Verlage der Wiener Gandelgammer

Regelung deg Augftellungewelens

Jm Gerlage der wiener fandelskammer

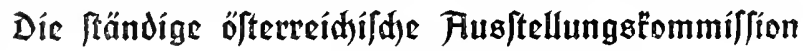
(Jm Verlage der letteren)

Das ölterreídilde Fuswanderungeproblem

Im Erfacinen begriffen bei Braumuller. 


BINDING SECT. JUN 2.31970

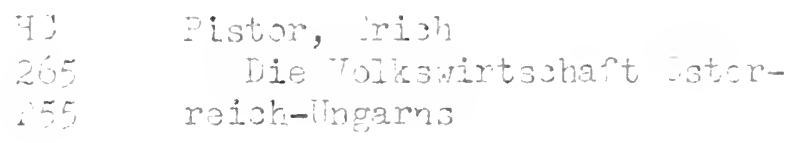

PLEASE DO NOT REMOVE CARDS OR SLIPS FROM THIS POCKET UNIVERSITY OF TORONTO LIBRARY 
